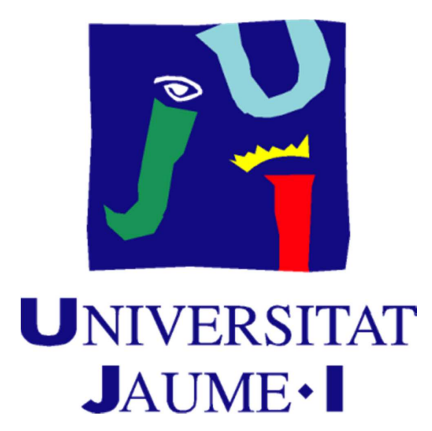

UNIVERSITAT JAUME I

Escola Superior de Tecnologia i Ciències Experimentals

Departament de Química Inorgànica i Orgànica

\title{
SÍNTESIS Y EVALUACIÓN BIOLÓGICA DE ANÁLOGOS DE COLCHICINA
}

Tesis Doctoral

Ana Marzo Mas

Castellón de la Plana, 2016 

D. Pedro Miguel Carda Usó, Catedrático de Química Orgánica de la Universidad Jaume I y D. Juan Alberto Marco Ventura, Catedrático de Química Orgánica de la Universidad de Valencia, certifican que:

Dña. Ana Marzo Mas ha realizado bajo su dirección el trabajo que se recoge en esta memoria para optar al grado de Doctora.

Asimismo, autorizan la presentación del trabajo ante la Universidad Jaume I de Castellón para que se cumplan los trámites correspondientes.

$Y$ para que así conste a los efectos legales presentamos dicha tesis y firmamos este certificado en Castellón de la Plana. 



\section{Agradecimientos}

La presente Tesis Doctoral ha sido realizada en el Departamento de Química Inorgánica y Orgánica de la Escuela Superior de Tecnología y Ciencias Experimentales de la Universitat Jaume I de Castellón de la Plana, bajo la dirección del Dr. D. Pedro Miguel Carda Usó y del Dr. D. Juan Alberto Marco Ventura. A ellos me gustaría agradecerles todo el apoyo, la ayuda proporcionada, la experiencia, la exigencia en el trabajo realizado, la paciencia y la dedicación mostradas tanto en el ámbito profesional como en el personal y sobre todo por haberme dado la oportunidad de iniciarme en el mundo de la investigación.

Al Dr. D. Juan Murga Clausell y a la Dra. Dña. Eva Falomir Ventura, muchísimas gracias por permitirme formar parte del grupo de trabajo, por sus consejos y aportaciones durante mis años de doctoranda.

Quiero hacer extensivo mi agradecimiento al Dr. Vincent Peyrot y la Dr. Pascale Barbier de la Aix-Marseille Université por aceptarme en su grupo de investigación y por su paciencia. También me gustaría agradecer a los compañeros del laboratorio de Marseille su cálida bienvenida y sobre todo su esfuerzo en hacerme sentir como en casa y sus prácticas clases de francés. Merci beaucoup!

También quiero expresar mi agradecimiento al Ministerio de Economía y Competitividad (proyecto CTQ2014-52949-P), a la Conselleria d'Empresa, Universitat i Ciència de la Generalitat Valenciana por el proyecto PROMETEO 2013/027, dentro del cual se incluía un contrato de personal investigador en formación del que he sido beneficiaria y por la ayuda para la estancia BEFPI/2015 y a la Universitat Jaume I por el proyecto con código PI-1B2015-75, mediante los cuales ha sido posible financiar el contenido de esta Tesis Doctoral.

Por supuesto, no pueden faltar mis compañeros de laboratorio junto a los cuales he compartido todos estos años. A Conxín, Laura, María, Raül, Rosa y Steven por vuestos consejos, correcciones de fallos, sana locura... Muchas 
gracias. A Andreu, por esos largos días escribiendo que se hacían infinitos pero siempre me ponías "buena" música para acompañarlos. A Bea, Nishant, Marco y Santi, por las risas y algún que otro moratón en los partidos de pádel, aunque creo que nunca llegaremos a ser jugadores profesionales.

No puedo olvidarme de mi profesora particular de computacional, Erica, que debo agradecerte toda la paciencia que has tenido conmigo y sobre todo el pan de queso tan bueno que haces.

También quiero agradecer a mis amigos, Carlos y Neus, que nos conocemos desde hace muchos años, hemos pasado muchísimas cosas juntos y aunque ahora cada uno este en un sitio diferente, sé que siempre estarán ahí cuando los necesite. No he podido tener mejores amigos para el largo proceso de la tesis y las horas pasadas en la universidad, y que sepáis que soy la jueza de la competición porque si no ganaría todos los puntos yo.

Por supuesto a las chicas del vermut, Andrea, Carmen, Elena y Marta y todos sus respectivos, por las cervezas de los viernes para ahogar las penas y los momentos de diversión compartidos. A mi amiga Paula, que juntas formamos el dúo dinamico, por toda tu paciencia, por escucharme (aunque a veces lo dudo que lo hagas) y sobre todo por estar ahí. Muchas gracias a todos.

Por último, me gustaría expresar un agradecimiento muy especial a mi familia, sobre todo a mis padres Jose y Ana, porque también habéis tenido que soportar mal humor, por animarme y por confiar siempre en mí y no dudar jamás. 


\section{Abreviaturas y acrónimos}

ABC: ATP-binding cassette.

Ac: Acetato.

app: Señal con multiplicidad aparente.

ATP: Trifosfato de adenosina.

Boc: tert-Butiloxicarbonilo.

br: Banda o señal ancha.

$c$ : Cuadruplete.

CLC: Colchicina.

d: Doblete.

DAMA-colchicina: $N$-deacetil-

$\mathrm{N}$-(2-mercaptoacetil)colchicina.

DCC: Diciclohexilcarbodiimida.

DMAP: 4-N,N-Dimetilaminopiridina.

DMSO: Dimetilsulfóxido.

DMF: $N, N$-dimetilformamida.

dNTP: Deoxyribonucleotide triphosphate.

EDCI: 1-etil-3-(3-dimetilaminopropil)

carbodiimida.

ELISA: Enzyme linked-inmuno-sorbent assay.

eq: Equivalente.

Et: Etilo.

FBS: Fetal bovine serum.

FDA: Food and drug administration.

FITC: Fluorescein isothiocyanate.

FMF: Fiebre mediterránea familiar.

GDP: Guanosín difosfato.

GTP: Guanosín trifosfato.

HR ESMS: High resolution electrospray mass

spectrometry.

hTERT: Human telomeric end reverse transcriptase.

hTR: Human telomerase RNA.

HTS: High throughput screening.

IR: Infrarojo.

IUPAC: International Union of Pure and Applied Chemistry.

lit.: Literatura.

$m$ : Multiplete.

MAP: Microtubule Associated Proteins.

Me: Metilo.

MDR: Multiple drug resistance.

MMPs: Matrix metalloproteinases.

MTOC: Microtubule Organizing Center.
MTT: bromuro de 3-(4,5-dimetiltiazol-

2-il)-2,5-difeniltetrazolio.

OMS: Organización Mundial de la Salud.

PBS: Phosphate-buffered saline.

PCR: Polymerase Chain Reaction.

Ph: Fenilo.

PIGF: Placental growth factor.

pf: Punto de fusión.

QSAR: Quantitative structure-activity

relationship.

Q-TOF: Quadrupole-time of flight.

RMN: Resonancia magnética nuclear.

$S$ : Singulete.

$t$ : Triplete.

T-C: Complejo tubulina-colchicina.

temp. amb.= temperatura ambiente.

THF: Tetrahidrofurano.

TFA: Ácido trifluoroacético.

TLC: Thin layer chromatography.

TMS: Tetrametilsilano.

VEGF: Vascular endothelial growth factor.

VEGFR: Vascular endothelial growth factor receptor. 

A mis padres, 



\section{ÍNDICE}

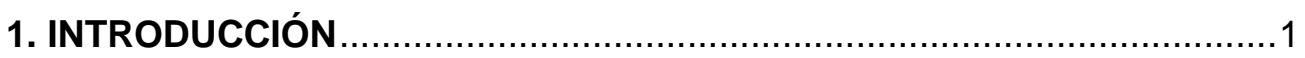

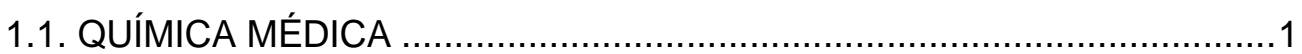

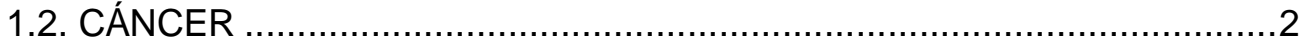

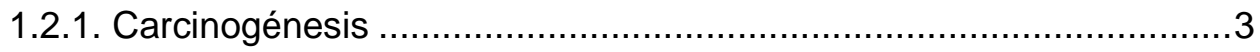

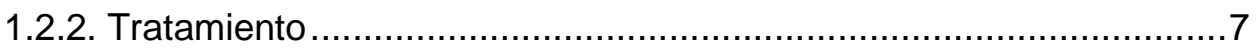

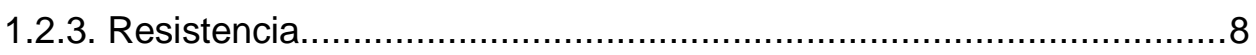

1.2.4. Señas de identidad de cáncer ...................................................

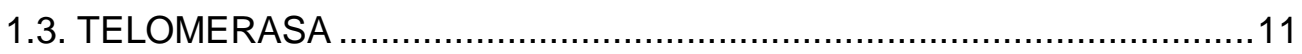

1.4. ANGIOGÉNESIS ................................................................. 13

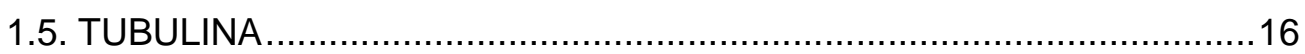

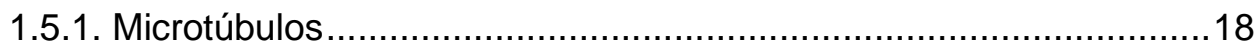

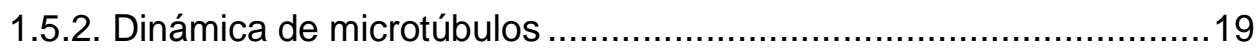

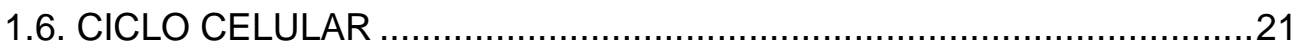

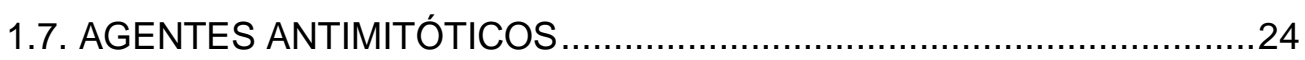

1.7.1. Agentes estabilizantes de microtúbulos........................................25

1.7.2. Agentes desestabilizantes de microtúbulos .................................27

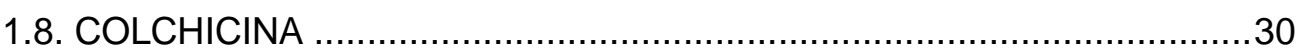

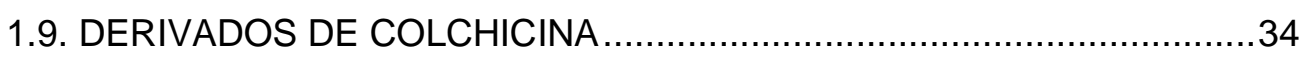

2. OBJETIVOS

3. SÍNTESIS DE ANÁLOGOS DE COLCHICINA ....................................41

3.1. SÍNTESIS DE N-DESACETILCOLCHICINA ....................................41

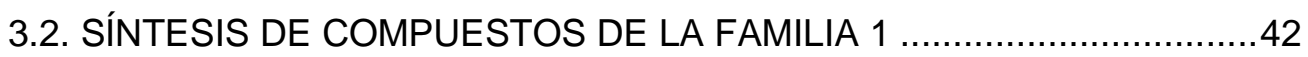

3.3. SÍNTESIS DE COMPUESTOS DE LA FAMILIA $2 \ldots \ldots \ldots \ldots \ldots \ldots \ldots \ldots . . . . . . . . . . . . . . . . . . .45$

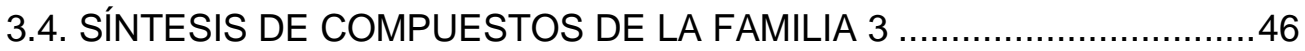

3.5. PROCEDIMIENTOS EXPERIMENTALES …...................................4 47

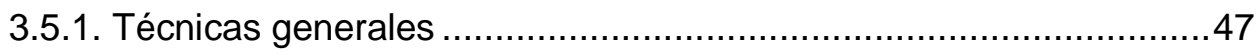


3.5.3.Procedimiento experimental para la $N$-Boc protección de aminoácidos .50

3.5.4. Síntesis de los aminoácidos $N$-Boc protegidos mediante acoplamiento peptídico con el trifluoroacetato de $\mathrm{N}$-desacetilcolchicinio .55

3.5.5. Procedimiento experimental para la $N$-Boc desprotección...............68

3.5.6. Procedimiento experimental para la síntesis de $\mathrm{N}$-acil derivados ....82

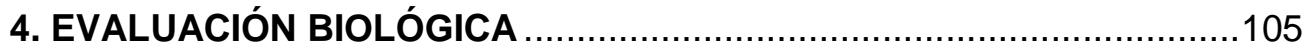

4.1. ENSAYOS BIOLÓGICOS ............................................................105

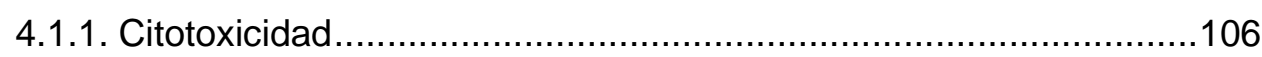

4.1.2. Efecto sobre el ensamblaje de microtúbulos ...............................107

4.1.3. Determinación del valor de $\mathrm{IC}_{50}$ frente a la formación de microtúbulos 110

4.1.4. Determinación de la constante de afinidad frente a la tubulina ......110

4.1.5. Efecto sobre el ciclo celular (citometría de flujo) ..........................112

4.1.6. Efecto sobre la red de microtúbulos (inmunofluorescencia) ...........113

4.1.7. Efecto sobre la expresión de los genes VEGF, $h T E R T$ y $c-M y c$ en HT-29.

4.1.8. Efecto sobre la secreción de la proteína VEGF-A ${ }_{165}$ en HT-29 ......119

4.2. EVALUACIÓN BIOLÓGICA DE LOS COMPUESTOS DE LA FAMILIA 1 122

4.2.1. Citotoxicidad. 122

4.2.2. Efecto sobre el ensamblaje de microtúbulos. Concentración crítica de tubulina $(\mathrm{Cr})$ 127

4.2.3. Efecto sobre la expresión de los genes VEGF, $h T E R T$ y c-Myc en HT-29. 132

4.2.4. Efecto sobre la secreción de la proteína VEGF-A ${ }_{165}$ en HT-29 ......135

4.2.5. Docking 136

4.2.6. Resumen y conclusiones. .145 


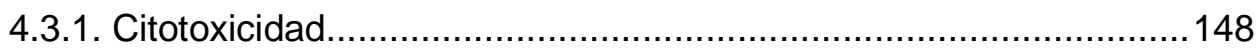

4.3.2. Efecto sobre el ensamblaje de microtúbulos. .............................151

4.3.3. Determinación del valor de $\mathrm{IC}_{50}$ frente a la formación de microtúbulos 155

4.3.4. Determinación de la constante de afinidad frente a la tubulina ......158

4.3.5. Efecto sobre el ciclo celular .......................................................160

4.3.6. Efecto sobre la red de microtúbulos ...........................................162

4.3.7. Efecto sobre la expresión de los genes VEGF, $h T E R T$ y $c-M y c$ en $\mathrm{HT}-29$. 163

4.3.8. Efecto sobre la secreción de la proteína VEGF-A ${ }_{165}$ en HT-29 ......166

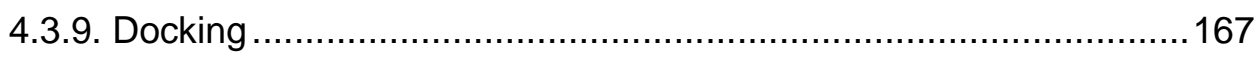

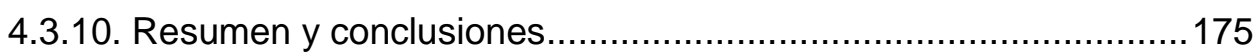

4.4. EVALUACIÓN BIOLÓGICA DE LOS COMPUESTOS DE LA FAMILIA 3 178

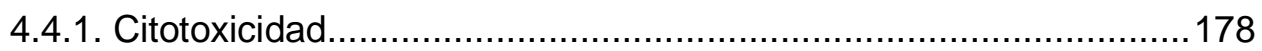

4.4.2. Efecto sobre el ensamblaje de microtúbulos. ..............................180

4.4.3. Efecto sobre la expresión de los genes VEGF, hTERT y c-Myc en

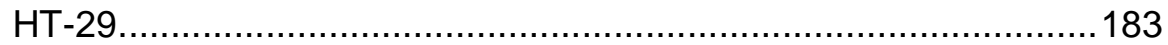

4.4.4. Efecto sobre la secreción de la proteína VEGF-A $A_{165}$ en HT-29 ......187

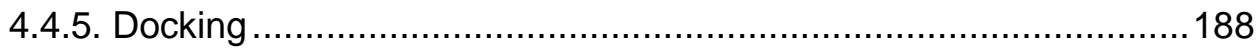

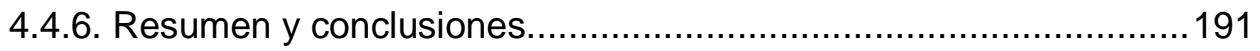

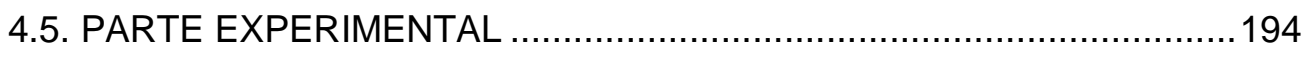

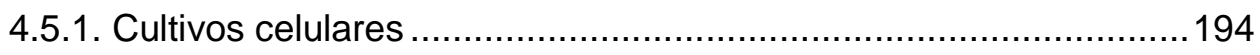

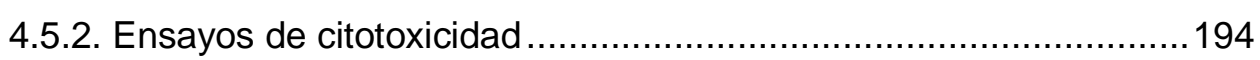

4.5.3. Determinación del efecto de los compuestos sobre el ensamblaje de microtúbulos y del valor de $\mathrm{IC}_{50}$ frente a la formación de microtúbulos 195

4.5.4. Determinación de la constante de afinidad frente a la tubulina......198

4.5.5. Efecto sobre el ciclo celular (citometría de flujo)..........................199 
4.5.6. Efecto sobre la red de microtúbulos (inmunofluorescencia). 199

4.5.7. Efecto sobre la expresión de los genes VEGF, hTERT y c-Myc en HT-29. 200

4.5.8. Efecto sobre la secreción de la proteína VEGF-A $A_{165}$ en HT-29 ......201

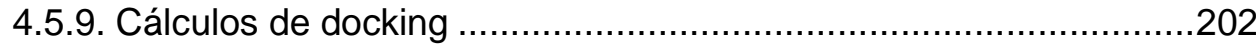

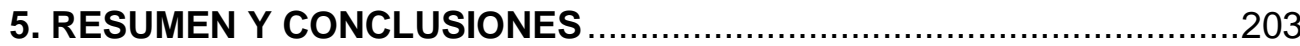

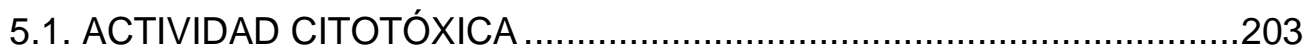

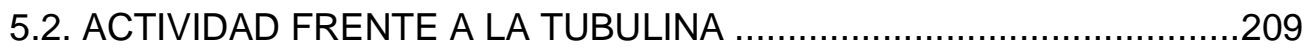

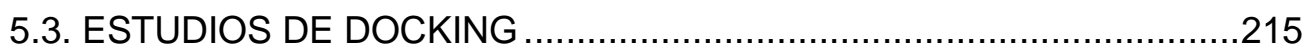

5.4. INHIBICIÓN DE LA EXPRESIÓN DE GENES Y DE LA SECRECIÓN DE

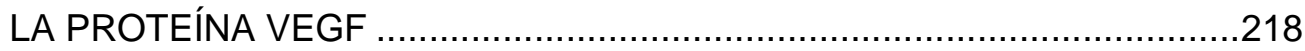

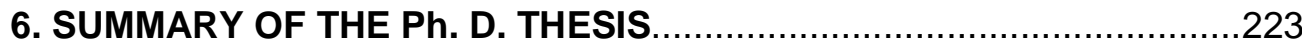

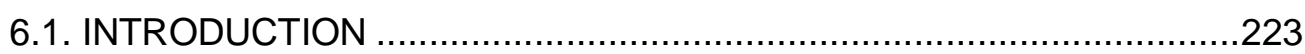

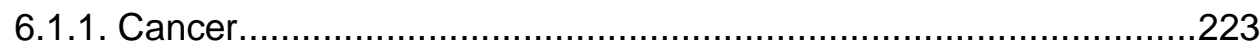

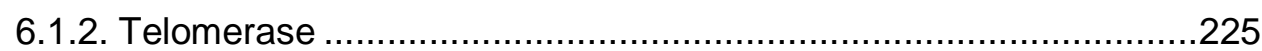

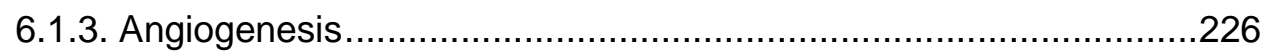

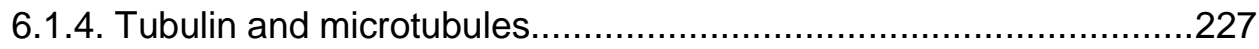

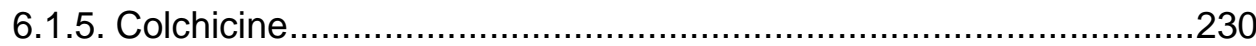

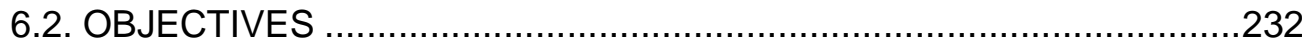

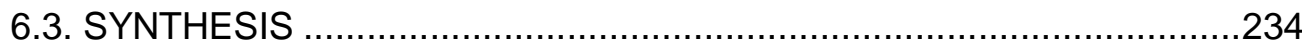

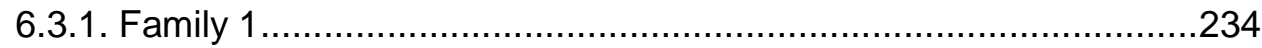

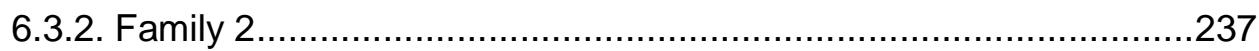

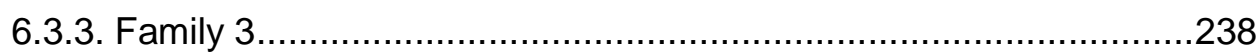

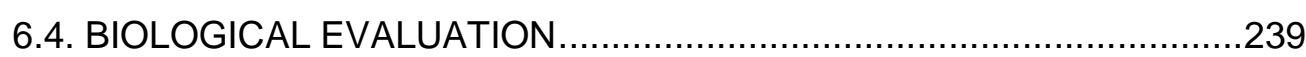

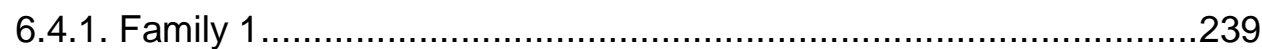

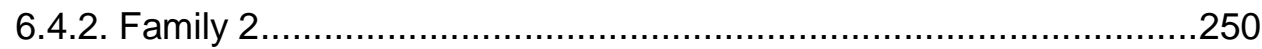

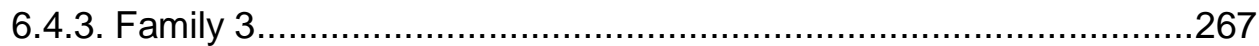

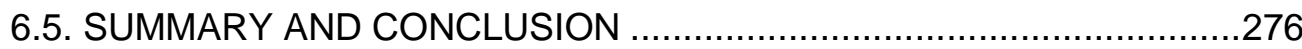


7. PUBLICACIONES Y COMUNICACIONES A CONGRESOS DERIVADAS DE LA TESIS DOCTORAL 281

7.1. COMUNICACIONES A CONGRESOS ...........................................281

7.2. PUBLICACIONES DERIVADAS DE LA TESIS DOCTORAL ................282

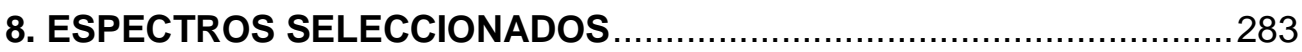





\section{CAPÍTULO 1 \\ INTRODUCCIÓN}

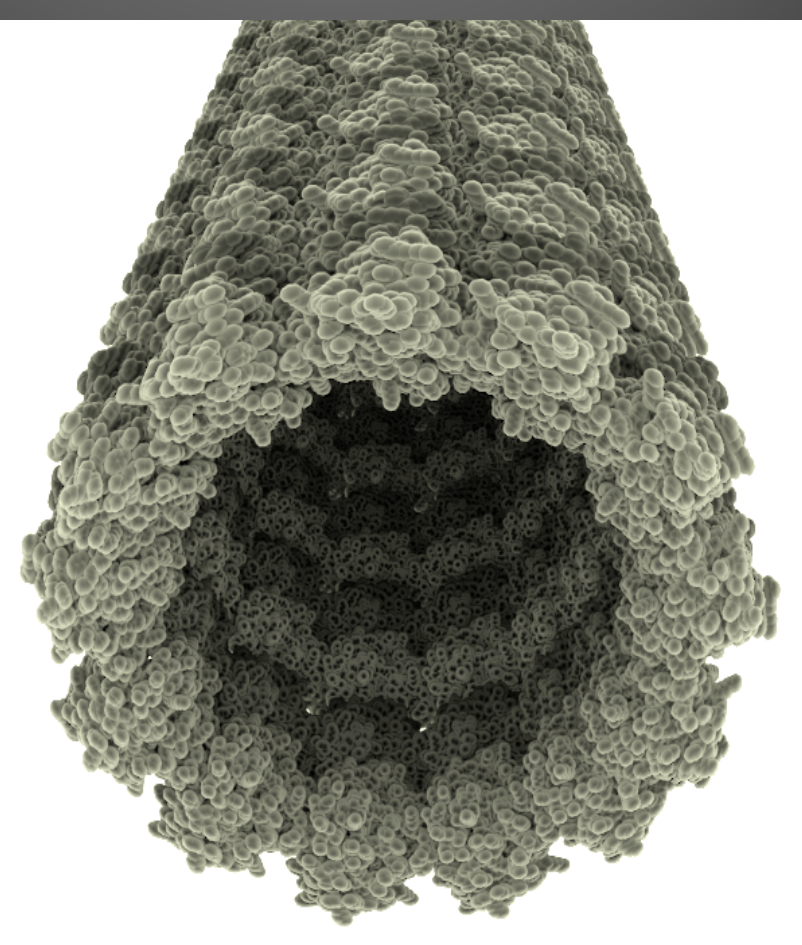





\section{CAPÍTULO 1: INTRODUCCIÓN}

\subsection{Química Médica}

El origen de la química se remonta a los primeros tiempos de la humanidad y va asociado al descubrimiento del fuego que permitió a nuestros ancestros controlarlo y reproducirlo. El fuego les proporcionaba a los hombres primitivos luz y calor pero también les permitía transformar la materia mediante la cocción de los alimentos.

La iatroquímica (del griego iatros, médico) se inició en el siglo XVI con el alquimista y científico suizo Paracelso (Theophrastus Bombastus von Hohenheim), quien proponía que la preparación de drogas para la curación de las enfermedades debería ser uno de los objetivos prioritarios de la química.

Los conceptos alquimistas que impregnaban las teorías de los iatroquímicos fueron definitivamente arrinconados en el siglo XVII por Robert Boyle, quien es para muchos uno de los fundadores de la química moderna. Su obra The Sceptical Chymist (El químico escéptico) está considerada como una pieza clave en la historia de la química. La práctica alquímica quedó en entredicho por las aportaciones de Boyle, quien consideraba que la materia estaba formada por átomos y agrupaciones de átomos en movimiento y que cada fenómeno químico era el resultado de colisiones entre estas partículas. Boyle abogaba por un acercamiento riguroso a la experimentación científica y proponía que todas las teorías deberían ser probadas experimentalmente antes de ser consideradas como verdaderas.

El término de Química Médica apareció por primera vez en 1948, cuando la Sociedad Americana de Química fundó una división de Química Médica. ${ }^{1}$ Posteriormente, en el año 1973, la IUPAC ${ }^{2}$ definió a la Química Médica como la rama de la química enfocada al descubrimiento, desarrollo, identificación e

\footnotetext{
${ }^{1}$ Timmerman, H. Medicinal and Pharmaceutical Chemistry, In Reference Module in Chemistry, Molecular Sciences and Chemical Engineering, Elsevier, 2013.

${ }^{2}$ IUPAC; Information Bulletin, Tech. Rep., 1974, 13.
} 
interpretación del modo de acción de compuestos biológicamente activos a nivel molecular.

La Química Médica es una ciencia altamente interdisciplinar que combina los conocimientos de la química orgánica, la bioquímica, la química física y computacional, la farmacología y la biología molecular.

Una de las mayores fuentes de compuestos biológicamente activos es la Naturaleza. En la actualidad se conocen más de 200.000 productos naturales pero quedan muchos más por descubrir ya que, hasta la fecha, sólo han sido investigadas entre el 5 y el $15 \%$ de las entre 250.000 y 500.000 plantas superiores que se calcula que existen. Los productos naturales se encuentran biológicamente validados ya que han sido seleccionados para unirse a sus dianas biológicas durante los millones de años que la vida lleva desarrollándose en el planeta Tierra. $^{3}$ De los 1010 nuevos fármacos aprobados por la FDA desde enero de 1986 hasta junio de 2006, 43 eran productos naturales inalterados y 232 (un 23\%) eran derivados de los mismos. ${ }^{4}$ Los productos naturales son capaces de interactuar con muchas dianas específicas dentro de la célula y juegan un papel central en el descubrimiento y desarrollo de nuevos fármacos, en particular en el área de las enfermedades infecciosas y de la oncología. ${ }^{5}$

\subsection{Cáncer}

Las enfermedades coronarias y el cáncer son las dos principales causas de muerte en los países desarrollados. El cáncer provocó más de 8 millones de muertes en el año $2012 .{ }^{6}$ En el año 2000 hubo unos 12 millones de nuevos afectados en todo el mundo y para el año 2030 se prevé que este número

\footnotetext{
${ }^{3}$ (a) Gutiérrez Ravelo, A.; Estévez Braun, A. Rev. R. Acad. Cienc. Exact. Fis. Nat. 2009, 103, 409-419. (b) Yuan, H.; Ma, Q.; Ye, L.; Piao, G. Molecules 2016, 21, ASAP.

4 Avendaño, C. Anales de la Real Academia Nacional de Farmacia 2011, 77, 12-26. http://www.analesranf.com/index.php/aranf/article/view/1150/1196.

${ }^{5}$ Mishra, B. B.; Tiwari, V. K. Eur. J. Med. Chem. 2011, 46, 4769-4807.

${ }^{6}$ http://www.cancer.gov/espanol/cancer/que-es/estadisticas
} 
alcance los 20 millones, lo que convertiría al cáncer en la primera causa de mortalidad en el mundo. ${ }^{7}$

En la figura 1.1 se presenta el porcentaje de incidencia y mortalidad de la población mundial según el tipo de cáncer.

INCIDENCIA

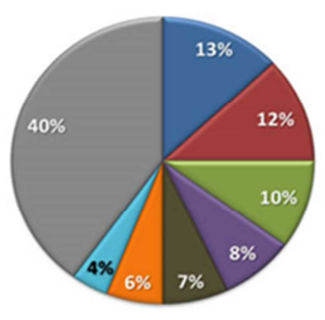

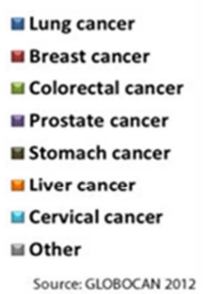

MORTALIDAD

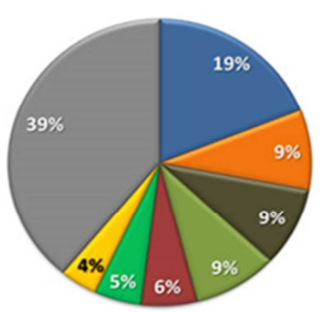

- Lung cancer

- Liver cancer

- Stomach cancer

a Colorectal cancer

Breast cancer

Esophagus cancer

$\square$ Pancreatic cancer

⿶other

Source: GLOBOCAN 2012

Figura 1.1. Porcentajes de incidencia y mortalidad del cáncer mundial en 2012.

Entre los tipos de cáncer de mayor incidencia destacan el de pulmón, el de mama y el colorrectal. Estos tres suponen el 35\% de los nuevos casos de cáncer diagnosticados en el año $2012 .^{8}$

El cáncer es una de las enfermedades que más preocupación social despierta, lo que explica la búsqueda incesante de nuevos tratamientos más selectivos, eficaces y con menores efectos secundarios.

\subsubsection{Carcinogénesis}

El cáncer no es una enfermedad unitaria sino que es un término amplio que comprende más de 100 enfermedades diferentes, todas ellas caracterizadas por la proliferación descontrolada de células anómalas capaces de invadir y colonizar otros órganos o tejidos distintos de aquellos en los que se han originado. $^{9}$

\footnotetext{
${ }^{7}$ Olsen, M. M.; Siegelmann, H. T. Procedia Comput. Sci. 2013, 18, 1016-1025.

${ }^{8} \mathrm{http}: / /$ www.cdc.gov/cancer/international/statistics.htm

${ }^{9}$ Ferlay, J.; Soerjomataram, I.; Ervik, M.; Dikshit, R.; Eser, S.; Mathers, C.; Rebelo, M.; Parkin, D. M.; Forman, D.; Bray, F. GLOBOCAN, 2012, v1.0, Cancer Incidence and Mortality Worldwide: IARC.
} 
Según la teoría monoclonal del cáncer esta enfermedad se origina a partir de una célula que experimenta una serie de mutaciones que la convierten en una célula cancerosa. ${ }^{10}$ Las mutaciones genéticas y/o epigenéticas ${ }^{11}$ no tienen que estar presentes todas ellas en la célula que va a originar el tumor. Así, la división de la célula cancerosa puede dar lugar a mutaciones en el ADN que son heredadas por las células hijas. A su vez, las células hijas pueden experimentar otras mutaciones que se transmiten, junto con las heredadas de la célula progenitora, a la siguiente estirpe celular, provocándose de esta forma la heterogeneidad celular del tumor ${ }^{12}$ (véase la figura 1.2).

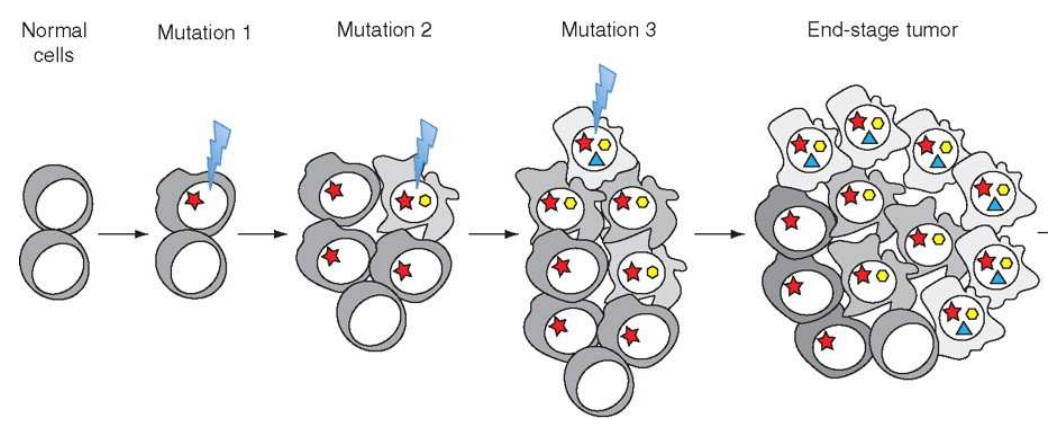

Figura 1.2. Proceso de carcinogénesis. ${ }^{13}$

La mayoría de los cánceres son el resultado de la exposición a agentes ambientales (carcinógenos exógenos) que, a su vez, son los responsables de las mutaciones en los genes que controlan el crecimiento celular. Los principales agentes exógenos implicados en el desarrollo del cáncer son el tabaquismo, el alcohol, las dietas inadecuadas, las radiaciones, agentes infecciosos tales como el virus de la hepatitis B y del papiloma humano, determinados tipos de infecciones bacterianas tales como las provocadas por

\footnotetext{
${ }^{10}$ Nowell, P. C. Science 1976, 194, 23-28.

${ }^{11}$ Ver número monográfico del J. Med. Chem. (2016, Vol. 59, issue 4) dedicado a la epigenética Y nuevas pautas terapéuticas relacionadas con la misma.

${ }_{2}$ Axelrod, R.; Axelrod, D. E.; Pienta, K. J. Proc. Natl. Acad. Sci. USA 2006, 103, 13474-12479.

${ }^{13} \mathrm{http}: / / c 2 p a t o l o g i a . b l o g s p o t . c o m . e s / 2014 / 03 / 1 . h t m l$
} 
Helicobacter pylori, la exposición a agentes químicos y la ingesta de fármacos tales como los anticonceptivos orales. ${ }^{14}$

Además de los anteriores factores exógenos, existen numerosas alteraciones genéticas y cromosómicas que están asociadas con el riesgo de desarrollo del cáncer (carcinógenos endógenos). La mayoría de los genes que predisponen al cáncer hereditario están implicados en el control del crecimiento celular. El cáncer hereditario se ha asociado con el cáncer de mama, colorrectal, de ovario, gástrico, de endometrio y con sarcomas y linfomas.

Los genes implicados en los procesos cancerígenos son los oncogenes y los genes supresores de tumores. Los oncogenes se originan a partir de mutaciones de genes normales denominados protooncogenes. Esta clase de genes están encargados de la proliferación celular, de la supervivencia, de la invasión y de la movilidad celular. En las células normales los protooncogenes están estrictamente regulados lo cual impide el crecimiento celular descontrolado. Cuando un protooncogen se convierte en oncogen se produce la división celular descontrolada, aumentando la supervivencia y la diseminación celular. La mutación a oncogen puede tener lugar por tres vías: ${ }^{15}$

$>$ Alteración de la secuencia genética.

> Multiplicación de la secuencia genética.

> Translocación de la secuencia genética.

Uno de los protooncogenes más estudiados es el denominado $c-M y c$. Se ha descubierto que en uno de cada tres casos de cáncer de mama y de colon este protooncogen se encuentra sobreexpresado. ${ }^{16}$ Las funciones de $c-M y c$ son muy variadas ya que se ha demostrado su participación en la actividad de

\footnotetext{
14 Trichopoulos, D.; Li, F. P.; Hunter, D. J. Sci. Am. 1996, 275, 50-57.

${ }_{15}^{15}$ Harrington K. J. Medicine 2016, 44, 1-5.

${ }^{16}$ Escot, C.; Theillet, C.; Lidereau, R.; Spyratos, F.; Champane, M. H.; Gest J. Proc. Natl. Acd. Sci. USA 1986, 83, 483-4838.
} 
la telomerasa, en la progresión del ciclo celular, en el metabolismo, en la angiogénesis, en la apoptosis y en la adherencia y motilidad celular. ${ }^{17}$

Los genes supresores de tumores tienen la función de inhibir la proliferación y la supervivencia celular. Están involucrados en el control del ciclo celular y en la muerte celular programada (apoptosis). Un ejemplo de esta clase de genes es el gen p53. Una de las funciones de este gen es el de controlar el estado del ADN y, junto un grupo adicional de proteínas, reconoce y repara el ADN dañado. Las respuestas hacia el ADN dañado incluyen su reparación, el bloqueo de la división celular y la inducción de la apoptosis. ${ }^{18}$ Los daños en el gen p53 aumentan la probabilidad de desarrollar un cáncer.

La proliferación anormal de células tiene como resultado la formación de un tumor o neoplasia. Hay dos tipos de tumores: benignos y malignos. Los tumores benignos se extienden de manera localizada y quedan confinados en su posición de origen. Por el contrario, los tumores malignos o cancerosos se caracterizan por su capacidad de invasión o metástasis. La metástasis se define como la propagación a distancia, por vía fundamentalmente linfática o sanguínea, de las células originarias del cáncer, con el consiguiente crecimiento de nuevos tumores en los lugares de destino de dicha metástasis. ${ }^{19}$ En la figura 1.3 se esquematiza el proceso de desarrollo del cáncer.

\footnotetext{
17 (a) Dang, C. V. Mol. Cell. Biol. 1999, 19, 1-11. (b) Hoffman, B.; Lieberman, D. A. Oncogene 2008, 27, 6462-6472.

${ }^{18}$ Wiesmueller, L. Angew. Chem. Int. Ed. 2000, 39, 1768-1770.

${ }^{19}$ Cooper, G. M. The Cell: A Molecular Approach, $2^{\text {nd }}$ ed. Sunderland (MA): Sinauer Associates. 2000.
} 


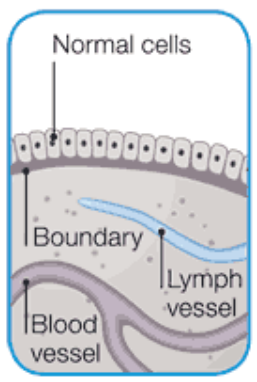

Normal cells

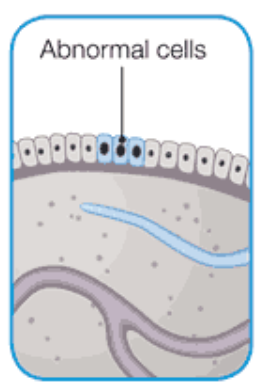

Abnormal cells

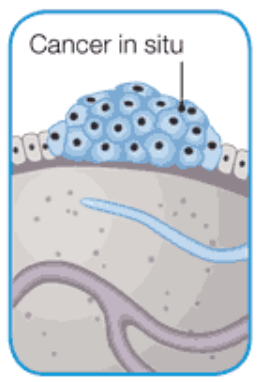

Abnormal cells multiply

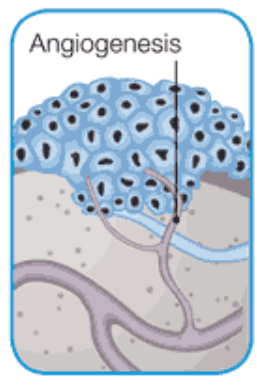

Malignant or invasive cancer

Figura 1.3. Proceso de desarrollo del cáncer. ${ }^{20}$

\subsubsection{Tratamiento}

En la lucha contra el cáncer se emplea, fundamentalmente, la cirugía, la radioterapia y la quimioterapia. ${ }^{21}$ Esta última se emplea sola o en combinación con las otras dos, lo que permite incrementar su eficacia, disminuir su toxicidad y evadir la resistencia a fármacos. ${ }^{22}$

Las células no tumorales exhiben una alta resistencia basal a agentes quimioterapéuticos, pero algunas células que se dividen rápidamente, como por ejemplo las de la medula ósea y las de la mucosa intestinal, son extremadamente susceptibles a estos agentes, provocando en estas células efectos secundarios altamente tóxicos. ${ }^{23}$

El descubrimiento de los oncogenes junto con el conocimiento de diferencias bioquímicas específicas entre células tumorales y no tumorales ha permitido el desarrollo de opciones terapéuticas más personalizadas como la inmunoterapia y la terapia génica. ${ }^{24}$

\footnotetext{
${ }^{20} \mathrm{http}: / /$ susanruth30901.blogspot.com.es/

${ }^{21}$ Mitra, A. K.; Agrahari, V.; Mandal, A.; Cholkar, K.; Natarajan, C.; Shah, S.; Joseph, M.; Trinh, H. M.; Vaishya, R.; Yang, X.; Hao, Y.; Khurana, V.; Pal, D. J. Control. Release 2015, 219, 248268.

${ }^{22}$ Graham, L. P. An Introduction to Medicinal Chemistry, $4^{\text {th }}$ ed. Oxford University Press. 2009.

${ }^{23}$ Lloyd, D. G.; Golfis, G.; Knox, A. J. S.; Fayne, D.; Meegan, M. J.; Oprea, T. I. Drug Discov. Today 2006, 11, 149-159.

${ }^{24}$ Talekar, M.; Tran, T.; Amiji, M. The AAPS Journal 2015, 17, 813-827.
} 


\subsubsection{Resistencia}

La quimioterapia es ampliamente utilizada en el tratamiento contra el cáncer. Sin embargo, en muchos casos la quimioterapia fracasa porque el tumor presenta mecanismos de resistencia innata a los fármacos o bien porque desarrolla resistencia una vez iniciado el tratamiento, ${ }^{21}$ lo que se traduce en una respuesta muy baja a la medicación. ${ }^{25}$

La resistencia múltiple a fármacos o MDR (MultiDrug Resistance) se describió por primera vez en células cancerosas y luego en virus, bacterias, hongos, plantas y animales. La MDR se ha definido como la capacidad que tienen las células para desarrollar resistencia a un fármaco que se usa como agente selectivo y para presentar resistencia cruzada a fármacos no relacionados ni bioquímica ni estructuralmente con el que se empleó en el tratamiento original. Los mecanismos que modulan la MDR se basan en: ${ }^{26}$

> La menor admisión del fármaco en el interior de la célula por una disminución en la expresión o mutación de los transportadores de soluto.

$>$ La presencia de regiones ácidas e hipóxicas en el microambiente del tumor, que provocan reacciones con el fármaco.

$>$ La modulación de las rutas de muerte celular.

$>$ La activación de la reparación de ADN, por lo que se revierte el daño celular provocado por los agentes empleados en la quimioterapia.

$>$ La alteración de las dianas biológicas mediante reducción de su expresión o mutación.

$>$ El secuestro de fármacos, lo que se traduce en una menor concentración del fármaco en la zona donde se ubica su diana.

$>$ La activación de la destoxificación mediante incremento del metabolismo celular del fármaco (enzimas P450).

$>$ El aumento del flujo de salida por sobreexpresión de las proteínas transportadoras de membrana. Este mecanismo se considera el predominante para la adquisición de MDR. Dentro de las proteínas transportadoras de membrana se encuentra la familia ATP-binding

\footnotetext{
${ }^{25}$ Gottesman, M. M.; Fojo, T.; Bates, S. E. Nat. Rev. Cancer 2002, 2, 48-58.

${ }^{26}$ (a) Gottesman, M. M. Annu. Rev. Med. 2002, 53, 615-627. (b) Vadlapatla, R. K.; Vadlapudi, A. D.; Pal, D.; Mitra, A. K. Curr. Pharm. Des. 2013, 19, 7126-7140.
} 
cassette $(\mathrm{ABC})$ y a esta familia pertenece la glicoproteína $\mathrm{P}$. En la figura 1.4 se representa el mecanismo de expulsión de un fármaco mediante la intervención de la glicoproteína $P$.

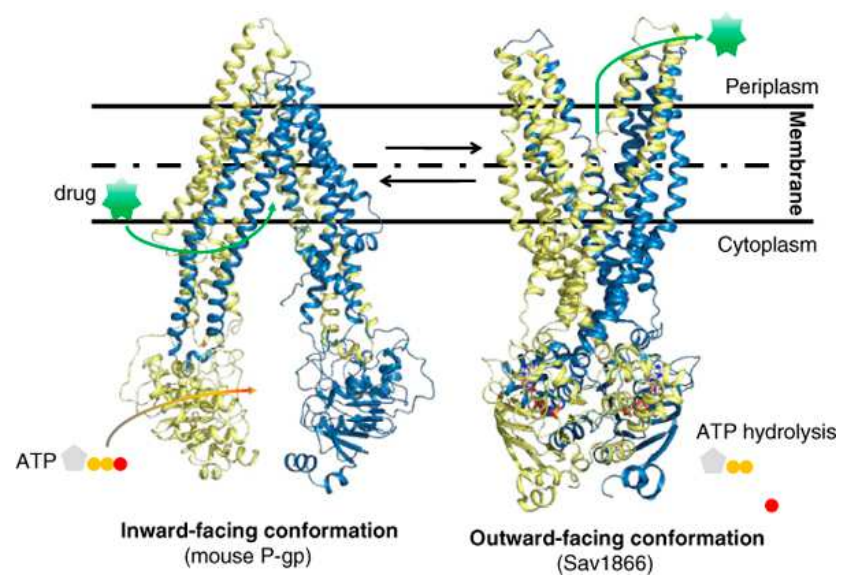

Figura 1.4. Esquema de expulsión del fármaco (verde) por la glicoproteína-P. ${ }^{27}$

Se ha propuesto que los fármacos pasan a través de un poro hidrofóbico formado por un dominio transmembranal y que su expulsión requiere de un cambio conformacional de la glicoproteína $\mathrm{P}$ dependiente de ATP. ${ }^{28}$ Se ha sugerido que el estado de fosforilación de la glicoproteína $\mathrm{P}$ podría regular este proceso y modular la resistencia a citotóxicos. ${ }^{29}$

\subsubsection{Señas de identidad del cáncer}

En un artículo de revisión publicado en el año 2000, D. Hanahan y R. A. Weinberg propusieron seis propiedades que caracterizan a los tumores cancerosos. Posteriormente, en el año 2011, estos mismos autores ampliaron las seis características anteriores con otras cuatro más. Las diez señas de identidad del cáncer son las siguientes: ${ }^{30}$

27 Martinez, L.; Falson, P. Adv. Cell. Mol. Otol. 2014, 2, 23955. doi:http://dx.doi.org/ 10.3402/acmo.v2.23955.

${ }^{28}$ Shapiro, A. B.; Ling, V. J. Biol. Chem. 1995, 270, 16167-16175.

${ }^{29}$ Aftab, D. T.; Yang, J. M.; Hait, W. N. Oncol. Res. 1994, 6, 59-70.

${ }^{30}$ (a) Hanahan, D.; Weinberg, R. A. Cell 2000, 100, 57-70. (b) Hanahan, D.; Weinberg, R. A. Cell 2011, 144, 646-674. 
- La inducción de señales estimuladoras del crecimiento mediante la activación de oncogenes y de factores de crecimiento.

> La insensibilidad a señales inhibitorias del crecimiento, principalmente por la inactivación de los genes supresores de tumores.

$>$ La resistencia a la apoptosis a través de la inactivación de factores proapoptóticos o de la activación de factores antiapoptóticos.

$>$ El potencial replicativo ilimitado o inmortalidad celular, que es consecuencia de la sobreexpresión de la telomerasa, enzima que mantiene y estabiliza los telómeros.

> La activación de la angiogénesis con el fin de conseguir el crecimiento del tumor a través del aporte de nutrientes y oxígeno.

> La elevada capacidad de invadir tejidos y generar metástasis.

$>$ La evasión del sistema inmunológico.

$>$ El desarrollo de inestabilidad genómica que da lugar a la generación de mutaciones.

$>$ La modificación o reprogramación del metabolismo energético tumoral para mantener el crecimiento y la proliferación celular.

$>$ La inflamación para estimular la progresión del tumor.

En la figura 1.5 se representan las diez señas de identidad del cáncer:

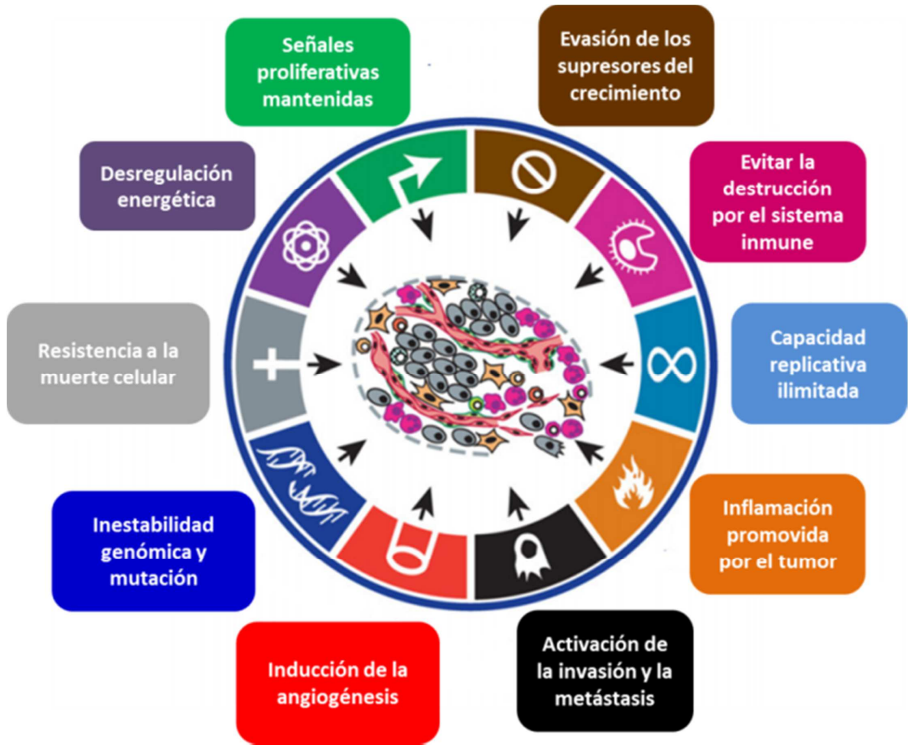

Figura 1.5. Señas de identidad del cáncer. 


\subsection{Telomerasa}

La capacidad proliferativa ilimitada es una de las señas de identidad de las células cancerosas. En esta anomalía celular juega un papel clave la telomerasa que es la enzima encargada del alargamiento telomérico.

Los telómeros (véase la figura 1.6) son estructuras nucleoproteicas no codificantes (TTAGGG) $\mathrm{n}$ que constituyen las extremidades de los cromosomas y cuya longitud predice la capacidad replicativa de las células, encargándose de regular la duración de la vida celular y la estabilidad e integridad de los cromosomas. ${ }^{31}$ Los telómeros fueron identificados por primera vez en 1938 por H. J. Muller. El premio Nobel de Medicina del año 2009 fue otorgado a E. H. Blackburn, C. W. Greider y J. W. Szostak por sus investigaciones sobre los telómeros y la telomerasa. ${ }^{32}$

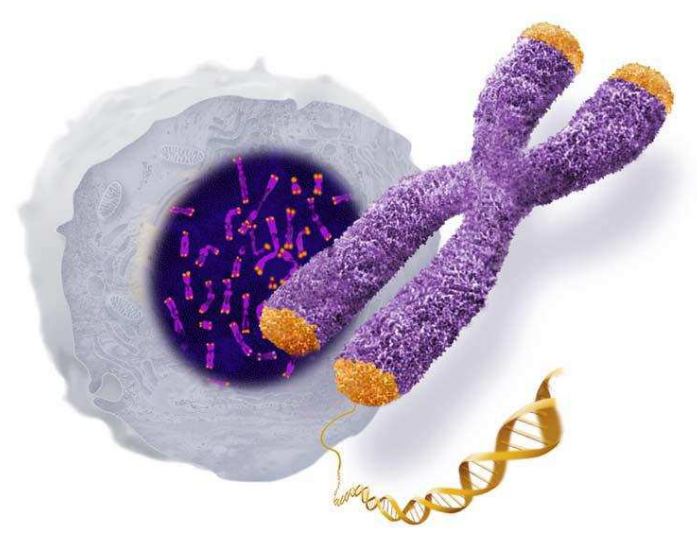

Figura 1.6. Representación de un cromosoma con la región telomérica en color naranja. $^{33}$

Durante cada división celular los telómeros se van acortando. ${ }^{34}$ Después de un cierto número de divisiones celulares los telómeros alcanzan una longitud

\footnotetext{
${ }^{31}$ Kim, K. W.; Piatyszek, M. A.; Prowse, K. R.; Harley, C. B.; West, M. D.; Ho, P. L.; Coviello, G. M.; Weinrich, S. L.; Shay, J. W. Science, 1994, 266, 2011-2015.

${ }^{32}$ Corey, D. R. Chem. Biol. 2009, 16, 1219-1223.

33 http://fiatalit.hu/2015/07/19/letezik-idealis-megoldas/

${ }^{34}$ Berg, J. M.; Tymoczko, J. L.; Stryer, L. Biochemistry, 6 ${ }^{\text {th }}$ ed. Editorial Reverté. 2007.
} 
crítica, conocida como el límite de Hayflick ${ }^{35}$ y en ese momento la célula entra en senescencia. La senescencia es un proceso biológico que afecta a casi todas las células del organismo humano, contribuyendo al envejecimiento del mismo y previniendo el desarrollo del cáncer. ${ }^{36}$

La telomerasa fue identificada por Greider y Blackburn en $1985 .{ }^{37}$ En 1989 Morin describió su actividad en células humanas. ${ }^{38}$ La telomerasa humana es una ribonucleoproteina con actividad de transcriptasa inversa.

La telomerasa contiene una subunidad proteica catalítica denominada hTERT (Human Telomerase Reverse Transcriptase) y una unidad de ARN, denominada hTR o TERC (Telomerase RNA Component) que actúa como molde para la síntesis del ADN telomérico. ${ }^{39}$ Además de hTERT y TERC la telomerasa contiene una serie de proteínas asociadas entre las que destacan TEP1 $1^{40}$ y DKC1 que está implicada en la estabilidad y el plegamiento de TERC. ${ }^{41}$ En la figura 1.7 se representa la telomerasa unida a ADN telomérico.

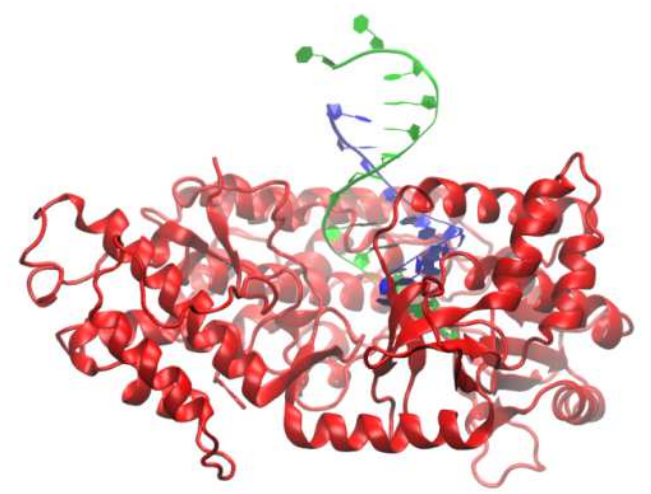

Figura 1.7. Representación de la telomerasa unida a ADN. La subunidad catalítica hTERT se representa en rojo, el componente ribonucleotídico TERC en azul y el ADN telomérico en verde.

\footnotetext{
${ }^{35}$ Mocellin, S.; Pooley, K. A.; Nitti, D. Trends Mol. Med. 2013, 19, 125-133.

${ }^{36}$ Martin, G. M.; Sprague, C. A.; Epstein, C. J. Lab. Invest. 1970, 23, 86-92.

${ }^{37}$ Greider, C. W.; Backburn, E. H. Cell 1985, 51, 405-413.

38 Morin, G.B. Cell 1989, 59, 521-529.

${ }^{39}$ Chen, C. H.; Chen, R. J. J. Formos Med. Assoc. 2011, 110, 275-279.

40 Ebrahimnezhad, Z.; Zarghami, N.; Keyhani, M.; Amirsaadat, S.; Akbarzadeh, A.; Rahmat, M.; Taheri, Z. M.; Nejati-Koshki, K. Biolmpacts 2013, 3, 67-74.

${ }^{41}$ Mitchell, J. R.; Wood, E.; Collins, K. Nature 1999, 402, 551-555.
} 
Durante la síntesis del ADN telomérico, representado en la figura 1.8, el extremo terminal 3' del telómero se posiciona en el sitio activo de hTERT (indicado en la figura como TERT) y se alinea con la plantilla de ARN situada en la subunidad TERC. La subunidad catalítica TERT añade la secuencia de nucleótidos en dirección 5 ' $\rightarrow 3$ '. Luego se produce la translocación de la telomerasa que inicia un nuevo ciclo de elongación. ${ }^{42}$

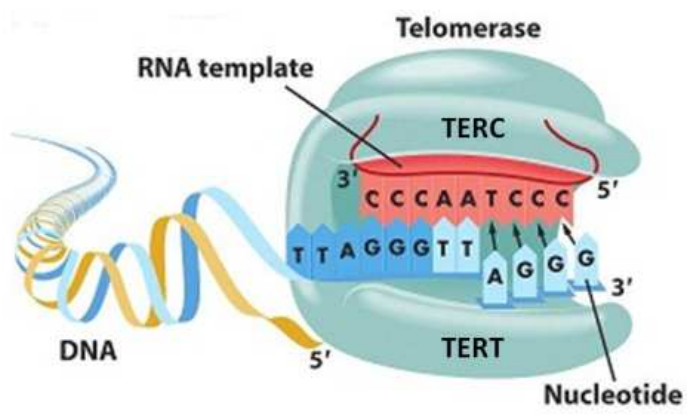

Figura 1.8. Elongación del telómero mediante acción combinada de TERC y hTERT ${ }^{43}$

La acción de la telomerasa contrarresta el acortamiento progresivo de los telómeros que se produce durante la replicación celular. ${ }^{44} \mathrm{Si}$ bien las células somáticas diferenciadas no presentan actividad telomerasa, dicho enzima está activado en el $85-90 \%$ de los cánceres. Además, la acción de la telomerasa está estrechamente relacionada con la malignidad y resistencia de algunos tipos de cáncer, por lo que la inhibición de la actividad telomerasa podría servir como un mecanismo selectivo supresor de tumores. ${ }^{45}$

\subsection{Angiogénesis}

La activación de la angiogénesis es otra de las señas de identidad de las células cancerosas. ${ }^{30}$ Con el término de angiogénesis se define el proceso de formación de nuevos vasos sanguíneos a partir de los vasos preexistentes.

\footnotetext{
${ }_{42}$ Philippi, C.; Loretz, B.; Schaefer, U. F.; Lehr, C. M. J. Control. Release 2010, 146, 228-240.

43 www.tankonyvtar.hu/hu/tartalom/tamop425/0011_1A_Gerontologia_en_book/ch02s04.html.

${ }^{44}$ Collins, K.; Mitchell, J. R. Oncogene, 2002, 21, 56 $4-5 \overline{7} 9$.

45 (a) Hernández, R. A. Rev. Cubana Invest. Biomed. 1999, 18, 121-129. (b) Buseman, C. M.; Wright, W. E.; Shay, J. W. Mutat. Res. 2012, 730, 90-97.
} 
Este proceso está altamente controlado mediante un balance dinámico entre factores pro- y antiangiogénicos, ${ }^{46}$ que se reúnen en la tabla 1.1.

Tabla 1.1. Factores proangiogénicos y antiangiogénicos. ${ }^{46}$

\begin{tabular}{|c|c|}
\hline PROANGIOGÉNICOS & ANTIANGIOGÉNICOS \\
\hline $\begin{array}{c}\text { Factor de crecimiento } \\
\text { endotelial vascular (VEGF) }\end{array}$ & Angiostatina \\
\hline Angiopoietinas & Endostatina \\
\hline $\begin{array}{c}\text { Factor de crecimiento de } \\
\text { fibroblastos }\end{array}$ & Trombospondina-1/2 \\
\hline $\begin{array}{c}\text { Factor de crecimiento } \\
\text { endotelial derivado de } \\
\text { plaquetas }\end{array}$ & Vasostatina \\
\hline $\begin{array}{c}\text { Factor de crecimiento } \\
\text { transformante-a/b }\end{array}$ & Factor plaquetario-4 \\
\hline Factor de necrosis tumoral-a & Osteopontina \\
\hline $\begin{array}{c}\text { Factor de crecimiento } \\
\text { epidermal }\end{array}$ & Inhibidores tisulares de \\
metaloproteinasas
\end{tabular}

La angiogénesis fisiológica normal se produce en la embriogénesis y continúa después del nacimiento en el desarrollo temprano postnatal. El objetivo de este proceso angiogénico es suministrar el oxígeno y los nutrientes requeridos por los órganos en crecimiento y proporcionar señales promotoras morfológicas para la formación de hueso endocondral y el crecimiento del esqueleto. En la etapa adulta, el proceso angiogénico tiene lugar únicamente

${ }^{46}$ (a) Carmeliet, P.; Jain, K. R. Nature 2000, 407, 249-257. (b) Makrilia, N.; Lappa, T.; Xyla, V.; Nikolaidis, I.; Syrigos, K. Eur. J. Intern. Med. 2009, 20, 663-671. 
en el ovario de las mujeres menstruantes y en la placenta durante el embarazo. La angiogénesis también se activa durante la reparación y la cicatrización de las heridas. ${ }^{34}$

La angiogénesis patológica o anormal es la que se activa en los tumores cancerosos. Así, las células cancerosas desregulan el equilibrio angiogénico promoviendo la neovascularización del tumor a fin de facilitar el acceso del oxígeno y de los nutrientes al mismo, lo que resulta en un rápido crecimiento tumoral. ${ }^{47}$ Los vasos sanguíneos que rodean al tumor no poseen una estructura normal y son funcionalmente inmaduros lo que facilita la diseminación de las células tumorales y favorece la metástasis. ${ }^{48}$ En la figura 1.9 se representa el proceso de activación de la angiogénesis tumoral.

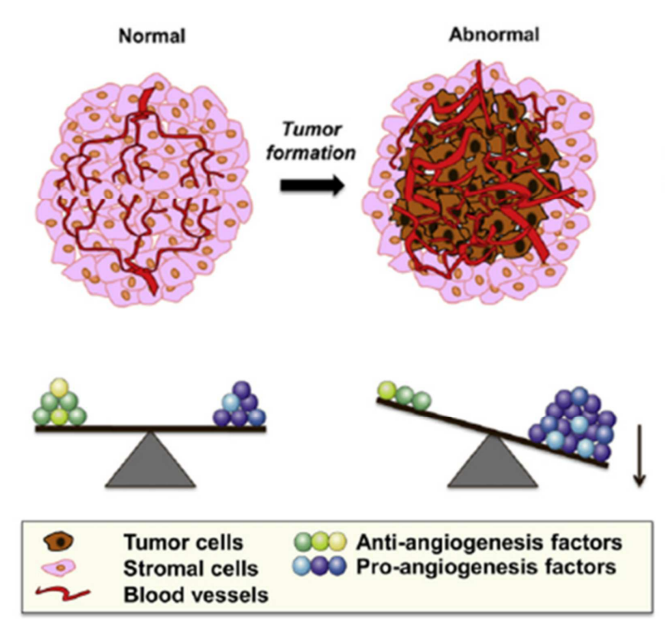

Figura 1.9. Activación de la angiogénesis en un tumor canceroso. ${ }^{47}$

Las proteínas VEGF (Vascular Endotelial Growth Factor) juegan un papel clave en la angiogénesis. La familia de factores VEGF incluye a VEGF-A, VEGF-B, VEGF-C, VEGF-D y VEGF-E y al factor de crecimiento placentario (PIGF). De todos los anteriores el más estudiado es el VEGF-A, cuyo efecto

\footnotetext{
47 (a) Giuliano, S.; Pagès, G. Biochimie 2013, 95, 110-119. (b) Martínez-Ezquerro, J. D.; Herrera, L. A. Cancerología 2006, 1, 83-96.

${ }^{48}$ Deryugina, E. I.; Quigley, J. P. Matrix Biol. 2015, 44, 94-112.
} 
biológico viene dado por la interacción con los receptores VEGFR-1 y VEGFR-2 situados en las células endoteliales. ${ }^{46}$ En la figura 1.10 se muestran distintos VEGF, sus receptores y el proceso que activan.

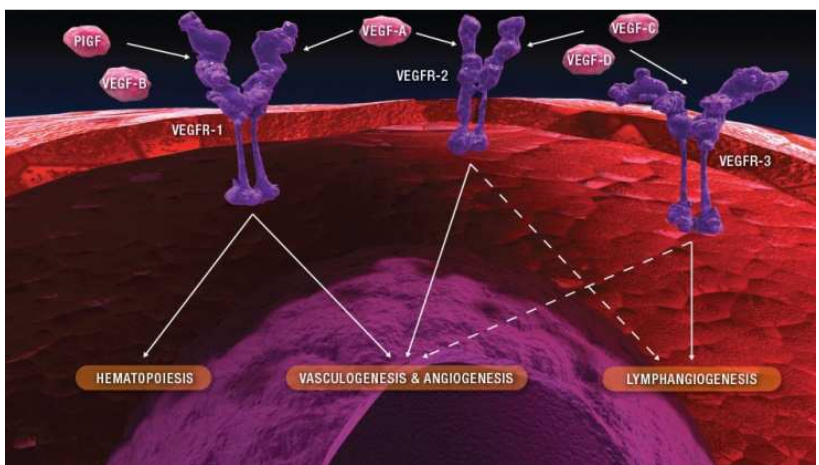

Figura 1.10. Familia de factores VEGF y receptores asociados. ${ }^{49}$

En condiciones de hipoxia la mayoría de células tumorales sobreexpresan el ARN mensajero del VEGF mientras que las células endoteliales adyacentes sobreexpresan los receptores VEGFR1 y VEGFR2. ${ }^{50}$

\subsection{Tubulina}

Con el nombre de tubulina se engloban las proteínas globulares denominadas alfa $(\alpha)$, beta $(\beta)$, gamma $(\gamma)$, delta $(\delta)$, épsilon $(\varepsilon)$ y zeta $(\zeta)$ tubulina $^{51}$. La a y $\beta$-tubulina son las más importantes ya que se unen formando un heterodímero. La unión cabeza-cola de este dímero forma protofilamentos los cuales se asocian longitudinalmente para formar una hoja que se pliega para dar lugar a un microtúbulo. ${ }^{52}$

\footnotetext{
${ }^{49} \mathrm{http}: / /$ www.lillyoncologypipeline.com/vegfr3-antibody.aspx

${ }^{50}$ Bellou, S.; Pentheroudakis, G.; Murphy, C.; Fotsis, T. Cancer Lett. 2013, 338, 219-228.

${ }^{51}$ Kaur, R.; Kaur, G.; Kaur Gill, R.; Soni, R.; Bariwal, J. Eur. J. Med.Chem. 2014, 87, 89-124.

${ }^{52}$ Zhou, J.; Giannakakou, P. Curr. Med. Chem. 2005, 5, 65-71.
} 
La secuencia de aminoácidos de la tubulina se encuentra muy conservada en todos los organismos eucariotas. ${ }^{53}$ Cada monómero contiene alrededor de 450 aminoácidos y una molécula de GTP. Los monómeros alfa y beta comparten aproximadamente el $50 \%$ de identidad de secuencia y sus estructuras tridimensionales son muy similares. ${ }^{54}$ La principal diferencia radica en el denominado bucle S9-S10, que contiene 8 aminoácidos más en el caso de la a-tubulina. Cada monómero tiene una estructura que consiste principalmente en tres dominios: ${ }^{55}$

$>$ El dominio N-terminal (residuos 1-206) que forma una estructura conocida como plegamiento de Rossman, con seis hojas $\beta$ paralelas (S1-S6) y seis hélices $\alpha(\mathrm{H} 1-\mathrm{H} 6)$ alternadas. Este dominio se encuentra involucrado en la unión del GTP/GDP.

$>$ El dominio central (residuos 207-384) que está formado por cuatro hojas $\beta$ paralelas (S7-S10) y tres hélices $\alpha(\mathrm{H} 8-\mathrm{H} 10)$ entremezcladas. Este dominio es el encargado de los contactos laterales entra los monómeros de $\alpha, \beta$-tubulina que van a originar los protofilamentos.

$>$ El domino C-terminal (a partir del residuo 385) que consiste en dos hélices $\alpha$ antiparalelas (H11 y H12). Este dominio está implicado en las interacciones con las proteínas asociadas a microtúbulos (MAPs), tales como la proteína tau.

El GTP de la subunidad beta es intercambiable por GDP mientras que el GTP de la subunidad alfa no es intercambiable. En la figura 1.11 se indica la estructura tridimensional del dímero de tubulina. En la parte superior de la figura se encuentra la subunidad beta (en verde), junto con una molécula de GDP asociada (en malva) y en la parte inferior se puede apreciar la subunidad alfa (en azul) que lleva asociada una molécula de GTP (en rojo).

\footnotetext{
53 (a) Burns, R. G.; Surridge, C. FEBS Lett. 1990, 271, 1. (b) Ducki, S.; Mackenzie, G.; Greedy, B.; Armitage, S.; Chabert, J.; Bennett E.; Nettles, J.; Snyder, J.; Lawrence, N. J. Bioorg. Med. Chem. Lett. 2009, 17, 7711-7722.

${ }^{54}$ Burns, R. G. Cell. Motil. Cytoskeleton 1991, 20, 181-189.

${ }_{55}$ Mcgrogan, B. T.; Gilmartin, B.; Carney, D. N.; McCann, A. Biochim. Biophys. Acta 2008, 1785, 96-132.
} 


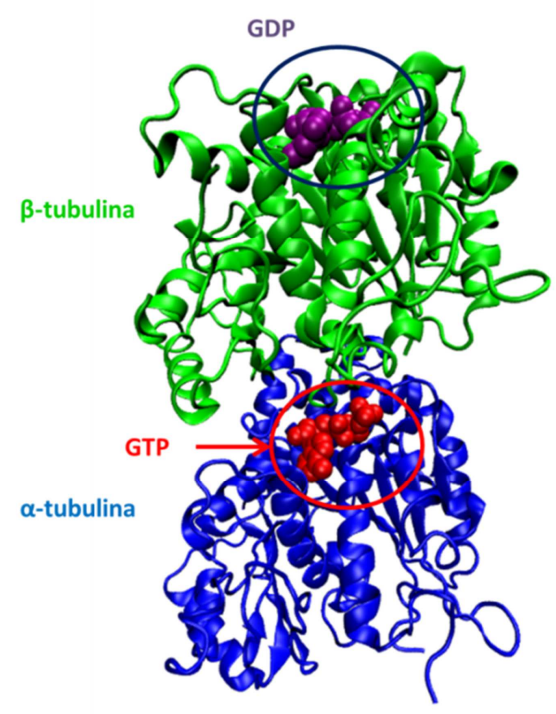

Figura 1.11. Estructura tridimensional del dímero de tubulina.

\subsubsection{Microtúbulos}

Los microtúbulos son cilindros huecos con un diámetro aproximado de $25 \mathrm{~nm}$ formados por la asociación longitudinal de protofilamentos de $\alpha, \beta$-tubulina. ${ }^{56}$ Los microtúbulos se pueden clasificar en microtúbulos estables, que son los que constituyen los cilios y flagelos, y los cambiantes o dinámicos, que se localizan en el citoplasma. Los microtúbulos citoplasmáticos forman el huso mitótico y son los encargados de la separación de los cromosomas en la fase de mitosis durante la división celular. También participan en el movimiento de orgánulos, como las mitocondrias, lisosomas, pigmentos, gotas de lípidos, etcétera y en la organización del tráfico vesicular. ${ }^{57}$

Cada protofilamento tiene una polaridad estructural. Así, la a-tubulina siempre está en un extremo del microtúbulo denominado extremo negativo (-) mientras que la $\beta$-tubulina siempre se sitúa en el extremo opuesto denominado extremo positivo $(+)$. Los nuevos dímeros de tubulina se añaden con una menor eficacia a la $\alpha$-tubulina que a la $\beta$-tubulina, por lo que el extremo (+) es

\footnotetext{
${ }^{56}$ Kaverina, I.; Straube, A. Sem. Cell Dev. Biol 2011, 22, 968-974.

57 Jordan, M. A.; Wilson L. Nat. Rev. Cancer 2004, 4, 253-265.
} 
el lugar preferente de crecimiento del microtúbulo. En la figura 1.12 se representa la estructura de un microtúbulo con los extremos $(+)$ ( $\beta$-tubulina) y $(-)$ ( $\alpha$-tubulina).

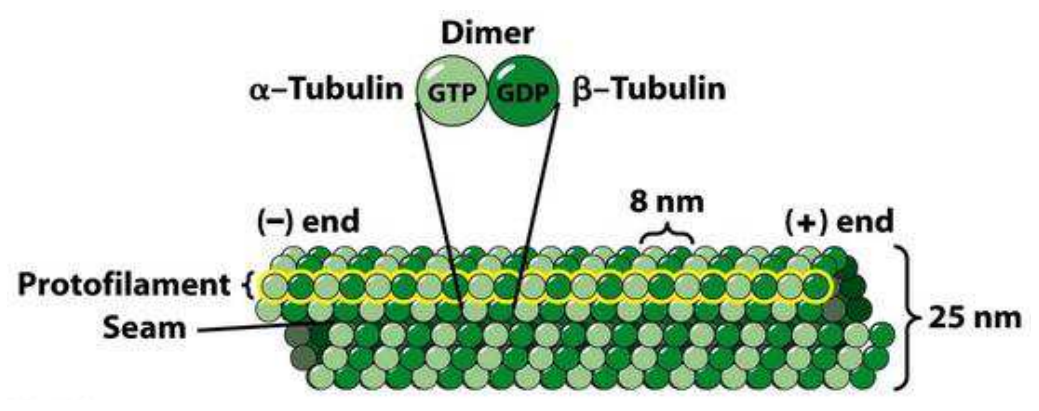

Figura 1.12. Representación de un microtúbulo. ${ }^{58}$

Como se ha indicado anteriormente, los monómeros constituyentes de la tubulina llevan asociada una molécula de GTP. La colocada en el monómero $\beta$ es hidrolizable a GDP mientras que la del monómero a no es hidrolizable.

Los microtúbulos se organizan de forma que el extremo positivo (+) está libre en el citoplasma, mientras que el extremo negativo (-) está asociado con el centrosoma o centro organizador de microtúbulos MTOC (MicroTubuleOrganizing Center). ${ }^{59}$ El centrosoma está constituido por dos centriolos y por el material pericentriolar PCM (Pericentriolar Material)..$^{60}$ Este material está compuesto por $y$-tubulina, que forma estructuras de tipo anillo que sirven como molde para la unión de los heterodímeros de $\alpha, \beta$-tubulina, permitiendo así el crecimiento del microtúbulo desde el centrosoma. ${ }^{61}$

\subsubsection{Dinámica de microtúbulos}

La dinámica de polimerización y despolimerización de microtúbulos juega un papel crucial en la función celular. El proceso de polimerización comienza

\footnotetext{
${ }^{58}$ https://biolcell4350. wikispaces.com/19.+Citoesqueleto+10+y+12+de+noviembre

${ }^{59}$ Orr, G.; Verdier-Pinard, P. Oncogene 2003, 22, 7280-7295.

${ }^{60}$ Nigg, E. A. Int. J. Cancer 2006, 119, 2717-2723.

${ }^{61}$ Warner, S. L.; Gray, P. J.; Von Hoff, D. D. Sem. Oncol. 2006, 33, 436-448.
} 
cuando un nuevo dímero de tubulina se añade al extremo (+) del microtúbulo en crecimiento, el dominio catalítico de la a-tubulina contacta con el GTP de la $\beta$-tubulina recién incorporada y provoca su hidrólisis a GDP. Como resultado, el cuerpo del microtúbulo está compuesto por $\beta$-tubulina GDP, salvo en el extremo (+), en el que existe una capa de dímeros de tubulina con la subunidad $\beta$ unida a GTP, denomina usualmente tapón (cap) de GTP. La pérdida del tapón de GTP provoca la despolimerización del microtúbulo, liberándose los heterodímeros de $\alpha, \beta$-tubulina al medio celular. ${ }^{62}$

La presencia de GTP y la hidrólisis a GDP en la $\beta$-tubulina proporcionan a los microtúbulos dos propiedades dinámicas denominadas treadmilling e inestabilidad dinámica. ${ }^{55}$

El término treadmilling designa el proceso que provoca el crecimiento neto en el extremo (+) del microtúbulo y el acortamiento neto en el extremo (-). La incorporación de nuevos dímeros de tubulina en el extremo (+) provoca el crecimiento del microtúbulo. Este crecimiento a veces se detiene repentinamente y el microtúbulo comienza su despolimerización, lo que puede provocar la desaparición del microtúbulo o, lo que ocurre más frecuentemente, el reinicio de proceso de polimerización. Esta alternancia entre fases de polimerización y despolimerización es lo que se denomina inestabilidad dinámica de los microtúbulos. ${ }^{63}$

El cambio de crecimiento a acortamiento del microtúbulo se denomina catástrofe mientras que el proceso contario, en el cual el microtúbulo aumenta su longitud, se denomina rescate (rescue). ${ }^{64}$ En la figura 1.13 se representa el proceso de inestabilidad dinámica de los microtúbulos.

\footnotetext{
62 (a) David-Pfeuty, T.; Erikson, H. P.; Panaloni, D. Proc. Natl. Acad. Sci. 1977, 74, 5371-5376.

(b) MacNeal, R. K.; Purich, D. L. J. Biol. Chem. 1978, 253, 4683-4687.

63 Jordan, M. A.; Wilson, L. Nat. Rev. Cancer 2004, 4, 253-265.

${ }^{64}$ Nogales, E. Annu. Rev. Biophys. Biomol. Struct. 2001, 30, 397-420.
} 


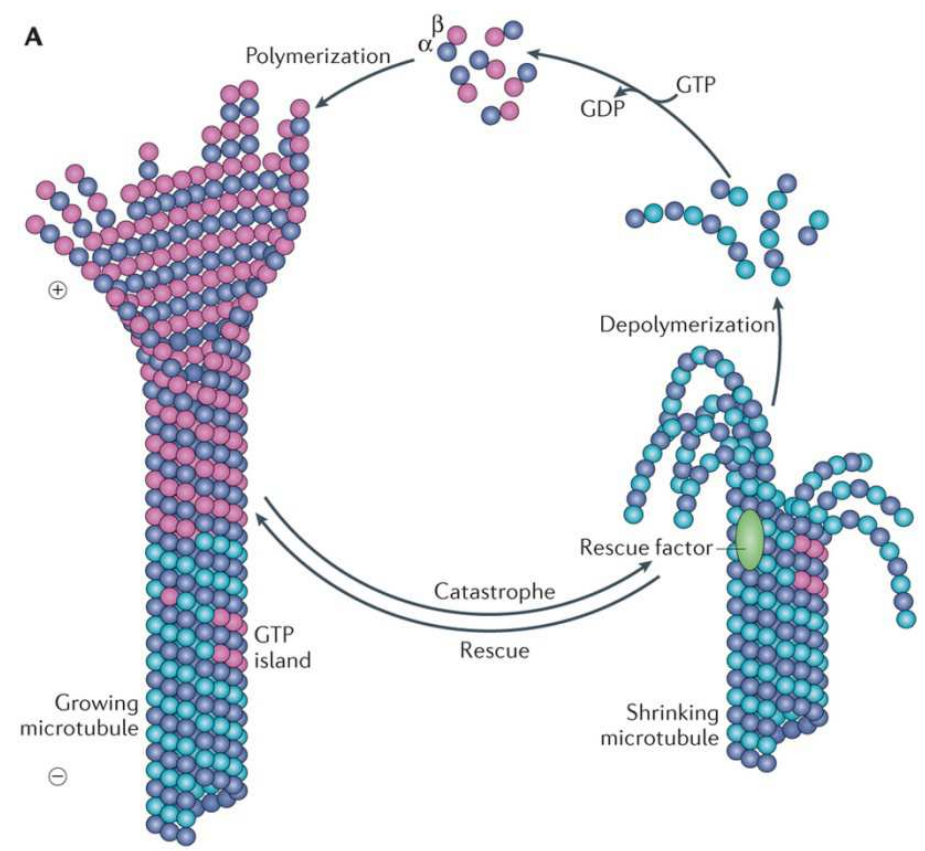

Figura 1.13. Proceso de catástrofe y rescate. ${ }^{65}$

La inestabilidad dinámica y el treadmilling ocurren en todas las células y están regulados por proteínas MAP (Microtubule Associated Proteins) que ayudan a estabilizar a los microtúbulos. La fosforilación de dichas proteínas provoca la inestabilidad de los microtúbulos. ${ }^{66}$

Estas propiedades dinámicas que presentan los microtúbulos juegan un papel fundamental en la división celular y en la segregación de los cromosomas durante la mitosis. ${ }^{67}$

\subsection{Ciclo celular}

El ciclo celular es una secuencia ordenada de procesos mediante los cuales las células se dividen dando lugar a dos células hijas. El ciclo celular

\footnotetext{
${ }^{65}$ Akhmanova, A.; Steinmetz, M. O. Nat. Rev. Mol. Cell Biol. 2015, 16, 711-726.

${ }^{66}$ Honore, S.; Pasquier, E.; Braguer, D. Cell. Mol. Life Sci. 2005, 62, 3039-3056.

${ }^{67}$ Mollinedo, F.; Gajate, C. Apoptosis 2003, 8, 413-450.
} 
consta de dos fases: estado de no división o interfase y estado de división o fase de mitosis (M) (véase la figura 1.14).

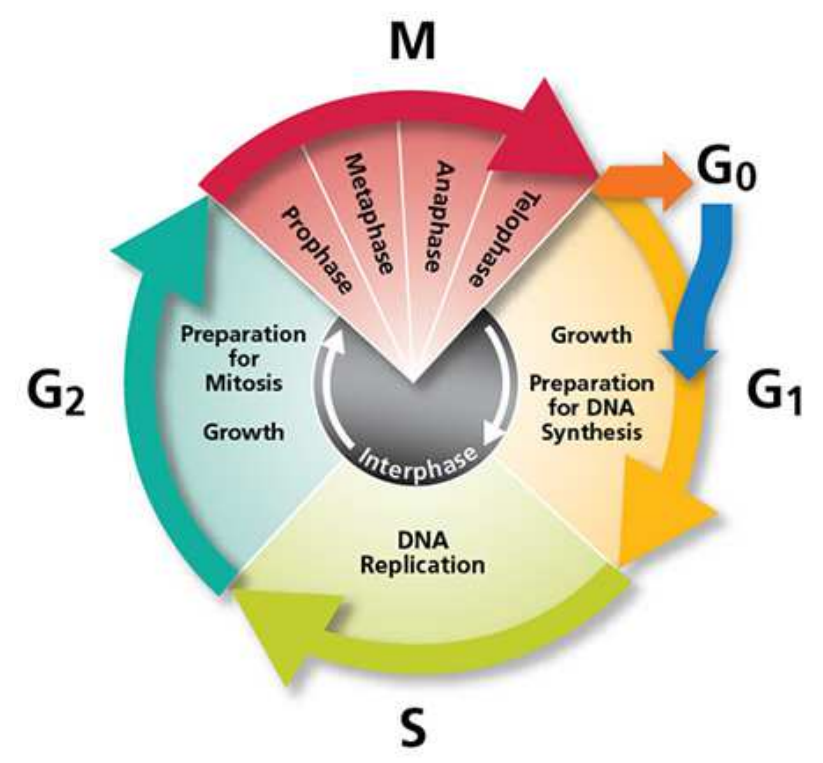

Figura 1.14. Esquema de las fases del ciclo celular. ${ }^{68}$

Como se muestra en la figura 1.14, la interfase se divide en tres etapas. La primera de ellas es la fase $G_{1}$ (Growth o Gap 1) en la que la célula crece mediante la síntesis continua de todos sus componentes, como el ARN y proteínas. En la siguiente fase, denominada $S$ (Synthesis), se replica el ADN y se duplican los centrosomas. La fase $S$ va seguida por la fase $G_{2}$ en la que se acumulan aquellas biomoléculas cuyas actividades serán necesarias durante la fase $\mathrm{M}^{69}$

La fase M (Mitosis) comprende dos procesos: la mitosis, en el cual los cromosomas de la célula, una vez duplicados, se distribuyen entre las que han de ser dos células hijas, y la citocinesis en la que se produce la separación física del citoplasma en dos células hijas.

\footnotetext{
${ }^{68} \mathrm{https}: / /$ oncogenesandcancer.wordpress.com/cell-cycle-checkpoints-and-effect-of-oncogenes-2/ ${ }^{69}$ http://www.profesorenlinea.cl/Ciencias/Celular_Ciclo.html
} 
La fase de mitosis se divide en cuatro fases denominadas profase, metafase, anafase y telofase. En la figura 1.15 se muestran todas las etapas del ciclo celular con los cambios que ocurren en la célula hasta originar las dos células hijas.

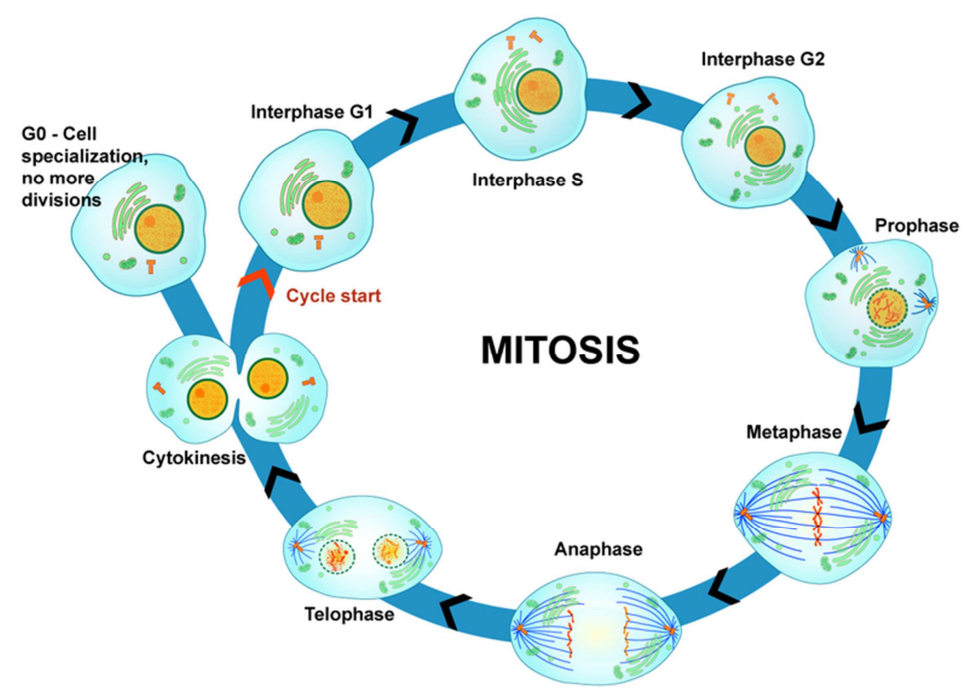

Figura 1.15. Fases del ciclo celular. ${ }^{70}$

En la profase las cromátidas se condensan en cromosomas, mientras que los centriolos empiezan a separarse y a moverse a los polos opuestos de la célula. A medida que los centriolos se desplazan se empieza a formar el huso mitótico, cuyo componente principal son los microtúbulos. La siguiente etapa es la metafase en la que los microtúbulos se unen a los cinetocoros, situados en los centrómeros del cromosoma, se rompe la membrana nuclear y se produce la alineación de los cromosomas. En la anafase se produce la separación de las cromátidas hermanas, que migran a polos opuestos de la célula. Esta separación tiene lugar gracias a la despolimerización de los microtúbulos que forman el huso mitótico. Finalmente en la telofase los cromosomas se envuelven en un nuevo núcleo formado alrededor de cada célula hija. ${ }^{66}$

${ }^{70}$ http://www.ck12.org/biology/Mitosis-and-Cytokinesis/lesson/Mitosis-and-Cytokinesis/ 
La fase con mayor duración es la fase G1, y la de menor, la M. Existe una fase, llamada $G_{0}$, de quiescencia permanente o temporal, en la que se detiene el ciclo celular. En esta fase quedan detenidas aquellas células que no se van a volver a dividir así como aquellas que necesitan estímulos externos o internos específicos para entrar en división. ${ }^{71}$

El ciclo celular es un proceso altamente regulado y se encuentra bajo la supervisión de los denominados puntos de control (checkpoints). Existen tres puntos de control claves en la progresión del ciclo celular. El situado en la fase $G_{1}$, denominado punto de restricción o de inicio, el situado al final de la fase $G_{2}$ y el de la mitosis, denominado punto de chequeo de la metafase o del huso mitótico. $^{72}$

Cualquier interferencia o anomalía que se produzca durante la división celular lleva a su interrupción y a la muerte celular por apoptosis. ${ }^{67}$

\subsection{Agentes antimitóticos}

Los fármacos empleados en los tratamientos de quimioterapia se pueden clasificar en base a su actuación en el ciclo celular. Así, los compuestos que ejercen su acción actuando sobre el ciclo celular se clasifican como cicloespecíficos mientras que los que actúan durante todo el ciclo de desarrollo de la célula se clasifican como ciclo-inespecíficos. ${ }^{73}$

Dentro de los fármacos ciclo-específicos se enmarcan los antimitóticos. Un compuesto antimitótico es el que inhibe o impide la mitosis celular. Esta acción biológica se puede conseguir alterando la dinámica de los microtúbulos. ${ }^{74} \mathrm{En}$ la figura 1.16 se clasifican los compuestos antimitóticos que interaccionan con

\footnotetext{
${ }_{71}^{71}$ http://medmol.es/glosario/55/

${ }^{72}$ De Maria, E.; Fages, F.; Rizk, A.; Soliman S. Theor. Comput. Sci. 2011, 21, 2108-2127.

${ }^{73}$ Alama, M. S.; Hossaina, M. A.; Algoul, S.; Majumader, M. A. A.; Al-Mamuna, M. A.; Sextona, G.; Phillips, R. Comput. Chem. Eng. 2013, 58, 14-32

${ }^{74}$ Carlson, R. O. Expert Opin. Investig. Drugs 2008, 17, 707-722.
} 
tubulina en función de su sitio de unión y de su acción estabilizadora o desestabilizadora de los microtúbulos. ${ }^{75}$

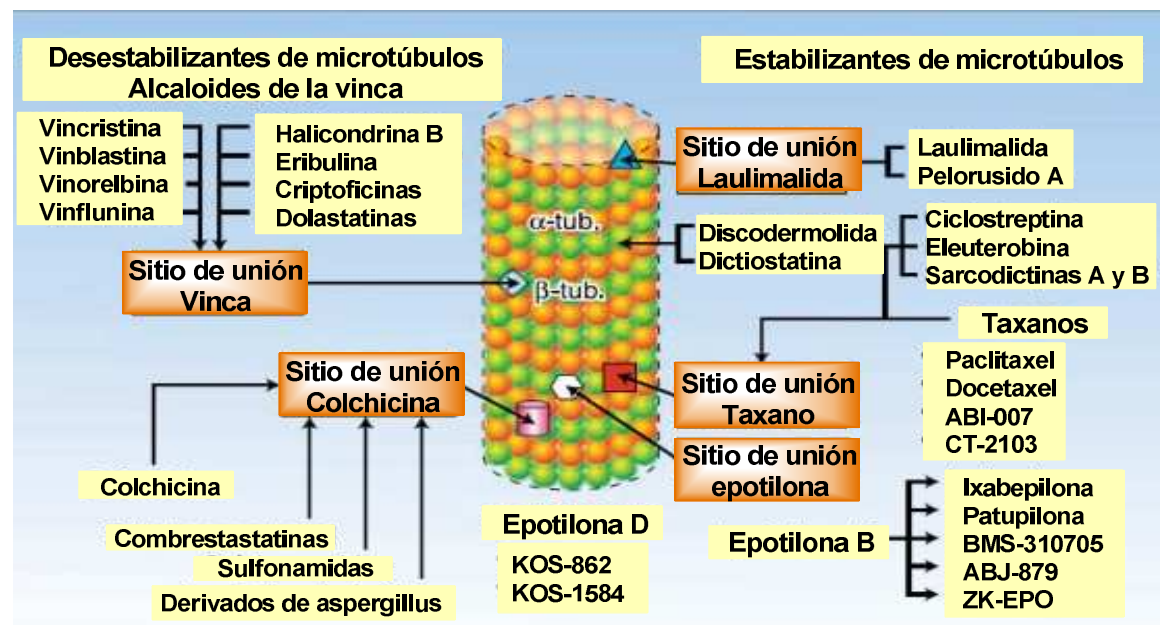

Figura 1.16. Compuestos que se unen a tubulina.

\subsubsection{Agentes estabilizantes de microtúbulos}

Los agentes estabilizantes de microtúbulos detienen el proceso de división celular mediante el bloqueo de la despolimerización de los microtúbulos. ${ }^{23}$ Dentro de esta familia se incluyen los taxanos, las epotilonas, la discodermolida, la eleuterobina, la sarcoditiina, la laulimalida y la pelorusida. Todos estos compuestos, cuyas estructuras se pueden ver en la figura 1.17, se unen a la $\beta$-tubulina en tres sitios de unión diferentes denominados sitio de taxano, sitio de epotilona y sitio de laulimalida, este último recientemente descubierto. ${ }^{76}$

\footnotetext{
${ }^{75}$ (a) Checchi, P. M.; Nettles, J. H.; Zhou, J.; Snyder, J. P.; Joshi, H. C. Trends Pharmacol. Sci. 2003, 24, 361-365. (b) Jordan, M. A.; Wilson, L. Nat. Rev. 2004, 4, 253-265.

${ }^{76}$ Prota, A. E.; Bargsten, K.; Northcote, P. T.; Marsh, M.; Altmann, K-H.; Miller, J. H.; Diaz, J. F.; Steinmetz, M. O. Angew. Chem. Int. Ed. 2014, 53, 1621-1625
} 


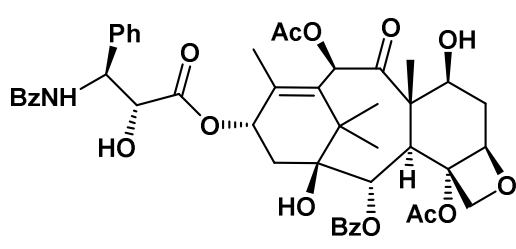

Paclitaxel $\left(\right.$ Taxol $^{\circledR}$ )<smiles>COC(CC1O[C@]1(C)CCC[C@H]1C(O)[C@@H](C)C(=O)C1(C)[C@H](O)CC(=O)O)/C(C)=C/c1csc(C)n1</smiles>

Patupilona (Epotilona B)

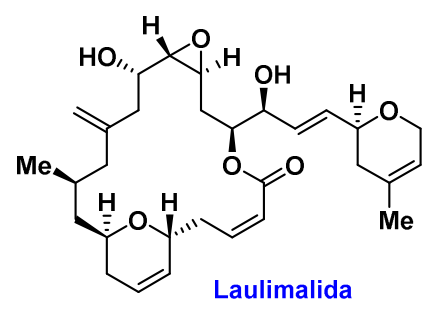
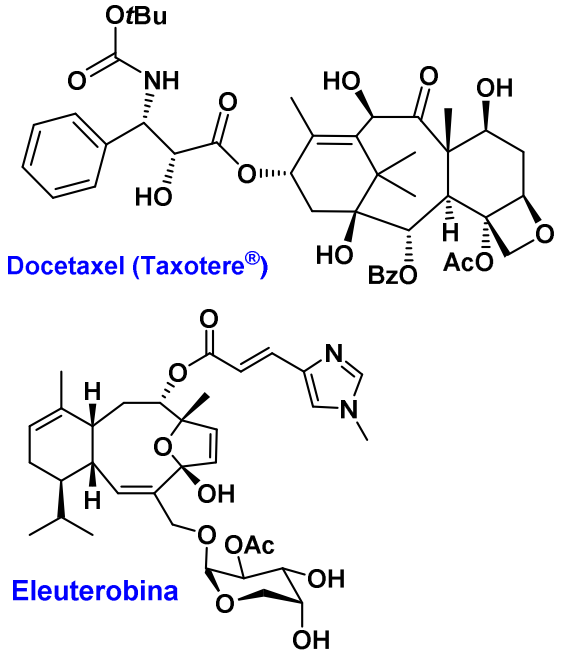

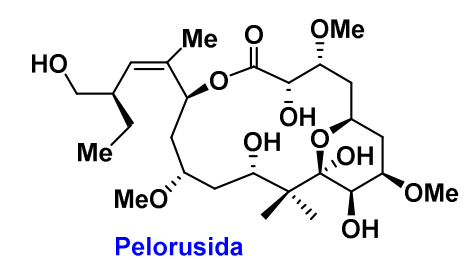<smiles>C=C/C=C\C(C)[C@@H](OC(N)=O)[C@@H](C)[C@H](O)/C(C)=C/C(C)C(O)C(C)/C=C\C(C)CC1OC(=O)C(C)[C@H](O)[C@H]1C</smiles><smiles>COC(=O)/C1=C/C2(O)C=CC(C)(O2)[C@H](OC(=O)/C=C/c2cn(C)cn2)C[C@H]2C1C(C)=CCC2C(C)C</smiles>

Sarcodityina A

Figura 1.17. Estructuras de agentes estabilizantes de microtúbulos.

El paclitaxel (Taxol®) es un metabolito diterpénico aislado por Wall y Wani en la década de los 60 de la corteza del árbol Taxus brevifolia. El paclitaxel es un estabilizante de los microtúbulos y fue aprobado en 1992 por la FDA para el tratamiento del cáncer de mama y de ovario refractario. Su éxito generó un enorme interés en la búsqueda de mejores análogos. El docetaxel es un derivado del taxol que se emplea en el tratamiento del cáncer de mama, 
cáncer de pulmón, cáncer de cabeza y cuello, cáncer de estómago y cáncer de próstata. ${ }^{77}$

En la figura 1.18 se representa el sitio de unión del paclitaxel (en verde) a la subunidad $\beta$ de la tubulina. ${ }^{78}$

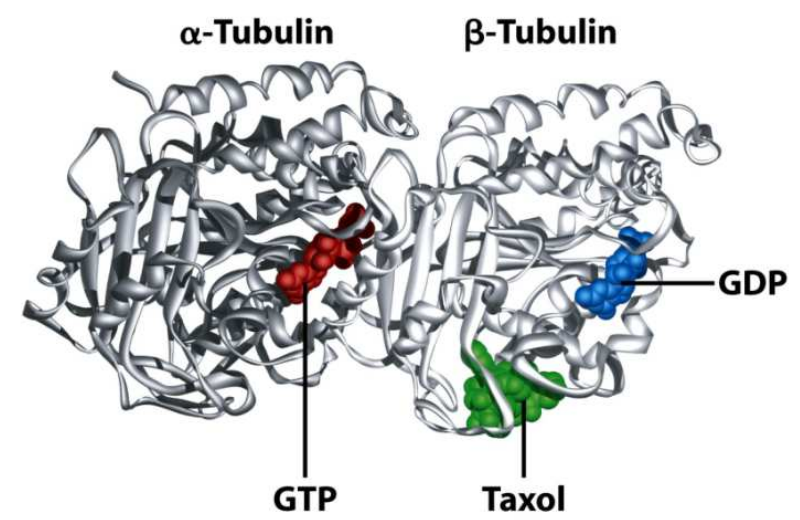

Figura 1.18. Sitio de unión del paclitaxel.

\subsubsection{Agentes desestabilizantes de microtúbulos}

Los agentes desestabilizantes de los microtúbulos detienen el proceso de división celular, facilitando el proceso de despolimerización de los microtúbulos. ${ }^{23}$ Dentro de esta familia se incluyen, entre otros, los alcaloides de la vinca tales como vinblastina y vincristina, así como otros compuestos como colchicina, criptoficina, combrestastatina A-4, dolastatina 10, halicondrina $B$ y espongistatina 1. Las estructuras de todos estos compuestos se dibujan en la figura 1.19 .

\footnotetext{
${ }^{77}$ Kingston, D. G. I. J. Nat. Prod. 2009, 72, 507-515.

${ }^{78}$ Schiff, P. B.; Fant, J.; Horwitz, S. B. Nature 1979, 277, 665-667.
} 

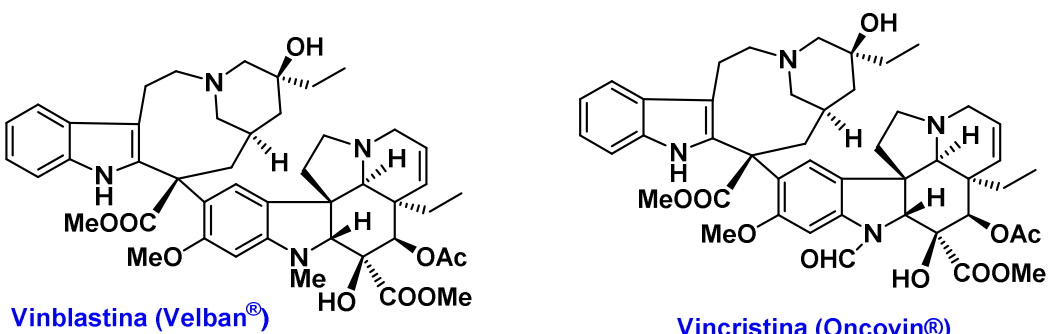

Vincristina (Oncovin®)<smiles>COc1ccc2c(c1)[C@H](NC(C)=O)CCc1cc(OC)c(OC)c(OC)c1-2</smiles>

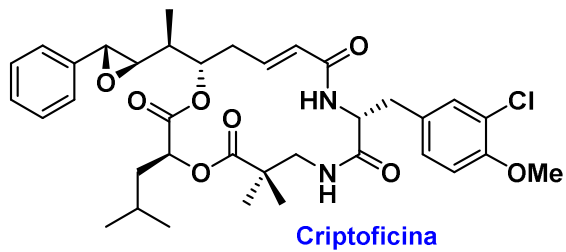<smiles>COc1ccc(/C=C\c2cc(OC)c(OC)c(OC)c2)cc1O</smiles>

Combretastatina A-4

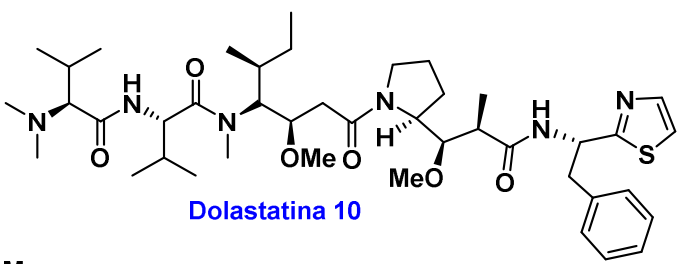

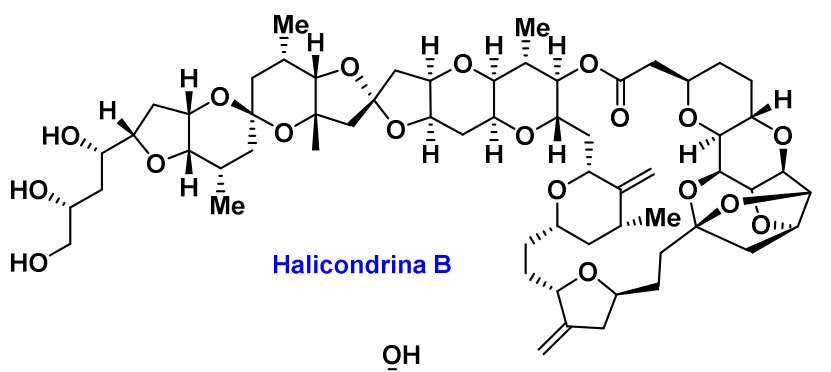

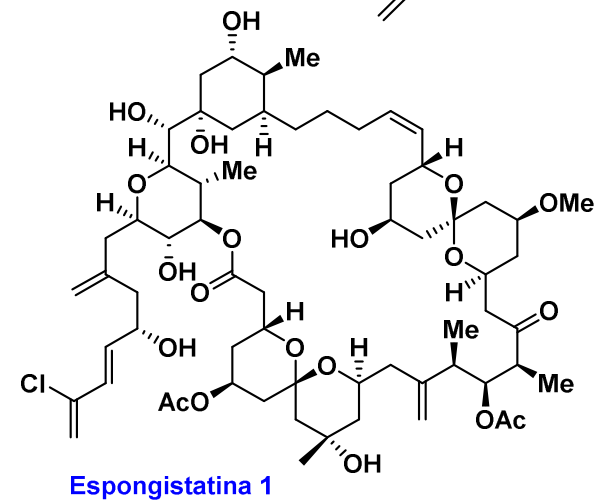

Figura 1.19. Estructuras de agentes desestabilizantes de microtúbulos. 
Recientemente se ha demostrado que la rhizoxina y la maytansina, dos potentes antimitóticos que inhiben el proceso de polimerización de la tubulina, se unen a la $\beta$-tubulina en un sitio diferente al sitio de los alcaloides de la vinca (véase la figura 1.20). ${ }^{79}$
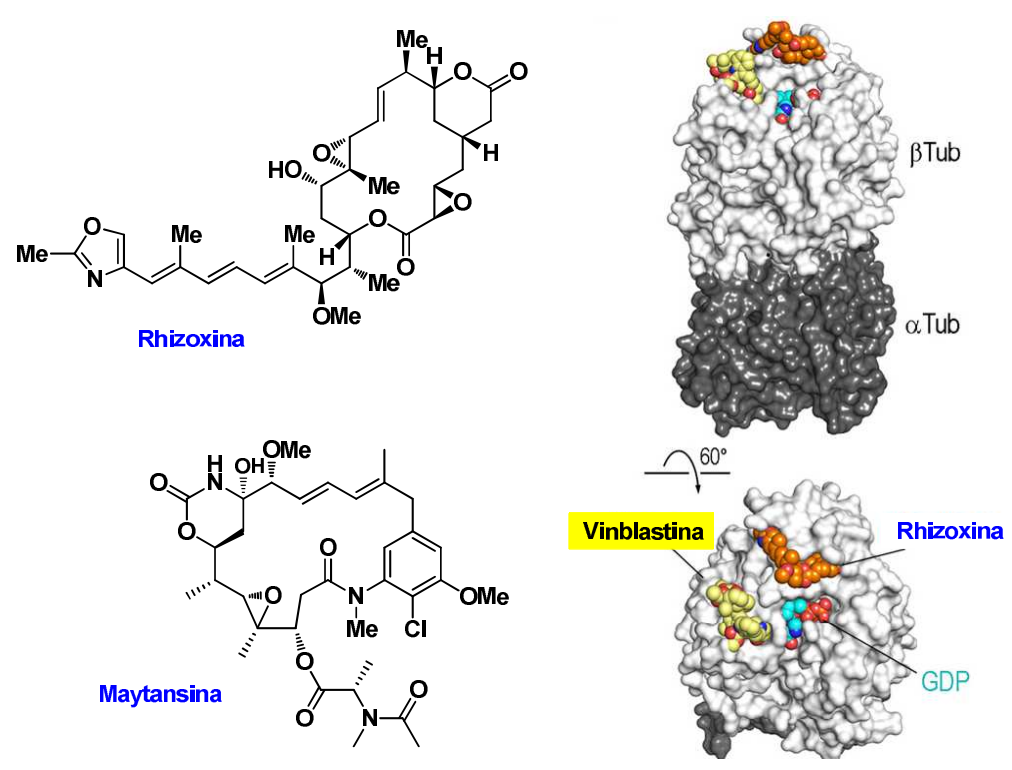

Figura 1.20. Estructuras de la rhizoxina y de la maytansina y su sitio de unión en la $\beta$ tubulina.

Todos los fármacos antimitóticos utilizados actualmente en los tratamientos oncológicos ejercen su acción antitumoral uniéndose a la $\beta$-tubulina. El número de esta clase de compuestos antimitóticos es relativamente elevado. Por el contrario, el número de compuestos antimitóticos que ejercen su acción antitumoral mediante unión a la subunidad de $\alpha$-tubulina es mucho menor. Entre esta clase de compuestos merece la pena mencionar productos naturales como la pironetina y las hemiasterlinas, y algunos compuestos

${ }_{79}$ Prota, A. E.; Bargsten, K.; Diaz, J. F.; Marsh, M.; Cuevas, C.; Liniger, M.; Neuhaus, C.; Andreu, J. M.; Altmann, K-H.; Steinmetz, M. O. Proc. Natl. Acad. Sci. USA 2014, 111, 1381713821. 
sintéticos tales como la trifluralina, la orizalina y la pendimetalina, ${ }^{80}$ cuyas estructuras pueden verse en la figura 1.21.<smiles>C/C=C/CC(C)[C@H](OC)[C@H](C)[C@@H](O)C[C@@H]1OC(=O)C=C[C@H]1CC</smiles><smiles>CCCN(CCC)c1c([N+](=O)[O-])cc(P(=O)(O)OC(N)=O)cc1[N+](=O)[O-]</smiles><smiles>[R]n1cc(C(C)(C)[C@H](NC)C(=O)N[C@H](C(=O)N(C)[C@H](/C=C(\C)C(=O)O)C(C)C)C(C)(C)C)c2ccccc21</smiles>
Hemiasterlina A R=H<smiles>CCC(CC)Nc1c([N+](=O)[O-])cc(C)c([N+](=O)[O-])c1[N+](=O)[O-]</smiles>

Pendimetalina

Figura 1.21. Estructuras de compuestos antimitóticos que se unen a la $\alpha$-tubulina.

\subsection{Colchicina}

La colchicina, cuya estructura se indica en la figura 1.22, es un alcaloide que se extrae de las hojas de Colchicum autumnale. En el papiro de Ebers, redactado en el Egipto antiguo cerca de 1.500 años antes de nuestra era, se menciona el extracto de colchicum como remedio para reducir la inflamación provocada por el reumatismo. ${ }^{81}$ La colchicina se ha empleado en el tratamiento de la amiloidosis, la enfermedad de Behçet, $^{82}$ la dermatitis herpetiforme, la fiebre mediterránea, la enfermedad de Paget $^{83}$ y la pericarditis. $^{84}$

\footnotetext{
${ }^{80}$ Sarabia, F.; García-Castro, M.; Sánchez-Ruiz, A. Curr. Bioact. Comp. 2006, 2, 269-299.

${ }^{81}$ Nuki, G.; Simkin, P. A. Arthritis Res. Ther. 2006, 8, Suppl 1:S1.

82 La enfermedad de Behçet es una dolencia reumática crónica que provoca inflamación de los vasos sanguíneos: http://www.niams.nih.gov/Portal_En_Espanol/Informacion_de_Salud/ Sindrome_de_Behcet/default.asp

${ }^{83}$ La enfermedad de Paget es una enfermedad inflamatoria del tejido óseo no metabólica que puede provocar una neoplasia benigna en las células formadoras del hueso, lo cual a su vez puede desembocar en un osteosarcoma agresivo: https://www.nlm.nih.gov/ medlineplus/spanish/ency/article/000414.htm.

${ }^{84}$ Leung, Y. Y.; Hui, L. L. Y.; Kraus, V. B. Semin. Arthritis Rheum. 2015, 45, 341-350.
} 

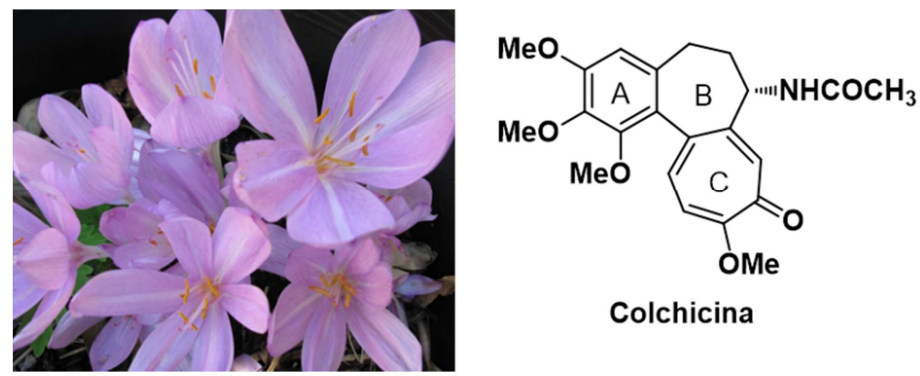

Colchicina

Figura 1.22. Colchicum autumnale y estructura de la colchicina.

La colchicina se considera como el fármaco de elección para el tratamiento de la gota. De hecho, los primeros informes sobre la utilización de este compuesto como remedio para esta dolencia datan de 1810. En el año 2009 la FDA aprobó la colchicina para el tratamiento de la gota y la fiebre mediterránea familiar (FMF). ${ }^{85}$ No se conoce con exactitud el mecanismo mediante el cual la colchicina es eficaz contra la gota. Parecer ser que disminuye la producción de ácido láctico por los leucocitos, lo que se traduce en una menor deposición de ácido úrico y en una reducción de la fagocitosis y de la inflamación. ${ }^{86}$

Uno de los mecanismos de acción terapéutica más estudiados de la colchicina es su capacidad de unión a la tubulina, lo que provoca el bloqueo del ensamblaje y la polimerización de los microtúbulos. En 1998, Downing y Nogales propusieron la colocación de la colchicina en la interfase entre las subunidades de a y $\beta$-tubulina. ${ }^{87}$ En 2004, Ravelli y colaboradores consiguieron determinar, mediante cristalografía de rayos $\mathrm{X}$, la ubicación de la colchicina en el dominio intermedio de la $\beta$-tubulina, al lado del dominio GTP de la subunidad de $\alpha$-tubulina (véase la figura 1.23). ${ }^{88}$

\footnotetext{
${ }^{85}$ Woodcock, J.; Okada, S. N. Engl. J. Med. 2010, 363, 1484.

${ }^{86}$ Malawista, S. E.; Bodel, P. T. J. Clin. Invest. 1967, 46, 786-796

${ }^{87}$ Nogales, E.; Wolf, S.; Downing, K. Nature 1998, 19, 1639.

${ }^{88}$ Ravelli, R.; Gigant, B.; Curmi, P.; Jourdain, I.; Lachkar, S.; Sobel, A. Nature 2004, 428, 198.
} 


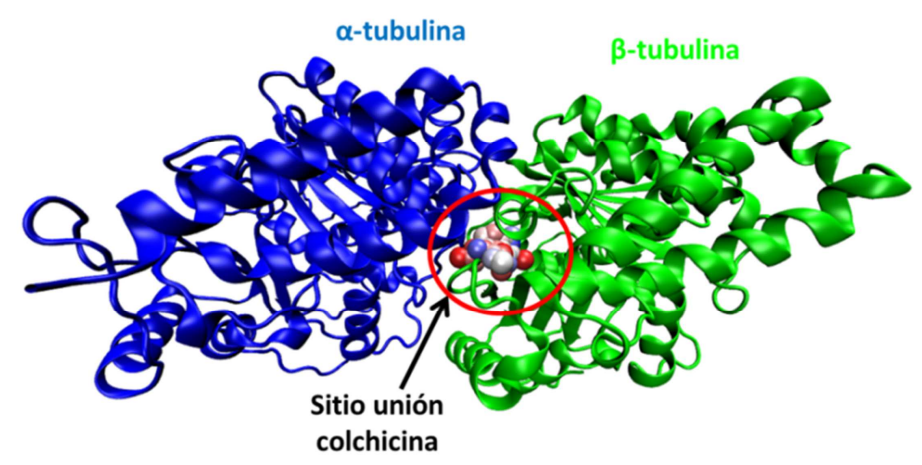

Figura 1.23. Sitio de unión de la colchicina en la $\beta$-tubulina.

La colchicina es un agente antimitótico que inhibe la polimerización de la tubulina mediante la formación de complejos tubulina-colchicina (T-C) ${ }^{89} \mathrm{La}$ velocidad de formación de estos complejos es lenta con respecto a la velocidad de formación de microtúbulos. El ensamblaje de los complejos T-C se realiza en dos etapas. En la primera de ellas se forma reversiblemente un complejo de baja afinidad colchicina-tubulina. En la segunda etapa se produce un cambio conformacional lento del mencionado complejo que desemboca en la formación de un complejo tubulina-colchicina mucho más estable y, por tanto, poco reversible, ${ }^{90}$ que copolimeriza en los extremos de los microtúbulos (véase la figura 1.24). ${ }^{91}$

\footnotetext{
${ }^{89}$ (a) Leung, Y. Y.; Hui, L. L. Y.; Kraus, V. B. Semin. Arthritis Rheum., 2015, 45, 341-350. (b) Deftereos, S.; Giannopoulos, G.; Papoutsidakis, N. et al. J. Am. Coll. Cardiol. 2013, 62, 18171825.

${ }_{90}$ Hastie, S. B. Pharmacol. Ther. 1991, 512, 377-401.

${ }^{91}$ (a) Skoufias, D.; Wilson, L. Biochemistry 1992, 31, 738-746. (b) Bergen, L. G.; Borisi, G. G. J. Cell Biochem. 1986, 30, 11-18.
} 


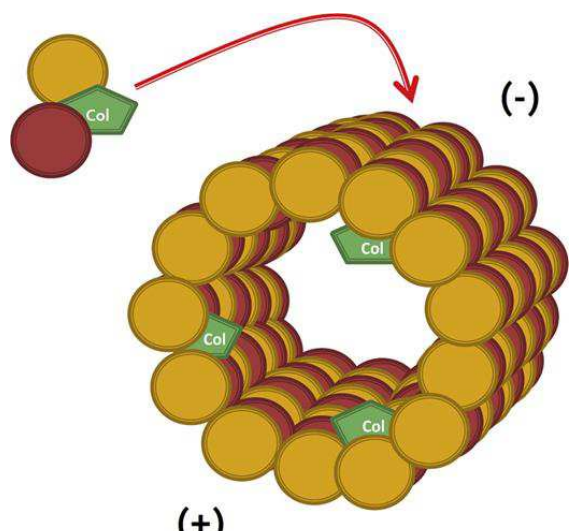

$(+)$

Figura 1.24. Colocación de los complejos tubulina-colchicina en el microtúbulo. ${ }^{89}$

A altas concentraciones la colchicina provoca la despolimerización de los microtúbulos y a bajas concentraciones impide el crecimiento de los mismos. ${ }^{92}$ Es posible observar diferentes efectos en las fases de iniciación y elongación de los microtúbulos en presencia de colchicina. Así, en la fase de iniciación se produce una pequeña inhibición debido a que el complejo T-C compite con los dímeros de tubulina, mientras que en la fase de elongación la asociación reversible del complejo T-C con el extremo del microtúbulo bloquea su elongación. ${ }^{93}$ Esta acción inhibidora del crecimiento de los microtúbulos se explica del siguiente modo. El complejo T-C adquiere una conformación ligeramente doblada debido al impedimento estérico entre la colchicina, el GTP y los residuos a101 y a181. La incorporación de este complejo T-C de conformación distorsionada perturba la formación de los contactos laterales entre los microtúbulos y detiene su elongación. ${ }^{94}$

\footnotetext{
92 (a) Stanton, R. A.; Gernert, K. M.; Nettles, J. H.; Aneja, R. Med. Res. Rev. 2011, 31, 443-481. (b) Skoufas, D.A.; Wilson, L. Biochemistry, 1992, 31,738-746. (c) Chen, J.; Liu, T.; Dong, X.; Hu, Y. Mini-Rev. Med. Chem. 2009, 9, 1174-1190.

${ }_{93}$ Keates, R. A.; Mason, G. B. Can. J. Biochem. 1981, 59, 361-370.

${ }^{94}$ Bhabatarak, B.; Panda, D.; Gupta, S.; Banerjee, M. Med. Res. Rev. 2008, 28, 155-183.
} 
A pesar de la interesante actividad biológica de la colchicina, su elevada toxicidad ha impedido su empleo como fármaco antitumoral. ${ }^{95} \mathrm{El}$ fosfato de $N$-acetilcolchinol ZD-6126 es un análogo de colchicina que es convertido in vivo en $\mathrm{N}$-acetilcolchinol (véase la figura 1.25).
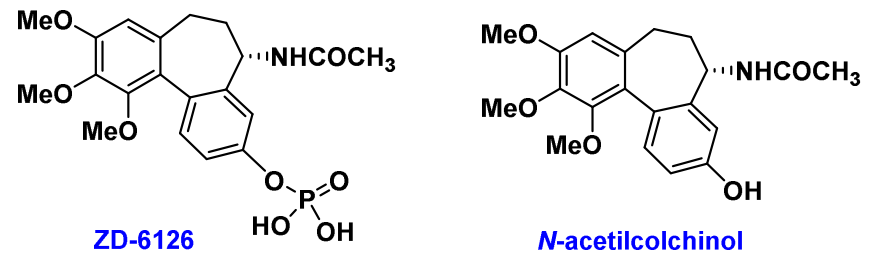

Figura 1.25. Estructuras del $\mathrm{N}$-acetilcolchinol y de ZD-6126.

El ZD-6126 es también un agente desestabilizante de microtúbulos que ha mostrado tener actividad antiangiogénica y antitumoral. ${ }^{96}$

\subsection{Derivados de colchicina}

En esta Tesis se sintetizarán y estudiarán desde el punto de vista de la actividad biológica una serie de derivados en los que formalmente se cambiará el grupo acetilo de la colchicina por otros grupos acilo, haloacetilo, aroílo y aminoacilo. Las estructuras generales de estos derivados de colchicina se indican la figura 1.26.
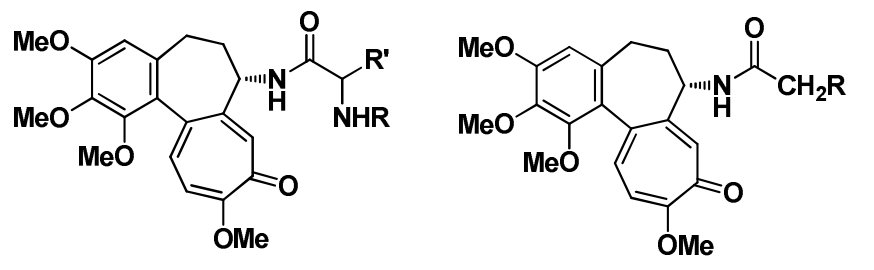<smiles></smiles>

$\mathrm{R}=\mathrm{alquilo,} \mathrm{ciclohexilo,} \mathrm{halógeno}$

Figura 1.26. Estructuras generales de derivados de colchicina.

\footnotetext{
${ }_{95}$ Massarotti, A.; Coluccia, A.; Silvestri, R.; Sorba, G.; Brancale, A. Minirev. ChemMedChem 2012, 7, 33-42.

${ }_{96}$ Goto, H.; Yano, S.; Zhang, H.; Matsumori, Y.; et al. Cancer Res. 2002, 62, 3711-3715.
} 
Una búsqueda bibliográfica de este tipo de compuestos ha revelado la síntesis previa de los compuestos cuyas estructuras se indican en la figura 1.27.<smiles>CCCC(=O)N[C@H]1CCc2cc(OC)c(OC)c(OC)c2-c2cc(OC)ccc21</smiles><smiles>COc1ccc2c(c1)CCC[C@H]2NC(=O)CF</smiles><smiles>COc1ccc2c(c1)CCC[C@H]2NC(=O)CCl</smiles><smiles></smiles><smiles>COc1ccc2c(c1)CCCC(NC(=O)CI)c1cc(OC)c(OC)cc1-2</smiles><smiles></smiles><smiles></smiles>

Figura 1.27. Derivados de colchicina previamente descritos en la literatura científica.

El compuesto I aparece descrito en un trabajo publicado por A. Brossi y colaboradores en J. Med. Chem. en el año $1983 .{ }^{97}$ La toxicidad de este compuesto, definida como la dosis en micromoles/kg que causa la pérdida de peso de más de $3 \mathrm{~g}$ en al menos uno de seis ratones o la muerte de uno de seis ratones, fue de 5.8 frente a 2.5 de la colchicina. Por otro lado, la unión a tubulina, definida como el porcentaje por el cual la unión a tubulina de $2.5 \mu \mathrm{M}$ de $\left[{ }^{3} \mathrm{H}\right]$ colchicina se reduce por la presencia de $25 \mu \mathrm{M}$ del compuesto, fue de 98 frente a 90 de la colchicina.

\footnotetext{
${ }^{97}$ Brossi, A.; Sharma, P. N.; Atwell, L.; Jacobson, A. E.; Iorio, M. A; Molinari, M.; Chignells, C. F. J. Med. Chem. 1983, 26, 1365-1369.
} 
Los compuestos II, III, IV y V, todos ellos haloacetil derivados de colchicina, se describen en una patente como agentes antimitóticos. ${ }^{98}$

La acción antitumoral de los compuestos II y VI fue estudiada por F. R. Quinn y J. A. Beisler en ratones a los que se les indujo leucemia linfocítica P388. ${ }^{99}$ En la publicación de estos autores se indica el valor de log (1/C), siendo C la concentración en mol/kg que produce un porcentaje de supervivencia en el tiempo igual o mayor al $40 \%$. Mayores valores de log (1/C) son indicativos de una mayor acción antileucémica del compuesto en cuestión. De todos los derivados de colchicina estudiados en la publicación de Quinn y Beisler, el más activo era el fluoroderivado II, con un valor de log $(1 / C)$ de 7.13. El compuesto VI tenía un valor de log $(1 / C)$ de 5.76 mientras que la colchicina exhibía un valor de 6.46 .

En una publicación posterior, Quinn, Beisler y Neiman determinaron el valor de $\mathrm{LD}_{50}$, en $\mathrm{mg} / \mathrm{Kg}$, de derivados de colchicina entre los que se encontraban los compuestos II y VI. El $L_{50}$ es la cantidad de compuesto que provoca la muerte del $50 \%$ de un grupo de animales de prueba. En la publicación de Quinn, Beisler y Neiman se utilizaron también ratones a los que se les indujo leucemia linfocítica P388. ${ }^{100}$ Menores valores de $L_{50}$, o mayores valores de $\log \left(1 / L D_{50}\right)$, implican mayor toxicidad del compuesto. Los valores log $\left(1 / L_{50}\right)$ eran de 5.69 para el fluoroderivado II, 4.24 para VI y 5.46 para la colchicina.

El cloroderivado II aparece en el contexto de una publicación de Reymond y colaboradores cuyo objetivo principal era la síntesis y la evaluación biológica de conjugados de colchicina con dendrímeros glicopeptídicos. Las líneas celulares investigadas fueron HeLa, correspondientes a cáncer cérvicouterino, y la línea no tumoral MEF, correspondiente a fibroblastos embrionarios de ratón. ${ }^{101}$ En este trabajo se indica el porcentaje de células tumorales HeLa

\footnotetext{
${ }^{98}$ E. Merck AG, Patent FR2002496, 1969.

${ }^{99}$ Quinn, F. R.; Beisler, J. A. J. Med. Chem. 1981, 24, 251-256.

${ }_{100}^{100}$ Quinn, F. R.; Neiman, Z.; Beisler, J. A. J. Med. Chem. 1981, 24, 636-639.

${ }^{101}$ Lagnoux, D.; Darbre, T.; Schmitz, M. L.; Reymond, J.-L. Chem. Eur. J. 2005, 11, 3941-3950.
} 
y MEF después de tres días de incubación en presencia de $5 \mu \mathrm{M}$ del compuesto en cuestión. En la línea HeLa los porcentajes fueron de 0.2 para el cloroderivado II y el mismo valor para la colchicina mientras que en la línea MEF los porcentajes fueron de 0.6 para II y 2.4 para la colchicina, lo que indica que la colchicina, en comparación con el compuesto II, es menos citotóxica en la línea no tumoral que en la línea tumoral.

La $N$-desacetil- $N$-valilcolchicina VII aparece descrita en la bibliografía como resultado de la escisión provocada por legumaina (una cisteínaproteasa) de un derivado tetrapeptídico de la colchicina (Suc-Al-Al-Asn-Valcolchicina). ${ }^{102}$ En este trabajo se indican los valores de viabilidad celular, obtenidos mediante el ensayo colorimétrico basado en la reducción del bromuro de 3-(4,5-dimetiltiazol-2-ilo)-2,5-difeniltetrazol (MTT) por la enzima mitocondrial succinato-deshidrogenasa de células metabólicamente activas. La enzima transforma al MTT, que es un compuesto hidrofílico de color amarillo, en un compuesto morado hidrofóbico, denominado formazán. En este ensayo la cantidad de células vivas es proporcional a la cantidad de formazán producido, por lo que este método permite medir la supervivencia y la proliferación celular y, en consecuencia, determinar la citotoxicidad de los compuestos. Los valores de viabilidad celular de la $\mathrm{N}$-desacetil$\mathrm{N}$-valilcolchicina VII se midieron sobre la línea celular M38L, que sobreexpresa legumaina, y la línea celular HK293 (células embrionarias de riñón humano) que sobreexpresa cistatina E/M. ${ }^{103}$ En la publicación se indican los valores de $E_{25}$, que es la concentración de compuesto capaz de inhibir al $25 \%$ la viabilidad celular. Los datos de $\mathrm{EC}_{25}$ para el compuesto VII fueron de $0.20 \mu \mathrm{M}$

\footnotetext{
102 Smith, R. L.; Åstrand, O. H. A.; Nguyen, L. M.; Elvestrand, T.; Hagelin, G.; Solberg, R.; Johansen, H. T.; Rongved. P. Bioorg. Med. Chem. 2014, 22, 3309-3315.

${ }_{103}$ Las cistatinas son una familia de proteínas algunas de las cuales tienen actividad inhibidora de cisteína-proteasas. En algunos tumores metastásicos de mama la expresión del gen que codifica cistatina está inhibida en relación con las células del tumor primario, por lo que se considera que la pérdida de la expresión del gen está asociada con la conversión del tumor primario en tumor metastásico (véase http://www.ncbi.nlm.nih.gov/gene/1474).
} 
en la línea M38L y de $0.08 \mu \mathrm{M}$ en la línea HEK293, mientras que el valor de la colchicina fue de $0.02 \mu \mathrm{M}$ en la línea M38L. 


\section{CAPÍTULO 2 \\ OBJETIVOS}

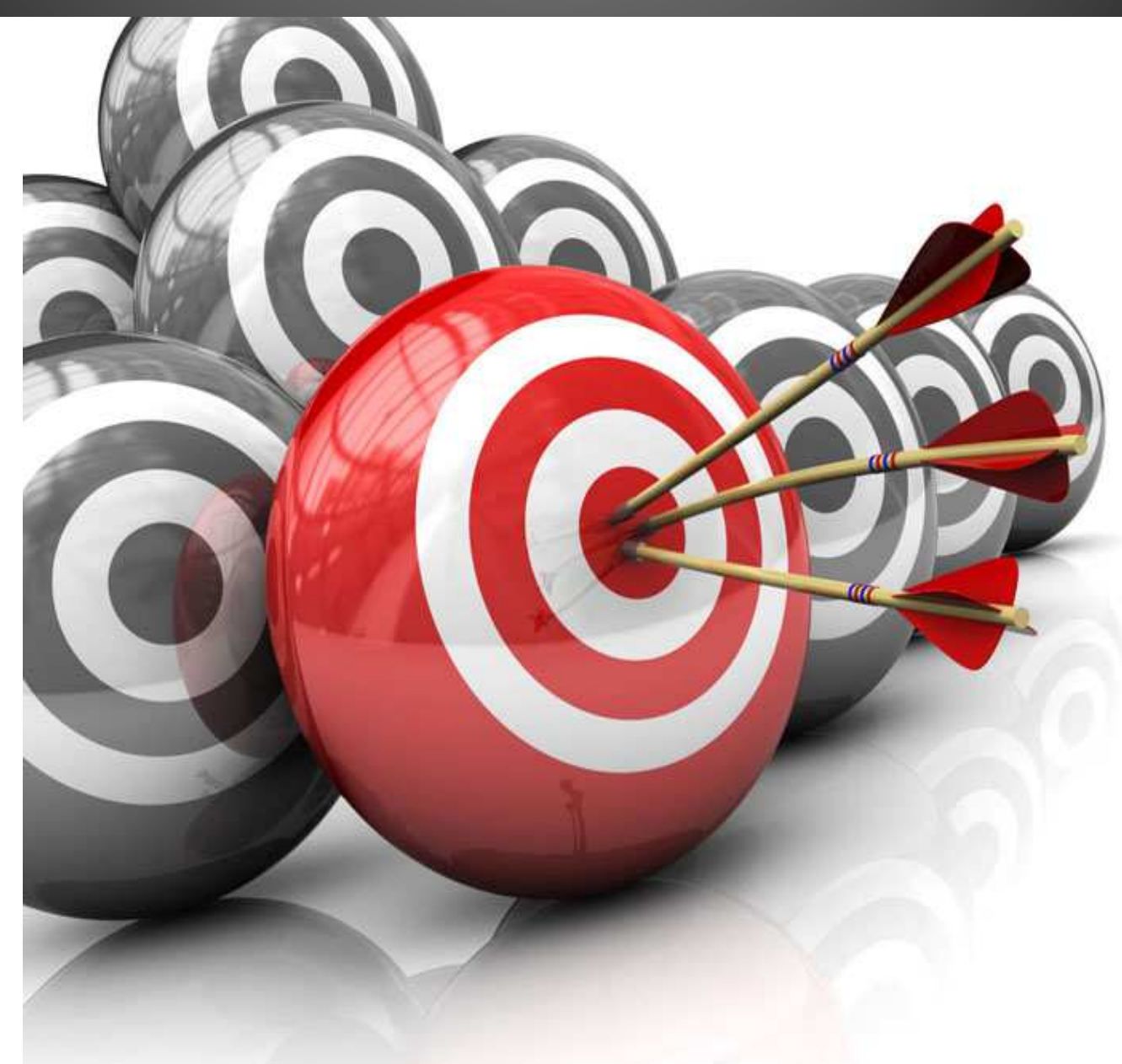





\section{CAPÍTULO 2: OBJETIVOS}

Según la OMS (Organización Mundial de la Salud), se prevé que el número de nuevos casos de cáncer aumente aproximadamente un $70 \%$ en los próximos años, ${ }^{104}$ lo que explica la perentoria necesidad de continuar investigando el desarrollo de nuevos fármacos que ayuden a combatir esta enfermedad.

Como se ha comentado en el apartado de introducción, la tubulina es el principal constituyente proteico de los microtúbulos. La formación de los microtúbulos que forman el huso mitótico es un proceso dinámico ya que los microtúbulos están continuamente polimerizándose y despolimerizándose en un proceso denominado inestabilidad dinámica de los microtúbulos. Cualquier compuesto que interfiera en la dinámica de los microtúbulos, inhibiendo bien la polimerización o bien la despolimerización de los mismos, provocará el boqueo mitótico y la muerte celular por apoptosis.

La colchicina es un producto natural aislado de Colchicum autumnale L. (Liliaceae) que impide el proceso de polimerización de la tubulina mediante unión con la subunidad $\beta$ de la misma. ${ }^{105} \mathrm{~A}$ pesar de ser una molécula ampliamente estudiada, su aplicación médica en el tratamiento de quimioterapia contra el cáncer está muy limitada debido a su elevada toxicidad. ${ }^{106}$

Los objetivos de esta Tesis se enfocan a la síntesis y evaluación biológica de derivados de colchicina.

1) En el apartado sintético se prepararán tres familias de derivados de colchicina cuyas estructuras generales se indican en la figura 2.1.

\footnotetext{
$104 \mathrm{http} / / /$ www.who.int/mediacentre/factsheets/fs297/es/

105 a) Chen, J.; Liu, T.; Dong, X.; Hu, Y. Mini-Rev. Med. Chem. 2009, 9, 1174-1190. (b) Petit, G. R.; Singh, S. B.; Niven, M. L.; Schmidt, J. M. J. Nat. Prod. 1987, 50, 119-131.

${ }^{106}$ Huczynski, A.; Rutkowski, J.; Popiel, K.; Maj, E.; Wietrzyk, J.; Stefanska, J.; Majcher, U.; Bartl, F. Eur. J. Med. Chem. 2015, 90, 296-301.
} 
a) La familia 1 está compuesta por derivados de colchicina en los que se ha sustituido el grupo acetilo del átomo de nitrógeno por grupos $\alpha$-aminoacilo derivados de aminoácidos.

b) La familia 2 está formada por compuestos en los que se ha cambiado el grupo acetilo por grupos acilo alifáticos de diversos tipos.

c) La familia 3 la constituyen compuestos en los que se ha cambiado el grupo acetilo por grupos aroílo.<smiles>[R]C(N)C(=O)N[C@H]1CCc2cc(OC)c(OC)c(OC)c2-c2ccc(OC)c(=O)cc21</smiles>

Familia 1<smiles>CCPC(=O)N[C@H]1CCc2cc(OC)c(OC)c(OC)c2-c2ccc(OC)c(=O)cc21</smiles>

Familia 2<smiles>CCC(=O)N[C@H]1CCc2cc(OC)c(OC)c(OC)c2-c2ccc(OC)c(=O)cc21</smiles>

Familia 3 R=alquilo, ciclohexilo, halógeno

Figura 2.1. Estructura general de los derivados de colchicina.

2) En el apartado de actividad biológica se investigará:

a) La actividad citotóxica de los derivados sintéticos frente a diferentes líneas celulares, tanto tumorales como no tumorales.

b) Las interacciones de los derivados de colchicina con tubulina.

c) El efecto de los derivados de colchicina sobre la secreción de la proteína VEGF y la inhibición de la expresión de su gen asociado, así como los efectos sobre la expresión de los genes hTERT y c-Myc, ambos implicados en la activación de la telomerasa. 


\section{CAPÍTULO 3 \\ SÍNTESIS DE ANÁLOGOS \\ DE COLCHICINA}

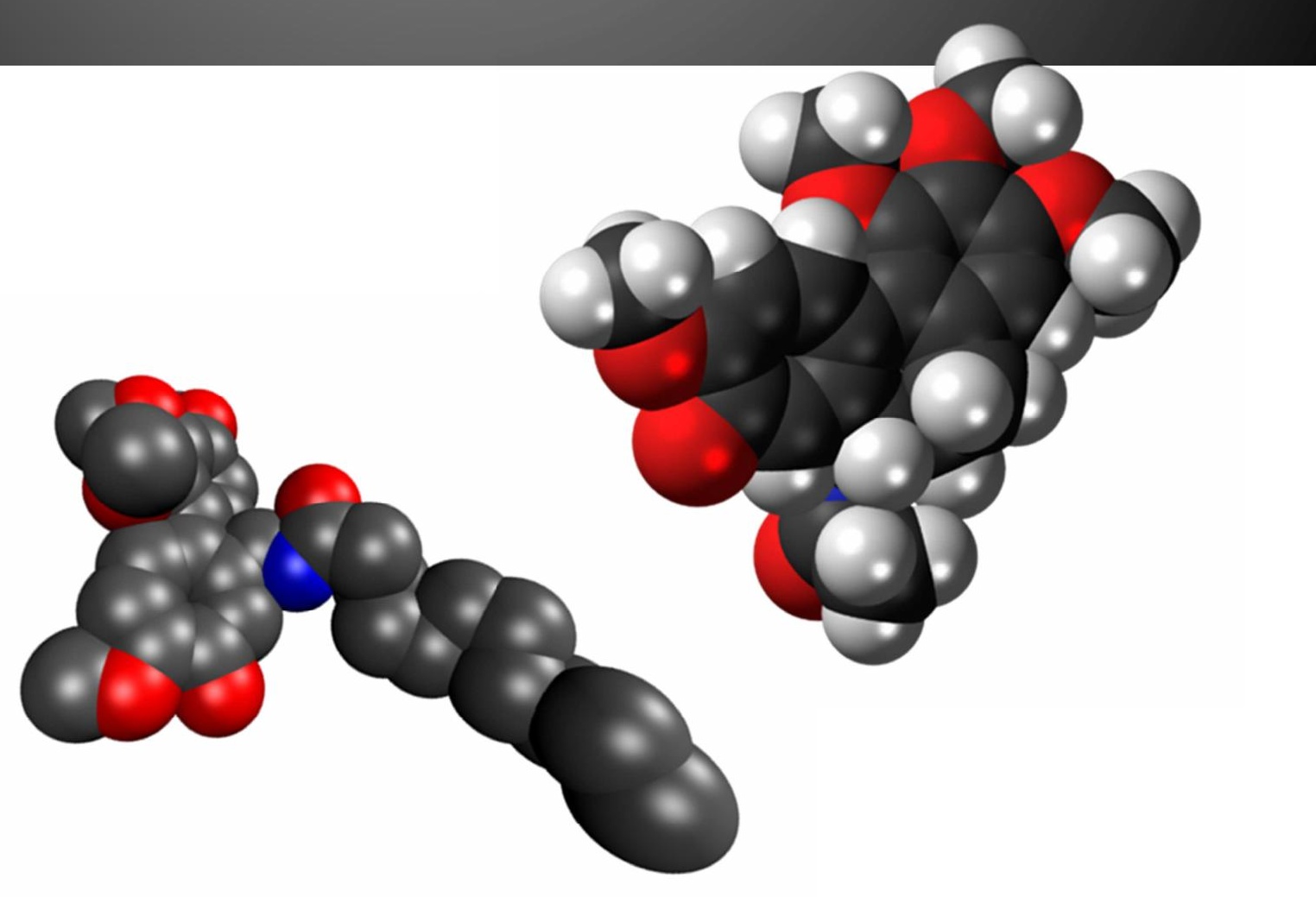





\section{CAPÍTULO 3: SÍNTESIS}

En este capítulo se describirán las secuencias sintéticas que han permitido obtener los compuestos que forman las tres familias de derivados de colchicina. Para la síntesis de todos estos compuestos se ha empleado como producto de partida $\mathrm{N}$-desacetilcolchicina, obtenida a partir de colchicina como se describe en el siguiente apartado.

\subsection{Síntesis de $\mathrm{N}$-desacetilcolchicina}

La $\mathrm{N}$-desacetilcolchicina se obtuvo a partir de la colchicina mediante una secuencia sintética descrita ${ }^{107}$ de tres pasos que se inicia con la $N$-Boc protección y que va seguida de $\mathrm{N}$-desacetilación y de $\mathrm{N}$-Boc desprotección, tal y como se indica en el esquema 3.1. ${ }^{108}$ Como la $N$-Boc desprotección se lleva a cabo por tratamiento con ácido trifluoroacético, la $N$-desacetilcolchicina se obtiene en forma de sal de trifluoroacetato (véase la estructura 3 del esquema 3.1).
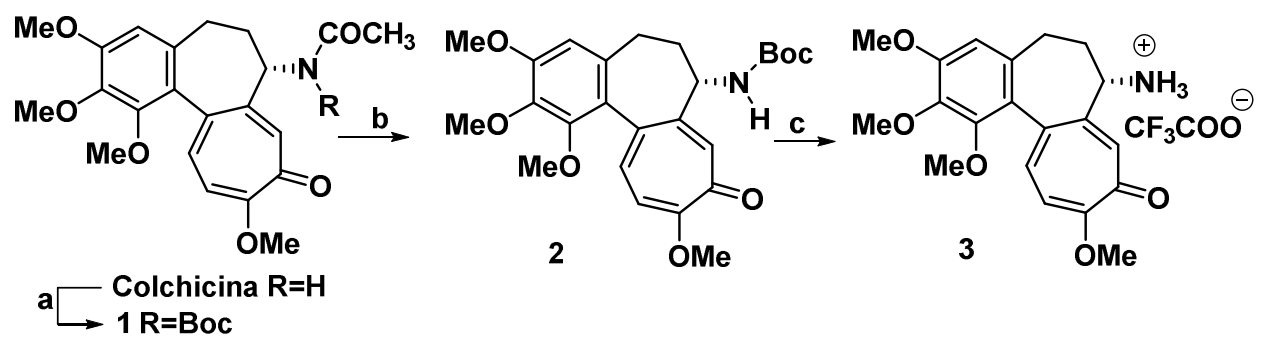

\section{Esquema 3.1}

Reactivos y condiciones: (a) $\mathrm{Boc}_{2} \mathrm{O}, \mathrm{Et}_{3} \mathrm{~N}, \mathrm{DMAP}, \mathrm{THF}, 45{ }^{\circ} \mathrm{C}, 24 \mathrm{~h}, 99 \%$. (b) $\mathrm{NaOMe}(2 \mathrm{M}$ en $\mathrm{MeOH})$, temp. amb., 2 h. (c) TFA ac. $98 \%$, temp. amb., 5 min (98\% de rendimiento global en los dos pasos).

\footnotetext{
107 Bagnato, J. D.; Eilers, A. L.; Horton, R. A.; Grissom, C. B. J. Org. Chem. 2004, 69, 89878996.

108 Johansson, E.; Dubois, J.; Darbre, T.; Reymond, J. L. Bioorg. Med. Chem. 2010, 18, 65896597.
} 


\subsection{Síntesis de los compuestos de la familia 1}

La familia 1 está constituida por derivados de colchicina que provienen de la sustitución formal del grupo acetilo de la colchicina por grupos $\alpha$-aminoacilo derivados de aminoácidos proteinogénicos de la serie configuracional L. Para la síntesis de los constituyentes de la familia 1 se procedió en primer lugar a la $N$-Boc protección ${ }^{109}$ de los aminoácidos tal y como se indica en el esquema 3.2 (entre paréntesis se indican los rendimientos obtenidos).<smiles>[R]C(N)C(=O)O</smiles>

$4 \mathrm{R}=\mathrm{H}, \mathrm{R}^{\prime}=\mathrm{H}$ (glicina)

$5 \mathrm{R}=\mathrm{CH}_{3}, \mathrm{R}^{\prime}=\mathrm{H}$ (alanina)

$6 \mathrm{R}=\mathrm{CH}\left(\mathrm{CH}_{3}\right)_{2}, \mathrm{R}^{\prime}=\mathrm{H}$ (valina)

$7 \mathrm{R}=\mathrm{CH}_{2} \mathrm{CH}\left(\mathrm{CH}_{3}\right)_{2}, \mathrm{R}^{\prime}=\mathrm{H}$ (leucina)

$8 \mathrm{R}=\mathrm{CH}_{2} \mathrm{Ph}, \mathrm{R}^{\prime}=\mathrm{H}$ (fenilalanina)

$9 \mathrm{R}, \mathrm{R}^{\prime}=\left(\mathrm{CH}_{2}\right)_{4}$ (prolina)

$10 \mathrm{R}=\mathrm{CH}_{2} \mathrm{OH}, \mathrm{R}^{\prime}=\mathrm{H}$ (serina)

$11 \mathrm{R}=\mathrm{CH}(\mathrm{OH}) \mathrm{CH}_{3}, \mathrm{R}^{\prime}=\mathrm{H}$ (treonina)

$12 \mathrm{R}=\mathrm{CH}_{2}\left(\mathrm{C}_{6} \mathrm{H}_{4} \mathrm{OH}\right), \mathrm{R}^{\prime}=\mathrm{H}$ (tirosina)

$13 \mathrm{R}=\left(\mathrm{CH}_{2}\right)_{2} \mathrm{SCH}_{3}, \mathrm{R}^{\prime}=\mathrm{H}$ (metionina)

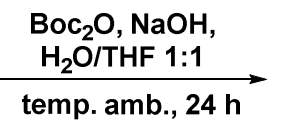

$14 \mathrm{R}=\mathrm{H}, \mathrm{R}^{\prime}=\mathrm{H}(95 \%)$

$15 \mathrm{R}=\mathrm{CH}_{3}, \mathrm{R}^{\prime}=\mathrm{H}(91 \%)$

$16 \mathrm{R}=\mathrm{CH}\left(\mathrm{CH}_{3}\right)_{2}, \mathrm{R}^{\prime}=\mathrm{H}(92 \%)$

$17 \mathrm{R}=\mathrm{CH}_{2} \mathrm{CH}\left(\mathrm{CH}_{3}\right)_{2}, \mathrm{R}^{\prime}=\mathrm{H}(96 \%)$

$18 \mathrm{R}=\mathrm{CH}_{2} \mathrm{Ph}, \mathrm{R}^{\prime}=\mathrm{H}(98 \%)$

$19 \mathrm{R}, \mathrm{R}^{\prime}=\left(\mathrm{CH}_{2}\right)_{4}(67 \%)$

$20 \mathrm{R}=\mathrm{CH}_{2} \mathrm{OH}, \mathrm{R}^{\prime}=\mathrm{H}(100 \%)$

$21 \mathrm{R}=\mathrm{CH}(\mathrm{OH}) \mathrm{CH}_{3}, \mathrm{R}^{\prime}=\mathrm{H}(99 \%)$

$22 \mathrm{R}=\mathrm{CH}_{2}\left(\mathrm{C}_{6} \mathrm{H}_{4} \mathrm{OH}\right), \mathrm{R}^{\prime}=\mathrm{H}(98 \%)$

$23 \mathrm{R}=\left(\mathrm{CH}_{2}\right)_{2} \mathrm{SCH}_{3}, \mathrm{R}^{\prime}=\mathrm{H}(98 \%)$

Esquema 3.2

Del mismo modo, unos pocos aminoácidos de la serie configuracional enantiomérica $\mathrm{D}$ se convirtieron también en sus $N$-Boc derivados del modo que se indica en el esquema 3.3.<smiles>[R]C(N)C(=O)O</smiles>

$24 \mathrm{R}=\mathrm{CH}\left(\mathrm{CH}_{3}\right)_{2}, \mathrm{R}=\mathrm{H}$ $25 \mathrm{R}=\mathrm{CH}_{2} \mathrm{CH}\left(\mathrm{CH}_{3}\right)_{2}, \mathrm{R}=\mathrm{H}$ $26 \mathrm{R}=\mathrm{CH}_{2} \mathrm{Ph}, \mathrm{R}=\mathrm{H}$ $27 \mathrm{R}, \mathrm{R}^{\prime}=\left(\mathrm{CH}_{2}\right)_{4}$ $28 \mathrm{R}=\mathrm{CH}_{2}\left(\mathrm{C}_{6} \mathrm{H}_{4} \mathrm{OH}\right), \mathrm{R}^{\prime}=\mathrm{H}$

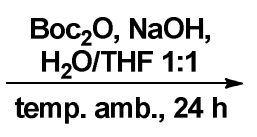<smiles>[R]C(=O)C(=O)O</smiles>

$29 \mathrm{R}=\mathrm{CH}\left(\mathrm{CH}_{3}\right)_{2}, \mathrm{R}^{\prime}=\mathrm{H}(92 \%)$ $30 \mathrm{R}=\mathrm{CH}_{2} \mathrm{CH}\left(\mathrm{CH}_{3}\right), \mathrm{R}^{\prime}=\mathrm{H}(98 \%)$ $31 \mathrm{R}=\mathrm{CH}_{2} \mathrm{Ph}, \mathrm{R}^{\prime}=\mathrm{H}(91 \%)$ $32 \mathrm{R}, \mathrm{R}^{\prime}=\left(\mathrm{CH}_{2}\right)_{4}(63 \%)$ $33 \mathrm{R}=\mathrm{CH}_{2}\left(\mathrm{C}_{6} \mathrm{H}_{4} \mathrm{OH}\right), \mathrm{R}^{\prime}=\mathrm{H}(76 \%)$

Esquema 3.3

\footnotetext{
${ }^{109}$ Boger, D.; Borzilleri, R.; Nukui, S. J.Org. Chem. 1996, 61, 3561-3565.
} 
Los péptidos Gly-Gly y Gly-Gly-Gly, comercialmente accesibles, se convirtieron asimismo en sus $N$-Boc derivados como se describe en el esquema 3.4.

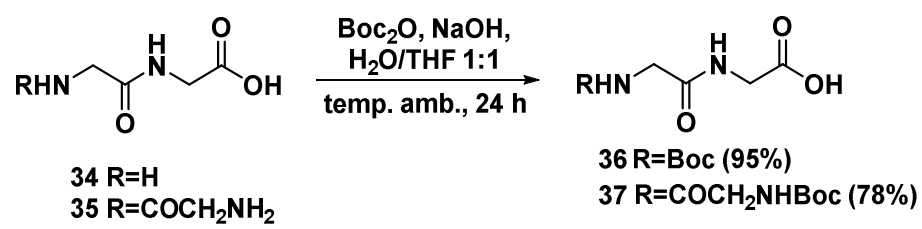

Esquema 3.4

La reacción del trifluoroacetato 3 con los $N$-Boc-L- $\alpha$-aminoácidos se llevó a cabo en presencia de EDCl y DMAP, en DMF como disolvente. ${ }^{110}$ Las reacciones de acoplamiento peptídico proporcionaron los compuestos indicados en el esquema 3.5, los cuales, mediante $N$-Boc desprotección con la resina ácida Amberlyst $15^{111}$ seguida de lavado con $\mathrm{NH}_{3} 4 \mathrm{M}$ en $\mathrm{MeOH}$, se convirtieron en los correspondientes $\mathrm{N}$ - $\alpha$-aminoacil derivados de colchicina dibujados en el esquema 3.5.

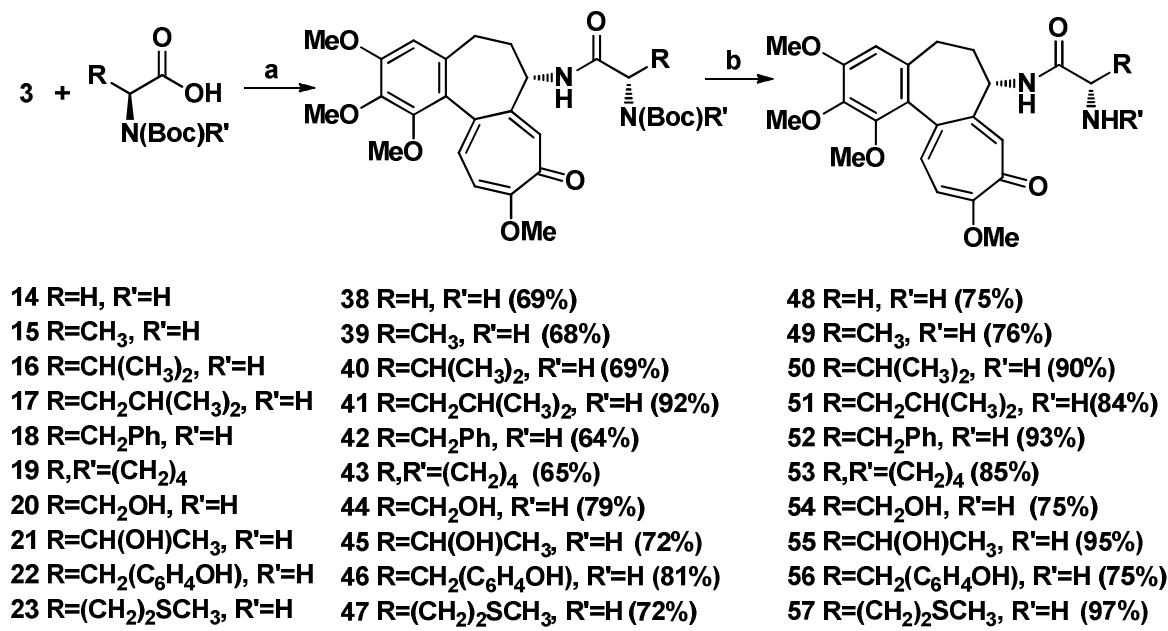

Esquema 3.5

Reactivos y condiciones: (a) EDCI, DMAP, DMF, de $0{ }^{\circ} \mathrm{C}$ a temp. amb. (b) Resina Amberlyst 15, $\mathrm{CH}_{2} \mathrm{Cl}_{2}$, temp. amb., 24 h, luego $\mathrm{NH}_{3} 4 \mathrm{M}$ en $\mathrm{MeOH}, 1 \mathrm{~h}$, temp. amb.

\footnotetext{
110 Iwaszkiewicz-Grzes, D.; Cholewinski, G.; Kot-Wasik, A.; Trzonkowski, P.; Dzierzbicka, K. Eur. J.Med. Chem. 2013, 69, 863-871.

${ }_{111}$ Liu, Y.; Zhao, C.; Bergbreiter, D. E.; Romo, D. J. Org. Chem. 1998, 63, 3471-3473.
} 
La síntesis de los derivados de colchicina con $\alpha$-aminoácidos de la serie $D$ se llevó a cabo de forma similar (véase el esquema 3.6).

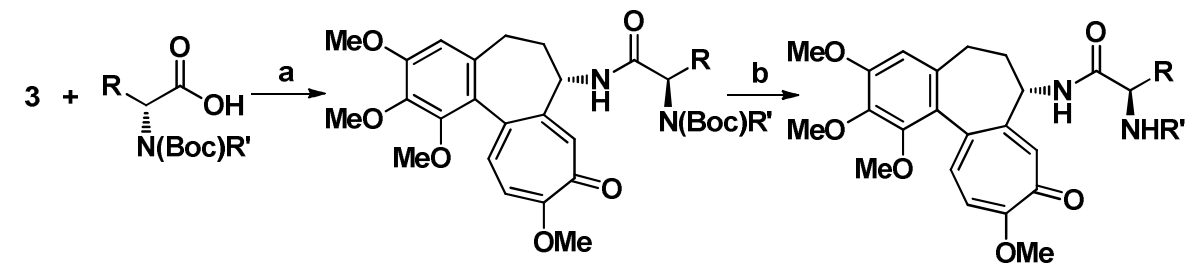

$29 \mathrm{R}=\mathrm{CH}\left(\mathrm{CH}_{3}\right)_{2}, \mathrm{R}^{\prime}=\mathrm{H}$ $30 \mathrm{R}=\mathrm{CH}_{2} \mathrm{CH}\left(\mathrm{CH}_{3}\right)_{2}, \mathrm{R}^{\prime}=\mathrm{H}$ $31 \mathrm{R}=\mathrm{CH}_{2} \mathrm{Ph}, \mathrm{R}^{\prime}=\mathrm{H}$ $32 \mathrm{R}, \mathrm{R}^{\prime}=\left(\mathrm{CH}_{2}\right)_{4}$ $33 \mathrm{R}=\mathrm{CH}_{2}\left(\mathrm{C}_{6} \mathrm{H}_{4} \mathrm{OH}\right), \mathrm{R}^{\prime}=\mathrm{H}$
$58 \mathrm{R}=\mathrm{CH}\left(\mathrm{CH}_{3}\right)_{2}, \mathrm{R}^{\prime}=\mathrm{H}(72 \%)$ $59 \mathrm{R}=\mathrm{CH}_{2} \mathrm{CH}\left(\mathrm{CH}_{3}\right)_{2}, \mathrm{R}^{\prime}=\mathrm{H}(72 \%)$ $60 \mathrm{R}=\mathrm{CH}_{2} \mathrm{Ph}, \mathrm{R}^{\prime}=\mathrm{H}(65 \%)$ $61 \mathrm{R}, \mathrm{R}^{\prime}=\left(\mathrm{CH}_{2}\right)_{4}(67 \%)$ $62 \mathrm{R}=\mathrm{CH}_{2}\left(\mathrm{C}_{6} \mathrm{H}_{4} \mathrm{OH}\right), \mathrm{R}^{\prime}=\mathrm{H}(75 \%)$
$63 \mathrm{R}=\mathrm{CH}\left(\mathrm{CH}_{3}\right)_{2}, \mathrm{R}^{\prime}=\mathrm{H}(97 \%)$

$64 \mathrm{R}=\mathrm{CH}_{2} \mathrm{CH}\left(\mathrm{CH}_{3}\right)_{2}, \mathrm{R}^{\prime}=\mathrm{H}(86 \%)$ $65 \mathrm{R}=\mathrm{CH}_{2} \mathrm{Ph}, \mathrm{R}=\mathrm{H}(99 \%)$ $66 \mathrm{R}, \mathrm{R}^{\prime}=\left(\mathrm{CH}_{2}\right)_{4}(75 \%)$

$67 \mathrm{R}=\mathrm{CH}_{2}\left(\mathrm{C}_{6} \mathrm{H}_{4} \mathrm{OH}\right), \mathrm{R}^{\prime}=\mathrm{H}(75 \%)$

\section{Esquema 3.6}

Reactivos y condiciones: (a) EDCI, DMAP, DMF, de $0{ }^{\circ} \mathrm{C}$ a temp. amb. (b) Resina Amberlyst $15, \mathrm{CH}_{2} \mathrm{Cl}_{2}$, temp. amb., $24 \mathrm{~h}$, luego $\mathrm{NH}_{3} 4 \mathrm{M}$ en $\mathrm{MeOH}, 1 \mathrm{~h}$, temp. amb.

Los derivados de colchicina con los péptidos Gly-Gly y Gly-Gly-Gly se obtuvieron también del mismo modo (véase el esquema 3.7).

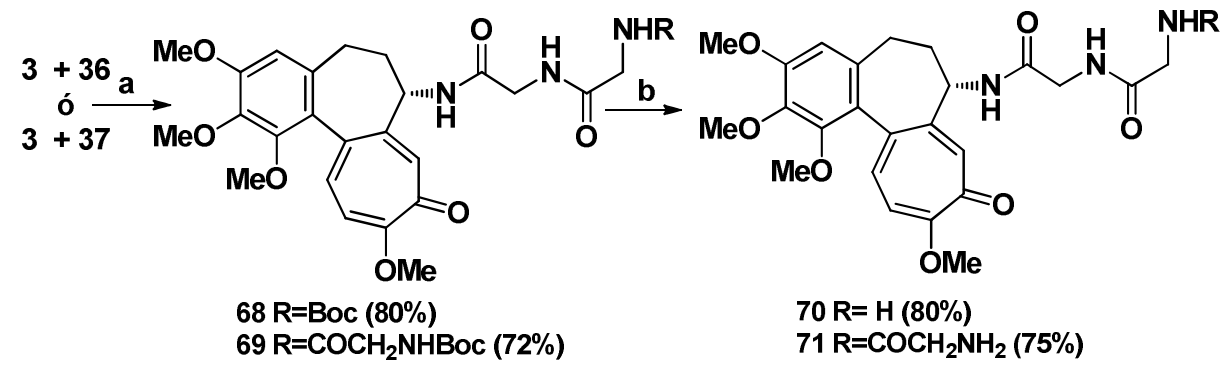

Esquema 3.7

Reactivos y condiciones: (a) EDCI, DMAP, DMF, de $0{ }^{\circ} \mathrm{C}$ a temp. amb. (b) Resina Amberlyst $15, \mathrm{CH}_{2} \mathrm{Cl}_{2}$, temp. amb., $24 \mathrm{~h}$, luego $\mathrm{NH}_{3} 4 \mathrm{M}$ en $\mathrm{MeOH}, 1 \mathrm{~h}$, temp. amb. 


\subsection{Síntesis de los compuestos de la familia 2}

La familia 2 la constituyen derivados de colchicina que provienen de la sustitución formal del grupo acetilo de la colchicina por otros grupos acilo de tipo alifático. Los compuestos se obtuvieron mediante acoplamiento de la sal $\mathbf{3}$ con los correspondientes ácidos en presencia de DCC y DMAP en $\mathrm{CH}_{2} \mathrm{Cl}_{2}$ como disolvente, ${ }^{112}$ tal y como se indica en el esquema esquema 3.8 (entre paréntesis se muestran los rendimientos obtenidos).<smiles>COc1cc2c(c(OC)c1OC)-c1ccc(OC)c(=O)cc1[C@@H]([NH3+])CC2</smiles><smiles>[R]C(=O)N[C@H]1CCc2cc(OC)c(OC)c(OC)c2-c2ccc(OC)c(=O)cc21</smiles>

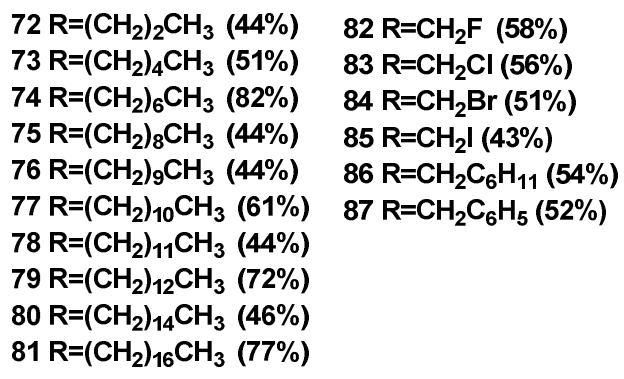

\section{Esquema 3.8}

Reactivos y condiciones: (a) $\mathrm{RCOOH}, \mathrm{DCC}$, DMAP, $\mathrm{CH}_{2} \mathrm{Cl}_{2}$, temp. amb., $3 \mathrm{~h}$.

\footnotetext{
${ }^{112}$ Vilanova, C.; Díaz-Oltra, S.; Murga, J.; Falomir, E.; Carda, M.; Redondo-Horcajo, M.; Díaz, J. F.; Barasoain, I.; Marco, J. A. J. Med. Chem. 2014, 57, 10391-10403.
} 


\subsection{Síntesis de los compuestos de la familia 3}

Los compuestos que forman la familia 3 se obtuvieron de forma muy similar a los de la familia anterior (véase el esquema 3.9, rendimientos entre paréntesis).

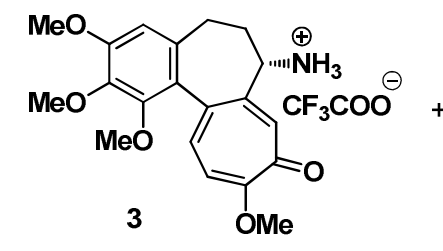<smiles>[R]C(=O)N[C@H]1CCc2cc(OC)c(OC)c(OC)c2-c2ccc(OC)c(=O)cc21</smiles>

$$
\begin{array}{ll}
88 \mathrm{R}=\mathrm{Ph}(45 \%) & 94 \mathrm{R}=2-\mathrm{ClC}_{6} \mathrm{H}_{4}(51 \%) \\
89 \mathrm{R}=4-\mathrm{BuC}_{6} \mathrm{H}_{4}(46 \%) & 95 \mathrm{R}=3-\mathrm{ClC}_{6} \mathrm{H}_{4}(55 \%) \\
90 \mathrm{R}=4-\mathrm{nPentC}_{6} \mathrm{H}_{4}(53 \%) & 96 \mathrm{R}=4-\mathrm{ClC}_{6} \mathrm{H}_{4}(53 \%) \\
91 \mathrm{R}=2-\mathrm{CH}_{3} \mathrm{C}_{6} \mathrm{H}_{4}(59 \%) & 97 \mathrm{R}=2-\mathrm{BrC}_{6} \mathrm{H}_{4}(49 \%) \\
92 \mathrm{R}=3-\mathrm{CH}_{3} \mathrm{C}_{6} \mathrm{H}_{4}(54 \%) & 98 \mathrm{R}=3-\mathrm{BrC}_{6} \mathrm{H}_{4}(51 \%) \\
93 \mathrm{R}=4-\mathrm{CH}_{3} \mathrm{C}_{6} \mathrm{H}_{4}(54 \%) & 99 \mathrm{R}=4-\mathrm{BrC}_{6} \mathrm{H}_{4}(58 \%)
\end{array}
$$

\section{Esquema 3.9}

Reactivos y condiciones: (a) $\mathrm{ArCOOH}, \mathrm{DCC}, \mathrm{DMAP}, \mathrm{CH}_{2} \mathrm{Cl}_{2}$, temp. amb. $3 \mathrm{~h}$. 


\subsection{Procedimientos experimentales}

\subsubsection{Técnicas generales}

Los espectros de RMN fueron registrados en un espectrómetro Varian Unity 500 (frecuencias aproximadas de operación, $500 \mathrm{MHz}$ para ${ }^{1} \mathrm{H}$; $125 \mathrm{MHz}$ para $\left.{ }^{13} \mathrm{C}\right)$. La naturaleza de las señales de carbono $\left(\mathrm{C}, \mathrm{CH}, \mathrm{CH}_{2}, \mathrm{CH}_{3}\right)$ y las asignaciones de las señales se han llevado a cabo mediante la secuencia de pulsos DEPT y correlaciones heteronucleares bidimensionales (COSY y $\mathrm{HSQC} / \mathrm{HMBC}$ ). Los espectros se midieron en disolución de $\mathrm{CDCl}_{3} / \mathrm{TMS}$, $\mathrm{CD}_{3} \mathrm{OD}$ y $\mathrm{DMSO}-d_{6}$. Los desplazamientos químicos $(\delta)$ están indicados en ppm usando como referencia las señales residuales de los disolventes. Para el ${ }^{1} \mathrm{H}$, se referencia sobre la señal a $\delta=7,27 \mathrm{ppm}$ para el $\mathrm{CDCl}_{3}$ o si estuviera solapada con la señal a $\delta=0,00$ ppm para el TMS, $\delta=3,31$ ppm para el $\mathrm{CD}_{3} \mathrm{OD}$ y $\delta=2,50$ ppm para el DMSO- $d_{6}$. Para el ${ }^{13} \mathrm{C}$, se referencia sobre la señal a $\delta=77,0$ ppm para $\mathrm{CDCl}_{3}$, a $\delta=49,0 \mathrm{ppm}$ para $\mathrm{CD}_{3} \mathrm{OD}$ y a $\delta=39,5 \mathrm{ppm}$ para DMSO- $d_{6}$. Las multiplicidades en el ${ }^{1} \mathrm{H}$-RMN se indican como $s$ cuando se trata de un singulete, $d$ para doblete, $t$ para triplete, $c$ para cuadruplete, $m$ para multiplete, $b r$ cuando se trata de una señal ancha y app cuando se trata de una señal con multiplicidad aparente.

Los espectros de IR se obtuvieron mediante el uso de pastillas de $\mathrm{KBr}$ en un espectrómetro Jasco FT/IR-6200, abarcando la región 4000-600 cm $\mathrm{cm}^{-1}$. Solo se indican las bandas de funciones relevantes (por ejemplo, $\mathrm{C}=\mathrm{O}, \mathrm{OH}$ ).

Los espectros de masas se midieron en un espectrómetro de masas Q-TOF (Waters, Manchester, UK) con fuente de ionización combinada electrospray y APCI con diseño Z-spray; la tensión capilar de 3,5 KV se utilizó en el sentido positivo y la tensión de cono se estableció en $20 \mathrm{~V}$.

Los puntos de fusión fueron medidos en un aparato de punto de fusión digital SMP10 (Stuart Scientific) y no fueron corregidos.

Para la cromatografía de capa fina (TLC) se utilizaron cromatofolios de gel de sílice de Merck 5554. 
Los disolventes tetrahidrofurano, diclorometano y éter, se secaron antes de su uso cuando fue necesario por medio de un sistema de purificación de solventes MBRAUN modelo MB-SPS-800 series. La trietilamina se destiló sobre hidróxido potásico. La DMF se destiló y se guardó sobre tamices de 3Å.

Los reactivos disponibles comercialmente se utilizaron sin tratamiento previo, directamente de Sigma-Aldrich, Fluka, Scharlab o Acros.

Los reactivos sensibles al aire se utilizaron bajo atmósfera de nitrógeno evitando en todo momento el contacto con el aire y humedad.

\subsubsection{Síntesis de $\mathrm{N}$-desacetilcolchicina}

\section{Síntesis del compuesto 1}

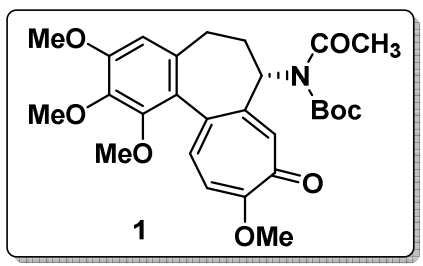

A una disolución de colchicina ( $1.58 \mathrm{~g}, 4.0 \mathrm{mmol}, 1.25$ eq.) en THF (20 mL) se le añadió secuencialmente, bajo atmosfera de $\mathrm{N}_{2}$ y a temperatura ambiente, $\mathrm{Boc}_{2} \mathrm{O}$ (4.32 g, $19.8 \mathrm{mmol}, 6.25$ eq.), $\mathrm{Et}_{3} \mathrm{~N}$ (0.5 mL, $3.6 \mathrm{mmol}, 1.12$ eq.) y DMAP $(0.67 \mathrm{~g}, 3.2 \mathrm{mmol})$. La mezcla resultante se calentó a $45^{\circ} \mathrm{C}$ durante 24 horas. Transcurrido este tiempo se eliminó el disolvente bajo presión reducida y el crudo resultante se cromatografió sobre gel de sílice con $\mathrm{CH}_{2} \mathrm{Cl}_{2}-\mathrm{MeOH}$ (9:1), obteniéndose $1.96 \mathrm{~g}$ (99\%) del compuesto 1 como un aceite amarillento.

Datos espectrales consistentes con la literatura. ${ }^{107}$ 


\section{Síntesis del compuesto 2}

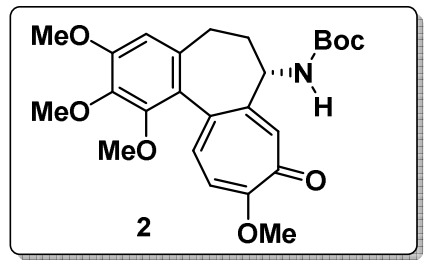

A una disolución del compuesto 1 (1.96 g, $3.9 \mathrm{mmol})$ en $\mathrm{MeOH}(3 \mathrm{~mL})$ se le añadió, bajo atmósfera de $\mathrm{N}_{2}$, una disolución de $\mathrm{NaOCH}_{3} 2 \mathrm{M}$ en $\mathrm{MeOH}(0.4$ $\mathrm{mL}$ ) y la mezcla resultante se agitó a temperatura ambiente durante 2 horas. Luego se vertió la mezcla de reacción sobre salmuera y se extrajo con AcOEt (3 x $15 \mathrm{~mL}$ ). Los extractos orgánicos reunidos se secaron sobre $\mathrm{MgSO}_{4}$. Después de filtrar y eliminar el disolvente bajo presión reducida, se obtuvo el compuesto $2(1.76 \mathrm{~g})$ como un aceite amarillento que se empleó sin purificación adicional en la siguiente reacción.

$\mathbf{R M N}^{1} \mathbf{H}\left(500 \mathrm{MHz}, \mathrm{CDCl}_{3}\right) \delta=7.42(\mathrm{~s}, 1 \mathrm{H}), 7.18(\mathrm{~d}, J=10.7 \mathrm{~Hz}, 1 \mathrm{H}), 6.79(\mathrm{~d}$, $J=10.7 \mathrm{~Hz}, 1 \mathrm{H}), 6.51(\mathrm{~s}, 1 \mathrm{H}), 4.98(\mathrm{~m}, 1 \mathrm{H}), 5.1(\mathrm{~d}, J=6.1,1 \mathrm{H}), 4.38(\mathrm{~s}, 1 \mathrm{H})$, $3.97(\mathrm{~s}, 3 \mathrm{H}), 3.91(\mathrm{~s}, 3 \mathrm{H}), 3.88(\mathrm{~s}, 3 \mathrm{H}), 3.63(\mathrm{~s}, 3 \mathrm{H}), 2.5(\mathrm{~m}, 1 \mathrm{H}), 2.3(\mathrm{~m}, 1 \mathrm{H})$, $2.2(\mathrm{~m}, 1 \mathrm{H}) 1.65(\mathrm{~m}, 1 \mathrm{H}), 1.4(\mathrm{~m}, 9 \mathrm{H})$.

RMN ${ }^{13} \mathbf{C}\left(125 \mathrm{MHz}, \mathrm{CDCl}_{3}\right) \delta=179.4,163.8,154.2,153.3,151.1,149.6$, 135.9, 134.8, 134.2, 131.1, 81.8 (C), 135.9, 125.6, 111.9, 107.2 (CH), 37.5, $29.9\left(\mathrm{CH}_{2}\right), 61.3,61.1,52.9,56.1,28.2,28.1,27.9\left(\mathrm{CH}_{3}\right)$.

\section{Síntesis del trifluoroacetato de $\mathrm{N}$-desacetilcolchicina 3}

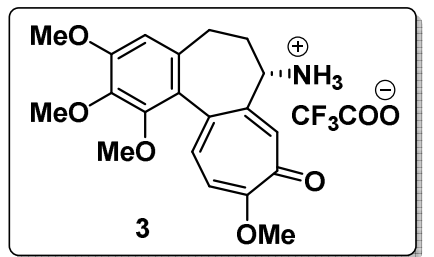

A una mezcla del crudo de la reacción anterior $2(1.76 \mathrm{~g}, 3.9 \mathrm{mmol})$ se le añadió, bajo atmósfera de $\mathrm{N}_{2}$ y a temperatura ambiente, TFA $98 \%(3.0 \mathrm{~mL}$, 
$38.5 \mathrm{mmol}, 10$ eq.). La mezcla de reacción se agitó durante 5 minutos y luego el TFA se eliminó bajo presión reducida. El residuo resultante se cromatografió sobre gel de sílice con $\mathrm{CH}_{2} \mathrm{Cl}_{2}-\mathrm{MeOH}$ (9:1) lo que proporcionó $1.81 \mathrm{~g}$ del compuesto 3 en forma de aceite.

$\mathbf{R M N}^{1} \mathbf{H}\left(500 \mathrm{MHz}, \mathrm{CDCl}_{3}\right) \delta=7.69(\mathrm{~s}, 1 \mathrm{H}), 7.37(\mathrm{~d}, \mathrm{~J}=11.3 \mathrm{~Hz}, 1 \mathrm{H}), 6.96(\mathrm{~d}$, $J=11.3 \mathrm{~Hz}, 1 \mathrm{H}), 6.54(\mathrm{~s}, 1 \mathrm{H}), 4.04(\mathrm{~m}, 1 \mathrm{H}), 3.91(\mathrm{~s}, 3 \mathrm{H}), 3.87(\mathrm{~s}, 3 \mathrm{H}), 3.69(\mathrm{~s}$, $6 \mathrm{H}), 2.80-2.60(\mathrm{~m}, 1 \mathrm{H}), 2.69-2.47(\mathrm{~m}, 2 \mathrm{H}), 2.46-2.11(\mathrm{~m}, 1 \mathrm{H})$.

RMN ${ }^{13} \mathbf{C}\left(125 \mathrm{MHz}, \mathrm{CDCl}_{3}\right) \delta=178.3,164.2,154.5(x 2), 150.6,148.4,141.4$, 138.4, 123.6 (C), 138.8, 133.6, 116.0, 107.7 (CH), 35.9, $29.3\left(\mathrm{CH}_{2}\right)$, 61.0, 60.9, $56.5,55.9,54.5\left(\mathrm{CH}_{3}\right)$.

\subsubsection{Procedimiento experimental para la $\mathbf{N}$-Boc protección de aminoácidos}

A una disolución del correspondiente aminoácido (15.0 mmol, 1 eq.) en $\mathrm{H}_{2} \mathrm{O} / \mathrm{THF} 1: 1$ se le adicionó, a temperatura ambiente, (Boc) $)_{2} \mathrm{O}$ (16.5 mmol, 1.1 eq.) y seguidamente $\mathrm{NaOH}$ (33.0 mmol, 2.2 eq.). La mezcla se dejó en agitación durante 24 horas y posteriormente se eliminó el THF bajo presión reducida. El residuo resultante se disolvió en AcOEt $(50 \mathrm{~mL})$ y la mezcla se acidificó con $\mathrm{HCl} 10 \%$ hasta $\mathrm{pH}=4$ y se extrajo con AcOEt $(3 \times 50 \mathrm{~mL})$. Los extractos orgánicos reunidos se secaron sobre $\mathrm{MgSO}_{4}$. Después de filtrar y eliminar el disolvente bajo presión reducida, se obtuvieron los aminoácidos $N$-Boc protegidos que se emplearon sin purificación adicional en las siguientes reacciones.

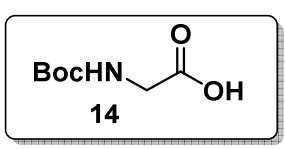

A partir de $1.30 \mathrm{~g}$ (17.3 mmol) del aminoácido glicina se obtuvieron $2.87 \mathrm{~g}$ (16.4 mmol, 95\%) del compuesto 14 como un sólido blanco. 


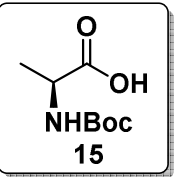

A partir de $1.03 \mathrm{~g}$ (11.6 mmol) del aminoácido L-alanina se obtuvieron $2.0 \mathrm{~g}$ (10.6 mmol, 91\%) del compuesto 15 como un sólido blanco.

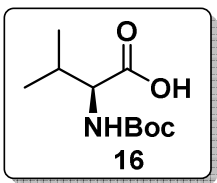

A partir de $1.00 \mathrm{~g}(8.5 \mathrm{mmol})$ del aminoácido L-valina se obtuvieron $1.69 \mathrm{~g}$ (7.8 mmol, 92\%) del compuesto 16 como un sólido blanco.

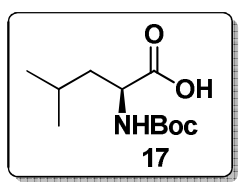

A partir de $1.97 \mathrm{~g}(15.0 \mathrm{mmol})$ del aminoácido L-leucina se obtuvieron $3.3 \mathrm{~g}$ (14.4 mmol, 96\%) del compuesto 17 como un sólido blanco.

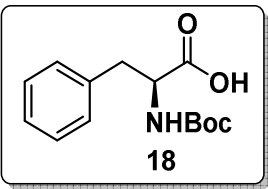

A partir de $1.47 \mathrm{~g}(8.9 \mathrm{mmol})$ del aminoácido L-fenilalanina se obtuvieron $2.30 \mathrm{~g}(8.7 \mathrm{mmol}, 98 \%)$ del compuesto 18 como un sólido blanco. 


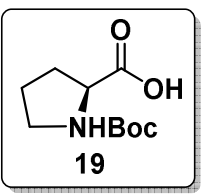

A partir de $1.00 \mathrm{~g}$ (8.7 mmol) del aminoácido L-prolina se obtuvieron $1.24 \mathrm{~g}$ (5.8 mmol, 67\%) del compuesto 19 como un sólido blanco.

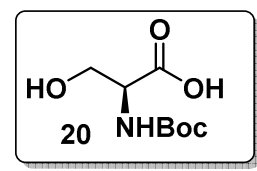

A partir de $1.50 \mathrm{~g}(14.3 \mathrm{mmol})$ del aminoácido L-serina se obtuvieron $2.93 \mathrm{~g}$ (14.3 mmol, 100\%) del compuesto 20 como un sólido blanco.

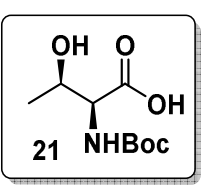

A partir de $0.99 \mathrm{~g}(8.3 \mathrm{mmol})$ del aminoácido L-treonina se obtuvieron $1.79 \mathrm{~g}$ (8.1 mmol, 99\%) del compuesto 21 como un sólido blanco.

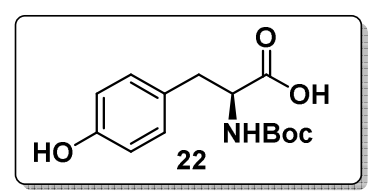

A partir de $1.00 \mathrm{~g}$ (5.5 mmol) del aminoácido L-tirosina se obtuvieron $1.52 \mathrm{~g}$ (5.4 mmol, 98\%) del compuesto 22 como un sólido blanco. 


$$
-\underbrace{\mathrm{O}}_{23} \mathrm{NHBOC}_{\mathrm{OH}}^{\mathrm{O}}
$$

A partir de $1.00 \mathrm{~g}(6.7 \mathrm{mmol})$ del aminoácido L-metionina se obtuvieron $1.63 \mathrm{~g}(6.5 \mathrm{mmol}, 98 \%)$ del compuesto 23 como un sólido blanco.

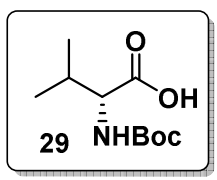

A partir de $1.00 \mathrm{~g}$ ( $8.5 \mathrm{mmol})$ del aminoácido D-valina se obtuvieron $1.69 \mathrm{~g}$ (7.8 mmol, 92\%) del compuesto 29 como un sólido blanco.

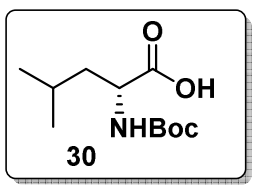

A partir de $1.96 \mathrm{~g} \mathrm{(15.0} \mathrm{mmol)} \mathrm{del} \mathrm{aminoácido} \mathrm{D-leucina} \mathrm{se} \mathrm{obtuvieron} 3.4 \mathrm{~g}$ (14.7 mmol, 98\%) del compuesto $\mathbf{3 0}$ como un sólido blanco.

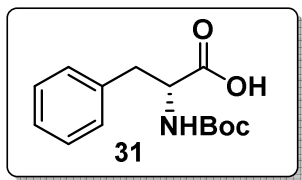

A partir de $1.47 \mathrm{~g}(8.9 \mathrm{mmol})$ del aminoácido D-fenilalanina se obtuvieron $2.15 \mathrm{~g}(8.1 \mathrm{mmol}, 91 \%)$ del compuesto 31 como un sólido blanco. 


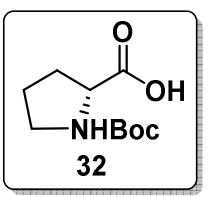

A partir de $1.00 \mathrm{~g}(8.7 \mathrm{mmol})$ del aminoácido D-prolina se obtuvieron $1.18 \mathrm{~g}$ (5.5 mmol, 63\%) del compuesto 32 como un sólido blanco.

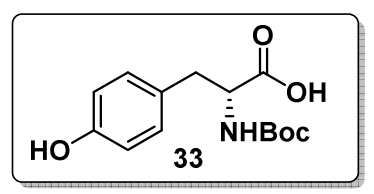

A partir de $1.20 \mathrm{~g}$ (6.6 mmol) del aminoácido D-tirosina se obtuvieron $1.42 \mathrm{~g}$ (5.0 mmol, 76\%) del compuesto 33 como un sólido blanco.

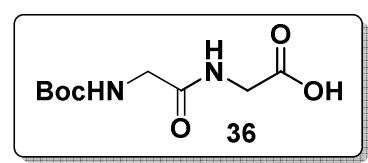

A partir de $1.20 \mathrm{~g}(9.1 \mathrm{mmol})$ del dipéptido Gly-Gly se obtuvieron $1.99 \mathrm{~g}$ (8.6 mmol, 95\%) del compuesto $\mathbf{3 6}$ como un sólido blanco.

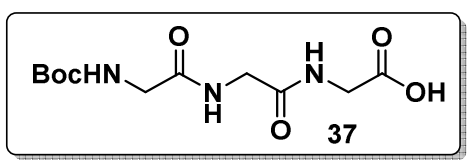

A partir de $1.20 \mathrm{~g}$ (6.3 mmol) del tripéptido Gly-Gly-Gly se obtuvieron $1.44 \mathrm{~g}$ (5.0 mmol, 78\%) del compuesto 37 como un sólido blanco. 


\subsubsection{Síntesis de los aminoácidos $N$-Boc protegidos mediante acoplamiento peptídico con el trifluoroacetato de $\mathrm{N}$-desacetilcolchicinio}

A una mezcla formada por la sal 3 (0.64 mmol, 1eq.), el correspondiente aminoácido $\mathrm{N}$-Boc protegido (1.28 mmol, 2 eq.) y DMAP (1.28 mmol, 2 eq.) en DMF (12.3 mL) se le añadió, gota a gota y a $0{ }^{\circ} \mathrm{C}, \mathrm{EDCl}(0.70 \mathrm{mmol}, 1.1$ eq.) en DMF seco $(2 \mathrm{~mL})$. La mezcla resultante se agitó a $0{ }^{\circ} \mathrm{C}$ durante 2 horas y luego 1 hora más a temperatura ambiente. Luego se adicionó AcOEt ( $30 \mathrm{~mL}$ ) y se lavó con una disolución acuosa saturada de $\mathrm{NH}_{4} \mathrm{Cl}(3 \times 30 \mathrm{~mL})$ y salmuera $(3 \times 30 \mathrm{~mL})$. El extracto orgánico se secó sobre $\mathrm{MgSO}_{4}$. Después se filtró y se eliminó el disolvente bajo presión reducida. El crudo resultante se cromatografió sobre gel de sílice con AcOEt-Acetona (6:1).

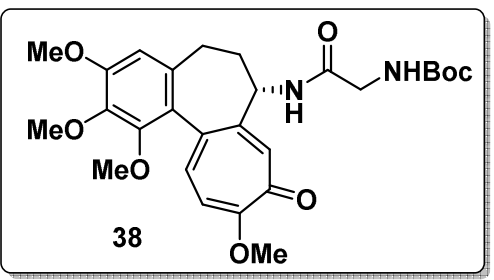

A partir de $0.30 \mathrm{~g}(0.64 \mathrm{mmol})$ del compuesto 3 se obtuvieron $0.23 \mathrm{~g}(0.44$ mmol, 69\%) del compuesto 38 como un sólido amarillento.

$[\alpha]_{D}=-103.9\left(\mathrm{c}=1.0, \mathrm{CHCl}_{3}\right)$.

P. f. $=138-140^{\circ} \mathrm{C}$.

IR $\mathbf{v}_{\text {máx }}\left(\mathrm{cm}^{-1}\right) 3400 \mathrm{br}, 3300 \mathrm{br}(\mathrm{NH}), 1715(\mathrm{C}=\mathrm{O})$.

$\mathbf{R M N}^{1} \mathbf{H}\left(500 \mathrm{MHz}, \mathrm{CDCl}_{3}\right) \delta=8.00(1 \mathrm{H}, \mathrm{br} \mathrm{s}, \mathrm{NH}), 7.45(1 \mathrm{H}, \mathrm{s}), 7.24(1 \mathrm{H}, \mathrm{d}, J$ $=10.8 \mathrm{~Hz}), 6.78(1 \mathrm{H}, \mathrm{d}, J=10.8 \mathrm{~Hz}), 6.47(1 \mathrm{H}, \mathrm{s}), 5.50(1 \mathrm{H}, \mathrm{br} \mathrm{s}, \mathrm{NH}), 4.60$ (1H, dt app, $J=12,6 \mathrm{~Hz}), 3.92(3 \mathrm{H}, \mathrm{s}), 3.87(3 \mathrm{H}, \mathrm{s}), 3.84(3 \mathrm{H}, \mathrm{s}), 3.80(2 \mathrm{H}, \mathrm{m})$, $3.58(3 \mathrm{H}, \mathrm{s}), 2.45(1 \mathrm{H}, \mathrm{dd}, J=13.5,6.5 \mathrm{~Hz}), 2.34(1 \mathrm{H}, \mathrm{td}$ app, $J=13.4,7 \mathrm{~Hz})$, $2.20(1 \mathrm{H}, \mathrm{m}), 1.90(1 \mathrm{H}, \mathrm{m}), 1.34(9 \mathrm{H}, \mathrm{s})$.

RMN ${ }^{13} \mathrm{C}\left(125 \mathrm{MHz}, \mathrm{CDCl}_{3}\right) \delta=179.3,169.2,163.9,156.0^{*}, 153.4,151.5$, $151.1,141.5,136.5,134.2,125.6,79.6$ (C), 135.1, 130.8, 112.5, 107.3, 52.2 
$(\mathrm{CH})$, 43.8, 36.5, $29.8\left(\mathrm{CH}_{2}\right)$, 61.4, 61.3, 56.2, 56.1, $28.2(\mathrm{x} 3)\left(\mathrm{CH}_{3}\right) .{ }^{*}$ Baja y ancha.

HR ESMS $m / z 515.2393\left(\mathrm{M}+\mathrm{H}^{+}\right)$. Calcd. para $\mathrm{C}_{27} \mathrm{H}_{35} \mathrm{~N}_{2} \mathrm{O}_{8}, 515.2393$.

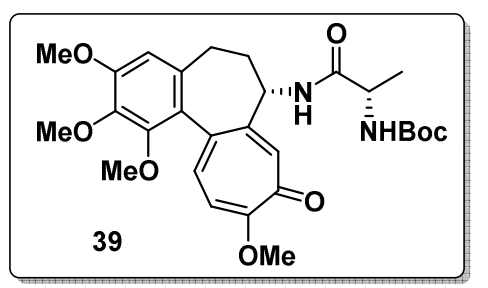

A partir de $0.30 \mathrm{~g}(0.64 \mathrm{mmol})$ del compuesto 3 se obtuvieron $0.23 \mathrm{~g}(0.44$ $\mathrm{mmol}, 68 \%$ ) del compuesto 39 como un sólido amarillento.

$[\alpha]_{D}=-163.1\left(\mathrm{c}=1.0, \mathrm{CHCl}_{3}\right)$.

P. f. $=148-150^{\circ} \mathrm{C}$.

IR $\mathbf{v}_{\text {máx }}\left(\mathrm{cm}^{-1}\right) 3420 \mathrm{br}, 3300 \mathrm{br}(\mathrm{NH}), 1714,1683(\mathrm{C}=\mathrm{O})$.

$\mathbf{R M N}^{1} \mathbf{H}\left(500 \mathrm{MHz}, \mathrm{CDCl}_{3}\right) \delta=7.90(1 \mathrm{H}, \mathrm{br} \mathrm{s}, \mathrm{NH}), 7.40(1 \mathrm{H}, \mathrm{s}), 7.23(1 \mathrm{H}, \mathrm{d}, J$ $=10.7 \mathrm{~Hz}), 6.78(1 \mathrm{H}, \mathrm{d}, J=10.7 \mathrm{~Hz}), 6.47(1 \mathrm{H}, \mathrm{s}), 5.25(1 \mathrm{H}, \mathrm{br} \mathrm{d}, J \sim 8 \mathrm{~Hz}$, $\mathrm{NH}), 4.56(1 \mathrm{H}, \mathrm{dt}$ app, $J=11.5,6.5 \mathrm{~Hz}), 4.24(1 \mathrm{H}, \mathrm{m}), 3.92(3 \mathrm{H}, \mathrm{s}), 3.87(3 \mathrm{H}$, s), $3.83(3 \mathrm{H}, \mathrm{s}), 3.60(3 \mathrm{H}, \mathrm{s}), 2.45(1 \mathrm{H}, \mathrm{dd}, J=13.7,6.5 \mathrm{~Hz}), 2.34(1 \mathrm{H}, \mathrm{td}$ app, $J=13.7,7 \mathrm{~Hz}), 2.13(1 \mathrm{H}, \mathrm{m}), 1.87(1 \mathrm{H}, \mathrm{m}), 1.34(9 \mathrm{H}, \mathrm{s}), 1.25(3 \mathrm{H}, \mathrm{d}, J=7 \mathrm{~Hz})$. RMN ${ }^{13} \mathbf{C}\left(125 \mathrm{MHz}, \mathrm{CDCl}_{3}\right) \delta=179.2,172.1,163.9,155.2^{*}, 153.2,151.0$, 150.9, 141.4, 136.1, 134.1, 125.5, 79.5* (C), 134.8, 130.7, 112.1, 107.3, 51.8, 49.4* $(\mathrm{CH}), 36.3,29.8\left(\mathrm{CH}_{2}\right), 61.2,61.1,56.1,56.0,28.2(\mathrm{x} \mathrm{3}), 18.6\left(\mathrm{CH}_{3}\right)$. *Baja y ancha.

HR ESMS $m / z 529.2556\left(\mathrm{M}+\mathrm{H}^{+}\right)$. Calcd. para $\mathrm{C}_{28} \mathrm{H}_{37} \mathrm{~N}_{2} \mathrm{O}_{8}, 529.2550$. 


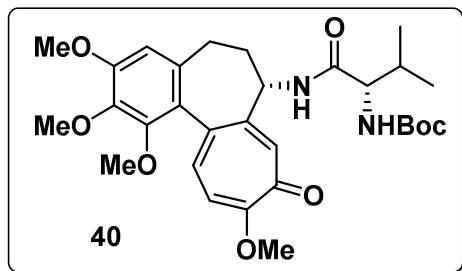

A partir de $0.20 \mathrm{~g}(0.42 \mathrm{mmol})$ del compuesto 3 se obtuvieron $0.16 \mathrm{~g}(0.29$ mmol, $69 \%$ ) del compuesto $\mathbf{4 0}$ como un sólido amarillento.

$[\alpha]_{D}=-168.3\left(\mathrm{c}=1.0, \mathrm{CHCl}_{3}\right)$.

P. f. $=142-144^{\circ} \mathrm{C}$.

IR $\mathbf{v}_{\text {máx }}\left(\mathrm{cm}^{-1}\right) 3430 \mathrm{br}, 3280 \mathrm{br}(\mathrm{NH}), 1708,1668(\mathrm{C}=\mathrm{O})$.

$\mathbf{R M N}^{1} \mathbf{H}\left(500 \mathrm{MHz}, \mathrm{CDCl}_{3}\right) \delta=7.90(1 \mathrm{H}, \mathrm{br} \mathrm{s}, \mathrm{NH}), 7.50(1 \mathrm{H}, \mathrm{s}), 7.24(1 \mathrm{H}, \mathrm{d}, J$ $=10.8 \mathrm{~Hz}), 6.79(1 \mathrm{H}, \mathrm{d}, J=10.8 \mathrm{~Hz}), 6.48(1 \mathrm{H}, \mathrm{s}), 5.15(1 \mathrm{H}, \mathrm{br} \mathrm{d}, J \sim 9 \mathrm{~Hz}$, $\mathrm{NH}), 4.62(1 \mathrm{H}, \mathrm{dt}$ app, $J=11.5,7 \mathrm{~Hz}), 4.05(1 \mathrm{H}, \mathrm{m}), 3.93(3 \mathrm{H}, \mathrm{s}), 3.87(3 \mathrm{H}, \mathrm{s})$, $3.83(3 \mathrm{H}, \mathrm{s}), 3.61(3 \mathrm{H}, \mathrm{s}), 2.46(1 \mathrm{H}, \mathrm{dd}, J=13.2,6.3 \mathrm{~Hz}), 2.35(1 \mathrm{H}, \mathrm{td}$ app, $J=$ 13.2, $6.5 \mathrm{~Hz}), 2.20-2.05(2 \mathrm{H}, \mathrm{br} \mathrm{m}), 1.95(1 \mathrm{H}, \mathrm{m}), 1.35(9 \mathrm{H}, \mathrm{s}), 0.84(3 \mathrm{H}, \mathrm{d}, J=$ $6.5 \mathrm{~Hz}), 0.76(3 \mathrm{H}, \mathrm{d}, J=6.5 \mathrm{~Hz})$.

RMN ${ }^{13} \mathbf{C}\left(125 \mathrm{MHz}, \mathrm{CDCl}_{3}\right) \delta=179.0,171.3,163.9,155.7^{*}, 153.2,151.2$, 151.0, 141.4, 136.1, 134.1, 125.6, 79.3* (C), 134.8, 131.0, 112.1, 107.3, 58.8*, 51.9, $31.5(\mathrm{CH}), 36.3,29.8\left(\mathrm{CH}_{2}\right), 61.3,61.1,56.1,56.0,28.2$ (x 3), 19.5, 17.0 $\left(\mathrm{CH}_{3}\right)$. ${ }^{*}$ Baja y ancha.

HR ESMS $m / z 579.2675\left(\mathrm{M}+\mathrm{Na}^{+}\right)$. Calcd. para $\mathrm{C}_{30} \mathrm{H}_{40} \mathrm{~N}_{2} \mathrm{NaO}_{8}, 579.2682$.

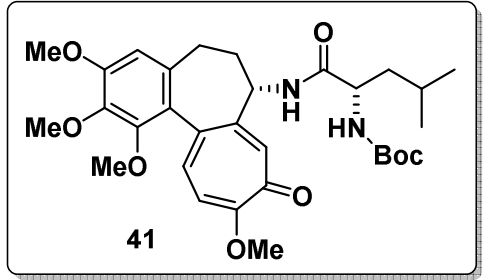

A partir de $0.20 \mathrm{~g}(0.42 \mathrm{mmol})$ del compuesto 3 se obtuvieron $0.22 \mathrm{~g}(0.39$ mmol, 92\%) del compuesto 41 como un sólido amarillento.

$[\alpha]_{D}=-169.1\left(\mathrm{c}=1.0, \mathrm{CHCl}_{3}\right)$. 
P. f. $=145-147^{\circ} \mathrm{C}$.

IR $\mathbf{v}_{\text {máx }}\left(\mathrm{cm}^{-1}\right) 3430 \mathrm{br}, 3280 \mathrm{br}(\mathrm{NH}), 1700,1666(\mathrm{C}=\mathrm{O})$.

$\operatorname{RMN}^{1} \mathbf{H}\left(500 \mathrm{MHz}, \mathrm{CDCl}_{3}\right) \delta=7.90(1 \mathrm{H}, \mathrm{br} \mathrm{s}, \mathrm{NH}), 7.40(1 \mathrm{H}, \mathrm{s}), 7.18(1 \mathrm{H}, \mathrm{d}, J$ $=10.7 \mathrm{~Hz}), 6.73(1 \mathrm{H}, \mathrm{d}, J=10.7 \mathrm{~Hz}), 6.43(1 \mathrm{H}, \mathrm{s}), 5.10(1 \mathrm{H}, \mathrm{br} \mathrm{s}, \mathrm{NH}), 4.52$ $(1 \mathrm{H}, \mathrm{dt}$ app, $J=11.5,7 \mathrm{~Hz}), 4.17(1 \mathrm{H}, \mathrm{m}), 3.90(3 \mathrm{H}, \mathrm{s}), 3.82(3 \mathrm{H}, \mathrm{s}), 3.80(3 \mathrm{H}$, s), $3.58(3 \mathrm{H}, \mathrm{s}), 2.41(1 \mathrm{H}, \mathrm{dd}, J=13.2,6.3 \mathrm{~Hz}), 2.30(1 \mathrm{H}$, td app, $J=13.2,6.5$ $\mathrm{Hz}), 2.08(1 \mathrm{H}, \mathrm{m}), 1.85(1 \mathrm{H}, \mathrm{m}), 1.60-1.25(3 \mathrm{H}, \mathrm{br} \mathrm{m}), 1.30(9 \mathrm{H}, \mathrm{s}), 0.79(3 \mathrm{H}, \mathrm{d}$, $J=6.5 \mathrm{~Hz}), 0.75(3 \mathrm{H}, \mathrm{d}, J=6.5 \mathrm{~Hz})$.

RMN ${ }^{13} \mathbf{C}\left(125 \mathrm{MHz}, \mathrm{CDCl}_{3}\right) \delta=179.0,172.0,163.7,155.4,153.1,150.9$, $150.7^{*}, 141.3,135.9,134.0,125.5,79.3^{*}(\mathrm{C}), 134.6,130.7,111.8,107.2$, $52.4^{*}, 51.7,24.4(\mathrm{CH}), 41.3,36.2,29.6\left(\mathrm{CH}_{2}\right), 61.1,61.0,56.0,55.8,28.1(\mathrm{x}$ 3), 22.8, $21.4\left(\mathrm{CH}_{3}\right)$. *Baja y ancha.

HR ESMS $m / z 593.2835\left(\mathrm{M}+\mathrm{Na}^{+}\right)$. Calcd. para $\mathrm{C}_{31} \mathrm{H}_{42} \mathrm{~N}_{2} \mathrm{NaO}_{8}, 593.2839$.

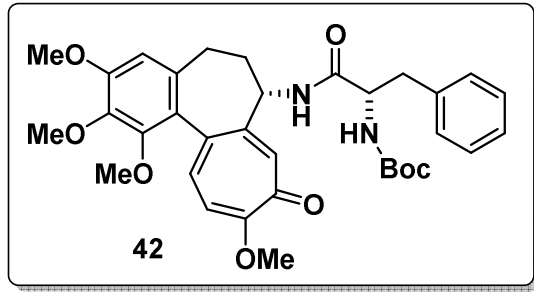

A partir de $0.30 \mathrm{~g}(0.64 \mathrm{mmol})$ del compuesto 3 se obtuvieron $0.25 \mathrm{~g}(0.41$ $\mathrm{mmol}, 64 \%$ ) del compuesto 42 como un sólido amarillento.

$[\alpha]_{D}=-84.6\left(\mathrm{c}=1.0, \mathrm{CHCl}_{3}\right)$.

P. f. $=130-132{ }^{\circ} \mathrm{C}$.

IR $\mathbf{v}_{\text {máx }}\left(\mathrm{cm}^{-1}\right) 3300 \mathrm{br}(\mathrm{NH}), 1708,1666(\mathrm{C}=\mathrm{O})$.

$\mathbf{R M N}^{1} \mathbf{H}\left(500 \mathrm{MHz}, \mathrm{CDCl}_{3}\right) \delta=7.80(1 \mathrm{H}, \mathrm{br} \mathrm{s}, \mathrm{NH}), 7.40(1 \mathrm{H}, \mathrm{br} \mathrm{s}), 7.25(1 \mathrm{H}, \mathrm{d}$, $J=10.7 \mathrm{~Hz}), 7.20-7.05(5 \mathrm{H}, \mathrm{br} \mathrm{m}), 6.78(1 \mathrm{H}, \mathrm{d}, J=10.7 \mathrm{~Hz}), 6.46(1 \mathrm{H}, \mathrm{s}), 5.20$ $(1 \mathrm{H}, \mathrm{br} d, J \sim 6 \mathrm{~Hz}, \mathrm{NH}), 4.54(1 \mathrm{H}, \mathrm{dt}$ app, $J=11.5,7 \mathrm{~Hz}), 4.42(1 \mathrm{H}, \mathrm{m}), 3.93$ $(3 \mathrm{H}, \mathrm{s}), 3.91(3 \mathrm{H}, \mathrm{s}), 3.84(3 \mathrm{H}, \mathrm{s}), 3.61(3 \mathrm{H}, \mathrm{s}), 3.13(1 \mathrm{H}, \mathrm{dd}, J=14,5 \mathrm{~Hz})$, 
$2.81(1 \mathrm{H}, \mathrm{m}), 2.40(1 \mathrm{H}, \mathrm{dd}, J=13.2,6.4 \mathrm{~Hz}), 2.33(1 \mathrm{H}$, td app, $J=13.2,7 \mathrm{~Hz})$, $2.05(1 \mathrm{H}, \mathrm{m}), 1.78(1 \mathrm{H}, \mathrm{m}), 1.28(9 \mathrm{H}, \mathrm{s})$.

RMN ${ }^{13} \mathbf{C}\left(125 \mathrm{MHz}, \mathrm{CDCl}_{3}\right) \delta=179.1,171.1,163.9,155.3^{*}, 153.2,151.0$, $150.8^{*}, 141.4,136.7,136.0,134.1,125.5,79.6^{*}$ (C), 134.7, 130.9*, 129.1 (x 2), 128.2 (x 2), 126.5, 112.0, 107.3, 55.2*, $51.9(\mathrm{CH}), 38.3^{*}, 36.3,29.7\left(\mathrm{CH}_{2}\right)$, 61.2, 61.1, 56.1, 55.9, 28.1 ( $\times 3)\left(\mathrm{CH}_{3}\right) .{ }^{*}$ Baja y ancha.

HR ESMS $m / z 627.2575\left(\mathrm{M}+\mathrm{Na}^{+}\right)$. Calcd. para $\mathrm{C}_{34} \mathrm{H}_{40} \mathrm{~N}_{2} \mathrm{NaO}_{8}, 627.2582$.

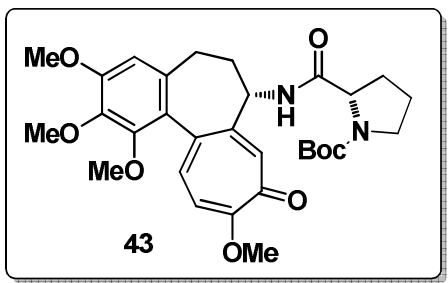

A partir de $0.30 \mathrm{~g}(0.64 \mathrm{mmol})$ del compuesto 3 se obtuvieron $0.23 \mathrm{~g}(0.42$ $\mathrm{mmol}, 65 \%$ ) del compuesto $\mathbf{4 3}$ como un sólido amarillento.

$[\alpha]_{D}=-190.4\left(\mathrm{c}=1.0, \mathrm{CHCl}_{3}\right)$.

P. f. $=146-148{ }^{\circ} \mathrm{C}$.

IR $\mathbf{v}_{\text {máx }}\left(\mathrm{cm}^{-1}\right) 3280 \mathrm{br}(\mathrm{NH}), 1686(\mathrm{C}=\mathrm{O})$.

$\mathbf{R M N}^{1} \mathbf{H}\left(500 \mathrm{MHz}, \mathrm{CDCl}_{3}\right) \delta=8.00(1 \mathrm{H}, \mathrm{br} \mathrm{s}, \mathrm{NH}), 7.40(1 \mathrm{H}, \mathrm{br} \mathrm{s}), 7.19(1 \mathrm{H}, \mathrm{d}$, $J=10.7 \mathrm{~Hz}), 6.73(1 \mathrm{H}, \mathrm{d}, J=10.7 \mathrm{~Hz}), 6.47(1 \mathrm{H}, \mathrm{s}), 4.49(1 \mathrm{H}, \mathrm{m}), 4.33(1 \mathrm{H}$, m), $3.91(3 \mathrm{H}, \mathrm{s}), 3.87(3 \mathrm{H}, \mathrm{s}), 3.83(3 \mathrm{H}, \mathrm{s}), 3.58(3 \mathrm{H}, \mathrm{s}), 3.26(2 \mathrm{H}, \mathrm{m}), 2.45$ (1H, dd, $J=13,6.4 \mathrm{~Hz}$ ), 2.35 (1H, td app, $J=13,7 \mathrm{~Hz}$ ), 2.25-2.05 (2H, br m), 1.90-1.70 (4H, br m), $1.40(9 \mathrm{H}, \mathrm{s})$.

RMN ${ }^{13} \mathbf{C}\left(125 \mathrm{MHz}, \mathrm{CDCl}_{3}\right) \delta=179.2,171.1^{*}, 163.8,155.8^{*}, 153.2,151.0$, $150.4^{*}, 141.5,135.8^{*}, 134.1^{*}, 125.6,80.1^{*}$ (C), 134.6, 130.9*, 111.7, 107.1, 59.1* $51.8(\mathrm{CH}), 46.9,36.5^{\star}, 29.7,27.2^{\star}, 24.4^{\star}\left(\mathrm{CH}_{2}\right), 61.3,61.1,56.0,55.9$, 28.2 (x 3) $\left(\mathrm{CH}_{3}\right) .{ }^{*}$ Baja y ancha.

HR ESMS $m / z 577.2531\left(\mathrm{M}+\mathrm{Na}^{+}\right)$. Calcd. para $\mathrm{C}_{30} \mathrm{H}_{38} \mathrm{~N}_{2} \mathrm{O}_{8}, 577.2526$. 


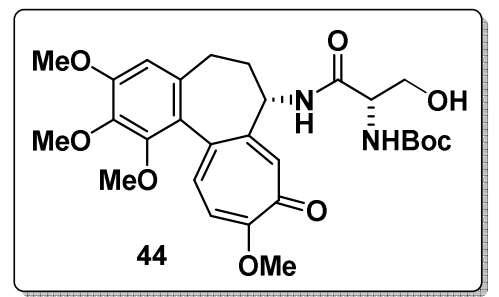

A partir de $0.20 \mathrm{~g}(0.42 \mathrm{mmol})$ del compuesto 3 se obtuvieron $0.18 \mathrm{~g}(0.33$ mmol, $79 \%$ ) del compuesto $\mathbf{4 4}$ como un sólido amarillento.

$[\alpha]_{D}=-131.8\left(\mathrm{c}=1.0, \mathrm{CHCl}_{3}\right)$.

P. f. $=127-129^{\circ} \mathrm{C}$.

IR $\mathbf{v}_{\text {máx }}\left(\mathrm{cm}^{-1}\right) 3400 \mathrm{br}, 3300 \mathrm{br}(\mathrm{OH}, \mathrm{NH}), 1708,1674(\mathrm{C}=\mathrm{O})$.

$\mathbf{R M N}^{1} \mathbf{H}\left(500 \mathrm{MHz}, \mathrm{CDCl}_{3}\right) \delta=7.65(1 \mathrm{H}, \mathrm{br} \mathrm{s}, \mathrm{NH}), 7.50(1 \mathrm{H}, \mathrm{s}), 7.31(1 \mathrm{H}, \mathrm{d}, J$ $=10.8 \mathrm{~Hz}), 6.84(1 \mathrm{H}, \mathrm{d}, J=10.8 \mathrm{~Hz}), 6.54(1 \mathrm{H}, \mathrm{s}), 5.50(1 \mathrm{H}, \mathrm{br} \mathrm{d}, J \sim 7 \mathrm{~Hz}$, $\mathrm{NH}), 4.61(1 \mathrm{H}, \mathrm{dt}$ app, $J=11.5,7 \mathrm{~Hz}), 4.26(1 \mathrm{H}, \mathrm{m}), 4.00(1 \mathrm{H}, \mathrm{m}$ solapado), $3.99(3 \mathrm{H}, \mathrm{s}), 3.94(3 \mathrm{H}, \mathrm{s}), 3.90(3 \mathrm{H}, \mathrm{s}), 3.65(4 \mathrm{H}, \mathrm{s}+\mathrm{m}$ solapado $), 2.80(1 \mathrm{H}, \mathrm{br}$ s, OH), $2.53(1 \mathrm{H}, \mathrm{dd}, J=13.5,6.3 \mathrm{~Hz}), 2.41(1 \mathrm{H}, \mathrm{td}$ app, $J=13.2,7 \mathrm{~Hz}), 2.23$ $(1 \mathrm{H}, \mathrm{m}), 1.90(1 \mathrm{H}, \mathrm{m}), 1.42(9 \mathrm{H}, \mathrm{s})$.

RMN ${ }^{13} \mathbf{C}\left(125 \mathrm{MHz}, \mathrm{CDCl}_{3}\right) \delta=179.3,170.4,163.7,155.5^{\star}, 153.2,151.4^{*}$, 150.9, 141.3, 136.4, 134.0, 125.4, 79.4* (C), 135.0, 130.9, 112.4, 107.2, 54.8*, $52.1(\mathrm{CH}), 62.7,36.2,29.7\left(\mathrm{CH}_{2}\right), 61.2,61.1,56.0,55.9,28.1(\mathrm{x} \mathrm{3})\left(\mathrm{CH}_{3}\right)$. *Baja y ancha.

HR ESMS $m / z 545.2492\left(\mathrm{M}+\mathrm{H}^{+}\right)$. Calcd. para $\mathrm{C}_{28} \mathrm{H}_{37} \mathrm{~N}_{2} \mathrm{O}_{9}, 545.2499$.

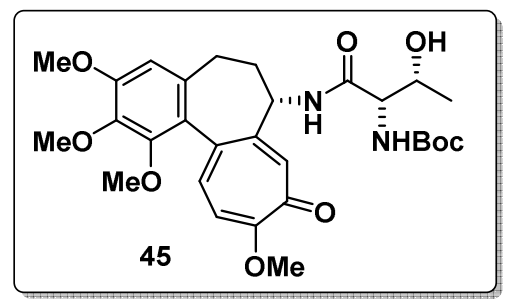

A partir de $0.20 \mathrm{~g}(0.42 \mathrm{mmol})$ del compuesto 3 se obtuvieron $0.17 \mathrm{~g}(0.30$ mmol, 72\%) del compuesto 45 como un sólido amarillento. 
$[\alpha]_{D}=-162.4\left(\mathrm{c}=1.0, \mathrm{CHCl}_{3}\right)$.

P. f. $=136-138^{\circ} \mathrm{C}$.

IR $\mathbf{v}_{\text {máx }}\left(\mathrm{cm}^{-1}\right) 3400 \mathrm{br}, 3300 \mathrm{br}(\mathrm{OH}, \mathrm{NH}), 1707,1671(\mathrm{C}=\mathrm{O})$.

$\mathbf{R M N}^{1} \mathbf{H}\left(500 \mathrm{MHz}, \mathrm{CDCl}_{3}\right) \delta=7.70(1 \mathrm{H}$, br d, $J \sim 7 \mathrm{~Hz}, \mathrm{NH}), 7.55(1 \mathrm{H}, \mathrm{s}), 7.28$ $(1 \mathrm{H}, \mathrm{d}, J=10.8 \mathrm{~Hz}), 6.82(1 \mathrm{H}, \mathrm{d}, J=10.8 \mathrm{~Hz}), 6.51(1 \mathrm{H}, \mathrm{s}), 5.45(1 \mathrm{H}, \mathrm{br} \mathrm{d}, J \sim$ $8 \mathrm{~Hz}, \mathrm{NH}), 4.60(1 \mathrm{H}, \mathrm{dt}$ app, $J=11.5,7 \mathrm{~Hz}), 4.26(1 \mathrm{H}, \mathrm{m}), 4.20(1 \mathrm{H}, \mathrm{br} \mathrm{d}, J \sim$ $7.5 \mathrm{~Hz}), 3.96(3 \mathrm{H}, \mathrm{s}), 3.92(3 \mathrm{H}, \mathrm{s}), 3.90(1 \mathrm{H}, \mathrm{br} \mathrm{s}$, solapado, $\mathrm{OH}), 3.88(3 \mathrm{H}, \mathrm{s})$, $3.64(3 \mathrm{H}, \mathrm{s}), 2.50(1 \mathrm{H}, \mathrm{dd}, J=13.5,6.4 \mathrm{~Hz}), 2.39(1 \mathrm{H}, \mathrm{td}$ app, $J=13.5,7 \mathrm{~Hz})$, $2.18(1 \mathrm{H}, \mathrm{m}), 1.88(1 \mathrm{H}, \mathrm{m}), 1.40(9 \mathrm{H}, \mathrm{s}), 1.13(3 \mathrm{H}, \mathrm{d}, J=6.5 \mathrm{~Hz})$.

RMN ${ }^{13} \mathbf{C}\left(125 \mathrm{MHz}, \mathrm{CDCl}_{3}\right) \delta=179.3,170.8,164.0,156.3^{*}, 153.4,151.1$, 151.0, 141.6, 136.2, 134.1, 125.6, 79.9* (C), 135.1, 131.1, 112.3, 107.3, 66.8*, 57.3*, $52.2(\mathrm{CH}), 36.7,29.8\left(\mathrm{CH}_{2}\right), 61.4,61.3,56.2,56.0,28.2$ (x 3), 18.2* $\left(\mathrm{CH}_{3}\right)$. *Baja y ancha.

HR ESMS $m / z 581.2483\left(\mathrm{M}+\mathrm{Na}^{+}\right)$. Calcd. para $\mathrm{C}_{29} \mathrm{H}_{38} \mathrm{~N}_{2} \mathrm{NaO}_{9}, 581.2475$.

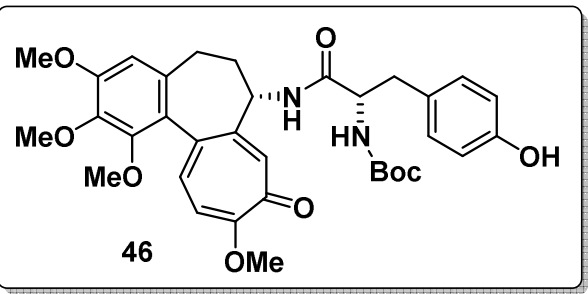

A partir de $0.30 \mathrm{~g}(0.64 \mathrm{mmol})$ del compuesto 3 se obtuvieron $0.32 \mathrm{~g}(0.52$ mmol, 81\%) del compuesto $\mathbf{4 6}$ como un sólido amarillento.

$[\alpha]_{D}=-139.2\left(\mathrm{c}=1.0, \mathrm{CHCl}_{3}\right)$.

P. f. $=168-170^{\circ} \mathrm{C}$.

IR $\mathbf{v}_{\text {máx }}\left(\mathrm{cm}^{-1}\right) 3400 \mathrm{br}, 3300 \mathrm{br}(\mathrm{OH}, \mathrm{NH}), 1676(\mathrm{C}=\mathrm{O})$.

$\mathbf{R M N}^{1} \mathbf{H}\left(500 \mathrm{MHz}, \mathrm{CDCl}_{3}\right) \delta=7.30(1 \mathrm{H}, \mathrm{d}, J=10.8 \mathrm{~Hz}), 7.18(1 \mathrm{H}, \mathrm{s}), 6.98$ $(3 \mathrm{H}, \mathrm{d}, J=7.5 \mathrm{~Hz}$, solapando la señal de $\mathrm{NH}), 6.83(1 \mathrm{H}, \mathrm{d}, J=10.8 \mathrm{~Hz}), 6.76$ $(2 \mathrm{H}, \mathrm{d}, J=7.5 \mathrm{~Hz}), 6.50(1 \mathrm{H}, \mathrm{s}), 5.10(1 \mathrm{H}, \mathrm{br} \mathrm{d}, J \sim 7 \mathrm{~Hz}, \mathrm{NH}), 4.58(1 \mathrm{H}, \mathrm{dt}$ app, $J=11.5,6.5 \mathrm{~Hz}), 4.30(1 \mathrm{H}, \mathrm{m}), 3.97(3 \mathrm{H}, \mathrm{s}), 3.94(3 \mathrm{H}, \mathrm{s}), 3.90(3 \mathrm{H}, \mathrm{s})$, 
$3.66(3 \mathrm{H}, \mathrm{s}), 2.94(1 \mathrm{H}, \mathrm{dd}, J=14,7 \mathrm{~Hz}), 2.84(1 \mathrm{H}, \mathrm{dd}, J=14,7.5 \mathrm{~Hz}), 2.47$ $(1 \mathrm{H}, \mathrm{dd}, J=13.5,6.4 \mathrm{~Hz}), 2.34(1 \mathrm{H}, \mathrm{td}$ app, $J=13.5,7 \mathrm{~Hz}), 2.20-2.10(1 \mathrm{H}, \mathrm{m})$, 2.00-1.90 $(1 \mathrm{H}, \mathrm{m}), 1.80-1.70(1 \mathrm{H}, \mathrm{br} \mathrm{s}, \mathrm{OH}), 1.38(9 \mathrm{H}, \mathrm{s})$.

RMN ${ }^{13} \mathbf{C}\left(125 \mathrm{MHz}, \mathrm{CDCl}_{3}\right) \delta=179.3,171.5,164.0,155.5,155.4,153.4$, $151.5^{\star}, 151.0,141.5,136.5^{\star}, 134.1,127.5,125.5,79.9^{*}(\mathrm{C}), 135.3,130.7^{\star}$, 130.1 (x 2), 115.8 (x 2), 112.6, 107.4, 55.8* $52.2(\mathrm{CH}), 37.8,36.5,29.8\left(\mathrm{CH}_{2}\right)$, 61.4, 61.3, 56.2, 56.0, 28.2 (x 3) $\left(\mathrm{CH}_{3}\right)$. "Baja y ancha.

HR ESMS $m / z 643.2635\left(\mathrm{M}+\mathrm{Na}^{+}\right)$. Calcd. para $\mathrm{C}_{34} \mathrm{H}_{40} \mathrm{~N}_{2} \mathrm{NaO}_{9}, 643.2632$.

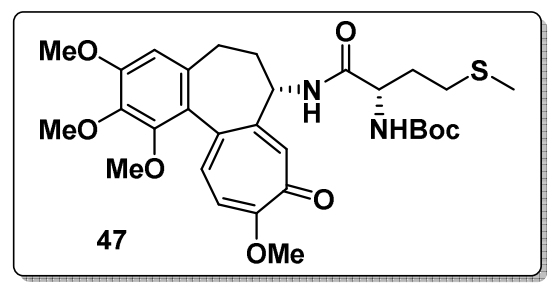

A partir de $0.30 \mathrm{~g}(0.64 \mathrm{mmol})$ del compuesto 3 se obtuvieron $0.27 \mathrm{~g}(0.46$ $\mathrm{mmol}, \mathbf{7 2} \%$ ) del compuesto 47 como un sólido amarillento.

$[\alpha]_{D}=-143.7\left(\mathrm{c}=1.0, \mathrm{CHCl}_{3}\right)$.

P. f. $=130-132^{\circ} \mathrm{C}$.

IR $\mathbf{v}_{\text {máx }}\left(\mathrm{cm}^{-1}\right) 3450 \mathrm{br}, 3280 \mathrm{br}(\mathrm{NH}), 1714,1699(\mathrm{C}=\mathrm{O})$.

$\mathbf{R M N}^{1} \mathbf{H}\left(500 \mathrm{MHz}, \mathrm{CDCl}_{3}\right) \delta=7.85(1 \mathrm{H}, \mathrm{br} \mathrm{s}, \mathrm{NH}), 7.43(1 \mathrm{H}, \mathrm{s}), 7.24(1 \mathrm{H}, \mathrm{d}, J$ $=10.8 \mathrm{~Hz}), 6.78(1 \mathrm{H}, \mathrm{d}, J=10.8 \mathrm{~Hz}), 6.48(1 \mathrm{H}, \mathrm{s}), 5.30(1 \mathrm{H}, \mathrm{br} \mathrm{s}, \mathrm{NH}), 4.59$ $(1 \mathrm{H}, \mathrm{dt}$ app, $J=11.5,6.5 \mathrm{~Hz}), 4.30(1 \mathrm{H}, \mathrm{m}), 3.94(3 \mathrm{H}, \mathrm{s}), 3.88(3 \mathrm{H}, \mathrm{s}), 3.84$ $(3 \mathrm{H}, \mathrm{s}), 3.60(3 \mathrm{H}, \mathrm{s}), 2.50-2.30(4 \mathrm{H}, \mathrm{br} \mathrm{m}), 2.18(1 \mathrm{H}, \mathrm{m}), 2.10-1.90(3 \mathrm{H}, \mathrm{br} \mathrm{m})$, $1.98(3 \mathrm{H}, \mathrm{s}), 1.80(1 \mathrm{H}, \mathrm{m}), 1.35(9 \mathrm{H}, \mathrm{s})$.

RMN ${ }^{13} \mathbf{C}\left(125 \mathrm{MHz}, \mathrm{CDCl}_{3}\right) \delta=179.0,171.0,163.9,155.4^{*}, 153.3,151.0$, $150.9^{*}, 141.5,136.0,134.1,125.5,79.6^{*}(\mathrm{C}), 134.8,130.9,112.0,107.3$, 53.1*, $52.0(\mathrm{CH}), 36.4,32.2^{*}, 29.9,29.7\left(\mathrm{CH}_{2}\right), 61.2,61.1,56.1,55.9,28.2(\mathrm{x}$ 3), $15.2\left(\mathrm{CH}_{3}\right)$. *Baja y ancha.

HR ESMS $m / z 589.2587\left(\mathrm{M}+\mathrm{H}^{+}\right)$. Calcd. para $\mathrm{C}_{30} \mathrm{H}_{41} \mathrm{~N}_{2} \mathrm{O}_{8} \mathrm{~S}, 589.2584$. 


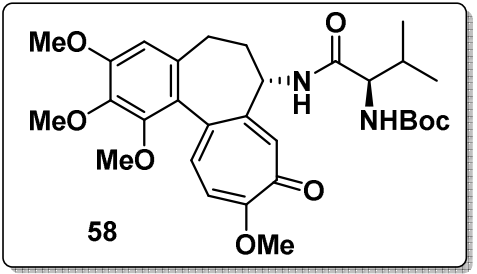

A partir de $0.34 \mathrm{~g}(0.85 \mathrm{mmol})$ del compuesto 3 se obtuvieron $0.34 \mathrm{~g}(0.61$ mmol, $72 \%$ ) del compuesto 58 como un sólido amarillento.

$[\alpha]_{\mathrm{D}}=-90.0\left(\mathrm{c}=1.0, \mathrm{CHCl}_{3}\right)$.

P. f. $=143-145^{\circ} \mathrm{C}$

IR $\mathbf{v}_{\text {máx }}\left(\mathrm{cm}^{-1}\right) 3300 \mathrm{br}(\mathrm{NH}), 1708,1667(\mathrm{C}=\mathrm{O})$.

$\mathbf{R M N}^{1} \mathbf{H}\left(500 \mathrm{MHz}, \mathrm{CDCl}_{3}\right) \delta=77.90(1 \mathrm{H}, \mathrm{br} \mathrm{s}, \mathrm{NH}), 7.40(1 \mathrm{H}, \mathrm{s}), 7.24(1 \mathrm{H}, \mathrm{d}$, $J=10.7 \mathrm{~Hz}), 6.79(1 \mathrm{H}, \mathrm{d}, J=10.7 \mathrm{~Hz}), 6.49(1 \mathrm{H}, \mathrm{s}), 5.45(1 \mathrm{H}, \mathrm{br} \mathrm{s}, \mathrm{NH}), 4.57$ $(1 \mathrm{H}, \mathrm{dt}$ app, $J=11,7 \mathrm{~Hz}), 4.05(1 \mathrm{H}, \mathrm{m}), 3.93(3 \mathrm{H}, \mathrm{s}), 3.91(3 \mathrm{H}, \mathrm{s}), 3.84(3 \mathrm{H}, \mathrm{s})$, $3.60(3 \mathrm{H}, \mathrm{s}), 2.46(1 \mathrm{H}, \mathrm{dd}, J=13.2,6.3 \mathrm{~Hz}), 2.37(1 \mathrm{H}, \mathrm{td}$ app, $J=13.2,7 \mathrm{~Hz})$, 2.20-2.10 (2H, br m), $1.93(1 \mathrm{H}, \mathrm{m}), 1.37(9 \mathrm{H}, \mathrm{s}), 0.87(3 \mathrm{H}, \mathrm{d}, J=6.5 \mathrm{~Hz}), 0.84$ $(3 \mathrm{H}, \mathrm{d}, J=6.5 \mathrm{~Hz})$.

RMN ${ }^{13} \mathbf{C}\left(125 \mathrm{MHz}, \mathrm{CDCl}_{3}\right) \delta=179.1,171.2,163.8,155.7^{*}, 153.2,151.3^{*}$, 151.0, 141.4, 136.2, 134.1, 125.6, 79.4* (C), 134.8, 130.9, 112.1, 107.3, 59.5*, 52.0, $31.0(\mathrm{CH})$, 36.5, $29.8\left(\mathrm{CH}_{2}\right)$, 61.3, 61.1, 56.0, 55.9, 28.2 (x 3), 19.2, 17.5 $\left(\mathrm{CH}_{3}\right) .{ }^{\star}$ Baja y ancha.

HR ESMS $m / z 579.2679\left(\mathrm{M}+\mathrm{Na}^{+}\right)$. Calcd. para $\mathrm{C}_{30} \mathrm{H}_{40} \mathrm{~N}_{2} \mathrm{NaO}_{8}, 579.2682$.

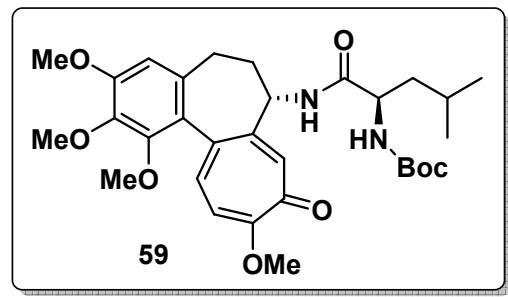

A partir de $0.15 \mathrm{~g}(0.32 \mathrm{mmol})$ del compuesto 3 se obtuvieron $0.13 \mathrm{~g}(0.23$ mmol, 72\%) del compuesto 59 como un sólido amarillento. 
$[\alpha]_{D}=-56.9\left(\mathrm{c}=1.0, \mathrm{CHCl}_{3}\right)$.

P. f. $=144-146{ }^{\circ} \mathrm{C}$.

IR $\mathbf{v}_{\text {máx }}\left(\mathrm{cm}^{-1}\right) 3300 \mathrm{br}(\mathrm{NH}), 1705,1670(\mathrm{C}=\mathrm{O})$.

$\mathbf{R M N}^{1} \mathbf{H}\left(500 \mathrm{MHz}, \mathrm{CDCl}_{3}\right) \delta=7.37(1 \mathrm{H}$, br s), $7.26(1 \mathrm{H}, \mathrm{d}, J=10.7 \mathrm{~Hz}), 6.95$ $(1 \mathrm{H}$, br s, NH), $6.78(1 \mathrm{H}, \mathrm{d}, J=10.7 \mathrm{~Hz}), 6.53(1 \mathrm{H}, \mathrm{s}), 4.80(1 \mathrm{H}, \mathrm{br} \mathrm{d}, J \sim 7 \mathrm{~Hz}$, $\mathrm{NH}), 4.59(1 \mathrm{H}, \mathrm{dt}$ app, $J=11.5,7 \mathrm{~Hz}), 4.14(1 \mathrm{H}, \mathrm{m}), 3.98(3 \mathrm{H}, \mathrm{s}), 3.94(3 \mathrm{H}, \mathrm{s})$, $3.90(3 \mathrm{H}, \mathrm{s}), 3.65(3 \mathrm{H}, \mathrm{s}), 2.52(1 \mathrm{H}, \mathrm{dd}, J=13.2,6.3 \mathrm{~Hz}), 2.43(1 \mathrm{H}, \mathrm{td}$ app, $J=$ 13, $7 \mathrm{~Hz}), 2.20(1 \mathrm{H}, \mathrm{m}), 1.85(1 \mathrm{H}, \mathrm{m}), 1.70-1.55(2 \mathrm{H}, \mathrm{br} \mathrm{m}), 1.50-1.40(1 \mathrm{H}, \mathrm{m})$, $1.42(9 \mathrm{H}, \mathrm{s}), 0.94(3 \mathrm{H}, \mathrm{d}, J=6.5 \mathrm{~Hz}), 0.91(3 \mathrm{H}, \mathrm{d}, J=6.5 \mathrm{~Hz})$.

RMN ${ }^{13} \mathbf{C}\left(125 \mathrm{MHz}, \mathrm{CDCl}_{3}\right) \delta=179.2,172.5^{\star}, 163.5,155.6^{\star}, 153.1,151.5^{\star}$, 150.9, 141.3, 136.2, 134.0, 125.5, 79.4 (C), 134.5, 130.6, 111.8, 107.2, 53.4*, 51.7, $24.4(\mathrm{CH}), 40.3^{*}, 36.6,29.6\left(\mathrm{CH}_{2}\right), 61.2,61.0,55.8,55.7,28.1$ (x 3), 23.0, 21.3* $\left(\mathrm{CH}_{3}\right) .{ }^{*}$ Baja y ancha.

HR ESMS $m / z 593.2831\left(\mathrm{M}+\mathrm{Na}^{+}\right)$. Calcd. para $\mathrm{C}_{31} \mathrm{H}_{42} \mathrm{~N}_{2} \mathrm{NaO}_{8}, 593.2839$.

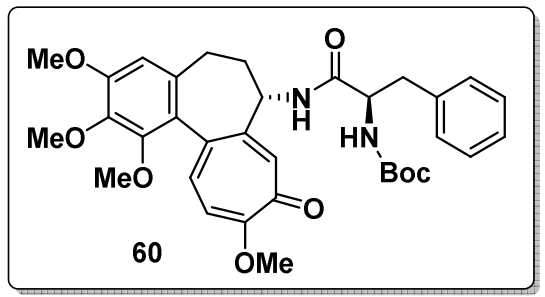

A partir de $0.30 \mathrm{~g}(0.64 \mathrm{mmol})$ del compuesto 3 se obtuvieron $0.26 \mathrm{~g}(0.42$ $\mathrm{mmol}, 65 \%$ ) del compuesto 60 como un sólido amarillento.

$[\alpha]_{D}=-73.9\left(\mathrm{c}=1.1, \mathrm{CHCl}_{3}\right)$.

P. f. $=137-139^{\circ} \mathrm{C}$.

IR $\mathbf{v}_{\text {máx }}\left(\mathrm{cm}^{-1}\right) 3300 \mathrm{br}(\mathrm{NH}), 1707,1671(\mathrm{C}=\mathrm{O})$.

$\mathbf{R M N}^{1} \mathbf{H}\left(500 \mathrm{MHz}, \mathrm{CDCl}_{3}\right) \delta=7.25-7.15(7 \mathrm{H}, \mathrm{br} \mathrm{m}), 6.73(1 \mathrm{H}, \mathrm{d}, J=10.7 \mathrm{~Hz})$, $6.47(1 \mathrm{H}, \mathrm{br} d, J \sim 7 \mathrm{~Hz}, \mathrm{NH}), 6.45(1 \mathrm{H}, \mathrm{s}), 5.20(1 \mathrm{H}, \mathrm{br} \mathrm{s}, \mathrm{NH}), 4.47(1 \mathrm{H}, \mathrm{dt}$ app, $J=11,7 \mathrm{~Hz}), 4.30(1 \mathrm{H}, \mathrm{m}), 3.89(3 \mathrm{H}, \mathrm{s}), 3.88(3 \mathrm{H}, \mathrm{s}), 3.84(3 \mathrm{H}, \mathrm{s}), 3.61$ $(3 \mathrm{H}, \mathrm{s}), 3.00(1 \mathrm{H}, \mathrm{dd}, J=13.5,7 \mathrm{~Hz}), 2.94(1 \mathrm{H}, \mathrm{dd}, J=13.5,7 \mathrm{~Hz}), 2.40(1 \mathrm{H}$, 
dd, $J=13.2,6.4 \mathrm{~Hz}), 2.30(1 \mathrm{H}, \mathrm{td}$ app, $J=13.2,6.5 \mathrm{~Hz}), 1.96(1 \mathrm{H}, \mathrm{m}), 1.57$ $(1 \mathrm{H}, \mathrm{m}), 1.34(9 \mathrm{H}, \mathrm{s})$.

RMN ${ }^{13} \mathbf{C}\left(125 \mathrm{MHz}, \mathrm{CDCl}_{3}\right) \delta=179.2,171.2^{*}, 163.7,155.3^{*}, 153.2,151.0$, $150.9,141.4,136.9^{*}, 136.1^{*}, 134.0,125.5,79.6$ (C), 134.8, 130.7, 129.0 (x 2), 128.2 (x 2), 126.4, 112.0, 107.3, 55.7*, $51.9(\mathrm{CH}), 37.9^{*}, 36.5,29.6\left(\mathrm{CH}_{2}\right)$, 61.2, 61.1, 56.0, 55.9, 28.1 ( $\times 3)\left(\mathrm{CH}_{3}\right)$. *Baja y ancha.

HR ESMS $m / z 627.2685\left(\mathrm{M}+\mathrm{Na}^{+}\right)$. Calcd. para $\mathrm{C}_{34} \mathrm{H}_{40} \mathrm{~N}_{2} \mathrm{NaO}_{8}, 627.2682$.

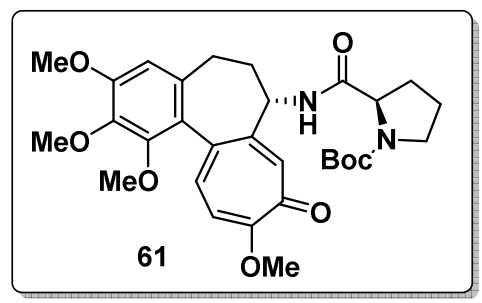

A partir de $0.30 \mathrm{~g}(0.64 \mathrm{mmol})$ del compuesto 3 se obtuvieron $0.24 \mathrm{~g}(0.42$ $\mathrm{mmol}, 67 \%$ ) del compuesto 61 como un sólido amarillento.

$[\alpha]_{D}=-33.1\left(\mathrm{c}=1.0, \mathrm{CHCl}_{3}\right)$.

P. f. $=145-147^{\circ} \mathrm{C}$.

IR $\mathbf{v}_{\text {máx }}\left(\mathrm{cm}^{-1}\right) 3280$ br $(\mathrm{NH}), 1690(\mathrm{C}=\mathrm{O})$.

$\mathbf{R M N}^{1} \mathbf{H}\left(500 \mathrm{MHz}, \mathrm{CDCl}_{3}\right) \delta=7.24(1 \mathrm{H}, \mathrm{d}, J=10.8 \mathrm{~Hz}), 7.18(1 \mathrm{H}, \mathrm{br} \mathrm{s}), 6.76$ $(1 \mathrm{H}, \mathrm{d}, J=10.8 \mathrm{~Hz}), 6.52(1 \mathrm{H}, \mathrm{s}), 4.55(1 \mathrm{H}, \mathrm{m}), 4.30(1 \mathrm{H}, \mathrm{m}), 3.96(3 \mathrm{H}, \mathrm{s}), 3.93$ $(3 \mathrm{H}, \mathrm{s}), 3.90(3 \mathrm{H}, \mathrm{s}), 3.65(3 \mathrm{H}, \mathrm{s}), 3.55(1 \mathrm{H}, \mathrm{m}), 3.40-3.35(1 \mathrm{H}, \mathrm{br} \mathrm{m}), 2.53(1 \mathrm{H}$, dd, $J=13.5,6.4 \mathrm{~Hz}), 2.44(1 \mathrm{H}$, td app, $J=13,7 \mathrm{~Hz}), 2.30-2.20(2 \mathrm{H}, \mathrm{br} \mathrm{m})$, 1.90-1.75 (4H, br m), $1.50(9 \mathrm{H}$, br s) (la señal del NH no detectada).

RMN ${ }^{13} \mathbf{C}\left(125 \mathrm{MHz}, \mathrm{CDCl}_{3}\right) \delta=179.0,171.1^{*}, 163.6,156.0^{*}, 153.1,150.9$, 150.3, 141.3, 135.6, 133.9, 125.4, 80.5* (C), 134.4, 130.3, 111.5, 107.1, 59.5*, $51.5(\mathrm{CH}), 46.9,36.6,29.6,27.2^{*}, 24.2^{*}\left(\mathrm{CH}_{2}\right), 61.1,61.0,55.9,55.8,28.1(\mathrm{x}$ 3) $\left(\mathrm{CH}_{3}\right)$. "Baja y ancha.

HR ESMS $m / z 577.2523\left(\mathrm{M}+\mathrm{Na}^{+}\right)$. Calcd. para $\mathrm{C}_{30} \mathrm{H}_{38} \mathrm{~N}_{2} \mathrm{NaO}_{8}, 577.2526$. 


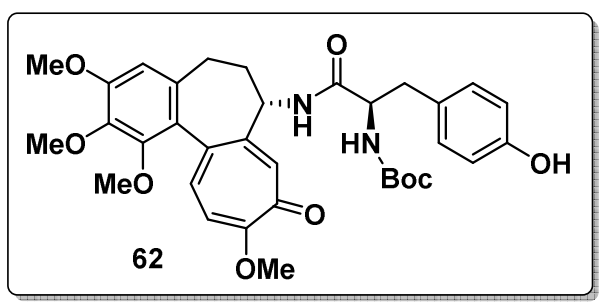

A partir de $0.30 \mathrm{~g}(0.64 \mathrm{mmol})$ del compuesto 3 se obtuvieron $0.30 \mathrm{~g}(0.48$ $\mathrm{mmol}, 75 \%$ ) del compuesto 62 como un sólido amarillento.

$[\alpha]_{D}=-93.1\left(\mathrm{c}=1.0, \mathrm{CHCl}_{3}\right)$.

P. f. $=170-172{ }^{\circ} \mathrm{C}$.

IR $\mathbf{v}_{\text {máx }}\left(\mathrm{cm}^{-1}\right) 3400 \mathrm{br}, 3350 \mathrm{br}(\mathrm{OH}, \mathrm{NH}), 1714,1698(\mathrm{C}=\mathrm{O})$.

$\mathbf{R M N}^{1} \mathbf{H}\left(500 \mathrm{MHz}, \mathrm{CDCl}_{3}\right) \delta=7.40(1 \mathrm{H}, \mathrm{s}), 7.32(1 \mathrm{H}, \mathrm{d}, J=10.8 \mathrm{~Hz}), 7.20$ $(1 \mathrm{H}, \mathrm{br} \mathrm{d}, J \sim 5 \mathrm{~Hz}, \mathrm{NH}), 6.91(2 \mathrm{H}, \mathrm{d}, J=8 \mathrm{~Hz}), 6.84(1 \mathrm{H}, \mathrm{d}, J=10.8 \mathrm{~Hz}), 6.74$ $(2 \mathrm{H}, \mathrm{d}, J=8 \mathrm{~Hz}), 6.50(1 \mathrm{H}, \mathrm{s}), 5.60(1 \mathrm{H}, \mathrm{br} \mathrm{s}, \mathrm{NH}), 4.56(1 \mathrm{H}, \mathrm{dt}$ app, $J=11.5$, $6.5 \mathrm{~Hz}), 4.36(1 \mathrm{H}, \mathrm{m}), 3.92(3 \mathrm{H}, \mathrm{s}), 3.89(3 \mathrm{H}, \mathrm{s}), 3.88(3 \mathrm{H}, \mathrm{s}), 3.64(3 \mathrm{H}, \mathrm{s}), 3.10$ $(1 \mathrm{H}, \mathrm{br} \mathrm{s}, \mathrm{OH}), 2.94(2 \mathrm{H}, \mathrm{m}), 2.45(1 \mathrm{H}, \mathrm{dd}, J=13,6 \mathrm{~Hz}), 2.33(1 \mathrm{H}, \mathrm{td}$ app, $J=$ 13, $7 \mathrm{~Hz}), 2.07(1 \mathrm{H}, \mathrm{m}), 1.75(1 \mathrm{H}, \mathrm{m}), 1.35(9 \mathrm{H}, \mathrm{s})$.

RMN ${ }^{13} \mathbf{C}\left(125 \mathrm{MHz}, \mathrm{CDCl}_{3}\right) \delta=179.3,171.6^{*}, 163.9,155.6,155.5,153.4$, $151.5,151.0,141.5,136.5,134.1,127.5,125.5,80.1^{*}(C), 135.4,130.7,130.1$ (x 2), 115.8 (x 2), 112.6, 107.4, 55.9, $52.3(\mathrm{CH}), 37.4^{*}, 36.6,29.7\left(\mathrm{CH}_{2}\right), 61.4$, 61.3, 56.1, 56.0, $28.2(\times 3)\left(\mathrm{CH}_{3}\right) .{ }^{*}$ Baja y ancha.

HR ESMS $m / z 621.2811\left(\mathrm{M}+\mathrm{H}^{+}\right)$. Calcd. para $\mathrm{C}_{34} \mathrm{H}_{41} \mathrm{~N}_{2} \mathrm{O}_{9}, 621.2812$.

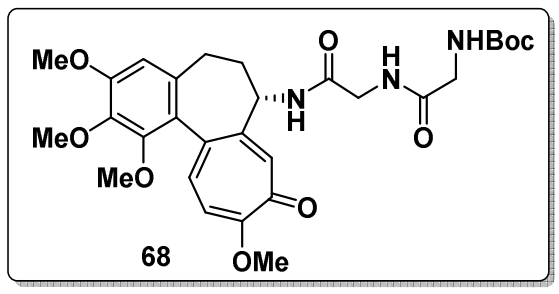

A partir de $0.30 \mathrm{~g}(0.64 \mathrm{mmol})$ del compuesto 3 se obtuvieron $0.29 \mathrm{~g}(0.51$ mmol, $80 \%$ ) del compuesto 68 como un sólido amarillento. 
$[\alpha]_{D}=-46.5\left(\mathrm{c}=1.0, \mathrm{CHCl}_{3}\right)$.

P. f. $=166-168^{\circ} \mathrm{C}$.

IR $\mathbf{v}_{\text {máx }}\left(\mathrm{cm}^{-1}\right) 3450 \mathrm{br}, 3300 \mathrm{br}(\mathrm{NH}), 1684 \mathrm{br}(\mathrm{C}=\mathrm{O})$.

RMN ${ }^{1} \mathbf{H}\left(500 \mathrm{MHz}, \mathrm{CDCl}_{3}\right) \delta=8.30(1 \mathrm{H}$, br s, NH), $7.60(1 \mathrm{H}$, br s, NH), 7.40 $(1 \mathrm{H}, \mathrm{s}), 7.25(1 \mathrm{H}, \mathrm{d}, J=10.7 \mathrm{~Hz}), 6.80(1 \mathrm{H}, \mathrm{d}, J=10.8 \mathrm{~Hz}), 6.44(1 \mathrm{H}, \mathrm{s}), 5.85$ $(1 \mathrm{H}$, br s, NH), $4.52(1 \mathrm{H}, \mathrm{dd}, J=11.5,6.8 \mathrm{~Hz}), 3.97(1 \mathrm{H}, \mathrm{dd}, J=16.5,5.5 \mathrm{~Hz})$, $3.91(3 \mathrm{H}, \mathrm{s}), 3.85(3 \mathrm{H}, \mathrm{s}), 3.85-3.70(3 \mathrm{H}, \mathrm{br} \mathrm{m}$ solapado), $3.80(3 \mathrm{H}, \mathrm{s}), 3.56$ $(3 \mathrm{H}, \mathrm{s}), 2.40(1 \mathrm{H}, \mathrm{dd}, J=13,6 \mathrm{~Hz}), 2.25(1 \mathrm{H}, \mathrm{td}$ app, $J=13,7 \mathrm{~Hz}), 2.14(1 \mathrm{H}$, $\mathrm{m}), 1.80(1 \mathrm{H}, \mathrm{m}), 1.31(9 \mathrm{H}, \mathrm{s})$.

RMN ${ }^{13} \mathrm{C}\left(125 \mathrm{MHz}, \mathrm{CDCl}_{3}\right) \delta=179.2,170.6,168.8,163.8,156.2^{*}, 153.3$, 152.0, 150.9, 141.4, 136.7, 134.1, 125.4, 79.7* (C), 135.3, 130.6, 112.7, 107.3, $52.3(\mathrm{CH}), 44.1^{*}, 42.7,35.9,29.7\left(\mathrm{CH}_{2}\right), 61.2,61.1,56.1,56.0,28.1$ (x 3) $\left(\mathrm{CH}_{3}\right)$. *Baja y ancha.

HR ESMS $m / z 572.2606\left(\mathrm{M}+\mathrm{H}^{+}\right)$. Calcd. para $\mathrm{C}_{29} \mathrm{H}_{38} \mathrm{~N}_{3} \mathrm{O}_{9}, 572.2608$.

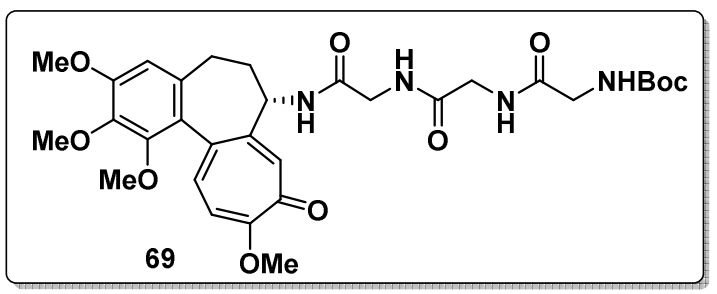

A partir de $0.30 \mathrm{~g}(0.64 \mathrm{mmol})$ del compuesto 3 se obtuvieron $0.29 \mathrm{~g}(0.46$ $\mathrm{mmol}, 72 \%$ ) del compuesto 69 como un sólido amarillento.

$[\alpha]_{D}=-62.1\left(\mathrm{c}=1.0, \mathrm{CHCl}_{3}\right)$.

P. f. $=142-144^{\circ} \mathrm{C}$.

IR $\mathbf{v}_{\text {máx }}\left(\mathrm{cm}^{-1}\right) 3450 \mathrm{br}, 3320 \mathrm{br}(\mathrm{NH}), 1670 \mathrm{br}(\mathrm{C}=\mathrm{O})$.

$\operatorname{RMN}^{1} \mathbf{H}\left(500 \mathrm{MHz}, \mathrm{CDCl}_{3}\right) \delta=8.10(1 \mathrm{H}$, br s, NH), $8.00(2 \mathrm{H}$, dos br s, NH), $7.38(1 \mathrm{H}, \mathrm{s}), 7.32(1 \mathrm{H}, \mathrm{d}, J=10.8 \mathrm{~Hz}), 6.87(1 \mathrm{H}, \mathrm{d}, J=10.8 \mathrm{~Hz}), 6.53(1 \mathrm{H}, \mathrm{s})$, $6.10(1 \mathrm{H}, \mathrm{br} \mathrm{s}, \mathrm{NH}) .4 .64(1 \mathrm{H}, \mathrm{dt}$ app, $J=11.5,6.5 \mathrm{~Hz}), 4.10-3.80(6 \mathrm{H}, \mathrm{br} \mathrm{m}$ solapado), $3.96(3 \mathrm{H}, \mathrm{s}), 3.93(3 \mathrm{H}, \mathrm{s}), 3.90(3 \mathrm{H}, \mathrm{s}), 3.63(3 \mathrm{H}, \mathrm{s}), 2.50(1 \mathrm{H}, \mathrm{dd}, J$ 
$=13,6 \mathrm{~Hz}), 2.34(1 \mathrm{H}, \mathrm{td}$ app, $J=13,7 \mathrm{~Hz}), 2.20(1 \mathrm{H}, \mathrm{m}), 2.00(1 \mathrm{H}, \mathrm{m}), 1.35$ $(9 \mathrm{H}, \mathrm{s})$.

RMN ${ }^{13} \mathbf{C}\left(125 \mathrm{MHz}, \mathrm{CDCl}_{3}\right) \delta=179.4,172.0,170.5,169.0,163.8,156.8^{*}$, 153.6, 152.4, 151.0, 141.5, 137.2, 134.3, 125.4, 79.9* (C), 135.5, 131.0, 113.0, $107.4,52.0^{\star}(\mathrm{CH}), 44.3^{*}, 43.6^{*}, 43.2^{*}, 36.1,29.9\left(\mathrm{CH}_{2}\right), 61.4,61.3,56.3,56.1$, $28.2(\times 3)\left(\mathrm{CH}_{3}\right) .{ }^{*}$ Baja y ancha.

HR ESMS $m / z 629.2817\left(\mathrm{M}+\mathrm{H}^{+}\right)$. Calcd. para $\mathrm{C}_{31} \mathrm{H}_{41} \mathrm{~N}_{4} \mathrm{O}_{10}, 629.2823$.

\subsubsection{Procedimiento experimental para la $\mathrm{N}$-Boc desprotección}

La resina Amberlyst $15(5 \mathrm{~g})$ se agitó en $\mathrm{MeOH}(20 \mathrm{~mL})$ durante 24 horas. Luego se filtró y la resina se lavó de nuevo con $\mathrm{MeOH}$. La resina lavada se neutralizó con una disolución de $\mathrm{NH}_{3} 4 \mathrm{M}$ en $\mathrm{MeOH}$. Seguidamente se acidificó hasta pH 3 con una disolución de $\mathrm{HCl} 3 \mathrm{M}$ en $50 \% \mathrm{MeOH}$. Luego se filtró y lavó secuencialmente con $\mathrm{MeOH}$, THF y $\mathrm{CH}_{2} \mathrm{Cl}_{2}$.

El $N$-Boc derivado obtenido en la reacción de acoplamiento se disolvió en $\mathrm{CH}_{2} \mathrm{Cl}_{2}(20 \mathrm{~mL})$ y se le añadió la resina Amberlyst-15 $(2 \mathrm{~g})$, previamente lavada y activada. Se dejó en agitación a temperatura ambiente durante 24 horas. A continuación, se filtró la resina y se lavó secuencialmente con hexano, THF y $\mathrm{MeOH}$. La resina se trató con una disolución de $\mathrm{NH}_{3} 4 \mathrm{M}$ en $\mathrm{MeOH}(10 \mathrm{~mL})$ durante 1 hora a temperatura ambiente. Luego, se añadió $\mathrm{MeOH}(20 \mathrm{~mL})$ y se filtró la resina. Los filtrados metanólicos reunidos se concentraron bajo presión reducida obteniéndose directamente el derivado $\mathrm{N}$-Boc desprotegido sin necesidad de purificación adicional.

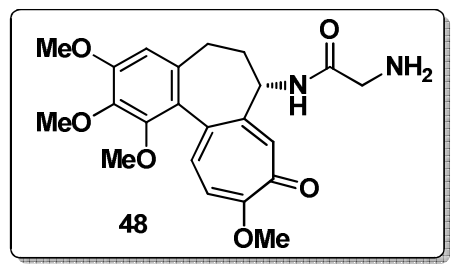

A partir de $0.14 \mathrm{~g}(0.26 \mathrm{mmol})$ del compuesto 38 se obtuvieron $0.081 \mathrm{~g}$ ( $0.20 \mathrm{mmol}, 75 \%)$ del compuesto 48 como un sólido marrón amarillento. 
$[\alpha]_{D}=-222.6(c=1.0, \mathrm{MeOH})$.

P. f. $=131-133^{\circ} \mathrm{C}$.

IR $\mathbf{v}_{\text {máx }}\left(\mathrm{cm}^{-1}\right) 3400 \mathrm{br}\left(\mathrm{NH}, \mathrm{NH}_{2}\right), 1682(\mathrm{C}=\mathrm{O})$.

RMN ${ }^{1} \mathbf{H}\left(500 \mathrm{MHz}, \mathrm{CD}_{3} \mathrm{OD}\right) \delta=7.45-7.35(2 \mathrm{H}, \mathrm{m}), 7.20(1 \mathrm{H}, \mathrm{d}, J=10.8 \mathrm{~Hz})$, $6.74(1 \mathrm{H}, \mathrm{s}), 4.53(1 \mathrm{H}, \mathrm{dd}, J=11.5,6 \mathrm{~Hz}), 4.00(3 \mathrm{H}, \mathrm{s}), 3.90(3 \mathrm{H}, \mathrm{s}), 3.88(3 \mathrm{H}$, s), $3.60(3 \mathrm{H}, \mathrm{s}), 3.45(2 \mathrm{H}, \mathrm{m}), 2.63(1 \mathrm{H}, \mathrm{dd}, J=13.5,6 \mathrm{~Hz}), 2.34(1 \mathrm{H}, \mathrm{m}), 2.22$ $(1 \mathrm{H}, \mathrm{m}), 1.95(1 \mathrm{H}, \mathrm{m})$ (señales de $\mathrm{NH}$ no detectadas, quizás solapadas con la señal hidroxil del disolvente a $\delta 4.80$ ).

RMN ${ }^{13} \mathbf{C}\left(125 \mathrm{MHz}, \mathrm{CD}_{3} \mathrm{OD}\right) \delta=180.8,172.5^{*}, 165.4,155.3,153.9,152.1$, 142.7, 138.5, 136.0, 126.7 (C), 137.7, 131.2, 115.1, 108.8, $53.6(\mathrm{CH}), 44.1$, 37.4, $30.5\left(\mathrm{CH}_{2}\right), 61.8,61.6,57.0,56.7\left(\mathrm{CH}_{3}\right) .{ }^{*}$ Baja y ancha.

HR ESMS $m / z 415.1868\left(M+\mathrm{H}^{+}\right)$. Calcd. para $\mathrm{C}_{22} \mathrm{H}_{27} \mathrm{~N}_{2} \mathrm{O}_{6}, 415.1869$.

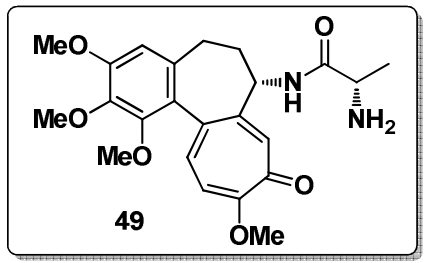

A partir de $0.17 \mathrm{~g}(0.32 \mathrm{mmol})$ del compuesto 39 se obtuvieron $0.10 \mathrm{~g}(0.24$ mmol, $76 \%$ ) del compuesto $\mathbf{4 9}$ como un sólido marrón amarillento.

$[\alpha]_{D}=-185.2(\mathrm{c}=1.0, \mathrm{MeOH})$.

P. f. $=139-141^{\circ} \mathrm{C}$.

IR $\mathbf{v}_{\text {máx }}\left(\mathrm{cm}^{-1}\right) 3400 \mathrm{br}\left(\mathrm{NH}, \mathrm{NH}_{2}\right), 1681,1680(\mathrm{C}=\mathrm{O})$.

$\mathbf{R M N}^{1} \mathbf{H}\left(500 \mathrm{MHz}, \mathrm{CD}_{3} \mathrm{OD}\right) \delta=7.39(1 \mathrm{H}, \mathrm{d}, J=10.8 \mathrm{~Hz}), 7.36(1 \mathrm{H}, \mathrm{s}), 7.18$ $(1 \mathrm{H}, \mathrm{d}, J=10.8 \mathrm{~Hz}), 6.74(1 \mathrm{H}, \mathrm{s}), 4.51(1 \mathrm{H}, \mathrm{dd}, J=11.5,6.5 \mathrm{~Hz}), 4.00(3 \mathrm{H}, \mathrm{s})$, $3.90(3 \mathrm{H}, \mathrm{s}), 3.88(3 \mathrm{H}, \mathrm{s}), 3.61(3 \mathrm{H}, \mathrm{s}), 3.56(1 \mathrm{H}, \mathrm{m}), 2.63(1 \mathrm{H}, \mathrm{dd}, J=13.5,6$ $\mathrm{Hz}$ ), $2.35(1 \mathrm{H}, \mathrm{m}), 2.21(1 \mathrm{H}, \mathrm{m}), 1.95(1 \mathrm{H}, \mathrm{m}), 1.31(3 \mathrm{H}, \mathrm{d}, J=7 \mathrm{~Hz}$ ) (señales de $\mathrm{NH}$ no detectadas, quizás solapadas con la señal hidroxil del disolvente a $\delta$ 4.80). 
RMN ${ }^{13} \mathbf{C}\left(125 \mathrm{MHz}, \mathrm{CD}_{3} \mathrm{OD}\right) \delta=180.8,177.1,165.4,155.2,154.0,152.2$, 142.7, 138.5, 136.0, 126.7 (C), 137.7, 131.2, 115.0, 108.8, 53.5, $51.2(\mathrm{CH})$, 37.3, $30.5\left(\mathrm{CH}_{2}\right), 61.8,61.6,57.0,56.6,21.2\left(\mathrm{CH}_{3}\right)$.

HR ESMS $m / z 429.2019\left(\mathrm{M}+\mathrm{H}^{+}\right)$. Calcd. para $\mathrm{C}_{23} \mathrm{H}_{29} \mathrm{~N}_{2} \mathrm{O}_{6}, 429.2025$.

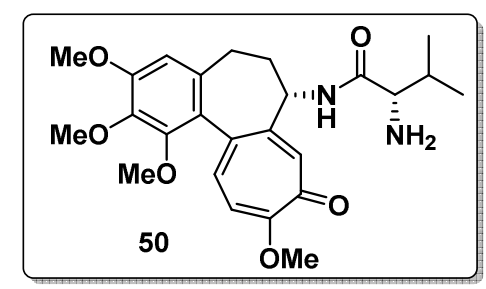

A partir de $0.16 \mathrm{~g}(0.29 \mathrm{mmol})$ del compuesto 40 Se obtuvieron $0.12 \mathrm{~g}$ (0.26 mmol, 90\%) del compuesto 50 como un sólido marrón amarillento.

$[\alpha]_{D}=-176.2(\mathrm{c}=0.13, \mathrm{MeOH})$.

P. f. $=204-206^{\circ} \mathrm{C}$.

IR $\mathbf{v}_{\text {máx }}\left(\mathrm{cm}^{-1}\right) 3420 \mathrm{br}, 3220\left(\mathrm{NH}, \mathrm{NH}_{2}\right), 1685(\mathrm{C}=\mathrm{O})$.

$\mathbf{R M N}^{1} \mathbf{H}\left(500 \mathrm{MHz}, \mathrm{CD}_{3} \mathrm{OD}\right) \delta=7.43(1 \mathrm{H}, \mathrm{d}, J=10.7 \mathrm{~Hz}), 7.35(1 \mathrm{H}, \mathrm{s}), 7.18$ $(1 \mathrm{H}, \mathrm{d}, J=10.7 \mathrm{~Hz}), 6.75(1 \mathrm{H}, \mathrm{s}), 4.60(1 \mathrm{H}, \mathrm{dd}, J=11.7,6.3 \mathrm{~Hz}), 4.00(3 \mathrm{H}, \mathrm{s})$, $3.90(3 \mathrm{H}, \mathrm{s}), 3.88(3 \mathrm{H}, \mathrm{s}), 3.62(3 \mathrm{H}, \mathrm{s}), 3.75(1 \mathrm{H}, \mathrm{d}, J=5 \mathrm{~Hz}), 2.66(1 \mathrm{H}, \mathrm{dd}, J=$ 13.7, $6 \mathrm{~Hz}), 2.38(2 \mathrm{H}, \mathrm{m}), 2.24(1 \mathrm{H}, \mathrm{m}), 2.00(1 \mathrm{H}, \mathrm{m}), 1.12(3 \mathrm{H}, \mathrm{d}, J=7 \mathrm{~Hz})$, $0.99(3 \mathrm{H}, \mathrm{d}, J=7 \mathrm{~Hz})$ (señales de $\mathrm{NH}$ no detectadas, quizás solapadas con la señal hidroxil del disolvente a $\delta 4.80$ ).

RMN ${ }^{13} \mathbf{C}\left(125 \mathrm{MHz}, \mathrm{CD}_{3} \mathrm{OD}\right) \delta=180.5,169.2,165.4,155.2,153.8,152.2$, 142.7, 138.4, 136.0, 126.7 (C), 137.7, 131.5, 115.0, 108.9, 59.6, 53.9, 31.5 $(\mathrm{CH}), 37.4,30.5\left(\mathrm{CH}_{2}\right), 61.8,61.6,57.1,56.7,19.4,17.3\left(\mathrm{CH}_{3}\right)$.

HR ESMS $m / z 457.2341\left(\mathrm{M}+\mathrm{H}^{+}\right)$. Calcd. para $\mathrm{C}_{25} \mathrm{H}_{33} \mathrm{~N}_{2} \mathrm{O}_{6}, 457.2338$. 


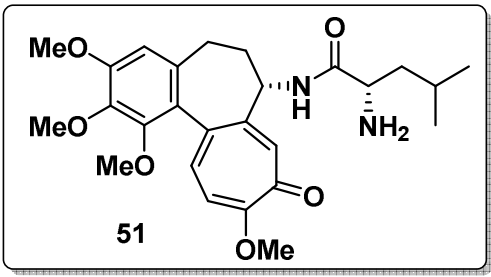

A partir de $0.22 \mathrm{~g}(0.38 \mathrm{mmol})$ del compuesto 41 se obtuvieron $0.15 \mathrm{~g}$ (0.33 mmol, 84\%) del compuesto 51 como un sólido marrón amarillento.

$[\alpha]_{D}=-256.8(\mathrm{c}=0.13, \mathrm{MeOH})$.

P. f. $=230-232^{\circ} \mathrm{C}$.

IR $\mathbf{v}_{\text {máx }}\left(\mathrm{cm}^{-1}\right) 3400 \mathrm{br}, 3210 \mathrm{br}\left(\mathrm{NH}, \mathrm{NH}_{2}\right), 1686(\mathrm{C}=\mathrm{O})$.

$\mathbf{R M N}^{1} \mathbf{H}\left(500 \mathrm{MHz}, \mathrm{CD}_{3} \mathrm{OD}\right) \delta=7.42(1 \mathrm{H}, \mathrm{d}, J=10.8 \mathrm{~Hz}), 7.31(1 \mathrm{H}, \mathrm{s}), 7.20$ $(1 \mathrm{H}, \mathrm{d}, J=10.8 \mathrm{~Hz}), 6.75(1 \mathrm{H}, \mathrm{s}), 4.58(1 \mathrm{H}, \mathrm{dd}, J=11.7,6.4 \mathrm{~Hz}), 4.00(3 \mathrm{H}, \mathrm{s})$, $3.90(3 \mathrm{H}, \mathrm{s}), 3.88(3 \mathrm{H}, \mathrm{s}+$ overlapped $\mathrm{m}, 1 \mathrm{H}), 3.62(3 \mathrm{H}, \mathrm{s}), 2.66(1 \mathrm{H}, \mathrm{dd}, J=$ 13.6, $6 \mathrm{~Hz}), 2.39(1 \mathrm{H}, \mathrm{m}), 2.24(1 \mathrm{H}, \mathrm{m}), 2.00(1 \mathrm{H}, \mathrm{m}), 1.85-1.60(3 \mathrm{H}, \mathrm{br} \mathrm{m})$, $1.08(3 \mathrm{H}, \mathrm{d}, J=6.5 \mathrm{~Hz}), 1.03(3 \mathrm{H}, \mathrm{d}, J=6.5 \mathrm{~Hz}$ ) (señales de $\mathrm{NH}$ no detectadas, quizás solapadas con la señal hidroxil del disolvente a $\delta 4.80$ ).

RMN ${ }^{13} \mathbf{C}\left(125 \mathrm{MHz}, \mathrm{CD}_{3} \mathrm{OD}\right) \delta=180.6,170.1,165.4,155.2,153.6,152.2$, 142.7, 138.3, 136.0, 126.7 (C), 137.7, 131.3, 115.0, 108.9, 53.9, 52.9, 25.6 $(\mathrm{CH}), 41.6,37.3,30.5\left(\mathrm{CH}_{2}\right), 61.8,61.6,57.1,56.7,23.1,22.2\left(\mathrm{CH}_{3}\right)$.

HR ESMS $m / z 471.2495\left(\mathrm{M}+\mathrm{H}^{+}\right)$. Calcd. para $\mathrm{C}_{26} \mathrm{H}_{35} \mathrm{~N}_{2} \mathrm{O}_{6}, 471.2495$.

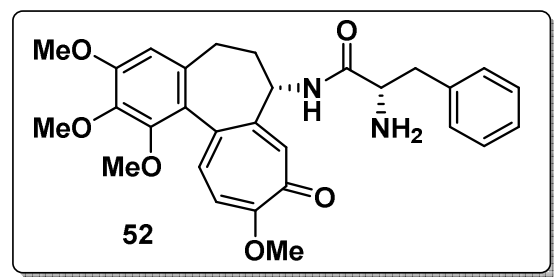

A partir de $0.25 \mathrm{~g}(0.41 \mathrm{mmol})$ del compuesto 42 se obtuvieron $0.19 \mathrm{~g}$ (0.38 mmol, 93\%) del compuesto 52 como un sólido marrón amarillento.

$[\alpha]_{D}=-207.2(\mathrm{c}=1.0, \mathrm{MeOH})$.

P. f. $=217-219^{\circ} \mathrm{C}$. 
IR $\mathbf{v}_{\text {máx }}\left(\mathrm{cm}^{-1}\right) 3380 \mathrm{br}, 3200 \mathrm{br}\left(\mathrm{NH}, \mathrm{NH}_{2}\right), 1686(\mathrm{C}=\mathrm{O})$.

$\mathbf{R M N}^{1} \mathbf{H}\left(500 \mathrm{MHz}, \mathrm{CD}_{3} \mathrm{OD}\right) \delta=7.41(1 \mathrm{H}, \mathrm{d}, J=10.8 \mathrm{~Hz}), 7.30-7.15(7 \mathrm{H}, \mathrm{br}$ m), $6.75(1 \mathrm{H}, \mathrm{s}), 4.54(1 \mathrm{H}, \mathrm{dd}, J=11.6,6.4 \mathrm{~Hz}), 4.00(3 \mathrm{H}, \mathrm{s}), 3.90(3 \mathrm{H}, \mathrm{s}), 3.89$ $(3 \mathrm{H}, \mathrm{s}), 3.63(4 \mathrm{H}, \mathrm{s}+$ solapado $\mathrm{m}), 3.06(1 \mathrm{H}, \mathrm{dd}, J=13.2,5.5 \mathrm{~Hz}), 2.74(1 \mathrm{H}$, dd, $J=13.2,8 \mathrm{~Hz}), 2.62(1 \mathrm{H}, \mathrm{dd}, J=13.3,6.3 \mathrm{~Hz}), 2.33(1 \mathrm{H}, \mathrm{m}), 2.16(1 \mathrm{H}, \mathrm{m})$, $1.93(1 \mathrm{H}, \mathrm{m})$ (señales de $\mathrm{NH}$ no detectadas, quizás solapadas con la señal hidroxil del disolvente a $\delta 4.80)$.

RMN ${ }^{13} \mathbf{C}\left(125 \mathrm{MHz}, \mathrm{CD}_{3} \mathrm{OD}\right) \delta=180.7,175.8,165.4,155.2,153.6,152.2$, $142.7,138.5,138.4,136.0,126.7$ (C), 137.5, 131.3, 130.4 (x 2), 129.6 (x 2), 127.9, 114.9, 108.9, 57.4, $53.4(\mathrm{CH}), 42.0,37.4,30.6\left(\mathrm{CH}_{2}\right), 61.8,61.7,57.0$, $56.6\left(\mathrm{CH}_{3}\right)$.

HR ESMS $m / z 505.2336\left(\mathrm{M}+\mathrm{H}^{+}\right)$. Calcd. para $\mathrm{C}_{29} \mathrm{H}_{33} \mathrm{~N}_{2} \mathrm{O}_{6}, 505.2339$.

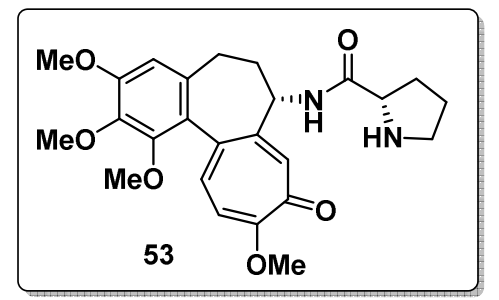

A partir de $0.19 \mathrm{~g}(0.34 \mathrm{mmol})$ del compuesto 43 se obtuvieron $0.13 \mathrm{~g}$ (0.29 $\mathrm{mmol}, 85 \%$ ) del compuesto 53 como un sólido marrón amarillento.

$[\alpha]_{D}=-265.2(c=0.13, \mathrm{MeOH})$.

P. f. $=246-248^{\circ} \mathrm{C}$.

IR $\mathbf{v}_{\text {máx }}\left(\mathrm{cm}^{-1}\right) 3420 \mathrm{br}, 3250\left(\mathrm{NH}, \mathrm{NH}_{2}\right), 1684(\mathrm{C}=\mathrm{O})$.

$\mathbf{R M N}^{1} \mathbf{H}\left(500 \mathrm{MHz}, \mathrm{CD}_{3} \mathrm{OD}\right) \delta=7.43(1 \mathrm{H}, \mathrm{d}, J=10.8 \mathrm{~Hz}), 7.30(1 \mathrm{H}, \mathrm{s}), 7.22$ $(1 \mathrm{H}, \mathrm{d}, J=10.8 \mathrm{~Hz}), 6.76(1 \mathrm{H}, \mathrm{s}), 4.55(1 \mathrm{H}, \mathrm{dd}, J=11.8,6 \mathrm{~Hz}), 4.27(1 \mathrm{H}, \mathrm{t}, J=$ $7.5 \mathrm{~Hz}), 4.01(3 \mathrm{H}, \mathrm{s}), 3.90(3 \mathrm{H}, \mathrm{s}), 3.88(3 \mathrm{H}, \mathrm{s}), 3.61(3 \mathrm{H}, \mathrm{s}), 3.30(2 \mathrm{H}, \mathrm{m}$ solapada con la señal del disolvente), $2.67(1 \mathrm{H}, \mathrm{dd}, J=13.2,6 \mathrm{~Hz}), 2.54(1 \mathrm{H}$, m), $2.38(1 \mathrm{H}, \mathrm{m}), 2.26(1 \mathrm{H}, \mathrm{m}), 2.15-1.95(4 \mathrm{H}, \mathrm{br} \mathrm{m})$. 
RMN ${ }^{13} \mathrm{C}\left(125 \mathrm{MHz}, \mathrm{CD}_{3} \mathrm{OD}\right) \delta=180.6,169.1,165.4,155.2,153.6,152.1$, 142.7, 138.3, 135.9, 126.6 (C), 137.8, 131.0, 115.1, 108.9, 61.1, 53.9 (CH), 47.4, 37.2, 31.1, 30.5, $25.1\left(\mathrm{CH}_{2}\right), 61.8,61.6,57.1,56.7\left(\mathrm{CH}_{3}\right)$.

HR ESMS $m / z 455.2187\left(\mathrm{M}+\mathrm{H}^{+}\right)$. Calcd. para $\mathrm{C}_{25} \mathrm{H}_{31} \mathrm{~N}_{2} \mathrm{O}_{6}, 455.2182$.

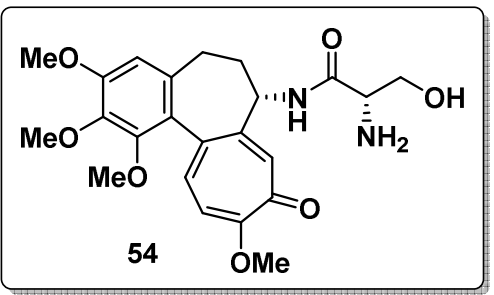

A partir de $0.16 \mathrm{~g}(0.29 \mathrm{mmol})$ del compuesto 44 se obtuvieron $0.097 \mathrm{~g}$ (0.22 mmol, $75 \%)$ del compuesto 54 como un sólido marrón amarillento.

$[\alpha]_{\mathrm{D}}=-108.7(\mathrm{c}=0.13, \mathrm{MeOH})$.

P. f. $=230-232^{\circ} \mathrm{C}$.

IR $\mathbf{v}_{\text {máx }}\left(\mathrm{cm}^{-1}\right) 3400 \mathrm{br}, 3220 \mathrm{br}\left(\mathrm{OH}, \mathrm{NH}, \mathrm{NH}_{2}\right), 1688(\mathrm{C}=\mathrm{O})$.

$\mathbf{R M N}^{1} \mathbf{H}\left(500 \mathrm{MHz}, \mathrm{CD}_{3} \mathrm{OD}\right) \delta=7.43(1 \mathrm{H}, \mathrm{d}, J=10.8 \mathrm{~Hz}), 7.36(1 \mathrm{H}, \mathrm{s}), 7.23$ $(1 \mathrm{H}, \mathrm{d}, J=10.8 \mathrm{~Hz}), 6.76(1 \mathrm{H}, \mathrm{s}), 4.57(1 \mathrm{H}, \mathrm{dd}, J=11.7,6.4 \mathrm{~Hz}), 4.08(1 \mathrm{H}, \mathrm{dd}$, $J=11,3.5 \mathrm{~Hz}), 4.00(3 \mathrm{H}, \mathrm{s}), 3.95-3.85(2 \mathrm{H}, \mathrm{m}$ solapada), $3.90(3 \mathrm{H}, \mathrm{s}), 3.88$ $(3 \mathrm{H}, \mathrm{s}), 3.61(3 \mathrm{H}, \mathrm{s}), 2.66(1 \mathrm{H}, \mathrm{dd}, J=13,6 \mathrm{~Hz}), 2.37(1 \mathrm{H}, \mathrm{m}), 2.25(1 \mathrm{H}, \mathrm{m})$, $2.00(1 \mathrm{H}, \mathrm{m})$ (señales de $\mathrm{OH}$ y $\mathrm{NH}$ no detectadas, quizás solapadas con la señal hidroxil del disolvente a $\delta 4.80$ ).

RMN ${ }^{13} \mathbf{C}\left(125 \mathrm{MHz}, \mathrm{CD}_{3} \mathrm{OD}\right) \delta=180.8,167.7,165.4,155.2,153.6,152.1$, $142.7,138.5,136.0,126.7$ (C), 137.8, 131.3, 115.2, 108.9, 56.2, $53.9(\mathrm{CH})$, 61.6, 37.4, $30.5\left(\mathrm{CH}_{2}\right), 61.7$ (x 2), 57.2, $56.7\left(\mathrm{CH}_{3}\right)$.

HR ESMS $m / z 445.1980\left(\mathrm{M}+\mathrm{H}^{+}\right)$. Calcd. para $\mathrm{C}_{23} \mathrm{H}_{29} \mathrm{~N}_{2} \mathrm{O}_{7}, 445.1975$. 


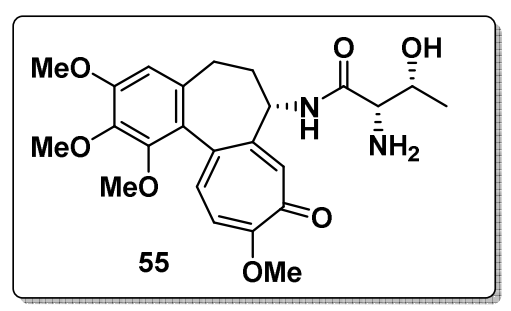

A partir de $0.12 \mathrm{~g}(0.21 \mathrm{mmol})$ del compuesto 45 se obtuvieron $0.093 \mathrm{~g}$ ( $0.20 \mathrm{mmol}, 95 \%)$ del compuesto 55 como un sólido marrón amarillento.

$[\alpha]_{D}=-158.9(\mathrm{c}=0.13, \mathrm{MeOH})$.

P. f. $=234-236^{\circ} \mathrm{C}$.

IR $\mathbf{v}_{\text {máx }}\left(\mathrm{cm}^{-1}\right) 3420 \mathrm{br}, 3200 \mathrm{br}\left(\mathrm{OH}, \mathrm{NH}, \mathrm{NH}_{2}\right), 1686(\mathrm{C}=\mathrm{O})$.

$\mathbf{R M N}^{1} \mathbf{H}\left(500 \mathrm{MHz}, \mathrm{CD}_{3} \mathrm{OD}\right) \delta=7.43(1 \mathrm{H}, \mathrm{d}, J=10.8 \mathrm{~Hz}), 7.39(1 \mathrm{H}, \mathrm{s}), 7.21$ $(1 \mathrm{H}, \mathrm{d}, J=10.8 \mathrm{~Hz}), 6.76(1 \mathrm{H}, \mathrm{s}), 4.60(1 \mathrm{H}, \mathrm{dd}, J=11.7,6.3 \mathrm{~Hz}), 4.14(1 \mathrm{H}$, quintuplete app, $J \sim 6 \mathrm{~Hz}), 4.00(3 \mathrm{H}, \mathrm{s}), 3.90(3 \mathrm{H}, \mathrm{s}), 3.88(3 \mathrm{H}, \mathrm{s}), 3.71(1 \mathrm{H}, \mathrm{d}$, $J=6 \mathrm{~Hz}), 3.61(3 \mathrm{H}, \mathrm{s}), 2.66(1 \mathrm{H}, \mathrm{dd}, J=13.3,6 \mathrm{~Hz}), 2.38(1 \mathrm{H}, \mathrm{m}), 2.26(1 \mathrm{H}$, m), $2.00(1 \mathrm{H}, \mathrm{m}), 1.34(3 \mathrm{H}, \mathrm{d}, J=6 \mathrm{~Hz}$ ) (señales de $\mathrm{OH}$ y NH no detectadas, quizás solapadas con la señal hidroxil del disolvente a $\delta 4.80)$.

RMN ${ }^{13} \mathbf{C}\left(125 \mathrm{MHz}, \mathrm{CD}_{3} \mathrm{OD}\right) \delta=180.6,168.1,165.4,155.2,153.6,152.1$, $142.7,138.4,136.0,126.6$ (C), 137.8, 131.6, 115.2, 108.9, 67.3, 60.1, 54.0 $(\mathrm{CH}), 37.4,30.5\left(\mathrm{CH}_{2}\right), 61.8,61.7,57.2,56.7,20.7\left(\mathrm{CH}_{3}\right)$.

HR ESMS $m / z 459.2128\left(\mathrm{M}_{+} \mathrm{H}^{+}\right)$. Calcd. para $\mathrm{C}_{24} \mathrm{H}_{31} \mathrm{~N}_{2} \mathrm{O}_{7}, 459.2131$.

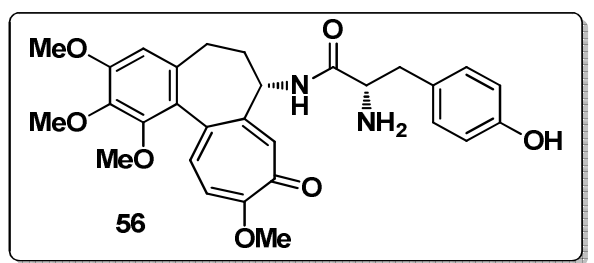

A partir de $0.32 \mathrm{~g}(0.52 \mathrm{mmol})$ del compuesto 46 se obtuvieron $0.20 \mathrm{~g}$ (0.39 $\mathrm{mmol}, 75 \%$ ) del compuesto 56 como un sólido marrón amarillento.

$[\alpha]_{D}=-166.1(c=0.12, \mathrm{MeOH})$.

P. f. $=236-238^{\circ} \mathrm{C}$. 
IR $\mathbf{v}_{\text {máx }}\left(\mathrm{cm}^{-1}\right) 3400 \mathrm{br}, 3200 \mathrm{br}\left(\mathrm{OH}, \mathrm{NH}, \mathrm{NH}_{2}\right), 1686(\mathrm{C}=\mathrm{O})$.

$\mathbf{R M N}^{1} \mathbf{H}\left(500 \mathrm{MHz}, \mathrm{CD}_{3} \mathrm{OD}\right) \delta=7.43(1 \mathrm{H}, \mathrm{d}, J=10.7 \mathrm{~Hz}), 7.30(1 \mathrm{H}, \mathrm{s}), 7.22$ $(1 \mathrm{H}, \mathrm{d}, J=10.7 \mathrm{~Hz}), 7.08(2 \mathrm{H}, \mathrm{d}, J=7.5 \mathrm{~Hz}), 6.74(3 \mathrm{H}, \mathrm{m}), 4.58(1 \mathrm{H}, \mathrm{dd}, J=$ 11.5, $6 \mathrm{~Hz}), 4.01(3 \mathrm{H}, \mathrm{s}), 3.90(3 \mathrm{H}, \mathrm{s}), 3.88(4 \mathrm{H}, \mathrm{s},+\mathrm{m}$ solapada), $3.63(3 \mathrm{H}, \mathrm{s})$, $3.22(1 \mathrm{H}, \mathrm{dd}, J=13.5,3.5 \mathrm{~Hz}), 2.80(1 \mathrm{H}, \mathrm{dd}, J=13.5,8,5 \mathrm{~Hz}), 2.66(1 \mathrm{H}, \mathrm{dd}, J$ $=13.5,6.5 \mathrm{~Hz}$ ), $2.37(1 \mathrm{H}, \mathrm{m}), 2.21(1 \mathrm{H}, \mathrm{m}), 1.96(1 \mathrm{H}, \mathrm{m})$ (señales de $\mathrm{OH}$ y $\mathrm{NH}$ no detectadas, quizás solapadas con la señal hidroxil del disolvente a $\delta 4.80$ ).

RMN ${ }^{13} \mathbf{C}\left(125 \mathrm{MHz}, \mathrm{CD}_{3} \mathrm{OD}\right) \delta=180.6,171.6,165.4,157.8,155.2,153.6$, 152.1, 142.7, 138.3, 136.0, 127.0, 126.7 (C), 137.6, 131.5 (x 2), 131.3, 116.8 (x 2), 115.0, 108.9, 57.2, $53.6(\mathrm{CH}), 39.0,37.5,30.5\left(\mathrm{CH}_{2}\right), 61.8,61.7,56.7$, $56.5\left(\mathrm{CH}_{3}\right)$.

HR ESMS $m / z 521.2285\left(\mathrm{M}+\mathrm{H}^{+}\right)$. Calcd. para $\mathrm{C}_{29} \mathrm{H}_{33} \mathrm{~N}_{2} \mathrm{O}_{7}, 521.2288$.

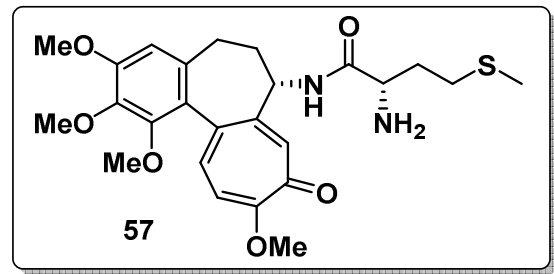

A partir de $0.22 \mathrm{~g}(0.37 \mathrm{mmol})$ del compuesto 47 se obtuvieron $0.18 \mathrm{~g}(0.36$ mmol, 97\%) del compuesto 57 como un sólido marrón amarillento.

$[\alpha]_{D}=-163.7(c=1.0, \mathrm{MeOH})$.

P. f. $=144-146^{\circ} \mathrm{C}$.

IR $\mathbf{v}_{\text {máx }}\left(\mathrm{cm}^{-1}\right) 3430 \mathrm{br}, 3250 \mathrm{br}\left(\mathrm{NH}, \mathrm{NH}_{2}\right), 1684(\mathrm{C}=\mathrm{O})$

RMN ${ }^{1} \mathbf{H}\left(500 \mathrm{MHz}, \mathrm{CD}_{3} \mathrm{OD}\right) \delta=7.41(1 \mathrm{H}, \mathrm{d}, J=10.8 \mathrm{~Hz}), 7.34(1 \mathrm{H}, \mathrm{s}), 7.19$ $(1 \mathrm{H}, \mathrm{d}, J=10.8 \mathrm{~Hz}), 6.75(1 \mathrm{H}, \mathrm{s}), 4.56(1 \mathrm{H}, \mathrm{dd}, J=11.7,6.3 \mathrm{~Hz}), 4.00(3 \mathrm{H}, \mathrm{s})$, $3.90(3 \mathrm{H}, \mathrm{s}), 3.88(3 \mathrm{H}, \mathrm{s}), 3.79(1 \mathrm{H}, \mathrm{t}, J=6 \mathrm{~Hz}), 3.62(3 \mathrm{H}, \mathrm{s}), 2.66(1 \mathrm{H}, \mathrm{dd}, J=$ 13.5, $6.2 \mathrm{~Hz}), 2.60-2.50(2 \mathrm{H}, \mathrm{m}), 2.38(1 \mathrm{H}, \mathrm{m}), 2.23(1 \mathrm{H}, \mathrm{m}), 2.14(4 \mathrm{H}, \mathrm{s}+\mathrm{m}$ solapada), 2.05-1.95 (2H, m) (señales de NH no detectadas, quizás solapadas con la señal hidroxil del disolvente a $\delta 4.80)$. 
RMN ${ }^{13} \mathbf{C}\left(125 \mathrm{MHz}, \mathrm{CD}_{3} \mathrm{OD}\right) \delta=180.6,172.6,165.4,155.2,153.7,152.1$, 142.7, 138.3, 136.0, 126.7 (C), 137.6, 131.3, 114.9, 108.9, 54.3, $53.7(\mathrm{CH})$, 37.3, 33.7, 30.5, $30.4\left(\mathrm{CH}_{2}\right), 61.8,61.6,57.0,56.7,15.3\left(\mathrm{CH}_{3}\right)$.

HR ESMS $m / z 489.2062\left(\mathrm{M}_{+} \mathrm{H}^{+}\right)$. Calcd. para $\mathrm{C}_{25} \mathrm{H}_{33} \mathrm{~N}_{2} \mathrm{O}_{6} \mathrm{~S}, 489.2059$.

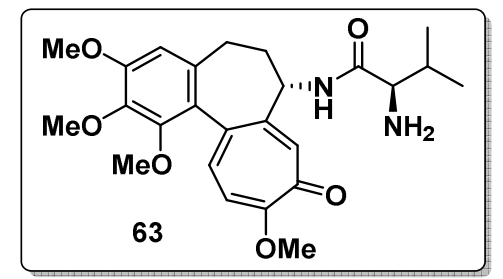

A partir de $0.20 \mathrm{~g}(0.36 \mathrm{mmol})$ del compuesto 58 se obtuvieron $0.16 \mathrm{~g}$ (0.35 mmol, 97\%) del compuesto 63 como un sólido marrón amarillento.

$[\alpha]_{D}=-231.5(\mathrm{c}=1.0, \mathrm{MeOH})$.

P. f. $=197-199^{\circ} \mathrm{C}$.

IR $\mathbf{v}_{\text {máx }}\left(\mathrm{cm}^{-1}\right) 3420 \mathrm{br}, 3220$ br $\left(\mathrm{NH}, \mathrm{NH}_{2}\right), 1685(\mathrm{C}=\mathrm{O})$.

$\mathbf{R M N}^{1} \mathbf{H}\left(500 \mathrm{MHz}, \mathrm{CD}_{3} \mathrm{OD}\right) \delta 7.41(1 \mathrm{H}, \mathrm{s}), 7.40(1 \mathrm{H}, \mathrm{d}, J=10.7 \mathrm{~Hz}), 7.19(1 \mathrm{H}$, $\mathrm{d}, J=10.7 \mathrm{~Hz}), 6.74(1 \mathrm{H}, \mathrm{s}), 4.53(1 \mathrm{H}, \mathrm{dd}, J=11.7,6.3 \mathrm{~Hz}), 4.00(3 \mathrm{H}, \mathrm{s}), 3.90$ $(3 \mathrm{H}, \mathrm{s}), 3.88(3 \mathrm{H}, \mathrm{s}), 3.62(3 \mathrm{H}, \mathrm{s}), 3.16(1 \mathrm{H}, \mathrm{d}, J=6 \mathrm{~Hz}), 2.64(1 \mathrm{H}, \mathrm{dd}, J=$ 13.6, $6 \mathrm{~Hz}), 2.35(1 \mathrm{H}, \mathrm{m}), 2.20(1 \mathrm{H}, \mathrm{m}), 2.00-1.85(2 \mathrm{H}, \mathrm{m}), 0.93(3 \mathrm{H}, \mathrm{d}, J=7$ $\mathrm{Hz}$ ), $0.91(3 \mathrm{H}, \mathrm{d}, J=7 \mathrm{~Hz})$ (señales de $\mathrm{NH}$ no detectadas, quizás solapadas con la señal hidroxil del disolvente a $\delta 4.80)$.

RMN ${ }^{13} \mathbf{C}\left(125 \mathrm{MHz}, \mathrm{CD}_{3} \mathrm{OD}\right) \delta=180.7,176.4,165.3,155.1,153.9,152.1$, 142.6, 138.4, 135.9, 126.7 (C), 137.5, 131.5, 115.0, 108.8, 61.5, 53.5, 33.4 $(\mathrm{CH}), 37.5,30.5\left(\mathrm{CH}_{2}\right), 61.8,61.6,57.1,56.7,19.8,18.0\left(\mathrm{CH}_{3}\right)$.

HR ESMS $m / z 457.2341\left(\mathrm{M}+\mathrm{H}^{+}\right)$. Calcd. para $\mathrm{C}_{25} \mathrm{H}_{33} \mathrm{~N}_{2} \mathrm{O}_{6}, 457.2338$. 


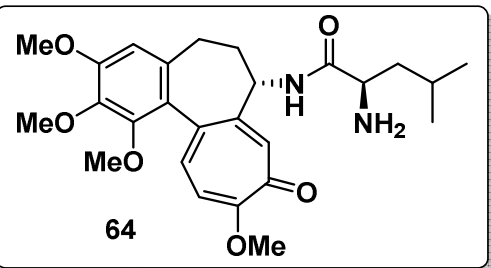

A partir de $0.12 \mathrm{~g}(0.21 \mathrm{mmol})$ del compuesto 59 se obtuvieron $0.085 \mathrm{~g}$ (0.18 mmol, 86\%) del compuesto 64 como un sólido marrón amarillento.

$[\alpha]_{D}=-200.3(c=0.13, \mathrm{MeOH})$.

P. f. $=231-233^{\circ} \mathrm{C}$.

IR $\mathbf{v}_{\text {máx }}\left(\mathrm{cm}^{-1}\right) 3420 \mathrm{br}, 3150 \mathrm{br}\left(\mathrm{NH}, \mathrm{NH}_{2}\right), 1676(\mathrm{C}=\mathrm{O})$.

$\mathbf{R M N}^{1} \mathbf{H}\left(500 \mathrm{MHz}, \mathrm{CD}_{3} \mathrm{OD}\right) \delta=7.44(1 \mathrm{H}, \mathrm{d}, J=10.8 \mathrm{~Hz}), 7.38(1 \mathrm{H}, \mathrm{s}), 7.25$ $(1 \mathrm{H}, \mathrm{d}, J=10.8 \mathrm{~Hz}), 6.75(1 \mathrm{H}, \mathrm{s}), 4.49(1 \mathrm{H}, \mathrm{dd}, J=11.7,6.6 \mathrm{~Hz}), 4.00(3 \mathrm{H}, \mathrm{s})$, $3.95(1 \mathrm{H}, \mathrm{m}), 3.90(3 \mathrm{H}, \mathrm{s}), 3.88(3 \mathrm{H}), 3.60(3 \mathrm{H}, \mathrm{s}), 2.67(1 \mathrm{H}, \mathrm{dd}, J=13.3,6$ $\mathrm{Hz}), 2.39(1 \mathrm{H}, \mathrm{m}), 2.24(1 \mathrm{H}, \mathrm{m}), 2.00(1 \mathrm{H}, \mathrm{m}), 1.75-1.60(3 \mathrm{H}, \mathrm{br} \mathrm{m}), 1.00(6 \mathrm{H}$, $\mathrm{d}, J=6.5 \mathrm{~Hz}$ ) (señales de $\mathrm{NH}$ no detectadas, quizás solapadas con la señal hidroxil del disolvente a $\delta 4.80)$.

RMN ${ }^{13} \mathbf{C}\left(125 \mathrm{MHz}, \mathrm{CD}_{3} \mathrm{OD}\right) \delta=180.8,170.1,165.4,155.2,153.4,152.1$, 142.7, 138.5, 135.9, 126.6 (C), 137.9, 131.3, 115.4, 108.9, 54.2, 53.2, 25.5 $(\mathrm{CH}), 41.7,37.3,30.5\left(\mathrm{CH}_{2}\right), 61.8,61.7,57.2,56.7,23.1,22.3\left(\mathrm{CH}_{3}\right)$.

HR ESMS $m / z 471.2494\left(\mathrm{M}+\mathrm{H}^{+}\right)$. Calcd. para $\mathrm{C}_{26} \mathrm{H}_{35} \mathrm{~N}_{2} \mathrm{O}_{6}, 471.2495$.

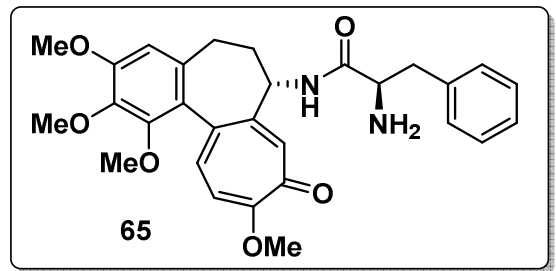

A partir de $0.17 \mathrm{~g}(0.28 \mathrm{mmol})$ del compuesto 60 se obtuvieron $0.14 \mathrm{~g}(0.27$ mmol, 99\%) del compuesto 65 como un sólido marrón amarillento. $[\alpha]_{D}=-204.2(c=0.13, \mathrm{MeOH})$. 
P. f. $=274-276{ }^{\circ} \mathrm{C}$.

IR $\mathbf{v}_{\text {máx }}\left(\mathrm{cm}^{-1}\right) 3370 \mathrm{br}, 3200\left(\mathrm{NH}, \mathrm{NH}_{2}\right), 1687(\mathrm{C}=\mathrm{O})$.

RMN ${ }^{1} \mathbf{H}\left(500 \mathrm{MHz}, \mathrm{CD}_{3} \mathrm{OD}\right) \delta=7.37(1 \mathrm{H}, \mathrm{d}, J=10.8 \mathrm{~Hz}), 7.35(1 \mathrm{H}, \mathrm{s}), 7.25-$ $7.15(6 \mathrm{H}, \mathrm{br} \mathrm{m}), 6.70(1 \mathrm{H}, \mathrm{s}), 4.38(1 \mathrm{H}, \mathrm{dd}, J=11.6,6.8 \mathrm{~Hz}), 3.98(3 \mathrm{H}, \mathrm{s}), 3.90$ $(3 \mathrm{H}, \mathrm{s}), 3.88(3 \mathrm{H}, \mathrm{s}), 3.62(4 \mathrm{H}, \mathrm{s}+\mathrm{m}$ solapado), $2.85(2 \mathrm{H}, \mathrm{m}), 2.54(1 \mathrm{H}, \mathrm{dd}, J=$ 13.5, $6.3 \mathrm{~Hz}), 2.26(1 \mathrm{H}, \mathrm{m}), 1.88(1 \mathrm{H}, \mathrm{m}), 1.78(1 \mathrm{H}, \mathrm{m})$ (señales de $\mathrm{NH}$ no detectadas, quizás solapadas con la señal hidroxil del disolvente a $\delta 4.80)$.

RMN ${ }^{13} \mathbf{C}\left(125 \mathrm{MHz}, \mathrm{CD}_{3} \mathrm{OD}\right) \delta=180.8,176.0,165.4,155.2,153.6,152.2$, 142.7, 138.7, 138.5, 136.0, 126.7 (C), 137.5, 131.3, 130.3 (x 2), 129.6 (x 2), 127.8, 115.0, 108.7, 57.7, $53.4(\mathrm{CH}), 42.3,37.3,30.5\left(\mathrm{CH}_{2}\right), 61.8,61.7,57.0$, $56.7\left(\mathrm{CH}_{3}\right)$.

HR ESMS $m / z 505.2346\left(M+\mathrm{H}^{+}\right)$. Calcd. para $\mathrm{C}_{29} \mathrm{H}_{33} \mathrm{~N}_{2} \mathrm{O}_{6}, 505.2338$.

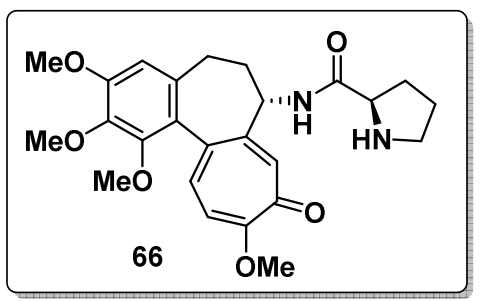

A partir de $0.13 \mathrm{~g}(0.23 \mathrm{mmol})$ del compuesto 61 se obtuvieron $0.076 \mathrm{~g}$ ( $0.17 \mathrm{mmol}, 75 \%)$ del compuesto 66 como un sólido marrón amarillento.

$[\alpha]_{D}=-135.4(\mathrm{c}=0.52, \mathrm{MeOH})$.

P. f. $=224-226^{\circ} \mathrm{C}$.

IR $\mathbf{v}_{\text {máx }}\left(\mathrm{cm}^{-1}\right) 3400 \mathrm{br}, 3250\left(\mathrm{NH}, \mathrm{NH}_{2}\right), 1683(\mathrm{C}=\mathrm{O})$.

RMN ${ }^{1} \mathbf{H}\left(500 \mathrm{MHz}, \mathrm{CD}_{3} \mathrm{OD}\right) \delta=7.42(1 \mathrm{H}, \mathrm{d}, J=10.8 \mathrm{~Hz}), 7.36(1 \mathrm{H}, \mathrm{s}), 7.22$ $(1 \mathrm{H}, \mathrm{d}, J=10.8 \mathrm{~Hz}), 6.76(1 \mathrm{H}, \mathrm{s}), 4.50(1 \mathrm{H}, \mathrm{dd}, J=11.8,6.3 \mathrm{~Hz}), 4.24(1 \mathrm{H}, \mathrm{br}$ t, $J \sim 7 \mathrm{~Hz}), 4.00(3 \mathrm{H}, \mathrm{s}), 3.90(3 \mathrm{H}, \mathrm{s}), 3.88(3 \mathrm{H}, \mathrm{s}), 3.60(3 \mathrm{H}, \mathrm{s}), 3.25(2 \mathrm{H}, \mathrm{m})$, $2.66(1 \mathrm{H}, \mathrm{dd}, J=13.5,6 \mathrm{~Hz}), 2.40-2.30(2 \mathrm{H}, \mathrm{m}), 2.25(1 \mathrm{H}, \mathrm{m}), 2.00-1.90(4 \mathrm{H}$, $\mathrm{m}$ ) (señales de $\mathrm{NH}$ no detectadas, quizás solapadas con la señal hidroxil del disolvente a $\delta 4.80)$. 
RMN ${ }^{13} \mathbf{C}\left(125 \mathrm{MHz}, \mathrm{CD}_{3} \mathrm{OD}\right) \delta=180.8,170.6,165.5,155.3,153.6,152.1$, 142.8, 138.4, 135.9, 126.7 (C), 137.8, 131.2, 115.1, 108.9, 61.3, $54.1(\mathrm{CH})$, 47.5, 37.3, 31.3, 30.4, $25.4\left(\mathrm{CH}_{2}\right), 61.7(\mathrm{x} 2), 57.1,56.7\left(\mathrm{CH}_{3}\right)$.

HR ESMS $m / z 455.2180\left(\mathrm{M}+\mathrm{H}^{+}\right)$. Calcd. para $\mathrm{C}_{25} \mathrm{H}_{31} \mathrm{~N}_{2} \mathrm{O}_{6}, 455.2182$.

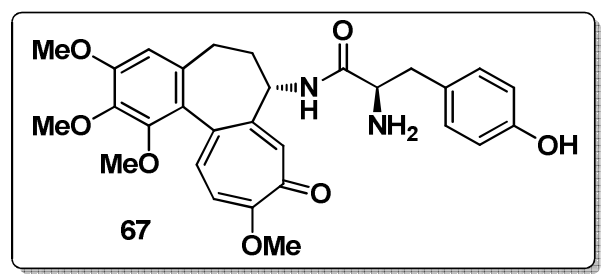

A partir de $0.19 \mathrm{~g}(0.31 \mathrm{mmol})$ del compuesto 62 se obtuvieron $0.12 \mathrm{~g}(0.23$ mmol, $75 \%$ ) del compuesto 67 como un sólido marrón amarillento.

$[\alpha]_{D}=-166.4(\mathrm{c}=0.50, \mathrm{MeOH})$.

P. f. $=246-248{ }^{\circ} \mathrm{C}$.

IR $\mathbf{v}_{\text {máx }}\left(\mathrm{cm}^{-1}\right) 3450 \mathrm{br}, 3200 \mathrm{br}\left(\mathrm{OH}, \mathrm{NH}, \mathrm{NH}_{2}\right), 1687(\mathrm{C}=\mathrm{O})$.

$\mathbf{R M N}^{1} \mathbf{H}\left(500 \mathrm{MHz}, \mathrm{DMSO}-\mathrm{d}_{6}\right) \delta=7.20(1 \mathrm{H}, \mathrm{s}), 7.12(1 \mathrm{H}, \mathrm{d}, J=10.7 \mathrm{~Hz}), 7.02$ $(3 \mathrm{H}, \mathrm{m}), 6.78(1 \mathrm{H}, \mathrm{s}), 6.69(2 \mathrm{H}, \mathrm{d}, J=8 \mathrm{~Hz}), 4.28(1 \mathrm{H}, \mathrm{m}), 4.02(1 \mathrm{H}, \mathrm{m}), 3.86$ $(3 \mathrm{H}, \mathrm{s}), 3.85(3 \mathrm{H}, \mathrm{s}), 3.79(4 \mathrm{H}, \mathrm{s},+\mathrm{m}$ solapado), $3.52(3 \mathrm{H}, \mathrm{s}), 2.90(2 \mathrm{H}, \mathrm{m})$, $2.58(1 \mathrm{H}, \mathrm{m}), 2.20(1 \mathrm{H}, \mathrm{m}), 1.80(2 \mathrm{H}, \mathrm{m})$ (señales de $\mathrm{OH}$ y $\mathrm{NH}$ no detectadas, quizás solapadas con la señal del disolvente a $\delta 4.80$ ).

RMN ${ }^{13} \mathbf{C}\left(125 \mathrm{MHz}\right.$, DMSO-d $\left.\mathrm{d}_{6}\right) \delta=178.1,167.6,163.5,156.5,153.0,150.4$, 149.8, 140.8, 134.9, 134.1, 125.3, 124.9 (C), 134.4, 130.8, 130.4 (x 2), 115.3 (x 2), 112.1, 107.9, 53.9, $51.7(\mathrm{CH}), 36.4,35.7,29.1\left(\mathrm{CH}_{2}\right), 60.8,60.7,56.1$, $55.9\left(\mathrm{CH}_{3}\right)$.

HR ESMS $m / z 521.2290\left(\mathrm{M}+\mathrm{H}^{+}\right)$. Calcd. para $\mathrm{C}_{29} \mathrm{H}_{33} \mathrm{~N}_{2} \mathrm{O}_{7}, 521.2288$. 


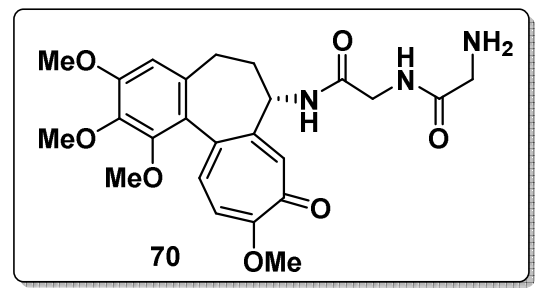

A partir de $0.20 \mathrm{~g}(0.35 \mathrm{mmol})$ del compuesto 68 se obtuvieron $0.13 \mathrm{~g}(0.28$ mmol, 80\%) del compuesto 70 como un sólido marrón amarillento.

$[\alpha]_{D}=-161.0(\mathrm{c}=0.13, \mathrm{MeOH})$.

P. f. $=170-172^{\circ} \mathrm{C}$.

IR $\mathbf{v}_{\text {máx }}\left(\mathrm{cm}^{-1}\right) 3440 \mathrm{br}, 3200 \mathrm{br}\left(\mathrm{NH}, \mathrm{NH}_{2}\right), 1683,1670(\mathrm{C}=\mathrm{O})$.

$\operatorname{RMN}^{1} \mathbf{H}\left(500 \mathrm{MHz}, \mathrm{CD}_{3} \mathrm{OD}\right) \delta=77.41(1 \mathrm{H}, \mathrm{d}, J=10.8 \mathrm{~Hz}), 7.39(1 \mathrm{H}, \mathrm{s}), 7.21$ $(1 \mathrm{H}, \mathrm{d}, J=10.8 \mathrm{~Hz}), 6.74(1 \mathrm{H}, \mathrm{s}), 4.51(1 \mathrm{H}, \mathrm{dd}, J=11.7,6.5 \mathrm{~Hz}), 4.00(5 \mathrm{H}, \mathrm{s}$, solapada a $2 \mathrm{H} \mathrm{m}), 3.90(3 \mathrm{H}, \mathrm{s}), 3.88(3 \mathrm{H}, \mathrm{s}), \mathrm{s}), 3.75(2 \mathrm{H}, \mathrm{m}), 3.59(3 \mathrm{H}, \mathrm{s})$, $2.64(1 \mathrm{H}, \mathrm{dd}, J=13,6 \mathrm{~Hz}), 2.34(1 \mathrm{H}$, td app, $J=13,7 \mathrm{~Hz}), 2.22(1 \mathrm{H}, \mathrm{m}), 2.00$ $(1 \mathrm{H}, \mathrm{m})$ (señales de $\mathrm{NH}$ no detectadas, quizás solapadas con la señal de hidroxilo del disolvente a $\delta 4.80$ ).

RMN ${ }^{13} \mathbf{C}\left(125 \mathrm{MHz}, \mathrm{CD}_{3} \mathrm{OD}\right) \delta=180.8,170.7,168.1,165.4,155.3,153.9$, 152.1, 142.7, 138.5, 136.0, 126.7 (C), 137.7, 131.5, 115.2, 108.8, $53.8(\mathrm{CH})$, 43.4, 41.6, 37.3, $30.5\left(\mathrm{CH}_{2}\right), 61.7,61.6,57.1,56.7\left(\mathrm{CH}_{3}\right)$.

HR ESMS $m / z 472.2086\left(\mathrm{M}+\mathrm{H}^{+}\right)$. Calcd. para $\mathrm{C}_{24} \mathrm{H}_{30} \mathrm{~N}_{3} \mathrm{O}_{7}, 472.2084$.

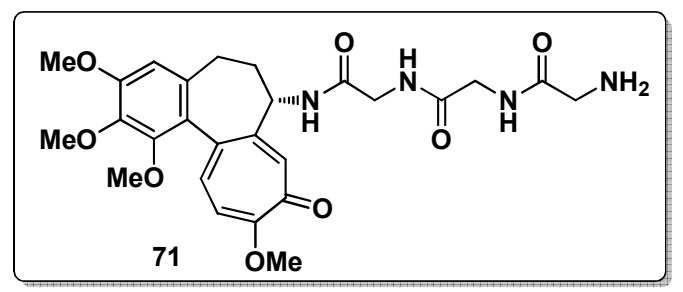

A partir de $0.18 \mathrm{~g}(0.28 \mathrm{mmol})$ del compuesto 69 se obtuvieron $0.11 \mathrm{~g}(0.21$ mmol, $75 \%$ ) del compuesto 71 como un sólido marrón amarillento.

$[\alpha]_{D}=-88.1(c=1.0, \mathrm{MeOH})$. 
P. f. $=218-220^{\circ} \mathrm{C}$.

IR $\mathbf{v}_{\text {máx }}\left(\mathrm{cm}^{-1}\right) 3400 \mathrm{br}, 3200 \mathrm{br}\left(\mathrm{NH}, \mathrm{NH}_{2}\right), 1683(\mathrm{C}=\mathrm{O})$.

$\mathbf{R M N}^{1} \mathbf{H}\left(500 \mathrm{MHz}, \mathrm{CD}_{3} \mathrm{OD}\right) \delta=7.42(1 \mathrm{H}, \mathrm{d}, J=10.8 \mathrm{~Hz}), 7.41(1 \mathrm{H}, \mathrm{s}), 7.22$ $(1 \mathrm{H}, \mathrm{d}, J=10.8 \mathrm{~Hz}), 6.75(1 \mathrm{H}, \mathrm{s}), 4.55(1 \mathrm{H}, \mathrm{dd}, J=11.7,6.5 \mathrm{~Hz}), 4.00(3 \mathrm{H}, \mathrm{s})$, 3.95-3.80 (6H, br m), $3.90(3 \mathrm{H}, \mathrm{s}), 3.88(3 \mathrm{H}, \mathrm{s}), 3.59(3 \mathrm{H}, \mathrm{s}), 2.64(1 \mathrm{H}, \mathrm{dd}, J=$ 13, $6 \mathrm{~Hz}$ ), $2.34(1 \mathrm{H}$, td app, $J=13,7 \mathrm{~Hz}), 2.21(1 \mathrm{H}, \mathrm{m}), 2.05(1 \mathrm{H}, \mathrm{m})$ (señales de $\mathrm{NH}$ no detectadas, quizás solapadas con la señal hidroxil del disolvente a $\delta$ 4.80).

RMN ${ }^{13} \mathbf{C}\left(125 \mathrm{MHz}, \mathrm{CD}_{3} \mathrm{OD}\right) \delta=180.8,171.8,170.9,168.6,165.4,155.3$, 154.0, 152.1, 142.7, 138.7, 136.0, 126.7 (C), 137.7, 131.7, 115.3, 108.9, 53.7 $(\mathrm{CH}), 43.8,43.5,41.8,37.5,30.5\left(\mathrm{CH}_{2}\right), 61.8,61.7,57.2,56.7\left(\mathrm{CH}_{3}\right)$.

HR ESMS $m / z 529.2303\left(M+\mathrm{H}^{+}\right)$. Calcd. para $\mathrm{C}_{26} \mathrm{H}_{33} \mathrm{~N}_{4} \mathrm{O}_{8}, 529.2298$. 


\subsubsection{Procedimiento experimental para la síntesis de $\mathbf{N}$-acil derivados}

A una disolución del compuesto $3(0.64 \mathrm{mmol}$, 1eq.) y el correspondiente ácido (1.28 mmol, 2 eq.) en $\mathrm{CH}_{2} \mathrm{Cl}_{2}(63 \mathrm{~mL})$ se le adicionó, bajo atmósfera de $\mathrm{N}_{2}$ y a temperatura ambiente, DCC (3.84 mmol, 6 eq.) y DMAP (1.28 mmol, 2 eq.). La mezcla resultante se agitó durante 3 horas a temperatura ambiente. Luego se filtró sobre celite y se lavó a fondo con AcOEt. El filtrado se concentró bajo presión reducida y el residuo resultante se cromatografió sobre gel de sílice con AcOEt-Acetona (8:1).

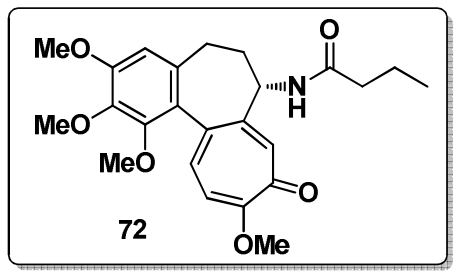

A partir de $0.38 \mathrm{~g}(0.80 \mathrm{mmol})$ del compuesto 3 se obtuvieron $0.15 \mathrm{~g}(0.35$ mmol, 44\%) del compuesto 72 como un aceite amarillento.

$[\alpha]_{D}=-109.9\left(\mathrm{c}=1.0, \mathrm{CHCl}_{3}\right)$.

IR $\mathbf{v}_{\text {máx }}\left(\mathrm{cm}^{-1}\right) 3270$ br (NH), $1660(\mathrm{C}=\mathrm{O})$.

$\mathbf{R M N}^{1} \mathbf{H}\left(500 \mathrm{MHz}, \mathrm{CDCl}_{3}\right) \delta=7.75(\mathrm{br} \mathrm{d}, J \sim 6 \mathrm{~Hz}, 1 \mathrm{H}, \mathrm{NH}), 7.53(\mathrm{~s}, 1 \mathrm{H}), 7.30$ (d, $J=10.7 \mathrm{~Hz}, 1 \mathrm{H}), 6.84$ (d, $J=10.7 \mathrm{~Hz}, 1 \mathrm{H}), 6.49$ (s, 1H), 4.63 (dt app, $J=$ 11.8, $6.5 \mathrm{~Hz}, 1 \mathrm{H}), 3.97(\mathrm{~s}, 3 \mathrm{H}), 3.91(\mathrm{~s}, 3 \mathrm{H}), 3.86(\mathrm{~s}, 3 \mathrm{H}), 3.63(\mathrm{~s}, 3 \mathrm{H}), 2.47$ (dd, $J=13.2,6 \mathrm{~Hz}, 1 \mathrm{H}$ ), 2.34 (td app, $J=13.2,6 \mathrm{~Hz}, 1 \mathrm{H}$ ), 2.30-2.15 (br m, 3H), 1.83 (td app, $J=12,6 \mathrm{~Hz}, 1 \mathrm{H}$ ), 1.57 (sext app, $J=7.5 \mathrm{~Hz}, 2 \mathrm{H}$ ), 0.84 (t, $J=7$ $\mathrm{Hz}, 3 \mathrm{H})$.

RMN ${ }^{13} \mathbf{C}\left(125 \mathrm{MHz}, \mathrm{CDCl}_{3}\right) \delta=179.3,172.8,163.9,153.4,152.4,151.1$, 141.6, 136.7, 134.1, 125.6 (C), 135.2, 130.5, 112.6, 107.3, $52.1(\mathrm{CH}), 37.9$, 36.5, 29.9, $18.7\left(\mathrm{CH}_{2}\right), 61.5,61.2,56.3,56.0,13.7\left(\mathrm{CH}_{3}\right)$.

HR ESMS $m / z 428.2066(\mathrm{M}+\mathrm{H})^{+}$. Calcd. for $\mathrm{C}_{24} \mathrm{H}_{30} \mathrm{NO}_{6}, 428.2073$. 


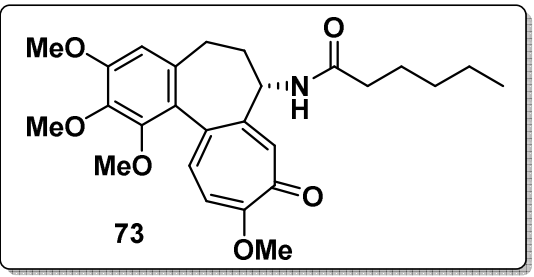

A partir de $0.30 \mathrm{~g}(0.64 \mathrm{mmol})$ del compuesto 3 se obtuvieron $0.15 \mathrm{~g}$ (0.33 mmol, $51 \%$ ) del compuesto 73 como un aceite amarillento.

$[\alpha]_{D}=-119.5\left(\mathrm{c}=0.9, \mathrm{CHCl}_{3}\right)$.

IR $\mathbf{v}_{\text {máx }}\left(\mathrm{cm}^{-1}\right) 3270$ br $(\mathrm{NH}), 1660(\mathrm{C}=\mathrm{O})$.

$\mathbf{R M N}^{1} \mathbf{H}\left(500 \mathrm{MHz}, \mathrm{CDCl}_{3}\right) \delta=7.47(\mathrm{~s}, 1 \mathrm{H}), 7.31(\mathrm{~d}, J=10.7 \mathrm{~Hz}, 1 \mathrm{H}), 7.00(\mathrm{br}$ d, $J \sim 7 \mathrm{~Hz}, 1 \mathrm{H}, \mathrm{NH}$ ), 6.84 (d, $J=10.7 \mathrm{~Hz}, 1 \mathrm{H}$ ), 6.52 (s, 1H), 4.66 (dt app, $J=$ 11.8, $6.5 \mathrm{~Hz}, 1 \mathrm{H}), 3.99(\mathrm{~s}, 3 \mathrm{H}), 3.94(\mathrm{~s}, 3 \mathrm{H}), 3.90(\mathrm{~s}, 3 \mathrm{H}), 3.66(\mathrm{~s}, 3 \mathrm{H}), 2.51$ (dd, $J=13.5,6.3 \mathrm{~Hz}, 1 \mathrm{H}$ ), 2.39 (td app, $J=13.5,6.8 \mathrm{~Hz}, 1 \mathrm{H}$ ), 2.30-2.15 (br m, $3 \mathrm{H}), 1.83$ (td app, $J=12,6 \mathrm{~Hz}, 1 \mathrm{H}), 1.57(\mathrm{~m}, 2 \mathrm{H}), 1.30-1.20(\mathrm{~m}, 4 \mathrm{H}), 0.84(\mathrm{t}, J$ $=7 \mathrm{~Hz}, 3 \mathrm{H})$.

RMN ${ }^{13} \mathbf{C}\left(125 \mathrm{MHz}, \mathrm{CDCl}_{3}\right) \delta=179.4,172.8,164.0,153.4,151.7,151.2$, 141.7, 136.5, 134.1, 125.7 (C), 135.2, 130.7, 112.4, 107.4, $52.0(\mathrm{CH}), 36.9$, 36.2, 31.4, 29.9, 25.0, $22.3\left(\mathrm{CH}_{2}\right), 61.6,61.3,56.3,56.0,13.8\left(\mathrm{CH}_{3}\right)$.

HR ESMS $m / z 456.2393(\mathrm{M}+\mathrm{H})^{+}$. Calcd. for $\mathrm{C}_{26} \mathrm{H}_{34} \mathrm{NO}_{6}, 456.2386$.

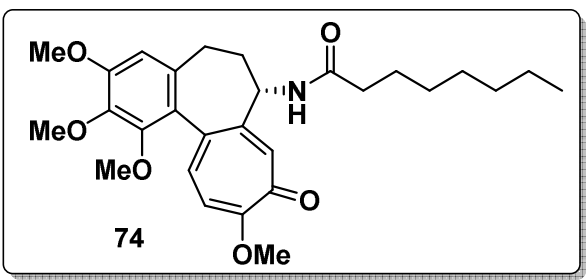

A partir de $0.15 \mathrm{~g}(0.32 \mathrm{mmol})$ del compuesto 3 se obtuvieron $0.13 \mathrm{~g}(0.26$ $\mathrm{mmol}, 82 \%$ ) del compuesto $\mathbf{7 4}$ como un aceite amarillento.

$[\alpha]_{D}=-123.3\left(\mathrm{c}=1.1, \mathrm{CHCl}_{3}\right)$. 
IR $\mathbf{v}_{\text {máx }}\left(\mathrm{cm}^{-1}\right) 3280$ br $(\mathrm{NH}), 1655(\mathrm{C}=\mathrm{O})$.

$\mathbf{R M N}^{1} \mathbf{H}\left(500 \mathrm{MHz}, \mathrm{CDCl}_{3}\right) \delta=7.52(\mathrm{~s}, 1 \mathrm{H}), 7.49(\mathrm{br} \mathrm{d}, J \sim 6.5 \mathrm{~Hz}, 1 \mathrm{H}, \mathrm{NH})$, 7.31 (d, $J=10.7 \mathrm{~Hz}, 1 \mathrm{H}$ ), 6.84 (d, $J=10.7 \mathrm{~Hz}, 1 \mathrm{H}$ ), 6.51 (s, 1H), 4.64 (dt app, $J=11.7,6.5 \mathrm{~Hz}, 1 \mathrm{H}), 3.98(\mathrm{~s}, 3 \mathrm{H}), 3.92(\mathrm{~s}, 3 \mathrm{H}), 3.88(\mathrm{~s}, 3 \mathrm{H}), 3.64(\mathrm{~s}, 3 \mathrm{H}), 2.48$ (dd, $J=13.5,6 \mathrm{~Hz}, 1 \mathrm{H}$ ), 2.36 (td app, $J=13.5,7 \mathrm{~Hz}, 1 \mathrm{H}$ ), 2.30-2.15 (br m, 3H), 1.84 (td app, $J=12,6 \mathrm{~Hz}, 1 \mathrm{H}), 1.60-1.50(\mathrm{~m}, 2 \mathrm{H}), 1.30-1.15(\mathrm{br} \mathrm{m}, 8 \mathrm{H}), 0.81$ (t, $J=7 \mathrm{~Hz}, 3 \mathrm{H})$.

RMN ${ }^{13} \mathbf{C}\left(125 \mathrm{MHz}, \mathrm{CDCl}_{3}\right) \delta=179.4,172.9,163.9,153.4,152.2,151.1$, 141.6, 136.6, 134.1, 125.6 (C), 135.1, 130.5, 112.5, 107.3, $52.1(\mathrm{CH}), 36.6$, $361,31.5,29.9,29.2,28.8,25.3,22.5\left(\mathrm{CH}_{2}\right), 61.5,61.3,56.3,56.0,13.9\left(\mathrm{CH}_{3}\right)$. HR ESMS $m / z 484.2700(\mathrm{M}+\mathrm{H})^{+}$. Calcd. for $\mathrm{C}_{28} \mathrm{H}_{38} \mathrm{NO}_{6}, 484.2699$.

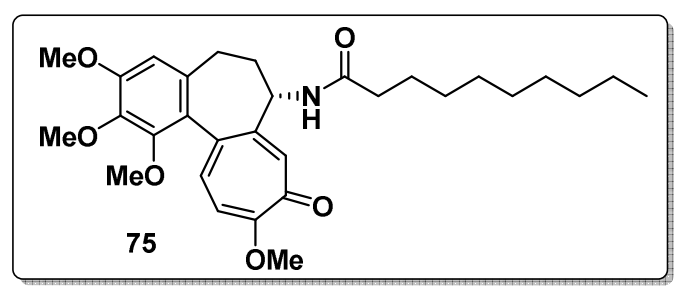

A partir de $0.30 \mathrm{~g}(0.64 \mathrm{mmol})$ del compuesto 3 se obtuvieron $0.14 \mathrm{~g}(0.28$ $\mathrm{mmol}, 44 \%$ ) del compuesto 75 como un aceite amarillento.

$[\alpha]_{D}=-124.4\left(\mathrm{c}=0.9, \mathrm{CHCl}_{3}\right)$.

IR $\mathbf{v}_{\text {máx }}\left(\mathrm{cm}^{-1}\right) 3280$ br $(\mathrm{NH}), 1659(\mathrm{C}=\mathrm{O})$.

$\mathbf{R M N}^{1} \mathbf{H}\left(500 \mathrm{MHz}, \mathrm{CDCl}_{3}\right) \delta=7.70(\mathrm{br} \mathrm{d}, J \sim 6 \mathrm{~Hz}, 1 \mathrm{H}, \mathrm{NH}), 7.52(\mathrm{~s}, 1 \mathrm{H}), 7.30$ (d, $J=10.7 \mathrm{~Hz}, 1 \mathrm{H}$ ), 6.84 (d, $J=10.7 \mathrm{~Hz}, 1 \mathrm{H}$ ), 6.50 (s, 1H), 4.63 (dt app, $J=$ 11.8, 6.3 Hz, 1H), 3.97 (s, 3H), 3.91 (s, 3H), 3.87 (s, 3H), $3.63(\mathrm{~s}, 3 \mathrm{H}), 2.47$ (dd, $J=13.2,6 \mathrm{~Hz}, 1 \mathrm{H}$ ), 2.34 (td app, $J=13.2,6.5 \mathrm{~Hz}, 1 \mathrm{H}$ ), 2.30-2.15 (br m, $3 \mathrm{H}$ ), 1.84 (td app, $J=11.8,6 \mathrm{~Hz}, 1 \mathrm{H}$ ), 1.60-1.50 (m, 2H), 1.30-1.15 (br m, $12 \mathrm{H}), 0.81(\mathrm{t}, J=7 \mathrm{~Hz}, 3 \mathrm{H})$. 
RMN ${ }^{13} \mathbf{C}\left(125 \mathrm{MHz}, \mathrm{CDCl}_{3}\right) \delta=179.3,172.9,163.9,153.4,152.3,151.1$, 141.6, 136.6, 134.1, 125.6 (C), 135.1, 130.5, 112.5, 107.3, 52.1 (CH), 36.5, 36.0, 31.7, 29.8, 29.2 (x2), 29.1, 29.0, 25.3, $22.5\left(\mathrm{CH}_{2}\right)$, 61.5, 61.2, 56.3, 56.0, $13.9\left(\mathrm{CH}_{3}\right)$.

HR ESMS $m / z 534.2833(\mathrm{M}+\mathrm{Na})^{+}$. Calcd. for $\mathrm{C}_{30} \mathrm{H}_{41} \mathrm{NNaO}_{6}, 534.2832$.

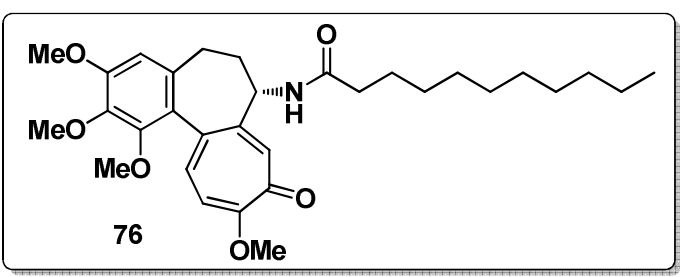

A partir de $0.20 \mathrm{~g}(0.42 \mathrm{mmol})$ del compuesto 3 se obtuvieron $0.097 \mathrm{~g}(0.18$ $\mathrm{mmol}, 44 \%$ ) del compuesto 76 como un aceite amarillento.

$[\alpha]_{D}=-107.3\left(\mathrm{c}=1.0, \mathrm{CHCl}_{3}\right)$

IR $\mathbf{v}_{\text {máx }}\left(\mathrm{cm}^{-1}\right) 3270$ br $(\mathrm{NH}), 1653(\mathrm{C}=\mathrm{O})$

$\mathbf{R M N}^{1} \mathbf{H}\left(500 \mathrm{MHz}, \mathrm{CDCl}_{3}\right) \delta=7.47(\mathrm{~s}, 1 \mathrm{H}), 7.31(\mathrm{~d}, J=10.7 \mathrm{~Hz}, 1 \mathrm{H}), 7.14(\mathrm{br}$ d, $J \sim 7 \mathrm{~Hz}, 1 \mathrm{H}, \mathrm{NH}$ ), 6.83 (d, $J=10.7 \mathrm{~Hz}, 1 \mathrm{H}$ ), 6.52 (s, 1H), 4.65 (dt app, $J=$ 11.8, $6.5 \mathrm{~Hz}, 1 \mathrm{H}), 3.99$ (s, 3H), $3.93(\mathrm{~s}, 3 \mathrm{H}), 3.89(\mathrm{~s}, 3 \mathrm{H}), 3.65(\mathrm{~s}, 3 \mathrm{H}), 2.50$ (dd, $J=13.2,6.3 \mathrm{~Hz}, 1 \mathrm{H}$ ), 2.38 (td app, $J=13.2,7 \mathrm{~Hz}, 1 \mathrm{H}$ ), 2.30-2.15 (br m, $3 \mathrm{H}$ ), 1.83 (td app, $J=12,7 \mathrm{~Hz}, 1 \mathrm{H}), 1.60-1.50(\mathrm{~m}, 2 \mathrm{H}), 1.30-1.15$ (br m, 14H), $0.85(\mathrm{t}, J=7 \mathrm{~Hz}, 3 \mathrm{H})$.

RMN ${ }^{13} \mathbf{C}\left(125 \mathrm{MHz}, \mathrm{CDCl}_{3}\right) \delta=179.4,172.8,164.0,153.4,151.8,151.2$, 141.7, 136.5, 134.2, 125.7 (C), 135.2, 130.6, 112.4, 107.4, 52.1 (CH), 36.8, 36.2, 31.8, 29.9, 29.5, 29.4, 29.3 (x2), 29.2, 25.4, $22.6\left(\mathrm{CH}_{2}\right), 61.6,61.3,56.3$, $56.1,14.0\left(\mathrm{CH}_{3}\right)$.

HR ESMS $m / z 526.3166(\mathrm{M}+\mathrm{H})^{+}$. Calcd. for $\mathrm{C}_{31} \mathrm{H}_{44} \mathrm{NO}_{6}, 526.3169$. 


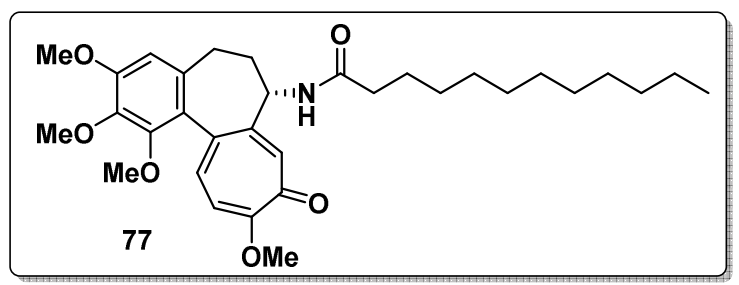

A partir de $0.15 \mathrm{~g}$ (0.32 mmol) del compuesto 3 se obtuvieron $0.10 \mathrm{~g}(0.19$ $\mathrm{mmol}, 61 \%$ ) del compuesto 77 como un aceite amarillento.

$[\alpha]_{D}=-113.8\left(\mathrm{c}=0.9, \mathrm{CHCl}_{3}\right)$.

IR $\mathbf{v}_{\text {máx }}\left(\mathrm{cm}^{-1}\right) 3270$ br $(\mathrm{NH}), 1663(\mathrm{C}=\mathrm{O})$.

$\mathbf{R M N}^{1} \mathbf{H}\left(500 \mathrm{MHz}, \mathrm{CDCl}_{3}\right) \delta=7.65(\mathrm{br} \mathrm{d}, J \sim 6 \mathrm{~Hz}, 1 \mathrm{H}, \mathrm{NH}), 7.51(\mathrm{~s}, 1 \mathrm{H}), 7.30$ (d, $J=10.7 \mathrm{~Hz}, 1 \mathrm{H}$ ), 6.83 (d, $J=10.7 \mathrm{~Hz}, 1 \mathrm{H}$ ), 6.50 (s, 1H), 4.63 (dt app, $J=$ 11.5, $6.5 \mathrm{~Hz}, 1 \mathrm{H}), 3.98$ (s, 3H), $3.92(\mathrm{~s}, 3 \mathrm{H}), 3.87$ (s, 3H), $3.64(\mathrm{~s}, 3 \mathrm{H}), 2.47$ (dd, $J=13,6 \mathrm{~Hz}, 1 \mathrm{H}$ ), 2.35 (td app, $J=13,6 \mathrm{~Hz}, 1 \mathrm{H}$ ), 2.30-2.15 (br m, 3H), 1.84 (td app, $J=12,7 \mathrm{~Hz}, 1 \mathrm{H}$ ), 1.60-1.50 (m, 2H), 1.30-1.15 (br m, 16H), 0.83 (t, $J=7 \mathrm{~Hz}, 3 \mathrm{H})$.

RMN ${ }^{13} \mathbf{C}\left(125 \mathrm{MHz}, \mathrm{CDCl}_{3}\right) \delta=179.4,172.9,163.9,153.4,152.2,151.1$, 141.6, 136.6, 134.1, 125.6 (C), 135.2, 130.5, 112.5, 107.3, $52.1(\mathrm{CH}), 36.6$, 36.0, 31.8, 29.9, 29.5, 29.4, 29.3 (x2), $29.2(x 2)$, 25.3, $22.5\left(\mathrm{CH}_{2}\right)$, 61.5, 61.2, 56.3, 56.0, $14.0\left(\mathrm{CH}_{3}\right)$.

HR ESMS $m / z 540.3320(\mathrm{M}+\mathrm{H})^{+}$. Calcd. for $\mathrm{C}_{32} \mathrm{H}_{46} \mathrm{NO}_{6}, 540.3325$.

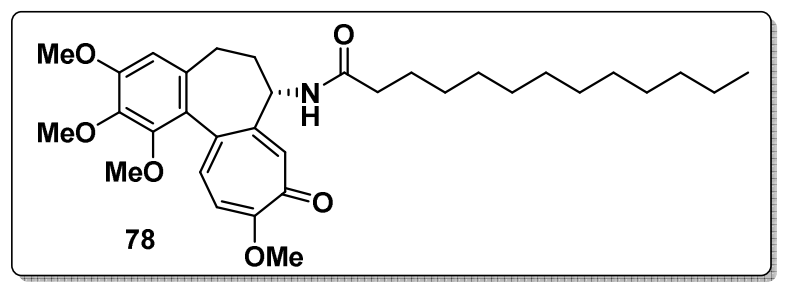

A partir de $0.20 \mathrm{~g}(0.42 \mathrm{mmol})$ del compuesto 3 se obtuvieron $0.10 \mathrm{~g}(0.18$ $\mathrm{mmol}, 44 \%$ ) del compuesto 78 como un aceite amarillento. 
$[\alpha]_{D}=-105.4\left(\mathrm{c}=1.0, \mathrm{CHCl}_{3}\right)$.

IR $\mathbf{v}_{\text {máx }}\left(\mathrm{cm}^{-1}\right) 3290 \mathrm{br}(\mathrm{NH}), 1653(\mathrm{C}=\mathrm{O})$.

$\mathbf{R M N}^{1} \mathbf{H}\left(500 \mathrm{MHz}, \mathrm{CDCl}_{3}\right) \delta=7.50(\mathrm{~s}, 1 \mathrm{H}), 7.41$ (br d, $\left.J \sim 7 \mathrm{~Hz}, 1 \mathrm{H}, \mathrm{NH}\right), 7.31$ (d, $J=10.7 \mathrm{~Hz}, 1 \mathrm{H}), 6.84(\mathrm{~d}, J=10.7 \mathrm{~Hz}, 1 \mathrm{H}), 6.51$ (s, 1H), 4.64 (dt app, $J=$ 11.5, $6.5 \mathrm{~Hz}, 1 \mathrm{H}), 3.98(\mathrm{~s}, 3 \mathrm{H}), 3.93(\mathrm{~s}, 3 \mathrm{H}), 3.88(\mathrm{~s}, 3 \mathrm{H}), 3.65(\mathrm{~s}, 3 \mathrm{H}), 2.49$ (dd, $J=13.2,6 \mathrm{~Hz}, 1 \mathrm{H}$ ), 2.36 (td app, $J=13.2,6.5 \mathrm{~Hz}, 1 \mathrm{H}$ ), 2.30-2.15 (br m, $3 \mathrm{H}$ ), 1.84 (td app, $J=12,6.5 \mathrm{~Hz}, 1 \mathrm{H}), 1.60-1.50(\mathrm{~m}, 2 \mathrm{H}), 1.30-1.15$ (br m, $18 \mathrm{H}), 0.85$ (t, $J=7 \mathrm{~Hz}, 3 \mathrm{H})$.

RMN ${ }^{13} \mathbf{C}\left(125 \mathrm{MHz}, \mathrm{CDCl}_{3}\right) \delta=179.4,172.9,163.9,153.4,152.1,151.2$, 141.6, 136.6, 134.2, 125.6 (C), 135.2, 130.5, 112.5, 107.3, 52.1 (CH), 36.7, 36.1, 31.8, 29.9, 29.5 (x2), 29.4, 29.3, 29.2 (x3), 25.3, $22.6\left(\mathrm{CH}_{2}\right)$, 61.5, 61.3, 56.3, 56.0, $14.0\left(\mathrm{CH}_{3}\right)$.

HR ESMS $\mathrm{m} / z 554.3484(\mathrm{M}+\mathrm{H})^{+}$. Calcd. for $\mathrm{C}_{33} \mathrm{H}_{48} \mathrm{NO}_{6}, 554.3482$.

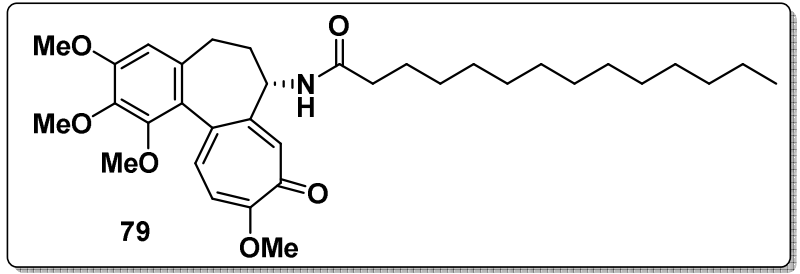

A partir de $0.15 \mathrm{~g}(0.32 \mathrm{mmol})$ del compuesto 3 se obtuvieron $0.13 \mathrm{~g}(0.23$ mmol, $72 \%$ ) del compuesto 79 como un aceite amarillento.

$[\alpha]_{D}=-98.2\left(\mathrm{c}=1.0, \mathrm{CHCl}_{3}\right)$.

IR $\mathbf{v}_{\text {máx }}\left(\mathrm{cm}^{-1}\right) 3280 \mathrm{br}(\mathrm{NH}), 1655(\mathrm{C}=\mathrm{O})$.

$\mathbf{R M N}^{1} \mathbf{H}\left(500 \mathrm{MHz}, \mathrm{CDCl}_{3}\right) \delta=7.47(\mathrm{~s}, 1 \mathrm{H}), 7.31(\mathrm{~d}, J=10.7 \mathrm{~Hz}, 1 \mathrm{H}), 7.10(\mathrm{br}$ d, $J \sim 7 \mathrm{~Hz}, 1 \mathrm{H}, \mathrm{NH}$ ), 6.83 (d, $J=10.7 \mathrm{~Hz}, 1 \mathrm{H}), 6.52$ (s, 1H), 4.65 (dt app, $J=$ 11.5, $6.5 \mathrm{~Hz}, 1 \mathrm{H}), 3.99$ (s, 3H), $3.94(\mathrm{~s}, 3 \mathrm{H}), 3.89$ (s, 3H), $3.66(\mathrm{~s}, 3 \mathrm{H}), 2.50$ (dd, $J=13.2,6.4 \mathrm{~Hz}, 1 \mathrm{H}$ ), 2.39 (td app, $J=13.2,6.8 \mathrm{~Hz}, 1 \mathrm{H}$ ), 2.30-2.15 (br m, 
$3 \mathrm{H}), 1.84$ (td app, $J=12,6.5 \mathrm{~Hz}, 1 \mathrm{H}), 1.60-1.50(\mathrm{~m}, 2 \mathrm{H}), 1.30-1.15$ (br m, $20 \mathrm{H}), 0.87$ (t, $J=7 \mathrm{~Hz}, 3 \mathrm{H})$.

RMN ${ }^{13} \mathbf{C}\left(125 \mathrm{MHz}, \mathrm{CDCl}_{3}\right) \delta=179.4,172.9,163.9,153.4,152.0,151.2$, 141.6, 136.6, 134.2, 125.6 (C), 135.2, 130.5, 112.5, 107.3, $52.1(\mathrm{CH}), 36.7$, 36.1, 31.8, 29.9, 29.6, 29.5 (x2), 29.4, 29.3 (x2), $29.2(x 2), 25.3,22.6\left(\mathrm{CH}_{2}\right)$, $61.5,61.3,56.3,56.0,14.0\left(\mathrm{CH}_{3}\right)$.

HR ESMS $m / z 568.3643(\mathrm{M}+\mathrm{H})^{+}$. Calcd. for $\mathrm{C}_{34} \mathrm{H}_{50} \mathrm{NO}_{6}, 568.3638$.

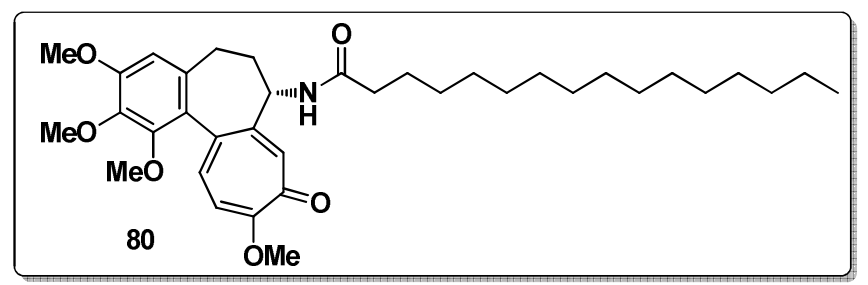

A partir de $0.15 \mathrm{~g}(0.32 \mathrm{mmol})$ del compuesto 3 se obtuvieron $0.087 \mathrm{~g}(0.15$ $\mathrm{mmol}, 46 \%$ ) del compuesto 80 como un aceite amarillento

$[\alpha]_{D}=-109.11\left(\mathrm{c}=0.7, \mathrm{CHCl}_{3}\right)$.

IR $\mathbf{v}_{\text {máx }}\left(\mathrm{cm}^{-1}\right) 3280$ br $(\mathrm{NH}), 1655(\mathrm{C}=\mathrm{O})$.

$\mathbf{R M N}^{1} \mathbf{H}\left(500 \mathrm{MHz}, \mathrm{CDCl}_{3}\right) \delta=7.48(\mathrm{~s}, 1 \mathrm{H}), 7.31(\mathrm{~d}, J=10.7 \mathrm{~Hz}, 1 \mathrm{H}), 7.25(\mathrm{br}$ d, $J \sim 7 \mathrm{~Hz}, 1 \mathrm{H}, \mathrm{NH}), 6.84$ (d, $J=10.7 \mathrm{~Hz}, 1 \mathrm{H}$ ), 6.52 (s, 1H), 4.65 (dt app, $J=$ 11.5, $6.5 \mathrm{~Hz}, 1 \mathrm{H}), 3.99(\mathrm{~s}, 3 \mathrm{H}), 3.93(\mathrm{~s}, 3 \mathrm{H}), 3.89(\mathrm{~s}, 3 \mathrm{H}), 3.65(\mathrm{~s}, 3 \mathrm{H}), 2.50$ (dd, $J=13.2,6.3 \mathrm{~Hz}, 1 \mathrm{H}$ ), 2.38 (td app, $J=13.2,6.3 \mathrm{~Hz}, 1 \mathrm{H}$ ), 2.30-2.15 (br m, $3 \mathrm{H}$ ), 1.84 (td app, $J=12,6.5 \mathrm{~Hz}, 1 \mathrm{H}), 1.60-1.50(\mathrm{~m}, 2 \mathrm{H}), 1.30-1.15$ (br m, $24 \mathrm{H}), 0.86(\mathrm{t}, J=7 \mathrm{~Hz}, 3 \mathrm{H})$.

RMN ${ }^{13} \mathbf{C}\left(125 \mathrm{MHz}, \mathrm{CDCl}_{3}\right) \delta=179.4,172.9,164.0,153.4,152.0,151.2$, 141.7, 136.6, 134.2, 125.7 (C), 135.2, 130.6, 112.5, 107.3, $52.1(\mathrm{CH}), 36.7$, 36.2, 31.8, 29.9, 29.6 (x4), $29.6(x 2), 29.4,29.3,29.3(x 2), 25.4,22.6\left(\mathrm{CH}_{2}\right)$, 61.6, 61.3, 56.3, 56.1, $14.0\left(\mathrm{CH}_{3}\right)$.

HR ESMS $m / z 596.3956(\mathrm{M}+\mathrm{H})^{+}$. Calcd. for $\mathrm{C}_{36} \mathrm{H}_{54} \mathrm{NO}_{6}, 596.3951$. 


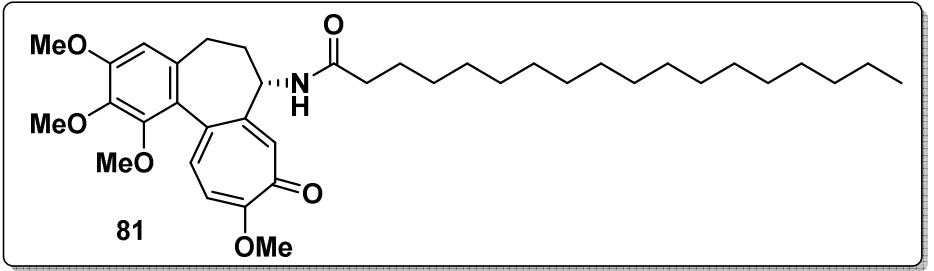

A partir de $0.15 \mathrm{~g}(0.32 \mathrm{mmol})$ del compuesto 3 se obtuvieron $0.15 \mathrm{~g}(0.25$ mmo, 77\%) del compuesto 81 como un aceite amarillento.

$[\alpha]_{D}=-96.5\left(\mathrm{c}=1.2, \mathrm{CHCl}_{3}\right)$.

IR $\mathbf{v}_{\text {máx }}\left(\mathrm{cm}^{-1}\right) 3280 \mathrm{br}(\mathrm{NH}), 1654(\mathrm{C}=\mathrm{O})$.

$\mathbf{R M N}^{1} \mathbf{H}\left(500 \mathrm{MHz}, \mathrm{CDCl}_{3}\right) \delta=7.78(\mathrm{br} \mathrm{d}, J \sim 7 \mathrm{~Hz}, 1 \mathrm{H}, \mathrm{NH}), 7.52(\mathrm{~s}, 1 \mathrm{H}), 7.30$ (d, $J=10.7 \mathrm{~Hz}, 1 \mathrm{H}), 6.83(\mathrm{~d}, J=10.7 \mathrm{~Hz}, 1 \mathrm{H}), 6.49$ (s, 1H), 4.63 (dt app, $J=$ 11.5, $6.5 \mathrm{~Hz}, 1 \mathrm{H}), 3.97(\mathrm{~s}, 3 \mathrm{H}), 3.91(\mathrm{~s}, 3 \mathrm{H}), 3.87$ (s, 3H), $3.63(\mathrm{~s}, 3 \mathrm{H}), 2.47$ (dd, $J=13.2,6.3 \mathrm{~Hz}, 1 \mathrm{H}$ ), 2.34 (td app, $J=13.2,6.3 \mathrm{~Hz}, 1 \mathrm{H}$ ), 2.30-2.15 (br m, $3 \mathrm{H}$ ), 1.84 (td app, $J=12,6.5 \mathrm{~Hz}, 1 \mathrm{H}), 1.60-1.50(\mathrm{~m}, 2 \mathrm{H}), 1.30-1.15$ (br m, $28 \mathrm{H}), 0.84(\mathrm{t}, J=7 \mathrm{~Hz}, 3 \mathrm{H})$.

RMN ${ }^{13} \mathbf{C}\left(125 \mathrm{MHz}, \mathrm{CDCl}_{3}\right) \delta=179.3,172.9,163.8,153.3,152.3,151.1$, $141.5,136.7,134.1,125.6(\mathrm{C}), 135.1,130.5,112.5,107.2,52.1(\mathrm{CH}), 36.5$, 36.0, 31.7, 29.8, 29.5 (x5), $29.3(x 4), 29.2(x 3)$, 25.3, $22.5\left(\mathrm{CH}_{2}\right), 61.5,61.2$, $56.2,56.0,13.9\left(\mathrm{CH}_{3}\right)$.

HR ESMS $m / z 624.4268(\mathrm{M}+\mathrm{H})^{+}$. Calcd. for $\mathrm{C}_{38} \mathrm{H}_{58} \mathrm{NO}_{6}, 624.4264$.

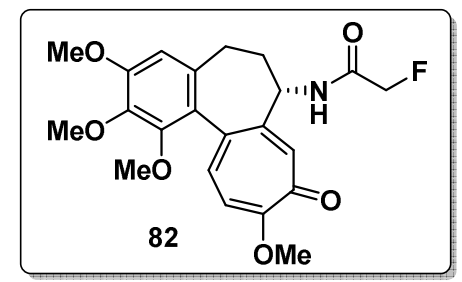

A partir de $0.20 \mathrm{~g}(0.42 \mathrm{mmol})$ del compuesto 3 se obtuvieron $0.10 \mathrm{~g}(0.24$ $\mathrm{mmol}, 58 \%$ ) del compuesto 82 como un sólido amarillento. 
$[\alpha]_{D}=-140\left(\mathrm{c}=1, \mathrm{CHCl}_{3}\right)$.

P. f. $=103-105^{\circ} \mathrm{C}$, lit. ${ }^{113} 137-142^{\circ} \mathrm{C}$.

IR $\mathbf{v}_{\text {máx }}\left(\mathrm{cm}^{-1}\right) 3270$ br $(\mathrm{NH}), 1680(\mathrm{C}=\mathrm{O})$.

RMN ${ }^{1} \mathbf{H}\left(500 \mathrm{MHz}, \mathrm{CDCl}_{3}\right) \delta=7.65(1 \mathrm{H}, \mathrm{br} \mathrm{d}, J \sim 6.5 \mathrm{~Hz}, \mathrm{NH}), 7.40(1 \mathrm{H}, \mathrm{s})$, $7.25(1 \mathrm{H}, \mathrm{d}, J=10.7 \mathrm{~Hz}), 6.80(1 \mathrm{H}, \mathrm{d}, J=10.7 \mathrm{~Hz}), 6.50(1 \mathrm{H}, \mathrm{s}), 4.80-4.60$ $(3 \mathrm{H}, \mathrm{m}), 3.95(3 \mathrm{H}, \mathrm{s}), 3.90(3 \mathrm{H}, \mathrm{s}), 3.87(3 \mathrm{H}, \mathrm{s}), 3.61(3 \mathrm{H}, \mathrm{s}), 2.51(1 \mathrm{H}, \mathrm{dd}, J=$ 13.7, $6.5 \mathrm{~Hz}), 2.39(1 \mathrm{H}$, td app, $J=13.2,6.8 \mathrm{~Hz}), 2.26(1 \mathrm{H}, \mathrm{m}), 1.97(1 \mathrm{H}, \mathrm{m})$.

RMN ${ }^{13} \mathbf{C}\left(125 \mathrm{MHz}, \mathrm{CDCl}_{3}\right) \delta=179.2,167.1$ (doblete con ${ }^{2} \mathrm{~J}_{\mathrm{C}-\mathrm{F}} \sim 18.5 \mathrm{~Hz}$ ), 163.9, 153.4, 151.1, 150.3, 141.6, 136.0, 133.9, 125.4 (C), 135.1, 130.6, 112.1, 107.3, $51.6(\mathrm{CH}), 80.0$ (punto central del doblete con ${ }^{1} J_{\mathrm{C}-\mathrm{F}} \sim 185 \mathrm{~Hz}$ ), 36.4, $29.7\left(\mathrm{CH}_{2}\right), 61.2,61.1,56.2,56.0\left(\mathrm{CH}_{3}\right)$.

HR ESMS $m / z 440.1485\left(M+\mathrm{Na}^{+}\right)$. Calcd. for $\mathrm{C}_{22} \mathrm{H}_{24} \mathrm{FNNaO}_{6}, 440.1485$.

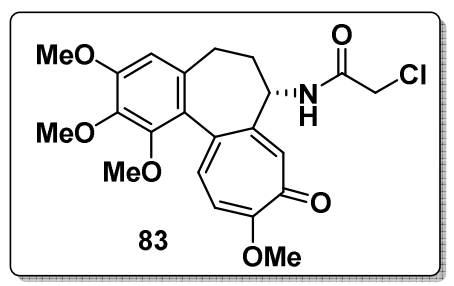

A partir de $0.20 \mathrm{~g}(0.42 \mathrm{mmol})$ del compuesto 3 se obtuvieron $0.10 \mathrm{~g}(0.24$ mmol, $56 \%$ ) del compuesto 83 como un sólido amarillento.

$[\alpha]_{D}=-82\left(\mathrm{c}=1, \mathrm{CHCl}_{3}\right)$.

P. f. $=116-118^{\circ} \mathrm{C}$, lit. ${ }^{113} 204-206^{\circ} \mathrm{C}$.

IR $\mathbf{v}_{\text {máx }}\left(\mathrm{cm}^{-1}\right) 3270$ br $(\mathrm{NH}), 1681(\mathrm{C}=\mathrm{O})$.

RMN ${ }^{1} \mathbf{H}\left(500 \mathrm{MHz}, \mathrm{CDCl}_{3}\right) \delta=8.15(1 \mathrm{H}, \mathrm{br} \mathrm{d}, J \sim 6.5 \mathrm{~Hz}, \mathrm{NH}), 7.45(1 \mathrm{H}, \mathrm{s})$, $7.30(1 \mathrm{H}, \mathrm{d}, J=10.7 \mathrm{~Hz}), 6.84(1 \mathrm{H}, \mathrm{d}, J=10.7 \mathrm{~Hz}), 6.51(1 \mathrm{H}, \mathrm{s}), 4.63(1 \mathrm{H}, \mathrm{dt}$

\footnotetext{
${ }^{113}$ Lettré, H.; Dönges, K. H.; Barthold, K.; Fitzgerald, T. J. Liebigs Ann. Chem. 1972, 758, $185-$ 189.
} 
app, $J=11.7,6.5 \mathrm{~Hz})$, 4.04-4.00 (2H, sistema $A B, J=14.5 \mathrm{~Hz}) .3 .97(3 \mathrm{H}, \mathrm{s})$, $3.91(3 \mathrm{H}, \mathrm{s}), 3.87(3 \mathrm{H}, \mathrm{s}), 3.62(3 \mathrm{H}, \mathrm{s}), 2.51(1 \mathrm{H}, \mathrm{dd}, J=13.7,6 \mathrm{~Hz}), 2.38(1 \mathrm{H}$, td app, $J=13.2,6.7 \mathrm{~Hz}), 2.28(1 \mathrm{H}, \mathrm{m}), 1.94(1 \mathrm{H}, \mathrm{m})$.

RMN ${ }^{13} \mathbf{C}\left(125 \mathrm{MHz}, \mathrm{CDCl}_{3}\right) \delta=179.3,166.0,164.1,153.6,151.2,151.0$, 141.7, 136.4, 134.0, 125.5 (C), 135.4, 130.6, 112.6, 107.4, 52.8 (CH), 42.5, 36.5, $29.8\left(\mathrm{CH}_{2}\right), 61.5,61.4,56.4,56.1\left(\mathrm{CH}_{3}\right)$.

HR ESMS $m / z 456.1194\left(\mathrm{M}+\mathrm{Na}^{+}\right)$. Calcd. for $\mathrm{C}_{22} \mathrm{H}_{24}{ }^{35} \mathrm{CINNaO}_{6}, 456.1190$.

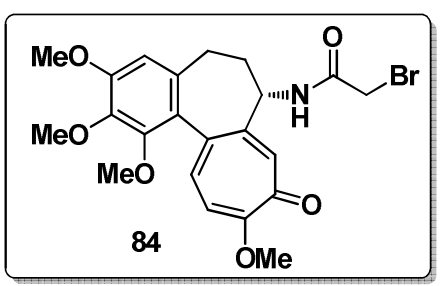

A partir de $0.30 \mathrm{~g}(0.64 \mathrm{mmol})$ del compuesto 3 se obtuvieron $0.16 \mathrm{~g}$ (0.33 mmol, $51 \%$ ) del compuesto 84 como un sólido marrón amarillento.

$[\alpha]_{D}=-81\left(\mathrm{c}=1, \mathrm{CHCl}_{3}\right)$.

P. f. $=140-142{ }^{\circ} \mathrm{C}$, lit. ${ }^{113} 203-206^{\circ} \mathrm{C}$.

IR $\mathbf{v}_{\text {máx }}\left(\mathrm{cm}^{-1}\right) 3260$ br $(\mathrm{NH}), 1681(\mathrm{C}=\mathrm{O})$.

$\mathbf{R M N}^{1} \mathbf{H}\left(500 \mathrm{MHz}, \mathrm{CDCl}_{3}\right) \delta=8.40(1 \mathrm{H}, \mathrm{br} \mathrm{d}, J \sim 6.5 \mathrm{~Hz}, \mathrm{NH}), 7.52(1 \mathrm{H}, \mathrm{s})$, $7.34(1 \mathrm{H}, \mathrm{d}, J=10.7 \mathrm{~Hz}), 6.87(1 \mathrm{H}, \mathrm{d}, J=10.7 \mathrm{~Hz}), 6.52(1 \mathrm{H}, \mathrm{s}), 4.63(1 \mathrm{H}, \mathrm{dt}$ app, $J=11.7,6.5 \mathrm{~Hz}), 3.99(3 \mathrm{H}, \mathrm{s}), 3.93(3 \mathrm{H}, \mathrm{s}), 3.89(3 \mathrm{H}, \mathrm{s}), 3.95-3.85(2 \mathrm{H}, \mathrm{m}$ solpada con las señales de $\mathrm{OMe}), 3.64(3 \mathrm{H}, \mathrm{s}), 2.51(1 \mathrm{H}, \mathrm{dd}, J=13.5,6 \mathrm{~Hz})$, $2.38(1 \mathrm{H}$, td app, $J=13,6.5 \mathrm{~Hz}), 2.28(1 \mathrm{H}, \mathrm{m}), 1.90(1 \mathrm{H}, \mathrm{m})$.

RMN ${ }^{13} \mathbf{C}\left(125 \mathrm{MHz}, \mathrm{CDCl}_{3}\right) \delta=179.3,166.0,164.0,153.6,151.4,151.1$, 141.7, 136.5, 134.0, 125.4 (C), 135.4, 130.4, 112.7, 107.4, $52.9(\mathrm{CH}), 36.4$, 29.7, $28.7\left(\mathrm{CH}_{2}\right), 61.4,61.3,56.4,56.1\left(\mathrm{CH}_{3}\right)$.

HR ESMS $m / z 500.0684\left(\mathrm{M}+\mathrm{Na}^{+}\right)$. Calcd. for $\mathrm{C}_{22} \mathrm{H}_{24}{ }^{79} \mathrm{BrNNaO}_{6}, 500.0685$. 


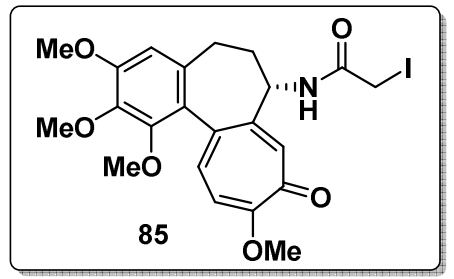

A partir de $0.20 \mathrm{~g}(0.42 \mathrm{mmol})$ del compuesto 3 se obtuvieron $0.095 \mathrm{~g}(0.18$ $\mathrm{mmol}, 43 \%$ ) del compuesto 85 como un sólido marrón amarillento.

$[\alpha]_{D}=-85\left(\mathrm{c}=1, \mathrm{CHCl}_{3}\right)$.

P. f. $=161-163^{\circ} \mathrm{C}$, lit..$^{113} 195^{\circ} \mathrm{C}$.

IR $\mathbf{v}_{\text {máx }}\left(\mathrm{cm}^{-1}\right) 3260$ br (NH), $1675(\mathrm{C}=\mathrm{O})$.

$\mathbf{R M N}^{1} \mathbf{H}\left(500 \mathrm{MHz}, \mathrm{CDCl}_{3}\right) \delta=8.70(1 \mathrm{H}, \mathrm{br} \mathrm{d}, J \sim 7 \mathrm{~Hz}, \mathrm{NH}), 7.64(1 \mathrm{H}, \mathrm{s}), 7.36$ $(1 \mathrm{H}, \mathrm{d}, J=10.7 \mathrm{~Hz}), 6.89(1 \mathrm{H}, \mathrm{d}, J=10.7 \mathrm{~Hz}), 6.51(1 \mathrm{H}, \mathrm{s}), 4.63(1 \mathrm{H}, \mathrm{dt}$ app, $J$ $=11.7,6.5 \mathrm{~Hz}), 4.00(3 \mathrm{H}, \mathrm{s}), 3.93(3 \mathrm{H}, \mathrm{s}), 3.89(3 \mathrm{H}, \mathrm{s}), 3.82(1 \mathrm{H}, \mathrm{d}, J=10.5$ $\mathrm{Hz}), 3.77(1 \mathrm{H}, \mathrm{d}, J=10.5 \mathrm{~Hz}), 3.65(3 \mathrm{H}, \mathrm{s}), 2.48(1 \mathrm{H}, \mathrm{dd}, J=13,6 \mathrm{~Hz}), 2.40-$ $2.25(2 \mathrm{H}, \mathrm{br} \mathrm{m}), 1.86(1 \mathrm{H}, \mathrm{m})$.

RMN ${ }^{13} \mathbf{C}\left(125 \mathrm{MHz}, \mathrm{CDCl}_{3}\right) \delta=179.5,167.6,164.0,153.5,152.2,151.1$, 141.7, 136.8, 134.0, $125.4(\mathrm{C}), 135.5,130.5,112.9,107.4,52.9(\mathrm{CH}), 36.4$, $29.8,-0.1\left(\mathrm{CH}_{2}\right), 61.5,61.3,56.4,56.1\left(\mathrm{CH}_{3}\right)$.

HR ESMS $m / z 548.0537\left(\mathrm{M}+\mathrm{Na}^{+}\right)$. Calcd. for $\mathrm{C}_{22} \mathrm{H}_{24} \mathrm{INNaO}_{6}, 548.0546$.

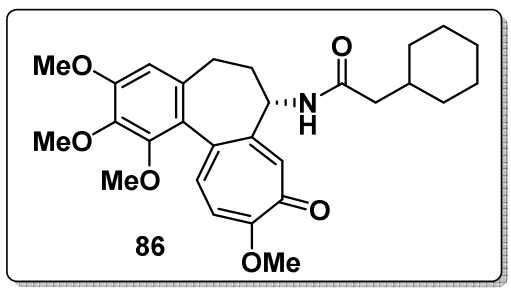

A partir de $0.30 \mathrm{~g}(0.64 \mathrm{mmol})$ del compuesto 3 se obtuvieron $0.17 \mathrm{~g}(0.35$ mmol, 54\%) del compuesto 86 como un sólido marrón amarillento.

$[\alpha]_{\mathrm{D}}=-138\left(\mathrm{c}=1, \mathrm{CHCl}_{3}\right)$. 
P. f. $=226-229^{\circ} \mathrm{C}$.

IR $\mathbf{v}_{\text {máx }}\left(\mathrm{cm}^{-1}\right) 3280 \mathrm{br}(\mathrm{NH}), 1656(\mathrm{C}=\mathrm{O})$.

$\mathbf{R M N}^{1} \mathbf{H}\left(500 \mathrm{MHz}, \mathrm{CDCl}_{3}\right) \delta=7.49(1 \mathrm{H}, \mathrm{s}), 7.35(1 \mathrm{H}, \mathrm{br} \mathrm{d}, J \sim 7 \mathrm{~Hz}, \mathrm{NH}), 7.28$ $(1 \mathrm{H}, \mathrm{d}, J=10.7 \mathrm{~Hz}), 6.82(1 \mathrm{H}, \mathrm{d}, J=10.7 \mathrm{~Hz}), 6.49(1 \mathrm{H}, \mathrm{s}), 4.64(1 \mathrm{H}, \mathrm{dt}$ app, $J$ $=11.7,6.5 \mathrm{~Hz}), 3.96(3 \mathrm{H}, \mathrm{s}), 3.91(3 \mathrm{H}, \mathrm{s}), 3.86(3 \mathrm{H}, \mathrm{s}), 3.63(3 \mathrm{H}, \mathrm{s}), 2.46(1 \mathrm{H}$, dd, $J=13,6 \mathrm{~Hz}), 2.34(1 \mathrm{H}$, td app, $J=13.2,6.8 \mathrm{~Hz}), 2.22(1 \mathrm{H}, \mathrm{m}), 2.05(2 \mathrm{H}, \mathrm{d}$ app, $J=7 \mathrm{~Hz}), 1.83(1 \mathrm{H}, \mathrm{m}), 1.75-1.50(6 \mathrm{H}, \mathrm{br} m), 1.20-1.00(3 \mathrm{H}, \mathrm{br} \mathrm{m}), 0.87$ $(2 \mathrm{H}, \mathrm{m})$.

RMN ${ }^{13} \mathbf{C}\left(125 \mathrm{MHz}, \mathrm{CDCl}_{3}\right) \delta=179.3,172.1,163.9,153.3,152.0,151.1$, $141.5,136.5,134.1,125.6(\mathrm{C}), 135.0,130.7,112.4,107.3,52.0,34.9(\mathrm{CH})$, 44.1, 36.7, 33.1, 33.0, 29.8, 26.1, 25.9, $25.8\left(\mathrm{CH}_{2}\right), 61.5,61.2,56.2,56.0$ $\left(\mathrm{CH}_{3}\right)$.

HR ESMS $m / z 504.2364\left(\mathrm{M}+\mathrm{Na}^{+}\right)$. Calcd. for $\mathrm{C}_{28} \mathrm{H}_{35} \mathrm{NNaO}_{6}, 504.2362$.

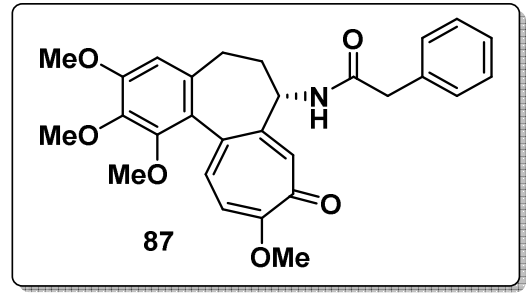

A partir de $0.20 \mathrm{~g}(0.42 \mathrm{mmol})$ del compuesto 3 se obtuvieron $0.10 \mathrm{~g}(0.22$ $\mathrm{mmol}, 52 \%)$ del compuesto 87 como un sólido amarillento.

$[\alpha]_{D}=-99\left(\mathrm{c}=1, \mathrm{CHCl}_{3}\right)$.

P. f. $=122-125^{\circ} \mathrm{C}$.

IR $\mathbf{v}_{\text {máx }}\left(\mathrm{cm}^{-1}\right) 3280$ br $(\mathrm{NH}), 1653(\mathrm{C}=\mathrm{O})$.

$\mathbf{R M N}^{1} \mathbf{H}\left(500 \mathrm{MHz}, \mathrm{CDCl}_{3}\right) \delta=7.40-7.25(7 \mathrm{H}$, br m), $6.80(1 \mathrm{H}, \mathrm{d}, J=10.7 \mathrm{~Hz})$, $6.50(1 \mathrm{H}, \mathrm{s}), 5.90(1 \mathrm{H}, \mathrm{br} \mathrm{d}, J \sim 7 \mathrm{~Hz}, \mathrm{NH}), 4.62(1 \mathrm{H}, \mathrm{dt}$ app, $J=11.7,6.5 \mathrm{~Hz})$, $4.00(3 \mathrm{H}, \mathrm{s}), 3.94(3 \mathrm{H}, \mathrm{s}), 3.89(3 \mathrm{H}, \mathrm{s}), 3.66(3 \mathrm{H}, \mathrm{s}), 3.57(2 \mathrm{H}, \mathrm{br} \mathrm{s}), 2.48(1 \mathrm{H}$, 
dd, $J=13.5,6.5 \mathrm{~Hz}), 2.38(1 \mathrm{H}$, td app, $J=13.2,6.5 \mathrm{~Hz}), 2.13(1 \mathrm{H}, \mathrm{m}), 1.65$ (1H, td app, $J=12,7 \mathrm{~Hz}$ ).

RMN ${ }^{13} \mathbf{C}\left(125 \mathrm{MHz}, \mathrm{CDCl}_{3}\right) \delta=179.3,170.6,163.9,153.4,151.6,151.1$, 141.6, 136.5, 134.8, 134.1, 125.6 (C), 135.1, 130.6, 129.2 (x 2), 128.7 (x 2), 127.0, 112.4, 107.3, $52.2(\mathrm{CH}), 43.1,36.6,29.8\left(\mathrm{CH}_{2}\right), 61.5,61.2,56.2,56.0$ $\left(\mathrm{CH}_{3}\right)$.

HR ESMS $m / z 476.2083\left(\mathrm{M}+\mathrm{H}^{+}\right)$. Calcd. for $\mathrm{C}_{28} \mathrm{H}_{30} \mathrm{NO}_{6}, 476.2073$.

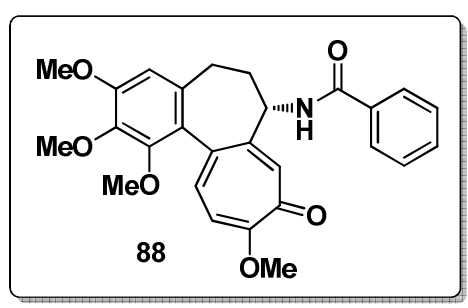

A partir de $0.20 \mathrm{~g}(0.42 \mathrm{mmol})$ del compuesto 3 Se obtuvieron $0.087 \mathrm{~g}$ (0.19 $\mathrm{mmol}, 45 \%$ ) del compuesto 88 como un sólido amarillento.

$[\alpha]_{D}=-40\left(\mathrm{c}=1.1, \mathrm{CHCl}_{3}\right)$.

P. f. $=171-173^{\circ} \mathrm{C}$, lit. $.^{114} 150-152^{\circ} \mathrm{C}$.

IR $\mathbf{v}_{\text {máx }}\left(\mathrm{cm}^{-1}\right) 3300 \mathrm{br}(\mathrm{NH}), 1654(\mathrm{C}=\mathrm{O})$.

$\mathbf{R M N}^{1} \mathbf{H}\left(500 \mathrm{MHz}, \mathrm{CDCl}_{3}\right) \delta=7.90(1 \mathrm{H}$, br d, $J \sim 7 \mathrm{~Hz}, \mathrm{NH}), 7.77(2 \mathrm{H}, \mathrm{d}, J=$ $7.8 \mathrm{~Hz}), 7.63(1 \mathrm{H}, \mathrm{s}), 7.35-7.25(2 \mathrm{H}, \mathrm{m}), 7.19(2 \mathrm{H}, \mathrm{t}, J=7.8 \mathrm{~Hz}), 6.85(1 \mathrm{H}, \mathrm{d}, J$ $=10.7 \mathrm{~Hz}), 6.53(1 \mathrm{H}, \mathrm{s}), 4.86(1 \mathrm{H}, \mathrm{dt}$ app, $J=11.5,7 \mathrm{~Hz}), 3.97(3 \mathrm{H}, \mathrm{s}), 3.95$ $(3 \mathrm{H}, \mathrm{s}), 3.89(3 \mathrm{H}, \mathrm{s}), 3.73(3 \mathrm{H}, \mathrm{s}), 2.49(1 \mathrm{H}, \mathrm{dd}, J=13,6.5 \mathrm{~Hz}), 2.43(1 \mathrm{H}, \mathrm{td}$ app, $J=13.5,7 \mathrm{~Hz}), 2.40(1 \mathrm{H}, \mathrm{m}), 2.00(1 \mathrm{H}, \mathrm{m})$.

RMN ${ }^{13} \mathbf{C}\left(125 \mathrm{MHz}, \mathrm{CDCl}_{3}\right) \delta=179.2,166.9,163.9,153.4,152.1,151.1$, $141.6,136.5,134.2,133.3,125.6(\mathrm{C}), 135.2,131.3,130.7,128.1$ (x 2), 127.0 (x 2), 112.4, 107.3, $52.7(\mathrm{CH}), 36.3,29.9\left(\mathrm{CH}_{2}\right), 61.5,61.2,56.2,56.0\left(\mathrm{CH}_{3}\right)$.

${ }^{114}$ Santavy, F. Chemicke Listy 1952, 46, 280-289. 
HR ESMS $m / z 462.1915\left(\mathrm{M}+\mathrm{H}^{+}\right)$. Calcd. for $\mathrm{C}_{27} \mathrm{H}_{28} \mathrm{NO}_{6}, 462.1916$.

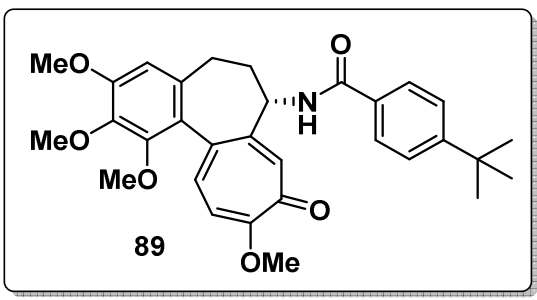

A partir de $0.20 \mathrm{~g}(0.42 \mathrm{mmol})$ del compuesto 3 se obtuvieron $0.099 \mathrm{~g}(0.19$ $\mathrm{mmol}, 46 \%)$ del compuesto 89 como un sólido amarillento.

$[\alpha]_{D}=-28\left(\mathrm{c}=1, \mathrm{CHCl}_{3}\right)$.

P. f. $=163-165^{\circ} \mathrm{C}$.

IR $\mathbf{v}_{\text {máx }}\left(\mathrm{cm}^{-1}\right) 3300$ br $(\mathrm{NH}), 1652(\mathrm{C}=\mathrm{O})$.

RMN ${ }^{1} \mathbf{H}\left(500 \mathrm{MHz}, \mathrm{CDCl}_{3}\right) \delta=7.70(2 \mathrm{H}, \mathrm{d}, J=7 \mathrm{~Hz}), 7.44(1 \mathrm{H}, \mathrm{s}), 7.43(2 \mathrm{H}, \mathrm{d}$, $J=7 \mathrm{~Hz}), 7.33(1 \mathrm{H}, \mathrm{d}, J=10.7 \mathrm{~Hz}), 6.82(1 \mathrm{H}, \mathrm{d}, J=10.7 \mathrm{~Hz}), 6.60(1 \mathrm{H}, \mathrm{br} \mathrm{d}, J$ $\sim 7 \mathrm{~Hz}, \mathrm{NH}), 6.57(1 \mathrm{H}, \mathrm{s}), 4.87(1 \mathrm{H}, \mathrm{dt}$ app, $J=11.7,7 \mathrm{~Hz}), 3.99(3 \mathrm{H}, \mathrm{s}), 3.97$ $(3 \mathrm{H}, \mathrm{s}), 3.92(3 \mathrm{H}, \mathrm{s}), 3.74(3 \mathrm{H}, \mathrm{s}), 2.57(1 \mathrm{H}, \mathrm{dd}, J=13,6.5 \mathrm{~Hz}), 2.50(1 \mathrm{H}, \mathrm{td}$ app, $J=13,7 \mathrm{~Hz}), 2.40-2.30(1 \mathrm{H}, \mathrm{m}), 1.92(1 \mathrm{H}$, td app, $J=11.5,7 \mathrm{~Hz}), 1.33$ $(9 \mathrm{H}, \mathrm{s})$.

RMN ${ }^{13} \mathbf{C}\left(125 \mathrm{MHz}, \mathrm{CDCl}_{3}\right) \delta=179.3,166.9,163.9,154.8,153.4,151.8$, 151.2, 141.6, 136.4, 134.2, 130.6, 125.7, 34.7 (C), 135.1, 130.7, 126.9 (x 2), 125.2 (x 2), 112.4, 107.4, $52.6(\mathrm{CH}), 36.6,29.9\left(\mathrm{CH}_{2}\right)$, 61.6, 61.3, 56.2, 56.0, $31.0(x 3)\left(\mathrm{CH}_{3}\right)$.

HR ESMS $m / z 518.2549\left(\mathrm{M}+\mathrm{H}^{+}\right)$. Calcd. for $\mathrm{C}_{31} \mathrm{H}_{36} \mathrm{NO}_{6}, 518.2543$. 


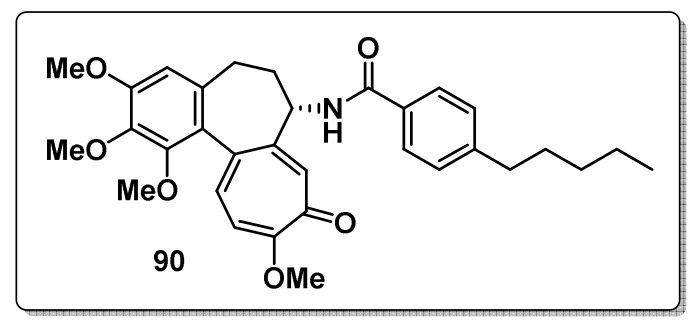

A partir de $0.20 \mathrm{~g}(0.42 \mathrm{mmol})$ del compuesto 3 se obtuvieron $0.12 \mathrm{~g}(0.22$ mmol, 53\%) del compuesto 90 como un sólido amarillento.

$[\alpha]_{D}=-20\left(\mathrm{c}=0.96, \mathrm{CHCl}_{3}\right)$.

P. f. $=136-138^{\circ} \mathrm{C}$.

IR $\mathbf{v}_{\text {máx }}\left(\mathrm{cm}^{-1}\right) 3290$ br (NH), $1653(\mathrm{C}=\mathrm{O})$.

$\mathbf{R M N}^{1} \mathbf{H}\left(500 \mathrm{MHz}, \mathrm{CDCl}_{3}\right) \delta=7.67(2 \mathrm{H}, \mathrm{d}, J=7 \mathrm{~Hz}), 7.47(1 \mathrm{H}, \mathrm{s}), 7.33(1 \mathrm{H}, \mathrm{d}$, $J=10.7 \mathrm{~Hz}), 7.18(2 \mathrm{H}, \mathrm{d}, J=7 \mathrm{~Hz}), 6.82(2 \mathrm{H}, \mathrm{m}), 6.56(1 \mathrm{H}, \mathrm{s}), 4.86(1 \mathrm{H}, \mathrm{dt}$ app, $J=11.7,7 \mathrm{~Hz}), 3.98(3 \mathrm{H}, \mathrm{s}), 3.96(3 \mathrm{H}, \mathrm{s}), 3.91(3 \mathrm{H}, \mathrm{s}), 3.73(3 \mathrm{H}, \mathrm{s}), 2.65-$ $2.55(3 \mathrm{H}, \mathrm{br} \mathrm{m}), 2.48(1 \mathrm{H}, \mathrm{td}$ app, $J=13,7 \mathrm{~Hz}), 2.40-2.30(1 \mathrm{H}, \mathrm{m}), 1.94(1 \mathrm{H}$, td app, $J=11.5,7 \mathrm{~Hz}), 1.65-1.55(2 \mathrm{H}, \mathrm{m}), 1.35-1.20(4 \mathrm{H}, \mathrm{m}), 0.89(3 \mathrm{H}, \mathrm{t}, J=6.5$ $\mathrm{Hz})$.

RMN ${ }^{13} \mathbf{C}\left(125 \mathrm{MHz}, \mathrm{CDCl}_{3}\right) \delta=179.3,166.9,164.0,153.4,151.7,151.2$, 146.8, 141.7, 136.4, 134.2, 130.8, 125.7 (C), 135.1, 130.7, 128.3 (x 2), 127.0 (x 2), 112.4, 107.4, $52.6(\mathrm{CH}), 36.7,35.7,31.3,30.7,29.9,22.4\left(\mathrm{CH}_{2}\right), 61.6$, 61.3, 56.2, 56.0, $13.9\left(\mathrm{CH}_{3}\right)$.

HR ESMS $m / z 532.2705\left(\mathrm{M}+\mathrm{H}^{+}\right)$. Calcd. for $\mathrm{C}_{32} \mathrm{H}_{38} \mathrm{NO}_{6}, 532.2699$.

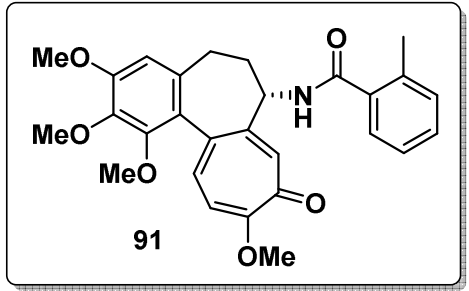

A partir de $0.20 \mathrm{~g}(0.42 \mathrm{mmol})$ del compuesto 3 se obtuvieron $0.12 \mathrm{~g}(0.25$ mmol, 59\%) del compuesto 91 como un un sólido amarillento. 
$[\alpha]_{D}=-160\left(\mathrm{c}=1.1, \mathrm{CHCl}_{3}\right)$.

P. f. $=202-205^{\circ} \mathrm{C}$.

IR $\mathbf{v}_{\text {máx }}\left(\mathrm{cm}^{-1}\right) 3260$ br (NH), $1653(\mathrm{C}=\mathrm{O})$.

$\mathbf{R M N}^{1} \mathbf{H}\left(500 \mathrm{MHz}, \mathrm{CDCl}_{3}\right) \delta=7.46(1 \mathrm{H}, \mathrm{s}), 7.40(1 \mathrm{H}, \mathrm{d}, J=7.5 \mathrm{~Hz}), 7.35-7.30$ $(2 \mathrm{H}, \mathrm{m}), 7.20(2 \mathrm{H}, \mathrm{m}), 6.83(1 \mathrm{H}, \mathrm{d}, J=10.7 \mathrm{~Hz}), 6.58(1 \mathrm{H}, \mathrm{s}), 6.20(1 \mathrm{H}, \mathrm{br} \mathrm{d}, J$ $\sim 7 \mathrm{~Hz}, \mathrm{NH}), 4.85(1 \mathrm{H}, \mathrm{dt}$ app, $J=11.5,7 \mathrm{~Hz}), 4.00(3 \mathrm{H}, \mathrm{s}), 3.97(3 \mathrm{H}, \mathrm{s}), 3.93$ $(3 \mathrm{H}, \mathrm{s}), 3.72(3 \mathrm{H}, \mathrm{s}), 2.58(1 \mathrm{H}, \mathrm{dd}, J=13,6.5 \mathrm{~Hz}), 2.50(1 \mathrm{H}, \mathrm{td}$ app, $J=13.5$, $7.2 \mathrm{~Hz}), 2.38(3 \mathrm{H}, \mathrm{s}), 2.35(1 \mathrm{H}, \mathrm{m}), 1.85(1 \mathrm{H}, \mathrm{td}$ app, $J=11.7,6.8 \mathrm{~Hz})$.

RMN ${ }^{13} \mathbf{C}\left(125 \mathrm{MHz}, \mathrm{CDCl}_{3}\right) \delta=179.2,169.3,163.9,153.4,151.2,151.0$, 141.6, 136.2, 136.0, 135.6, 134.1, 125.6 (C), 135.0, 130.8, 130.7, 129.7, 126.8, 125.5, 112.1, 107.3, 52.2 (CH), 36.9, $29.8\left(\mathrm{CH}_{2}\right)$, 61.4, 61.2, 56.1, 56.0, $19.7\left(\mathrm{CH}_{3}\right)$.

HR ESMS $m / z 476.2067\left(\mathrm{M}+\mathrm{H}^{+}\right)$. Calcd. for $\mathrm{C}_{28} \mathrm{H}_{30} \mathrm{NO}_{6}, 476.2073$.

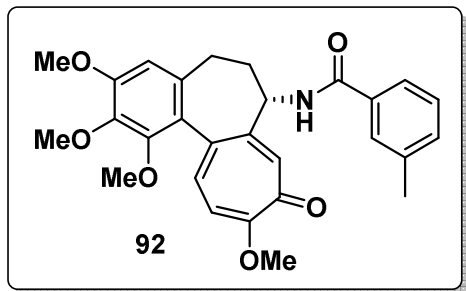

A partir de $0.20 \mathrm{~g}(0.42 \mathrm{mmol})$ del compuesto 3 se obtuvieron $0.11 \mathrm{~g}(0.23$ mmol, 54\%) del compuesto 92 como un sólido amarillento.

$[\alpha]_{D}=-48\left(\mathrm{c}=1, \mathrm{CHCl}_{3}\right)$.

P. f. $=145-147^{\circ} \mathrm{C}$.

IR $\mathbf{v}_{\text {máx }}\left(\mathrm{cm}^{-1}\right) 3290$ br $(\mathrm{NH}), 1653(\mathrm{C}=\mathrm{O})$.

RMN ${ }^{1} \mathbf{H}\left(500 \mathrm{MHz}, \mathrm{CDCl}_{3}\right) \delta=7.57(1 \mathrm{H}, \mathrm{s}), 7.54(1 \mathrm{H}, \mathrm{br} \mathrm{d}, J \sim 7 \mathrm{~Hz}), 7.46$ $(1 \mathrm{H}, \mathrm{s}), 7.33(1 \mathrm{H}, \mathrm{d}, J=10.7 \mathrm{~Hz}), 7.30-7.25(2 \mathrm{H}, \mathrm{m}) 6.83(1 \mathrm{H}, \mathrm{d}, J=10.7 \mathrm{~Hz})$, $6.70(1 \mathrm{H}, \mathrm{br} \mathrm{d}, J \sim 7 \mathrm{~Hz}, \mathrm{NH}), 6.57(1 \mathrm{H}, \mathrm{s}), 4.86(1 \mathrm{H}, \mathrm{dt}$ app, $J=11.7,7 \mathrm{~Hz})$, 
$4.00(3 \mathrm{H}, \mathrm{s}), 3.97(3 \mathrm{H}, \mathrm{s}), 3.92(3 \mathrm{H}, \mathrm{s}), 3.73(3 \mathrm{H}, \mathrm{s}), 2.59(1 \mathrm{H}, \mathrm{dd}, J=13,6.5$ $\mathrm{Hz}), 2.50(1 \mathrm{H}$, td app, $J=13,7 \mathrm{~Hz}), 2.37(3 \mathrm{H}, \mathrm{s}), 2.40-2.35(1 \mathrm{H}, \mathrm{m}), 1.95(1 \mathrm{H}$, td app, $J=11.7,6.8 \mathrm{~Hz})$.

RMN ${ }^{13} \mathbf{C}\left(125 \mathrm{MHz}, \mathrm{CDCl}_{3}\right) \delta=179.2,166.9,163.9,153.4,152.1,151.1$, 141.6, 137.8, 136.6, 134.2, 133.2, 125.6 (C), 135.1, 132.0, 130.8, 128.0, 127.5, 124.1, 112.5, 107.3, $52.7(\mathrm{CH}), 36.4,29.9\left(\mathrm{CH}_{2}\right), 61.5,61.3,56.2,56.0$, $20.9\left(\mathrm{CH}_{3}\right)$.

HR ESMS $m / z 476.2079\left(\mathrm{M}+\mathrm{H}^{+}\right)$. Calcd. for $\mathrm{C}_{28} \mathrm{H}_{30} \mathrm{NO}_{6}, 476.2073$.

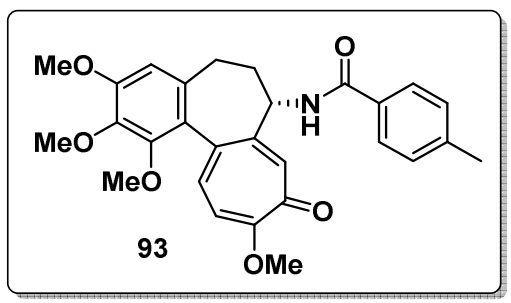

A partir de $0.20 \mathrm{~g}(0.42 \mathrm{mmol})$ del compuesto 3 se obtuvieron $0.11 \mathrm{~g}(0.23$ mmol, 54\%) del compuesto 93 como un sólido amarillento.

$[\alpha]_{\mathrm{D}}=-28\left(\mathrm{c}=1, \mathrm{CHCl}_{3}\right)$.

P. f. $=179-181^{\circ} \mathrm{C}$.

IR $\mathbf{v}_{\text {máx }}\left(\mathrm{cm}^{-1}\right) 3300$ br $(\mathrm{NH}), 1652(\mathrm{C}=\mathrm{O})$.

RMN ${ }^{1} \mathbf{H}\left(500 \mathrm{MHz}, \mathrm{CDCl}_{3}\right) \delta=7.67(2 \mathrm{H}, \mathrm{d}, J=7.8 \mathrm{~Hz}), 7.49(1 \mathrm{H}, \mathrm{s}), 7.33(1 \mathrm{H}$, $\mathrm{d}, J=10.7 \mathrm{~Hz}), 7.16(2 \mathrm{H}, \mathrm{d}, J=7.8 \mathrm{~Hz}) 6.90(1 \mathrm{H}, \mathrm{br} d, J \sim 7 \mathrm{~Hz}, \mathrm{NH}), 6.83$ $(1 \mathrm{H}, \mathrm{d}, J=10.7 \mathrm{~Hz}), 6.56(1 \mathrm{H}, \mathrm{s}), 4.86(1 \mathrm{H}, \mathrm{dt}$ app, $J=11.7,7 \mathrm{~Hz}), 3.99(3 \mathrm{H}$, s), $3.96(3 \mathrm{H}, \mathrm{s}), 3.91(3 \mathrm{H}, \mathrm{s}), 3.73(3 \mathrm{H}, \mathrm{s}), 2.57(1 \mathrm{H}, \mathrm{dd}, J=13,6.5 \mathrm{~Hz}), 2.48$ $(1 \mathrm{H}$, td app, $J=13,7 \mathrm{~Hz}), 2.40-2.30(1 \mathrm{H}, \mathrm{m}), 2.35(3 \mathrm{H}, \mathrm{s}), 1.95(1 \mathrm{H}, \mathrm{td}$ app, $J=$ $11.7,6.8 \mathrm{~Hz}$ ).

RMN ${ }^{13} \mathbf{C}\left(125 \mathrm{MHz}, \mathrm{CDCl}_{3}\right) \delta=179.2,166.8,163.9,153.4,152.1,151.2,141.6$ (x 2), 136.6, 134.2, 130.4, 125.6 (C), 135.1, 130.7, 128.8 (x 2), 127.0 (x 2), 112.4, 107.3, $52.7(\mathrm{CH}), 36.4,29.9\left(\mathrm{CH}_{2}\right), 61.5,61.3,56.2,56.0,21.2\left(\mathrm{CH}_{3}\right)$. 
HR ESMS $m / z 476.2070\left(\mathrm{M}+\mathrm{H}^{+}\right)$. Calcd. for $\mathrm{C}_{28} \mathrm{H}_{30} \mathrm{NO}_{6}, 476.2073$.

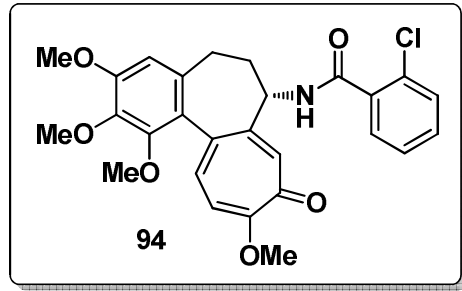

A partir de $0.15 \mathrm{~g}(0.32 \mathrm{mmol})$ del compuesto 3 se obtuvieron $0.081 \mathrm{~g}(0.16$ mmol, 51\%) del compuesto 94 como un sólido amarillento.

$[\alpha]_{D}=-134\left(\mathrm{C}=1, \mathrm{CHCl}_{3}\right)$.

P. f. $=153-155^{\circ} \mathrm{C}$.

IR $\mathbf{v}_{\text {máx }}\left(\mathrm{cm}^{-1}\right) 3250$ br $(\mathrm{NH}), 1666(\mathrm{C}=\mathrm{O})$.

$\mathbf{R M N}^{1} \mathbf{H}\left(500 \mathrm{MHz}, \mathrm{CDCl}_{3}\right) \delta=7.64(1 \mathrm{H}, \mathrm{d}, J=7.5 \mathrm{~Hz}), 7.48(1 \mathrm{H}, \mathrm{s}), 7.40-7.30$ $(4 \mathrm{H}, \mathrm{br} \mathrm{m}), 6.85-6.80(2 \mathrm{H}, \mathrm{m}), 6.57(1 \mathrm{H}, \mathrm{s}), 4.87(1 \mathrm{H}, \mathrm{dt}$ app, $J=11.5,7 \mathrm{~Hz})$, $3.99(3 \mathrm{H}, \mathrm{s}), 3.96(3 \mathrm{H}, \mathrm{s}), 3.92(3 \mathrm{H}, \mathrm{s}), 3.72(3 \mathrm{H}, \mathrm{s}), 2.58(1 \mathrm{H}, \mathrm{dd}, J=13,6.5$ $\mathrm{Hz}), 2.49(1 \mathrm{H}, \mathrm{td}$ app, $J=13.2,7 \mathrm{~Hz}), 2.40(1 \mathrm{H}, \mathrm{m}), 1.92(1 \mathrm{H}, \mathrm{td}$ app, $J=11.5$, $6.5 \mathrm{~Hz})$.

RMN ${ }^{13} \mathbf{C}\left(125 \mathrm{MHz}, \mathrm{CDCl}_{3}\right) \delta=179.2,165.8,163.9,153.4,151.1,150.5$, 141.6, 136.0, 134.4, 134.0, 130.5, 125.6 (C), 134.9, 131.1, 131.0, 130.0, 129.8, 126.8, 112.1, 107.3, 52.6 (CH), 36.8, $29.8\left(\mathrm{CH}_{2}\right), 61.4,61.2,56.1,56.0$ $\left(\mathrm{CH}_{3}\right)$.

HR ESMS $m / z 496.1523\left(M+\mathrm{H}^{+}\right)$. Calcd. for $\mathrm{C}_{27} \mathrm{H}_{27}{ }^{35} \mathrm{CINO}_{6}, 496.1527$. 


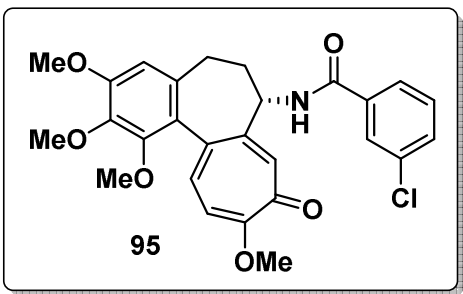

A partir de $0.20 \mathrm{~g}(0.42 \mathrm{mmol})$ del compuesto 3 se obtuvieron $0.11 \mathrm{~g}(0.23$ mmol, 55\%) del compuesto 95 como un sólido amarillento.

$[\alpha]_{\mathrm{D}}=-15\left(\mathrm{C}=0.92, \mathrm{CHCl}_{3}\right)$.

P. f. $=153-155^{\circ} \mathrm{C}$.

IR $\mathbf{v}_{\text {máx }}\left(\mathrm{cm}^{-1}\right) 3290$ br $(\mathrm{NH}), 1662(\mathrm{C}=\mathrm{O})$.

$\mathbf{R M N}^{1} \mathbf{H}\left(500 \mathrm{MHz}, \mathrm{CDCl}_{3}\right) \delta=7.85(1 \mathrm{H}, \mathrm{br} \mathrm{s}, \mathrm{NH}), 7.74(1 \mathrm{H}, \mathrm{s}), 7.62(2 \mathrm{H}, \mathrm{m})$, $7.47(1 \mathrm{H}, \mathrm{d}, J=10.7 \mathrm{~Hz}), 7.33(1 \mathrm{H}, \mathrm{d}, J=7.8 \mathrm{~Hz}), 7.17(1 \mathrm{H}, \mathrm{t}, J=7.8 \mathrm{~Hz}), 6.89$ $(1 \mathrm{H}, \mathrm{d}, J=10.7 \mathrm{~Hz}), 6.56(1 \mathrm{H}, \mathrm{s}), 4.87(1 \mathrm{H}, \operatorname{app} \mathrm{dt}, J=11.5,7 \mathrm{~Hz}), 4.00(3 \mathrm{H}$, s), $3.96(3 \mathrm{H}, \mathrm{s}), 3.91(3 \mathrm{H}, \mathrm{s}), 3.73(3 \mathrm{H}, \mathrm{s}), 2.57(1 \mathrm{H}, \mathrm{dd}, J=13,6.5 \mathrm{~Hz}), 2.50-$ $2.35(2 \mathrm{H}, \mathrm{br} \mathrm{m}), 2.07(1 \mathrm{H}$, app td, $J=11.5,6.5 \mathrm{~Hz})$.

RMN ${ }^{13} \mathbf{C}\left(125 \mathrm{MHz}, \mathrm{CDCl}_{3}\right) \delta=179.2,165.2,164.1,153.5,152.4,151.2$, 141.6, 136.9, 134.8, 134.3, 130.5, 125.6 (C), 135.5, 131.3, 130.7, 129.5, 127.5, 125.0, 112.9, 107.4, $53.0(\mathrm{CH}), 36.2,29.9\left(\mathrm{CH}_{2}\right)$, 61.6, 61.3, 56.4, 56.1 $\left(\mathrm{CH}_{3}\right)$.

HR ESMS $m / z 496.1527\left(\mathrm{M}+\mathrm{H}^{+}\right)$. Calcd. for $\mathrm{C}_{27} \mathrm{H}_{27}{ }^{35} \mathrm{CINO}_{6}, 496.1527$.

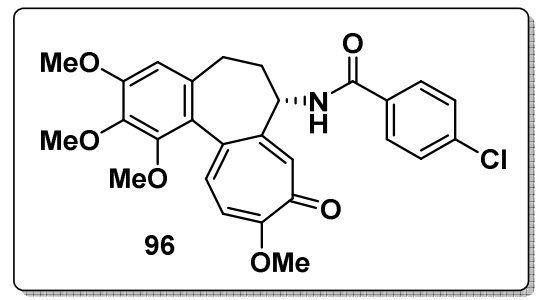

A partir de $0.15 \mathrm{~g}$ (0.32 mmol) del compuesto 3 se obtuvieron $0.084 \mathrm{~g}(0.17$ mmol, 53\%) del compuesto 96 como un sólido amarillento. 
$[\alpha]_{D}=+56.5\left(\mathrm{c}=1.1, \mathrm{CHCl}_{3}\right)$.

P. f. $=122-124^{\circ} \mathrm{C}$.

IR $\mathbf{v}_{\text {máx }}\left(\mathrm{cm}^{-1}\right) 3290$ br (NH), $1662(\mathrm{C}=\mathrm{O})$.

$\mathbf{R M N}^{1} \mathbf{H}\left(500 \mathrm{MHz}, \mathrm{CDCl}_{3}\right) \delta=7.73(2 \mathrm{H}, \mathrm{d}, J=7.8 \mathrm{~Hz}), 7.62(1 \mathrm{H}, \mathrm{s}), 7.39(1 \mathrm{H}$, d, $J=10.7 \mathrm{~Hz}), 7.20-7.15(3 \mathrm{H}, \mathrm{m}), 6.90(1 \mathrm{H}, \mathrm{d}, J=10.7 \mathrm{~Hz}), 6.55(1 \mathrm{H}, \mathrm{s}), 4.85$ $(1 \mathrm{H}, \mathrm{dt}$ app, $J=11.5,7 \mathrm{~Hz}), 4.00(3 \mathrm{H}, \mathrm{s}), 3.96(3 \mathrm{H}, \mathrm{s}), 3.91(3 \mathrm{H}, \mathrm{s}), 3.75(3 \mathrm{H}$, s), 2.60-2.55 $(1 \mathrm{H}, \mathrm{m}), 2.50-2.35(2 \mathrm{H}, \mathrm{br} \mathrm{m}), 2.10-2.00(1 \mathrm{H}, \mathrm{m})$.

RMN ${ }^{13} \mathbf{C}\left(125 \mathrm{MHz}, \mathrm{CDCl}_{3}\right) \delta=179.1,165.7,164.0,153.5,152.8,151.2$, 141.6, 137.4, 137.0, 134.2, 131.3, 125.5 (C), 135.6, 130.4, 128.5 (x 2), 128.3 (x 2), 112.9, 107.4, 53.2 (CH), 36.0, $30.0\left(\mathrm{CH}_{2}\right), 61.6,61.3,56.3,56.1\left(\mathrm{CH}_{3}\right)$.

HR ESMS $m / z 496.1527\left(\mathrm{M}+\mathrm{H}^{+}\right)$. Calcd. for $\mathrm{C}_{27} \mathrm{H}_{27}{ }^{35} \mathrm{CINO}_{6}, 496.1527$.

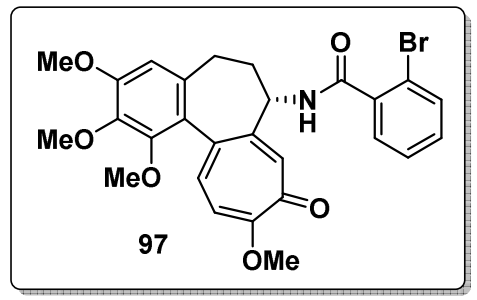

A partir de $0.20 \mathrm{~g}(0.42 \mathrm{mmol})$ del compuesto 3 se obtuvieron $0.11 \mathrm{~g}(0.21$ mmol, 49\%) del compuesto 97 como un sólido amarillento.

$[\alpha]_{D}=-152\left(\mathrm{c}=1, \mathrm{CHCl}_{3}\right)$.

P. f. $=174-176^{\circ} \mathrm{C}$.

IR $\mathbf{v}_{\text {máx }}\left(\mathrm{cm}^{-1}\right) 3250$ br $(\mathrm{NH}), 1665(\mathrm{C}=\mathrm{O})$.

$\mathbf{R M N}^{1} \mathbf{H}\left(500 \mathrm{MHz}, \mathrm{CDCl}_{3}\right) \delta=7.59(1 \mathrm{H}, \mathrm{d}, J=7.8 \mathrm{~Hz}), 7.55(1 \mathrm{H}, \mathrm{d}, J=7.8$ $\mathrm{Hz}), 7.50(1 \mathrm{H}, \mathrm{s}), 7.40-7.30(3 \mathrm{H}, \mathrm{br} \mathrm{m}), 6.82(1 \mathrm{H}, \mathrm{d}, J=10.8 \mathrm{~Hz}), 6.57(1 \mathrm{H}, \mathrm{s})$, $6.50(1 \mathrm{H}, \mathrm{br} d, J \sim 7 \mathrm{~Hz}, \mathrm{NH}), 4.88(1 \mathrm{H}, \mathrm{dt}$ app, $J=11.3,7 \mathrm{~Hz}), 4.00(3 \mathrm{H}, \mathrm{s})$, $3.97(3 \mathrm{H}, \mathrm{s}), 3.93(3 \mathrm{H}, \mathrm{s}), 3.72(3 \mathrm{H}, \mathrm{s}), 2.58(1 \mathrm{H}, \mathrm{dd}, J=13,6.5 \mathrm{~Hz}), 2.50(1 \mathrm{H}$, td app, $J=13.2,6.5 \mathrm{~Hz}), 2.44(1 \mathrm{H}, \mathrm{m}), 1.90(1 \mathrm{H}, \mathrm{td}$ app, $J=11.5,6.5 \mathrm{~Hz})$. 
RMN ${ }^{13} \mathbf{C}\left(125 \mathrm{MHz}, \mathrm{CDCl}_{3}\right) \delta=179.2,166.8,163.9,153.4,151.1,150.5$, 141.6, 137.1, 136.1, 134.0, 125.6, 119.1 (C), 135.0, 133.0, 131.2, 131.1, 129.6, 127.4, 112.1, 107.4, $52.6(\mathrm{CH}), 36.9,29.8\left(\mathrm{CH}_{2}\right), 61.4,61.2,56.1,56.0$ $\left(\mathrm{CH}_{3}\right)$.

HR ESMS $m / z 540.1019\left(\mathrm{M}+\mathrm{H}^{+}\right)$. Calcd. for $\mathrm{C}_{27} \mathrm{H}_{27}{ }^{79} \mathrm{BrNO}_{6}, 540.1022$.

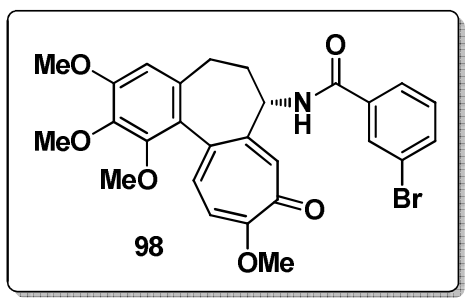

A partir de $0.20 \mathrm{~g}(0.42 \mathrm{mmol})$ del compuesto 3 se obtuvieron $0.12 \mathrm{~g}(0.21$ $\mathrm{mmol}, 51 \%$ ) del compuesto 98 como un sólido amarillento.

$[\alpha]_{D}=-11\left(\mathrm{c}=0.96, \mathrm{CHCl}_{3}\right)$.

P. f. $=137-139^{\circ} \mathrm{C}$.

IR $\mathbf{v}_{\text {máx }}\left(\mathrm{cm}^{-1}\right) 3290$ br $(\mathrm{NH}), 1654(\mathrm{C}=\mathrm{O})$.

$\mathbf{R M N}^{1} \mathbf{H}\left(500 \mathrm{MHz}, \mathrm{CDCl}_{3}\right) \delta=8.50(1 \mathrm{H}, \mathrm{br} \mathrm{d}, J \sim 7 \mathrm{~Hz}, \mathrm{NH}), 7.90(1 \mathrm{H}, \mathrm{br} \mathrm{s})$, $7.68(1 \mathrm{H}, \mathrm{s}), 7.64(1 \mathrm{H}, \mathrm{d}, J=7.8 \mathrm{~Hz}), 7.40(1 \mathrm{H}, \mathrm{br} d, J \sim 8 \mathrm{~Hz}), 7.38(1 \mathrm{H}, \mathrm{d}, J=$ $10.7 \mathrm{~Hz}), 6.99(1 \mathrm{H}, \mathrm{t}, J=8 \mathrm{~Hz}), 6.90(1 \mathrm{H}, \mathrm{d}, J=10.7 \mathrm{~Hz}), 6.52(1 \mathrm{H}, \mathrm{s}), 4.85$ $(1 \mathrm{H}, \mathrm{dt}$ app, $J=11.5,7 \mathrm{~Hz}), 3.99(3 \mathrm{H}, \mathrm{s}), 3.95(3 \mathrm{H}, \mathrm{s}), 3.89(3 \mathrm{H}, \mathrm{s}), 3.72(3 \mathrm{H}$, s), $2.49(1 \mathrm{H}, \mathrm{dd}, J=13,6 \mathrm{~Hz}), 2.45-2.30(2 \mathrm{H}$, br m), $2.13(1 \mathrm{H}, \mathrm{m})$.

RMN ${ }^{13} \mathbf{C}\left(125 \mathrm{MHz}, \mathrm{CDCl}_{3}\right) \delta=179.2,165.2,164.1,153.5,152.4,151.2$, 141.6, 136.9, 134.8, 134.3, 130.5, 125.6 (C), 135.5, 131.3, 130.7, 129.5, 127.5, 125.0, 112.9, 107.4, $53.0(\mathrm{CH}), 36.2,29.9\left(\mathrm{CH}_{2}\right), 61.6,61.3,56.4,56.1$ $\left(\mathrm{CH}_{3}\right)$.

HR ESMS $m / z 540.1025\left(M+\mathrm{H}^{+}\right)$. Calcd. for $\mathrm{C}_{27} \mathrm{H}_{27}{ }^{79} \mathrm{BrNO}_{6}, 540.1022$. 


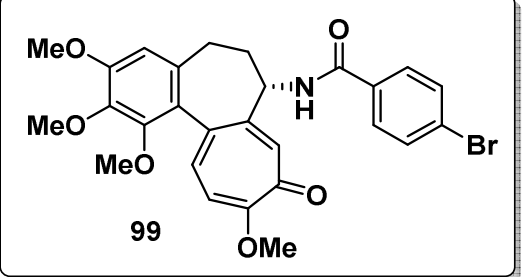

A partir de $0.20 \mathrm{~g}(0.42 \mathrm{mmol})$ del compuesto 3 se obtuvieron $0.13 \mathrm{~g}(0.24$ $\mathrm{mmol}, 58 \%$ ) del compuesto 99 como un sólido amarillento.

$[\alpha]_{D}=+61.6\left(\mathrm{c}=0.92, \mathrm{CHCl}_{3}\right)$.

P. f. $=154-156^{\circ} \mathrm{C}$.

IR $\mathbf{v}_{\text {máx }}\left(\mathrm{cm}^{-1}\right) 3290 \mathrm{br}(\mathrm{NH}), 1654(\mathrm{C}=\mathrm{O})$.

RMN ${ }^{1} \mathbf{H}\left(500 \mathrm{MHz}, \mathrm{CDCl}_{3}\right) \delta=7.80(1 \mathrm{H}, \mathrm{br} \mathrm{s}, \mathrm{NH}), 7.66(2 \mathrm{H}, \mathrm{d}, J=8 \mathrm{~Hz}), 7.57$ $(1 \mathrm{H}, \mathrm{s}), 7.40-7.35(3 \mathrm{H}, \mathrm{m}), 6.88(1 \mathrm{H}, \mathrm{d}, J=10.8 \mathrm{~Hz}), 6.55(1 \mathrm{H}, \mathrm{s}), 4.84(1 \mathrm{H}, \mathrm{dt}$ app, $J=11.5,7 \mathrm{~Hz}), 4.01(3 \mathrm{H}, \mathrm{s}), 3.97(3 \mathrm{H}, \mathrm{s}), 3.92(3 \mathrm{H}, \mathrm{s}), 3.74(3 \mathrm{H}, \mathrm{s}), 2.57$ $(1 \mathrm{H}, \mathrm{dd}, J=13,6.5 \mathrm{~Hz}), 2.50-2.35(2 \mathrm{H}, \mathrm{br} \mathrm{m}), 2.05-2.00(1 \mathrm{H}, \mathrm{m})$.

RMN ${ }^{13} \mathbf{C}\left(125 \mathrm{MHz}, \mathrm{CDCl}_{3}\right) \delta=179.0,165.7,164.0,153.5,152.8,151.1$, 141.6, 137.0, 134.2, 131.7, 126.0, 125.5 (C), 135.6, 131.2 (x 2), 130.3, 128.7 (x 2), 113.0, 107.3, 53.2 (CH), 35.8, $29.9\left(\mathrm{CH}_{2}\right), 61.6,61.2,56.3,56.0\left(\mathrm{CH}_{3}\right)$.

HR ESMS $m / z 540.1022\left(\mathrm{M}+\mathrm{H}^{+}\right)$. Calcd. for $\mathrm{C}_{27} \mathrm{H}_{27}{ }^{79} \mathrm{BrNO}_{6}, 540.1022$. 



\section{CAPÍTULO 4 \\ EVALUACIÓN BIOLÓGICA}
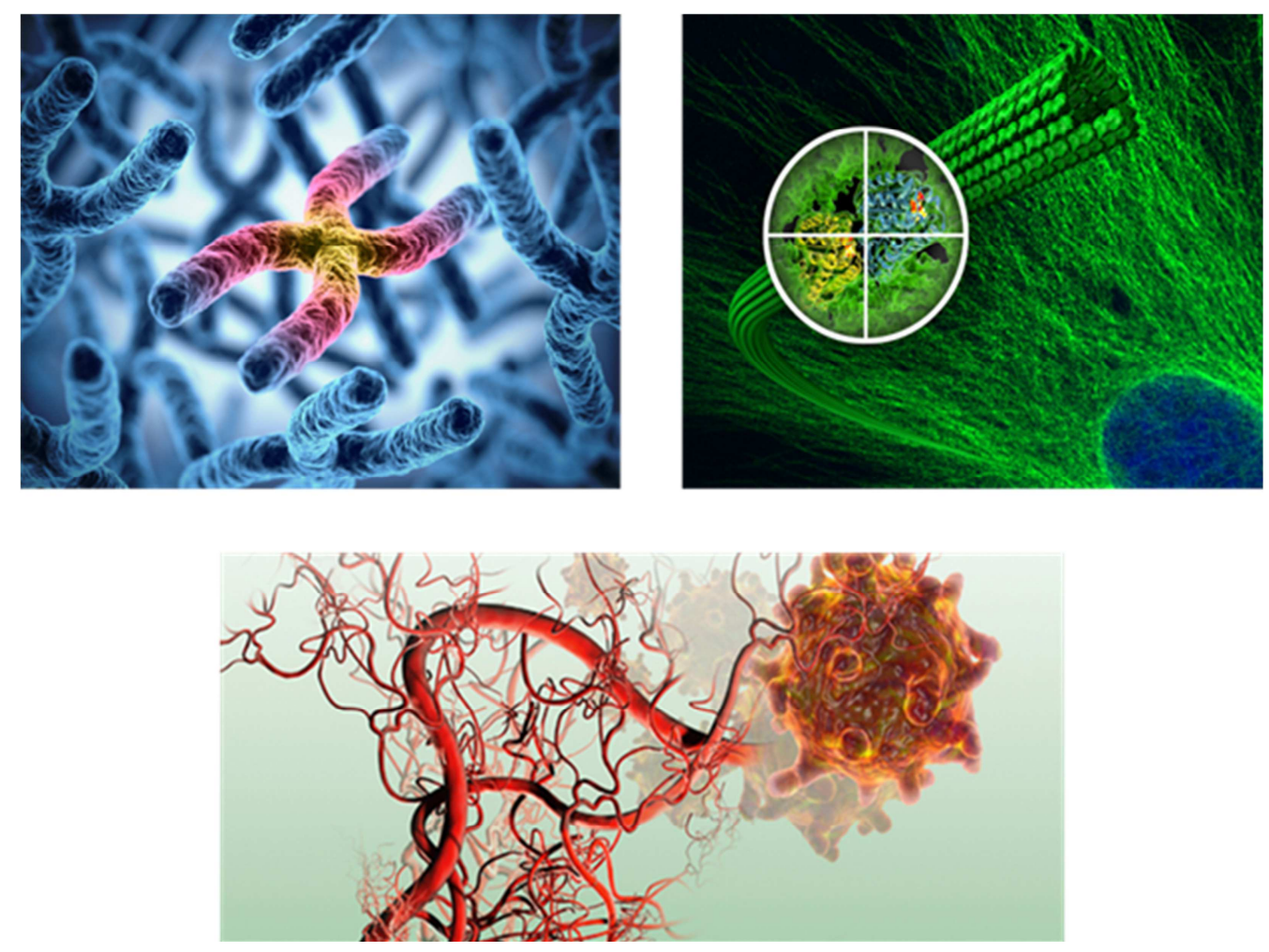



\section{CAPÍTULO 4: EVALUACIÓN BIOLÓGICA}

En este capítulo se van a describir todos los ensayos realizados para llevar a cabo la evaluación biológica de los compuestos sintetizados. Dichos ensayos son los siguientes:

1. Citotoxicidad.

2. Efecto sobre el ensamblaje de microtúbulos.

3. Determinación del valor de $\mathrm{IC}_{50}$ frente a la formación de microtúbulos.

4. Determinación de la constante de afinidad frente a la tubulina.

5. Efecto sobre el ciclo celular (citometría de flujo).

6. Efecto sobre la red de microtúbulos (inmunofluorescencia).

7. Efecto sobre la expresión de los genes VEGF, hTERT y c-Myc en HT-29.

8. Efecto sobre la secreción de la proteína VEGF-A ${ }_{165}$ en HT-29.

Parte de los ensayos biológicos relacionados con la tubulina para los compuestos 73-77 (ensayos 2, 3, 4, 5 y 6) y para los compuestos $\mathbf{8 7}, \mathbf{8 8}, \mathbf{9 4 -}$ 96 y 98 (ensayo 2) se realizaron en los laboratorios de la Facultad de Farmacia pertenecientes a la Universidad de Aix-Marseille, Francia. Todo ello fue gracias a una estancia de investigación financiada por la Conselleria d'Educació, Investigació, Cultura i Esport de la Generalitat Valenciana, que se realizó desde septiembre de 2015 a diciembre del mismo año. La actividad investigadora que llevé a cabo en dicha estancia estuvo dirigida por el Prof. Vincent Peyrot y la Dra. Pascale Barbier, ambos miembros del Center for Research in Oncobiology and Oncopharmacology (C.R.O.2).

Las actividades biológicas del resto de compuestos relacionadas con el ensamblaje de los microtúbulos (ensayo 2) se midieron en los laboratorios del grupo del Dr. Fernando Díaz, en colaboración con el Dr. Fernando Josa, en el Centro de Investigaciones Biológicas (CIB, CSIC-Madrid). 
El resto de ensayos biológicos (ensayos 1,7 y 8 ) se realizaron en los laboratorios del Grupo de Síntesis Orgánica, perteneciente al Departamento de Química Inorgánica y Orgánica de la Universidad Jaume I de Castellón, lugar dónde se ha desarrollado esta Tesis.

Para la redacción de este capítulo se han agrupado los compuestos sintéticos en tres familias, tal y como se ha explicado en el capítulo 2 (véase el esquema 2.1 del Capítulo 2).

\subsection{Ensayos biológicos}

\subsubsection{Citotoxicidad}

La citotoxicidad de los compuestos sintetizados se estableció mediante el valor de $\mathrm{IC}_{50}$, que es la concentración de compuesto capaz de inhibir el 50\% de la proliferación celular.

Para determinar la citotoxicidad se utilizaron las líneas celulares tumorales humanas HT-29 (adenocarcinoma de colon), MCF-7 (adenocarcinoma de mama) y A549 (adenocarcinoma de pulmón), así como la línea celular no tumoral HEK-293 (células embrionarias de riñón). Esta última línea se utilizó para evaluar el margen de seguridad terapéutica de los compuestos mediante el cálculo de los coeficientes de selectividad. Estos coeficientes se obtienen al dividir los valores de $\mathrm{IC}_{50}$ de la línea HEK-293 por los valores de $\mathrm{IC}_{50}$ de la correspondiente línea tumoral.

La citotoxicidad se midió mediante el ensayo de reducción del bromuro de 3-(4,5-dimetiltiazol-2-il)-2,5-difeniltetrazolio (MTT) cuya estructura se presenta en el esquema 4.1. Se trata de un ensayo colorimétrico en el que el MTT, de color amarillo y soluble en agua, es incorporado por las células vivas y convertido por la enzima mitocondrial succinato-deshidrogenasa en formazán, un sólido de color morado insoluble en disolución acuosa (véase el esquema 
4.1). La cantidad de células vivas es proporcional a la cantidad de formazán formado.
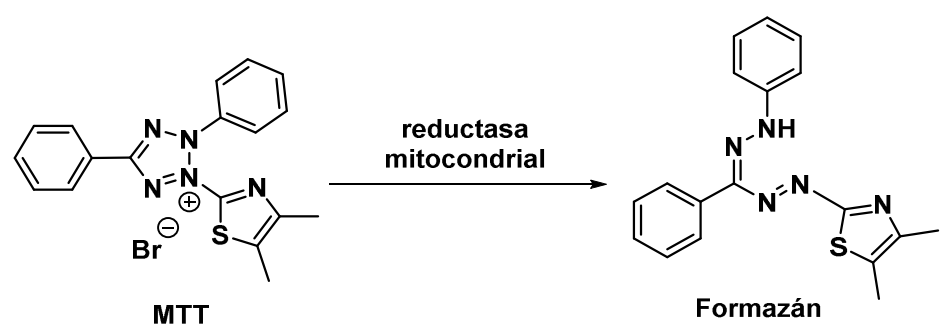

Esquema 4.1. Reducción de MTT a formazán.

Para llevar a cabo los ensayos de citotoxicidad las células se incubaron entre 48 y 72 horas con disoluciones de cada compuesto en diferentes concentraciones. Transcurrido este tiempo se añadió el MTT y se dejó en incubación a $37{ }^{\circ} \mathrm{C}$ durante 3 horas. Seguidamente se eliminó el medio de cultivo, que contiene el MTT no reducido, y el formazán se disolvió en DMSO. Luego se determinó la absorbancia en un lector de placas y se calcularon los valores de $\mathrm{IC}_{50}$ mediante el programa GraphPad Prism 4.

Todos los valores de citotoxicidad vienen expresados por el valor medio de $I_{50} \pm S D$ (tres valores experimentales como mínimo). Los compuestos con menores valores de $\mathrm{IC}_{50}$, por tanto más citotóxicos, fueron seleccionados para los siguientes estudios biológicos, que se explican a continuación.

\subsubsection{Efecto sobre el ensamblaje de microtúbulos}

El proceso de polimerización de los microtúbulos se indica de forma gráfica en la figura 4.1 y consta de las siguientes fases: ${ }^{115}$

a) Fase de nucleación, en la que se empiezan a formar los oligómeros de tubulina.

b) Fase de elongación, en la que se añaden subunidades de tubulina a ambos lados del microtúbulo.

${ }^{115}$ Para una animación sobre el proceso de inestabilidad dinámica de los microtúbulos véase: http://www.hhmi.org/research/structural-studies-macromolecular-assemblies 
c) Fase meseta, durante la cual el microtúbulo entra en un equilibrio dinámico en el que se añaden subunidades en un extremo y se eliminan en el otro. En esta fase, el valor de la concentración de subunidades de tubulina que permanece en disolución se conoce como concentración crítica $(\mathrm{Cr})$.

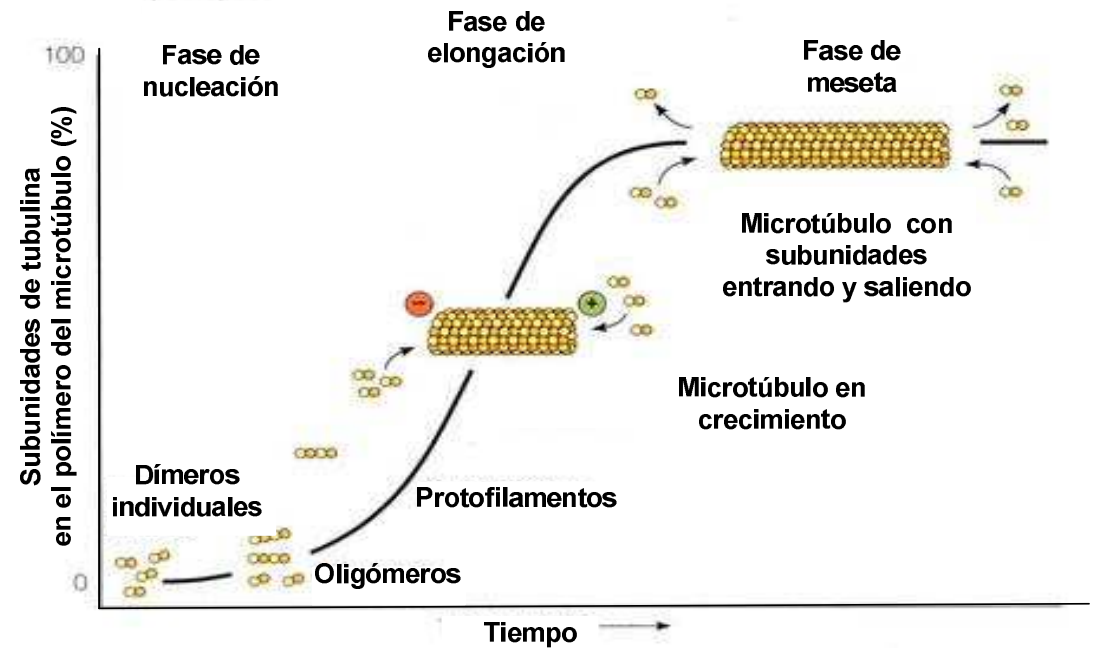

Figura 4.1. Polimerización de microtúbulos en función del tiempo. ${ }^{116}$

La concentración crítica de tubulina se define como la concentración mínima necesaria para que se produzca el ensamblaje reversible de los microtúbulos. Esta concentración depende de las condiciones en las que se encuentre la proteína como, por ejemplo, la temperatura, el $\mathrm{pH}$ y las concentraciones de compuestos presentes en el medio. ${ }^{117}$ Aquellos compuestos que actúan estabilizando los microtúbulos presentan un valor de concentración crítica menor que el que se mide en la prueba de control, mientras que los agentes desestabilizantes presentan un valor de concentración crítica mayor que el que se mide en la prueba de control.

\footnotetext{
${ }^{116}$ Adaptada al castellano de:

https://biolcell4350. wikispaces.com/19.+Citoesqueleto+10+y+12+de+noviembre

${ }_{117}$ Oosawa, F.; Asakura, S. Thermodynamics of the Polymerization of Proteins, Academic

Press, London, 1975.
} 
Los microtúbulos no son solubles en agua y mediante turbidimetría también se puede estudiar el efecto de los compuestos en el proceso de polimerización de la tubulina. En este caso la medida de la absorbancia es proporcional a la cantidad de masa de polímero formado.

Para todos los experimentos se realizó un control mediante incubación de la tubulina en presencia del máximo volumen de DMSO utilizado en la disolución de los compuestos.

Una vez realizados los experimentos se comprobó mediante microscopía electrónica de transmisión que las absorbancias obtenidas correspondían a microtúbulos. Un ejemplo de la estructura de los microtúbulos se puede observar en la figura 4.2 .

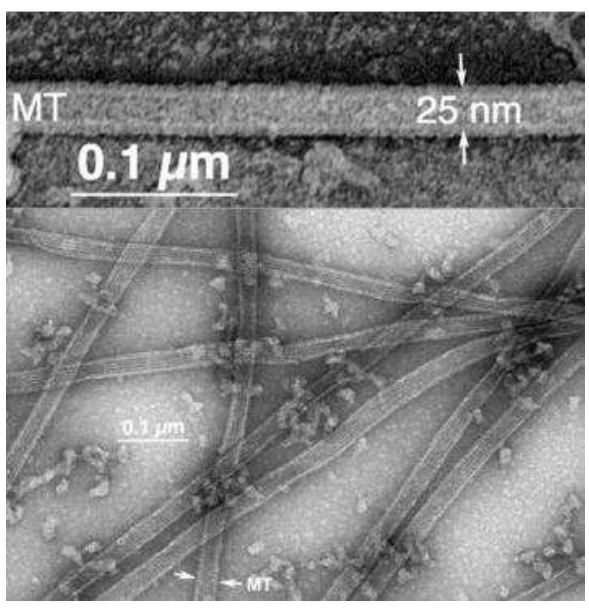

Figura 4.2. Microtúbulo (arriba) y disposición de los microtúbulos en el interior celular. ${ }^{118}$

Las imágenes de los microtúbulos generados en esta Tesis se tomaron con el microscopio de transmisión electrónica JEOL JEM-1400 ubicado en los servicios centrales de la Facultad de Medicina de la Universidad de AixMarseille.

\footnotetext{
$\overline{{ }^{118} \mathrm{https}: / / \text { citoesqueleto.wikispaces.com/Microtubulos }}$
} 


\subsubsection{Determinación del valor de $I_{50}$ frente a la formación de microtúbulos}

El valor de $\mathrm{IC}_{50}$ frente a la formación de microtúbulos se define como la concentración de compuesto capaz de inhibir el $50 \%$ el proceso de polimerización de la tubulina. Los valores de $\mathrm{IC}_{50}$ frente a la formación de microtúbulos se determinaron mediante turbidimetría. Para ello se utilizó una concentración fija de tubulina igual a $15 \mu \mathrm{M}$ y disoluciones de los compuestos a distintas concentraciones. Se realizó un control mediante incubación de la tubulina en presencia del máximo volumen de DMSO utilizado en la disolución de los compuestos.

\subsubsection{Determinación de la constante de afinidad frente a la tubulina}

La determinación de la constante de afinidad se basó en el siguiente equilibrio:

$$
\mathrm{Tub}+\mathrm{C} 1 \stackrel{\mathrm{Ka}}{\Leftrightarrow} \mathrm{TubC} 1
$$

En este equilibrio Tub hace referencia a la tubulina añadida a una concentración conocida, C1 es el ligando y TubC1 es el complejo formado por la unión del ligando a la tubulina.

Seguidamente se muestran las ecuaciones de la constante de afinidad (1) y la de disociación (2) de dicho equilibrio:

$$
\mathrm{Ka}=\frac{[\mathrm{TubC} 1]}{[\mathrm{Tub}]_{\text {libre }}[\mathrm{C} 1]_{\text {libre }}} \quad \text { (1) } \quad \mathrm{Kd}=\frac{[\mathrm{Tub}]_{\text {libre }}[\mathrm{C} 1]_{\text {libre }}}{[\mathrm{TubC} 1]}
$$

donde [TubC1] equivale a la concentración del complejo ligando-tubulina formado, [Tub] libre a la concentración de tubulina libre y [C1] libre a la concentración de ligando libre.

En esta Tesis se utilizó la fluorescencia de los restos de triptófano de la tubulina para determinar la constante de afinidad aparente mediante el programa SigmaPlot. La señal de fluorescencia F, obtenida de las medidas del 
instrumento, corresponde al valor experimental. El valor teórico correspondiente a la fracción saturada $B$ se calcula de la siguiente manera:

$$
\mathrm{B}=\frac{\text { moles de ligando unido }}{\text { moles totales de proteína }}=\frac{[\text { TubC1 }]}{[\text { TubC1 }]+[\text { Tub }]_{\text {libre }}}
$$

La concentración de tubulina libre se despeja de la ecuación de la constante de disociación (2) y se sustituye en (3) y se obtiene la ecuación para B (valor teórico):

$$
\mathrm{B}=\frac{[\mathrm{C} 1]_{\text {libre }}}{[\mathrm{C} 1]_{\text {libre }}+\mathrm{K}_{\mathrm{d}}}
$$

Para calcular la concentración del complejo tubulina-ligando se parte de concentraciones conocidas de tubulina y de ligando totales y a partir de ellas se obtienen las concentraciones libres.

$$
\begin{aligned}
{[\text { Tub }]_{\text {libre }} } & =[\text { Tub }]_{\text {total }}-[\text { TubC1] } \\
{[C 1]_{\text {libre }} } & =[\text { C1 }]_{\text {total }}-[\text { TubC1] }
\end{aligned}
$$

Sustituyendo estas expresiones en la expresión de la constante de disociación (2) y reajustando se obtiene una ecuación de segundo grado tal que:

$$
0=[\mathrm{Tub}]_{\text {tot }}[\mathrm{C} 1]_{\text {tot }}-\left(\mathrm{K}_{\mathrm{d}}+[\mathrm{Tub}]_{\mathrm{tot}}+[\mathrm{C} 1]_{\mathrm{tot}}\right)[\mathrm{TubC} 1]+[\mathrm{TubC} 1]^{2}
$$

De esta ecuación se obtiene el valor de la concentración del complejo tubulina-ligando y así se puede calcular la concentración de ligando libre. Fijando el valor de la constante de disociación para cada concentración de ligando se realiza un ajuste no lineal por mínimos cuadrados con el valor de B teórico (4) confrontándolo con el valor experimental F, obtenido mediante las medidas de fluorescencia.

De esta manera se obtiene el valor de la constante de disociación aparente. Realizando la inversa obtenemos el valor de la constante de afinidad aparente de formación del complejo tubulina-ligando. 


\subsubsection{Efecto sobre el ciclo celular (citometría de flujo)}

Los estudios de ciclo celular permiten cuantificar la parada de las células en fase G2/M y se llevaron a cabo sobre la línea celular de adenocarcinoma de pulmón humano (A549) empleando la técnica de citometría de flujo.

Esta técnica permite contar y clasificar las células según sus características morfológicas. En los citómetros de flujo, las células suspendidas en un fluido atraviesan un finísimo tubo transparente sobre el que incide un delgado rayo de luz láser. La luz transmitida y dispersada por el pasaje de las células a través del tubo se recoge por medio de unos dispositivos de detección, permitiendo hacer inferencias en cuanto a tamaño y complejidad de las células. Generalmente se utilizan fluoróforos como etiquetas para el marcado fluorescente.

Para el análisis del ciclo celular mediante citometría de flujo se utilizó el yoduro de propidio (PI). Este compuesto se intercala en el ADN y aporta información sobre la distribución de las células en las diferentes fases del ciclo celular (G1, S, G2 o M). Sin embargo, no es posible diferenciar entre G2 y M mediante este método ya que en las dos fases el contenido de ADN de la célula es el mismo.

Los datos recogidos se representan en una gráfica que muestra las variaciones en el contenido de ADN frente al número de células analizadas, tal y como se indica en la figura 4.3. En esta figura se puede observar:

1) La fase de reposo y presíntesis (G0/G1), en la cual la célula tiene un contenido diploide de ADN correspondiente a 23 pares de cromosomas (2N).

2) La fase de síntesis (S), en la cual se está sintetizando el ADN.

3) La fase $G 2 / M$, en la que se ha duplicado el contenido genético de la célula respecto a la fase $\mathrm{G} 1(4 \mathrm{~N})$. 


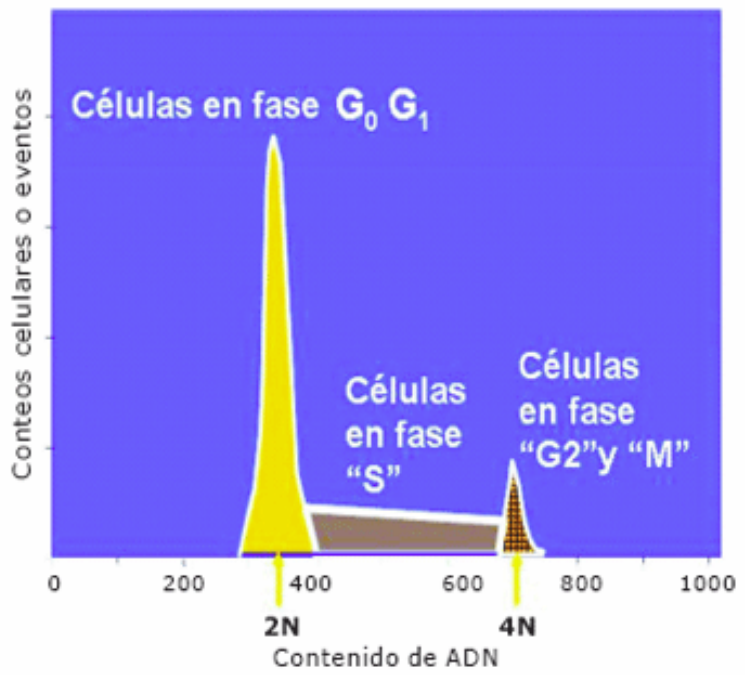

Figura 4.3. Histograma del ciclo celular y contenido de ADN. ${ }^{119}$

Los compuestos que actúan frente a la tubulina son capaces de detener el ciclo celular en la fase G2/M, por lo que en el histograma obtenido se observa una acumulación de células en dicha fase.

Todos los resultados de citometría de flujo de esta Tesis se obtuvieron mediante un FACScan "Becton Dickinson" perteneciente a los servicios centrales de la Facultad de Farmacia de la Universidad de Aix-Marseille.

\subsubsection{Efecto sobre la red de microtúbulos (inmunofluorescencia)}

Los estudios de inmunofluorescencia permiten observar el aspecto de los husos mitóticos y la morfología nuclear de células. En la técnica de inmunofluorescencia se utiliza un marcador fluorescente, que en nuestro caso es el isotiocianato de fluoresceína (FITC por sus siglas en inglés), unido a un anticuerpo que reconoce a la proteína objetivo, por ejemplo la a-tubulina. El anticuerpo marcado se incorpora a las células tratadas y luego éstas son irradiadas con una fuente de luz de onda corta (ultravioleta o azul)

\footnotetext{
${ }^{119}$ http://www.scielo.org.co/scielo.php?script=sci_arttext\&pid=S0122-02682007000200015
} 
seleccionada por medio de un monocromador. La molécula marcadora o sonda fluorescente emite luz a una longitud de onda más larga (verde para el FITC) y puede ser observada por medio de un microscopio de fluorescencia. En la figura 4.4 se adjunta, a modo de ejemplo, una fotografía de células Hela tomada mediante la técnica de inmunofluorescencia.

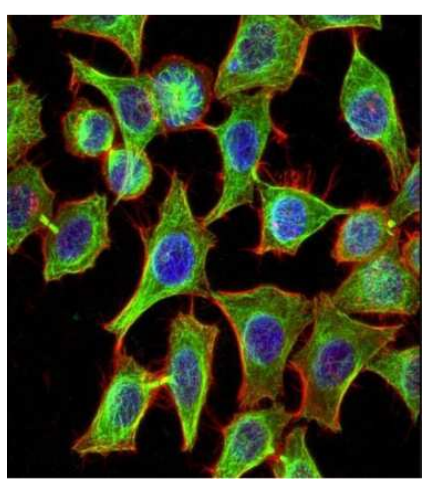

Figura 4.4. Células Hela en las que se observa el citoesqueleto de actina (verde), la membrana plasmática (rojo) y los núcleos celulares (azul). ${ }^{120}$

Todos las imágenes de esta Tesis se obtuvieron mediante un Confocal Laser Scanning Microsocope (CLSM) Leica SP5 perteneciente a los servicios centrales de la Facultad de Medicina de la Universidad de Aix-Marseille.

\subsubsection{Efecto sobre la expresión de los genes VEGF, $h T E R T$ y $c-M y c$ en HT-29}

La reacción en cadena de la polimerasa (PCR de sus siglas en inglés) está basada en la amplificación de una región específica del ADN. Para ello se usan unos cebadores o primers, que son pequeños fragmentos de una sola hebra de $A D N$ que contienen la secuencia complementaria a las regiones iniciales (forward) y finales (reverse) que se quieren amplificar, la ADN polimerasa, enzima encargada de sintetizar nuevas hebras de ADN, y los

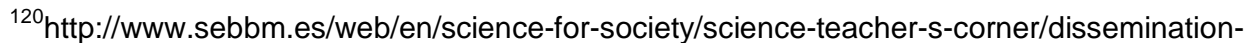
articles/919-uso-de-la-fluorescencia-y-la-microscopia-confocal-en-la-investigacion-cientifica
} 
dNTPs (oligonucleótidos), que son los bloques de construcción para sintetizar la nueva hebra de ADN.

En la figura 4.5 se resumen los pasos de la PCR. Durante la PCR se llevan a cabo entre 20 y 40 ciclos. Estos ciclos se realizan en un termociclador y constan de tres etapas: ${ }^{121}$

$>$ Desnaturalización del ADN que ocurre a una temperatura aproximada de $95^{\circ} \mathrm{C}$. Esta etapa permite la separación de las dos hebras del ADN.

- Alineación del cebador que ocurre a una temperatura ente $40-68{ }^{\circ} \mathrm{C}$.

$>$ Extensión de la cadena que tiene lugar a una temperatura de $72{ }^{\circ} \mathrm{C}$. En esta etapa la ADN polimerasa sintetiza la hebra de ADN complementario partiendo del cebador.

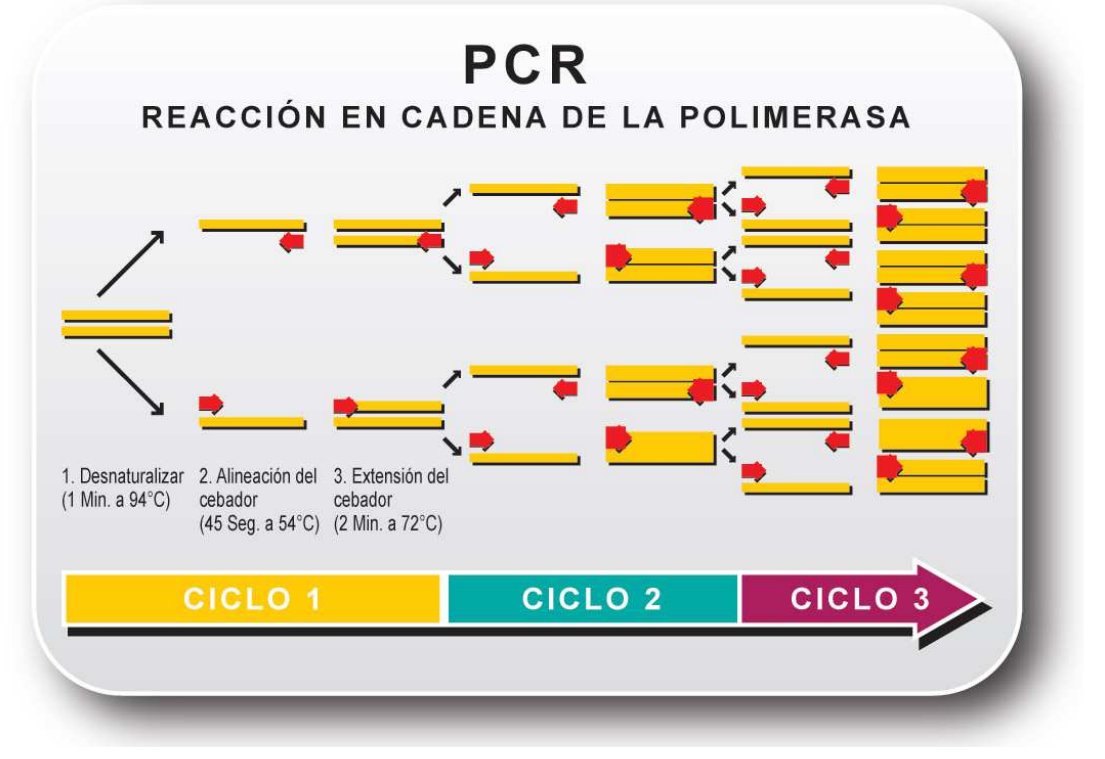

Figura 4.5. Esquema del funcionamiento de la reacción en cadena de la polimerasa. $^{122}$

121 White, B. A. PCR protocols: Current Methods and Applications. In: Methods I molecular biology. Human Press. 1993.

${ }^{122} \mathrm{http}$ ://exsheffield.org/soloparaingenierosnet/wpcontent/uploads/2013/12/securedownload25.jpeg 
Existen dos tipos de PCR, la convencional, que es cualitativa, y la PCR cuantitativa en tiempo real (RT-QPCR o qPCR). En esta Tesis se han realizado ambas.

En el caso de la PCR convencional se realizó una electroforesis en gel de agarosa al $1 \%$, que se utiliza para separar, identificar y purificar fragmentos de ADN. Así, a pH neutro los grupos fosfatos del ADN están cargados negativamente y cuando se aplica un campo eléctrico, el ADN migra hacia el ánodo. La velocidad de la migración depende del tamaño del fragmento de ADN. ${ }^{123}$ Para facilitar el revelado se tiñe el gel con bromuro de etidio, que es un agente fluorescente capaz de intercalarse en el ADN. Las manchas observadas en el transiluminador corresponden a los fragmentos de ADN.

El revelado del gel no permite obtener resultados cuantitativos pero la técnica de PCR convencional se llevó a cabo en los compuestos de las familias 1 y 3 a fin de seleccionar los compuestos que serían estudiados luego mediante PCR cuantitativa (qPCR).

La qPCR es altamente sensible y específica y permite la cuantificación del gen expresado y no requiere realizar una electroforesis ya que amplifica y cuantifica el ADN simultáneamente. En qPCR se utilizan especies fluorescentes que, en nuestros ensayos, fueron las sondas TaqMan. Estas sondas contienen entre 20-30 nucleótidos y se encuentran marcadas con un fluoróforo (FAM o $\mathrm{VIC}$ ) en el extremo 5' y un amortiguador o quencher (TAMRA) en el extremo 3', que absorbe la energía de excitación del fluoróforo. Cuando se produce la amplificación del ADN, la sonda se degrada por acción de la ADN polimerasa lo que permite la liberación del fluoróforo. ${ }^{124}$ Todo este proceso está resumido en la figura 4.6.

\footnotetext{
${ }^{123}$ Westermeier, R. Electrophoresis in Practice: a Guide to Methods and Applications of DNA and Protein Separations 1997, 2a. ed., VCH Press Weinheim.

${ }_{124}$ StepOne Plus Real Time PCR System User Training. Applied Biosystems by Life Technologies.
} 


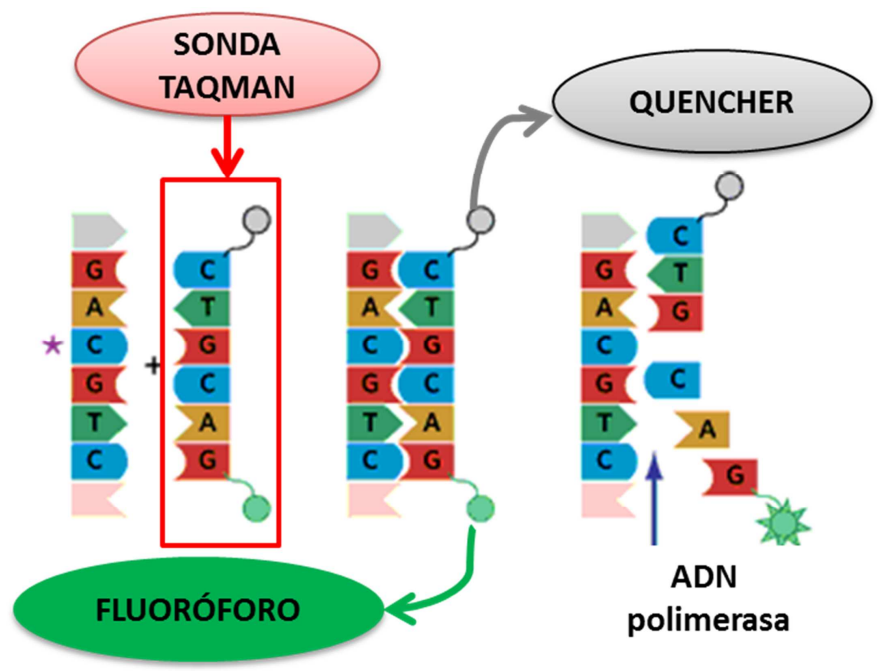

Figura 4.6. Funcionamiento de la sonda Taqman.

A continuación se describen las fases de la técnica qPCR:

a) Fase lineal, caracterizada porque la fluorescencia no puede ser detectada. En esta etapa se calcula la línea base.

b) Fase exponencial, que empieza en el momento en el que la fluorescencia alcanza un umbral que supera el mínimo del medio circundante (aproximadamente 10 veces la línea base) y continúa durante el período de amplificación óptima de la PCR.

c) Fase de meseta, en la que la polimerasa alcanza su punto de saturación y la fluorescencia se mantiene constante.

Para el análisis de estas curvas (véase la figura 4.7) se fija un umbral con un nivel de fluorescencia particular, que se denomina $\mathrm{C}_{\mathrm{T}}$ y es el que permite cuantificar la expresión génica. ${ }^{125} \mathrm{El}$ valor de $\mathrm{C}_{\mathrm{T}}$ es inversamente proporcional a la cantidad de $A D N .{ }^{126}$

\footnotetext{
${ }^{125}$ Kubista, M.; Andrade, J.M.; Bengtsson, M.; Forootan, A.; Jonak, J.; Lind, K., et al. Mol. Aspects Med. 2006, 27, 95-125.

${ }^{126}$ Larionov, A.; Krause, A.; Miller, W. BMC Bioinformatics 2005, 6, 62-78.
} 


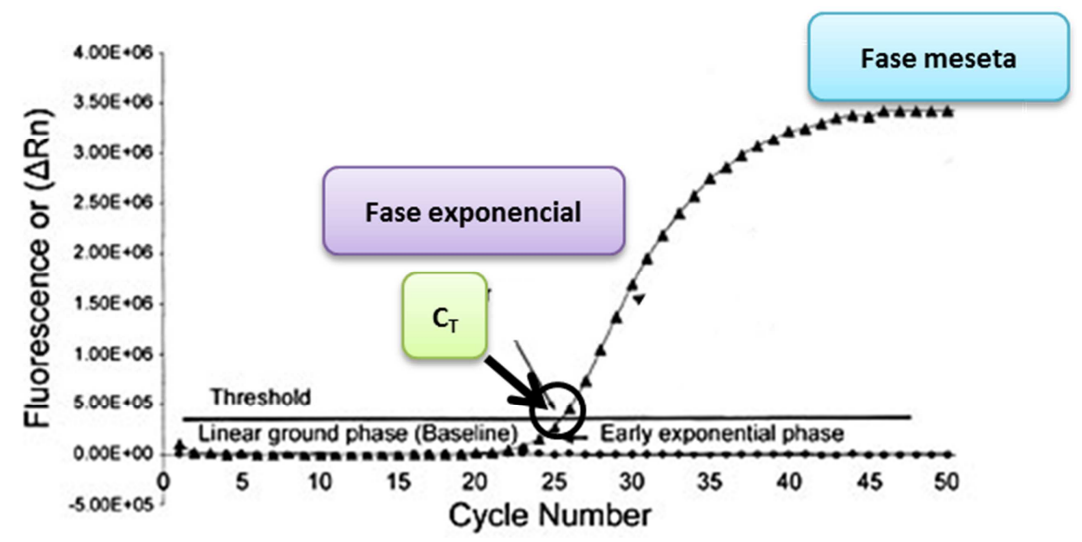

Figura 4.7. Fases de la qPCR.

La eficiencia de una PCR es la capacidad de la reacción de duplicar el número de copias de las cadenas de ADN en cada ciclo. ${ }^{127}$ La eficiencia se determina con una curva de calibración realizada con diluciones seriadas de una concentración de ADN conocida y sus valores de $C_{T}$. La eficiencia se calcula a partir de la pendiente de la curva de calibrado según la siguiente expresión matemática:

$$
\mathrm{E}=10^{[-1 / \text { pendiente }]}-1
$$

La cuantificación de ADN puede ser absoluta o relativa. En el caso de esta Tesis se optó por una cuantificación relativa. Esta técnica compara los niveles de expresión de un gen en estudio o diana con uno o más genes de referencia. En nuestro caso el gen de referencia era $\beta$-Actina.

Para realizar esta cuantificación, se utiliza la diferencia en los valores $\mathrm{C}_{\mathrm{T}}$ que se emplea cuando se quiere comparar la expresión de un determinado gen en células que han recibido un determinado tratamiento respecto a las células sin tratar.

Existen dos modelos matemáticos diferentes dependiendo de si la eficiencia de la reacción es la misma o no para el gen a determinar (diana) y el gen de referencia:

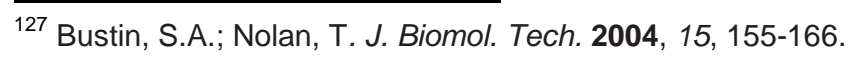


A) Si la eficiencia es la misma se normaliza el $\mathrm{C}_{\mathrm{T}}$ del gen diana con respecto al gen endógeno.

$$
\left.\Delta \mathrm{C}_{\mathrm{T}}=\mathrm{C}_{\mathrm{T}}(\text { gen diana })-\mathrm{C}_{\mathrm{T}} \text { (gen endógeno }\right)
$$

Posteriormente se compara la muestra tratada con respecto al control.

$$
\Delta \Delta \mathrm{C}_{\mathrm{T}}=\Delta \mathrm{C}_{\mathrm{T}} \text { (muestra tratada) }-\Delta \mathrm{C}_{\mathrm{T}} \text { (control) }
$$

Finalmente se calcula el índice $R Q$, que indica las veces que se expresa el gen específico en una muestra tratada en comparación a la muestra control. ${ }^{128}$

$$
\mathrm{RQ}=2^{-\Delta \Delta \mathrm{C}_{\mathrm{T}}}
$$

B) Si la eficiencia no es la misma, el valor de $R Q$ se calcula según la siguiente ecuación matemática:

$$
\mathrm{RQ}=\frac{\text { muestra normalizada }}{\text { control normalizado }}=\frac{\frac{\text { ADN(gen diana)muestra }}{\text { ADN(gen endógeno)muestra }}}{\frac{\text { ADN(gen diana)control }}{\text { ADN(gen endógeno)control }}}
$$

La cantidad de ADN se obtiene de extrapolar el valor de $\mathrm{C}_{\mathrm{T}}$ en la recta de calibrado realizada para el cálculo de la eficiencia del gen específico. ${ }^{124}$

$$
\begin{gathered}
\mathrm{C}_{\mathrm{T}}=\mathrm{a} \times \log (\mathrm{ADN})+\mathrm{b} \\
\mathrm{ADN}=10^{\frac{\mathrm{C}_{\mathrm{T}}-\mathrm{b}}{\mathrm{a}}}
\end{gathered}
$$

Para realizar estos ensayos se incubaron los compuestos seleccionados de cada familia con células de la línea tumoral HT-29 durante 48 horas.

\subsubsection{Efecto sobre la secreción de la proteína VEGF-A $A_{165}$ en HT-29}

La proteína secretada en el medio de cultivo fue medida mediante el ensayo ELISA (Enzyme-Linked Immuno-Sorbent Assay). En la figura 4.8 se muestra la secuencia del ensayo ELISA. El ensayo se efectúa con un

${ }^{128}$ (a) Bustin, S. A.; Benes, V.; Garson, J. A.; Hellemans, J.; Huggett, J.; Kubista, M.; Mueller, R.; Nolan, T.; Pfaffl, M. W.; Shipley, G. L.; Vandesompele, J.; Wittwer, C. T. Clin. Chem. 2009, 55, 611-622. (b) Willems, E.; Leyns L.; Vandesompele, J. Anal. Biochem., 2008, 379, 127-129. 
anticuerpo policlonal que reconoce la isoforma 165 del VEGF-A humano y que se encuentra inmovilizado sobre un soporte sólido (figura 4.8, parte 1). La proteína VEGF del medio de cultivo, que actúa de antígeno, se une al anticuerpo formándose un complejo anticuerpo-antígeno (figura 4.8, parte 2).

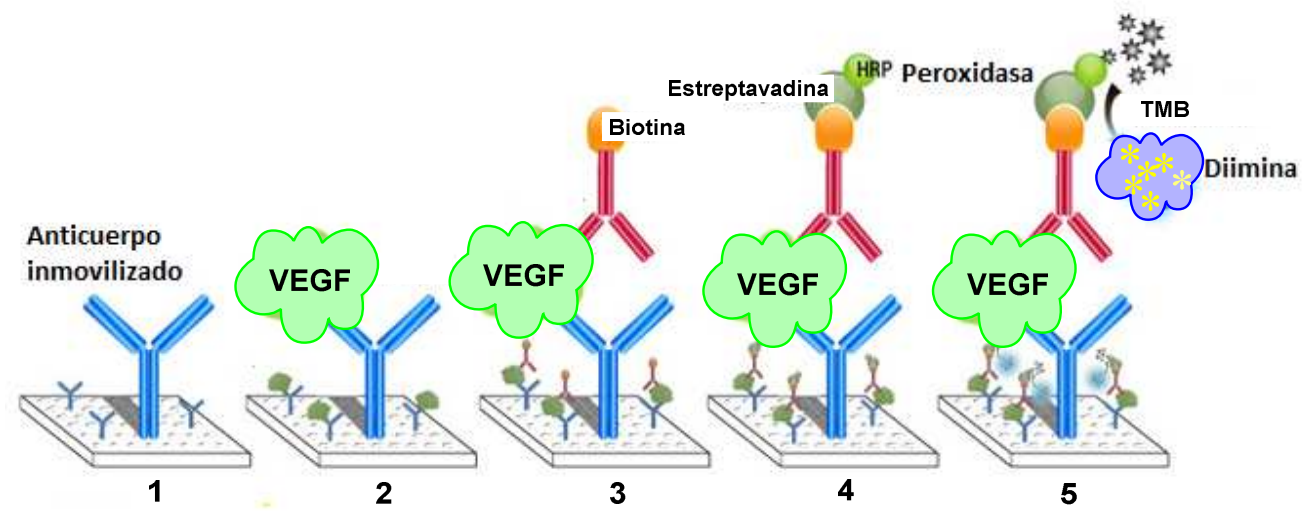

Figura 4.8. Fases del ensayo ELISA. ${ }^{129}$

Luego se añade un anticuerpo monoclonal biotinilado que reconoce a la proteína VEGF originándose una estructura tipo sándwich (figura 4.8, parte 3). En el siguiente paso se adiciona una enzima peroxidasa (HRP) conjugada con estreptavidina (figura 4.8, parte 4). Finalmente se añade una disolución de tetrametilbencidina (TBM) incolora que es oxidada por la HRP a una diimina de color amarillo (figura 4.8, parte 5, véase también el esquema 4.2). La concentración de VEGF en la muestra es proporcional a la medida de absorbancia de la disolución coloreada obtenida.

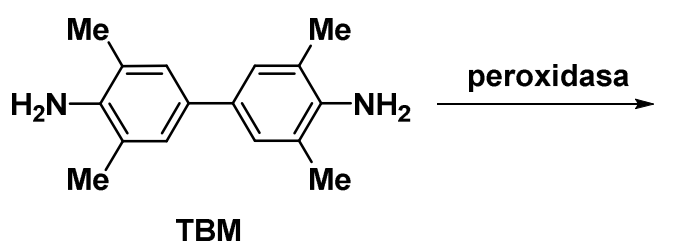

TBM<smiles>CC1=CC(=C2C=C(C)C(=N)C(C)=C2)C=C(C)C1=N</smiles>

Diimina

Esquema 4.2. Reacción de oxidación del TBM.

\footnotetext{
${ }^{129}$ Figura modificada de http://www.epitomics.com/products/product_info/1257
} 
Para realizar estos ensayos se incubaron los compuestos seleccionados de cada familia con células de la línea tumoral HT-29 durante 48 horas. Los valores obtenidos se compararon con un control (células tratadas con DMSO). 


\subsection{Evaluación biológica de los compuestos de la familia 1}

La familia 1 está constituida por derivados de colchicina que provienen de la sustitución formal del grupo acetilo de la colchicina por grupos a-aminoacilo derivados de aminoácidos.

Tal y como se ha hecho en el apartado de síntesis, esta familia se agrupará en derivados que contienen L- $\alpha$-aminoácidos, en derivados que contienen D-a-aminoácidos y en derivados que contienen los péptidos Gly-Gly y Gly-GlyGly.

\subsubsection{Citotoxicidad}

Los valores de citotoxicidad de los compuestos sintetizados se midieron en las líneas celulares tumorales HT-29 (adenocarcinoma de colon) y MCF-7 (adenocarcinoma de mama). También se midieron los valores de citotoxicidad en la línea no tumoral HEK-293 (células embrionarias de riñón).

En la figura 4.9 se indican las estructuras de los derivados con L-a-aminoácidos.<smiles></smiles>

$38 \mathrm{R}=\mathrm{H}, \mathrm{R}^{\prime}=\mathrm{H}$ $39 \mathrm{R}=\mathrm{CH}_{3}, \mathrm{R}^{\prime}=\mathrm{H}$ $40 \mathrm{R}=\mathrm{CH}\left(\mathrm{CH}_{3}\right)_{2}, \mathrm{R}^{\prime}=\mathrm{H}$ $41 \mathrm{R}=\mathrm{CH}_{2} \mathrm{CH}\left(\mathrm{CH}_{3}\right)_{2}, \mathrm{R}=\mathrm{H}$ $42 \mathrm{R}=\mathrm{CH}_{2} \mathrm{Ph}, \mathrm{R}^{\prime}=\mathrm{H}$ $43 \mathrm{R}, \mathrm{R}^{\prime}=\left(\mathrm{CH}_{2}\right)_{4}$ $44 \mathrm{R}=\mathrm{CH}_{2} \mathrm{OH}, \mathrm{R}^{\prime}=\mathrm{H}$ $45 \mathrm{R}=\mathrm{CH}(\mathrm{OH}) \mathrm{CH}_{3}, \mathrm{R}^{\prime}=\mathrm{H}$ $46 \mathrm{R}=\mathrm{CH}_{2}\left(\mathrm{C}_{6} \mathrm{H}_{4} \mathrm{OH}\right), \mathrm{R}^{\prime}=\mathrm{H}$ $47 \mathrm{R}=\left(\mathrm{CH}_{2}\right)_{2} \mathrm{SCH}_{3}, \mathrm{R}^{\prime}=\mathrm{H}$<smiles>[R]NC([R])C([R])NC(=O)[C@H]1CCc2cc(OC)c(OC)c(OC)c2-c2ccc(OC)cc21</smiles>

$48 \mathrm{R}=\mathrm{H}, \mathrm{R}^{\prime}=\mathrm{H}$ $49 \mathrm{R}=\mathrm{CH}_{3}, \mathrm{R}^{\prime}=\mathrm{H}$ $50 \mathrm{R}=\mathrm{CH}\left(\mathrm{CH}_{3}\right)_{2}, \mathrm{R}^{\prime}=\mathrm{H}$ $51 \mathrm{R}=\mathrm{CH}_{2} \mathrm{CH}\left(\mathrm{CH}_{3}\right)_{2}$, $\mathrm{R}^{\prime}=\mathrm{H}$ $52 \mathrm{R}=\mathrm{CH}_{2} \mathrm{Ph}, \mathrm{R}^{\prime}=\mathrm{H}$ $53 \mathrm{R}, \mathrm{R}^{\prime}=\left(\mathrm{CH}_{2}\right)_{4}$ $54 \mathrm{R}=\mathrm{CH}_{2} \mathrm{OH}, \mathrm{R}^{\prime}=\mathrm{H}$ $55 \mathrm{R}=\mathrm{CH}(\mathrm{OH}) \mathrm{CH}_{3}, \mathrm{R}^{\prime}=\mathrm{H}$ $56 \mathrm{R}=\mathrm{CH}_{2}\left(\mathrm{C}_{6} \mathrm{H}_{4} \mathrm{OH}\right), \mathrm{R}^{\prime}=\mathrm{H}$ $57 \mathrm{R}=\left(\mathrm{CH}_{2}\right)_{2} \mathrm{SCH}_{3}, \mathrm{R}^{\prime}=\mathrm{H}$

Figura 4.9. Estructuras de derivados con L- $\alpha$-aminoácidos. 
Los valores de citotoxicidad y los coeficientes de selectividad de estos derivados se muestran en la tabla 4.1.

Tabla 4.1. Citotoxicidad y coeficientes de selectividad de L-a-aminoácidos.

\begin{tabular}{|c|c|c|c|c|c|}
\hline \multirow[t]{2}{*}{ Compuesto } & \multicolumn{3}{|c|}{$\mathrm{IC}_{50} \pm \mathrm{SD}(\mathrm{nM})$} & \multicolumn{2}{|c|}{$\begin{array}{c}\text { Coeficientes de } \\
\text { selectividad }\end{array}$} \\
\hline & HT-29 & MCF-7 & HEK-293 & $\alpha^{*}$ & $\beta^{* *}$ \\
\hline Colchicina & $50 \pm 3$ & $12 \pm 7$ & $5 \pm 1$ & 0,10 & 0,4 \\
\hline 3 & $12,4 \pm 1,5$ & $15,5 \pm 1,5$ & $25,1 \pm 0,3$ & 2,0 & 1,6 \\
\hline 38 & $8,5 \pm 0,8$ & $8,8 \pm 0,9$ & $13,6 \pm 0,5$ & 1,6 & 1,6 \\
\hline 39 & $139 \pm 25$ & $37 \pm 4$ & $45 \pm 7$ & 0,3 & 1,2 \\
\hline 40 & $61 \pm 5$ & $1,2 \pm 0,1$ & $0,8 \pm 0,1$ & 0,01 & 0,7 \\
\hline 41 & $238 \pm 21$ & $1600 \pm 300$ & $240 \pm 30$ & 1,0 & 0,15 \\
\hline 42 & $100 \pm 13$ & $1150 \pm 40$ & $15 \pm 4$ & 0,15 & 0,01 \\
\hline 43 & $80 \pm 3$ & $44 \pm 6$ & $150 \pm 10$ & 1,9 & 3,4 \\
\hline 44 & $62 \pm 3$ & $67,6 \pm 1,4$ & $63,4 \pm 0,3$ & 1,0 & 0,9 \\
\hline 45 & $100 \pm 5$ & $161 \pm 11$ & $170 \pm 40$ & 1,7 & 1,1 \\
\hline 46 & $716,9 \pm 0,5$ & $300 \pm 30$ & $2600 \pm 300$ & 3,6 & 8,7 \\
\hline 47 & $81 \pm 3$ & $160 \pm 30$ & $150 \pm 12$ & 1,9 & 0,9 \\
\hline 48 & $94 \pm 6$ & $67 \pm 14$ & $300 \pm 30$ & 3,2 & 4,5 \\
\hline 49 & $41 \pm 3$ & $55 \pm 3$ & $131,0 \pm 0,5$ & 3,2 & 2,4 \\
\hline 50 & $84 \pm 8$ & $85 \pm 12$ & $398 \pm 25$ & 4,7 & 4,7 \\
\hline 51 & $278 \pm 14$ & $400 \pm 32$ & $980 \pm 60$ & 3,5 & 2,5 \\
\hline 52 & $181 \pm 43$ & $240 \pm 51$ & $470 \pm 30$ & 2,6 & 2,0 \\
\hline 53 & $23 \pm 4$ & $3,3 \pm 0,3$ & $790 \pm 30$ & 34,4 & 239 \\
\hline 54 & $166 \pm 7$ & $1140 \pm 60$ & $2900 \pm 80$ & 17,5 & 2,5 \\
\hline 55 & $138 \pm 11$ & $340 \pm 40$ & $1510 \pm 6$ & 10,9 & 4,4 \\
\hline
\end{tabular}




\begin{tabular}{|c|c|c|c|c|c|}
\hline 56 & $116 \pm 20$ & $86 \pm 18$ & $1600 \pm 100$ & 13,8 & 18,6 \\
\hline 57 & $50 \pm 5$ & $139 \pm 19$ & $272 \pm 24$ & 5,4 & 2,0 \\
\hline
\end{tabular}

$\alpha=I_{50}(H E K-293) / I C_{50}(H T-29) . " ~ \beta=I C_{50}(H E K-293) / I C_{50}(M C F-7)$.

Todos los compuestos de la familia 1 presentan actividad nanomolar en la línea celular HT-29. Además los compuestos 3, 38, 40, 42, 43, 44, 45, 47, 48, 49, 50, 53 y 57 presentan un $\mathrm{IC}_{50}$ igual o inferior a $100 \mathrm{nM}$. De entre estos cabe destacar a los compuestos $3,38,49$ y 53 que exhiben un $I_{50}$ inferior al de la colchicina.

En lo referente a la línea celular MCF-7, los compuestos $38,39,40,43,44$, 48, 49, 50, 53 y 56 muestran unos valores de $\mathrm{IC}_{50}$ menores a $100 \mathrm{nM}$. Hay que resaltar a los compuestos $\mathbf{3 8 , 4 0}$ y $\mathbf{5 3}$ que presentan un $\mathrm{IC}_{50}$ inferior a la colchicina.

Todos los valores de selectividad, a excepción de los compuestos $\mathbf{4 0}$ (en HT-29) y 42 (en MCF-7), son mayores que los de la colchicina, lo que proporcionaría a estos compuestos un mayor margen de seguridad terapéutica.

En la figura 4.10 se indican las estructuras de los derivados con D-a-aminoácidos.<smiles>[R]O[R16](=O)C([R])C(=O)N[C@H]1CCc2cc(OC)c(OC)c(OC)c2-c2ccc(OC)c(=O)cc21</smiles>

$58 \mathrm{R}=\mathrm{CH}\left(\mathrm{CH}_{3}\right)_{2}, \mathrm{R}^{\prime}=\mathrm{H}$

$59 \mathrm{R}=\mathrm{CH}_{2} \mathrm{CH}\left(\mathrm{CH}_{3}\right)_{2}, \mathrm{R}^{\prime}=\mathrm{H}$

$60 \mathrm{R}=\mathrm{CH}_{2} \mathrm{Ph}, \mathrm{R}^{\prime}=\mathrm{H}$

$61 \mathrm{R}, \mathrm{R}^{\prime}=\left(\mathrm{CH}_{2}\right)_{4}$ $62 \mathrm{R}=\mathrm{CH}_{2}\left(\mathrm{C}_{6} \mathrm{H}_{4} \mathrm{OH}\right), \mathrm{R}^{\prime}=\mathrm{H}$<smiles>[R]CNC([R])C(=O)N[C@H]1CCc2cc(OC)c(OC)c(OC)c2-c2ccc(OC)c(=O)cc21</smiles>

$63 \mathrm{R}=\mathrm{CH}\left(\mathrm{CH}_{3}\right)_{2}, \mathrm{R}^{\prime}=\mathrm{H}$ $64 \mathrm{R}=\mathrm{CH}_{2} \mathrm{CH}\left(\mathrm{CH}_{3}\right)_{2}, \mathrm{R}^{\prime}=\mathrm{H}$ $65 \mathrm{R}=\mathrm{CH}_{2} \mathrm{Ph}, \mathrm{R}^{\prime}=\mathrm{H}$ $66 \mathrm{R}, \mathrm{R}^{\prime}=\left(\mathrm{CH}_{2}\right)_{4}$ $67 \mathrm{R}=\mathrm{CH}_{2}\left(\mathrm{C}_{6} \mathrm{H}_{4} \mathrm{OH}\right), \mathrm{R}^{\prime}=\mathrm{H}$

Figura 4.10. Estructuras de derivados de D-a-aminoácidos. 
Los valores de citotoxicidad y los coeficientes de selectividad de estos derivados se resumen a continuación.

Tabla 4.2. Citotoxicidad y coeficientes de selectividad de D-a-aminoácidos.

\begin{tabular}{|c|c|c|c|c|c|}
\hline \multirow[t]{2}{*}{ Producto } & & $C_{50} \pm S D(n M$ & & \multicolumn{2}{|c|}{$\begin{array}{c}\text { Coeficientes } \\
\text { de } \\
\text { selectividad }\end{array}$} \\
\hline & HT-29 & MCF-7 & HEK-293 & $\alpha^{*}$ & $\beta^{* *}$ \\
\hline Colchicina & $50 \pm 3$ & $12 \pm 7$ & $5 \pm 1$ & 0,10 & 0,4 \\
\hline 58 & $230 \pm 10$ & $30 \pm 4$ & $2000 \pm 1000$ & 8,7 & 66,7 \\
\hline 59 & $125 \pm 7$ & $5,5 \pm 1,1$ & $360 \pm 30$ & 2,9 & 65,5 \\
\hline 60 & $158 \pm 24$ & $1920 \pm 30$ & $660 \pm 40$ & 4,2 & 0,3 \\
\hline 61 & $114,6 \pm 2,3$ & $63 \pm 12$ & $110 \pm 10$ & 1,0 & 1,8 \\
\hline 62 & $458 \pm 3$ & $790 \pm 70$ & $1660 \pm 110$ & 3,6 & 2,1 \\
\hline 63 & $295 \pm 38$ & $80 \pm 10$ & $20 \pm 3$ & 0,07 & 0,25 \\
\hline 64 & $31 \pm 3$ & $3,3 \pm 0,3$ & $390 \pm 30$ & 12,6 & 118,2 \\
\hline 65 & $10,3 \pm 2,5$ & $82,0 \pm 2,0$ & $350 \pm 30$ & 34,0 & 4,3 \\
\hline 66 & $112,1 \pm 2,1$ & $88 \pm 21$ & $690 \pm 50$ & 6,2 & 7,8 \\
\hline 67 & $460 \pm 10$ & $1100 \pm 300$ & $3400 \pm 300$ & 7,4 & 3,1 \\
\hline
\end{tabular}

Todos los compuestos exhiben actividad nanomolar en la línea celular $\mathrm{HT}$-29. Además los compuestos 64 y 65 presentan un $\mathrm{IC}_{50}$ inferior al de la colchicina.

En cuanto a la línea celular MCF-7, los compuestos 58, 59, 61, 63, 64, 65 y 66 muestran un $\mathrm{IC}_{50}$ inferior a $100 \mathrm{nM}$. De estos cabe destacar a los compuestos 59 y 64 que presentan un $\mathrm{IC}_{50}$ inferior al producto natural. 
En general, los índices de selectividad de estos derivados son mejores que los de la colchicina, con excepción de los compuestos 60 (en MCF-7) y 63 (en ambas líneas celulares).

En figura 4.11 se indican las estructuras de los derivados con Gly-Gly (68 y 70) y Gly-Gly-Gly (69 y 71).<smiles>[R]NCC(=O)NCC(=O)N[C@H]1CCc2cc(OC)c(OC)c(OC)c2-c2ccc(OC)c(=O)cc21</smiles>

$68 \mathrm{R}=\mathrm{Boc}$ $69 \mathrm{R}=\mathrm{COCH}_{2} \mathrm{NHBoc}$<smiles>[R]NCC(=O)NCC(=O)N[C@H]1CCc2cc(OC)c(OC)c(OC)c2-c2ccc(OC)c(=O)cc21</smiles>

$70 \mathrm{R}=\mathrm{H}$ $71 \mathrm{R}=\mathrm{COCH}_{2} \mathrm{NH}_{2}$

Figura 4.11. Estructuras de los derivados con Gly-Gly y Gly-Gly-Gly.

Los valores de citotoxicidad y los coeficientes de selectividad de estos derivados se muestran en la tabla 4.3.

Tabla 4.3. Citotoxicidad y coeficientes de selectividad de los derivados con Gly-Gly y Gly-Gly-Gly.

\begin{tabular}{|c|c|c|c|c|c|}
\hline \multirow[t]{2}{*}{ Producto } & \multicolumn{3}{|c|}{$I_{50} \pm S D(n M)$} & \multicolumn{2}{|c|}{$\begin{array}{c}\text { Coeficientes } \\
\text { de } \\
\text { selectividad }\end{array}$} \\
\hline & HT-29 & MCF-7 & HEK-293 & $\alpha^{*}$ & $\beta^{\star \star}$ \\
\hline Colchicina & $50 \pm 3$ & $12 \pm 7$ & $5 \pm 1$ & 0,10 & 0,4 \\
\hline 68 & $39 \pm 5$ & $51,9 \pm 1,2$ & $150 \pm 40$ & 3,9 & 2,9 \\
\hline 69 & $129 \pm 8$ & $341 \pm 17$ & $415 \pm 24$ & 3,2 & 1,2 \\
\hline 70 & $531 \pm 23$ & $2400 \pm 210$ & $810 \pm 40$ & 1,5 & 0,3 \\
\hline 71 & $480 \pm 50$ & $460 \pm 60$ & $610 \pm 60$ & 1,3 & 1,3 \\
\hline
\end{tabular}

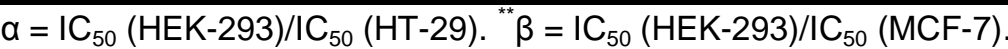


En general, estos compuestos presentan valores de $\mathrm{IC}_{50}$ en el rango nanomolar y, aunque son menos citotóxicos que la colchicina, a excepción del compuesto 68 en la línea tumoral HT-29, exhiben mejores márgenes de seguridad terapéutica. También merece la pena mencionar que los derivados 68 y 69, con el grupo amino terminal protegido como $t$-butiloxicarbonilo, son más citotóxicos que los derivados 70 y 71 que presentan el grupo amino terminal libre.

\subsubsection{Efecto sobre el ensamblaje de microtúbulos. Concentración crítica de tubulina $(\mathrm{Cr})$}

Para todos los compuestos de la familia 1 se determinó la concentración crítica de tubulina en presencia de un tampón de polimerización de glicerol (GAB). En la tabla 4.4 se indican los valores de concentración crítica de tubulina obtenidos en presencia de los derivados con L-a-aminoácidos. Los valores obtenidos se comparan con el de la muestra control (DMSO) y con los de la podofilotoxina y la colchicina, que son agentes desestabilizantes de los microtúbulos. Todos los compuestos se ensayaron a una concentración de $27,5 \mu \mathrm{M}$ y la tubulina se utilizó a una concentración de $25 \mu \mathrm{M}$.

Tabla 4.4. Concentraciones críticas para los derivados con L-a-aminoácidos.

\begin{tabular}{|c|c|}
\hline Compuesto & $\mathrm{Cr}(\mu \mathrm{M})$ \\
\hline Control & $8,0 \pm 0,2$ \\
\hline Podofilotoxina & $23,3 \pm 0,8$ \\
\hline Colchicina & $24,4 \pm 0,1$ \\
\hline 38 & $22,9 \pm 0,1$ \\
39 & $24,0 \pm 0,4$ \\
40 & $21,2 \pm 1,7$ \\
41 & $17,4 \pm 4,8$ \\
\hline
\end{tabular}




\begin{tabular}{c|c}
\hline 42 & $21,9 \pm 0,1$ \\
43 & $13,1 \pm 0,7$ \\
44 & $23,38 \pm 0,02$ \\
45 & $22,6 \pm 0,6$ \\
46 & $21,2 \pm 0,5$ \\
47 & $24,2 \pm 0,4$ \\
\hline 48 & $22,94 \pm 0,05$ \\
\hline 49 & $22,8 \pm 1,0$ \\
\hline 50 & $22,8 \pm 0,9$ \\
\hline 51 & $21,7 \pm 2,4$ \\
\hline 52 & $23,5 \pm 0,5$ \\
\hline 53 & $20,6 \pm 0,7$ \\
\hline 54 & $23,2 \pm 0,4$ \\
\hline 55 & $22,8 \pm 0,5$ \\
\hline 56 & $22,3 \pm 0,7$ \\
\hline 57 & $23,30 \pm 0,04$ \\
\hline
\end{tabular}

La mayoría de derivados exhiben valores de concentración crítica de tubulina mayores que el obtenido en la situación control, por lo que podría concluirse que son agentes desestabilizantes de los microtúbulos. Concretamente, hay que destacar los ligandos 39, 44, 47, 52, 54 y 57 que muestran unos valores de Cr próximos al de la colchicina $(24,4 \mu \mathrm{M})$ y al de la podofilotoxina $(23,3 \mu \mathrm{M})$.

Los valores de concentración crítica de los derivados con D-a-aminoácidos se muestran en la tabla 4.5 
Tabla 4.5. Concentraciones críticas para los derivados con D- $\alpha$-aminoácidos.

\begin{tabular}{|c|c|}
\hline Compuesto & Cr $(\mu \mathrm{M})$ \\
\hline Control & $8,0 \pm 0,2$ \\
\hline Podofilotoxina & $23,3 \pm 0,8$ \\
\hline Colchicina & $24,4 \pm 0,1$ \\
\hline 58 & $22,1 \pm 0,6$ \\
\hline 59 & $21,3 \pm 1,7$ \\
60 & $21,2 \pm 0,1$ \\
61 & $16,0 \pm 1,1$ \\
62 & $21,9 \pm 0,2$ \\
63 & $20,9 \pm 2,6$ \\
64 & $21,8 \pm 0,1$ \\
65 & $22,3 \pm 0,3$ \\
66 & $14,1 \pm 0,2$ \\
67 & $20,1 \pm 0,2$ \\
\hline
\end{tabular}

Los valores de concentración crítica de la serie de D-a-aminoácidos son menores que para la serie de L-a-aminoácidos. Aun así, la mayoría de compuestos presentan un valor de Cr mayores que el obtenido en la situación control, por lo que se podría concluir que alteran la dinámica de microtúbulos provocando la desestabilización de los mismos.

Los valores de concentración crítica para los derivados con Gly-Gly y GlyGly-Gly se muestran en la tabla 4.6. 
Tabla 4.6. Concentraciones críticas para los derivados con Gly-Gly y Gly-Gly-Gly.

\begin{tabular}{c|c|}
\hline Producto & $\operatorname{Cr}(\mu \mathrm{M})$ \\
\hline Control & $8,0 \pm 0,2$ \\
\hline Podofilotoxina & $23,3 \pm 0,8$ \\
\hline Colchicina & $24,4 \pm 0,1$ \\
68 & $5,9 \pm 2,5$ \\
69 & $18,3 \pm 0,3$ \\
70 & $23,6 \pm 0,7$ \\
71 & $22,7 \pm 0,1$ \\
\hline
\end{tabular}

Todos los derivados, a excepción del compuesto 68, aumentan la concentración crítica respecto al control, por lo que se podrían clasificar como agentes desestabilizantes de microtúbulos. En esta serie hay que destacar a los compuestos $\mathbf{7 0}$ y $\mathbf{7 1}$ que presentan un valor de concentración crítica similar al de la podofilotoxina.

Algunos de los derivados anteriores fueron seleccionados para representar gráficamente sus efectos en la polimerización in vitro de tubulina obtenidos mediante turbidimetría. Como puede apreciarse en la gráfica 4.1, los compuestos 39 y 55, son capaces de inhibir completamente la polimerización mostrando un comportamiento similar al de la colchicina. Sin embargo, los derivados de colchicina 41, 43, 61, 66 y 69, no son capaces de inhibir por completo el proceso de polimerización ya que el valor de absorbancia en la fase estacionaria no está cercano a cero sino ligeramente por debajo del valor medido en la situación control. Además, los derivados 41 y 43 ralentizan el proceso de nucleación unos 5 minutos respecto del control, 61 y 66 lo ralentizan hasta unos 10 minutos y por último, 69 ralentiza el proceso unos 15 minutos. 


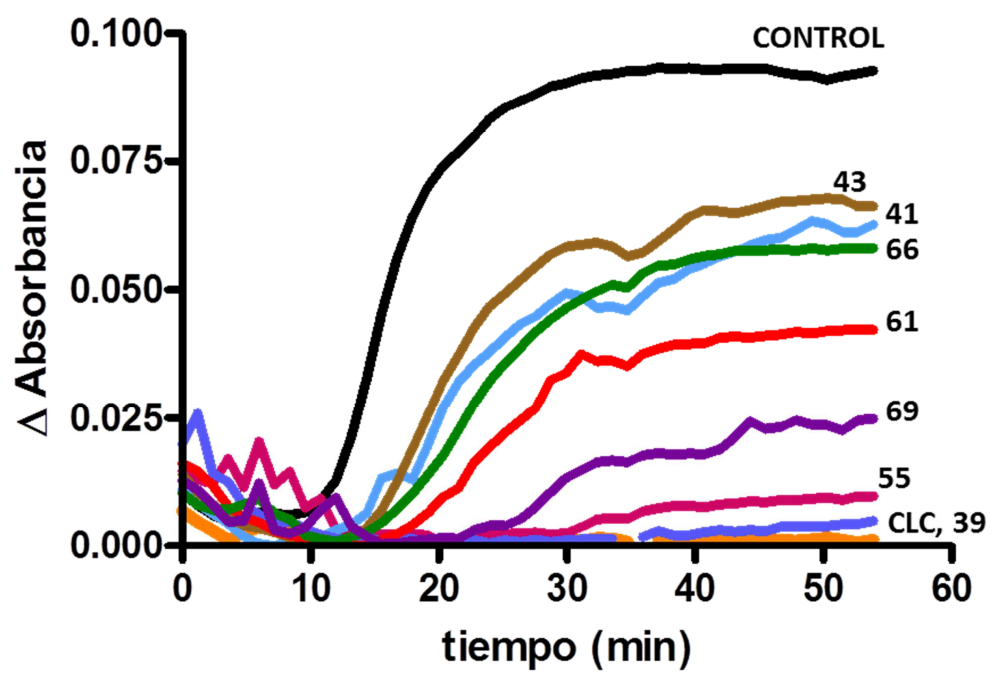

Gráfica 4.1. Resultados de la concentración crítica de tubulina. Las líneas representan la turbidimetría de la polimerización para la tubulina (línea negra), colchicina (línea naranja, CLC), 39 (línea azul), 41 (línea azul clara), 43 (línea marrón), 55 (línea fucsia), 61 (línea roja), 66 (línea verde) y 69 (línea morada).

Para cuantificar cómo afectan estos compuestos a la fase de nucleación y de elongación, calculamos el valor de $\mathrm{It}_{50}$ que se define como el tiempo que se necesita para alcanzar el $50 \%$ de la polimerización. Los $I_{50}$ de los compuestos $41,43,61,66$ y 69 se muestran en la tabla 4.7 .

Tabla 4.7. Valores de $\mathrm{It}_{50}$ para los derivados de aminoácidos.

\begin{tabular}{c|c|ccccc}
\hline Prod. & Control & 41 & 43 & 61 & 66 & 69 \\
\hline $\mathrm{It}_{50}(\min )$ & $16,5 \pm 0,8$ & $29 \pm 9$ & $21,6 \pm 0,6$ & $25,9 \pm 0,7$ & $24,4 \pm 0,4$ & $32,31 \pm 0,10$ \\
\hline
\end{tabular}

Como puede observarse, los $\mathrm{It}_{50}$ de los compuestos 41, 43, 61, 66 y 69 son mayores que los que se obtienen en la prueba de control.

Los compuestos que presenten un valor comparativamente alto de concentración crítica con respecto al control (menor absorbancia de la fase estacionaria) y un mayor valor de $\mathrm{It}_{50}$ con respecto al control (aumento del 
tiempo necesario para la nucleación y elongación) se pueden considerar inhibidores parciales de la polimerización de la tubulina.

\subsubsection{Efecto sobre la expresión de los genes VEGF, hTERT y c-Myc en HT-29}

Para la medición de la expresión de genes se seleccionaron aquellos compuestos que tuviesen:

a) Un valor de $\mathrm{IC}_{50}$ inferior a $150 \mathrm{nM}$ en la línea tumoral HT-29.

b) Mayor coeficiente de selectividad que la colchicina en dicha línea tumoral.

Los compuestos seleccionados fueron $38,43,48,49,50,53,55,56,57,61$, 64, 65, 68 y 69. Las células HT-29 fueron incubadas durante $48 \mathrm{~h}$ con los diferentes compuestos a concentraciones próximas a su $I_{50}$. En primer lugar se realizó una PCR convencional seguida de electroforesis para seleccionar los compuestos que pasarían a ser investigados mediante qPCR. En la figura 4.12 se muestran los resultados obtenidos del revelado del gel. El control (C) corresponde a células incubadas en presencia de DMSO. La acción de la colchicina (CLC) se midió a una concentración de $40 \mathrm{nM}$ y la de la $\mathrm{N}$-desacetilcolchina (3) a una concentración de $12 \mathrm{nM}$.

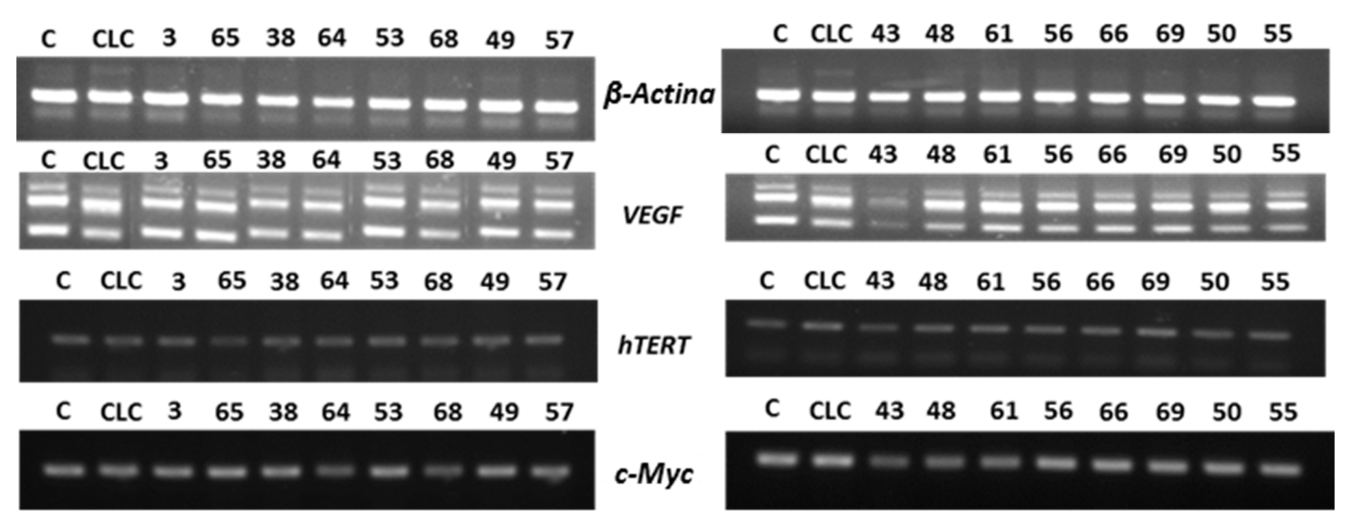

Figura 4.12. Ampliación de $\beta$-Actina, VEGF, hTERT y $c$-Myc mediante PCR convencional. 
Como se puede observar en la figura anterior, los compuestos 64 y 68 inhiben principalmente la expresión del gen $c-M y c$ (menor intensidad de la mancha), mientras que los compuestos 38 y 68 son capaces de inhibir parcialmente la expresión del gen VEGF. El derivado 43 inhibe la expresión de los tres genes estudiados. Por ello estos cuatro compuestos se seleccionaron para su estudio mediante qPCR.

Para la medición de la expresión de los genes mediante qPCR los compuestos 38, 43, 64 y 68 fueron incubados nuevamente con células HT-29, durante $48 \mathrm{~h}$, en las concentraciones indicadas en la figura 4.13. La colchicina, cuyo efecto sobre la expresión de los genes se midió a modo de comparación, se empleó en concentración de 40 nM.<smiles>COc1cc2c(c(OC)c1OC)-c1ccc(OC)c(=O)cc1[C@@H](NC(=O)CNC(=O)OCc1ccccc1)CC2</smiles><smiles>COc1cc2c(c(OC)c1OC)-c1ccc(OC)c(=O)cc1[C@@H](NC(=O)C1CCCN1C(=O)O)CC2</smiles><smiles>COc1cc2c(c(OC)c1OC)-c1ccc(OC)c(=O)cc1[C@@H](NC(=O)C(N)CC(C)C)CC2</smiles><smiles>COc1cc2c(c(OC)c1OC)-c1ccc(OC)c(=O)cc1[C@@H](NC(=O)CNC(=O)CNC(C)(C)C)CC2</smiles>

Figura 4.13. Estructuras de los derivados seleccionados. 
Los resultados de expresión del gen VEGF se muestran en la gráfica 4.2.

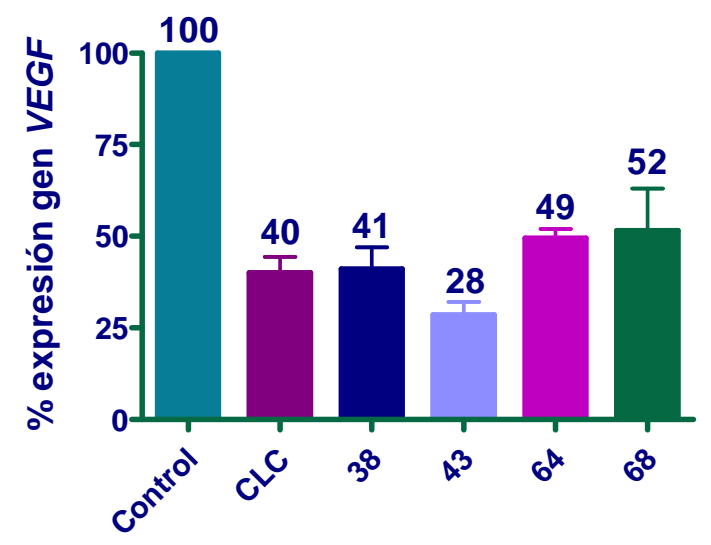

Gráfica 4.2. Resultados de la expresión del gen VEGF.

Los compuestos ensayados muestran valores de expresión del gen VEGF similares a los de la colchicina (40-50\% aproximadamente), excepto el $\mathbf{4 3}$ que reduce la expresión del gen a un $28 \%$. También hay que remarcar que el compuesto 38, que en términos absolutos exhibe una capacidad de disminución de la expresión del gen VEGF similar a la de la colchicina, consigue dichos valores de expresión a concentraciones casi cinco veces menores que las de la colchicina.

En la gráfica 4.3 se presentan los resultados de expresión del gen $h T E R T$.

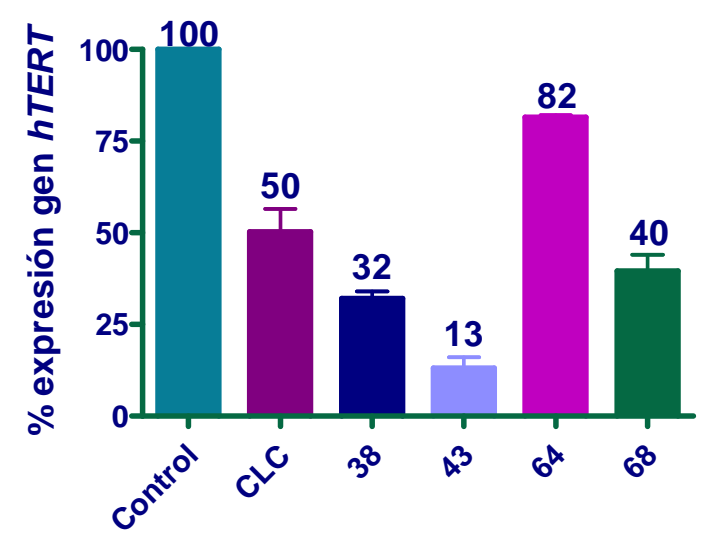

Gráfica 4.3. Resultados de la expresión del gen hTERT. 
En la gráfica anterior se aprecia que los derivados 38, 43 y 68 presentan una menor expresión del gen hTERT que la propia colchicina. Cabe destacar de nuevo a los compuestos 38 y $\mathbf{4 3}$, que son capaces de reducir la expresión del gen $h T E R T$ a un $32 \%$ y a un $13 \%$ respectivamente.

En la gráfica 4.4 se muestran los resultados de expresión del gen c-Myc.

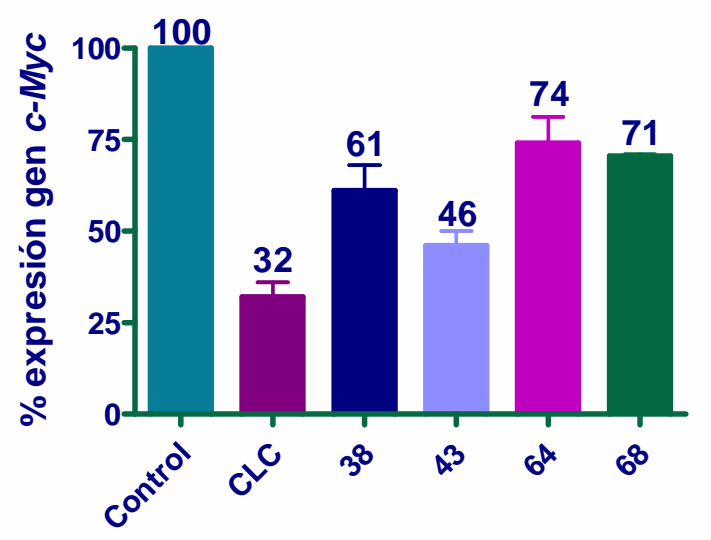

Gráfica 4.4. Resultados de la expresión del gen c-Myc.

En este caso, ningún derivado es capaz de mejorar la reducción de la expresión que muestra la colchicina para el gen $c-M y c$.

\subsubsection{Efecto sobre la secreción de la proteína VEGF-A $A_{165}$ en HT-29}

Los mismos compuestos estudiados en los ensayos de inhibición génica se investigaron en relación a su capacidad para reducir la expresión de la secreción de la proteína VEGF- $A_{165}$ en el medio de cultivo. Para ello se incubaron las células HT-29 durante $48 \mathrm{~h}$ con dichos compuestos a las mismas concentraciones indicadas en la figura 4.13. 
Los resultados obtenidos se resumen en la gráfica 4.5.

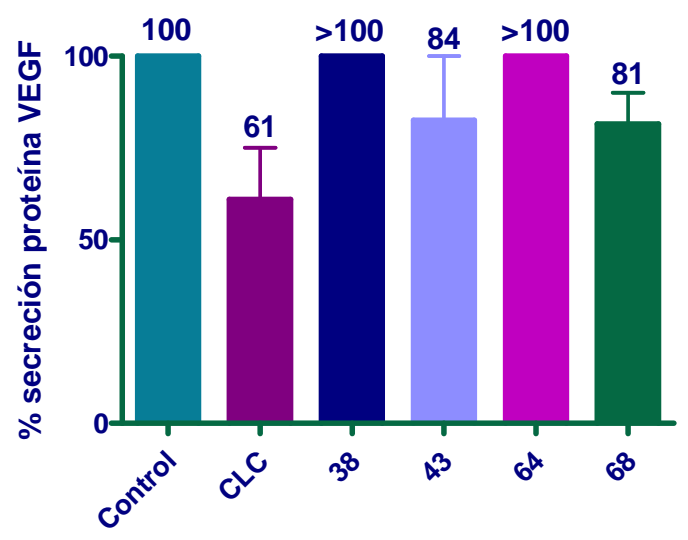

Gráfica 4.5. Resultados de la secreción de la proteína VEGF.

De la gráfica anterior se deduce que ningún derivado presenta la capacidad de reducción de la secreción de la proteína VEGF-A que muestra la colchicina. Los compuestos 43 y 68 secretan aproximadamente un $80 \%$ la proteína VEGF, contra un $61 \%$ de secreción que consigue la colchicina.

\subsubsection{Docking}

Para los estudios de docking, y a efectos comparativos, se decidieron estudiar los compuestos 38, 48, 68, 69, 70 y 71, que contenían glicina en sus estructuras. Los cálculos de docking se llevaron a cabo utilizando el programa Autodock 4.2. ${ }^{130}$ Se empleó la estructura cristalográfica de la tubulina perteneciente al PDB 1SA0. ${ }^{131}$

Los resultados del docking muestran que $38,48,68,69,70$ y 71 se unen al sitio de la colchicina, situado en la interfaz de la a $\beta$-tubulina, con una conformación similar a la que presenta la estructura cristalográfica de la

\footnotetext{
${ }^{130}$ Morris, G. M.; Huey, R.; Lindstrom, W.; Sanner, M. F.; Belew, R. K.; Goodsell, D. S.; Olson, A. J. Comp. Chem. 2009, 16, 2785-2791.

${ }_{131}$ Ravelli, R. B.; Gigant, B.; Curmi, P. A.; Jourdain, I.; Lachkar, S.; Sobel, A.; Knossow, M. Nature 2004, 428, 198-202.
} 
$\mathrm{N}$-desacetil- $\mathrm{N}$-(2-mercaptoacetil)-colchicina (DAMA-colchicina, datos obtenidos del PDB 1SA0).

En la figura 4.14, en el panel $A$, se muestra la superposición de la colchicina (negro) con los derivados 38 (azul claro) y $\mathbf{4 8}$ (azul oscuro). En el panel $B$ se muestra la posición de la colchicina en la tubulina. La colocación de 38 y de 48 en la tubulina se muestra en los paneles C y D, respectivamente.

A
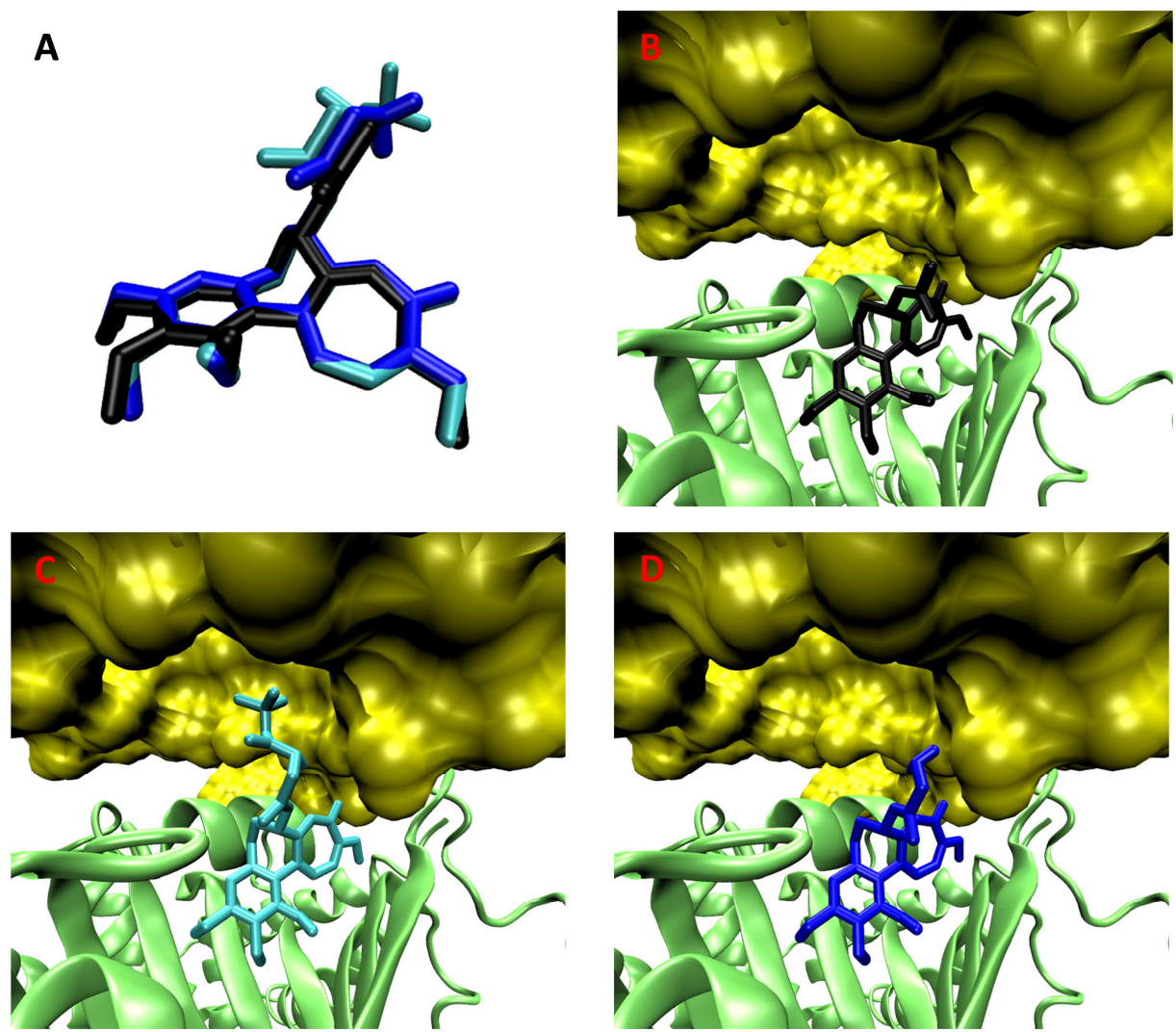

Figura 4.14. Panel A: Superposición de los derivados de colchicina (negro), 38 (azul claro) y 48 (azul). Panel B: Sitio de unión de la colchicina en la tubulina, con la subunidad $\beta$ en verde y la subunidad $\alpha$ en amarillo. Panel C: Sitio de unión del compuesto 38 (azul claro). Panel D: Sitio de unión del compuesto 48 (azul oscuro).

La parte tricíclica de los derivados se coloca en el sitio de unión de la colchicina en la $\beta$-tubulina (verde). En el derivado $\mathbf{3 8}$ el residuo Boc se coloca 
cerca de un surco presente en la a-tubulina (amarillo), mientras que el compuesto 48, que no contiene el grupo Boc, no puede alcanzar dicho hueco y se queda en la interfaz entre la $\beta$-tubulina y la $\alpha$-tubulina.

Mediante el programa LigPlot $+{ }^{132}$ se obtuvieron las interacciones de los ligandos con los aminoácidos de la tubulina (interacciones 2D). Las estructuras de los ligandos y de los aminoácidos se representan sin hidrógenos. En la figura 4.15 se representan las interacciones de la DAMAcolchicina (panel A) y las de la colchicina (panel B) obtenidas mediante este programa.

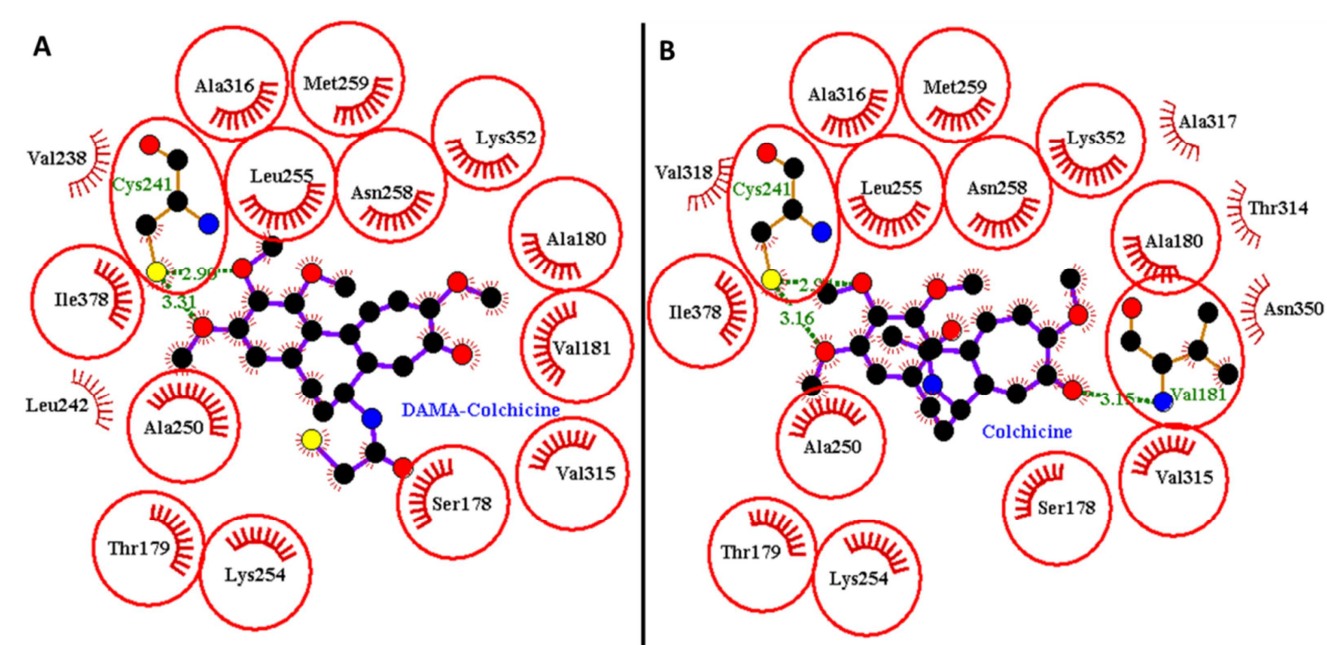

Figura 4.15. Interacciones de DAMA-colchicina (panel A) y colchicina (panel B) con la tubulina.

Los aminoácidos que interaccionan con la DAMA-colchicina y la colchicina se enmarcan en rojo en la figura anterior y, además, concuerdan con los descritos en la bibliografía. ${ }^{131,133}$ Por otra parte, los aminoácidos no enmarcados en rojo son los que sólo interactúan con el ligando en cuestión, como por ejemplo Val-238 y Leu-242, que interaccionan con la DAMA-

\footnotetext{
${ }_{132}$ Laskowski, R. A.; Swindells, M. B. J. Chem. Inf. Model., 2011, 51, 2778-2786.

${ }^{133}$ Rai, A.; Gupta, T. K.; Kini, S.; Kunwar, A.; Surolia, A.; Panda, D. Biochem. Pharmacol., 2013, 86, 378-391.
} 
colchicina y Val-318, Ala-317, Thr-314 y Asn-350, que interaccionan con la colchicina. En el caso de la DAMA-colchicina se pueden observar también los enlaces de hidrógeno (líneas verdes) que se establecen entre el grupo tiol de la Cys-241 de la subunidad de $\beta$-tubulina ${ }^{134}$ con dos de los oxígenos metoxílicos del anillo fenílico de la DAMA-colchicina. En el caso de la colchicina se aprecian también estos dos enlaces de hidrógeno y otro enlace de hidrógeno adicional entre el oxígeno del carbonilo cetónico de la colchicina con el $\mathrm{NH}$ de la Val-181 de la $\alpha$-tubulina. ${ }^{134}$

En todas las representaciones 2D que aparecerán de ahora en adelante en esta Tesis se enmarcarán en rojo los aminoácidos que establecen interacciones con el ligando en cuestión y con la DAMA-colchicina. En la figura 4.16 se representan las interacciones 2D de $\mathbf{3 8}$ (panel A) y $\mathbf{4 8}$ (panel B) con la tubulina. En el caso del compuesto 38 se observan los tres enlaces de hidrógeno que establece este compuesto con la tubulina, que son coincidentes con los de la colchicina y, además, se observan dos enlaces de hidrógeno adicionales con los residuos Thr-179, que interacciona con el nitrógeno de la glicina, y Asn-101, que interacciona con un oxígeno del grupo Boc, ambos aminoácidos pertenecientes a la subunidad de a-tubulina. ${ }^{134}$ El compuesto 38 también interacciona con Glu-183 de la $\alpha$-tubulina y Leu-248 de la $\beta$-tubulina, no presentes ni en la colchicina ni en la DAMA-colchicina. Otra interacción de 38, que no se aprecia en los dos ligandos anteriores, es la que se establece con el GTP de la a-tubulina.

En el caso del compuesto $\mathbf{4 8}$ se observan las mismas interacciones que con la colchicina y además una interacción adicional con Leu-248.

\footnotetext{
134 La pertenencia de los aminoácidos a una u otra subunidad de tubulina se determinó mediante el programa VMD y las referencias bibliográficas anteriores.
} 

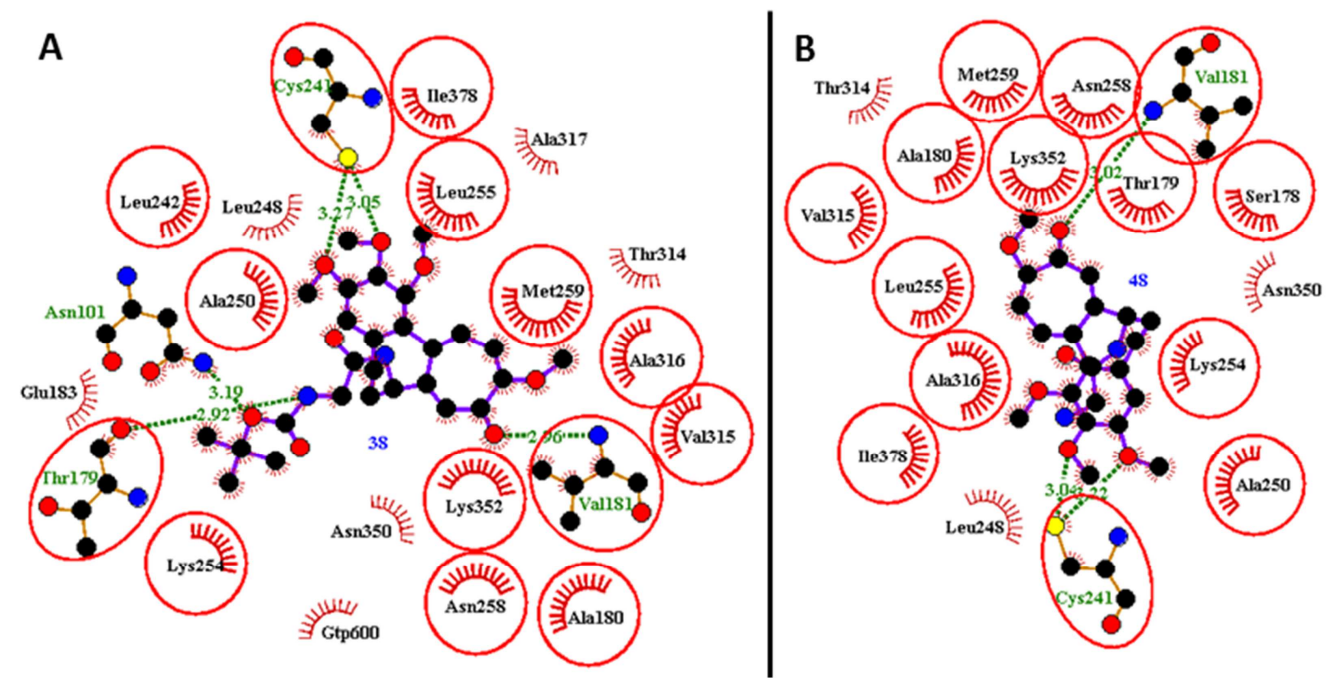

Figura 4.16. Interacciones 2D con tubulina del derivado $\mathbf{3 8}$ (panel A) y $\mathbf{4 8}$ (panel B).

A pesar de que $\mathbf{3 8}$ presenta más interacciones con la tubulina que $\mathbf{4 8}$, los valores de concentración crítica de estos dos compuestos son muy similares (alrededor de $23 \mu \mathrm{M}$ ).

Los resultados de los cálculos de docking de los derivados Gly-Gly-Boc (68) y Gly-Gly (70) se representan en la figura 4.17. Como en el caso de 38 y 48, la parte tricíclica de estos compuestos se coloca en el sitio de unión de la colchicina en la subunidad de $\beta$-tubulina (verde). El derivado 68 (panel C) situa el residuo Boc en la interfaz entre la $\beta$-tubulina y la $\alpha$-tubulina (amarilla) y el compuesto 70 , que no contiene el voluminoso grupo Boc, extiende la parte dipeptídica hacia el interior del bolsillo presente en la $\alpha$-tubulina. 
A
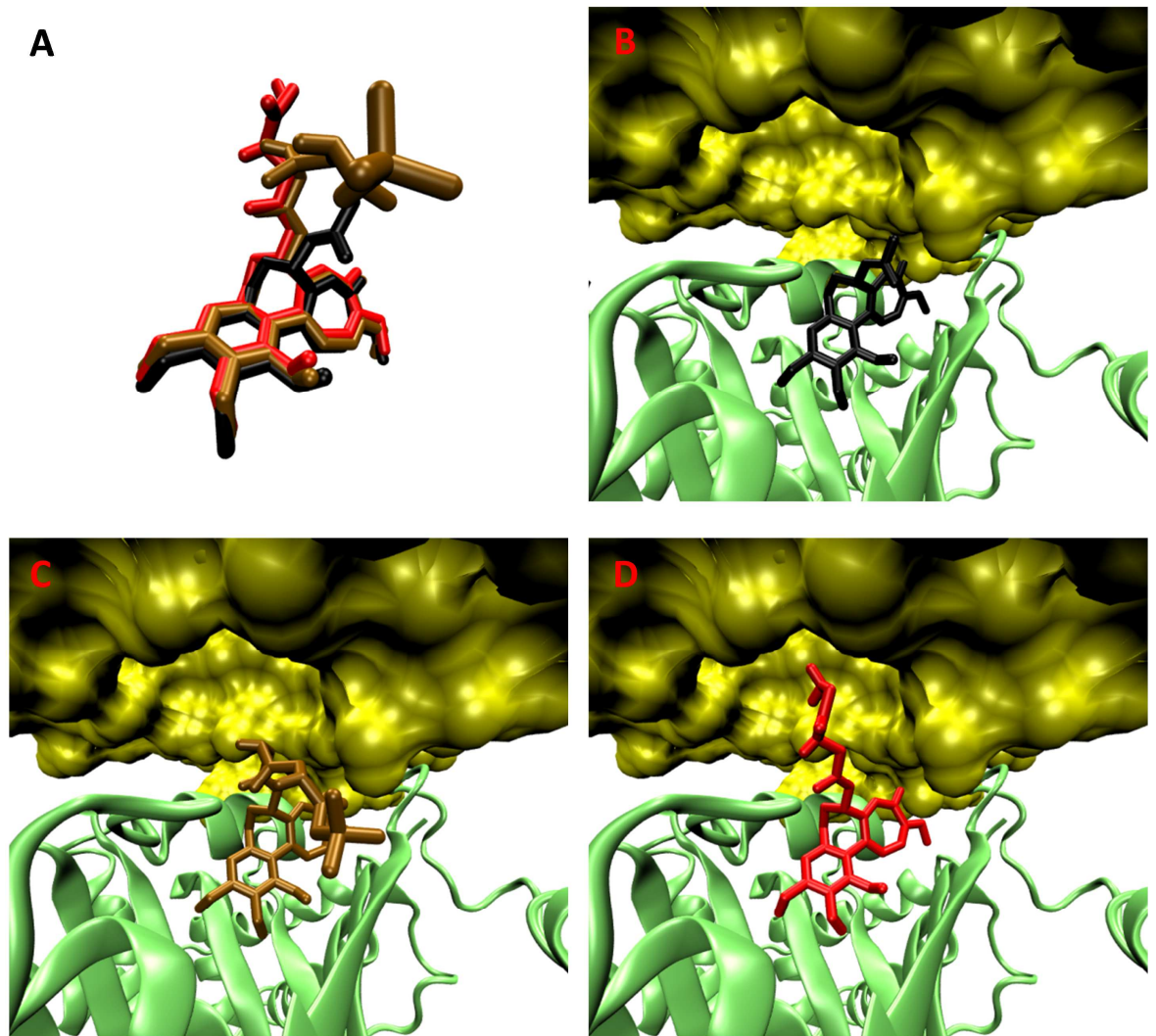

Figura 4.17. Panel A: Superposición de colchicina (negro) y de los compuestos 68 (ocre) y 70 (rojo). Panel B: Sitio de unión de la colchicina en la tubulina con la subunidad $\beta$ representada en verde y la $\alpha$ en amarillo. Panel C: Sitio de unión del compuesto 68 (ocre). Panel D: Sitio de unión del compuesto 70 (rojo).

Las representaciones en 2D de las interacciones de los derivados 68 y 70 se indican en la figura 4.18. El compuesto 68 (panel A) presenta, además de los dos enlaces de hidrógeno con el residuo Cys-241 de la $\beta$-tubulina, un enlace de hidrógeno con el residuo Ser-178 de $\alpha$-tubulina orientado hacia la interfaz de separación entre las dos subunidades.

Las interacciones que establece $\mathbf{7 0}$ (panel B) con los aminoácidos de la tubulina son similares a las de 68 . Sin embargo, el compuesto $\mathbf{7 0}$, como se deduce de los cálculos de docking, inserta su cadena Gly-Gly en el hueco de la a-tubulina. La representación en 2D explica esta inserción mediante la 
formación de un enlace de hidrógeno entre el grupo amino de la glicina y el grupo fosfato de la unidad de GTP.

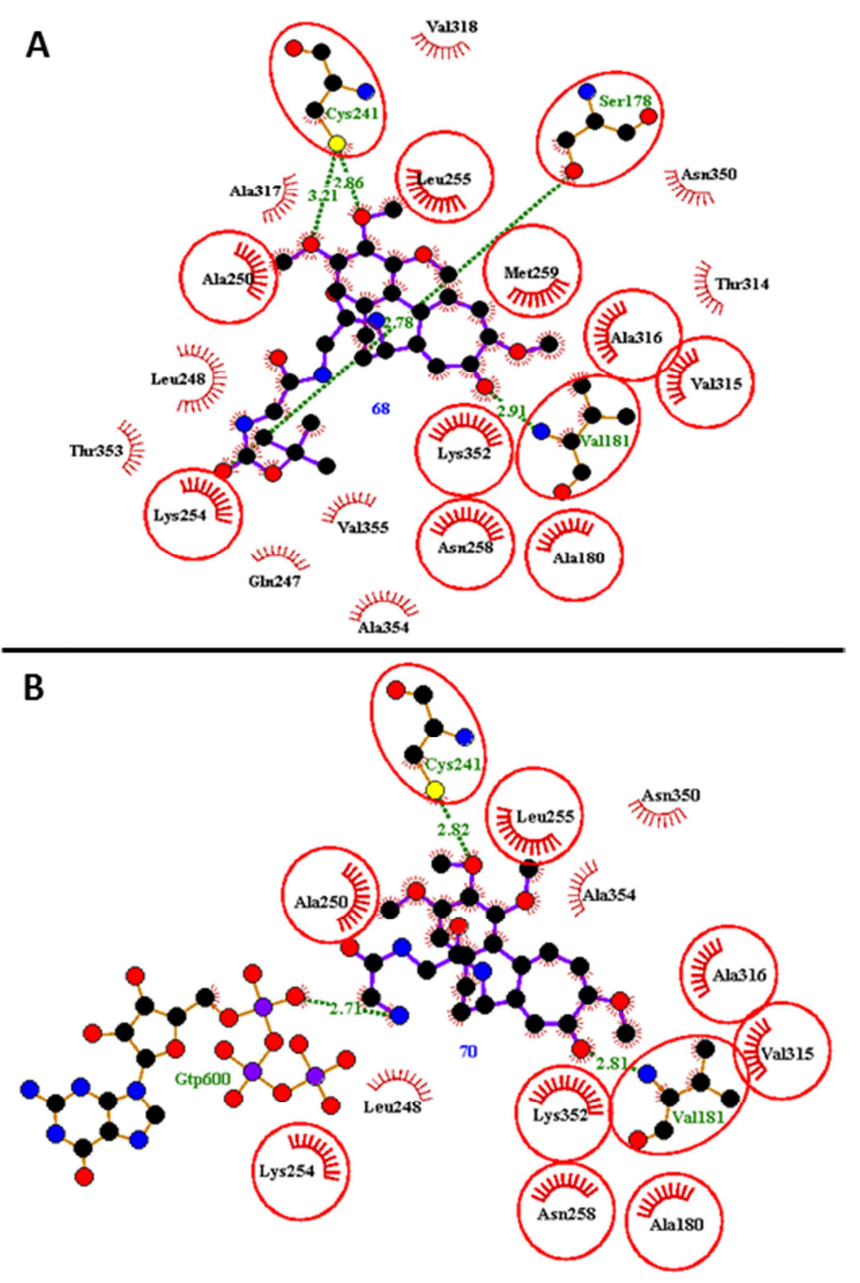

Figura 4.18. Interacciones 2D con tubulina del derivado 68 (panel A) y 70 (panel B).

Los cálculos de docking para los derivados Gly-Gly-Gly-Boc (69) y Gly-GlyGly (71) se muestran en la figura 4.19. Como en los dos casos anteriores, la parte tricíclica de los derivados se coloca en el sitio de unión de la colchicina en la $\beta$-tubulina. El derivado 71 (panel D) se introduce en el surco presente en la a-tubulina, al igual que ocurre con el compuesto 70 . En cambio, el 
compuesto 69 no introduce su cadena lateral en el surco de la a-tubulina, quedándose ésta en la interfaz del heterodímero. Esto podría explicarse por el impedimento estérico entre el grupo protector Boc y la molécula de GTP en la a-tubulina que provoca el plegamiento de la cadena Gly-Gly-Gly-Boc.

A
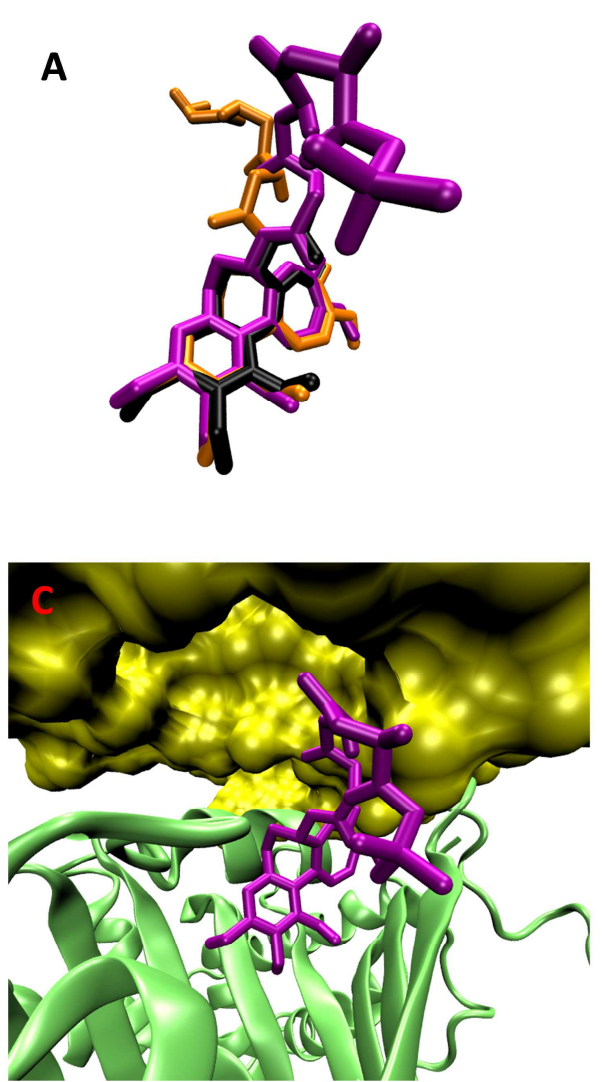
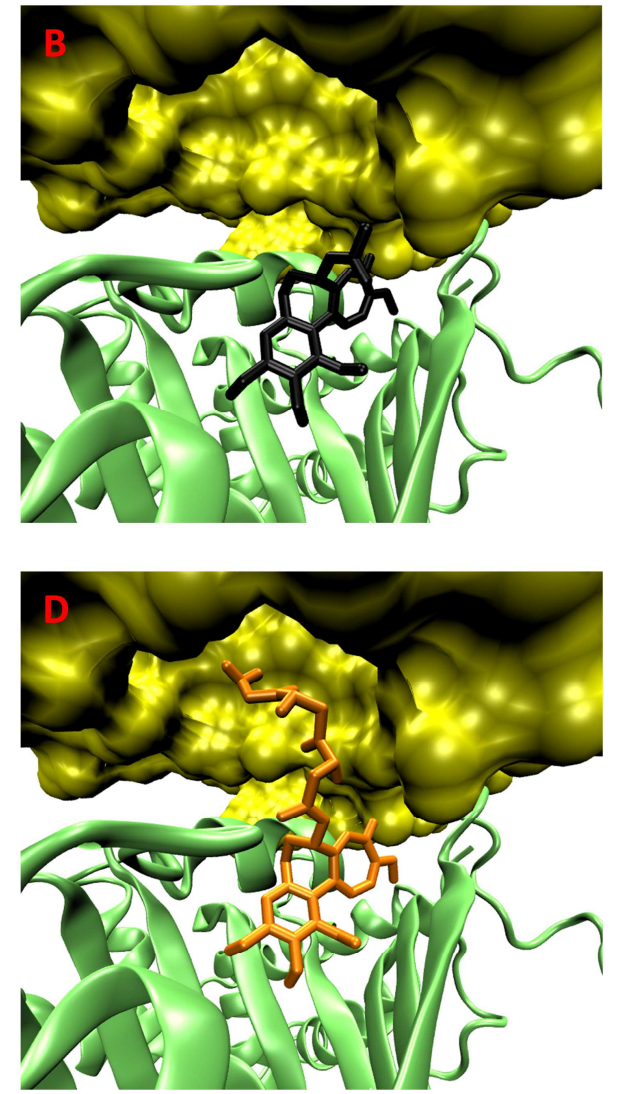

Figura 4.19. Panel A: Superposición de colchicina (negro), y los compuestos 69 (morado) y 71 (naranja). Panel B: Sitio de unión de la colchicina en la tubulina con la subunidad $\beta$ en verde y la $\alpha$ en amarillo. Panel C: Sitio de unión del compuesto 69 (morado). Panel D: Sitio de unión del compuesto 71 (naranja).

Las representaciones 2D de 69 y 71 se indican en la figura 4.20. El compuesto 69 presenta 5 enlaces de hidrógeno, dos de ellos con el residuo de Cys-241, situado en la $\beta$-tubulina y otros tres con los residuos de la $\alpha$-tubulina Thr-179, Val-181 y Tyr-224. 
El compuesto 71 (panel B), además de presentar los dos enlaces de hidrogeno de la Cys-241 y los de Thr-179 y Val-181, presenta interacciones adicionales a través de enlaces de hidrógeno con los residuos Asn-101 y Gly-144, pertenecientes a la a-tubulina. También alcanza el bolsillo de la a-tubulina y establece un enlace de hidrógeno con un grupo fosfato del GTP.

El mayor número de interacciones de 71 explicaría el mayor valor de su concentración crítica $(22,7 \mu \mathrm{M})$ en relación con la del compuesto $69(18,3 \mu \mathrm{M})$.

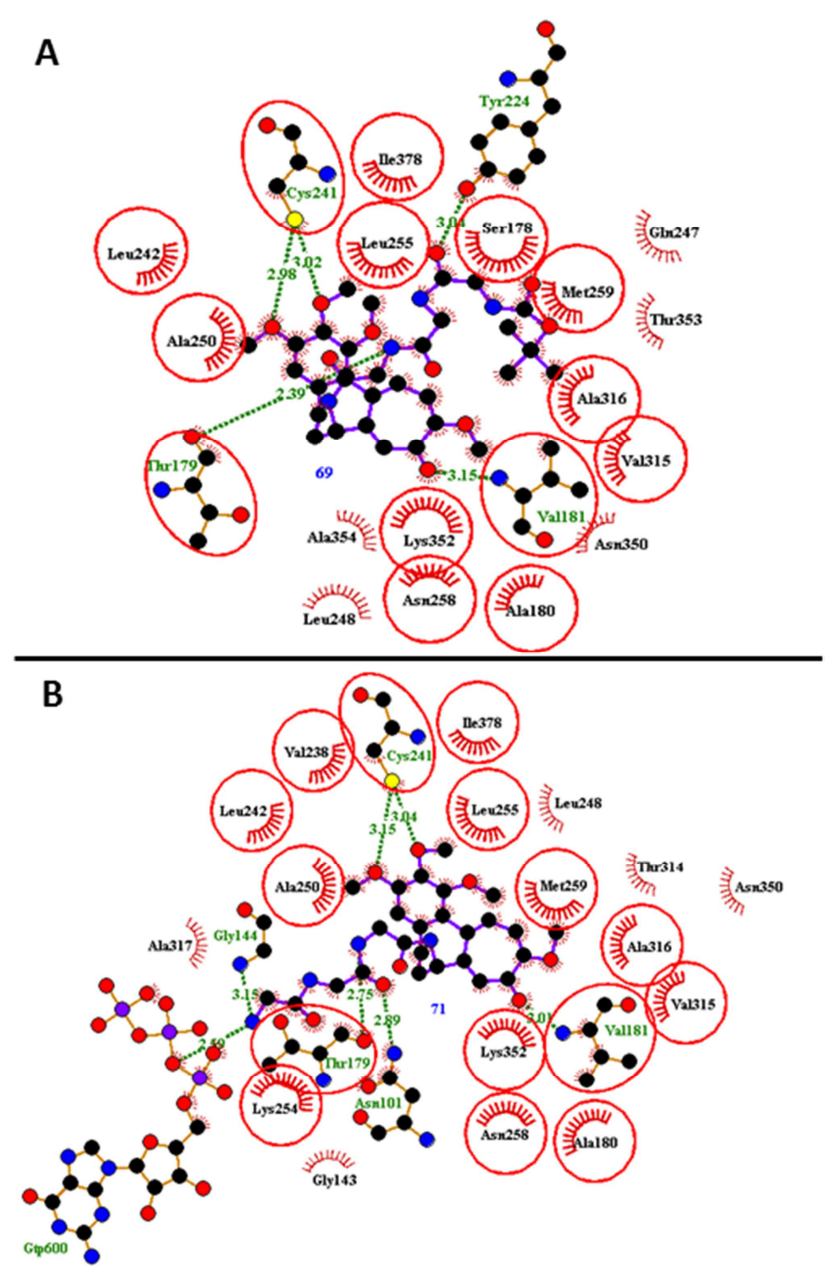

Figura 4.20. Interacciones 2D con tubulina del derivado 69 (panel A) y 71 (panel B). 


\subsubsection{Resumen y conclusiones}

- La mayoría de compuestos de la familia 1 presentan una actividad citotóxica en el rango nanomolar. Destacan los compuestos 38, 53 y 64 (véase la figura 4.21) que exhiben una actividad citotóxica mayor que la colchicina en ambas líneas tumorales y, además, presentan unos coeficientes de selectividad mayores, lo que ofrecería un mejor margen de seguridad terapéutica.<smiles>COc1cc2c3c(OC)c(OC)ccc3c3c(OC)c(OC)ccc3c2c(OC)c1OC</smiles>

Figura 4.21.

- En cuanto a la concentración crítica se puede concluir que la serie de L- $\alpha$-aminoácidos es más activa que la de los D-a-aminoácidos. Dentro de los L-a-aminoácidos, los compuestos (véase la figura 4.9) que presentan como sustituyente un residuo apolar pequeño $(\mathbf{3 8}, 39,48$ y 49) o un grupo polar $(44,45,47,54,55$ y 57) presentan valores de concentración crítica más próximos a los de la colchicina. En cambio, los derivados (véase la figura 4.9, 4.10 y 4.11) que tienen un residuo estéricamente voluminoso, como 41, 43, 61, 66 y 69, no muestran unos valores de concentración crítica tan elevados. Además, éstos últimos retrasan también el tiempo de polimerización de la tubulina. Por ello cabría deducir que estos compuestos son inhibidores parciales de la polimerización de la tubulina y que su influencia sobre la dinámica de 
microtúbulos es diferente a la de la colchicina, que se caracteriza por una completa inhibición.

- En referencia a la expresión de genes, el compuesto que muestra un comportamiento similar a la colchicina es el $\mathbf{4 3}$ (véase la figura 4.22). La ventaja que ofrece éste frente al compuesto natural es que tiene un margen de seguridad terapéutica más amplio. Cabe resaltar también el derivado 38 (véase la figura 4.22) que tiene una capacidad inhibitoria del gen VEGF igual que la colchicina y mejora además la capacidad inhibitoria de ésta respecto al gen $h T E R T$, pero a una concentración aproximadamente 5 veces menor que la del producto natural.<smiles>COc1cc2c(c(OC)c1OC)-c1ccc(OC)c(=O)cc1[C@@H](NC(=O)CNC(=O)O)CC2</smiles><smiles></smiles>

Figura 4.22.

- En relación con los cálculos de docking cabe mencionar que los derivados de glicina estudiados sitúan su parte tricíclica en el sitio de unión de la colchicina en la $\beta$-tubulina. Además, cuando el sustituyente tiene una longitud adecuada se alcanza un surco presente en la $\alpha$ tubulina y se establecen enlaces de hidrógeno con los residuos fosfato del GTP, como en el caso de los compuestos 70 y 71 (véase la figura 4.23). Sin embargo, cuando dicho sustituyente presenta un grupo muy voluminoso, como el del grupo Boc de los compuestos 68 y 69 (véase la figura 4.23), se produce una interacción estérica con el grupo GTP de la subunidad alfa que impide la introducción de la cadena lateral en el surco de dicha subunidad, situándose el compuesto en la interfaz entre las dos subunidades de la tubulina. Esto podría explicar por qué los derivados que contienen el aminoácido glicina presentan mayor actividad frente a tubulina cuando carecen del grupo Boc. 
<smiles>[R]NCC(=O)NCC(=O)N[C@H]1CCc2cc(OC)c(OC)c(OC)c2-c2ccc(OC)c(=O)cc21</smiles>

$68 \mathrm{R}=\mathrm{Boc}$ $69 \mathrm{R}=\mathrm{COCH}_{2} \mathrm{NHBoc}$<smiles>[R]NCC(=O)NCC(=O)N[C@H]1CCc2cc(OC)c(OC)c(OC)c2-c2ccc(OC)c(=O)cc21</smiles>

$70 \mathrm{R}=\mathrm{H}$

$71 \mathrm{R}=\mathrm{COCH}_{2} \mathrm{NH}_{2}$

Figura 4.23. 


\subsection{Evaluación biológica de los compuestos de la familia 2}

La familia 2 está formada por derivados de colchicina que provienen de la sustitución formal del grupo acetilo de la colchicina por otros grupos acilo alifáticos de cadena larga, así como grupos haloacetilo, fenilacetilo y ciclohexilacetilo.

\subsubsection{Citotoxicidad}

Los valores de citotoxicidad de los compuestos de la familia 2 se midieron, como en los casos anteriores, en las líneas celulares tumorales HT-29 y MCF-7 y en la línea no tumoral HEK-293.

En la figura 4.24 se indican las estructuras y los códigos numéricos de lo derivados de la familia 2.<smiles></smiles>

$$
\begin{array}{ll}
72 \mathrm{R}=\left(\mathrm{CH}_{2}\right)_{2} \mathrm{CH}_{3} & 82 \mathrm{R}=\mathrm{CH}_{2} \mathrm{~F} \\
73 \mathrm{R}=\left(\mathrm{CH}_{2}\right)_{4} \mathrm{CH}_{3} & 83 \mathrm{R}=\mathrm{CH}_{2} \mathrm{Cl} \\
74 \mathrm{R}=\left(\mathrm{CH}_{2}\right)_{6} \mathrm{CH}_{3} & 84 \mathrm{R}=\mathrm{CH}_{2} \mathrm{Br} \\
75 \mathrm{R}=\left(\mathrm{CH}_{2}\right)_{8} \mathrm{CH}_{3} & 85 \mathrm{R}=\mathrm{CH}_{2} \mathrm{I} \\
76 \mathrm{R}=\left(\mathrm{CH}_{2}\right)_{9} \mathrm{CH}_{3} & 86 \mathrm{R}=\mathrm{CH}_{2} \mathrm{C}_{6} \mathrm{H}_{11} \\
77 \mathrm{R}=\left(\mathrm{CH}_{2}\right)_{10} \mathrm{CH}_{3} & 87 \mathrm{R}=\mathrm{CH}_{2} \mathrm{C}_{6} \mathrm{H}_{5} \\
78 \mathrm{R}=\left(\mathrm{CH}_{2}\right)_{11} \mathrm{CH}_{3} & \\
79 \mathrm{R}=\left(\mathrm{CH}_{2}\right)_{12} \mathrm{CH}_{3} & \\
80 \mathrm{R}=\left(\mathrm{CH}_{2}\right)_{14} \mathrm{CH}_{3} & \\
81 \mathrm{R}=\left(\mathrm{CH}_{2}\right)_{16} \mathrm{CH}_{3} &
\end{array}
$$

Figura 4.24. Estructuras de los derivados de la familia 2.

Los valores de citotoxicidad y los coeficientes de selectividad de los derivados anteriores se resumen en la siguiente tabla. 
Tabla 4.8. Citotoxicidad y coeficientes de selectividad de los derivados de la familia 2 .

\begin{tabular}{|c|c|c|c|c|c|}
\hline \multirow[t]{2}{*}{ Producto } & \multicolumn{3}{|c|}{$\mathrm{IC}_{50} \pm \mathrm{SD}(\mathrm{nM})$} & \multicolumn{2}{|c|}{$\begin{array}{c}\text { Coeficientes } \\
\text { de } \\
\text { selectividad }\end{array}$} \\
\hline & HT-29 & MCF-7 & HEK-293 & $\alpha^{*}$ & $\beta^{* *}$ \\
\hline CLC & $50 \pm 3$ & $12 \pm 7$ & $5 \pm 1$ & 0,10 & 0,4 \\
\hline 72 & $10 \pm 2$ & $13 \pm 1$ & $13,5 \pm 0,2$ & 1,3 & 1,0 \\
\hline 73 & $3,37 \pm 0,15$ & $7,02 \pm 0,05$ & $7,1 \pm 0,3$ & 2,1 & 1,0 \\
\hline 74 & $1,69 \pm 0,09$ & $23,0 \pm 0,5$ & $18,9 \pm 1,1$ & 11,2 & 0,8 \\
\hline 75 & $0,143 \pm 0,011$ & $29 \pm 4$ & $0,242 \pm 0,005$ & 1,7 & 0,01 \\
\hline 76 & $0,041 \pm 0,004$ & $1,77 \pm 0,13$ & $0,17 \pm 0,04$ & 4,2 & 0,10 \\
\hline 77 & $0,27 \pm 0,03$ & $0,53 \pm 0,23$ & $0,23 \pm 0,06$ & 0,9 & 0,4 \\
\hline 78 & $7,0 \pm 0,7$ & $6,8 \pm 1,7$ & $1,5 \pm 0,3$ & 0,2 & 0,2 \\
\hline 79 & $36,1 \pm 1,0$ & $20 \pm 7$ & $46 \pm 3$ & 1,3 & 2,3 \\
\hline 80 & $184 \pm 6$ & $720 \pm 60$ & $244 \pm 7$ & 1,3 & 0,3 \\
\hline 81 & $1010 \pm 80$ & $120 \pm 50$ & $766 \pm 10$ & 0,8 & 6,4 \\
\hline 82 & $4,7 \pm 1,3$ & $7,3 \pm 1,2$ & $7,1 \pm 0,5$ & 1,5 & 1,0 \\
\hline 83 & $4,6 \pm 0,4$ & $29 \pm 1$ & $4,56 \pm 0,08$ & 1,0 & 0,16 \\
\hline 84 & $13,7 \pm 0,2$ & $16,4 \pm 0,3$ & $14,36 \pm 1,06$ & 1,0 & 0,9 \\
\hline 85 & $10 \pm 1$ & $4,1 \pm 0,8$ & $19 \pm 1$ & 1,9 & 4,6 \\
\hline 86 & $8,7 \pm 0,5$ & $9 \pm 2$ & $10,5 \pm 0,9$ & 1,2 & 1,2 \\
\hline 87 & $2,84 \pm 0,04$ & $2,6 \pm 0,9$ & $3,9 \pm 0,7$ & 1,4 & 1,5 \\
\hline
\end{tabular}

De la tabla anterior cabe destacar que la mayoría de los compuestos presentan actividad nanomolar en todas las líneas celulares, a excepción de los compuestos 75 (cadena de ácido decanoico), 76 (cadena de ácido undecanoico) y $\mathbf{7 7}$ (cadena de ácido dodecanoico) que exhiben valores de $\mathrm{IC}_{50}$ en el rango picomolar en HT-29 y HEK-293 y el compuesto 81 (cadena de 
ácido octadecanoico) que exhibe un valor de $\mathrm{IC}_{50}$ en el rango micromolar en HT-29.

En el caso de los derivados acilados 72-81, y en la línea HT-29, cabe señalar la relación que existe entre la actividad de estos compuestos y la longitud de la cadena, alcanzándose un máximo de citotoxicidad, ya dentro del rango picomolar, con el compuesto 76 (cadena de ácido undecanoico).

En lo referente a la línea celular MCF-7, los compuestos 73, 76, 77, 78, 82, 85, 86 y 87 presentan un $I_{50}$ inferior a la colchicina. En esta línea celular también destaca el compuesto 77 que muestra un $\mathrm{IC}_{50}$ en el rango picomolar. Los valores de selectividad, salvo los compuestos $75,76,78,80$ y 83 , son mayores que los de la colchicina, lo que dotaría a los compuestos de la familia 2 de un mayor margen de seguridad terapéutica.

Los compuestos 73-77 y 87, que presentaban las mayores citotoxicidades en la línea HT-29, fueron seleccionados para los siguientes estudios biológicos, que se llevaron a cabo en la Facultad de Farmacia de la Universidad de Aix-Marseille. En estos laboratorios se estudió en primer lugar la citotoxicidad de los compuestos seleccionados en la línea celular tumoral A549. Los resultados obtenidos se indican en la tabla 4.9.

Tabla 4.9. Citotoxicidad en la línea celular A549.

\begin{tabular}{c|c}
\hline \multirow{2}{*}{ Producto } & $\mathrm{IC}_{50} \pm \mathrm{SD}(\mathrm{nM})$ \\
\cline { 2 - 2 } Colchicina & $\mathbf{A 5 4 9}$ \\
73 & $14 \pm 6$ \\
74 & $18 \pm 2$ \\
75 & $133 \pm 23$ \\
76 & $25 \pm 4$ \\
77 & $62 \pm 4$ \\
87 & $71,9 \pm 0,8$ \\
\hline
\end{tabular}


Todos los compuestos presentan actividad nanomolar en la línea A549 aunque sólo 73, 75 y 87 muestran valores de citotoxicidad similares a los de la colchicina.

\subsubsection{Efecto en el ensamblaje de microtúbulos}

Los efectos de estos derivados sobre la polimerización in vitro de tubulina se midieron mediante turbidimetría utilizando un tampón GAB. En la tabla 4.10 se indican los poncentajes de polimerización de tubulina obtenidos para estos derivados y la colchicina con respecto al control (DMSO).

Tabla 4.10. Porcentaje de polimerización de tubulina de los derivados de la familia $2^{135}$

\begin{tabular}{|c|c|}
\hline Producto & \% polimerización \\
\hline Control & 100 \\
\hline Colchicina & 6 \\
\hline 72 & 13 \\
\hline 73 & 11 \\
\hline 74 & 28 \\
\hline 75 & 245 \\
\hline 76 & 172 \\
\hline 77 & 244 \\
\hline 78 & 78 \\
\hline 79 & 45 \\
\hline 80 & 43 \\
\hline 81 & 94 \\
\hline
\end{tabular}

${ }^{135}$ Véase la parte experimental para obtener información más detallada. 


\begin{tabular}{l|l}
\hline 82 & 3 \\
83 & 2 \\
84 & 2 \\
85 & 5 \\
86 & 13 \\
87 & 18 \\
\hline
\end{tabular}

Como puede observarse en la tabla anterior, la colchicina, que es un agente desestabilizante de microtúbulos, reduce el procentaje de polimerización de la tubulina hasta un $6 \%$. Con un comportamiento similar encontramos los compuestos $72,73,82,83,84,85,86$ y 87 , que podrían ser clasificados como agentes inhibidores del proceso de polimerización. Dentro de ellos, debemos destacar a los derivados haloacetilo $82-85$, que consiguen la casi total inhibición del proceso de polimerización.

Los derivados $\mathbf{7 4 , 7 8 , 7 9}$ y $\mathbf{8 0}$ disminuyen el porcentaje de polimerización en relación con la prueba de control, pero no alcanzan los valores mostrados por la colchicina, por lo que estos compuestos se podrían clasificar como inhibidores parciales de la polimerización de la tubulina. El derivado 81 afecta débilmente al proceso de polimerización de la tubulina.

Los compuestos $\mathbf{7 5}, \mathbf{7 6}$ y 77 muestran un mayor incremento de la masa de polímero que el propio control. Esto podría deberse a un efecto estabilizador de los microtúbulos, como el que exhibe el paclitaxel, pero también podría ser la consecuencia de la formación de polímeros anómalos inducida por estos tres compuestos.

Para descartar una de estas dos hipótesis se estudió, mediante microscopia electrónica, la polimerización de la tubulina inducida por los compuestos $\mathbf{7 5}, \mathbf{7 6}$ y $\mathbf{7 7}$. Las imágenes obtenidas se muestran en la figura 4.25. En la imagen A, correspondiente al control, se aprecian los microtúbulos 
como estructuras cilíndricas alargadas. Por el contrario, en las imágenes B y $\mathrm{D}$, correspondientes a la polimerización en presencia de los compuestos 75 y 77, respectivamente, no se observa la formación de microtúbulos, sino de agregados de tubulina que explicarían el aumento de la turbidez con estos compuestos. En el panel C, correspondiente a la polimerización en presencia del compuesto 76, se observan microtúbulos pero en mucha menor cantidad que los que se aprecian en el control (imagen A), por lo que el aumento de la turbidez que se mide con el compuesto 76 también cabe achacarla a la formación de polímeros anómalos o agregados, como en el caso de los compuestos 75 y 77 .
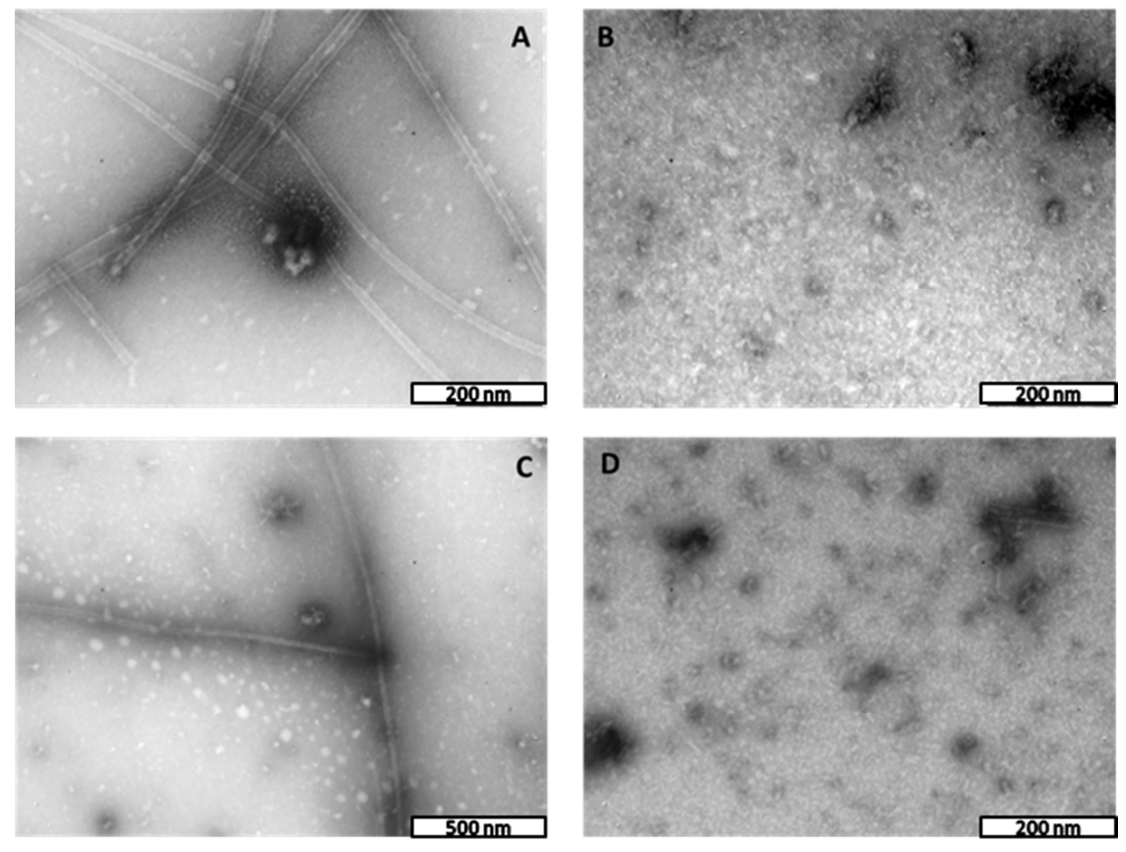

Figura 4.25. Polimerización de la tubulina mediante microscopia electrónica (tampón GAB). A control, B en presencia de 75, C en presencia de 76 y $D$ en presencia de 77 .

Tras estos resultados se determinó de nuevo el efecto de los compuestos 73-77 en el ensamblaje de microtúbulos mediante turbidimetría pero en un tampón sin glicerol que contenía $20 \mathrm{mM}$ de $\mathrm{NaPi}, 16 \mathrm{mM} \mathrm{MgCl}_{2}$ y $0,1 \mathrm{mM}$ de GTP a pH=7,0 (tampón 2). Se utilizó una concentración de $50 \mu \mathrm{M}$ para cada 
uno de los compuestos y la colchicina y de $15 \mu \mathrm{M}$ para la tubulina. En estas condiciones la tubulina no es capaz de formar microtúbulos, por lo que toda la señal de absorbancia obtenida correspondería a la formación de polímeros anómalos o agregados. ${ }^{136}$ En la gráfica 4.6 se indican los resultados obtenidos.

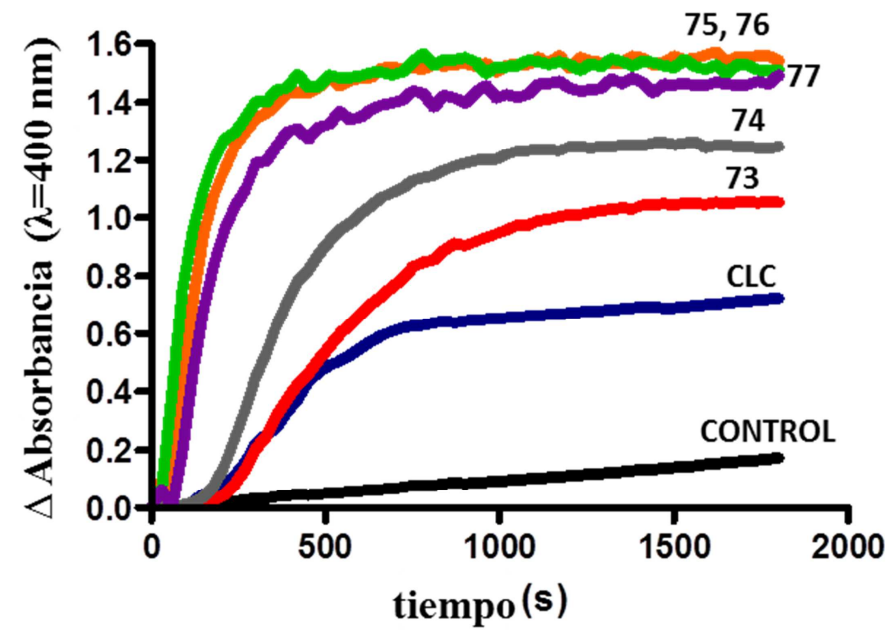

Gráfica 4.6. Efectos de la colchicina y derivados acilo en el ensamblaje de microtúbulos in vitro en el tampón 2. Las líneas representan la turbidimetría de la polimerización para la tubulina (línea negra), colchicina (línea azul), 73 (línea roja), 74 (línea gris), 75 (línea naranja), 76 (línea verde) y 77 (línea morada).

De la gráfica anterior se concluye que la colchicina y los derivados 73-77 tienen un comportamiento similar, provocando, en presencia del tampón sin glicerol (tampón 2), la formación de agregados o polímeros anómalos de tubulina.

El proceso de polimerización en el tampón sin glicerol también se observó mediante microscopia electrónica. Las imágenes obtenidas se muestran en la figura 4.26. En la imagen A, correspondiente al control, no se aprecian microtúbulos, a diferencia de lo que si ocurría cuando la polimerización se

${ }^{136}$ Andreu, J. M.; Timasheff S. N. Biochemistry 1982, 79, 6753-6756. 
llevaba a cabo en el tampón con glicerol. Cuando la polimerización se llevó a cabo en presencia de colchicina (imagen B) y de los compuestos 74 (imagen C) y 77 (imagen D), se apreció la formación de agregados (zonas oscuras), lo que explicaría el aumento de la señal de absorbancia y descartaría un efecto estabilizador de microtúbulos por parte de estos compuestos.
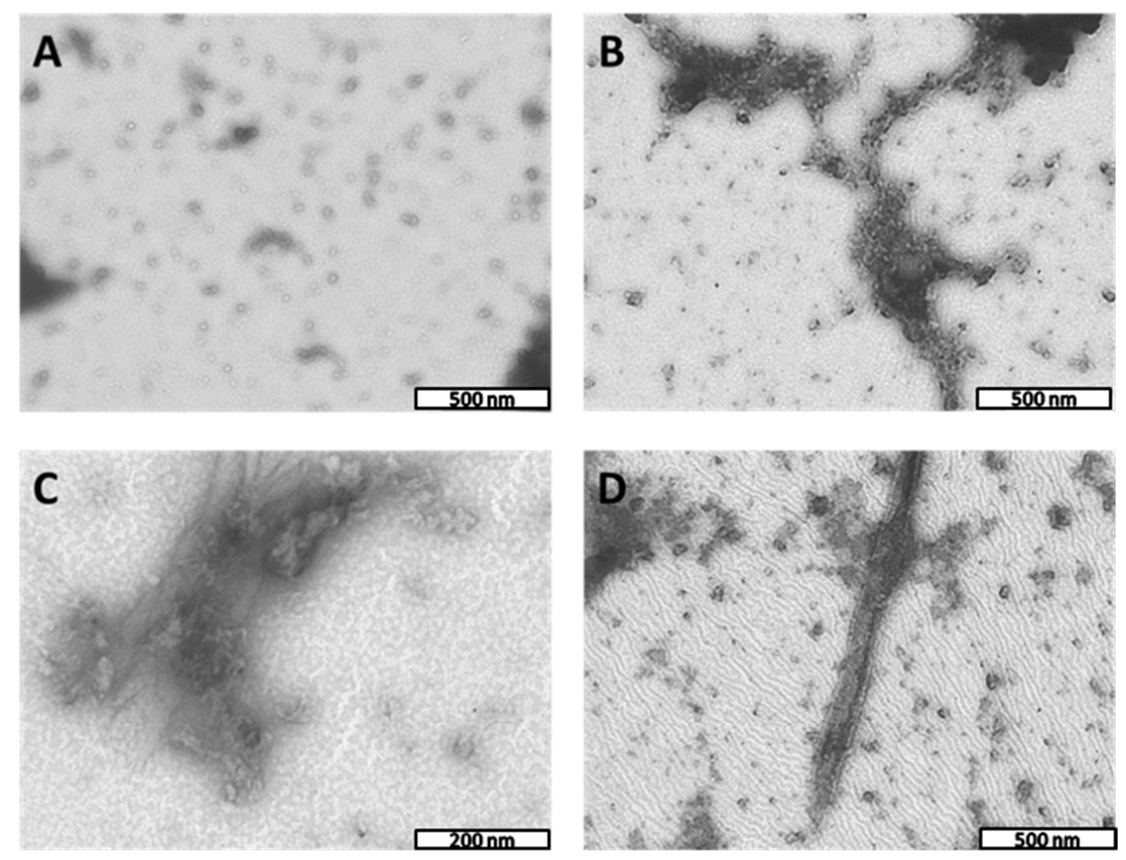

Figura 4.26. Polimerización de la tubulina mediante microscopia electrónica (tampón 2). A control; B en presencia de colchicina; $C$ en presencia de 74; $D$ en presencia de 77.

\subsubsection{Determinación de $I_{50}$ en el proceso de formación de microtúbulos}

Para la medida del valor de $\mathrm{IC}_{50}$ en la polimerización de la tubulina se prepararon disoluciones de los compuestos a diferentes concentraciones. Así, la colchicina y los compuestos 73 y 74 se estudiaron a $0.5,1,1.5,2$ y $4 \mu \mathrm{M}$, mientras que los compuestos 75,76 y 77 , debido a su capacidad de formación de agregados, se estudiaron a concentraciones más bajas de $0.1,0.25,0.5$, 0.75 y $1 \mu \mathrm{M}$. La tubulina se utilizó a una concentración de $15 \mu \mathrm{M}$ preparada en 
el tampón 1. A modo de ejemplo se muestran en la gráfica 4.7 los resultados obtenidos con el compuesto 75. La parte izquierda de la gráfica corresponde a los resultados obtenidos por turbidimetría y la parte derecha es el ajuste lineal de dichos datos, considerando el control como el cero por ciento de inhibición de la polimerización.
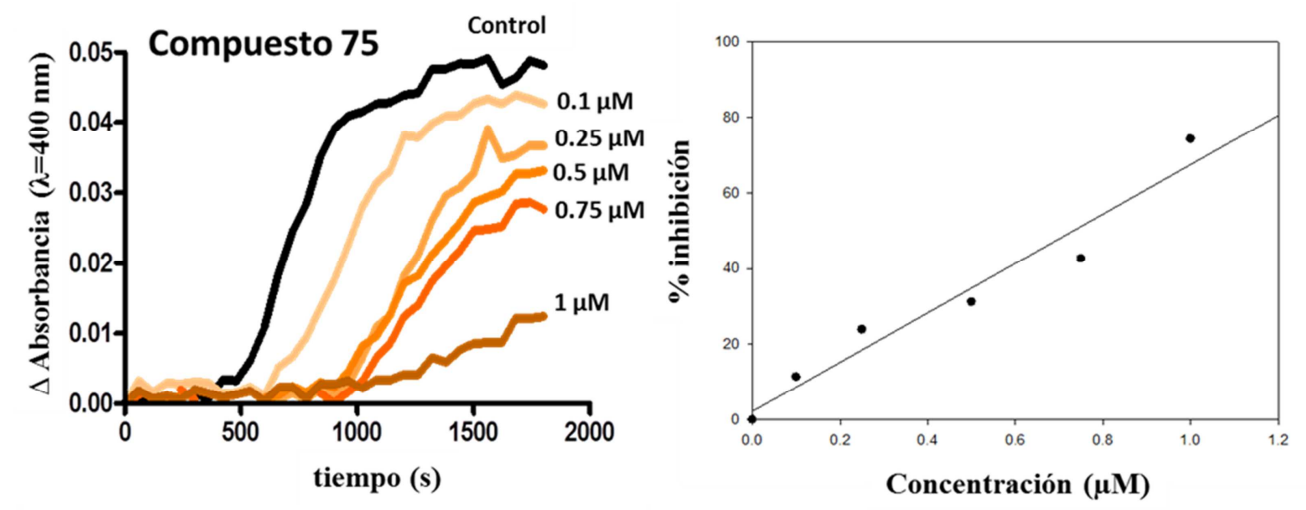

Gráfica 4.7. Efecto del compuesto 75 en la formación de microtúbulos in vitro. El panel de arriba muestra la polimerización de tubulina a $15 \mu \mathrm{M}$ sin 75 (línea control), y en presencia de $0.1,0.25,0.5,0.75$ y $1 \mu \mathrm{M}$ de 75 . En el panel derecho se presenta el porcentaje de inhibición de 75 .

Para comprobar que la señal de absorbancia en presencia de 75 era debida a microtúbulos, en lugar de a polímeros anómalos, se tomaron las imágenes de microscopia electrónica que se muestran en la figura 4.27. 


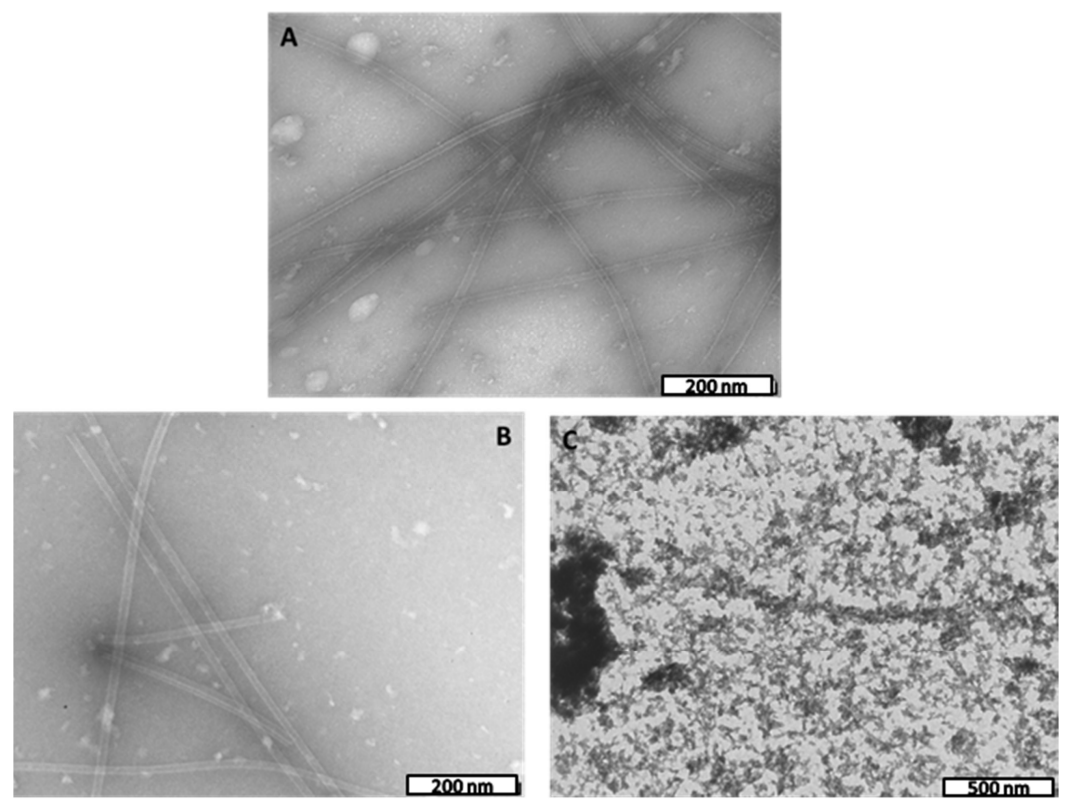

Figura 4.27. Polimerización de la tubulina mediante microscopia electrónica. A control; B en presencia de $0,1 \mu \mathrm{M}$ de 75 y $\mathrm{C}$ en presencia de $1 \mu \mathrm{M}$ de 75 .

Como se puede apreciar, a concentración de $0,1 \mu \mathrm{M}$ de 75 (imagen B) la absorbancia medida corresponde a la formación de microtúbulos, mientras que a concentración de $1 \mu \mathrm{M}$ de 75 (imagen C) la absorbancia se debe a la formación de agregados.

Para todos los compuestos se realizaron los mismos experimentos por triplicado y los resultados se presentan en la tabla 4.11 .

Tabla 4.11. Valores $\mathrm{IC}_{50}$ de polimerización a $15 \mu \mathrm{M}$ de tubulina.

\begin{tabular}{c|c|}
\hline Producto & $\mathrm{IC}_{50} \pm \mathrm{SD}(\mu \mathrm{M})$ \\
\hline Colchicina & $1,8 \pm 0,3$ \\
73 & $2,1 \pm 0,2$ \\
74 & $1,08 \pm 0,05$ \\
\hline
\end{tabular}




\begin{tabular}{c|c}
\hline 75 & $0,70 \pm 0,07$ \\
76 & $0,79 \pm 0,06$ \\
77 & $1,2 \pm 0,4$ \\
\hline
\end{tabular}

Los valores $\mathrm{IC}_{50}$ de polimerización de la tubulina de los compuestos 74-77, con excepción de 73 , son menores que los de la colchicina, de lo que se deduce que estos compuestos son agentes desestabilizantes de microtúbulos más potentes que la colchicina. El mínimo corresponde al compuesto 75 que contiene una cadena de decanoílo.

\subsubsection{Determinación de la constante de afinidad frente a la tubulina}

La constante de afinidad aparente frente a la tubulina de los compuestos 73-77 se determinó mediante fluorescencia. Para ello se estudió previamente la solubilidad de estos compuestos obteniéndose los coeficientes de extinción $\varepsilon$ que se indican en la la tabla 4.12. Los resultados se presentan como la media y la desviación estándar de tres experimentos.

Tabla 4.12. Coeficientes de extinción $\varepsilon$.

\begin{tabular}{c|c|}
\hline Producto & $\varepsilon \pm \mathrm{SD}\left(\mathrm{M}^{-1} \mathrm{~cm}^{-1}\right)$ \\
\hline 73 & $14100 \pm 2500$ \\
\hline 74 & $12800 \pm 1700$ \\
\hline 75 & $9100 \pm 2500$ \\
76 & $10300 \pm 1400$ \\
77 & $9300 \pm 1500$ \\
\hline
\end{tabular}

La emisión de la fluorescencia intrínseca de la tubulina se midió excitando los residuos de triptófano a $295 \mathrm{~nm}$. Las medidas se tomaron después de 15 min de incubación del respectivo compuesto a diferentes concentraciones, 
con la tubulina en concentración aproximada de $2 \mu \mathrm{M}$ utilizando un tampón de $20 \mathrm{mM}$ de NaPi y $0,1 \mathrm{mM}$ de GTP a $\mathrm{pH} 7$.

A modo de ejemplo se muestran en la gráfica 4.8 los resultados obtenidos para el compuesto 75. En ella se puede observar un descenso de la intensidad de la emisión de fluorescencia a partir de $330 \mathrm{~nm}$. Esta disminución se utilizó para llevar a cabo experimentos de valoración de unión cuya gráfica (véase la parte superior de la gráfica 4.8) representa el ajuste entre los valores experimentales (puntos negros) con la línea teórica calculada (véase la parte experimental).

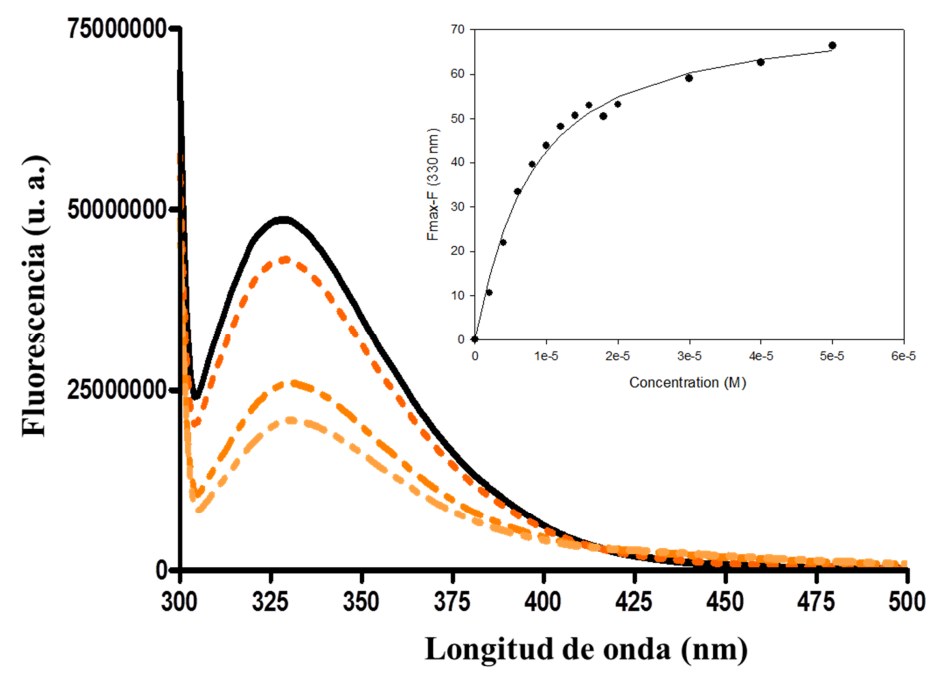

Gráfica 4.8. Modificación de los valores de fluorescencia del triptófano de la tubulina tras la unión al compuesto 75. Emisión de fluorescencia de $2 \mu \mathrm{M}$ tubulina (línea negra), con $2 \mu \mathrm{M}(\cdots), 10 \mu \mathrm{M}(-\cdot-)$ y $20 \mu \mathrm{M}(-\cdots)$ de 75 . Esquina superior: curva de valoración a diferentes concentraciones del compuesto 75 .

Tras el análisis de la curva se obtuvieron los valores de la constante de afinidad aparente de la colchicina y de los compuestos seleccionados. Dichos valores se indican en la siguiente tabla. 
Tabla 4.13. Constante de afinidad aparente.

\begin{tabular}{c|c}
\hline Producto & $\left(\mathrm{K}_{\mathrm{a}} \pm \mathrm{SD}\right) \times 10^{4}\left(\mathrm{M}^{-1}\right)$ \\
\hline Colchicina & $9 \pm 3$ \\
73 & $6,4 \pm 2,0$ \\
74 & $5,2 \pm 1,1$ \\
75 & $17,9 \pm 2,3$ \\
76 & $18,4 \pm 1,6$ \\
77 & $19,0 \pm 2,3$ \\
\hline
\end{tabular}

La colchicina y los compuestos 73 y $\mathbf{7 4}$ (con restos hexanoílo y octanoílo, respectivamente) presentan constantes de afinidad aparente en el mismo rango. Sin embargo, los derivados 75,76 y 77 (con restos decanoílo, undecanoílo y dodecanoílo, respectivamente) presentan un mayor valor de la constante de afinidad aparente, siendo el compuesto de mayor longitud de cadena, el $\mathbf{7 7}$ (dodecanoílo) el que presenta el valor más elevado.

\subsubsection{Efecto sobre el ciclo celular}

Los agentes que se unen a la tubulina paran el ciclo celular en la fase G2/M provocando el bloqueo mitótico.

La acumulación de células en fase G2/M se midió mediante citometría de flujo. En la tabla 4.14 se resumen los resultados obtenidos para la colchicina y los derivados 73-77. Los compuestos se incubaron durante $24 \mathrm{~h}$ con células A549 a dos concentraciones: su valor de $\mathrm{IC}_{50}$ y diez veces dicho valor. 
Tabla 4.14. Distribución del ciclo celular.

\begin{tabular}{|c|c|c|c|c|c|}
\hline Prod. & [C] (nM) & SubG1 & G1 & $\mathbf{S}$ & G2/M \\
\hline Control & -- & $0,6 \pm 0,5$ & $38,4 \pm 2,8$ & $52,3 \pm 8,0$ & $6,6 \pm 1,8$ \\
\hline \multirow{2}{*}{ CLC } & $\mathrm{IC}_{50}(14 \mathrm{nM})$ & $0,4 \pm 0,6$ & $32,3 \pm 9,1$ & $57,2 \pm 11,7$ & $7,9 \pm 2,8$ \\
\hline & $10 \times I_{50}$ & $2,3 \pm 0,2$ & $7,4 \pm 3,0$ & $52,1 \pm 10,1$ & $31,8 \pm 1,8$ \\
\hline \multirow{2}{*}{73} & $\mathrm{IC}_{50}(18 \mathrm{nM})$ & $2,8 \pm 1,1$ & $14,8 \pm 6,1$ & $56,0 \pm 5,0$ & $27,0 \pm 9,2$ \\
\hline & $10 \times I_{50}$ & $4,4 \pm 4,3$ & $8,5 \pm 5,2$ & $47,7 \pm 5,9$ & $36,2 \pm 10,0$ \\
\hline \multirow{2}{*}{74} & $\mathrm{IC}_{50}(133 \mathrm{nM})$ & $2,5 \pm 1,5$ & $4,6 \pm 1,4$ & $55,7 \pm 2,4$ & $38,3 \pm 5,2$ \\
\hline & $10 \times I_{50}$ & $1,9 \pm 0,9$ & $4,9 \pm 0,7$ & $60,5 \pm 2,0$ & $33,2 \pm 2,1$ \\
\hline \multirow{2}{*}{75} & $\mathrm{IC}_{50}(25 \mathrm{nM})$ & $1,7 \pm 0,2$ & $8,1 \pm 7,5$ & $53,8 \pm 9,9$ & $37,2 \pm 16,3$ \\
\hline & $10 \times 1 C_{50}$ & $1,8 \pm 0,9$ & $5,1 \pm 1,0$ & $52,3 \pm 9,2$ & $36,3 \pm 3,5$ \\
\hline \multirow{2}{*}{76} & $\mathrm{IC}_{50}(62 \mathrm{nM})$ & $1,5 \pm 0,5$ & $3,9 \pm 1,4$ & $53,3 \pm 2,1$ & $41,6 \pm 4,4$ \\
\hline & $10 \times I_{50}$ & $2,2 \pm 0,7$ & $8,7 \pm 2,0$ & $57,6 \pm 9,5$ & $32,1 \pm 12,1$ \\
\hline \multirow{2}{*}{77} & $\mathrm{IC}_{50}(71,9 \mathrm{nM})$ & $3,7 \pm 0,5$ & $13,8 \pm 2,0$ & $55,5 \pm 1,5$ & $27,2 \pm 3,2$ \\
\hline & $10 \times 1 C_{50}$ & $1,6 \pm 0,3$ & $12,9 \pm 2,4$ & $54,7 \pm 1,1$ & $31,0 \pm 1,3$ \\
\hline
\end{tabular}

Todos los compuestos analizados provocaron una acumulación de células, de alrededor del $30 \%$, en la fase G2/M (en el control sólo se acumulaba un $6 \%$ ). Cabe destacar que los compuestos sintéticos detienen las células en la fase G2/M independientemente de la concentración de compuesto utilizada, a diferencia de la colchicina, que requiere una concentración diez veces el valor de su $\mathrm{IC}_{50}$ para conseguir dicho efecto. Los compuestos 73 y 75 son los que logran la acumulación de células en G2/M a menor concentración (18 nM y $25 \mathrm{nM}$, respectivamente). 


\subsubsection{Efecto sobre la red de microtúbulos}

El efecto de los derivados de colchicina sobre la red de microtúbulos se estudió sobre la línea celular A549 mediante inmunofluorescencia. En el apartado 4.3.1 se muestran los valores de citotoxicidad de los compuestos y en función de estos datos se seleccionaron los compuestos 73 y 75 , que presentaban un valor de $\mathrm{IC}_{50}$ próximo al de la colchicina.

En la figura 4.28 se muestra el efecto sobre la red de microtúbulos. La imagen A corresponde a células A549 sin tratar. Se puede apreciar que la red citoplasmática de microtúbulos está totalmente organizada. Las imágenes $B$, C y D corresponden a células tratadas con colchicina y con 73 y 75 , respectivamente. Se observa en estas tres imágenes la completa despolimerización de la red de microtúbulos citoplasmáticos. 

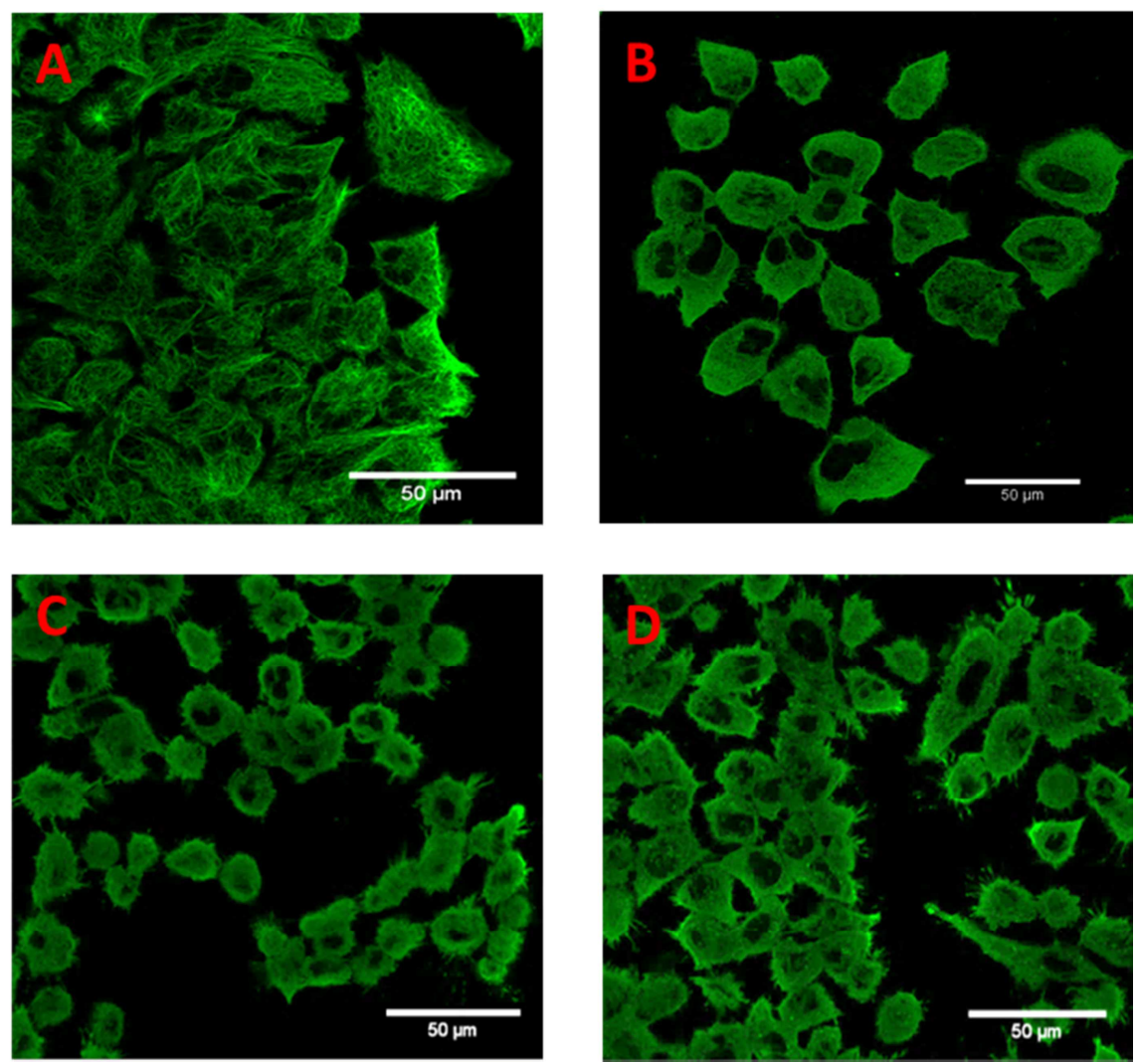

Figura 4.28. A: redes de microtúbulos citoplasmáticos de células A549 sin tratar. B: en presencia de $100 \mathrm{nM}$ de colchicina. C: en presencia de $100 \mathrm{nM}$ de 73. D: en presencia de $100 \mathrm{nM}$ de 75. La escala representa $50 \mu \mathrm{m}$.

\subsubsection{Efecto sobre la expresión de los genes VEGF, hTERT y c-Myc en HT-29}

Para estudiar el efecto sobre la expresión de los genes VEGF, hTERT y $c-M y c$ se seleccionaron los compuestos 73-77, que contienen cadenas de acilo, y los compuestos $\mathbf{8 2 - 8 5}$, que contienen cadenas de haloacetilo. El efecto se investigó sobre células HT-29. En la figura 4.29 se indican las estructuras de los compuestos investigados en este apartado así como las concentraciones empleadas de cada uno de ellos, que era siempre alrededor o por debajo de su $\mathrm{IC}_{50}$. A efectos de comparación también se incluyen los resultados obtenidos con la colchicina a $10 \mathrm{nM}$ y a $40 \mathrm{nM}$. 
<smiles>[R]C(=O)N[C@H]1CCc2cc(OC)c(OC)c(OC)c2-c2ccc(OC)c(=O)cc21</smiles>

$73 \mathrm{R}=\left(\mathrm{CH}_{2}\right)_{4} \mathrm{CH}_{3}(3 \mathrm{nM})$

$74 \mathrm{R}=\left(\mathrm{CH}_{2}\right)_{6} \mathrm{CH}_{3} \quad(1,5 \mathrm{nM})$

$75 \mathrm{R}=\left(\mathrm{CH}_{2}\right)_{8} \mathrm{CH}_{3} \quad(1,5 \mathrm{nM})$

$76 \mathrm{R}=\left(\mathrm{CH}_{2}\right)_{9} \mathrm{CH}_{3} \quad(0,5 \mathrm{nM})$

$77 \mathrm{R}=\left(\mathrm{CH}_{2}\right){ }_{10} \mathrm{CH}_{3}(1,5 \mathrm{nM})$<smiles>[X]CC(=O)N[C@H]1CCc2cc(OC)c(OC)c(OC)c2-c2ccc(OC)c(=O)cc21</smiles>

$82 X=F \quad(3 \mathrm{nM})$

$83 \mathrm{X}=\mathrm{Cl}(3 \mathrm{nM})$

$84 \mathrm{X}=\mathrm{Br}(10 \mathrm{nM})$

$85 \mathrm{X}=\mathrm{I} \quad(10 \mathrm{nM})$

Figura 4.29. Estructuras y concentraciones de los derivados de acilo y haloacetilo.

Los resultados de expresión del gen VEGF, obtenidos mediante qPCR, se muestran en la gráfica 4.9.

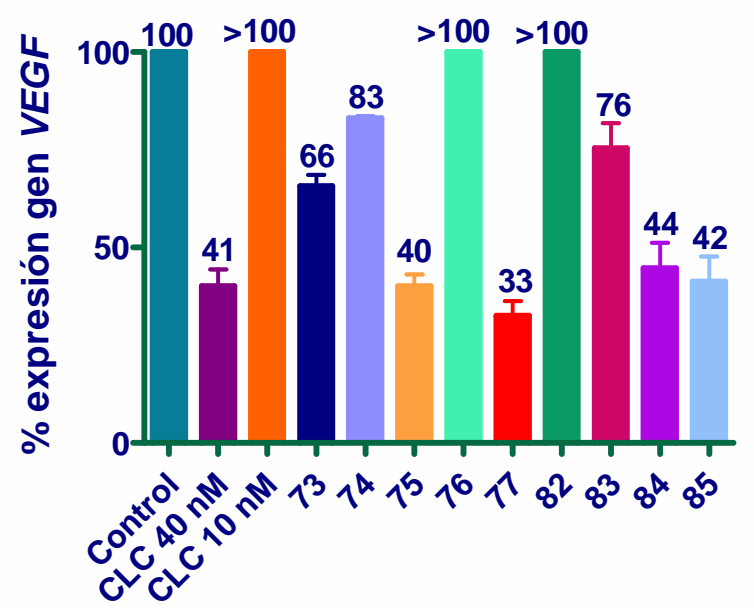

Gráfica 4.9. Resultados de la expresión del gen VEGF.

Como muestra la figura anterior, la mayoría de los compuestos presentan unos porcentajes de expresión del gen VEGF menores que el de la colchicina (a $10 \mathrm{nM}$ ). Los compuestos más activos son 75, 77, 84 y 85 que presentan 
valores de expresión similares a los de la colchicina (a $40 \mathrm{nM}$ ), pero a concentraciones 25 veces menores (compuestos 75 y 77 ) y cuatro veces menores (compuestos 84 y 85 ).

Los resultados de expresión del gen hTERT se indican en la gráfica 4.10.

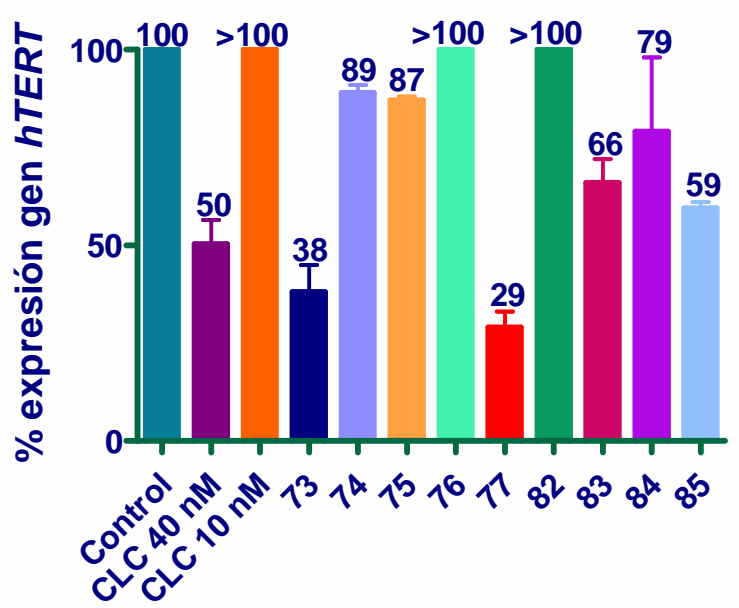

Gráfica 4.10. Resultados de la expresión del gen hTERT.

De nuevo, la mayoría de los compuestos provocan una disminución en la expresión del gen $h T E R T$ que la que provoca la colchicina a $10 \mathrm{nM}$, que apenas da lugar a inhibición. Los más activos son 73 y 77 ya que a concentraciones 12 y 25 veces menores que la colchicina, respectivamente, reducen más la expresión del gen $h T E R T$ que el producto natural a $40 \mathrm{nM}$. 
Los resultados de expresión del gen $c-M y c$ se muestran en la gráfica 4.11.

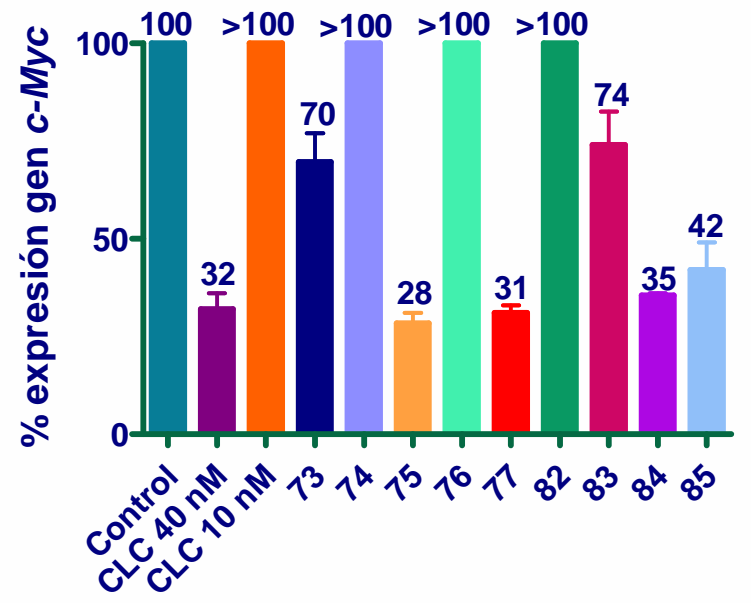

Gráfica 4.11. Resultados de la expresión del gen c-Myc.

Los compuestos más activos en la reducción de la expresión del gen $c-M y c$ son $73,75,77,83,84$ y 85 ya que mejoran la actividad de la colchicina (a 10 nM). Los derivados 75,77 y $\mathbf{8 4}$ presentan valores de expresión alrededor del $30 \%$, similares a los del producto natural (a $40 \mathrm{nM}$ ), pero a concentraciones cuatro veces menores (compuesto 84) y 25 veces menores (compuestos 75 y 77).

\subsubsection{Efecto sobre la secreción de la proteína VEGF-A ${ }_{165}$ en HT-29}

Los compuestos seleccionados para el estudio de la expresión de genes se emplearon también en el estudio de inhibición de la secreción de la proteína VEGF- $A_{165}$ en la línea celular HT-29. Los derivados se estudiaron en las mismas concentraciones mostradas en la figura 4.29. Los resultados obtenidos se muestran en la gráfica 4.12 . 


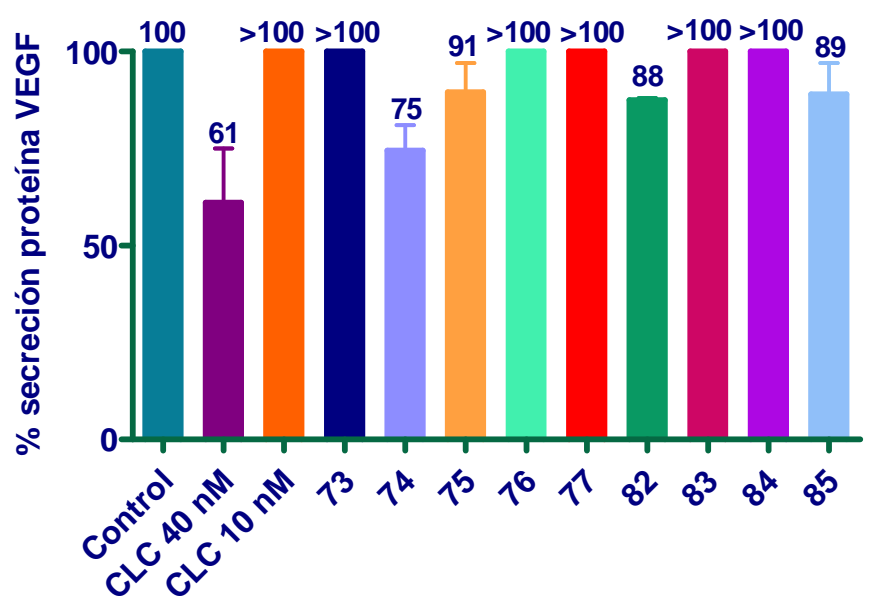

Gráfica 4.12. Resultados de la secreción de la proteína VEGF.

Se observa en la gráfica anterior que ningún derivado es capaz de mejorar la reducción de la secreción de la proteína VEGF mostrada por la colchicina a 40 nM. No obstante, los compuestos 74, 75, 82 y 85 son capaces de disminuir la secreción de la proteína VEGF con más intensidad que la colchicina cuando la concentración del producto natural es de $10 \mathrm{nM}$.

\subsubsection{Docking}

La interacción con tubulina de algunos derivados de la familia 2 se ha estudidado mediante cálculos computacionales utilizando el programa Autodock 4.2 y el PDB 1SA0. En la figura 4.30 se muestra la superposición de la estructura de la colchicina (negro) con la de los compuestos 75 (naranja), 76 (rojo) y 77 (morado) y con la estructura cristalográfica de la DAMAcolchicina (azul). 


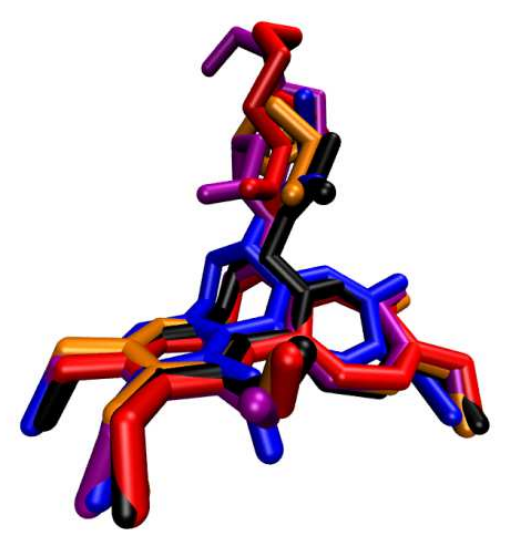

Figura 4.30. Superposición de la estructura de la colchicina (negro), 75 (naranja), 76 (rojo) y $\mathbf{7 7}$ (morado) con la estructura cristalográfica de la DAMA-colchicina (azul).

En la figura 4.31 se muestra la unión de la colchicina y de 75, 76 y 77 en la interfaz del fragmento de aß-tubulina, en una conformación similar a la que presenta la estructura cristalográfica de la DAMA-colchicina (datos obtenidos del PDB 1SA0). Los resultados de docking muestran que la parte tricíclica de 75, 76 y 77 (paneles $B, C$ y D, respectivamente) se coloca en la subunidad de $\beta$-tubulina (verde) en una posición similar a la de la colchicina (panel A). A diferencia de la colchicina, la longitud de la cadena acílica de 75, 76 y 77 les permite a estos compuestos introducir su resto acílico en un surco presente en la subunidad de la a-tubulina (amarillo). 

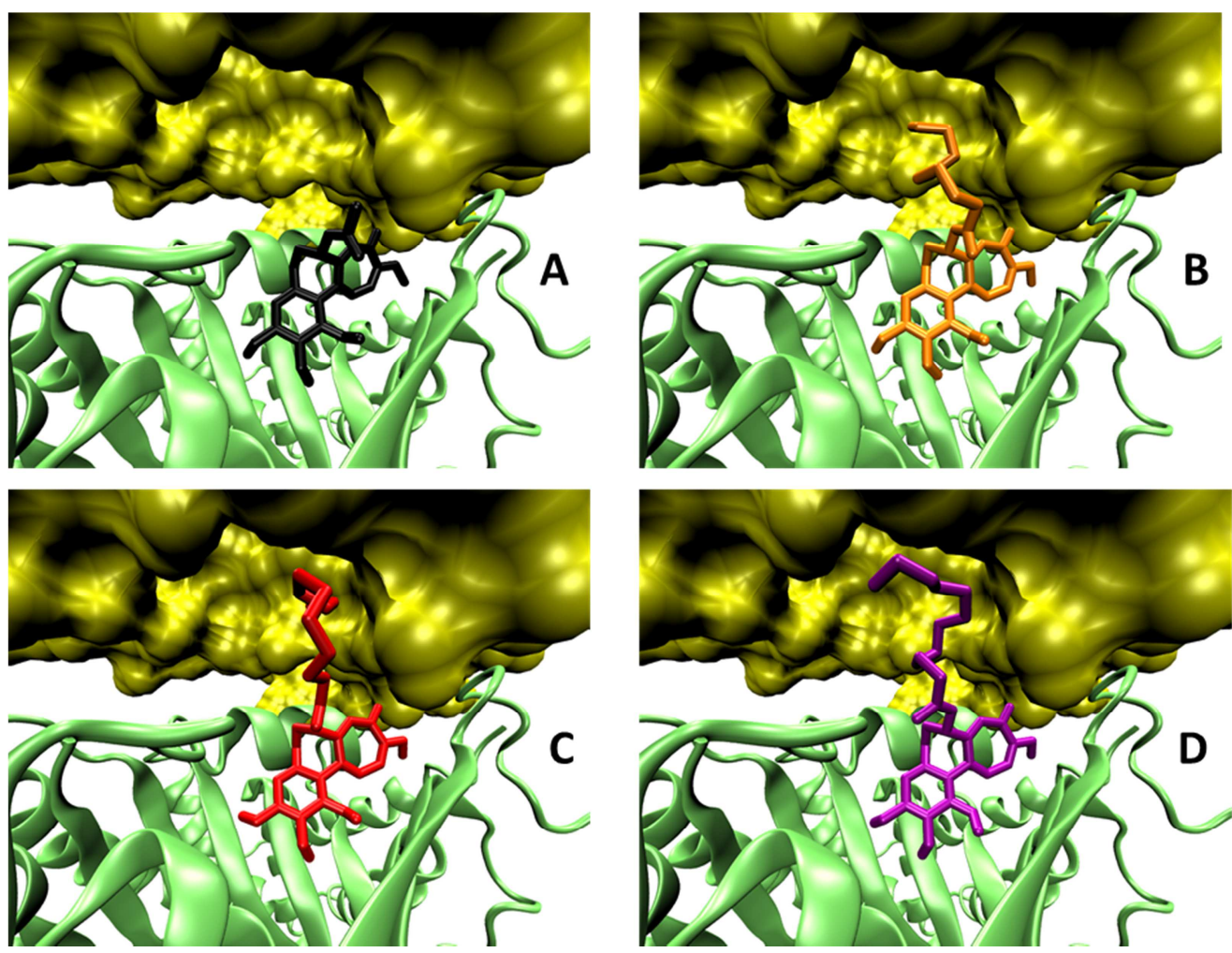

Figura 4.31. Sitio de unión del compuesto colchicina (A), $75(B), 76(C)$ y 77 (D) en la tubulina, cuya subunidad $\beta$ se representa en verde y la $\alpha$ en amarillo.

La interacción con la a-tubulina de la cadena acílica de $\mathbf{7 5 ,} 76$ y 77 (decanoílo, undecanoílo y dodecanoílo, respectivamente) podría explicar su mayor constante de afinidad aparente con la tubulina y también su capacidad de formación de polímeros anómalos.

Los cálculos de docking con los compuestos con restos acílicos más largos, como $\mathbf{8 0}$ (hexadecanoílo) y $\mathbf{8 1}$ (octadecanoílo) se muestran en la figura 4.32. Se aprecia que sus cadenas alifáticas también son capaces de introducirse en el bolsillo de la a-tubulina. Sin embargo estos resultados teóricos no concuerdan con la menor actividad inhibitoria de 80 y 81 en el ensayo de la concentración crítica de tubulina, en el cual estos dos compuestos presentan menor potencia que la colchicina. 

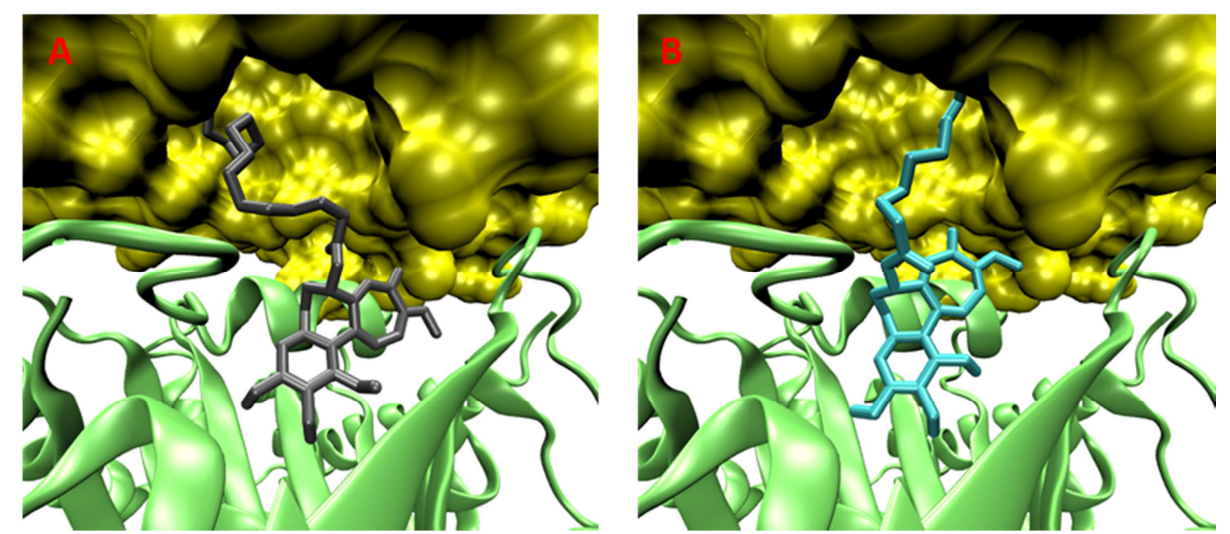

Figura 4.32. Sitio de unión del compuesto 80 (A) y 81 (B) en la tubulina, cuya subunidad $\beta$ se representa en verde y la $\alpha$ en amarillo.

En los anteriores cálculos computacionales se empleó una versión simplificada del PDB, en la que se eliminaron las moléculas de GTP y GDP. El GTP de la a-tubulina se coloca en las proximidades del centro de unión de la colchicina, por lo que es muy probable que dicha molécula impida la inserción de las cadenas alifáticas muy largas, como las de 80 y $\mathbf{8 1}$, en el bolsillo de la a-tubulina. En la figura 4.33 se representa en su parte izquierda la unión de $\mathbf{7 7}$ (panel A), de $\mathbf{8 0}$ (panel B) y de $\mathbf{8 1}$ (panel C) a la tubulina que no contiene GTP en la subunidad $\alpha$, mientras que la parte derecha de la figura 4.33 representa la unión de los mismos compuestos a la tubulina que contiene GTP en la subunidad $\alpha$. Se observa que la cadena acílica de 77 (resto de dodecanoílo) encaja bien en el surco de la $\alpha$-tubulina, independientemente de la presencia de GTP. Por el contrario, 80 (hexadecanoílo) y 81 (octadecanoílo) se introducen en el surco de a-tubulina, cuando no está presente el GTP, pero no son capaces de introducirse en este bolsillo cuando en él está presente dicha molécula, lo que obliga al doblamiento de sus restos acílicos, colocándose éstos en la interfaz de la $\alpha \beta$-tubulina. 


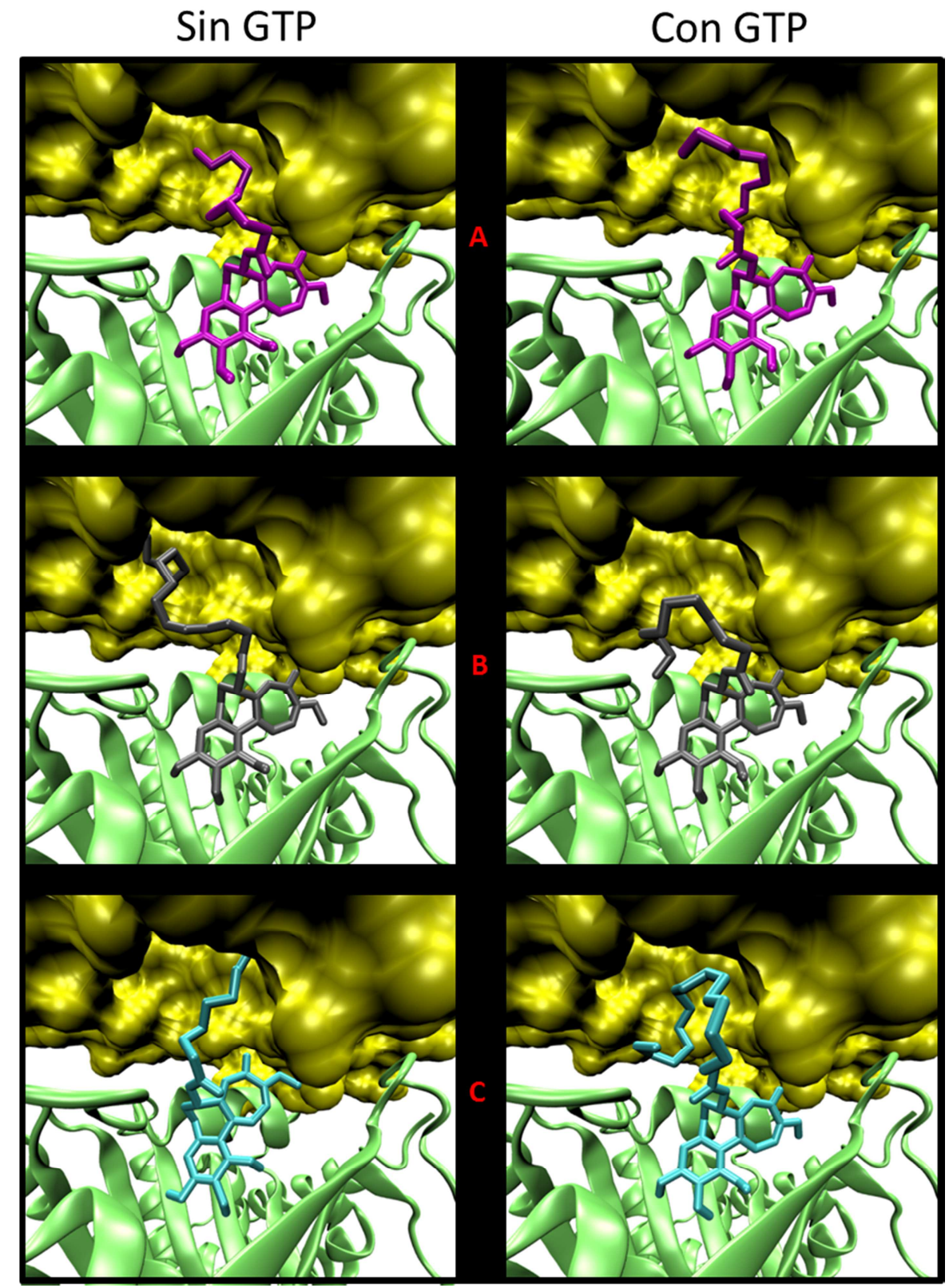

Figura 4.33. Sitio de unión del compuesto 77 (A), 80 (B) y 81 (C) en la tubulina, cuya subunidad $\beta$ se representa en verde y la $\alpha$ en amarillo. La columna de la izquierda corresponde a los cálculos realizados sin el GTP y la columna de la derecha representa los resultados incluyendo la molécula de GTP. EI GTP no está visible en estas representaciones. 
Para los tres compuestos $75-77$, cuya actividad frente a tubulina ha sido ampliamente estudiada, se ha realizado una representación 2D de su unión a tubulina utilizado el programa LigPlot+.

Las interacciones 2D de $\mathbf{7 5}$ con la tubulina se representan en la figura 4.34. Se observa que el derivado 75 establece un enlace de hidrógeno con el residuo Val-181 de $\alpha$-tubulina y Cys-241 de la $\beta$-tubulina. Además, la longitud de su cadena acílica le permite establecer interacciones con el residuo de GTP presente en la $\alpha$-tubulina.

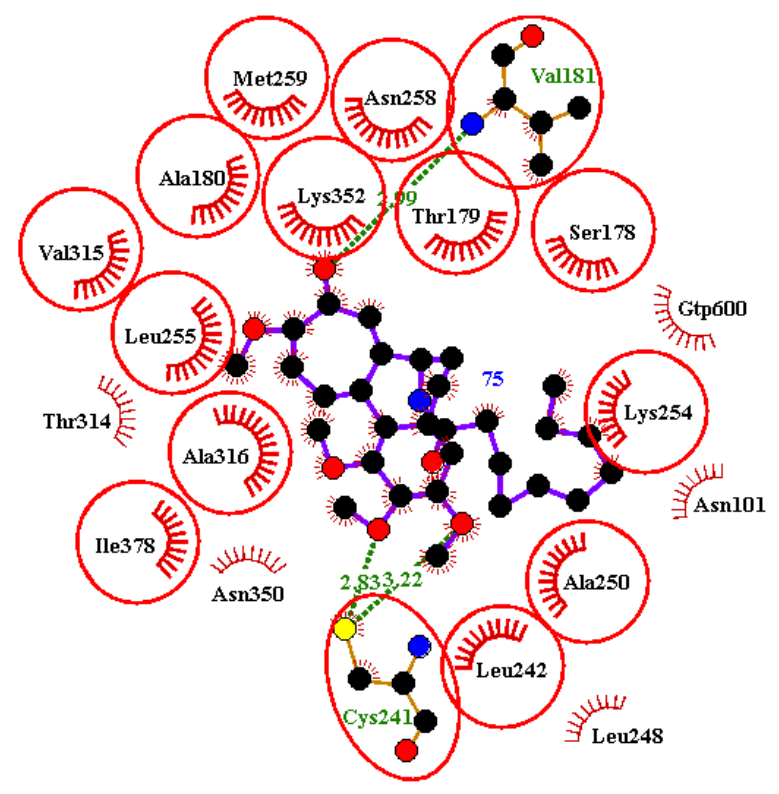

Figura 4.34. Interacciones en 2D de 75 con tubulina.

Las interacciones 2D de 76 con la tubulina se representan en la figura 4.35. Este compuesto presenta enlaces de hidrógeno con los residuos Ser-178 de $\alpha$-tubulina y Cys-241 de la $\beta$-tubulina y también establece una interacción con el GTP. Otras interacciones de 76 con aminoácidos de la $\alpha$-tubulina son las que se establecen con Tyr-224 y Glu-183. 


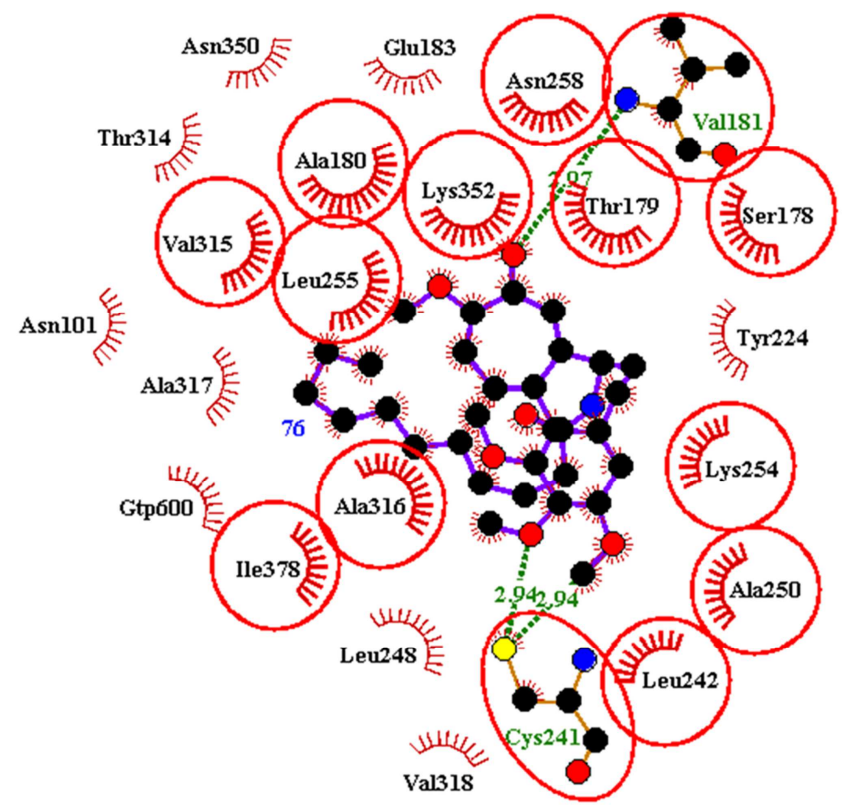

Figura 4.35. Interacciones en 2D con tubulina del derivado 76 .

Las interacciones 2D de 77 con la tubulina se representan en la figura 4.36. Se aprecian tres enlaces de hidrógeno, dos con el residuo Cys-241 ( $\beta$-tubulina) y uno con el residuo Val-181 ( $\alpha$-tubulina). La longitud de su cadena acílica también le permite interactuar con el GTP de la $\alpha$-tubulina. El compuesto 77 también muestra un mayor número de interacciones con la subunidad $\alpha$ a través de los residuos Gln-11, Asn-101, Glu-183 y Tyr-224. Estas interacciones no están presentes en la DAMA-colchicina y podrían explicar la capacidad de estos compuestos para formar polímeros anómalos a concentraciones más bajas que las de la colchicina, como también su menor valor de $\mathrm{IC}_{50}$ frente a la polimerización de tubulina y su mayor constante de afinidad aparente. 


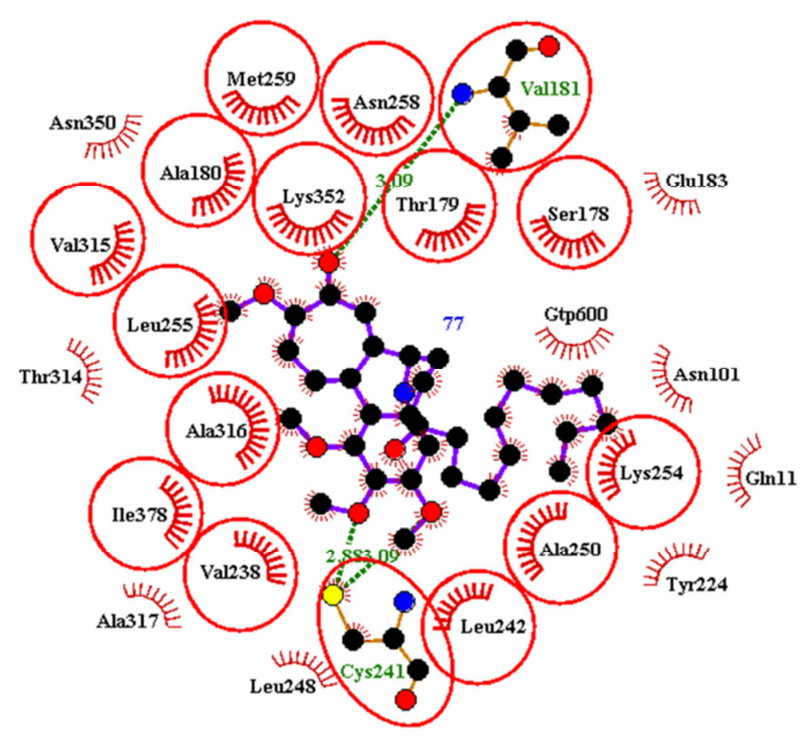

Figura 4.36. Interacciones en 2D con tubulina del derivado 77 .

Los compuestos 82-85, que presentan cadenas de haloacetilo, también se estudiaron mediante modelización docking. Como puede observarse en la figura 4.37, todos estos derivados se unen en el sitio de la colchicina, situado en la interfaz de la $\alpha \beta$-tubulina, en una conformación similar a la que presenta la estructura cristalográfica de la DAMA-colchicina (datos obtenidos del PDB 1SA0).
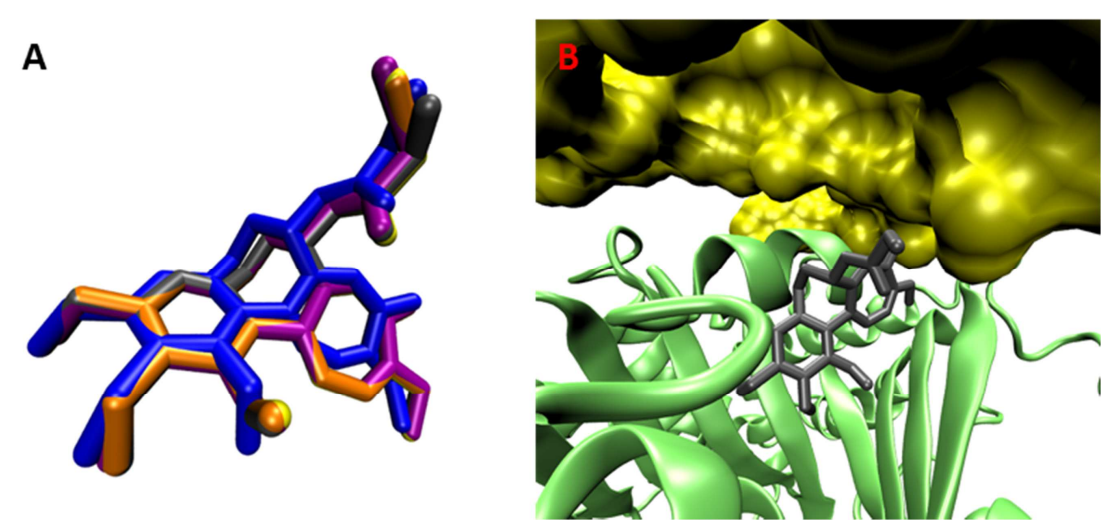

Figura 4.37. Panel A: Superposición de DAMA-colchicina (azul) con los haloacetil derivados 82 (gris), 83 (naranja), 84 (amarillo) y 85 (morado). Panel B: Sitio de unión de 82 (gris) en la tubulina, cuya subunidad $\beta$ se representa en verde y la $\alpha$ en amarillo. 
Las interacciones 2D de 82 con la tubulina se indican en la figura 4.38. Puede observarse que $\mathbf{8 2}$ presenta casi las mismas interacciones que la DAMA-colchicina, ${ }^{131}$ lo que está de acuerdo con los valores de concentración crítica de estos haloderivados, que son muy similares a los de la colchicina.

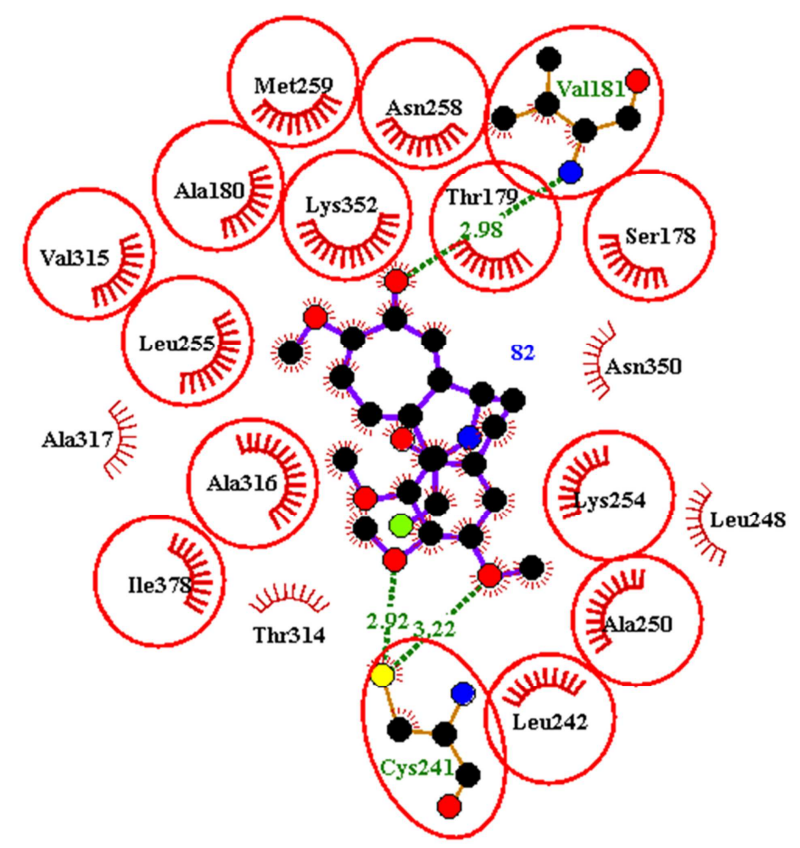

Figura 4.38. Interacciones en 2D con tubulina del derivado $\mathbf{8 2}$.

\subsubsection{Resumen y conclusiones}

- La mayoría de compuestos sintetizados presentan una alta actividad citotóxica en el rango nanomolar en todas las líneas celulares estudiadas. Los derivados 75, 76 y 77 (véase la figura 4.39) exhiben incluso actividad en el rango picomolar en la línea celular HT-29, lo que los hace dos-tres órdenes de magnitud más citotóxicos que la propia colchicina. En la misma línea celular, las actividades se encuentran estrechamente relacionadas con la longitud de la cadena, alcanzándose el máximo de actividad citotóxica (mínimo 
valor de $\mathrm{IC}_{50}$ ) con el compuesto 76 (véase la figura 4.39), que contiene una cadena de undecanoílo.

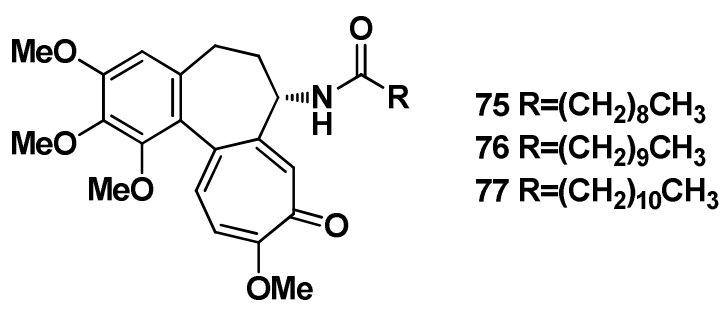

Figura 4.39.

- En el proceso de polimerización de tubulina los derivados 72, 73 y 82-85 (véase la figura 4.40) exhiben un comportamiento similar al de la colchicina y son capaces de impedir la formación de microtúbulos, mostrándose los derivados haloacetilados 82-85 (véase la figura 4.40) más activos que la propia colchicina. Los compuestos $\mathbf{7 4}, \mathbf{7 8}, \mathbf{7 9}$ y $\mathbf{8 0}$ se pueden clasificar como inhibidores parciales de la polimerización de tubulina, mientras que el compuesto 81 parace no afectar a dicho proceso. Además, 75-77 (véase la figura 4.39) inducen la formación de polímeros anómalos y son mucho más activos que la propia colchicina, exhibiendo menores valores de $\mathrm{IC}_{50}$ en el proceso de polimerización de tubulina y mayores constantes de afinidad.

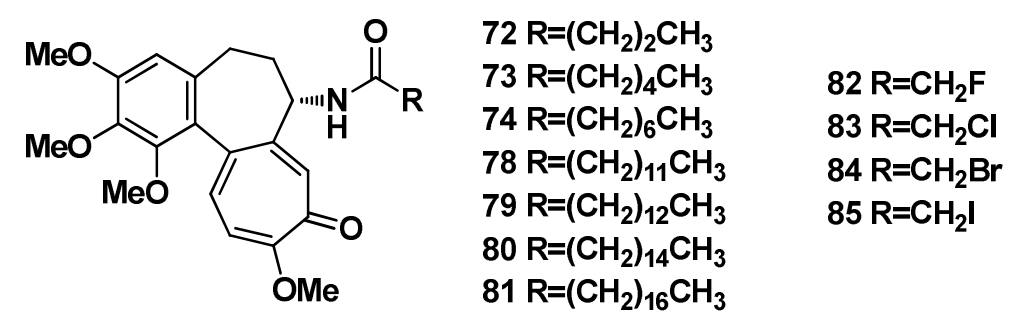

Figura 4.40.

- Los compuestos 73-77 (véase la figura 4.41) son asimismo capaces de provocar la detención del ciclo celular en la fase G2/M, con independencia de la concentración ensayada. Además, los 
derivados 73 y 75 (véase la figura 4.41) afectan a la red de microtúbulos citoplasmáticos.

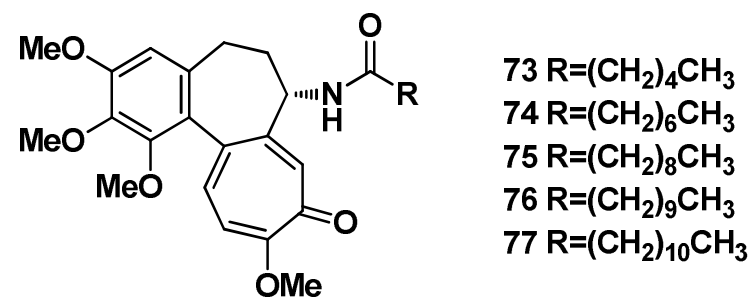

Figura 4.41.

- El compuesto que muestra la mayor capacidad de inhibición frente a los tres genes estudiados es el compuesto 77 (véase la figura 4.41), ya que a concentración de $1.5 \mathrm{nM}$ mejora la potencia inhibitoria de la propia colchicina medida a $40 \mathrm{nM}$. Los compuestos 75,84 y 85 (véase la figura 4.39 y 4.40), sin alcanzar la potencia de 77, también exhiben una capacidad inhibitoria del gen VEGF y del gen $h T E R T$ mayor que la de la colchicina.

- Los estudios de docking respaldan la interacción de los derivados con el sitio de unión de la colchicina, situado en la subunidad de $\beta$-tubulina. Además, el incremento de la longitud de la cadena acilo origina nuevas interacciones con un surco presente en la subunidad de a-tubulina lo que podría explicar la diferencia de comportamiento de los compuestos $\mathbf{7 5 ,} 76$ y 77 (véase la figura 4.39) en relación con la colchicina. 


\subsection{Evaluación biológica de los compuestos de la familia 3}

La familia 3 la constituyen derivados de colchicina generados por sustitución formal del grupo acetilo de la colchicina por grupos aroílo. En la figura 4.42 se indican las estructuras de esta serie de compuestos.<smiles></smiles>

$\begin{array}{ll}88 \mathrm{R}=\mathrm{Ph} & 94 \mathrm{R}=2-\mathrm{ClC}_{6} \mathrm{H}_{4} \\ 89 \mathrm{R}=4--\mathrm{BuC}_{6} \mathrm{H}_{4} & 95 \mathrm{R}=3-\mathrm{ClC}_{6} \mathrm{H}_{4} \\ 90 \mathrm{R}=4-n \mathrm{PentC}_{6} \mathrm{H}_{4} & 96 \mathrm{R}=4-\mathrm{ClC}_{6} \mathrm{H}_{4} \\ 91 \mathrm{R}=2-\mathrm{CH}_{3} \mathrm{C}_{6} \mathrm{H}_{4} & 97 \mathrm{R}=2-\mathrm{BrC}_{6} \mathrm{H}_{4} \\ 92 \mathrm{R}=3-\mathrm{CH}_{3} \mathrm{C}_{6} \mathrm{H}_{4} & 98 \mathrm{R}=3-\mathrm{BrC}_{6} \mathrm{H}_{4} \\ 93 \mathrm{R}=4-\mathrm{CH}_{3} \mathrm{C}_{6} \mathrm{H}_{4} & 99 \mathrm{R}=4-\mathrm{BrC}_{6} \mathrm{H}_{4}\end{array}$

Figura 4.42. Estructuras de los derivados de aroílo.

\subsubsection{Citotoxicidad}

Los valores de citotoxicidad de los compuestos sintetizados se midieron en las líneas celulares tumorales HT-29 y MCF-7 y en la no tumoral HEK-293. Los valores obtenidos se muestran en la tabla 4.15.

Tabla 4.15. Citotoxicidad y coeficientes de selectividad de los derivados de aroílo.

\begin{tabular}{|c|c|c|c|c|c|}
\hline \multirow[t]{2}{*}{ Producto } & & \pm SD $(n)$ & & \multicolumn{2}{|c|}{$\begin{array}{c}\text { Coeficientes } \\
\text { de } \\
\text { selectividad }\end{array}$} \\
\hline & HT-29 & MCF-7 & HEK-293 & $\alpha^{*}$ & $\beta^{\star \star}$ \\
\hline CLC & $50 \pm 3$ & $12 \pm 7$ & $5 \pm 1$ & 0,10 & 0,4 \\
\hline 88 & $8,1 \pm 0,9$ & $5 \pm 2$ & $13 \pm 5$ & 1,6 & 2,6 \\
\hline 89 & $32,7 \pm 2,1$ & $24 \pm 4$ & $58 \pm 11$ & 1,8 & 2,4 \\
\hline
\end{tabular}




\begin{tabular}{|c|c|c|c|c|c|}
\hline 90 & $4,2 \pm 1,2$ & $5,8 \pm 1,8$ & $1,6 \pm 0,4$ & 0,4 & 0,3 \\
\hline 91 & $5,7 \pm 0,5$ & $2,02 \pm 0,04$ & $9,0 \pm 1,2$ & 1,6 & 4,5 \\
\hline 92 & $2,23 \pm 0,23$ & $5,6 \pm 1,5$ & $3,1 \pm 0,9$ & 1,4 & 0,6 \\
\hline 93 & $9,0 \pm 2,2$ & $31 \pm 8$ & $16,1 \pm 0,6$ & 1,8 & 0,5 \\
\hline 94 & $2,3 \pm 0,4$ & $4,5 \pm 0,6$ & $5,93 \pm 0,06$ & 2,6 & 1,3 \\
\hline 95 & $1,8 \pm 0,3$ & $3,4 \pm 0,6$ & $3,0 \pm 0,3$ & 1,7 & 0,9 \\
\hline 96 & $1,79 \pm 0,15$ & $6,7 \pm 0,4$ & $10,1 \pm 2,4$ & 5,6 & 1,5 \\
\hline 97 & $5,8 \pm 0,3$ & $7,6 \pm 1,9$ & $8,5 \pm 2,8$ & 1,5 & 1,1 \\
\hline 98 & $0,56 \pm 0,04$ & $0,363 \pm 0,013$ & $1,1 \pm 0,3$ & 2,0 & 3,0 \\
\hline 99 & $11,4 \pm 1,2$ & $8,9 \pm 0,7$ & $7,8 \pm 1,9$ & 0,7 & 0,9 \\
\hline
\end{tabular}

Todos los derivados de aroílo presentan actividad nanomolar baja en todas las líneas celulares estudiadas. En la línea celular tumoral HT-29, estos derivados se muestran más citotóxicos que la propia colchicina y exhiben además mayores valores de selectividad que el producto natural. El compuesto más citotóxico en HT-29 es 98 que presenta un valor de $\mathrm{IC}_{50}$ en el rango picomolar.

En la línea celular MCF-7 la mayoría de los compuestos presentan también valores de $\mathrm{IC}_{50}$ inferiores a los de la colchicina. Hay que resaltar de nuevo al compuesto 98, que presenta un $\mathrm{IC}_{50}$ en el rango picomolar.

De los resultados obtenidos en la línea celular HT-29 se seleccionaron los compuestos 88, 92, 94, 95, 96 y 98 para los siguientes análisis biológicos. La citotoxicidad de todos estos derivados de aroílo en la línea celular tumoral 
A549 se estudió en los laboratorios de la Facultad de Farmacia de la Universidad de Aix-Marseille.

Tabla 4.16. Citotoxicidad en la línea celular A549.

\begin{tabular}{c|c}
\hline \multirow{2}{*}{ Producto } & $\mathrm{IC}_{50} \pm$ SD $(\mathrm{nM})$ \\
\cline { 2 - 2 } Colchicina & A549 \\
\hline 88 & $14 \pm 6$ \\
92 & $12 \pm 3$ \\
94 & $20,1 \pm 0,4$ \\
95 & $18,9 \pm 0,9$ \\
96 & $27 \pm 4$ \\
98 & $60 \pm 3$ \\
\hline
\end{tabular}

De los datos obtenidos podemos destacar que todos los compuestos presentan actividad nanomolar. Sin embargo, solamente los compuestos $\mathbf{8 8}$, 92 y 94 exhiben una actividad parecida a la colchicina.

\subsubsection{Efecto sobre el ensamblaje de microtúbulos}

Los efectos de estos derivados sobre la polimerización in vitro de tubulina se midieron mediante turbidimetría utilizando un tampón GAB. En la tabla 4.17 se indican los poncentajes de polimerización de tubulina obtenidos con estos derivados y con la colchicina respecto del control (DMSO). 
Tabla 4.17. Porcentaje de polimerización de tubulina de los derivados de la familia $3^{137}$

\begin{tabular}{|c|c|}
\hline Producto & \% polimerización \\
\hline Control & 100 \\
Colchicina & 6 \\
\hline 88 & 119 \\
89 & 14 \\
90 & 70 \\
91 & 33 \\
92 & 90 \\
93 & 25 \\
94 & 169 \\
95 & 113 \\
96 & 135 \\
97 & 35 \\
98 & 119 \\
99 & 33 \\
\hline
\end{tabular}

Como puede observarse en la tabla anterior, solamente el compuesto $\mathbf{8 9}$ presenta un comportamiento similar al de la colchicina, ya que reduce el proceso de polimerización de la tubulina hasta un $14 \%$.

Los derivados 90, 91, 93, 97 y 99 disminuyen el porcentaje de polimerización en relación con el control, pero no alcanzan los valores mostrados por la colchicina, por lo que estos compuestos se podrían clasificar como inhibidores parciales de la polimerización de la tubulina. El derivado $\mathbf{9 2}$ afecta débilmente al proceso de polimerización de la tubulina.

Los compuestos 88, 94, 95, 96 y 98 muestran un mayor incremento de la masa de polímero que el propio control. Esto podría deberse a un efecto

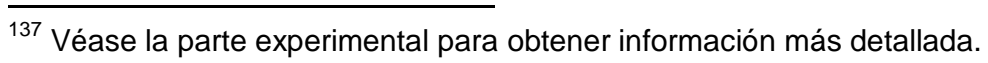


estabilizador de los microtúbulos, como el que exhibe el paclitaxel, pero también podría ser debido a la formación de polímeros anómalos. Si tenemos en cuenta los resultados de los derivados de la familia 2, es probable que estos derivados también favorezcan la formación de polímeros anómalos, aunque habrían de realizarse más experimentos para poder respaldar esta hipótesis.

Para estudiar el efecto sobre la cinética de la polimerización de la tubulina se seleccionaron los compuestos $90,91,93,97$ y 99 . En la la gráfica 4.13 se representan los efectos de estos compuestos en la polimerización in vitro de tubulina seguida mediante turbidimetría. Como puede apreciarse, los derivados 90, 91, 93, 97 y 99, disminuyen la absorbancia de la fase estacionaria en relación con la que se mide en la prueba de control. Además, los derivados 93 y 99 ralentizan el proceso de nucleación unos 10 minutos respecto del control, mientras que 91 y 97 ralentizan este proceso unos 15 minutos.

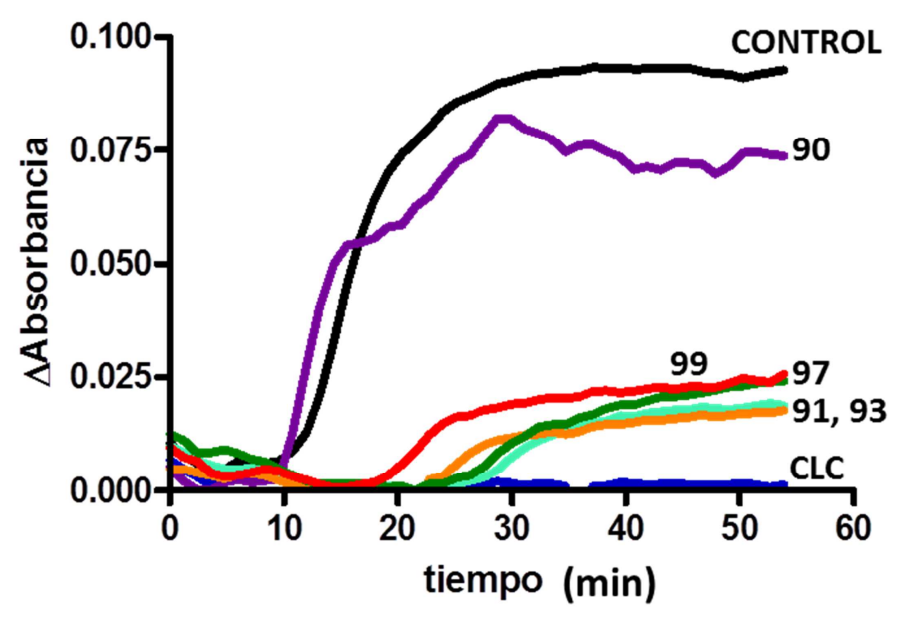

Gráfica 4.13. Resultados de la concentración crítica de tubulina de la familia 3. Las líneas representan la turbidimetría de la polimerización para la tubulina (línea negra), colchicina (línea azul), 90 (línea morada), 91 (línea naranja), 93 (línea verde clara), 97 (línea verde) y 99 (línea roja). 
En la tabla 4.18 se muestran los valores de $\mathrm{It}_{50}$ de 91, 93, 97 y 99, que son mayores que los que se obtienen en la prueba de control.

Tabla 4.18. Valores de $\mathrm{It}_{50}$ para los derivados de aroílo.

\begin{tabular}{cccccc}
\hline Prod. & Control & 91 & 93 & 97 & 99 \\
\hline $\mathrm{It}_{50}(\min )$ & $16,5 \pm 0,8$ & $32,6 \pm 0,3$ & $28,8 \pm 1,0$ & $34,0 \pm 0,5$ & $27 \pm 3$ \\
\hline
\end{tabular}

Los compuestos $91,93,97$ y 99 que presentan un valor comparativamente alto de concentración crítica con respecto al control (menor absorbancia de la fase estacionaria) y un mayor valor de $\mathrm{It}_{50}$ con respecto al control (aumento del tiempo necesario para la nucleación y elongación) se pueden considerar inhibidores parciales de la polimerización de la tubulina.

\subsubsection{Efecto sobre la expresión de los genes VEGF, hTERT y c-Myc en HT-29}

La expresión génica se estudió inicialmente mediante PCR convencional seguida de electroforesis. Todos los compuestos se ensayaron a concentraciones próximas a su $\mathrm{IC}_{50}$, a excepción del compuesto 89 , que se estudió a $30 \mathrm{nM}$ y a $5 \mathrm{nM}\left(\mathbf{8 9}^{*}\right)$. En la figura 4.43 se muestran los resultados de la electroforesis que incluyen también a la colchicina (empleada en concentración de $5 \mathrm{nM}$ ) y el control (células incubadas con DMSO).

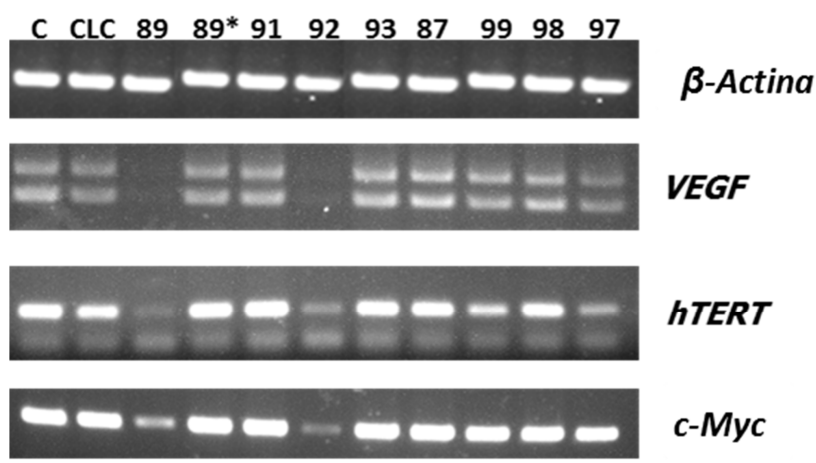

Figura 4.43. Resultados de la PCR convencional de los derivados aroílo. 
De los resultados anteriores se deduce que los compuestos 89 y 92 son capaces de inhibir la expresión de los tres genes objeto de estudio y que 97 y 99 inhiben principalmente la expresión del gen hTERT. Para los posteriores estudios mediante qPCR se eligieron estos cuatro compuestos junto con los derivados con un átomo de cloro (94-96) y el compuesto 98. Las estructuras y las concentraciones empleadas en los análisis mediante qPCR se indican en la figura 4.44 .<smiles>COc1cc2c(c(OC)c1OC)-c1ccc(OC)c(=O)cc1[C@@H](NC(=O)c1ccc(C(C)(C)C)cc1)CC2</smiles><smiles>COc1cc2c(c(OC)c1OC)-c1ccc(OC)c(=O)cc1[C@@H](NC(=O)c1cccc(C)c1)CC2</smiles><smiles>COc1cc2c(c(OC)c1OC)-c1ccc(OC)c(=O)cc1[C@@H](NC(=O)c1ccccc1Cl)CC2</smiles><smiles>COc1cc2c(c(OC)c1OC)-c1ccc(OC)c(=O)cc1[C@@H](NC(=O)c1cccc(Cl)c1)CC2</smiles><smiles>COc1cc2c(c(OC)c1OC)-c1ccc(OC)c(=O)cc1[C@@H](NC(=O)c1ccc(Cl)cc1)CC2</smiles><smiles>COc1cc2c(c(OC)c1OC)-c1ccc(OC)c(=O)cc1[C@@H](NC(=O)c1ccccc1Br)CC2</smiles><smiles>COc1cc2c(c(OC)c1OC)-c1ccc(OC)c(=O)cc1[C@@H](NC(=O)c1cccc(Br)c1)CC2</smiles><smiles></smiles>

Figura 4.44. Estructuras de los derivados aroílo seleccionados. 
En la siguiente gráfica se presentan los resultados obtenidos para el gen VEGF mediante qPCR.

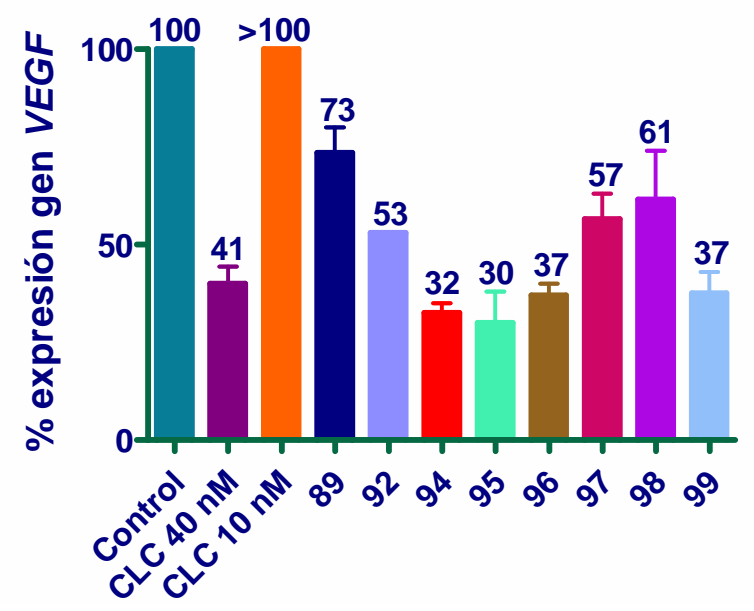

Gráfica 4.14. Resultados de la expresión del gen VEGF.

Todos los compuestos analizados muestran una mayor reducción de la expresión del gen VEGF que la colchicina a 10 nM. Los derivados 94, 95, 96 y 99 presentan valores de expresión de alrededor del 30\% a concentraciones menores que $10 \mathrm{nM}$, un efecto bastante mayor que el exhibido por la colchicina a concentración $40 \mathrm{nM}$. Conviene señalar también que el derivado 98 expresa aproximadamente un $60 \%$ el gen VEGF pero a la muy baja concentración de $0,5 \mathrm{nM}$. 
Los valores de expresión del gen $h T E R T$ se indican en la gráfica siguiente.

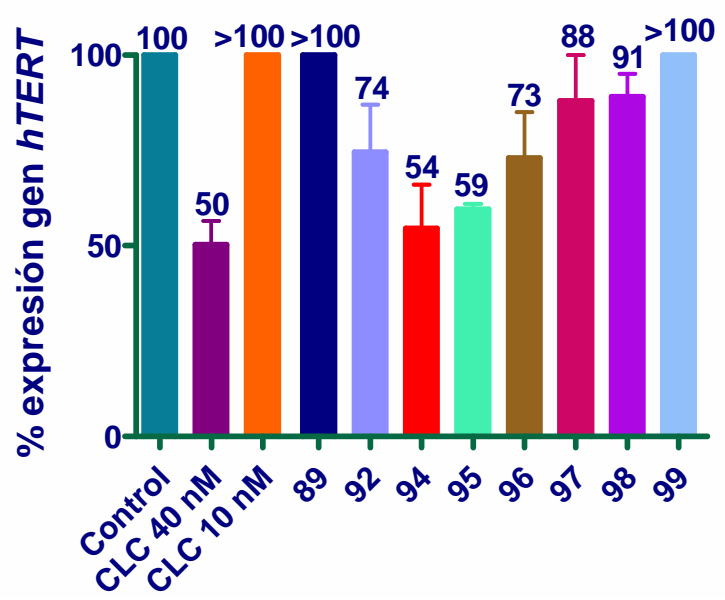

Gráfica 4.15. Resultados de la expresión del gen $h T E R T$.

Todos los compuestos, con excepción de 89 y 99, mejoran la actividad de la colchicina a $10 \mathrm{nM}$. Los derivados 94 y 95 expresan el gen $h T E R T$ de manera similar, en términos absolutos, a la colchicina a $40 \mathrm{nM}$, pero su acción inhibitoria es mucho mayor ya que fueron ensayados a concentraciones 25 veces menores a las de la colchicina.

Los valores de expresión del gen c-Myc se indican en la gráfica siguiente.

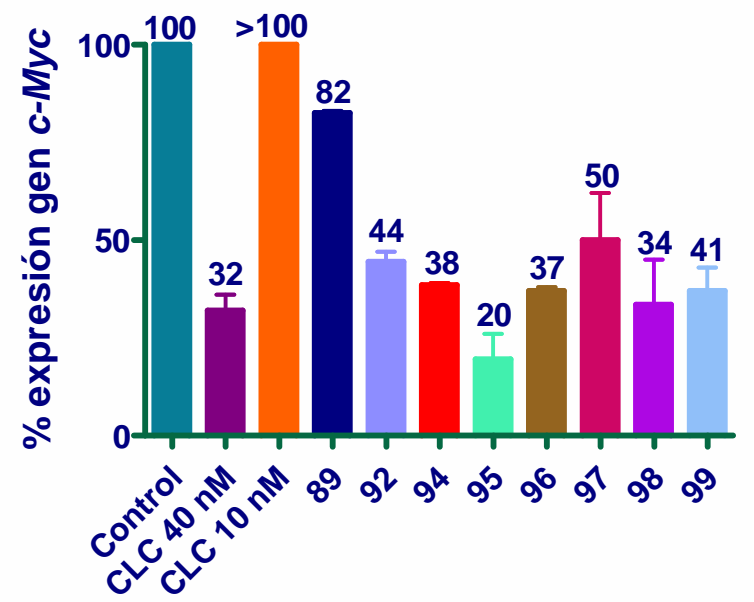

Gráfica 4.16. Resultados de la expresión del gen c-Myc. 
En lo referente al gen $c-M y c$, todos compuestos mejoran la actividad de la colchicina a $10 \mathrm{nM}$. Los derivados 94, 95, 96 y 98 presentan valores de expresión de entre el $20 \%$ y el $40 \%$, similares en valores absolutos a los del producto natural a $40 \mathrm{nM}$, pero mucho mayores en términos relativos ya que fueron ensayados a concentraciones 25 veces menores a las de la colchicina.

\subsubsection{Efecto sobre la secreción de la proteína VEGF-A $A_{165}$ en HT-29}

Los compuestos seleccionados para el estudio de la expresión de genes se emplearon también en el estudio de inhibición de la secreción de la proteína VEGF- $A_{165}$ en la línea celular HT-29. Los derivados se estudiaron en las mismas concentraciones mostradas en la figura 4.44. Los resultados obtenidos se muestran en la siguiente gráfica.

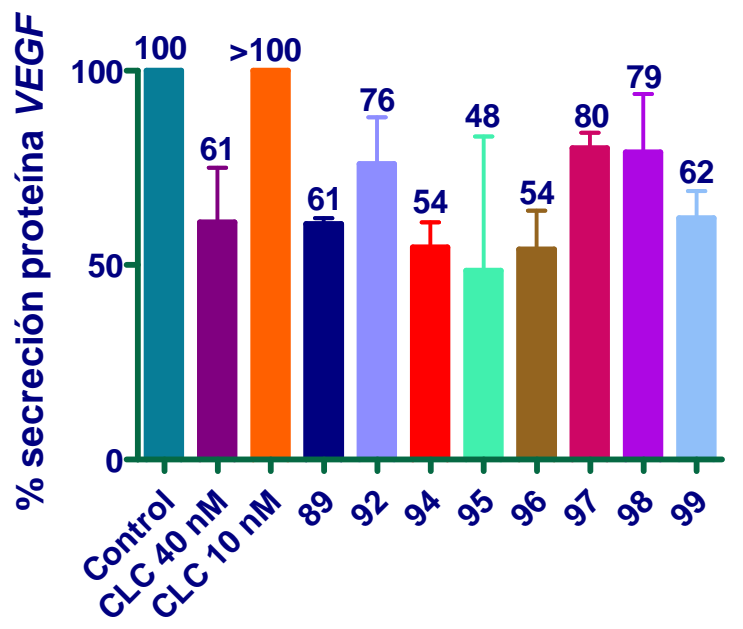

Gráfica 4.17. Resultados de la secreción de la proteína VEGF.

Los compuestos $89,94,95,96$ y 99 reducen la secreción de la proteína en porcentajes similares a los de la colchicina $40 \mathrm{nM}$, pero su acción inhibitoria es en realidad mucho mayor ya que estos derivados se ensayaron a concentraciones menores que las del producto natural. Hay que destacar que los compuesto 94, 95 y 96, que exhiben los mayores porcentajes de reducción de la secreción, se ensayaron a concentraciones de solamente $1.5 \mathrm{nM}$. 


\subsubsection{Docking}

La interacción de los compuestos 94-96 con la tubulina se analizó mediante estudios de docking. Estos tres compuestos se unen en el sitio de la colchicina (véase la figura 4.45), situado en la interfaz de la a $\beta$-tubulina, en una conformación similar a la que presenta la estructura cristalográfica de la DAMA-colchicina (datos obtenidos del PDB 1SA0).

A
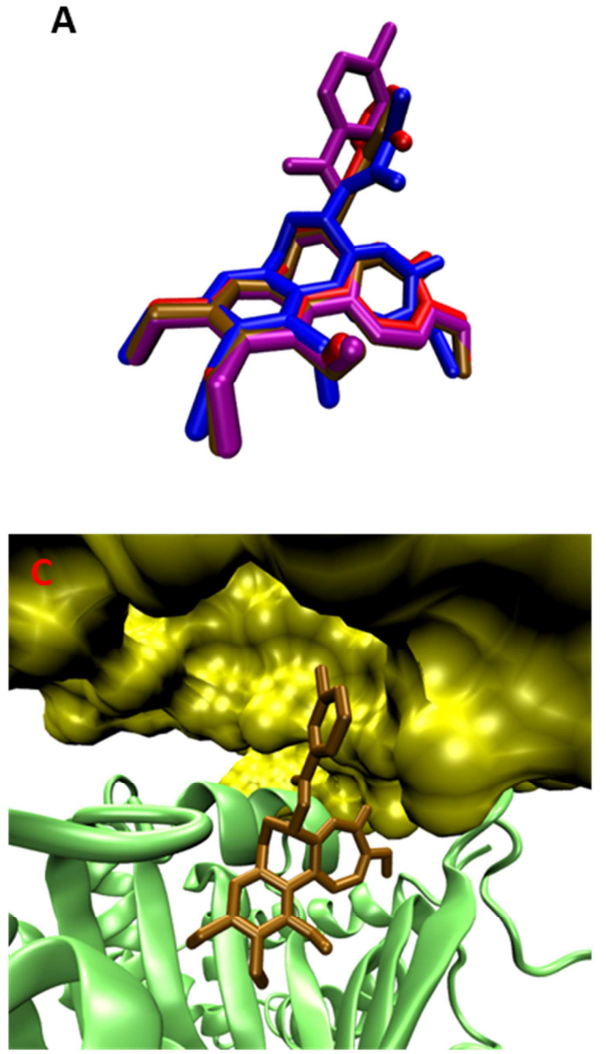
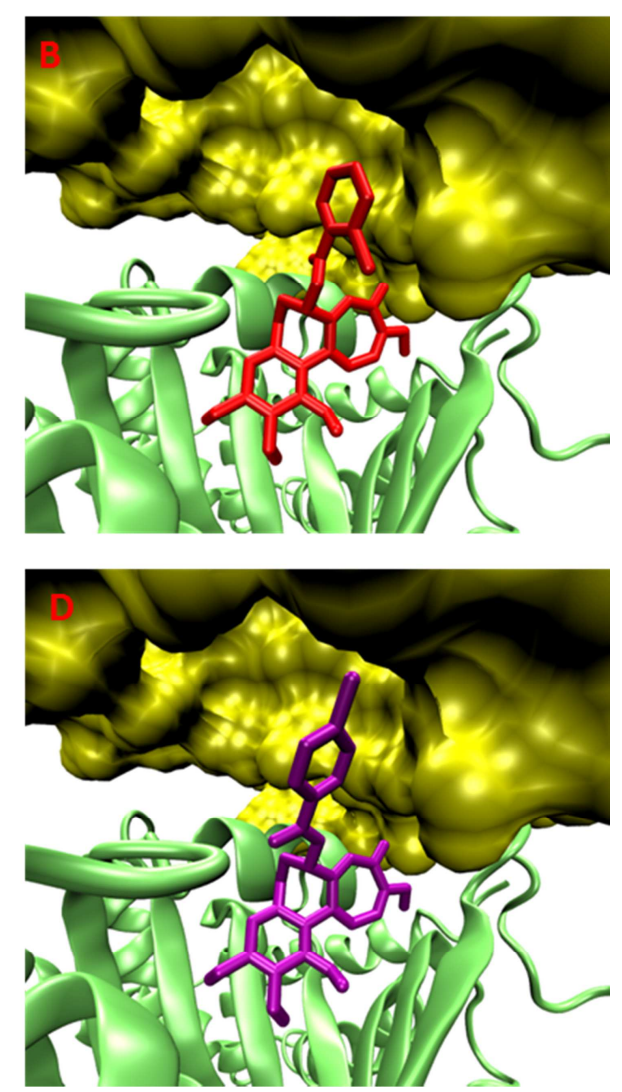

Figura 4.45. Panel A: Superposición de DAMA-colchicina (azul) con 94 (rojo), 95 (marrón), 96 (morado). Panel B: Sitio de unión de 94 (rojo) en la tubulina, cuya subunidad $\beta$ se representa en verde y la $\alpha$ en amarillo. Panel C: Sitio de unión del compuesto 95 (marrón). Panel D: Sitio de unión del compuesto 96 (morado).

Los estudios de docking indican que el derivado 94 (2-clorobenzoílo) coloca al átomo de cloro en una posición opuesta a la del surco de la a-tubulina, 
mientras que 95 (3-clorobenzoílo) y 96 (4-clorobenzoílo) orientan el átomo de cloro hacia dicho surco.

Para estos tres compuestos también se ha realizado una representación 2D mediante el programa LigPlot+. Las interacciones del derivado 94 con la tubulina quedan esquematizas en la siguiente figura:

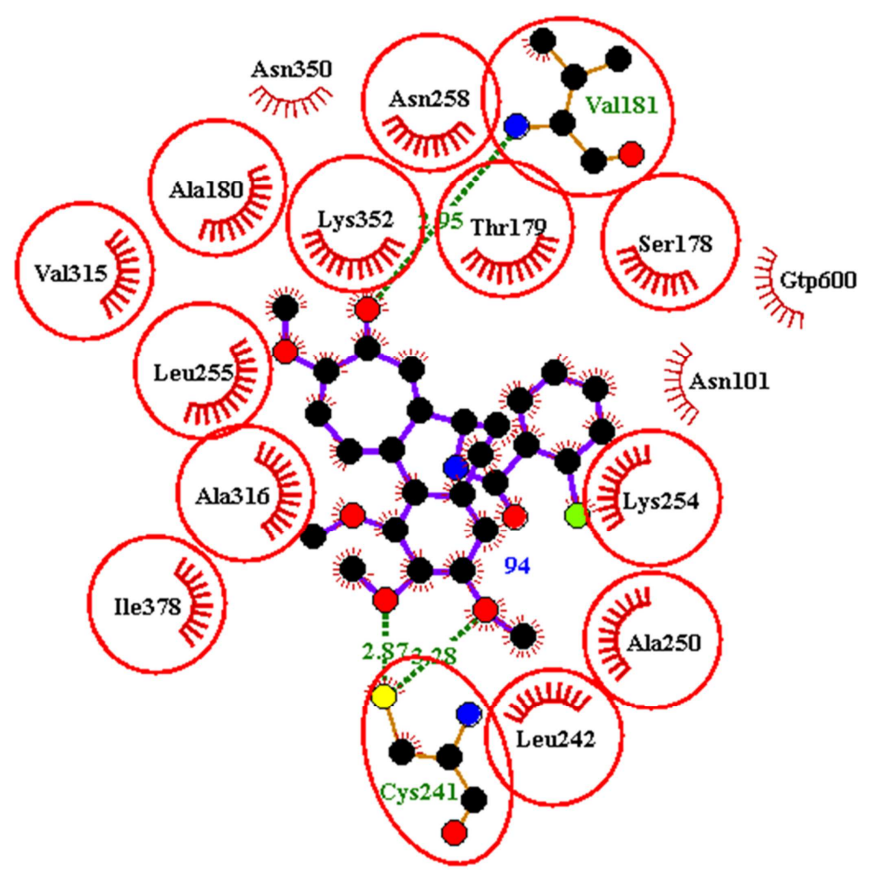

Figura 4.46. Interaciones en 2D con tubulina del derivado 94.

Además de las interacciones que presenta la DAMA-colchicina, el derivado 94 establece contacto con aminoácidos situados en a-tubulina, como Asn-101 y también interacciona con el residuo de GTP situado en esta subunidad. 
La próxima figura muestra las interacciones para el derivado 95:

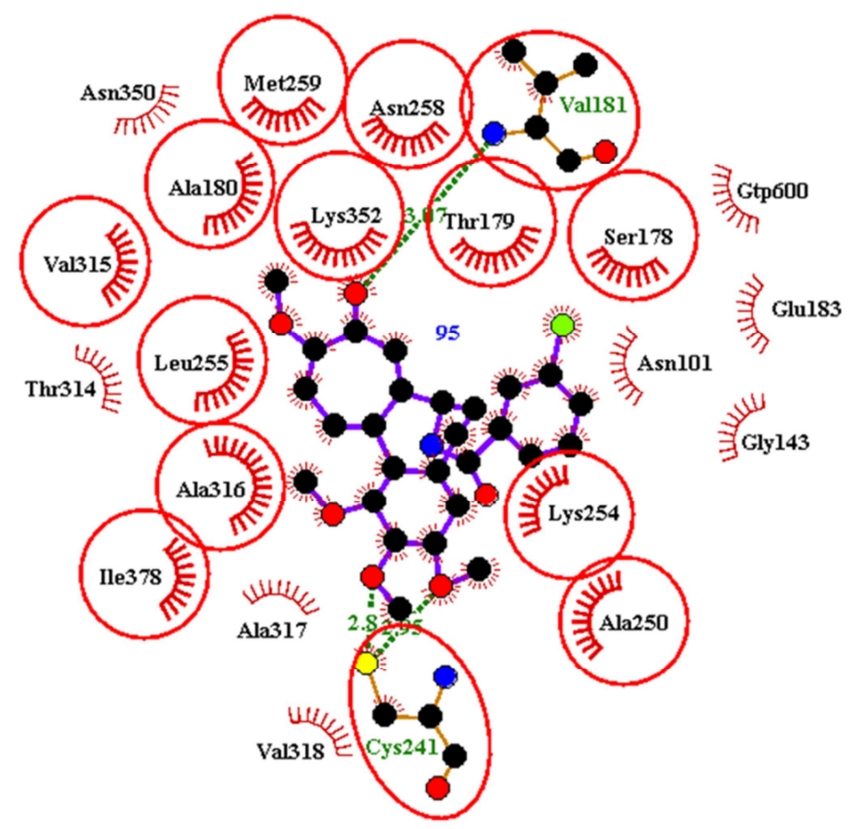

Figura 4.47. Interaciones en 2D con tubulina del derivado 95.

El derivado 95 (3-clorobenzoílo) establece contacto con más aminoácidos situados en la $\alpha$-tubulina que el compuesto 94 (2-clorobenzoílo), como son Gly 143 y el Glu 183. También interacciona con el residuo de GTP. 
Las interacciones del derivado 96 (4-clorobenzoílo) con la tubulina quedan esquematizas en la siguiente figura:

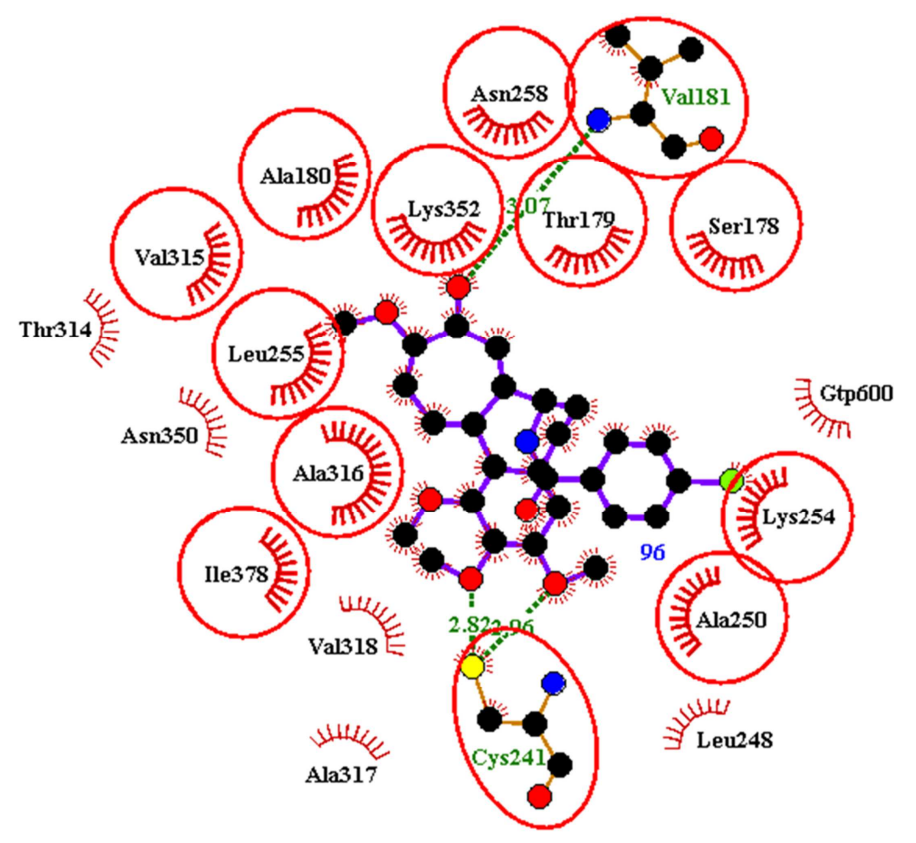

Figura 4.48. Interaciones en 2D con tubulina del derivado 96 .

El derivado 96 (4-clorobenzoílo) establece contacto principalmente con aminoácidos situados en la $\beta$-tubulina. Sin embargo, también interacciona con el residuo de GTP localizado en la subunidad $\alpha$.

Los tres derivados del ácido clorobenzoico exhiben interacciones diferentes con la tubulina, por lo que explicaría su comportamiento diferente en el proceso de polimerización de la tubulina.

\subsubsection{Resumen y conclusiones}

- Los compuestos sintetizados presentan una actividad citotóxica en el rango nanomolar en todas las líneas celulares estudiadas, mejorando todos ellos la actividad de la colchicina en la línea celular HT-29 y la mayor parte de ellos también en MCF-7. Hay que destacar el derivado 
98 (véase la figura 4.49) que exhibe una actividad en el rango picomolar en la línea anterior y en la línea MCF-7. De hecho, y en general, los derivados con el sustituyente en la posición meta son los más citotóxicos. Estos resultados se observan también en una serie de derivados de 4-clorocolchicina. ${ }^{138}$<smiles>COc1cc2c(c(OC)c1OC)-c1ccc(OC)c(=O)cc1[C@H](NC(=O)c1cccc(Br)c1)CC2</smiles>

Figura 4.49.

- Solamente el compuesto 89 (véase la figura 4.42) presenta un efecto inhibidor del proceso de la polimerización similar al de la colchicina. Los derivados 90, 91, 93, 97 y 99 (véase la figura 4.42) se pueden clasificar como inhibidores parciales de la polimerización de la tubulina. Por último, los compuestos 88, 94, 95, 96 y 98 (véase la figura 4.42) muestran un mayor incremento de la masa de polímero que el propio control. Si tenemos en cuenta los resultados de los derivados de la familia anterior, es probable que estos derivados favorezcan la formación de polímeros anómalos, pero habrían de realizarse más experimentos para poder confirmar esta hipótesis.

- Todos los compuestos elevan el grado de inhibición de la expresión de los genes VEGF, hTERT y c-Myc. Cabe destacar a los derivados con restos de tipo clorobenzoílo (94-96, véase la figura 4.50), que son los que muestran mayor grado de inhibición, tanto de los genes

\footnotetext{
${ }^{138}$ Nishiyama, H.; Ono, M.; Sugimoto, T.; Sasai, T.; Asakawa, N.; Yaegashi, T.; Nagaoka, T.; Matsuzaki, T.; Kogure, N.; Kitajima, M.; Takayama, H. Med. Chem. Commun., 2012, 3, 15001504.
} 
como de la secreción de la proteína VEGF a concentraciones 25 veces menores que las de la colchicina.

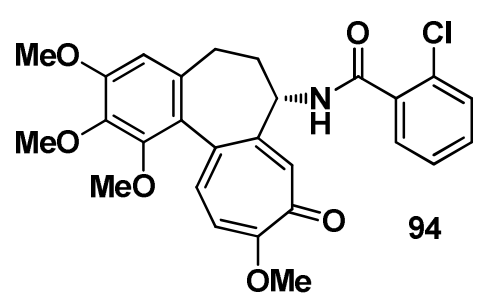<smiles>COc1cc2c(c(OC)c1OC)-c1ccc(OC)c(=O)cc1[C@@H](NC(=O)c1cccc(Cl)c1)CC2</smiles><smiles></smiles>

Figura 4.50. 


\subsection{Parte experimental}

\subsubsection{Cultivos celulares}

Las células de adenocarcinoma de colon humano (HT-29), de adenocarcinoma de mama (MCF-7) y las células embrionarias de riñón humano (HEK-293) se cultivaron en un medio de cultivo compuesto por DMEM suplementado con un $10 \%$ de FBS, $1 \%$ de glutamina y $1 \%$ de penicilina/estreptomicina tal como se indica en la bibliografía. ${ }^{139}$

Las células de carcinoma no microcítico de pulmón humano (A549) se cultivaron en RPMI 1640 suplementado con un 10\% de FBS, glutamina y antibióticos tal como se describe en la bibliografía. ${ }^{140}$

Todos los derivados de colchicina sintetizados se disolvieron en DMSO hasta una concentración de $10 \mathrm{mg} / \mathrm{mL}$ y se almacenaron a $-20^{\circ} \mathrm{C}$ hasta su uso.

\subsubsection{Ensayos de citotoxicidad}

La evaluación de la citotoxicidad se llevó a cabo mediante el ensayo con MTT. ${ }^{141}$ Se sembraron unas 5000 células por pocillo de las diferentes líneas celulares estudiadas (HT-29, MCF-7 y HEK-293) en placas de 96 pocillos con un volumen de medio de cultivo de $80 \mu \mathrm{L}$ y se dejaron en incubación durante $24 \mathrm{~h}$.

Transcurrido este tiempo se añadió a cada pocillo $20 \mu \mathrm{L}$ de cada una de las disoluciones de los distintos compuestos a ensayar y se incubaron de nuevo durante $48 \mathrm{~h}$. Las condiciones de la incubación fueron $37^{\circ} \mathrm{C}$ y un $5 \%$ de $\mathrm{CO}_{2}$ en una atmosfera húmeda.

\footnotetext{
139 Buey, R.M.; Calvo, E.; Barasoain, I.; Pineda, O.; Edler, M. C.; Matesanz, R.; Cerezo, G.; Vanderwal, C. D.; Day, B. W.; Sorensen, E. J.; López, J. A.; Andreu, J. M.; Hamel, E.; Díaz, J. F. Nat. Chem. Biol. 2007, 3, 117-125.

${ }^{140}$ De Ines, C.; Leynadier, D.; Barasoain, I.; Peyrot, V.; García, P.; Briand, C.; Rener, G. A.; Temple, C. Jr. Cancer Res. 1994, 54, 75.

${ }^{141}$ Yang, C.; Barasoain, I.; Li, X.; Matesanz, R.; Liu, R.; Sharom, F. J.; Yin, D. L.; Díaz, J. F.; Fang, W. S. Chem. Med. Chem. 2007, 2, 691-701.
} 
Finalmente se añadió a cada pocillo $10 \mu \mathrm{L}$ de MTT ( $5 \mathrm{mg} / \mathrm{mL}$ en PBS) y de nuevo se incubaron las células durante $3 \mathrm{~h}$ en las condiciones anteriores. Posteriormente se eliminó el medio de cultivo y el formazán formado se disolvió en $100 \mu \mathrm{L}$ de DMSO y se midió la absorbancia a $492 \mathrm{~nm}$. Todas las medidas se realizaron por triplicado.

En el caso de la línea celular A549 se sembraron unas 3600 células por pocillo en placas de 96 pocillos con un volumen de medio de cultivo de $200 \mu \mathrm{L}$ y se dejaron en incubación durante $24 \mathrm{~h}$. Pasado este tiempo, se eliminó el medio de cultivo y se añadió de nuevo a cada pocillo $200 \mu \mathrm{L}$ de medio de cultivo en el que se encontraba los productos a estudiar a diferentes concentraciones. Las células se dejaron en incubación durante 72 horas en las mismas condiciones anteriores $\left(37^{\circ} \mathrm{C}\right.$ y $5 \%$ de $\left.\mathrm{CO}_{2}\right)$.

Finalmente se añadió a cada pocillo $20 \mu \mathrm{L}$ de MTT ( $5 \mathrm{mg} / \mathrm{mL}$ en PBS) y de nuevo se incubaron las células durante $3 \mathrm{~h}$ en las condiciones anteriores. Posteriormente se eliminó el medio de cultivo y el formazán formado se disolvió en $200 \mu \mathrm{L}$ de DMSO y se midió la absorbancia a $492 \mathrm{~nm}$. Todas las medidas se realizaron por triplicado.

\subsubsection{Determinación del efecto de los compuestos en el ensamblaje de microtúbulos y del $\mathrm{IC}_{50}$ frente a la formación de microtúbulos}

Previamente a la realización de los ensayos con la tubulina se realizó su purificación. La tubulina se obtuvo de cerebros de cordero homogenizados con sulfato amónico y mediante una columna cromatografía de intercambio iónico según indica la bibliografía. ${ }^{142}$ Seguidamente se almacenó en nitrógeno líquido.

\footnotetext{
142 a) Weisenberg, R. C.; Borisy, G. G.; Taylor, E. W.; Biochemistry, 1968, 7, 4466-4479. b) Lee, J. C.; Frigon, R. P.; Timasheff, S. N. J. Biol. Chem., 1973, 248, 7253-7262. c) Andreu, J. M.; Gorbunoff, M. J.; Lee, J. C.; Timasheff, S. N. Biochemistry, 1984, 23, 1742-1752.
} 
La concentración de la tubulina se calculó utilizando un espectrofotómetro Perkin-Elmer Lambda 800 asumiendo que el coeficiente de extinción a 275 nm es $1.091 \mathrm{~g}^{-1} \mathrm{~cm}^{-1}$ en una disolución $6 \mathrm{M}$ de clorhidrato de guanidina.

También se determinó la solubilidad y los coeficientes de extinción, $\varepsilon$, de los compuestos mediante dilución de la concentración patrón $(10 \mathrm{mg} / \mathrm{mL}$ en DMSO) en $20 \mathrm{mM}$ de NaPi a pH 7 midiendo su espectro de UV visible. Los ensayos se realizaron por triplicado.

Para estudiar el efecto de los compuestos en el ensamblaje de microtúbulos se utilizaron dos buffers. El primero de ellos está compuesto por $20 \mathrm{mM}$ de NaPi, $3.4 \mathrm{M}$ de glicerol, $10 \mathrm{mM} \mathrm{MgCl}_{2}, 1 \mathrm{mM}$ de EGTA y $0.1 \mathrm{mM}$ de GTP a un pH 6.5. Se utilizó una concentración de $10 \mu \mathrm{M}$ de los compuestos y de tubulina. Los compuestos se dejaron $10 \mathrm{~min}$ incubando a temperatura ambiente con la disolución de tubulina. Transcurrido los $10 \mathrm{~min}$, se monitorizó la masa de polímero formado en un espectrofotómetro Beckman DU 7400 a $354 \mathrm{~nm}$ como se describe en la bibliografía. ${ }^{143}$

Este tiempo de espera, necesario para que se forme el complejo tubulinaligando, se estableció tras realizarse unas medidas de fluorescencia con el espectrofotómetro de luminiscencia Perkin-Elmer 50 con una longitud de onda de excitación de $354 \mathrm{~nm}$ y un ancho de abertura de $20 \mathrm{~nm}$ y con una longitud de onda de emisión de $435 \mathrm{~nm}$ y un ancho de abertura de $5 \mathrm{~nm}$. Se utilizó una concentración de $50 \mu \mathrm{M}$ para los compuestos y posteriormente se añadió una disolución de $10 \mu \mathrm{M}$ de tubulina en un tampón de $20 \mathrm{mM}$ de $\mathrm{NaPi}$ y $0,1 \mathrm{mM}$ de GTP a pH 7. Los efectos de los compuestos 73-77, 87, 88, 92, 94-96 y 98 fueron estudiados mediante este buffer. Las medidas se realizaron una única vez.

El segundo tampón está compuesto por $20 \mathrm{mM}$ de $\mathrm{NaPi}, 16 \mathrm{mM} \mathrm{MgCl}_{2}$ y $0.1 \mathrm{mM}$ de GTP a un pH 7. Se utilizó una concentración de $50 \mu \mathrm{M}$ para los compuestos y de $15 \mu \mathrm{M}$ para la tubulina. Como anteriormente, los compuestos

${ }^{143}$ Barbier, P.; Gregoire, C.; Devred, F.; Sarrazin, M.; Peyrot, V. Biochemistry, 2001, 40, 1351013519. 
se dejaron 10 min incubando a temperatura ambiente con la disolución de tubulina y se midió la formación de masa de polímero formado utilizando el mismo instrumento que anteriormente. Los efectos de los compuestos 73-77 fueron estudiados mediante este buffer.

Para el resto de compuestos, su efecto en el ensamblaje de microtúbulos se estudió mediante el cálculo de la concentración crítica. Para determinar la concentración crítica se utilizó la tubulina a una concentración de $25 \mu \mathrm{M}$ en el tampón de ensamblaje de glicerol (GAB) que está formado por glicerol (30\% en volumen), $10 \mathrm{mM}$ de $\mathrm{NaPi}, 1 \mathrm{mM}$ de EGTA a pH 7.5, $6 \mathrm{mM}$ de $\mathrm{MgCl}_{2}$ y 0.1 $\mathrm{mM}$ de GTP. Si consideramos una polimerización por condensación nucleada no covalente, la concentración crítica es igual a la concentración de tubulina en el sobrenadante. ${ }^{144}$

Las medidas se realizaron con un Varioskan Flash de Fisher utilizando una placa de 96 pocillos. Los compuestos se añadieron a una concentración de $27.5 \mu \mathrm{M}$. Los ensayos se realizaron por duplicado en el caso de la familia $1 \mathrm{y}$ por triplicado para los derivados de la familia 2 y 3.

Para poder comparar los resultados, se estableció que la absorbancia obtenida a tiempo final por el control correspondia al 100\% y con ella se recalcularon el resto de los compuestos. Con un agente desestabilizante de microtúbulos se obtiene un porcentaje muy bajo, mientras que con un agente estabilizante se obtienen porcentajes mayores del $100 \%$.

La determinación del $\mathrm{IC}_{50}$ se monitorizó mediante turbidimetría en un equipo POLARstar Omega (BMG Labtech) utilizando una placa de 96 pocillos. La masa de polímero formado se midió a $400 \mathrm{~nm}$. Los experimentos se llevaron a cabo a $37{ }^{\circ} \mathrm{C}$, pero previamente se realizó una incubación a temperatura ambiente de los compuestos, la colchicina y un control (DMSO) con la tubulina durante $10 \mathrm{~min}$. El contenido de DMSO no superaba el $2 \%$ del volumen total de cada pocillo.

${ }^{144}$ Díaz, J. F.; Menendez, M.; Andreu, J. M. Biochemistry 1993, 32, 10067-10077. 
La tubulina se utilizó a una concentración $15 \mu \mathrm{M}$ en el buffer de polimerización compuesto por $20 \mathrm{mM}$ de fosfato de sodio, 3.4 M de glicerol, 10 $\mathrm{mM} \mathrm{MgCl}_{2}, 1 \mathrm{mM}$ de EGTA y $0.1 \mathrm{mM}$ de GTP a un $\mathrm{pH}$ 6.5. Los compuestos y la colchicina se añadieron a diferentes concentraciones. Los valores de $\mathrm{IC}_{50} \mathrm{se}$ interpolaron de las gráficas que muestran el porcentaje de inhibición como función de la concentración de compuesto. Los experimentos se realizaron por triplicado.

Para la preparación de muestras para realizar las imágenes de microscopia electrónica se tomaron alícuotas de $3 \mu \mathrm{L}$ de la solución a estudiar y éstas se adsorbían en una malla Formvar (rejilla de cobre revestida de carbono). Para la tinción negativa se utilizaba una disolución 2\% (w / v) de acetato de uranilo. Se observaron los grids en un microscopio electrónico de transmisión JEM1400 JEOL operado a $80 \mathrm{kV}$.

\subsubsection{Determinación de la constante de afinidad frente a la tubulina}

La determinación de la constante de afinidad aparente se realizó mediante el espectrofotómetro de luminiscencia Perkin-Elmer 50 con una longitud de onda de excitación de $295 \mathrm{~nm}$ y un ancho de abertura de $5 \mathrm{~nm}$, para excitar específicamente los residuos de triptófano presentes en la tubulina. En cuanto a la emisión, se realizó un espectro entre 300-500 nm con un ancho de abertura de $5 \mathrm{~nm}$.

La corrección de la fluorescencia se obtuvo en un tampón de $20 \mathrm{mM}$ de $\mathrm{NaPi}$ a pH 7 usando celdas Hellma con un ancho $0.2 \mathrm{~cm}$ (en dirección de excitación) x $1 \mathrm{~cm}$. Las celdas se termostataron a $25{ }^{\circ} \mathrm{C}$ mediante la circulación de agua proveniente de un baño de agua externo. La tubulina (1-4 $\mu \mathrm{M})$ se valoró con diferentes concentraciones de los análogos. Los cálculos de la disminución de la señal de la fluorescencia se llevaron a cabo 
utilizando el programa SigmaPlot y utilizando las ecuaciones que aparecen descritas en la bibliografía. ${ }^{145}$

\subsubsection{Efecto sobre el ciclo celular (citometría de flujo)}

Para el estudio del efecto en el ciclo celular se utilizó la línea celular A549. Un total de 400.000 se cultivaron a lo largo de la noche y se incubaron 24 horas más en presencia del vehículo DMSO o en presencia la colchicina y los compuestos seleccionados a dos concentraciones, su valor de $\mathrm{IC}_{50}$ y diez veces dicho valor.

Las células se fijaron con una disolución fría de $\mathrm{EtOH} 70 \%$ en PBS y se dejaron $30 \mathrm{~min}$ a $-20^{\circ} \mathrm{C}$. Seguidamente se lavaron con PBS frío y se trataron con RNAsa A (Roche) y se tiñeron con yoduro de propidio (PI). Se dejaron en la oscuridad con un balanceo suave durante 20 min a temperatura ambiente y se analizaron mediante la utilización del clitómetro de flujo FACScan "Becton Dickinson". Los experimentos se realizaron por triplicado.

\subsubsection{Efecto sobre la red de microtúbulos (inmunofluorescencia)}

Para el estudio del efecto de los compuestos sobre la red de microtúbulos se utilizó la línea celular A549. Un total de $10^{6}$ células se cultivaron a lo largo de la noche en cubreobjetos redondos de $12 \mathrm{~mm}$ e incubadas 4 horas más en presencia del vehículo DMSO o en presencia de diferentes concentraciones de colchicina y los compuestos seleccionados.

Las células se fijaron con formaldehído al 3.7\% en PBS durante $20 \mathrm{~min}$ a temperatura ambiente y se permeabilizaron con Tritón X100 0.5\% en PBS durante $10 \mathrm{~min}$ a temperatura ambiente. Los microtúbulos se tiñeron con anticuerpos monoclonales específicos dirigidos contra $\alpha$-tubulina, DM1A (Sigma-Aldrich) durante toda la noche a $4^{\circ} \mathrm{C}$. Seguidamente, las células se

\footnotetext{
${ }^{145}$ Combes, S.; Barbier, P.; Douillard, S.; McLeer-Florin, A.; Bourgarel-Rey, V.; Pierson, J. T.; Fedorov, A. Y.; Finet, J. P.; Boutonnat, J.; Peyrot, V. J Med Chem., 2011, 54, 3153-3162.
} 
incubaron en la oscuridad durante 1 hora a temperatura ambiente con el anticuerpo secundario FITC (Invitrogen).

Las células se lavaron con PBS y los cubreobjetos se montaron con una gota de una solución de ProLong® (Invitrogen). El citoesqueleto se observó con un CLSM (Confocal Laser Scanning Microsocope) Leica SP5 con un microscopio Leica invertido, equipado con un objetivo de inversión PlanApochromat $63 \times(N A=1.4)$. Cada imagen se grabó con el modo espectral del CLSM seleccionando específicamente los dominios de emisión del espectro. El fluoróforo FITC se excitó a 488 nm mediante un láser de Argón y su emisión se recogió entre $500 \mathrm{~nm}$ y $535 \mathrm{~nm}$. Las imágenes se examinaron con el software ImageJ. ${ }^{146}$

\subsubsection{Efecto sobre la expresión de los genes VEGF, hTERT y c-Myc en HT-29}

Para determinar la expresión de los genes VEGF, hTERT y c-Myc, se sembraron unas $10^{5}$ células por pocillo de la línea celular HT-29 en placas de 6 pocillos con un volumen de medio de cultivo de $1,5 \mathrm{~mL}$ y se dejaron incubar durante 24h.

Posteriormente se cambió el medio de cultivo y se añadió a cada pocillo las disoluciones de los respectivos compuestos a las concentraciones indicadas en cada caso. Además se añadió la muestra control que posee la misma cantidad de DMSO que la empleada para disolver los productos. Las células se incubaron en presencia de los compuestos durante $48 \mathrm{~h}$.

Tras cumplirse el tiempo de incubación, se recogieron las células y se aisló su correspondiente ARN utilizando las instrucciones del kit de extracción de ARN Ambion. Seguidamente se retrotranscribió el ARN a ADN

\footnotetext{
146 a) Rasband, W. S. ImageJ, U. S. National Institutes of Health, Bethesda, Maryland, USA, http://imagej.nih.gov/ij/, 1997-2015. b) Schneider, C. A.; Rasband, W. S.; Eliceiri, K. W. Nat. Methods, 2012, 9, 671-675.
} 
complementario mediante la utilización de la retrotranscriptasa M-MLV, 1-21 $\mu \mathrm{g}$ de ARN extraído y oligo(dT)15 seguiendo el protocolo.

Para la realización de la PCR convencional la amplificación se realizó utilizando cebadores específicos comercialmente adquiridos y usando las siguientes condiciones experimentales:

$>\beta$-Actina: $94^{\circ} \mathrm{C}$ durante $30 \mathrm{~s}, 58^{\circ} \mathrm{C}$ durante $50 \mathrm{~s}$ y $72{ }^{\circ} \mathrm{C}$ durante 50 $\mathrm{s}$ (30 ciclos).

> VEGF: $94{ }^{\circ} \mathrm{C}$ durante $30 \mathrm{~s}, 58^{\circ} \mathrm{C}$ durante 1 min y $72{ }^{\circ} \mathrm{C}$ durante $1 \mathrm{~min} 50 \mathrm{~s}$ (30 ciclos).

$>$ hTERT: $94^{\circ} \mathrm{C}$ durante $1 \mathrm{~min}, 57^{\circ} \mathrm{C}$ durante 1 min y $72{ }^{\circ} \mathrm{C}$ durante $1 \mathrm{~min} 30 \mathrm{~s}$ (30 ciclos).

$>$ c-Myc: $94{ }^{\circ} \mathrm{C}$ durante $30 \mathrm{~s}, 58^{\circ} \mathrm{C}$ durante 1 min y $72{ }^{\circ} \mathrm{C}$ durante 1 min $50 \mathrm{~s}$ (30 ciclos).

Los productos obtenidos se analizaron por electroforesis horizontal en gel de agarosa $1 \%$ y se revelaron con bromuro de etidio bajo transilminación ultravioleta.

En el caso de la qPCR convencional la amplificación se realizó mediante la utilización de un termociclador StepOnePlus ${ }^{\mathrm{TM}}$ y sondas Taqman®. Se utilizó Taqman ${ }^{\circledR}$ Gene Expression Fast Master Mix, que contiene el tampón adecuado para las condiciones de amplificación, dNTPs, la enzima ADN polimerasa termoestable y una sonda de referencia pasiva.

Para amplificar cada uno de los genes se utilizaron los cebadores prediseñados y comercializados por Life Technologies Taqman® Gene Expression Assays.

Todas las medidas se realizaron como mínimo por triplicado.

\subsubsection{Efecto sobre la secreción de la proteína VEGF- $A_{165}$ en HT-29. Ensayo ELISA}

Para determinar la secreción de la proteína VEGF se sembraron unas $10^{5}$ células por pocillo de la línea celular HT-29 en placas de 6 pocillos con un volumen de medio de cultivo de $1,5 \mathrm{~mL}$ y se dejaron incubar durante $24 \mathrm{~h}$. 
Posteriormente se cambió el medio de cultivo y se añadió a cada pocillo las disoluciones de los respectivos compuestos a las concentraciones indicadas en cada caso. Además se añadió la muestra control que posee la misma cantidad de DMSO que la empleada para disolver los productos. Las células se incubaron en presencia de los compuestos durante $48 \mathrm{~h}$.

Tras cumplirse el tiempo de incubación, se recogieron los sobrenadantes de los cultivos y se midió el VEGF secretado mediante el uso del kit ELISA de Invitrogen. Todas las medidas se realizaron como mínimo por triplicado.

\subsubsection{Cálculos de docking}

Los cálculos computacionales se llevaron a cabo utilizando el programa Autodock 4.2. La estructura cristalográfica de la tubulina seleccionada fue la correspondiente al PDB 1SA0. De dicha estructura se eliminaron las subunidades $C$ y $D$, la estatmina, las moléculas de agua y los ligandos presentes. Las estructuras de los derivados se dibujaron mediante el programa GaussView $5.0^{147}$ a partir de la estructura cristalina del derivado de colchicina presente en el PDB utilizado.

En cuanto al programa Autodock, la malla se localizó cubriendo íntegramente la interfaz a $\beta$-tubulina teniendo unas dimensión de 126 puntos en las direcciones ( $x, y$ y $z$ ) y un espaciado de $0,247 \AA$. El algoritmo genético Lamarckiano se seleccionó para la búsqueda de las mejores conformaciones. Dichas conformaciones se agruparon según su energía de enlace y de ellas se eligió la de menor energía para ser representada mediante el programa Visual Molecular Dynamics (VMD). ${ }^{148}$ Todas las imágenes que aparecen en la Tesis en las que aparecen la tubulina y los derivados sintetizados se han realizado con este programa.

Mediante el programa LigPlot+ ${ }^{132}$ se obtuvieron las interacciones en dos dimensiones de los ligandos con los aminoácidos de la tubulina.

\footnotetext{
${ }^{147}$ Dennington, R.; Keith, T.; Millam, J.Semichem Inc., Shawnee Mission, KS, 2009.

${ }^{148}$ Humphrey, W.; Dalke, A.; Schulten, K. J. Molec. Graphics, 1996, 14, 33-38.
} 


\author{
CAPÍTULO 5 \\ RESUMEN Y \\ CONCLUSIONES
}





\section{CAPÍTULO 5: RESUMEN Y CONCLUSIONES}

En este capítulo se van a resumir las conclusiones obtenidas tras la realización de la tesis.

\subsection{Actividad citotóxica}

Familia 1. Los derivados de $\alpha$-aminoacilo exhiben valores de citotoxicidad en el rango nanomolar y además son los que exhiben mayores coeficientes de selectividad en ambas líneas tumorales, lo que, en comparación con la colchicina, les proporciona un mayor margen de seguridad terapéutico. En la siguiente gráfica se representan conjuntamente los valores de $\mathrm{IC}_{50}$ para todos los derivados de esta familia en las líneas tumorales HT-29 (línea azul), MCF-7 (línea roja) y HEK-293 (línea verde).

Familia 1

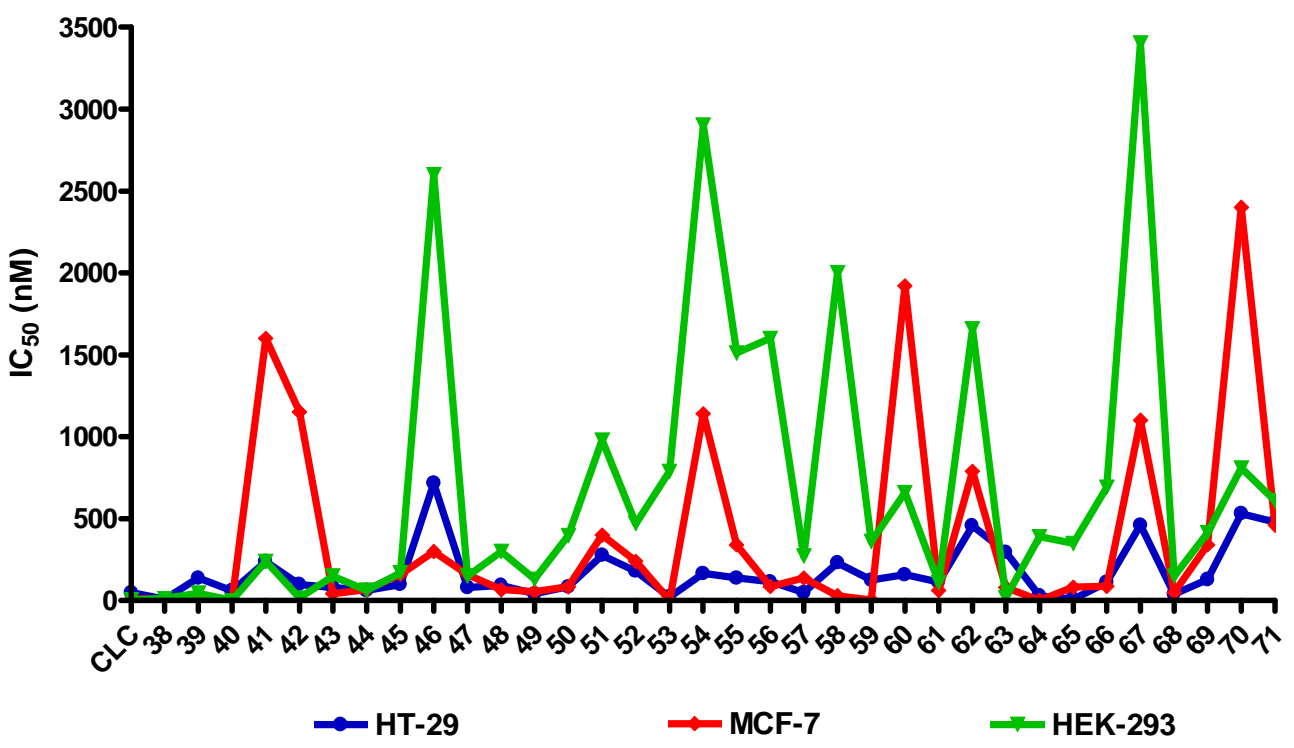

Gráfica 5.1. Valores de $\mathrm{IC}_{50}$ de los derivados de la familia 1. 
Como puede observarse en la gráfica anterior, los menores valores de $\mathrm{IC}_{50}$ (mayor actividad citotóxica) se obtienen, para ambas líneas celulares, con los derivados $38,53,64$ y 68 , cuyas estructuras se representan en la siguiente figura.<smiles>CCCCCCCCCCCCCCCCCCCNCC(=O)N[C@H]1CCc2cc(OC)c(OC)c(OC)c2-c2ccc(OC)c(=O)cc21</smiles><smiles>COc1cc2c(c(OC)c1OC)-c1ccc(OC)c(=O)cc1[C@@H](NC(=O)[C@@H]1CCCN1)CC2</smiles><smiles>COc1cc2c(c(OC)c1OC)-c1ccc(OC)c(=O)cc1[C@@H](NC(=O)C(N)CC(C)C)CC2</smiles><smiles>COc1cc2c(c(OC)c1OC)-c1ccc(OC)c(=O)cc1[C@@H](NC(=O)CNC(=O)CNC(=O)OCc1ccccc1)CC2</smiles>

Figura 5.1. 
Familia 2. Los derivados de colchicina que provienen de la sustitución formal del grupo acetilo de la colchicina por otros grupos acilo exhiben valores de citotoxicidad en el rango nanomolar bajo. En la siguiente gráfica se representan conjuntamente los valores de $\mathrm{IC}_{50}$ para algunos derivados de esta familia en las líneas tumorales HT-29 (línea azul) y MCF-7 (línea roja) y en la línea no tumoral HEK-293 (línea verde).

\section{Familia 2}

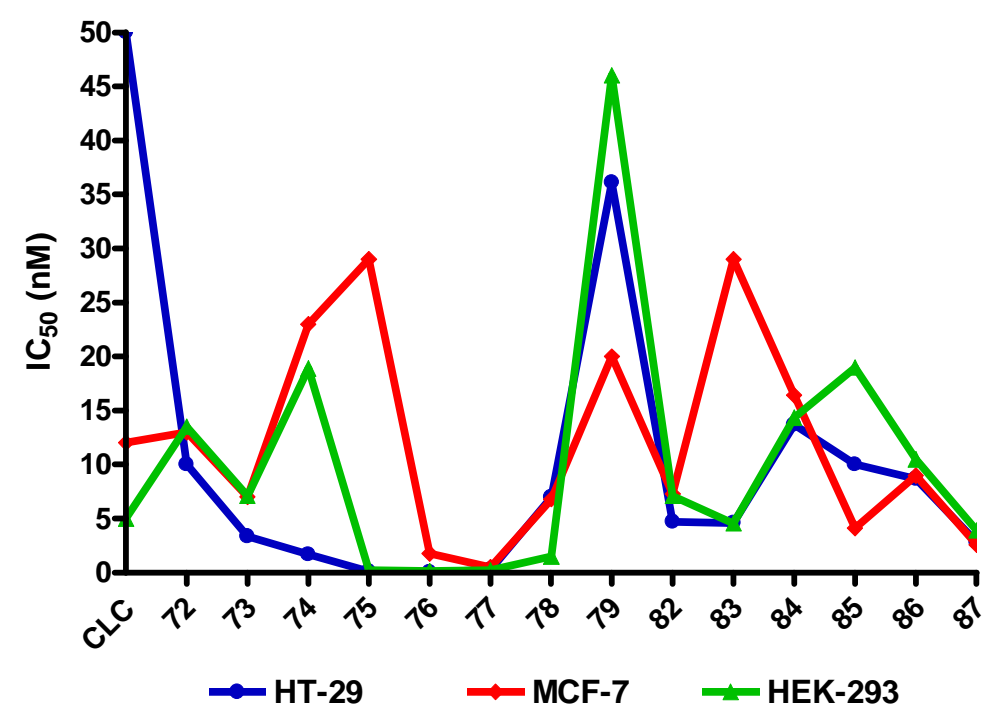

Gráfica 5.2. Valores de $I C_{50}$ de los derivados de la familia 2.

Como puede observarse en la gráfica anterior, los mínimos valores de $\mathrm{IC}_{50}$ (mayor actividad citotóxica) se obtienen con los derivados $\mathbf{7 4}$ (cadena de ácido octanóico), 75 (cadena de ácido decanóico), 76 (cadena de ácido undecanóico) y $\mathbf{7 7}$ (cadena de ácido dodecanóico), cuyas estructuras pueden verse en la siguiente figura. Es interesante resaltar la relación existente en la línea HT-29 entre la actividad citotóxica de los compuestos y su longitud de cadena, alcanzándose un máximo, ya dentro del rango picomolar, con el compuesto 76 que supera claramente la actividad de la colchicina. Cabe destacar también al compuesto 85 (véase la gráfica 5.2 y la figura 5.2) que, en 
la línea tumoral HT-29 y en relación con la colchicina, combina una elevada actividad citotóxica y un buen margen terapéutico.<smiles>CCCCCCCC(=O)N[C@H]1CCc2cc(OC)c(OC)c(OC)c2-c2ccc(OC)c(=O)cc21</smiles><smiles>CCCCCCCCCC(=O)N[C@H]1CCc2cc(OC)c(OC)c(OC)c2-c2ccc(OC)c(=O)cc21</smiles><smiles>CCCCCCCCCCCCCCCC(=O)N[C@H]1CCc2cc(OC)c(OC)c(OC)c2-c2ccc(OC)c(=O)cc21</smiles><smiles>COc1cc2c(c(OC)c1OC)-c1ccc(OC)c(=O)cc1[C@@H](NC(=O)CI)CC2</smiles>

Figura 5.2. 
Familia 3. Los derivados de colchicina que provienen de la sustitución formal del grupo acetilo de la colchicina por grupos aroílo exhiben valores de citotoxicidad en el rango nanomolar bajo. En la siguiente gráfica se representa conjuntamente los valores de $\mathrm{IC}_{50}$ para estos compuestos en las líneas tumorales HT-29 (línea azul) y MCF-7 (línea roja) y en la línea no tumoral HEK-293 (línea verde).

\section{Familia 3}

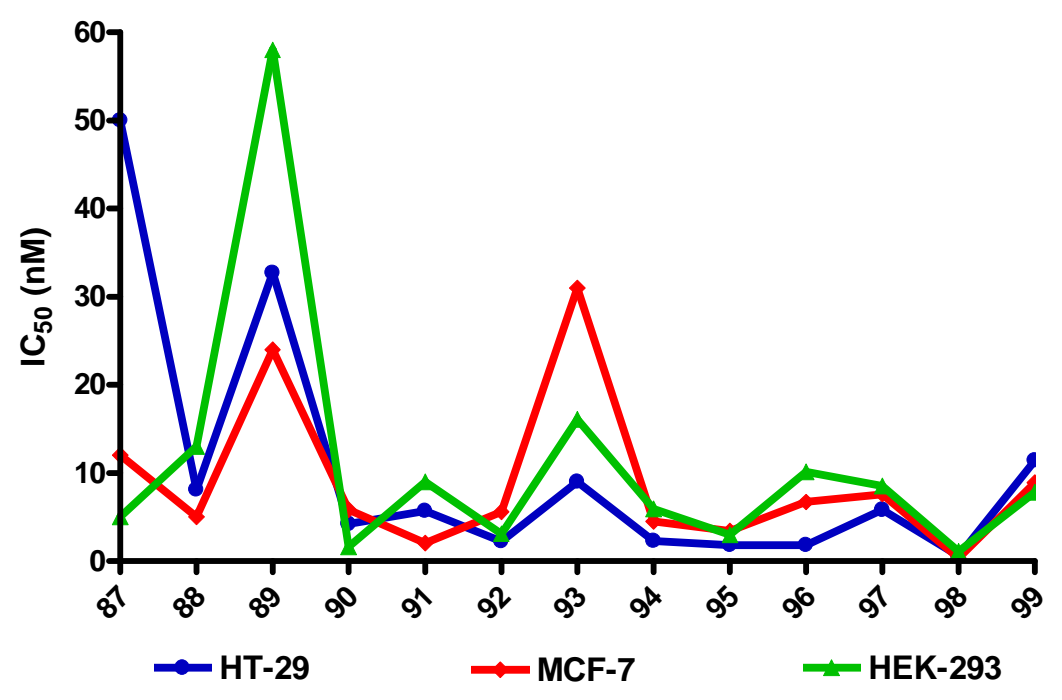

Gráfica 5.3. Valores de $\mathrm{IC}_{50}$ de los derivados de la familia 3.

Como puede observarse en la gráfica anterior, todos los compuestos mejoran la actividad de la colchicina en la línea tumoral HT-29. El compuesto 89 (véase la figura 5.3) es el que presenta mayor margen de seguridad terapéutico en ambas líneas tumorales. El mínimo valor de $\mathrm{IC}_{50}$ (mayor actividad citotóxica) se obtiene con el derivado 98 (véase la figura 5.3). En la línea celular HT-29 hay que destacar a los tres derivados del ácido clorobenzoico 94-96 (véase la figura 5.3) que presentan mayor citotoxicidad y además ofrecen mejores márgenes terapéuticos que la propia colchicina. 

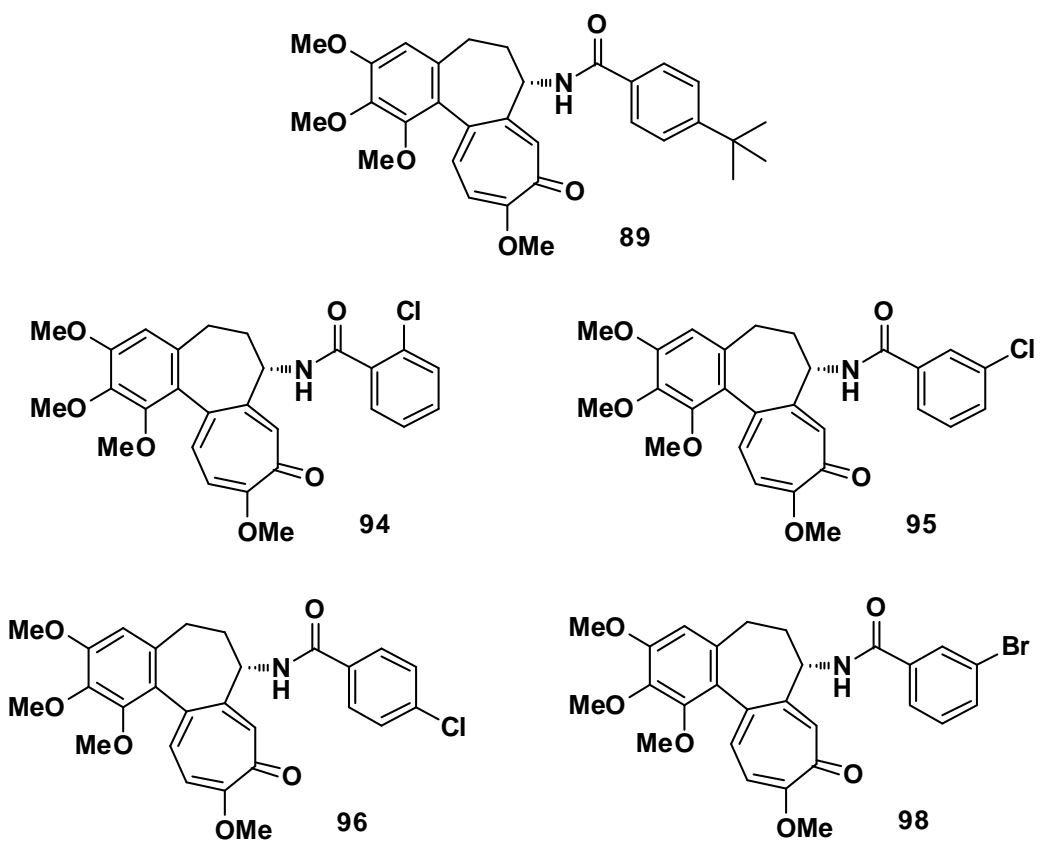

Figura 5.3. 


\subsection{Actividad frente a la tubulina}

\section{Familia 1. Concentración crítica de tubulina}

En la gráfica 5.4 se representan los valores de concentración crítica de los compuestos de la familia 1. En esta gráfica se aprecia que todos los compuestos de esta familia, excepto uno de ellos, son capaces de inhibir el proceso de polimerización de la tubulina, ya sea de forma total o parcial.

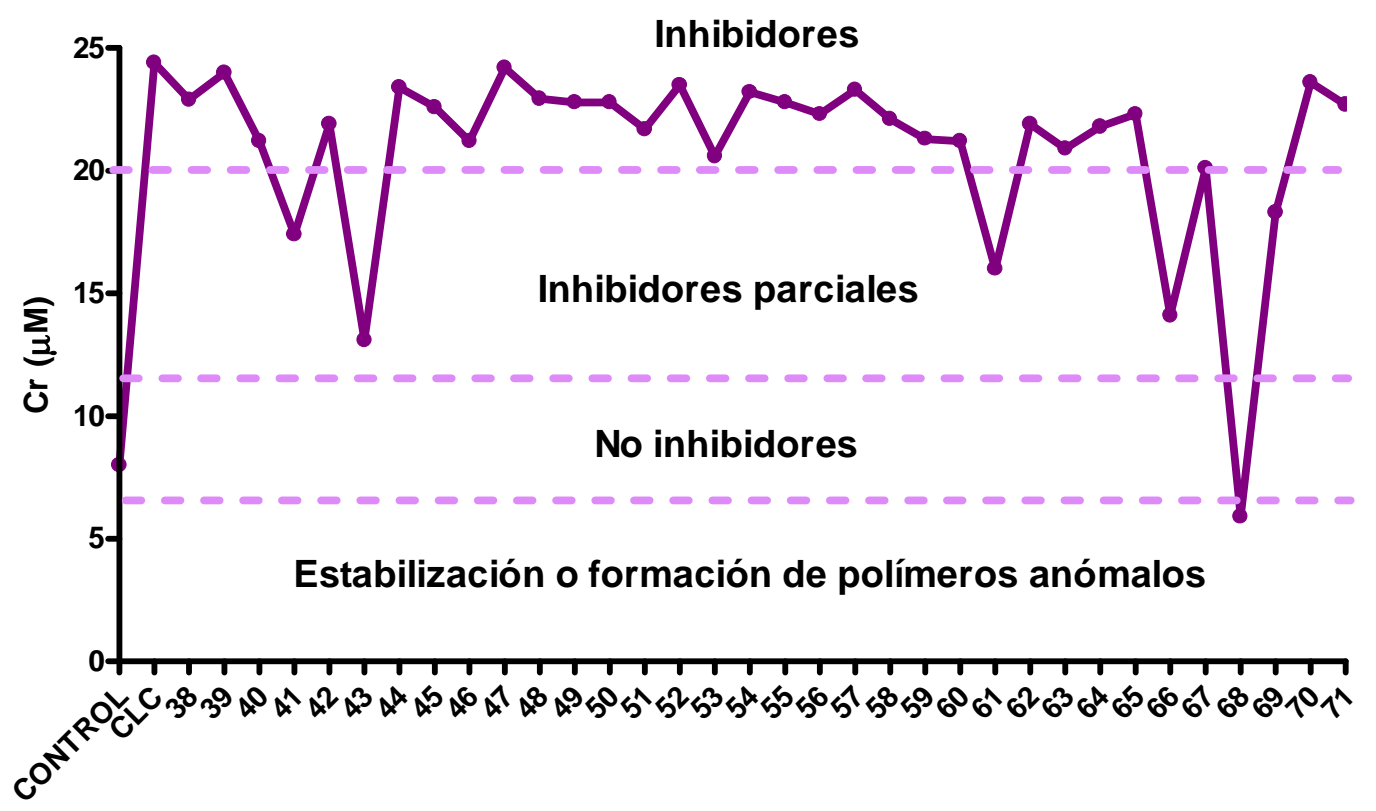

Gráfica 5.4. Valores de concentración crítica de derivados de la familia 1.

La serie de L-a-aminoácidos es más activa que la de los D-a-aminoácidos. Dentro del subgrupo de L- $\alpha$-aminoácidos, los compuestos que presentan como sustituyente un residuo apolar pequeño $(38,39,48$ y 49 , véase la figura 5.4) o un grupo polar $(\mathbf{4 4}, \mathbf{4 5}, \mathbf{4 7}, \mathbf{5 4}, 55$ y $\mathbf{5 7}$, véase figura 5.4) presentan valores de concentración crítica más próximos a los de la colchicina. 
<smiles>[R]O[R16](=O)C([R])C(=O)N[C@H]1CCc2cc(OC)c(OC)c(OC)c2-c2ccc(OC)c(=O)cc21</smiles>

$38 \mathrm{R}=\mathrm{H}, \mathrm{R}^{\prime}=\mathrm{H}$

$39 \mathrm{R}=\mathrm{CH}_{3}, \mathrm{R}=\mathrm{H}$

$44 \mathrm{R}=\mathrm{CH}_{2} \mathrm{OH}, \mathrm{R}^{\prime}=\mathrm{H}$

$45 \mathrm{R}=\mathrm{CH}(\mathrm{OH}) \mathrm{CH}_{3}, \mathrm{R}^{\prime}=\mathrm{H}$

$47 \mathrm{R}=\left(\mathrm{CH}_{2}\right)_{2} \mathrm{SCH}_{3}, \mathrm{R}^{\prime}=\mathrm{H}$<smiles>[R][NH2+]C([R])C(=O)N[C@H]1CCc2cc(OC)c(OC)c(OC)c2-c2ccc(OC)c(=O)cc21</smiles>

$48 \mathrm{R}=\mathrm{H}, \mathrm{R}^{\prime}=\mathrm{H}$

$49 \mathrm{R}=\mathrm{CH}_{3}, \mathrm{R}^{\prime}=\mathrm{H}$

$54 \mathrm{R}=\mathrm{CH}_{2} \mathrm{OH}, \mathrm{R}^{\prime}=\mathrm{H}$

$55 \mathrm{R}=\mathrm{CH}(\mathrm{OH}) \mathrm{CH}_{3}, \mathrm{R}^{\prime}=\mathrm{H}$

$57 \mathrm{R}=\left(\mathrm{CH}_{2}\right)_{2} \mathrm{SCH}_{3}, \mathrm{R}^{\prime}=\mathrm{H}$

Figura 5.4.

En cambio, los derivados que tienen un residuo estéricamente voluminoso, como 41, 43, 61, 66 y 69 (véase figura 5.5) actúan como inhibidores parciales de la polimerización de la tubulina.<smiles>COc1ccc2c(c1)C(NC(=O)C(CC(C)C)NC(=O)O)CCc1cc(OC)c(OC)cc1-2</smiles><smiles>COc1cc2c(c(OC)c1OC)-c1ccc(OC)c(=O)cc1[C@@H](NC(=O)C1CCCN1C(=O)O)CC2</smiles><smiles></smiles><smiles></smiles><smiles>COc1ccc2c(c1)C(NC(=O)CNC(=O)CNC(=O)CNC(C)(C)C)CCC2c1cc(OC)c(OC)cc1OC</smiles>

Figura 5.5. 


\section{Familia 2. Porcentaje de polimerización}

Los valores de porcentaje de polimerización de la tubulina de los compuestos de la familia 2 se representan en la gráfica 5.5 .

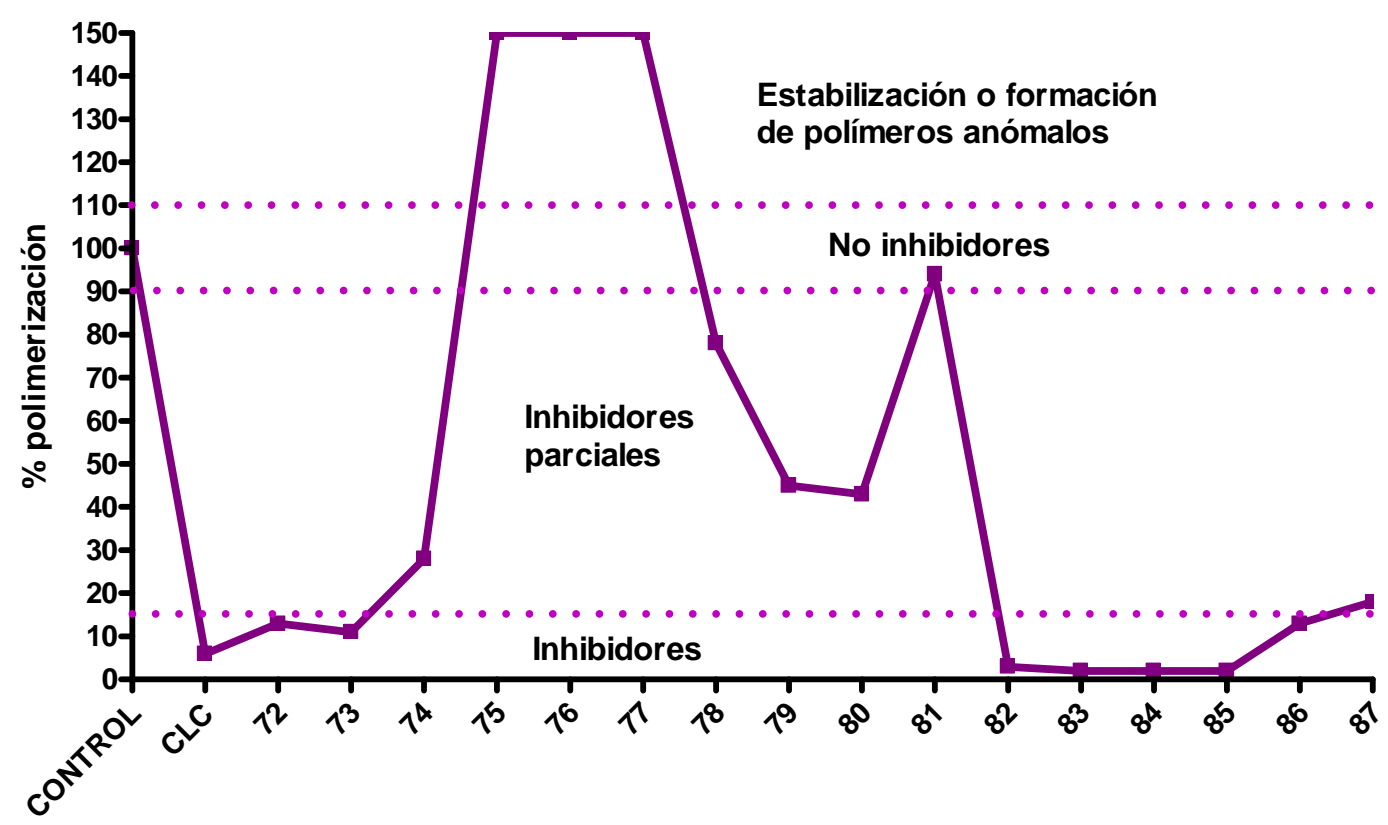

Gráfica 5.5. Porcentaje de polimerización de la tubulina con derivados de la familia 2.

En esta familia destacan los derivados de haloacetilo 82-85 (véase la figura 5.6) que se muestran más activos que la colchicina inhibiendo el proceso de formación de los microtúbulos.

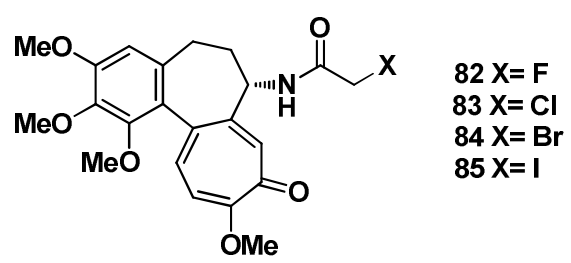

Figura 5.6. 
Los derivados con cadenas alifáticas 75, 76 y 77 (véase la figura 5.7) aumentan la masa de polímero induciendo la formación de polímeros anómalos.

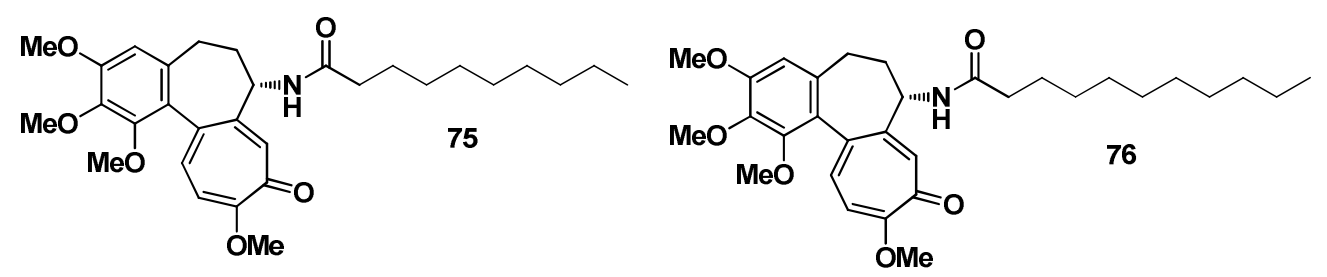<smiles>CCCCCCCCCCCC(=O)N[C@H]1CCc2cc(OC)c(OC)c(OC)c2-c2ccc(OC)c(=O)cc21</smiles>

Figura 5.7. 


\section{Familia 3. Porcentaje de polimerización}

Los valores de porcentaje de polimerización de la tubulina de los compuestos de la familia 3 se representan en la gráfica 5.6.

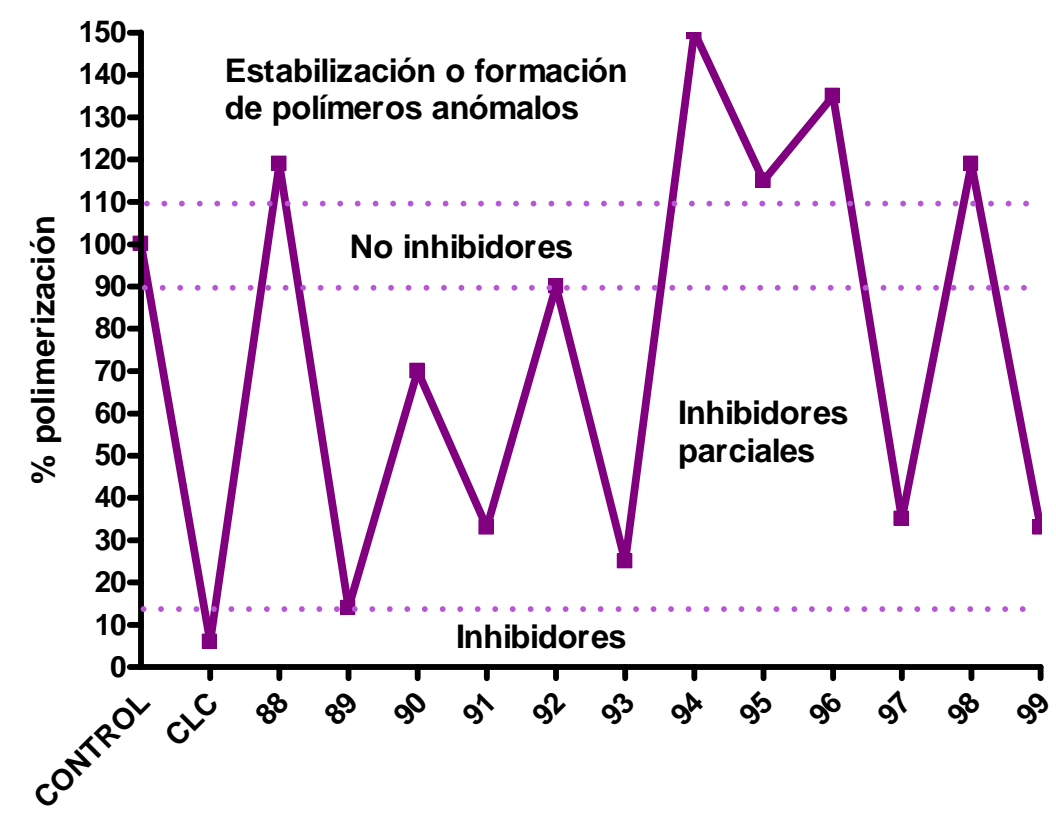

Gráfica 5.6. Porcentaje de polimerización de la tubulina con derivados de la familia 3.

En esta familia solamente el compuesto 89 (véase la figura 5.8) inhibe el proceso de formación de los microtúbulos de forma similar a la colchicina.

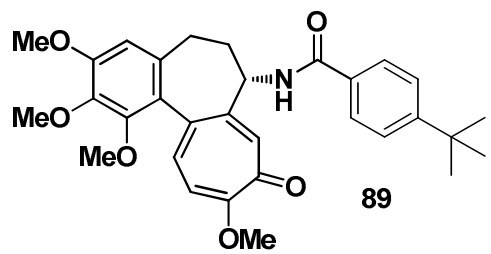

Figura 5.8.

De hecho, la mayoría de los derivados de aroílo, como 90, 91, 93, 97 y 99 (véase la figura 5.9), se podrían clasificar cómo inhibidores parciales de la polimerización de la tubulina. 


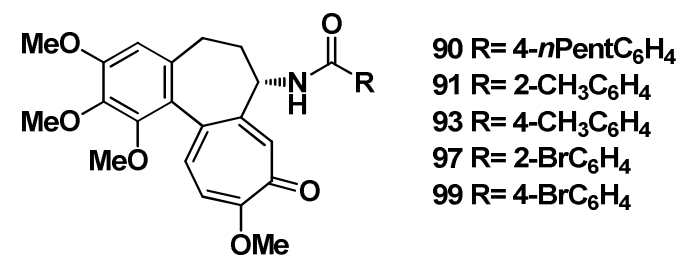

Figura 5.9.

Los derivados 88, 94, 95, 96 y 98 (véase figura 5.10) aumentan la masa de polímero.

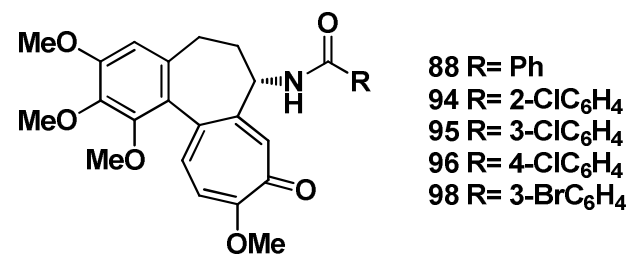

Figura 5.10. 


\subsection{Estudios de docking}

Familia 1. En relación con los cálculos de docking cabe mencionar que los compuestos estudiados de la familia 1 sitúan su parte tricíclica en el sitio de unión de la colchicina en la $\beta$-tubulina. Si el sustituyente es de una longitud adecuada se alcanza un surco presente en la a-tubulina estableciéndose enlaces de hidrógeno con los residuos fosfato del GTP, como en el caso de los compuestos 70 y 71 (véase la figura 5.11). Sin embargo, sí dicho sustituyente presenta un grupo muy voluminoso, como el del grupo Boc de los compuestos 68 y 69 , se produce una interacción estérica con el GTP y el compuesto se sitúa en la interfaz entre las dos subunidades de la tubulina. Esto podría explicar por qué los derivados que contienen el aminoácido glicina presentan mayor actividad frente a tubulina cuando carecen del grupo Boc.
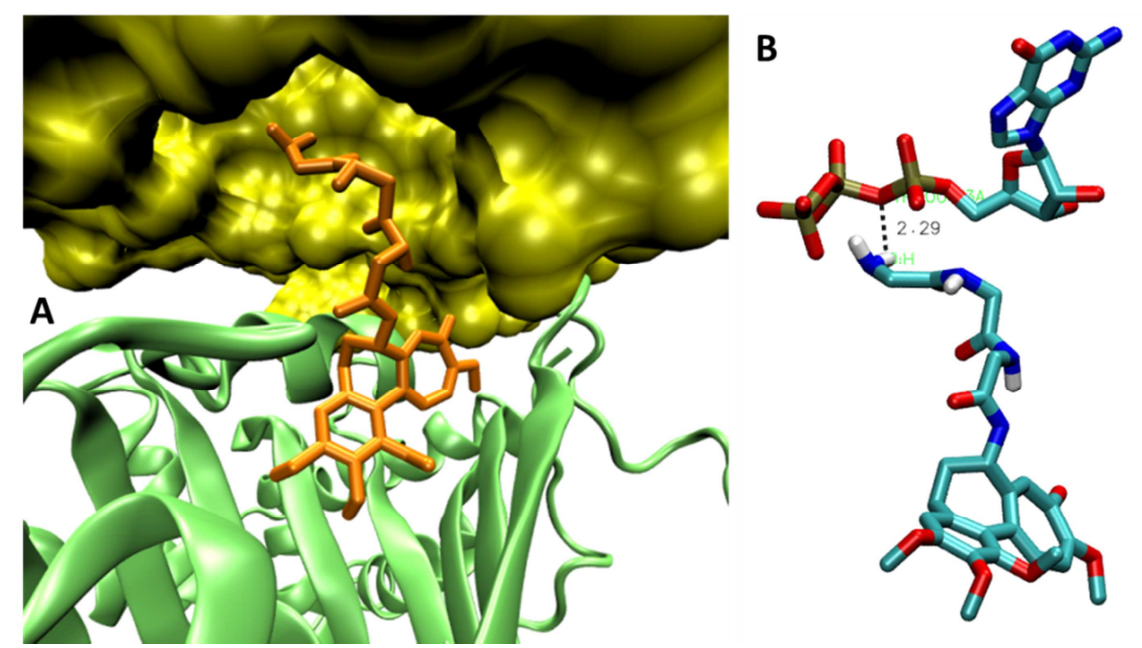

Figura 5.11. Panel A: Sitio de unión del compuesto 71 (naranja) en la tubulina con la subunidad $\beta$ en verde y la $\alpha$ en amarillo. Panel B: Interacciones del compuesto 71 con el GTP presente en la $\alpha$-tubulina. 
Familia 2. Para los compuestos 75-77 (véase la figura 5.2) los cálculos de docking sugieren que su parte tricíclica se sitúa en el sitio de unión de la colchicina en la $\beta$-tubulina. Con el aumento de la longitud de la cadena alifática se establecen más interacciones con la subunidad de $\alpha$-tubulina (véase la figura 5.12) lo que podría explicar la capacidad de estos compuestos de inducir la formación de polímeros anómalos.
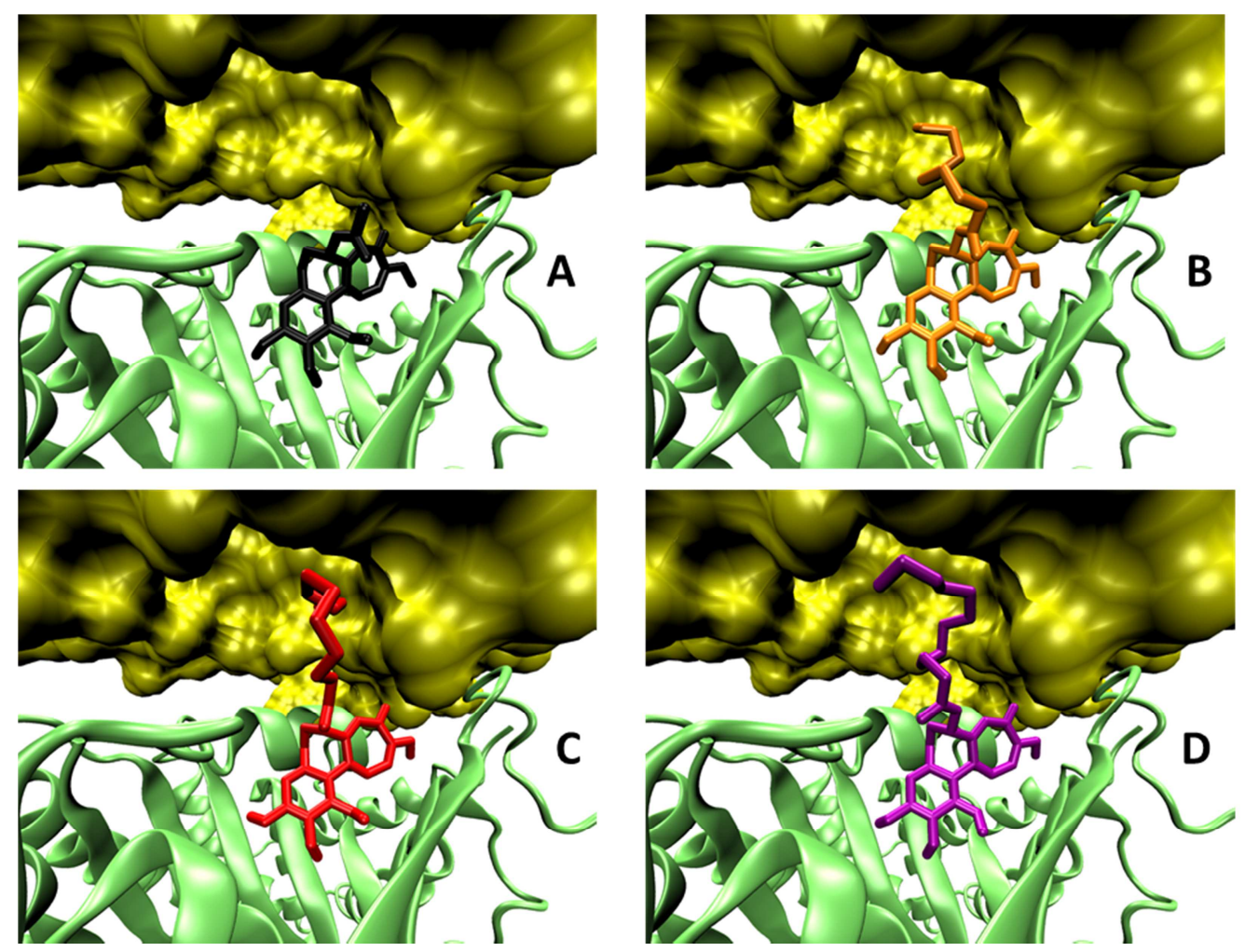

Figura 5.12. Sitio de unión del compuesto colchicina (A), 75 (B), 76 (C) y 77 (D) en la tubulina, cuya subunidad $\beta$ se representa en verde y la $\alpha$ en amarillo. 
Familia 3. Los compuestos 94-96 se unen en el sitio de la colchicina (véase la figura 5.13), situado en la interfaz de la aß-tubulina, en una conformación similar a la que presenta la estructura cristalográfica de la DAMA-colchicina (datos obtenidos del PDB 1SA0). Los estudios de docking indican que el derivado 94 (2-clorobenzoílo) coloca al átomo de cloro en una posición opuesta a la del surco de la a-tubulina, mientras que 95 (3-clorobenzoílo) y 96 (4-clorobenzoílo) orientan el átomo de cloro hacia dicho surco.
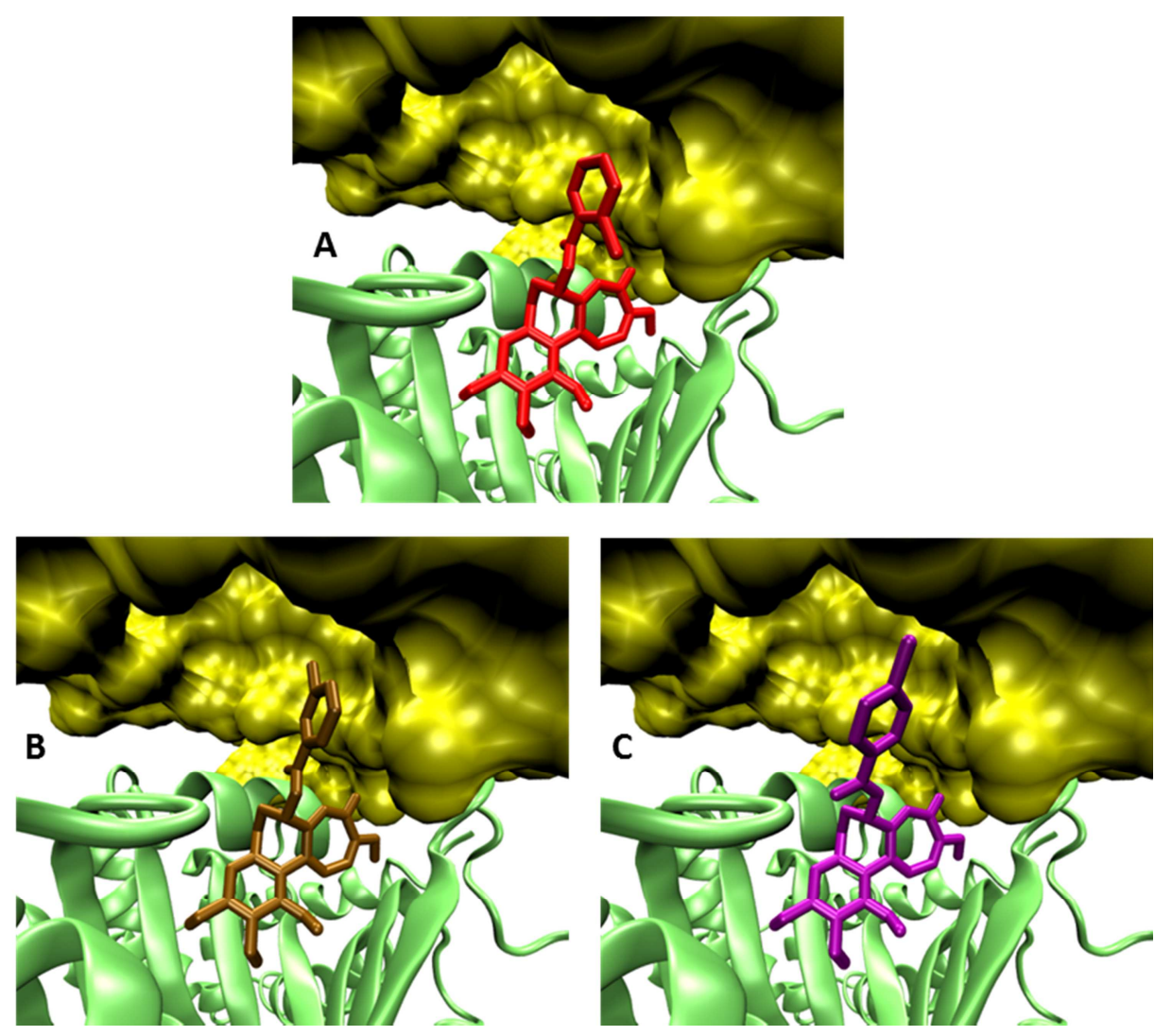

Figura 5.13. Panel A: Sitio de unión de 94 (rojo) en la tubulina, cuya subunidad $\beta$ se representa en verde y la $\alpha$ en amarillo. Panel B: Sitio de unión del compuesto 95 (marrón). Panel C: Sitio de unión del compuesto 96 (morado). 


\subsection{Inhibición de la expresión de genes y de la secreción de la proteína VEGF}

Para la medición de la secreción de la proteína VEGF y de la expresión de los genes VEGF, hTERT y $c-M y c$ se seleccionaron una serie de compuestos de las tres familias en función de sus valores de citotoxicidad (véase el capítulo 4). En la gráfica 5.7 se representan conjuntamente los valores de expresión de los genes VEGF (línea naranja), hTERT (línea morada) y c-Myc (línea verde) en presencia de cada uno de los compuestos seleccionados.

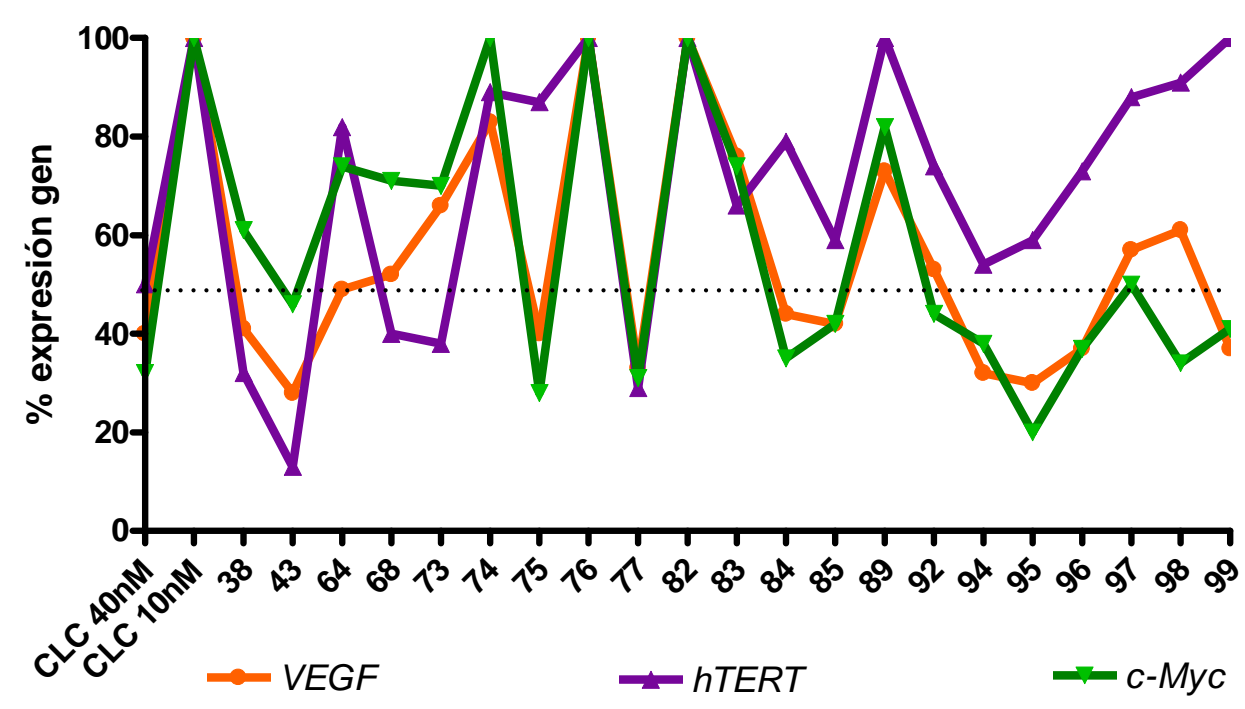

Gráfica 5.7. Porcentajes de expresión génica de derivados de colchicina.

Como puede observarse en la gráfica anterior, el compuesto 77 (véase la figura 5.14) es el más activo ya que inhibe en un $70 \%$ la expresión de los tres genes estudiados.<smiles>CCCCCCCCCCCC(=O)N[C@H]1CCc2cc(OC)c(OC)c(OC)c2-c2ccc(OC)cc21</smiles>

Figura 5.14. 
Los derivados de a-aminoacilo 38 y $\mathbf{4 3}$ (véase la figura 5.15) presentan actividad dual frente a los genes VEGF y $h T E R T$ reduciendo su expresión a valores inferiores al 50\%, destacando el compuesto $\mathbf{4 3}$ frente al gen $h T E R T$ que reduce su expresión hasta aproximadamente el 15\%.
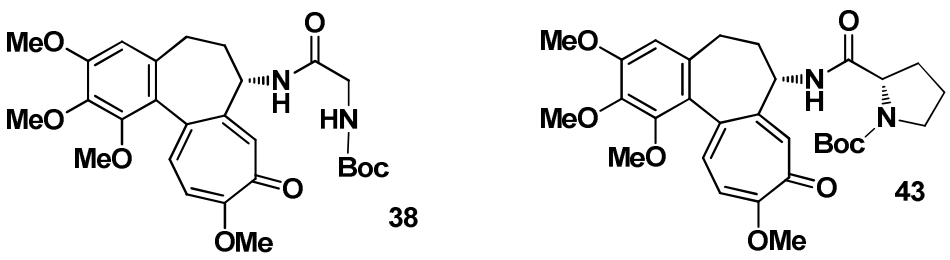

Figura 5.15.

También hay que destacar a los compuestos 75, 84, 85, 94, 95 y 96 (véase la figura 5.16), que presentan actividad dual frente a los genes VEGF y c-Myc reduciendo su expresión a valores inferiores al 50\%. Varios estudios ${ }^{149}$ han remarcado el papel del gen $c-M y c$ en el proceso de regulación de la angiogénesis. De hecho, indican que la activación del gen $c-M y c$ es suficiente para desencadenar la expresión del VEGF. A la vista de nuestros resultados, parece que nuestros compuestos favorecen la reducción de la expresión del gen VEGF a través de la regulación de la expresión del gen c-Myc.

\footnotetext{
149 a) Rahden, B. H. A.; Stein, H. J.; Pühringer-Oppermann, F.; Sarbia, M. Neoplasia, 2006, 8, 702-707. b) Baudino, T. A.; McKay, C.; Pendeville-Samain, H.; Nilsson, J. A.; Maclean, K. H.; White, E. L.; Davis, A. C.; Ihle, J. N.; Cleveland, J. L. Genes Dev., 2002, 16, 2530-2543.
} 
<smiles>CCCCCCCCCC(=O)N[C@H]1CCc2cc(OC)c(OC)c(OC)c2-c2ccc(OC)c(=O)cc21</smiles><smiles>COc1cc2c(c(OC)c1OC)-c1ccc(OC)c(=O)cc1[C@@H](NC(=O)CBr)CC2</smiles><smiles>COc1cc2c(c(OC)c1OC)-c1ccc(OC)c(=O)cc1[C@@H](NC(=O)CI)CC2</smiles><smiles></smiles><smiles>COc1cc2c(c(OC)c1OC)-c1ccc(OC)c(=O)cc1[C@@H](NC(=O)c1cccc(Cl)c1)CC2</smiles><smiles>COc1cc2c(c(OC)c1OC)-c1ccc(OC)c(=O)cc1[C@@H](NC(=O)c1ccc(Cl)cc1)CC2</smiles>

Figura 5.16.

En cuanto a la secreción de la proteína VEGF, solamente algunos derivados de aroílo pertenecientes a la familia 3 (compuestos 89, 94-96 y 99 , véase la figura 5.17) reducen la secreción de la proteína VEGF-A en unos porcentajes entre el $40-50 \%$, valores próximos al que se obtiene con la colchicina ( $40 \%$ de reducción de la secreción de la proteína). 

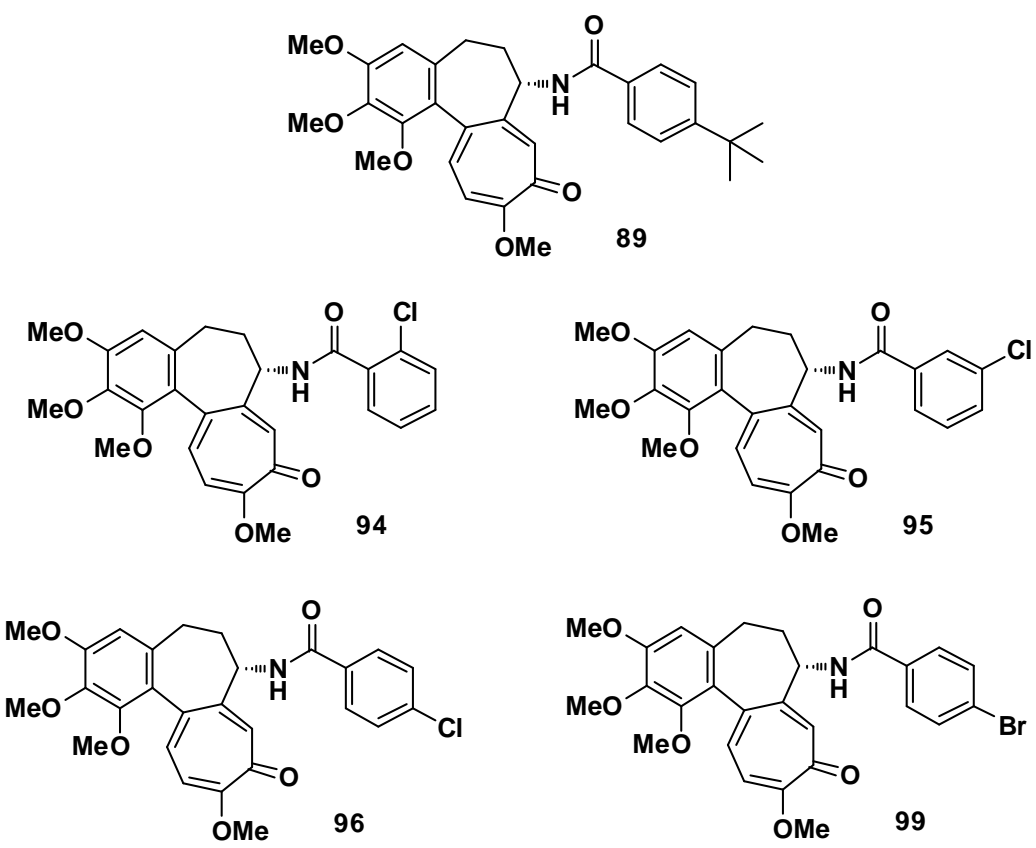

Figura 5.17. 



\section{CHAPTER 6}

\section{SUMMARY OF THE}

Ph.D THESIS

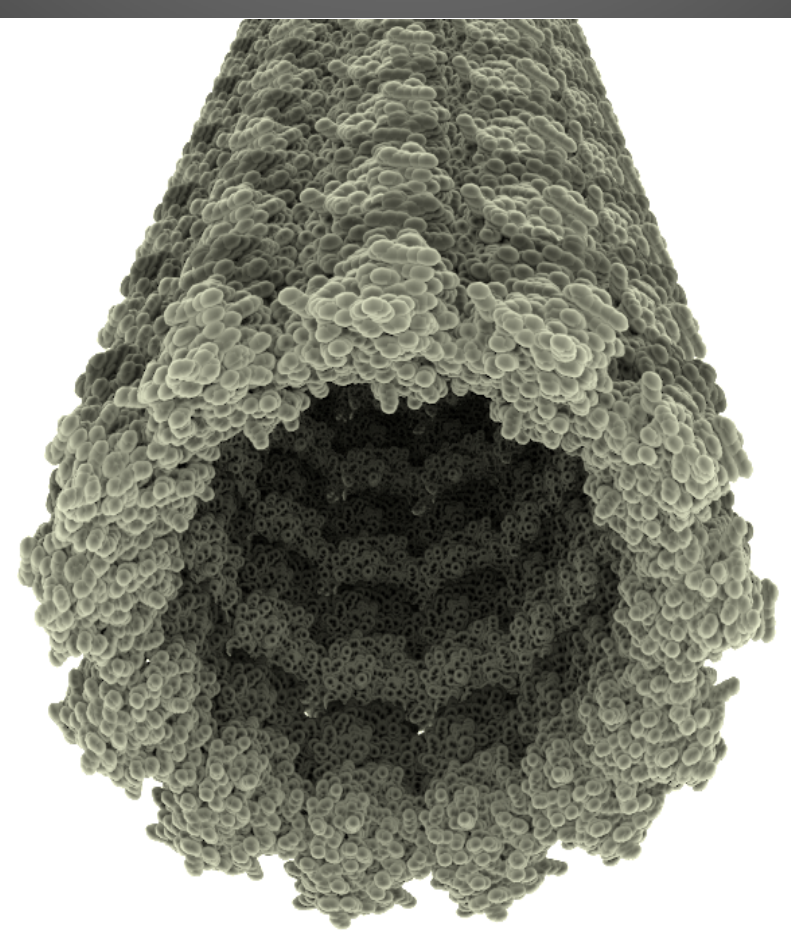





\section{CHAPTER 6: SUMMARY OF THE Ph. D. THESIS}

\subsection{Introduction}

Medicinal chemistry is an interdisciplinary science focused on the design, synthesis and chemical and biological study of new molecules with potential pharmacological and therapeutic activities.

Nature is arguably the biggest source of pharmacologically active compounds. Natural products are able to interact with a high number of molecular targets and play therefore a central role in the discovery and development of new drugs. A particularly outstanding example of a natural product successfully employed in chemotherapy is Paclitaxel (Taxol®), which is being used in clinical practice since several years. ${ }^{150}$

\subsubsection{Cancer}

Cancer is not a single disease but a complex group of diseases (over 200 types described), all being characterized by an uncontrolled proliferation of mutated cells which have potential to invade or spread to other parts of the body. ${ }^{151}$

The incidence of cancer is expected to rise worldwide from 12 million new people affected annually in the year 2000 to an anticipated 20 million in the year 2030. Until present, only cardiovascular diseases have given rise to a higher death rate than cancer but this situation is expected to change in the forthcoming years, with cancer reaching the top of the list for the first time. ${ }^{152}$ For this reason, novel anticancer drugs are urgently required.

\footnotetext{
${ }^{150}$ Mishra, B. B.; Tiwari, V. K. Eur. J. Med. Chem. 2011, 46, 4769-4807.

${ }^{151}$ Ferlay, J.; Soerjomataram, I.; Ervik, M.; Dikshit, R.; Eser, S.; Mathers, C.; Rebelo, M.; Parkin, D. M.; Forman, D.; Bray, F. GLOBOCAN, 2012, v1.0, Cancer Incidence and Mortality Worldwide: IARC.

152 Olsen, M. M.; Siegelmann, H. T. Procedia Comput. Sci. 2013, 18, 1016-1025.
} 
The main drawbacks of antitumor drugs are the lack of selectivity and specificity for cancer cells, the emergence of drug resistance and the inability to penetrate aggressive solid tumours. ${ }^{153}$

One way to minimize side effects of antitumor drugs is to find molecules that interact with proteins present solely in tumour cells. In the year 2000, Hanahan and Weinberg ${ }^{154}$ published a list of common features present in tumour cells. The list was then updated in $2011^{155}$ by the same researchers as depicted in Figure 6.1, which shows the ten hallmarks of cancer cells.

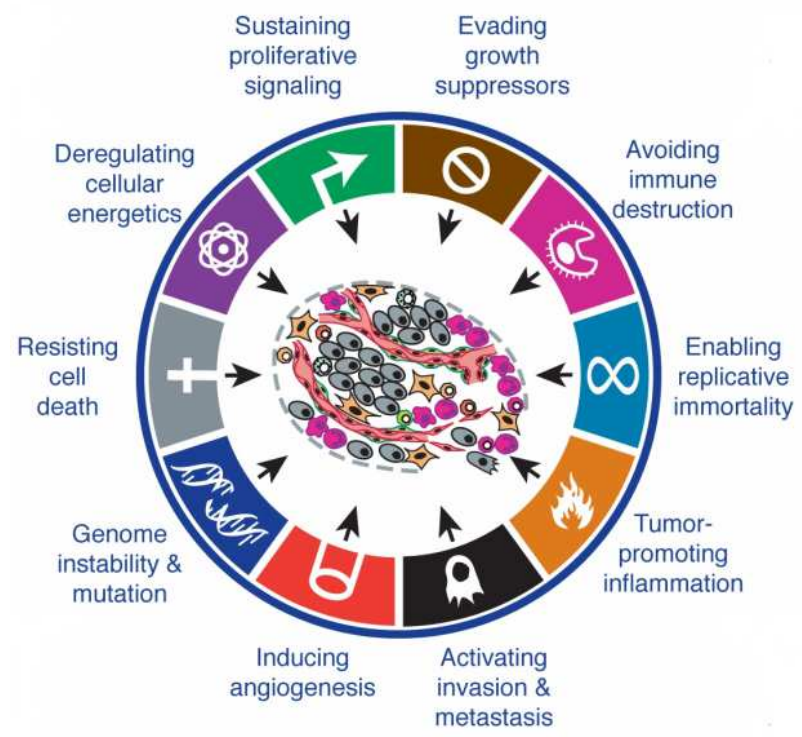

Figure 6.1. Hallmarks of cancer cells.

This Ph. D. Thesis focuses on the synthesis and biological evaluation of colchicine derivatives with potential anticancer properties. Particular attention is paid to their effect on replicative capacity of some types of cancer cells, induction of apoptosis through interaction of microtubules and downregulation of genes related to telomerase activity and angiogenesis. ${ }^{156}$

\footnotetext{
153 Panchal, R. G. Biochem. Pharm. 1998, 55, 247-252.

${ }_{155}^{154}$ Hanahan, D.; Weinberg, R. A. Cell 2000, 100, 57-70.

${ }_{155}^{155}$ Hanahan, D.; Weinberg, R. A. Cell 2011, 144, 646-674.

${ }^{156}$ Martin-Sabroso, C.; Torres-Suárez, A. I. An. Real Acad. Farm. 2013, 79, 213-228.
} 


\subsubsection{Telomerase}

Telomerase is an enzyme with reverse transcriptase activity that fulfils the role of elongating the chromosomal telomeres. Telomeres (Figure 6.2) are noncoding DNA regions consisting of arrays of repetitive DNA sequences $(\text { TTAGGG })_{n}$ and associated proteins which are placed at the end of linear chromosomes. The properties of the eukaryotic telomeres are usually identified as the "capping function", with a principal mission to protect chromosome ends from degradation and fusion, both of which stimulate checkpoint activation, ultimately leading cells to apoptosis or irreversible growth arrest known as replicative senescence. The length of telomeres serves as an intrinsic biological clock that regulates the life span of the cell, i.e. they provide limits on the number of replications a cell can go through. ${ }^{157}$ During each cell division the telomeres are shortened ${ }^{158}$ and after a certain number of cell divisions, the cells enter senescence. ${ }^{159}$

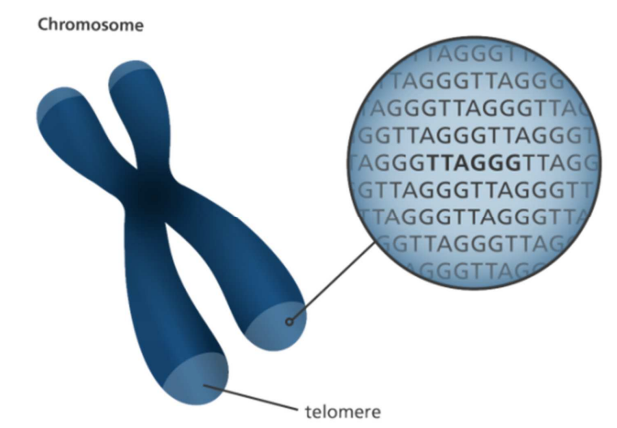

Figure 6.2. Representation of the telomeres in the chromosome.

By expressing telomerase tumour cells are able to arrest the progressive shortening of telomeres avoiding aging. This leads to the hallmark known as replicative immortality (Figure 6.1).

${ }^{157}$ Kim, K. W.; Piatyszek, M. A.; Prowse, K. R.; Harley, C. B.; West, M. D.; Ho, P. L.; Coviello, G. M.; Weinrich, S. L.; Shay, J. W. Science, 1994, 266, 2011-2015.

${ }^{158}$ Berg, J. M.; Tymoczko, J. L.; Stryer, L. Biochemistry, $6^{\text {th }}$ ed. Editorial Reverté, 2007.

${ }^{159}$ Martin, G. M.; Sprague, C. A.; Epstein, C. J. Lab. Invest. 1970, 23, 86-92. 
It is worth noting here that, while somatic cells do not express telomerase ${ }^{160}$ the latter has been found to be overexpressed in more than $85 \%$ of cancers. This makes this enzyme a very attractive therapeutic target, a circumstance that has stimulated the development of new compounds that show ability to inhibit its function.

\subsubsection{Angiogenesis}

Angiogenesis is the formation of new blood vessels from existing ones. Under physiological conditions angiogenesis occurs during processes such as embryonic development or wound healing, as well as in the female reproductive cycle. This process is highly controlled through a dynamic balance between pro- and anti-angiogenic factors. Tumours are able of secreting chemical signals (pro-angiogenic factors) that disrupt the angiogenic equilibrium and trigger angiogenesis (Figure 6.3). ${ }^{161}$

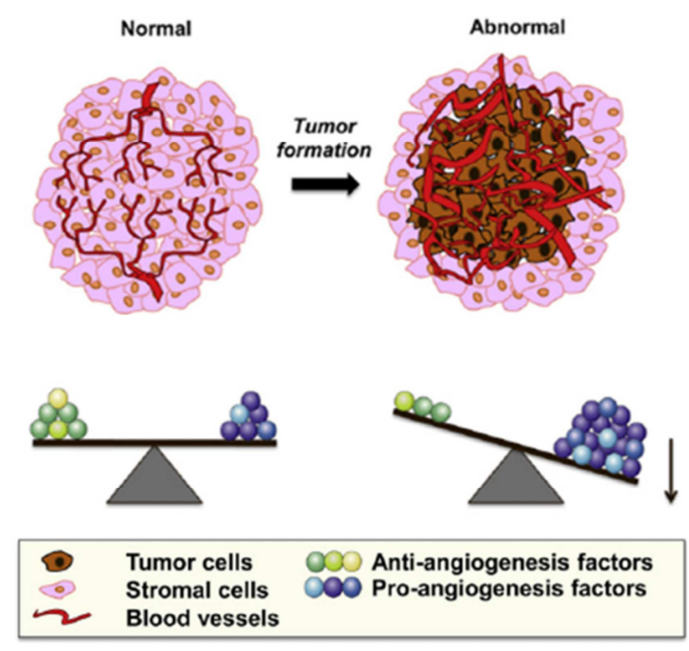

Figure 6.3. Angiogenesis equilibrium.

\footnotetext{
${ }^{160}$ Buseman, C. M.; Wright, W. E.; Shay, J. W. Mutation Research, 2012, 730, 90-97.

${ }^{161}$ (a) Carmeliet, P.; Jain, K. R. Nature 2000, 407, 249-257. (b) Makrilia, N.; Lappa, T.; Xyla, V.; Nikolaidis, I.; Syrigos, K. Eur. J. Intern. Med. 2009, 20, 663-671.
} 
The formation of new blood vessels in the tumour environment allows them to grow because of the supply of oxygen and nutrients. Moreover, these new blood vessels do not display a normal structure and are functionally immature. This favours the dispersion of tumour cells, a process known as metastasis. ${ }^{162}$

One of the pro-angiogenic factors that play a crucial role in tumour angiogenesis is the Vascular Endothelial Growth Factor (VEGF). VEGF binds to different tyrosine kinase membrane receptors (VEGFR) to promote endothelial cell proliferation, invasion, migration, survival and vascular permeability. ${ }^{163}$

\subsubsection{Tubulin and microtubules}

Tubulin is one of several members of a family of globular proteins. The tubulin superfamily includes five distinct families: the alpha-, beta-, gamma-, delta- and epsilon-tubulins, as well as a sixth family (zeta-tubulin) which is present only in kinetoplastid protozoa. The most common members of the tubulin family are $\alpha$-tubulin and $\beta$-tubulin, the two proteins that constitute the bulk of microtubule mass. Each one has a molecular weight of approximately 55,000 Dalton. ${ }^{164} \alpha$-Tubulin and $\beta$-tubulin bind to each other in a noncovalent way to yield a heterodimeric protein that assembles in a head-to-tail fashion way to form protofilaments. The protofilaments (13 in most cells) associate longitudinally to form a sheet, which then closes up to form a microtubule with a diameter of $25 \mathrm{~nm} .{ }^{165}$

Microtubules possess a very imperative feature of polarity. Thus, in a protofilament the (-) end has the a subunits exposed whereas the $(+)$ end has the $\beta$ subunits exposed (Figure 6.4). Each subunit contains two GTP binding sites: a) site-1, located on a-tubulin, where GTP binds irreversibly and does not

\footnotetext{
162 Deryugina, E. I.; Quigley, J. P. Matrix Biol. 2015, 44, 94-112.

163 Hicklin, D. J.; Ellis, L. M. J. Clin. Oncol. 2005, 23, 1011-1027.

${ }^{164}$ Kaur, R.; Kaur, G.; Kaur Gill, R.; Soni, R.; Bariwal, J. Eur. J. Med.Chem. 2014, 87, 89-124.

${ }^{165}$ Zhou, J.; Giannakakou, P. Curr. Med. Chem. 2005, 5, 65-71.
} 
undergo hydrolysis, and b) site-2, located on $\beta$-tubulin, where GTP binds reversibly and undergoes hydrolysis to GDP, so that it is also known as the exchangeable site (E-site).

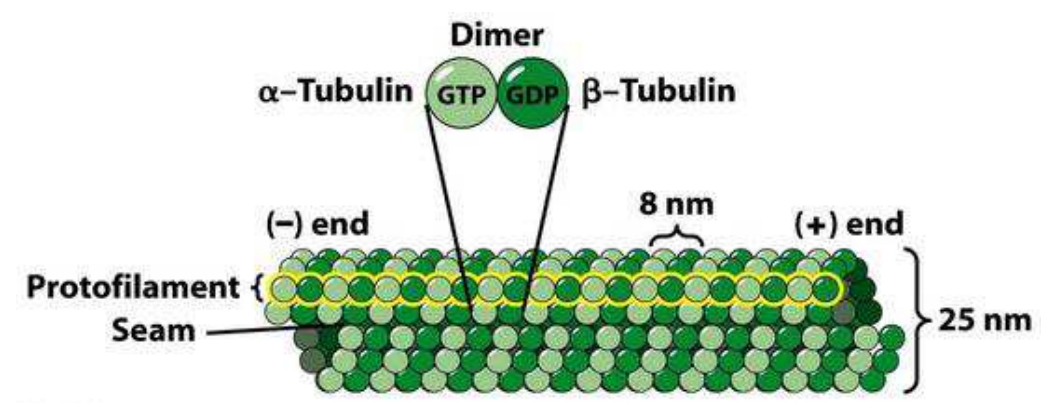

Figure 6.4. Microtubule's representation.

Microtubules possess a dynamic equilibrium in which they are continuously undergoing the process of growing and shrinking. During polymerization, both the $\alpha$ - and $\beta$-subunits of the tubulin dimers bound a GTP molecule. ${ }^{166} \mathrm{At}$ $\alpha \beta$-tubulin concentrations above the critical concentration $\left(C_{\mathrm{c}}\right)$, the dimers polymerize into microtubules. Dimers add to both ends but, at the equilibrium, subunits are exchanged rapidly at the $(+)$ end and more slowly at the (-) end. When the tubulin concentration is diluted below the $C_{\mathrm{c}}$, the microtubules disassemble two times faster at the $(+)$ end than at the $(-)$ end. Thus, both assembly and disassembly occur preferentially at the (+) end.

This non-equilibrium behaviour, known as dynamic instability, is based on the binding and hydrolysis of GTP at the E-site in $\beta$-tubulin. Only dimers that have GTP in their E-site can polymerize. After polymerization, GTP in $\beta$-tubulin is hydrolysed and becomes nonexchangeable. The microtubule structure is stabilized ("capped") by a layer of GTP tubulin subunits at the (+) end to maintain association between protofilaments. When the cap is lost, the protofilaments peel outward and the microtubule rapidly depolymerizes. This switching from growth to shrinking is known as catastrophe. GTP-bound tubulin

$\overline{166}$ Jordan, M. A.; Wilson, L. Nat. Rev. Cancer 2004, 4, 253-265. 
can be added to the tip of the microtubule again, providing a new cap and protecting the microtubule from shrinking. This is referred to as rescue. ${ }^{167}$ All these steps are summarised in Figure 6.5.

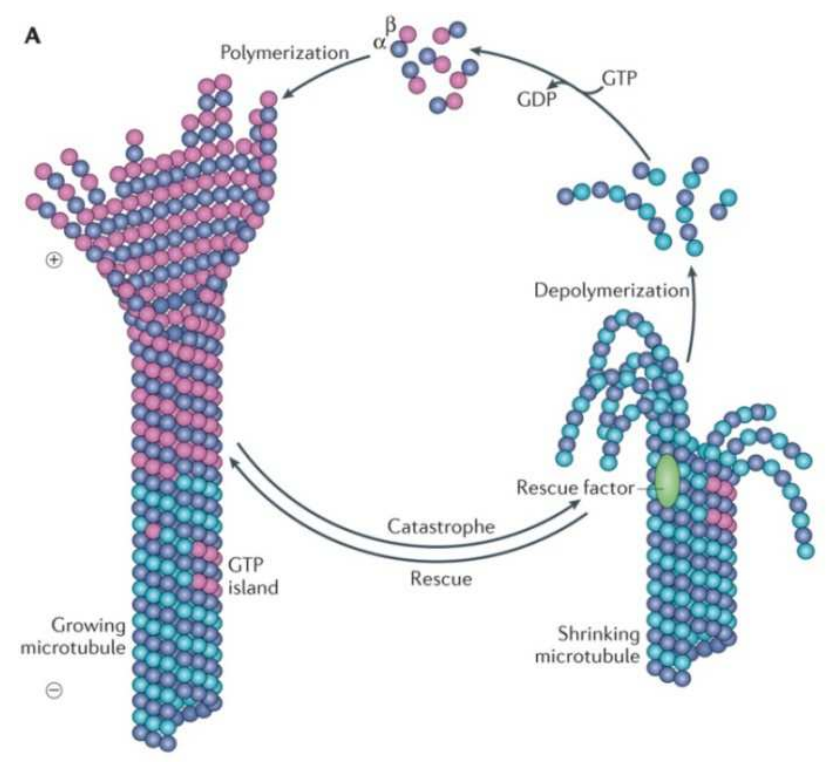

Figure 6.5. Microtubule dynamics.

Microtubules are involved in the organization of intracellular structure and intracellular transport, as well as in other cellular phenomena such as ciliary and flagellar motility. Microtubules play a key role in cell division. ${ }^{166}$ Their primary cell division function is to connect to the chromosomes helping them to complete their first split and then shifting the new chromosomes to their places in the new daughter cells. This task is performed by the microtubules that make up the centrioles, organelles that have been given the specific job of helping cells divide. After cell division has finished, the same microtubules return to their functions in other parts of the cell.

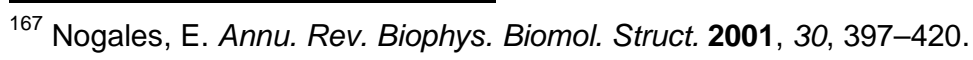




\subsubsection{Colchicine}

Antimitotic agents are commonly used in treatment of cancer as they are able to inhibit or arrest the cellular mitosis. Their biological action is achieved through interaction with microtubules. ${ }^{168}$ The compounds that interact with tubulin can be classified according to their action on microtubules, which may be either stabilizing or destabilizing. ${ }^{166,169}$

Colchicine (Figure 6.6), is a natural product extracted from the leaves of the plant species Colchicum autumnale. The FDA (Food and Drug Administration) approved colchicine to treat gout and familial Mediterranean fever. ${ }^{170}$ In addition to this application, it has a broad therapeutic potential against other diseases such as Behcet's disease, pericarditis and atrial fibrillation. ${ }^{171}$
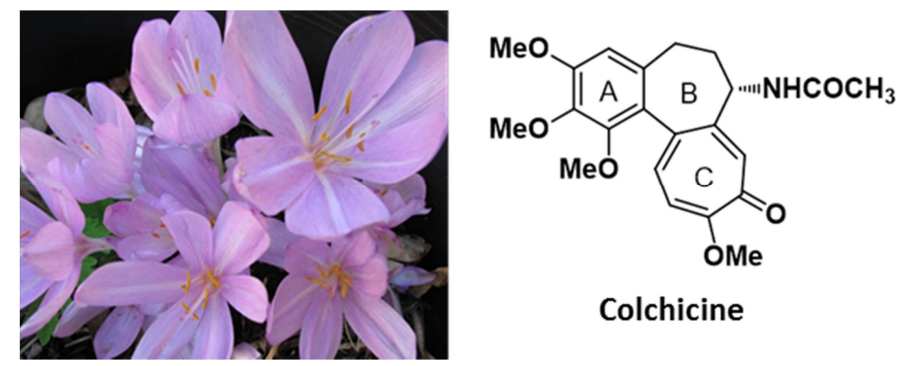

Colchicine

Figure 6.6. Colchicum autumnale and structure of colchicine.

Colchicine is able to bind to $\beta$-tubulin ${ }^{172}$ (Figure 6.7) causing arrest of the polymerization of microtubules. Colchicine binds to unpolymerized tubulin heterodimers, forming a stable complex (T-C). ${ }^{173}$ The rate of formation of these complexes is relatively slow as compared with the rate of microtubule

\footnotetext{
${ }^{168}$ Carlson, R. O. Expert Opin. Investig. Drugs 2008, 17, 707-722.

${ }^{169}$ Checchi, P. M.; Nettles, J. H.; Zhou, J.; Snyder, J. P.; Joshi, H. C. Trends Pharmacol. Sci. 2003, 24, 361-365.

${ }_{170}$ Woodcock, J., Okada, S., N Engl J Med, 2010, 363, 1484.

${ }^{171}$ Leung, Y. Y.; Hui, L. L. Y.; Kraus, V. B. Semin. Arthritis Rheum., 2015, 45, 341-350.

${ }_{172}^{172}$ Ravelli, R.; Gigant, B.; Curmi, P.; Jourdain, I.; Lachkar, S.; Sobel, A. Nature 2004, 428, 198.

173 Deftereos, S.; Giannopoulos, G.; Papoutsidakis, N.; et al. J Am Coll Cardiol. 2013, 62, 18171825.
} 
formation due to a slow conformational change that occurs on the T-C complex and makes it more stable. ${ }^{174}$ When T-C complexes join the microtubule, the lateral contacts between protofilaments are disrupted, with ensuing microtubule depolyme-risation. ${ }^{175}$

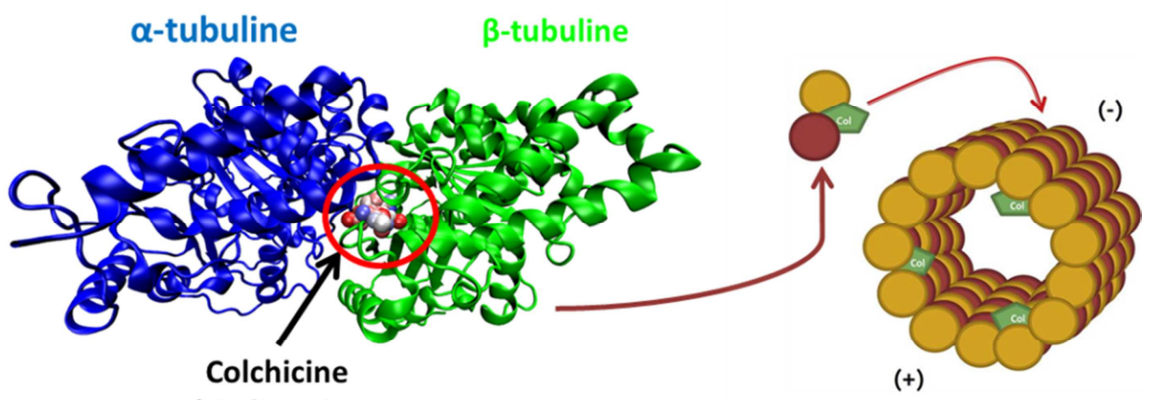

binding site

Figure 6.7. Colchicine binding site on tubulin.

Despite the interesting biological activity of colchicine, its high toxicity has precluded its use as an antitumor drug. ${ }^{176}$

\footnotetext{
174 Hastie, S. B. Pharmacol. Ther. 1991, 512, 377-401.

175 Bhabatarak, B.; Panda, D.; Gupta, S.; Banerjee, M. Med. Res. Rev 2008, 28, 155-183.

${ }^{176}$ Massarotti, A.; Coluccia, A.; Silvestri, R.; Sorba, G.; Brancale, A. Minirev. ChemMedChem, 2012, 7, 33-42.
} 


\subsection{Objectives}

The objectives of this Thesis have been focused on the synthesis and biological evaluation of a range of colchicine derivatives.

1) The synthetic part is centered on the preparation of three families of colchicine derivatives whose general structures are shown in Figure 6.8.

a) Family 1 is composed of colchicine derivatives in which the acetyl group on the nitrogen atom has been substituted by $\alpha$-aminoacyl groups derived from amino acids.

b) Family 2 is formed by compounds in which the acetyl group is replaced by aliphatic, long-chain acyl, cyclohexylacetyl, phenylacetyl and a-haloacetyl groups.

c) Family 3 is constituted by compounds in which the acetyl group is replaced by substituted benzoyl groups.<smiles>[R]NC([R])C(=O)NC1CCc2cc(OC)c(OC)c(OC)c2-c2ccc(OC)cc21</smiles>

Family 1<smiles></smiles>

Family 2

$$
\text { (Y = alkyl, cyclohexyl, halogen) }
$$<smiles>COc1cc2c(c(OC)c1OC)-c1ccc(OC)c(=O)cc1[C@H](NC(=O)[Al])CC2</smiles>

Family 3

Figure 6.8. General structures of the colchicine derivatives used in this $\mathrm{Ph}$. D. Thesis.

2) The biological part is devoted to the biological evaluation of the synthetic compounds. The following biological activities will be studied:

a) The cytotoxic activity of the synthetic derivatives against different cell lines, both tumoral and non tumoral. 
b) The interactions of colchicine analogues with tubulin.

c) The effects of colchicine analogues on the secretion of VEGF protein and on the inhibition of its associated VEGF gene, which are involved in the activation of angiogenesis.

d) The effects of colchicine analogues on the inhibition of the hTERT and $c-M y c$ genes, both involved in polymerase activation. 


\subsection{Synthesis}

Colchicine derivatives have been prepared from $\mathrm{N}$-deacetylcolchicine, obtained in turn from colchicine as reported. Thus, $N$-Boc protection of the latter followed by $\mathrm{N}$-deacetylation and $\mathrm{N}$-Boc deprotection afforded the $\mathrm{N}$-deacetylcolchicine salt 3 (Scheme 6.1). ${ }^{177}$<smiles>CCN(C(=O)OC)[C@H]1CCc2cc(OC)c(OC)c(OC)c2-c2ccc(OC)c(OC)c2[C@H]1NC(C)=O</smiles>

Scheme 6.1. (a) $\mathrm{Boc}_{2} \mathrm{O}, \mathrm{Et}_{3} \mathrm{~N}, \mathrm{DMAP}, \mathrm{THF}, 45{ }^{\circ} \mathrm{C}, 24 \mathrm{~h}, 99 \%$. (b) $\mathrm{NaOMe}(2 \mathrm{M}$ in $\mathrm{MeOH})$, r. t., 2 h. (c) TFA ac. $98 \%$, r. t., 5 min, (98\% global yield of both steps).

\subsubsection{Family 1}

For the preparation of the compounds of family 1 , salt 3 was submitted to peptide coupling with the corresponding $N$-Boc protected L-aminoacid (Scheme 6.2). ${ }^{178}$ Peptide coupling, carried out in the presence of $\mathrm{EDCl}$ and DMAP in DMF, yielded compounds 38-47. ${ }^{179}$ Finally, colchicine derivatives 48-57 were prepared upon $\mathrm{N}$-Boc deprotection by treatment with Amberlyst 15 resin. $^{180}$

\footnotetext{
177 Johansson, E.; Dubois, J.; Darbre, T.; Reymond, J. L. Bioorg. Med. Chem. 2010, 18, 65896597.

${ }^{178}$ Boger, D.; Borzilleri, R.; Nukui, S. J.Org. Chem. 1996, 61, 3561-3565.

${ }^{179}$ Iwaszkiewicz-Grzes, D.; Cholewinski, G.; Kot-Wasik, A.; Trzonkowski, P.; Dzierzbicka, K. Eur. J.Med. Chem. 2013, 69, 863-871.

${ }^{180}$ Liu, Y.; Zhao, C.; Bergbreiter, D. E.; Romo, D. J. Org. Chem. 1998, 63, 3471-3473.
} 


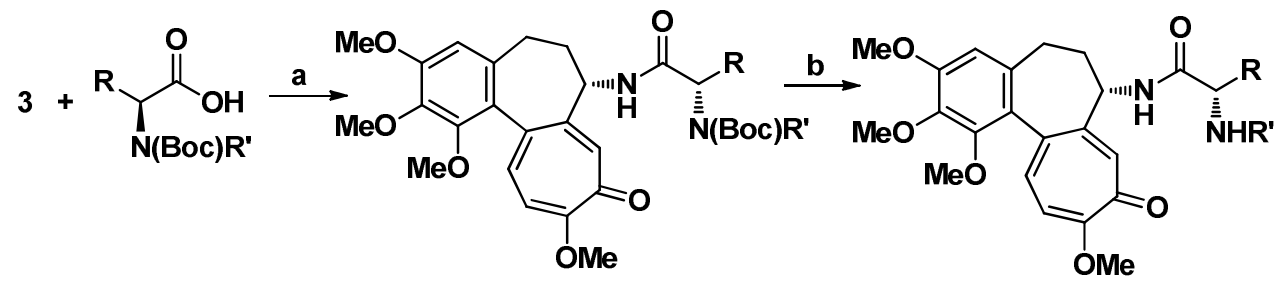

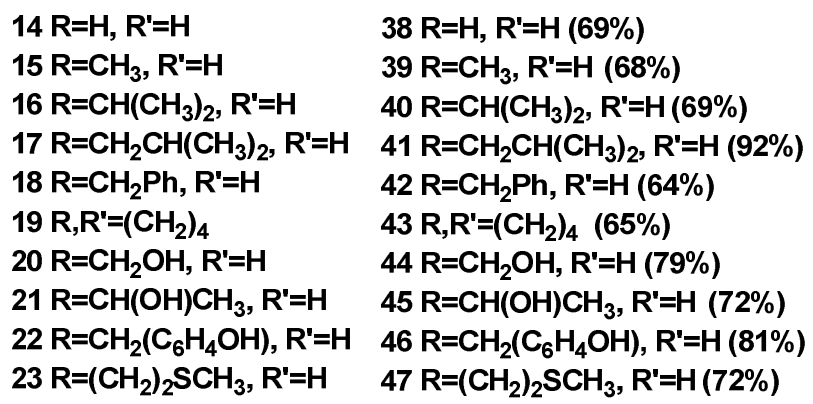

Scheme 6.2. (a) EDCI, DMAP, DMF, $0{ }^{\circ} \mathrm{C}$ to r. t. (b) Amberlyst 15 resin, $\mathrm{CH}_{2} \mathrm{Cl}_{2}$, r. t., $24 \mathrm{~h}$, then $\mathrm{NH}_{3} 4 \mathrm{M}$ in $\mathrm{MeOH}, 1$ h, r. t.

The corresponding colchicine derivatives bearing $\mathrm{D}$ - $\alpha$-amino acids were prepared in the same way as their L counterparts (Scheme 6.3).<smiles></smiles>

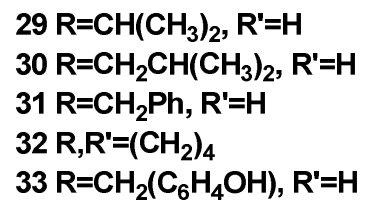

$58 \mathrm{R}=\mathrm{CH}\left(\mathrm{CH}_{3}\right)_{2}, \mathrm{R}=\mathrm{H}(72 \%)$

$59 \mathrm{R}=\mathrm{CH}_{2} \mathrm{CH}\left(\mathrm{CH}_{3}\right)_{2}, \mathrm{R}^{\prime}=\mathrm{H}(72 \%)$

$60 \mathrm{R}=\mathrm{CH}_{2} \mathrm{Ph}, \mathrm{R}^{\prime}=\mathrm{H}(65 \%)$

$61 \mathrm{R}, \mathrm{R}^{\prime}=\left(\mathrm{CH}_{2}\right)_{4}(67 \%)$

$62 \mathrm{R}=\mathrm{CH}_{2}\left(\mathrm{C}_{6} \mathrm{H}_{4} \mathrm{OH}\right), \mathrm{R}^{\prime}=\mathrm{H}(75 \%)$
$48 \mathrm{R}=\mathrm{H}, \mathrm{R}^{\prime}=\mathrm{H}(\mathbf{7 5 \% )}$

$49 \mathrm{R}=\mathrm{CH}_{3}, \mathrm{R}^{\prime}=\mathrm{H}(76 \%)$

$50 \mathrm{R}=\mathrm{CH}\left(\mathrm{CH}_{3}\right)_{2}, \mathrm{R}^{\prime}=\mathrm{H}(90 \%)$

$51 \mathrm{R}=\mathrm{CH}_{2} \mathrm{CH}\left(\mathrm{CH}_{3}\right)_{2}, \mathrm{R}^{\prime}=\mathrm{H}(84 \%)$

$52 \mathrm{R}=\mathrm{CH}_{2} \mathrm{Ph}, \mathrm{R}^{\prime}=\mathrm{H}(93 \%)$

$53 \mathrm{R}, \mathrm{R}^{\prime}=\left(\mathrm{CH}_{2}\right)_{4}(85 \%)$

$54 \mathrm{R}=\mathrm{CH}_{2} \mathrm{OH}, \mathrm{R}^{\prime}=\mathrm{H}(\mathbf{7 5 \% )}$

$55 \mathrm{R}=\mathrm{CH}(\mathrm{OH}) \mathrm{CH}_{3}, \mathrm{R}^{\prime}=\mathrm{H}(95 \%)$

$56 \mathrm{R}=\mathrm{CH}_{2}\left(\mathrm{C}_{6} \mathrm{H}_{4} \mathrm{OH}\right), \mathrm{R}^{\prime}=\mathrm{H}(75 \%)$

$57 \mathrm{R}=\left(\mathrm{CH}_{2}\right)_{2} \mathrm{SCH}_{3}, \mathrm{R}=\mathrm{H}(\mathbf{9 7 \%})$

Scheme 6.3. (a) EDCl, DMAP, DMF, $0{ }^{\circ} \mathrm{C}$ to r. t. (b) Amberlyst 15 resin, $\mathrm{CH}_{2} \mathrm{Cl}_{2}$, r. t., $24 \mathrm{~h}$, then $\mathrm{NH}_{3} 4 \mathrm{M}$ in $\mathrm{MeOH}, 1 \mathrm{~h}$, r. t. 
The Gly-Gly and Gly-Gly-Gly derivatives were obtained following the sequence depicted in Scheme 6.4.

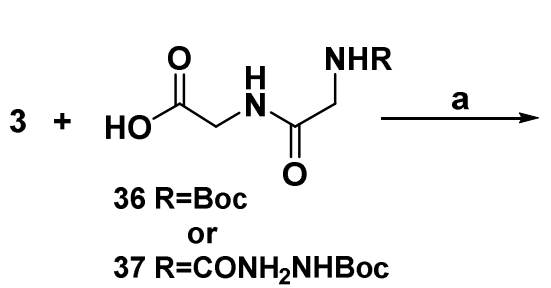

$37 \mathrm{R}=\mathrm{CONH}_{2} \mathrm{NHBOC}$<smiles>[R]NCC(=O)NCC(=O)N[C@H]1CCc2cc(OC)c(OC)c(OC)c2-c2ccc(OC)c(=O)cc21</smiles>

$68 \mathrm{R}=\mathrm{Boc}(80 \%)$

$69 \mathrm{R}=\mathrm{COCH}_{2} \mathrm{NHBoc}(72 \%)$<smiles></smiles>

Scheme 6.4. (a) EDCI, DMAP, DMF, $0{ }^{\circ} \mathrm{C}$ to r. t. (b) Amberlyst 15 resin, $\mathrm{CH}_{2} \mathrm{Cl}_{2}$, r. t., $24 \mathrm{~h}$, then $\mathrm{NH}_{3} 4 \mathrm{M}$ in $\mathrm{MeOH}, 1 \mathrm{~h}$, r. t. 


\subsubsection{Family 2}

The structures of colchicine derivatives of family 2 are depicted in Scheme 6.5. These compounds were obtained by coupling salt 3 with the corresponding acids in the presence of DCC and DMAP in $\mathrm{CH}_{2} \mathrm{Cl}_{2}$ as solvent. ${ }^{181}$<smiles>COc1cc2c(c(OC)c1OC)-c1ccc(OC)c(=O)cc1[C@@H]([NH3+])CC2</smiles><smiles>[R]C(=O)O</smiles><smiles></smiles>

$72 \mathrm{R}=\left(\mathrm{CH}_{2}\right)_{2} \mathrm{CH}_{3}(44 \%)$ $73 \mathrm{R}=\left(\mathrm{CH}_{2}\right)_{4} \mathrm{CH}_{3}(51 \%)$ $74 \mathrm{R}=\left(\mathrm{CH}_{2}\right)_{6} \mathrm{CH}_{3}(82 \%)$ $75 \mathrm{R}=\left(\mathrm{CH}_{2}\right)_{8} \mathrm{CH}_{3}(44 \%)$ $76 \mathrm{R}=\left(\mathrm{CH}_{2}\right)_{9} \mathrm{CH}_{3}(44 \%)$ $77 \mathrm{R}=\left(\mathrm{CH}_{2}\right)_{10} \mathrm{CH}_{3}(61 \%)$ $78 \mathrm{R}=\left(\mathrm{CH}_{2}\right)_{11} \mathrm{CH}_{3}(44 \%)$ $79 \mathrm{R}=\left(\mathrm{CH}_{2}\right)_{12} \mathrm{CH}_{3}(72 \%)$ $80 \mathrm{R}=\left(\mathrm{CH}_{2}\right)_{14} \mathrm{CH}_{3}(46 \%)$

$81 \mathrm{R}=\left(\mathrm{CH}_{2}\right){ }_{16} \mathrm{CH}_{3}(77 \%)$

Scheme 6.5. (a) $\mathrm{RCOOH}, \mathrm{DCC}, \mathrm{DMAP}, \mathrm{CH}_{2} \mathrm{Cl}_{2}$, r. t., 3 h.

${ }^{181}$ Vilanova, C.; Díaz-Oltra, S.; Murga, J.; Falomir, E.; Carda, M.; Redondo-Horcajo, M.; Díaz, J. F.; Barasoain, I.; Marco, J. A. J. Med. Chem. 2014, 57, 10391-10403. 


\subsubsection{Family 3}

The structures of colchicine derivatives belonging to family 3 were obtained by means of coupling salt 3 with the corresponding acids in the presence of DCC and DMAP in $\mathrm{CH}_{2} \mathrm{Cl}_{2}$ as the solvent (Scheme 6.6).<smiles>COc1cc2c(c(OC)c1OC)-c1ccc(OC)c(=O)cc1[C@@H]([NH3+])CC2</smiles><smiles>[R]C(=O)N[C@H]1CCc2cc(OC)c(OC)c(OC)c2-c2ccc(OC)c(=O)cc21</smiles>

$$
\begin{array}{ll}
88 \mathrm{R}=\mathrm{Ph}(45 \%) & 94 \mathrm{R}=2-\mathrm{ClC}_{6} \mathrm{H}_{4}(51 \%) \\
89 \mathrm{R}=4-\mathrm{BuC}_{6} \mathrm{H}_{4}(46 \%) & 95 \mathrm{R}=3-\mathrm{ClC}_{6} \mathrm{H}_{4}(55 \%) \\
90 \mathrm{R}=4-n \mathrm{PentC}_{6} \mathrm{H}_{4}(53 \%) & 96 \mathrm{R}=4-\mathrm{ClC}_{6} \mathrm{H}_{4}(53 \%) \\
91 \mathrm{R}=2-\mathrm{CH}_{3} \mathrm{C}_{6} \mathrm{H}_{4}(59 \%) & 97 \mathrm{R}=2-\mathrm{BrC}_{6} \mathrm{H}_{4}(\mathbf{4 9 \% )} \\
92 \mathrm{R}=3-\mathrm{CH}_{3} \mathrm{C}_{6} \mathrm{H}_{4}(54 \%) & 98 \mathrm{R}=3-\mathrm{BrC}_{6} \mathrm{H}_{4}(51 \%) \\
93 \mathrm{R}=4-\mathrm{CH}_{3} \mathrm{C}_{6} \mathrm{H}_{4}(54 \%) & 99 \mathrm{R}=4-\mathrm{BrC}_{6} \mathrm{H}_{4}(58 \%)
\end{array}
$$

Scheme 6.6. (a) $\mathrm{RCOOH}, \mathrm{DCC}$, DMAP, $\mathrm{CH}_{2} \mathrm{Cl}_{2}$, r. t., $3 \mathrm{~h}$.

The structures of all the synthetic compounds were elucidated by using a combination of mass spectrometry (MS) and nuclear magnetic resonance $(N M R)$ techniques (Experimental part). 


\subsection{Biological Evaluation}

\subsubsection{Family 1}

\section{Cytotoxicity}

The cytotoxic ability of all the synthetic compounds was established by means of their $\mathrm{IC}_{50}$ values towards the tumoral cell lines HT-29 (human colon adenocarcinoma) and MCF-7 (breast adenocarcinoma), as well as towards the non-tumoral cell line HEK-293 (human embryonic kidney cells) after $48 \mathrm{~h}$ of incubation. The therapeutic safety margin of each compound was calculated by means of the $\alpha$ and $\beta$ coefficients which were obtained by dividing the $I_{50}$ value of the non-tumoral cell line HEK-293 by those for the HT-29 ( $\alpha$ ) and the MCF-7 ( $\beta$ ) tumoral cell line. The higher the value of either coefficient, the greater the therapeutic safety margin for the corresponding compound.

The observed $\mathrm{IC}_{50}$ values (Graphic 6.1) for the $\alpha$-aminoacyl derivatives are in most cases in the medium to low nanomolar range. Some of them were more cytotoxic than colchicine itself. They also exhibit higher selectivity coefficients than the latter in both tumoral cell lines, this providing them with a higher therapeutic safety margin. The following graphic represents $I_{50}$ values for all the derivatives of this family in the cell lines HT-29 (blue line), MCF-7 (red line) and HEK-293 (green line). 


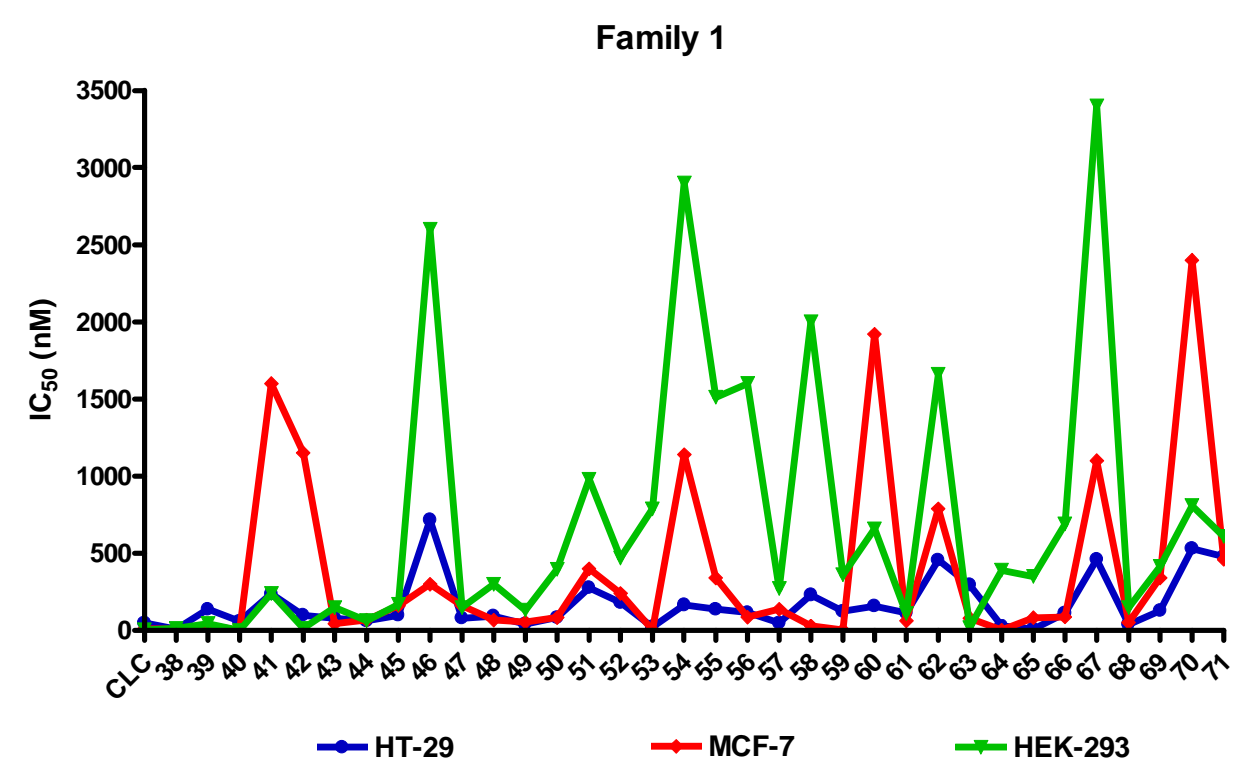

Graphic 6.1. Representation of $I C_{50}$ values of derivatives from family 1.

It is worth to highlight that compounds $38,49,53,64,65$ and 68 exhibit very high cytotoxicities towards the HT-29 cell line, even higher than that of colchicine itself (Graphic 6.1). In the case of MCF-7 cell line, compounds $\mathbf{3 8}$, 40, 53, 59, 64 and 68 are also able to surpass colchicine's activity. As shown in Graphic 6.1, the lowest ${ } \mathrm{C}_{50}$ values (highest cytotoxic activity) towards both tumoral cell lines were observed with derivatives 38, 53, 64 and 68 (Table 6.1). 
Table 6.1. Cytotoxicity and selectivity coefficients for colchicine analogues of family $1^{182}$

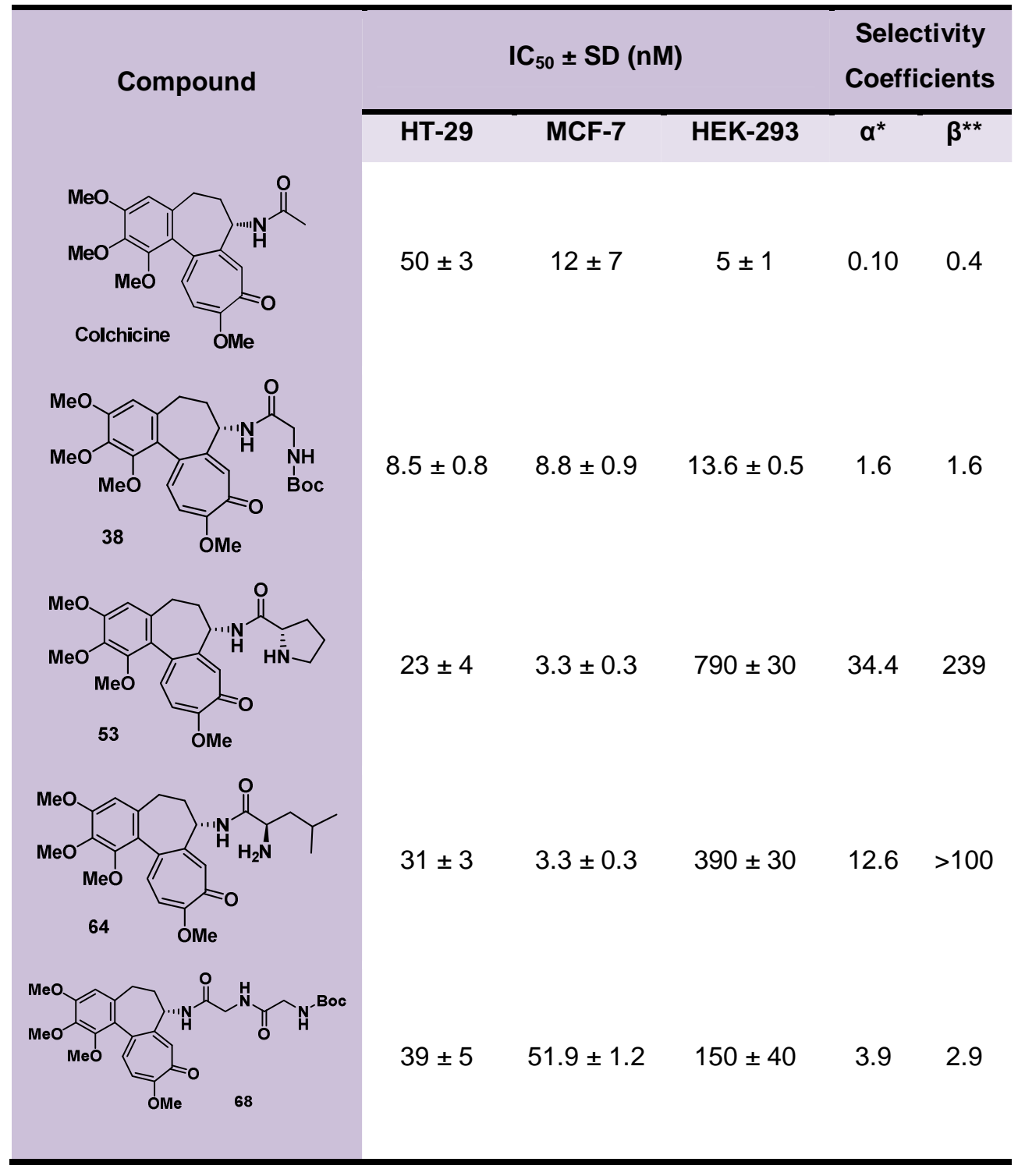

182 More detailed information about the $\mathrm{IC}_{50}$ values of compounds of family 1 can be found on Table 4.1 (p. 123), on Table 4.2 (p. 125) and Table 4.3 (p. 126) in Chapter 4. 


\section{The critical concentration of tubulin}

The critical concentration $(\mathrm{Cr})$ required for tubulin assembly was determined in glycerol-assembling buffer (GAB) for all derivatives of family 1 . For the sake of comparison, colchicine activity, which is a microtubule-destabilizing agent, was also measured. Graphic 6.2 depicts the critical concentration values achieved by the compounds of family 1 .

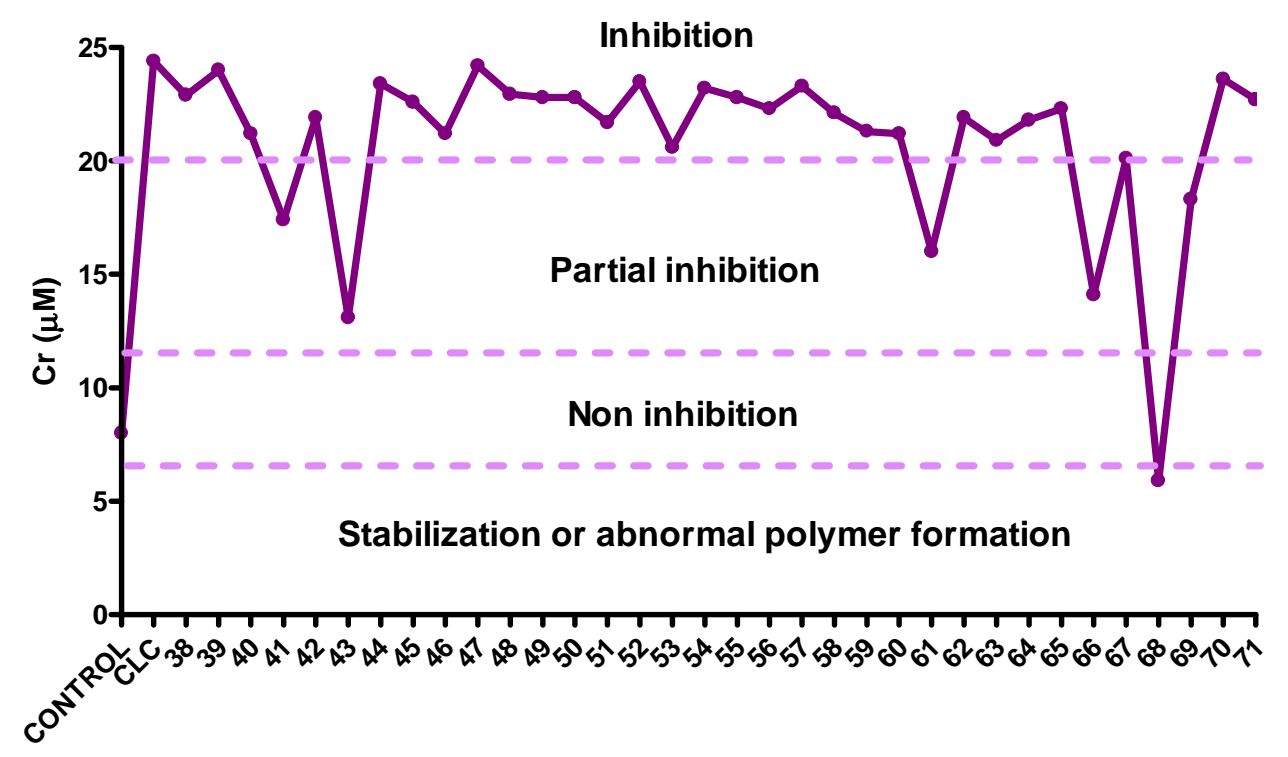

Graphic 6.2. Representation of critical concentration values for derivatives of family 1 .

This graphic shows that all but one of the compounds of family 1 are able to inhibit tubulin polymerization process in an either complete or partial way. The majority of compounds increase the tubulin concentration required to produce tubulin assembly from $8.0 \mu \mathrm{M}$ in the absence of ligands (control, DMSO vehicle) to a maximum value of $24.2 \mu \mathrm{M}$, which is shown by compound 47 . Compounds 41, 43, 61, 66 and 69 therefore could be classified as partial inhibitors of tubulin polymerization. ${ }^{183}$

\footnotetext{
${ }^{183}$ More detailed information about the $\mathrm{Cr}$ values of compounds of family 1 can be found on Table 4.4 (p. 127), on Table 4.5 (p. 129) and Table 4.6 (p. 130) in Chapter 4.
} 


\section{VEGF, $h T E R T$ and $c-M y c$ gene expression and VEGF protein secretion}

In order to evaluate VEGF, hTERT and $c-M y c$ gene expression and VEGF protein secretion, 15 compounds $(38,43,48,49,50,53,55,56,57,61,64,65$, 66, 68 and 69) were selected according to their $I_{50}$ values (less than $150 \mathrm{nM}$ ) and their selectivity coefficient.

PCR followed by electrophoresis (Figure 4.12, p. 132) was done with the aim at reducing the number of selected compounds to be further investigated. These were finally 38, 43, 64 and 68 . The results achieved with these compounds are disclosed in Table 6.2.

Table 6.2. \% gene expression and protein secretion for compounds of family 1 .

\begin{tabular}{|c|c|c|c|c|}
\hline Compound & $\begin{array}{c}\% \\
\text { secreted } \\
\text { VEGF }\end{array}$ & $\begin{array}{c}\text { \% VEGF } \\
\text { gene } \\
\text { exp. }\end{array}$ & $\begin{array}{c}\% \text { hTERT } \\
\text { gene } \\
\text { exp. }\end{array}$ & $\begin{array}{l}\% c-M y c \\
\text { gene exp. }\end{array}$ \\
\hline Colchicine $(40 \mathrm{nM})$ & $61 \pm 20$ & $40 \pm 7$ & $50 \pm 11$ & $32 \pm 5$ \\
\hline $38(9 \mathrm{nM})$ & $>100$ & $41 \pm 8$ & $32 \pm 3$ & $61 \pm 10$ \\
\hline 43 (80 nM) & $84 \pm 27$ & $28 \pm 5$ & $13 \pm 4$ & $46 \pm 5$ \\
\hline $64(25 \mathrm{nM})$ & $>100$ & $49 \pm 4$ & $82 \pm 1$ & $74 \pm 13$ \\
\hline
\end{tabular}




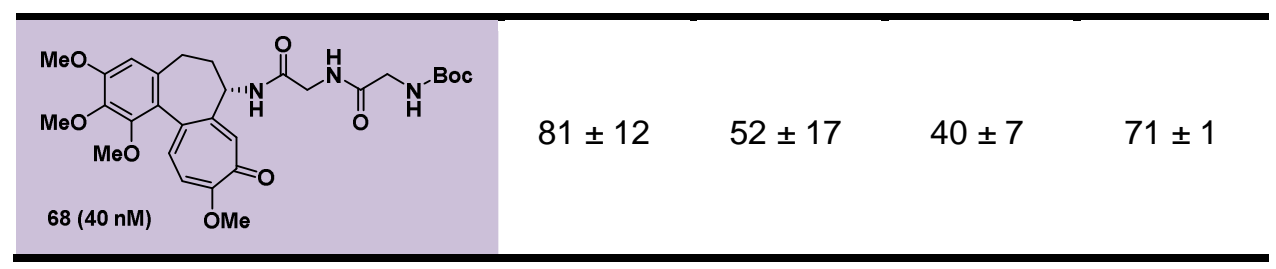

As regards the expression of the VEGF gene (Table 6.2), compound 43 (28\% gene expression) shows a higher inhibitory ability than colchicine $(40 \%$ gene expression). It is also worth noting that compound 38 at $9 \mathrm{nM}(41 \%$ gene expression) shows almost the same inhibitory ability as colchicine at $40 \mathrm{nM}$, a concentration almost five times higher.

Compounds 38, 43 and 68 exhibit a higher inhibitory ability of the expression of the $h T E R T$ gene $(32 \%, 13 \%$ and $40 \%$ gene expression, respectively) than the natural alkaloid at $40 \mathrm{nM}$ (Table 6.2).

As regards the expression of the $c-M y c$ gene and the secretion of the VEGF protein (Table 6.2), the synthetic derivatives are less active than colchicine and scarcely reduce the VEGF production.

\section{Docking}

With the aim at gaining insight about the binding site of the compounds that have a glycine moiety $(38,48,68,69,70$ and 71 , structures on Figure 6.9), molecular docking was performed using Autodock 4.2. ${ }^{184}$ The crystal structure of $\alpha \beta$ tubulin (PDB ID 1SA0) was used as a template.

${ }^{184}$ Morris, G. M.; Huey, R.; Lindstrom, W.; Sanner, M. F.; Belew, R. K.; Goodsell, D. S.; Olson, A. J. J. Comput Chem. 2009, 16, 2785-2791. 
<smiles></smiles>

$38 \mathrm{R}=\mathrm{Boc}$

$68 \mathrm{R}=\mathrm{COCH}_{2} \mathrm{NHBoc}$ $69 \mathrm{R}=\mathrm{COCH}_{2} \mathrm{NHCOCH}_{2} \mathrm{NHBoc}$<smiles></smiles>

$48 \mathrm{R}=\mathrm{H}$

$70 \mathrm{R}=\mathrm{COCH}_{2} \mathrm{NH}_{2}$

$71 \mathrm{R}=\mathrm{COCH}_{2} \mathrm{NHCOCH}_{2} \mathrm{NH}_{2}$

Figure 6.9.

The docking experiments suggest that the binding site of the colchicine fragment is situated, as expected, at the $\beta$-tubulin domain. Compounds 70 and 71 span their peptide side chains into the intradimer interface zone that separates the $\alpha$ and $\beta$ subunits and insert them in a pocket located in the a-tubulin domain, therefore establishing a hydrogen bond with the phosphate residues of GTP (Figure 6.10). However, if the lateral peptide side chain bears the very bulky $t$-butyloxycarbonyl (Boc) group, as in the case of compounds $\mathbf{6 8}$ and 69, a steric interaction takes place and the lateral peptide chain is located at the interface between the two subunits of tubulin. This may possibly explain why the above mentioned derivatives bearing the free amino group exhibit a greater interaction with tubulin than the corresponding $N$-Boc derivatives. ${ }^{185}$

\footnotetext{
${ }^{185}$ More detailed information about the binding site of glycine derivatives can be found on Figure 4.14 (p. 137) and Figure 4.16 (p. 140) for compounds 38 and 48; Figure 4.17 (p. 141) and Figure 4.18 (p. 142) for compounds 68 and 70, and Figure 4.19 (p. 143) and Figure 4.20 (p. 144) for compounds 69 and 71.
} 

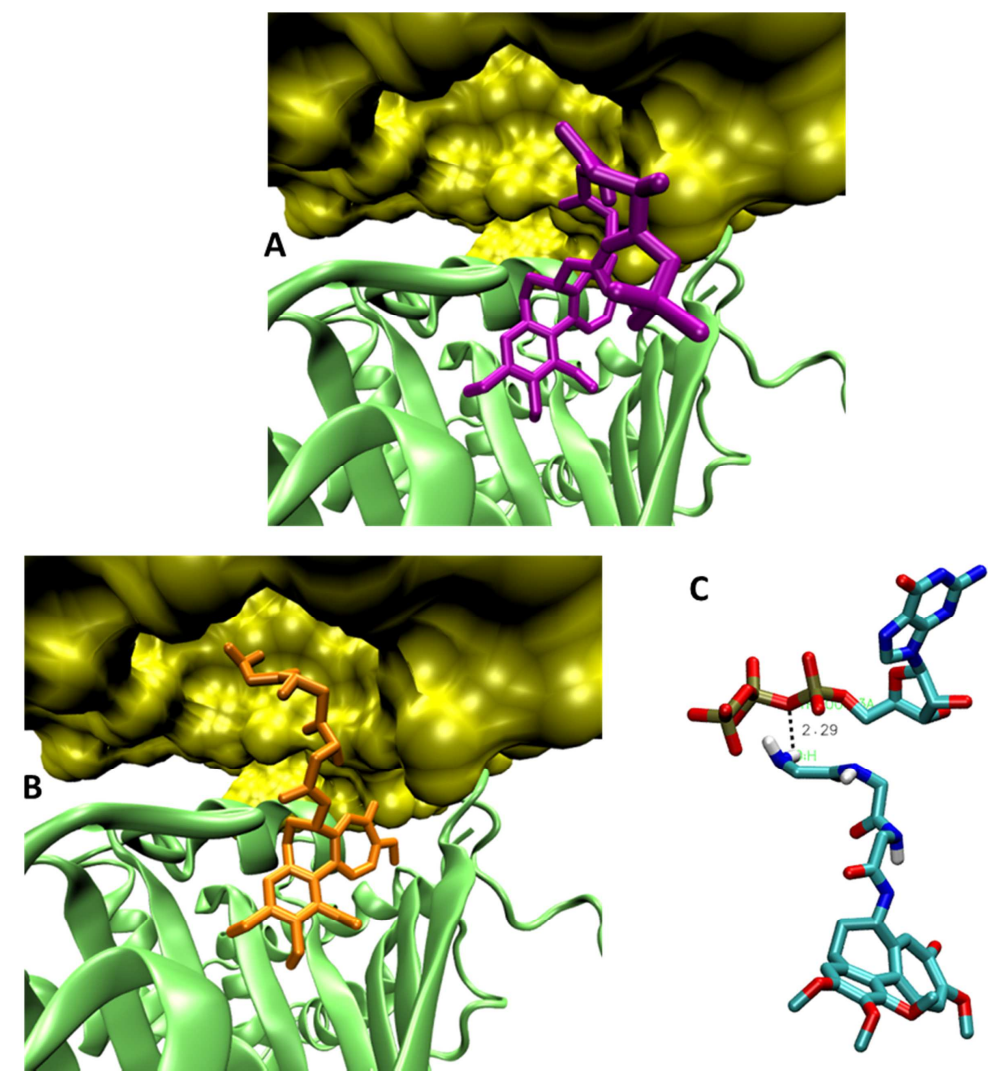

Figure 6.10. Panel A: Binding site of compound 69 (purple) in tubulin ( $\beta$-subunit in green and $\alpha$-subunit in yellow). Panel B: Binding site of compound 71 (orange) in tubulin. Panel C: Interaction of compound 71 with the GTP present in the a-tubulin.

\section{Conclusions}

- Compounds of family 1 exhibit $I_{50}$ values which are in most cases in the medium to low nanomolar range. Compounds 38, 53, 64 and 68 (Figure 6.11) exhibit the highest cytotoxic activities in both tumor cell lines and also higher selectivity coefficients, especially in the case of $\mathbf{5 3}$ and 64 on the MCF-7 cell line, therefore providing a wider therapeutic safety range than colchicine. 
<smiles>COc1ccc2c(c1)C(NC(=O)CNC(C)(C)C)CCc1cc(OC)c(OC)cc1-2</smiles><smiles>COc1ccc2c(c1)CCC[C@H](NC(=O)C1CCCN1)c1cc(OC)c(OC)cc1-2</smiles><smiles></smiles><smiles></smiles>

Figure 6.11.

- With respect to the critical concentration of tubulin, it may be concluded that L- $\alpha$-amino acids derivatives are the most active drugs. Within this subgroup, compounds having a small hydrophobic residue $(38,39,48$ and 49) or a polar group (44, 45, 47, 54, 55 and 57) show critical concentration values closer to that of colchicine (Figure 6.12).<smiles></smiles>

$38 \mathrm{R}=\mathrm{H}, \mathrm{R}^{\prime}=\mathrm{H}$ $39 \mathrm{R}=\mathrm{CH}_{3}, \mathrm{R}^{\prime}=\mathrm{H}$ $44 \mathrm{R}=\mathrm{CH}_{2} \mathrm{OH}, \mathrm{R}^{\prime}=\mathrm{H}$ $45 \mathrm{R}=\mathrm{CH}(\mathrm{OH}) \mathrm{CH}_{3}, \mathrm{R}^{\prime}=\mathrm{H}$ $47 \mathrm{R}=\left(\mathrm{CH}_{2}\right)_{2} \mathrm{SCH}_{3}, \mathrm{R}^{\prime}=\mathrm{H}$<smiles>[R]NC([R])[C@H]([R])NC(=O)[C@@H]1CCc2cc(OC)c(OC)c(OC)c2-c2ccc(OC)c(=O)cc21</smiles>

$48 \mathrm{R}=\mathrm{H}, \mathrm{R}^{\prime}=\mathrm{H}$ $49 \mathrm{R}=\mathrm{CH}_{3}, \mathrm{R}^{\prime}=\mathrm{H}$ $54 \mathrm{R}=\mathrm{CH}_{2} \mathrm{OH}, \mathrm{R}^{\prime}=\mathrm{H}$ $55 \mathrm{R}=\mathrm{CH}(\mathrm{OH}) \mathrm{CH}_{3}, \mathrm{R}^{\prime}=\mathrm{H}$ $57 \mathrm{R}=\left(\mathrm{CH}_{2}\right)_{2} \mathrm{SCH}_{3}, \mathrm{R}^{\prime}=\mathrm{H}$

Figure 6.12.

However, derivatives having a large bulky residue $(41,43,61,66$ and 69, Figure 6.13) can be classified as partial inhibitors of tubulin polymerization. 


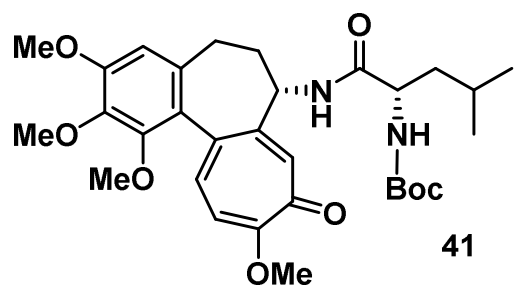<smiles>COc1cc2c(c(OC)c1OC)-c1cc(OC)c(=O)ccc1[C@@H](NC(=O)[C@@H]1CCCN1C(=O)OCc1ccccc1)CC2</smiles><smiles>COc1cc2c(c(OC)c1OC)-c1ccc(OC)c(=O)cc1[C@@H](NC(=O)[C@@H]1CCCN1C(=O)O)CC2</smiles><smiles>COc1cc2c(c(OC)c1OC)-c1ccc(OC)c(=O)cc1[C@@H](NC(=O)C1CCCN1)CC2</smiles><smiles>COc1cc2c(c(OC)c1OC)-c1ccc(OC)c(=O)cc1[C@@H](NC(=O)CNC(=O)CNC(=O)CNC(=O)OCc1ccccc1)CC2</smiles>

Figure 6.13.

- As regards gene expression, compound 43 (Figure 6.14) shows a similar behaviour as colchicine. In addition, it presents higher selectivity coefficients than colchicine itself, which provides it with a wider therapeutic safety range. Compound $\mathbf{3 8}$ also performs better than colchicine in its inhibitory activity towards the expression of the VEGF and $h T E R T$ genes. It is worth remembering here that $\mathbf{3 8}$ was tested at concentrations five times lower than that of colchicine.
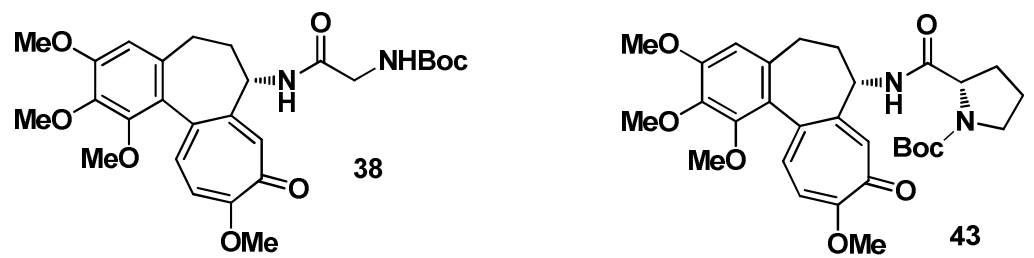

Figure 6.14. 
- Docking studies show that unprotected glycine derivatives (70 and 71, Figure 6.15) can interact with a-tubulin establishing hydrogen bonds with the GTP phosphate residues. However, if the peptide side chain bears a very large group, such as the Boc protecting group in $\mathbf{6 8}$ and 69 (Figure 6.15), a steric hindrance is developed with the GTP residue of the $\alpha$-subunit, thus preventing location of the side chain in the groove and placing it in the interface between the two subunits of tubulin. This could explain why unprotected derivatives $\mathbf{7 0}$ and $\mathbf{7 1}$ have a greater activity against tubulin than their $N$-Boc protected counterparts 68 and 70.<smiles></smiles>

Figure 6.15. 


\subsubsection{Family 2}

\section{Cytotoxicity}

Family 2 is formed by compounds in which the acetyl group has been replaced by aliphatic, long-chain acyl groups, and by the cyclohexylacetyl, phenylacetyl and $\alpha$-haloacetyl groups. The cytotoxic ability was measured as previously described. Graphic 6.3 depicts $I_{50}$ values for all derivatives of this family in the tumor cell lines HT-29 (blue line) and MCF-7 (red line) and in the non-tumor cell line HEK-293 (green line). The majority of compounds (Graphic 6.3) present $\mathrm{IC}_{50}$ values in the low nanomolar range, a few of them even in the picomolar zone.

\section{Family 2}

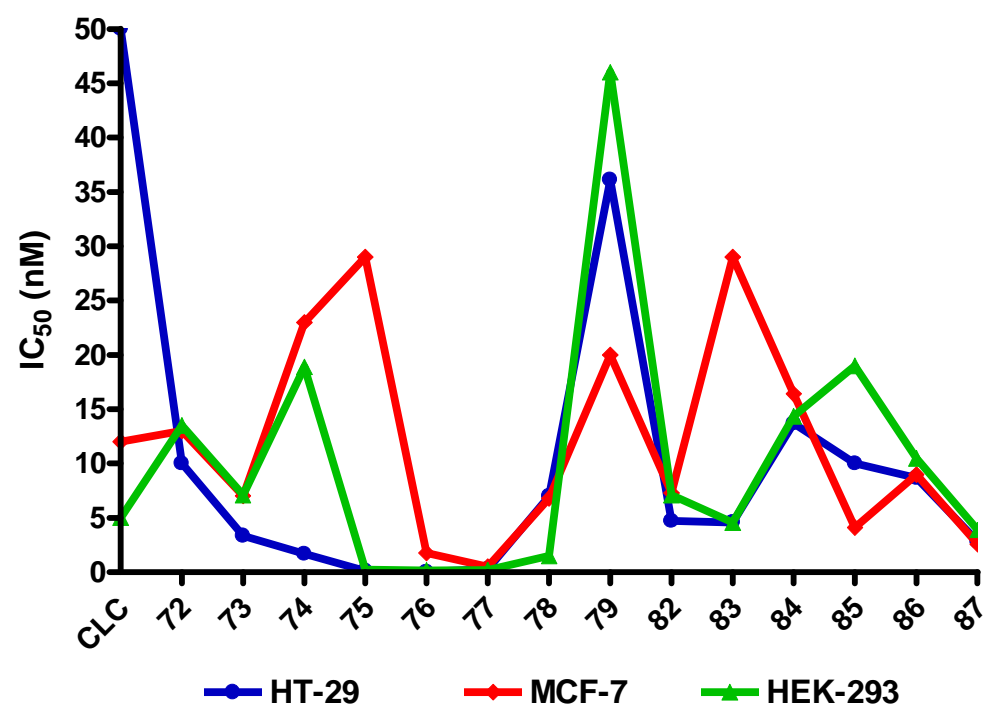

Graphic 6.3. Representation of $\mathrm{IC}_{50}$ values of derivatives of family 2.

As shown in Graphic 6.3, the lowest $I C_{50}$ values (highest cytotoxic activity) were observed with derivatives 74 (octanoic acid chain), 75 (decanoic acid 
chain), 76 (undecanoic acid chain) and 77 (dodecanoic acid chain). Their structures and $\mathrm{IC}_{50}$ values are shown in the following table. ${ }^{186}$

Table 6.3. Cytotoxicity for some colchicine analogues of family 2 .

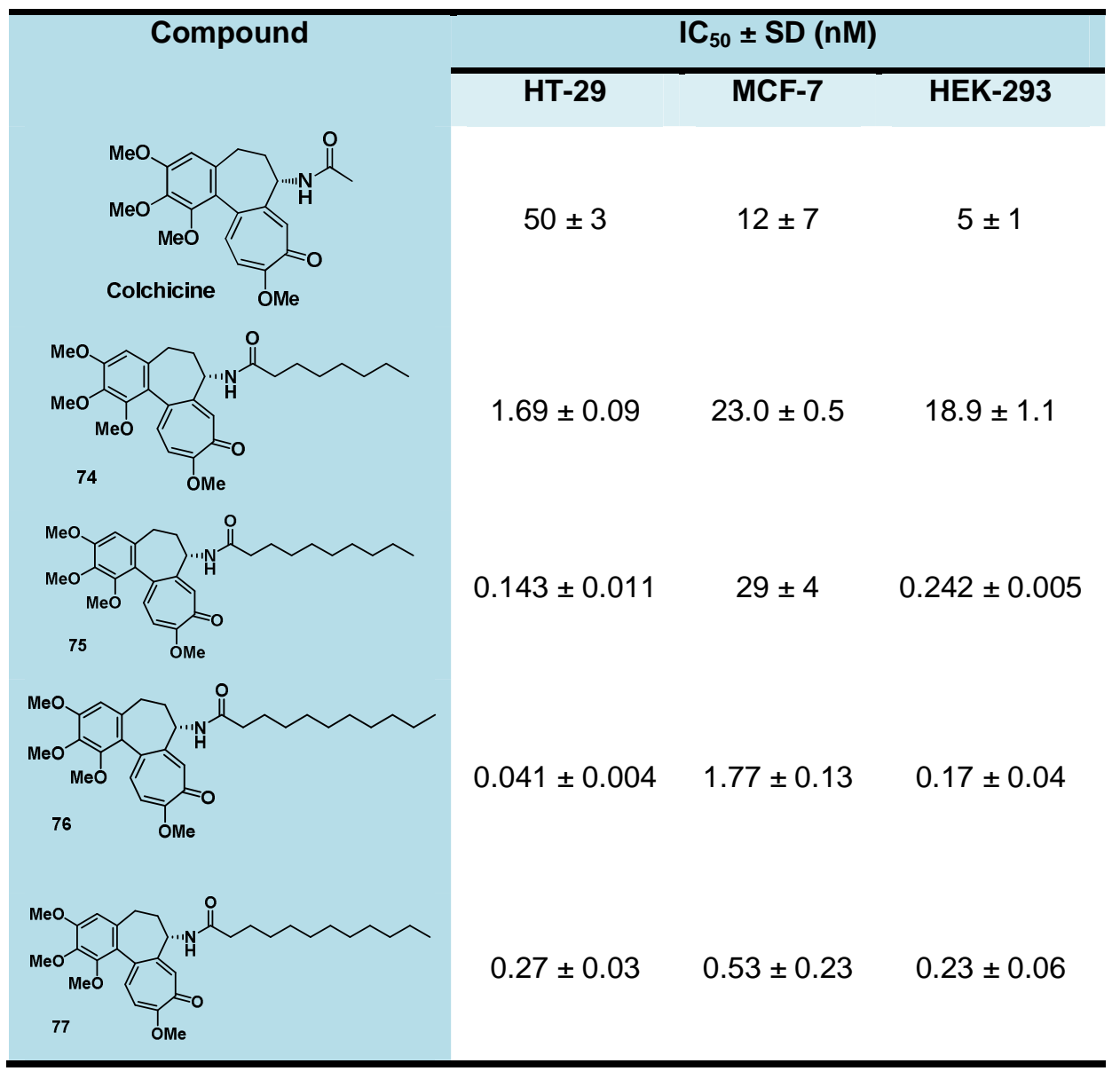

The correlation between the length of the chain and the cytotoxicity of the compounds towards the HT-29 cell line is also worth mentioning. Thus, the longer the chain, the lower the $\mathrm{IC}_{50}$ value. The optimal chain length is reached with compound 76 (Table 6.3), whose $I_{50}$ value is $0.041 \pm 0.004 \mathrm{nM}$. In

\footnotetext{
${ }^{186}$ More detailed information about the $\mathrm{IC}_{50}$ values of compounds of family 2 can be found on Table 4.8 (p. 149) in Chapter 4.
} 
addition to this compound, derivatives 75 and 77 (Table 6.3) also show very low $\mathrm{IC}_{50}$ values in the picomolar range $\left(\mathrm{IC}_{50}<1 \mathrm{nM}\right)$.

Also noteworthy is the cytotoxic activity of compound 85 (Figure 6.16) which exhibits a higher cytotoxic activity and better therapeutic margin than colchicine towards both tumour cell lines.

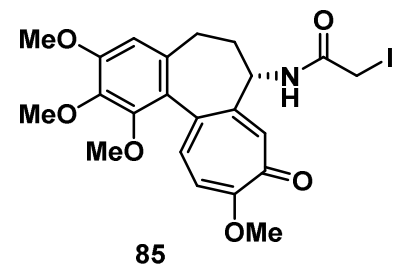

Figure 6.16.

The cytotoxicity of the selected compounds (73-77 and 87) was also measured on the A549 tumor cell line (Table 4.9, p. 150) after $72 \mathrm{~h}$ of incubation. All compounds exhibit $I_{50}$ values in the nanomolar range. However, only compounds $\mathbf{7 3 , 7 5}$ and $\mathbf{8 7}$ present an activity similar to that of colchicine.

\section{Effect on tubulin polymerization}

Effect on the microtubule assembly was determined in glycerol-assembling buffer (GAB) in the presence of colchicine (as a positive control inhibitor). The percentage of tubulin polymerization observed with the compounds of family 2 is depicted In Graphic 6.4. 


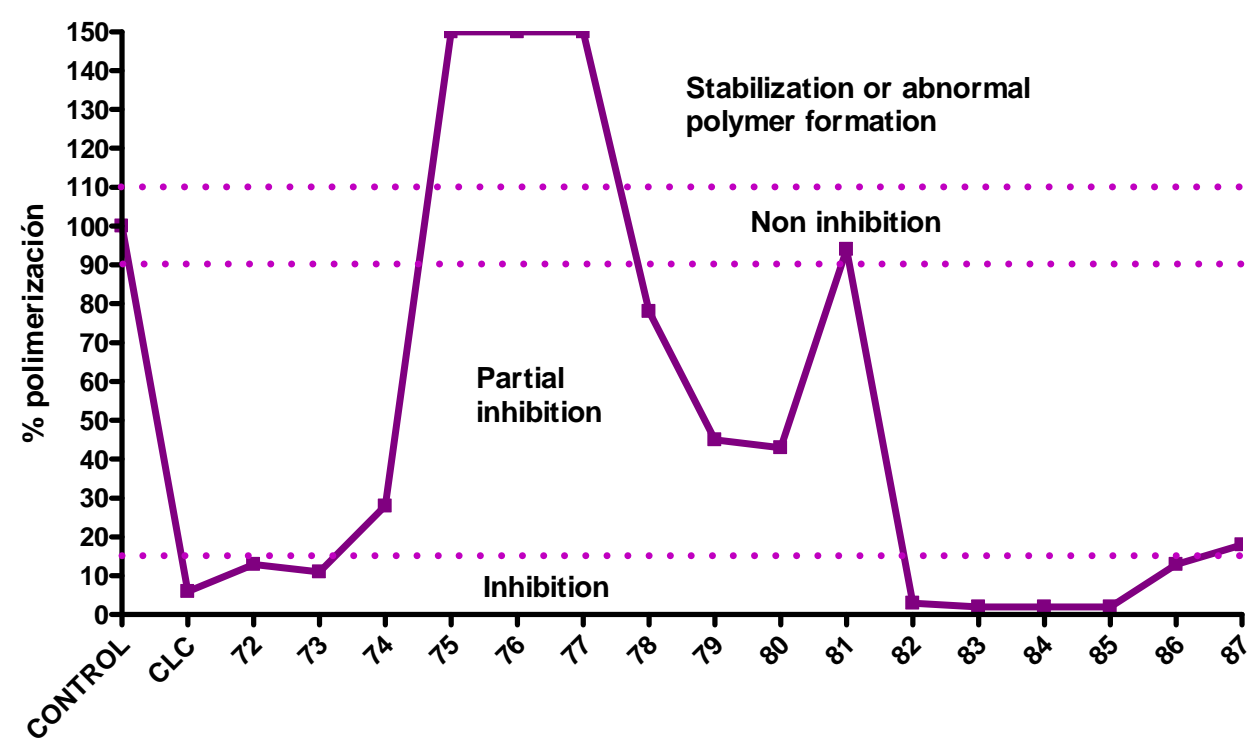

Graphic 6.4. Representation of percentage of tubulin polymerization of compounds of family 2.

Colchicine, which is a microtubule destabilizing agent, reduces the percentage of polymerization of tubulin to $6 \%$ (Graphic 6.4). Compounds $\mathbf{7 2}$, 73, 82, 83, 84, 85, 86 and 87 present similar behaviour as colchicine, so they could be classified as inhibitors of the polymerization process. As can be deduced from Graphic 6.4, the most active compound within this family are the haloacetyl derivatives 82-85 (Figure 6.17), which are even more active than colchicine in the inhibition of microtubules.

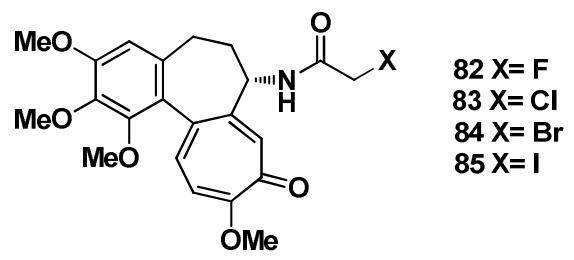

Figure 6.17 . 
Derivatives 75, 76 and 77, which bear aliphatic straight chains (Figure 6.18), increase the polymer mass. This could be due to a stabilizing effect of these compounds on microtubules, as in the case of paclitaxel, but could also be the result of formation of abnormal polymers.

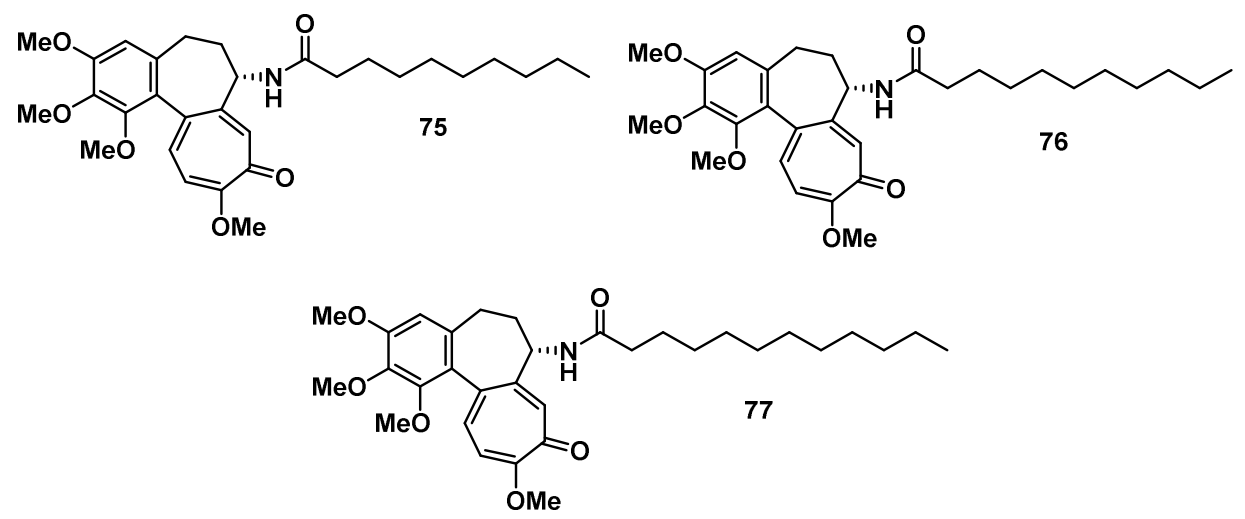

Figure 6.18.

Electron micrograph of polymers, depicted in Figure 6.19, shows that the mass increase is due to the formation of anomalous structures, as previously described for colchicine and some derivatives. ${ }^{187}$

${ }^{187}$ (a) Andreu, J. M.; Timasheff, S. N. Proc. Natl. Acad. Sci. U.S.A. 1982, 79, 6753-6756. (b) Barbier, P.; Peyrot, V.; Leynadier, D.; Andreu, J. M. Biochemistry 1998, 37, 758-768. 

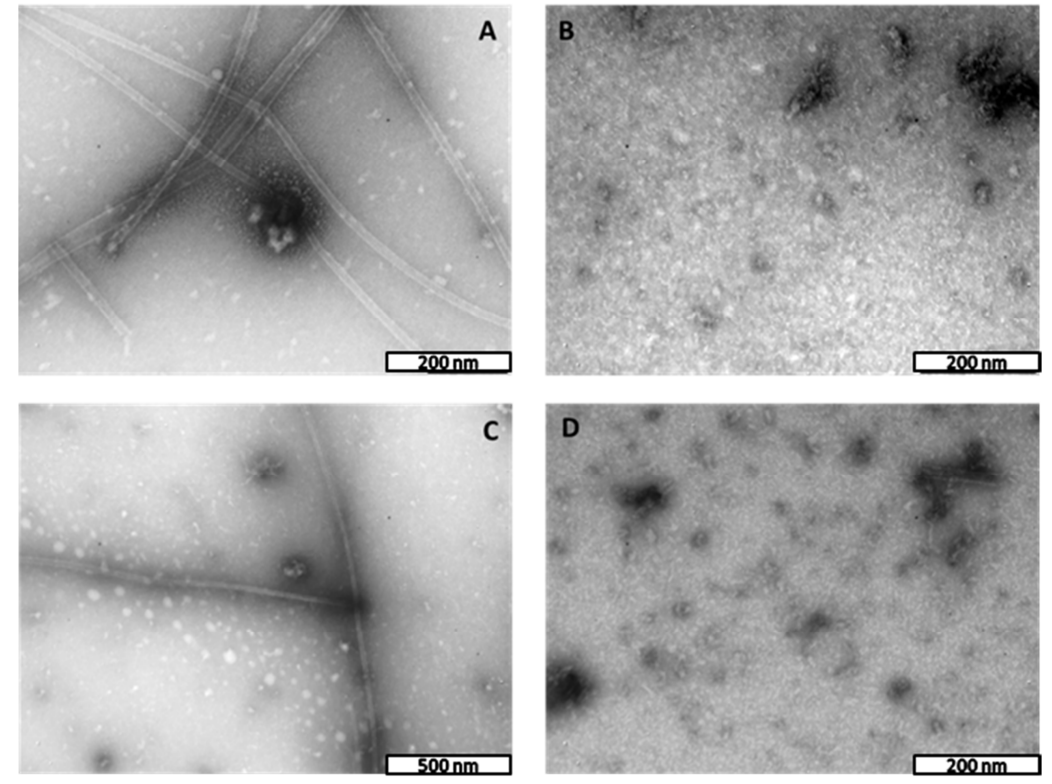

Figure 6.19. Tubulin polymerization in presence of DMSO (panel A), 75 (panel B), 76 (panel C) and 77 (panel D).

In order to verify that this increase in turbidity was due to the formation of abnormal polymers, a new buffer, consisting in $20 \mathrm{mM} \mathrm{NaPi}, 16 \mathrm{mM} \mathrm{MgCl}$ and $0.1 \mathrm{mM}$ GTP at $\mathrm{pH} 7$, was used. ${ }^{187}$ A solution of $15 \mu \mathrm{M}$ of tubulin and $50 \mu \mathrm{M}$ solutions of colchicine and compounds 73-77 were employed. As expected, tubulin alone did not polymerize in the absence of glycerol but an increase in turbidity was observed for all compounds (Graphic 6.5). 


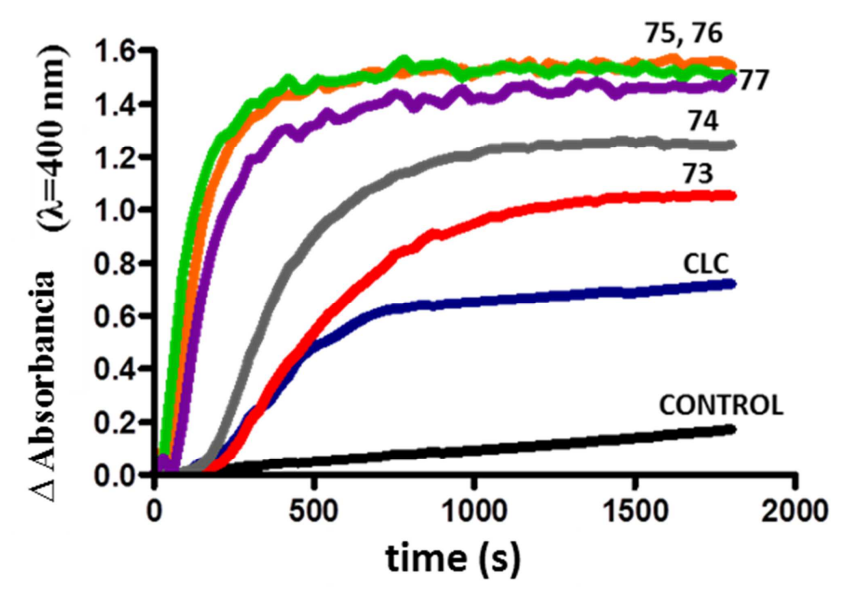

Graphic 6.5. Effect of colchicine and compounds 73-77 on in vitro abnormal polymer formation. The lines in the Figure show the effect of tubulin alone (black) at $15 \mu \mathrm{M}$, colchicine (blue) at $50 \mu \mathrm{M}, 73$ (red) at $50 \mu \mathrm{M}, 74$ (grey) at $50 \mu \mathrm{M}, 75$ (orange) at 50 $\mu \mathrm{M}, 76$ (green) at $50 \mu \mathrm{M}$ and 77 (purple) at $50 \mu \mathrm{M}$.

Moreover, electron micrographs show poorly defined filamentous sheet structures (Figure 6.20, panels B, C and D).
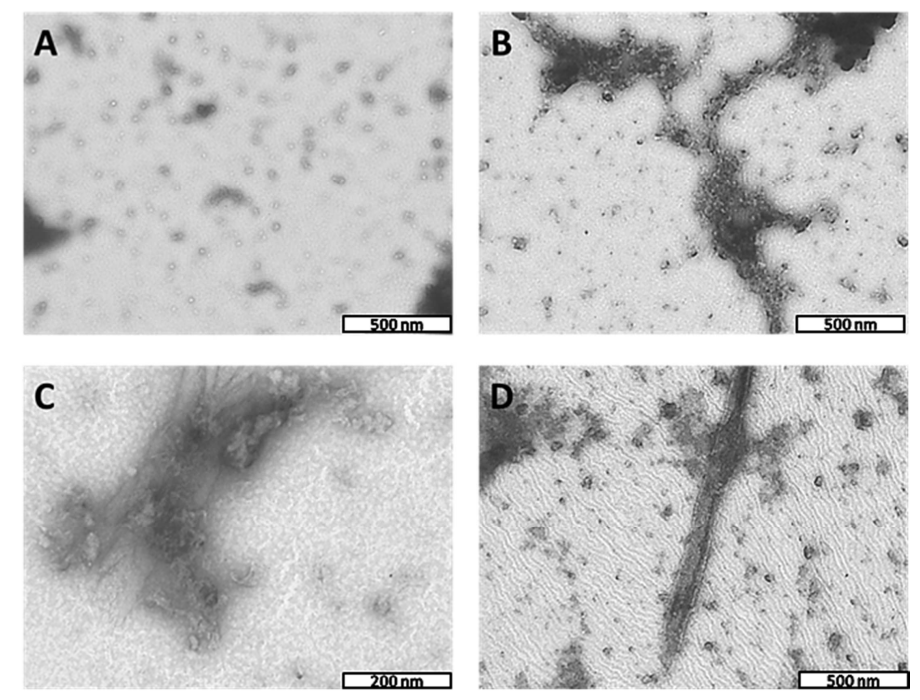

Figure 6.20. Characteristic electron micrographs of abnormal polymers formation induced by colchicine and compounds $\mathbf{7 4}$ and $\mathbf{7 7}$. Panel A shows control solution of 15 $\mu \mathrm{M}$ tubulin alone. Panels $\mathrm{B}, \mathrm{C}$ and $\mathrm{D}$ shows polymers formed in the presence of $50 \mu \mathrm{M}$ of colchicine, $50 \mu \mathrm{M}$ of 74 and $50 \mu \mathrm{M}$ of 77 , respectively. 
Having established that derivatives $\mathbf{7 5}, 76$ and 77 have the ability to form abnormal polymers, we studied their inhibitory effects on microtubule formation by measuring the $\mathrm{IC}_{50}$ values (Table 6.4).

Table 6.4. Inhibitory effects on microtubule assembly at $37^{\circ} \mathrm{C}$ and $15 \mu \mathrm{M}$ of tubulin.

\begin{tabular}{cc}
\hline Compound & $\mathrm{IC}_{50} \pm \mathrm{SD}(\mu \mathrm{M})$ \\
\hline Colchicine & $1.8 \pm 0.3$ \\
$\mathbf{7 3}$ & $2.1 \pm 0.2$ \\
74 & $1.08 \pm 0.05$ \\
75 & $0.70 \pm 0.07$ \\
76 & $0.79 \pm 0.06$ \\
77 & $1.2 \pm 0.4$ \\
\hline
\end{tabular}

Compound 73 presents a behaviour similar to that of colchicine. However, compounds $\mathbf{7 4 - 7 7}$ get $50 \%$ of the inhibition at lower concentrations than colchicine. The most active compound in the inhibition of tubulin polymerization was 75.

\section{Binding parameters}

The intrinsic fluorescence emission spectra of tubulin were tested by exciting the tryptophan residues at $295 \mathrm{~nm}$ and it can be seen on the next graphic. 


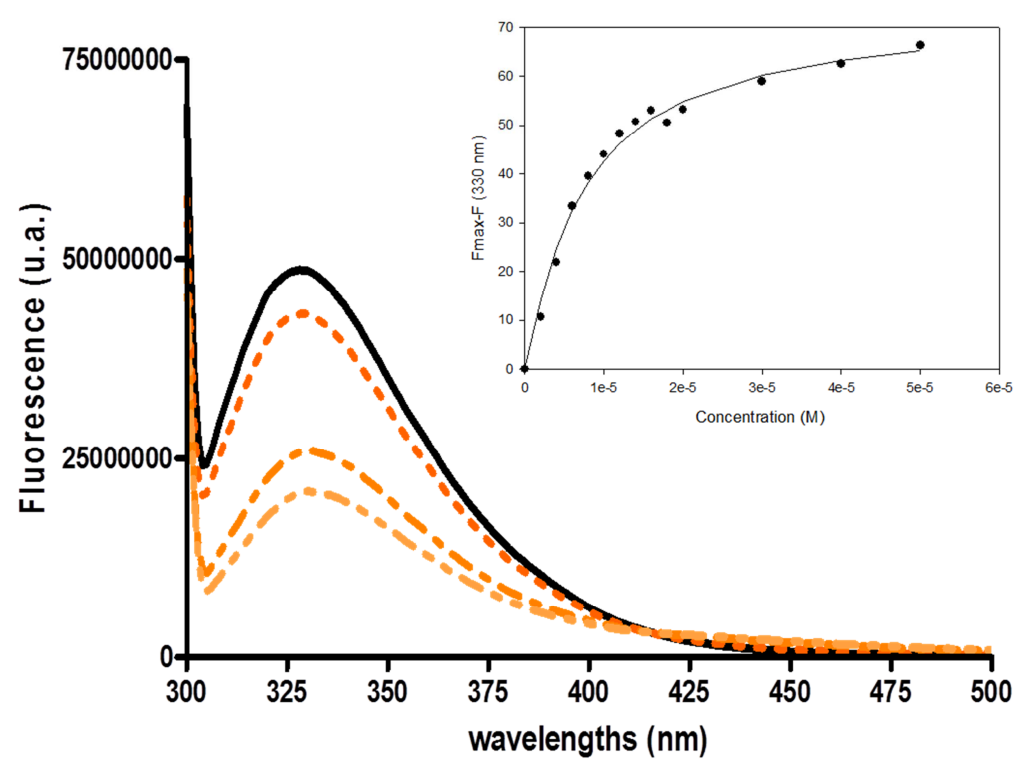

Graphic 6.6. Tryptophan fluorescence modifications of tubulin upon binding of compound 4 at $25^{\circ} \mathrm{C}$ in PG buffer, $\mathrm{pH}$ 7. The excitation wavelength was $295 \mathrm{~nm}$. Fluorescence emission of $2 \mu \mathrm{M}$ tubulin alone (black line), with $2 \mu \mathrm{M}(\cdots), 10 \mu \mathrm{M}(-\cdot-)$ and $20 \mu \mathrm{M}(\cdots-)$ of 75 . The inset shows the quenching fluorescence titration curve inverted produced by 75 binding to $2 \mu \mathrm{M}$ tubulin; the solid line is the fitting curve obtained as described below.

A decrease in fluorescence emission intensity at $330 \mathrm{~nm}$ was observed with an increase of the concentration of compound 75 . This quenching of fluorescence was used to carry out binding titration experiments. Similar results are obtained for the other compounds.

The apparent affinity stoichiometric constants $\left(\mathrm{K}_{\mathrm{a}}\right)$ were calculated for colchicine and selected derivatives and are displayed in the next table. 
Table 6.5. Binding parameters of colchicine and compounds 73-77 to tubulin in PG Buffer at $25^{\circ} \mathrm{C}$.

\begin{tabular}{cc}
\hline Compound & $\left(\mathrm{K}_{\mathrm{a}} \pm \mathrm{SD}\right) \times 10^{4}\left(\mathrm{M}^{-1}\right)$ \\
\hline Colchicine & $9 \pm 3$ \\
$\mathbf{7 3}$ & $6.4 \pm 2.0$ \\
$\mathbf{7 4}$ & $5.2 \pm 1.1$ \\
$\mathbf{7 5}$ & $17.9 \pm 2.3$ \\
$\mathbf{7 6}$ & $18.4 \pm 1.6$ \\
$\mathbf{7 7}$ & $19.0 \pm 2.3$ \\
\hline
\end{tabular}

Derivatives $\mathbf{7 3}$ and $\mathbf{7 4}$ have an apparent affinity constant in the same range as colchicine, which is $(9 \pm 3) \times 10^{4} \mathrm{M}^{-1}$. Compounds 75,76 and 77 present the highest apparent affinity binding constant, even higher than colchicine. Moreover, these apparent binding constant values obtained by quenching were close to that of the colchicine analogue MTC $\left(4.9 \times 10^{5} \mathrm{M}^{-1}\right) .{ }^{188}$

\section{Effect on cell cycle and in the microtubule network of cultured cells}

For cell cycle distribution, A549 cells were treated with colchicine and compounds 73-77 at $\mathrm{IC}_{50}$ values and 10 times the $\mathrm{IC}_{50}$ values for 24 hours (Table 6.6).

Tabla 6.6. Cell cycle distribution.

\begin{tabular}{cccccc}
\hline Prod. & {$[\mathrm{C}](\mathrm{nM})$} & SubG1 & G1 & S & G2/M \\
\hline Control & -- & $0.6 \pm 0.5$ & $38.4 \pm 2.8$ & $52.3 \pm 8.0$ & $6.6 \pm 1.8$ \\
& $I_{50}(14 \mathrm{nM})$ & $0.4 \pm 0.6$ & $32.3 \pm 9.1$ & $57.2 \pm 11.7$ & $7.9 \pm 2.8$ \\
CLC & $10 \times \mathrm{IC}_{50}$ & $2.3 \pm 0.2$ & $7.4 \pm 3.0$ & $52.1 \pm 10.1$ & $31.8 \pm 1.8$ \\
& & & & & \\
\cline { 2 - 6 }
\end{tabular}

${ }^{188}$ Andreu, J. M.; Gorbunopff, M. J.; Lee, J. C.; Timasheff, S. N Biochemistry 1984, 23, 17421752. 


\begin{tabular}{|c|c|c|c|c|c|}
\hline \multirow{2}{*}{73} & $\mathrm{IC}_{50}(18 \mathrm{nM})$ & $2.8 \pm 1.1$ & $14.8 \pm 6.1$ & $56.0 \pm 5.0$ & $27.0 \pm 9.2$ \\
\hline & $10 \times 1 C_{50}$ & $4.4 \pm 4.3$ & $8.5 \pm 5.2$ & $47.7 \pm 5.9$ & $36.2 \pm 10.0$ \\
\hline \multirow{2}{*}{74} & $\mathrm{IC}_{50}(133 \mathrm{nM})$ & $2.5 \pm 1.5$ & $4.6 \pm 1.4$ & $55.7 \pm 2.4$ & $38.3 \pm 5.2$ \\
\hline & $10 \times 1 C_{50}$ & $1.9 \pm 0.9$ & $4.9 \pm 0.7$ & $60.5 \pm 2.0$ & $33.2 \pm 2.1$ \\
\hline \multirow{2}{*}{75} & $\mathrm{IC}_{50}(25 \mathrm{nM})$ & $1.7 \pm 0.2$ & $8.1 \pm 7.5$ & $53.8 \pm 9.9$ & $37.2 \pm 16.3$ \\
\hline & $10 \times 1 C_{50}$ & $1.8 \pm 0.9$ & $5.1 \pm 1.0$ & $52.3 \pm 9.2$ & $36.3 \pm 3.5$ \\
\hline \multirow{2}{*}{76} & $\mathrm{IC}_{50}(62 \mathrm{nM})$ & $1.5 \pm 0.5$ & $3.9 \pm 1.4$ & $53.3 \pm 2.1$ & $41.6 \pm 4.4$ \\
\hline & $10 \times 1 C_{50}$ & $2.2 \pm 0.7$ & $8.7 \pm 2.0$ & $57.6 \pm 9.5$ & $32.1 \pm 12.1$ \\
\hline \multirow{2}{*}{77} & $\mathrm{IC}_{50}(71.9 \mathrm{nM})$ & $3.7 \pm 0.5$ & $13.8 \pm 2.0$ & $55.5 \pm 1.5$ & $27.2 \pm 3.2$ \\
\hline & $10 \times 1 C_{50}$ & $1.6 \pm 0.3$ & $12.9 \pm 2.4$ & $54.7 \pm 1.1$ & $31.0 \pm 1.3$ \\
\hline
\end{tabular}

All compounds are able to arrest the cell cycle at G2/M due to their capacity to interact with tubulin, thus blocking the formation of microtubules. However, it is also worth highlighting that our derivatives present the same activity regardless of the concentration tested.

\section{Immunofluorescence}

Compounds $\mathbf{7 3}$ and $\mathbf{7 5}$ were selected, along with colchicine, to perform the immunofluorescence assay as they showed to be the most cytotoxic compounds on the A549 cell line (Figure 6.21). 

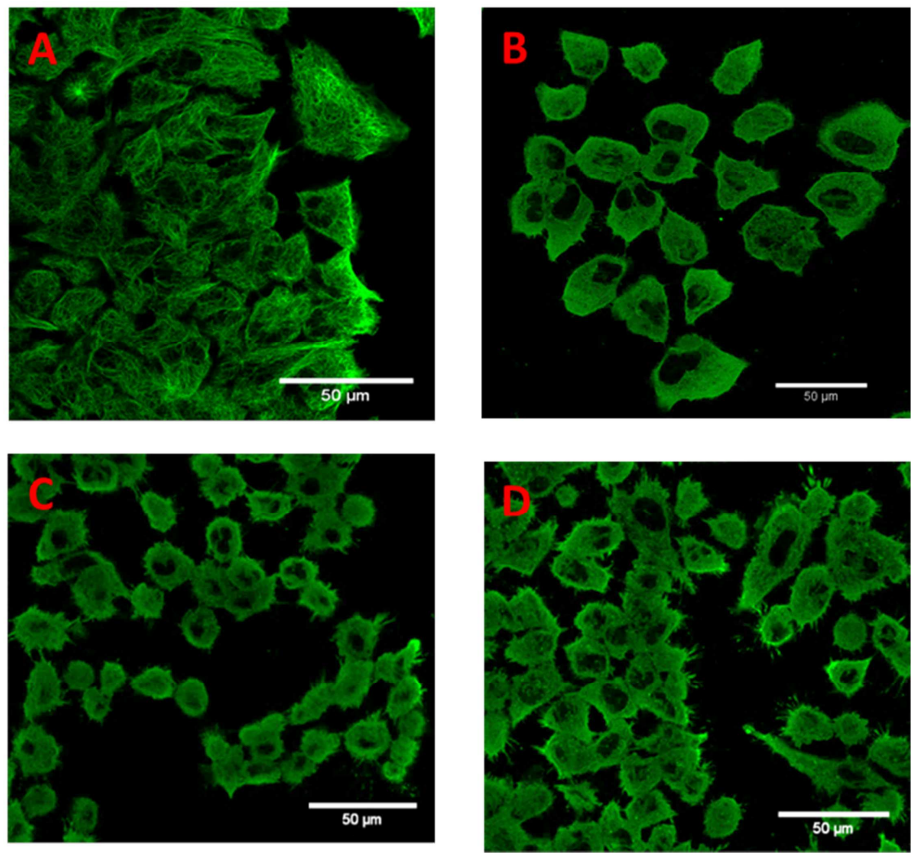

Figure 6.21. Effects of compounds 73 and 75 as compared to colchicine on the microtubule network. A549 cells were treated for 4 hours and processed for immunofluorescence microscopy: (A) microtubules of cells without inhibitor, (B) $100 \mathrm{nM}$ colchicine, (C) $100 \mathrm{nM}$ compound 73 and (D) $100 \mathrm{nM}$ compound 75. Microtubules were stained with $\alpha$-tubulin antibodies. The scale bar represents $50 \mu \mathrm{m}$.

Colchicine (Panel B) and compounds 73 (panel C) and 75 (panel D) at 100 $\mathrm{nM}$ are able to completely depolymerize cellular microtubules.

\section{VEGF, $h T E R T$ and $c-M y c$ gene expression and VEGF protein secretion}

Compounds 73-77 and 82-85 were selected according to their $I_{50}$ values ( $<15 \mathrm{nM})$ towards the cell line HT-29. The results observed with these compounds as regards gene inhibition are depicted in Table 6.7. 
Table 6.7. \% gene expression for selected compounds of family 2.

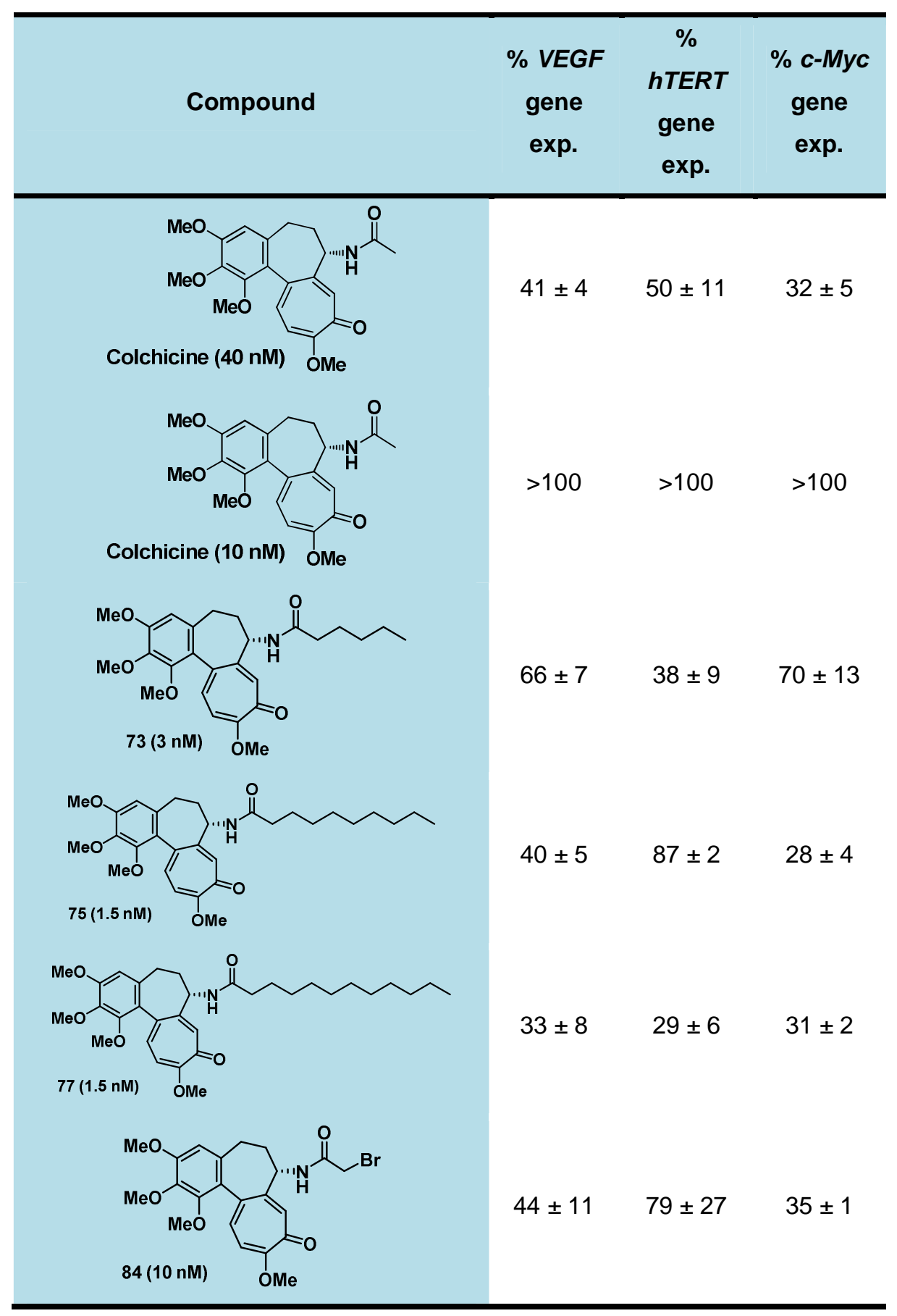


In relation to the expression of the VEGF gene, the majority of compounds show higher inhibition levels than colchicine at $10 \mathrm{nM}$. Indeed, it is worth noting

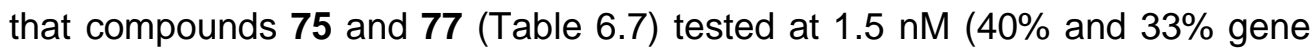
expression, respectively) show approximately the same inhibition as colchicine at $40 \mathrm{nM}$ (41\% gene expression), a concentration around 25 times higher. ${ }^{189}$

Compounds 73, 74, 75, 77, 83, 84 and 85 present higher inhibition of hTERT gene expression as compared with the natural alkaloid at $10 \mathrm{nM}$. The best ones are 73 and 77 (Table 6.7), which show 39\% and 29\% of hTERT gene expression, a much higher inhibition degree than colchicine at $40 \mathrm{nM}$ (50\% gene expression). ${ }^{190}$

As regards the $c-M y c$ gene expression, almost all compounds show higher inhibition levels than colchicine at $10 \mathrm{nM}$. Indeed, it is worth noting that derivatives 75, 77 and 84 (Table 6.7), tested at lower concentration than colchicine at $40 \mathrm{nM}$, cause approximately the same inhibition as the natural alkaloid. ${ }^{191}$

Regarding the expression of the VEGF protein, compounds 74, 75, 82 and 85 show higher inhibition levels than colchicine at $10 \mathrm{nM}$. However, these synthetic derivatives are less active than colchicine at $40 \mathrm{nM}$ and only derivative $\mathbf{7 5}$ is able to reduce $25 \%$ the VEGF production. ${ }^{192}$

\section{Docking}

Molecular docking was performed using Autodock 4.2 and the PDB ID 1SA0 as a template. The docking experiments suggest that the binding site of the colchicine fragment is situated, as expected, at the $\beta$-tubulin domain. Furthermore, these calculations suggest that the aliphatic chain spans the

\footnotetext{
${ }^{189}$ More detailed information about the VEGF gene expression of compounds of family 2 can be found on Graphic 4.9 (p. 164) in Chapter 4.

${ }_{190}$ More detailed information about the $h T E R T$ gene expression of compounds of family 2 can be found on Graphic 4.10 (p. 165) in Chapter 4.

${ }_{191}$ More detailed information about the $c-M y c$ gene expression of compounds of family 2 can be found on Graphic 4.11 (p. 166) in Chapter 4.

192 More detailed information about the VEGF protein secretion of compounds of family 2 can be found on Graphic 4.12 (p. 167) in Chapter 4.
} 
intradimer interface zone that separates the $\alpha$ and $\beta$ subunits and inserts itself in a hydrophobic pocket located in the a-tubulin domain. Sufficiently long aliphatic chains (e.g. 75, 76 or $\mathbf{7 7}$, Figure 6.22) fit well into the $\alpha$-tubulin pocket while the shorter aliphatic chains, as in colchicine itself, are unable to reach it. ${ }^{193}$
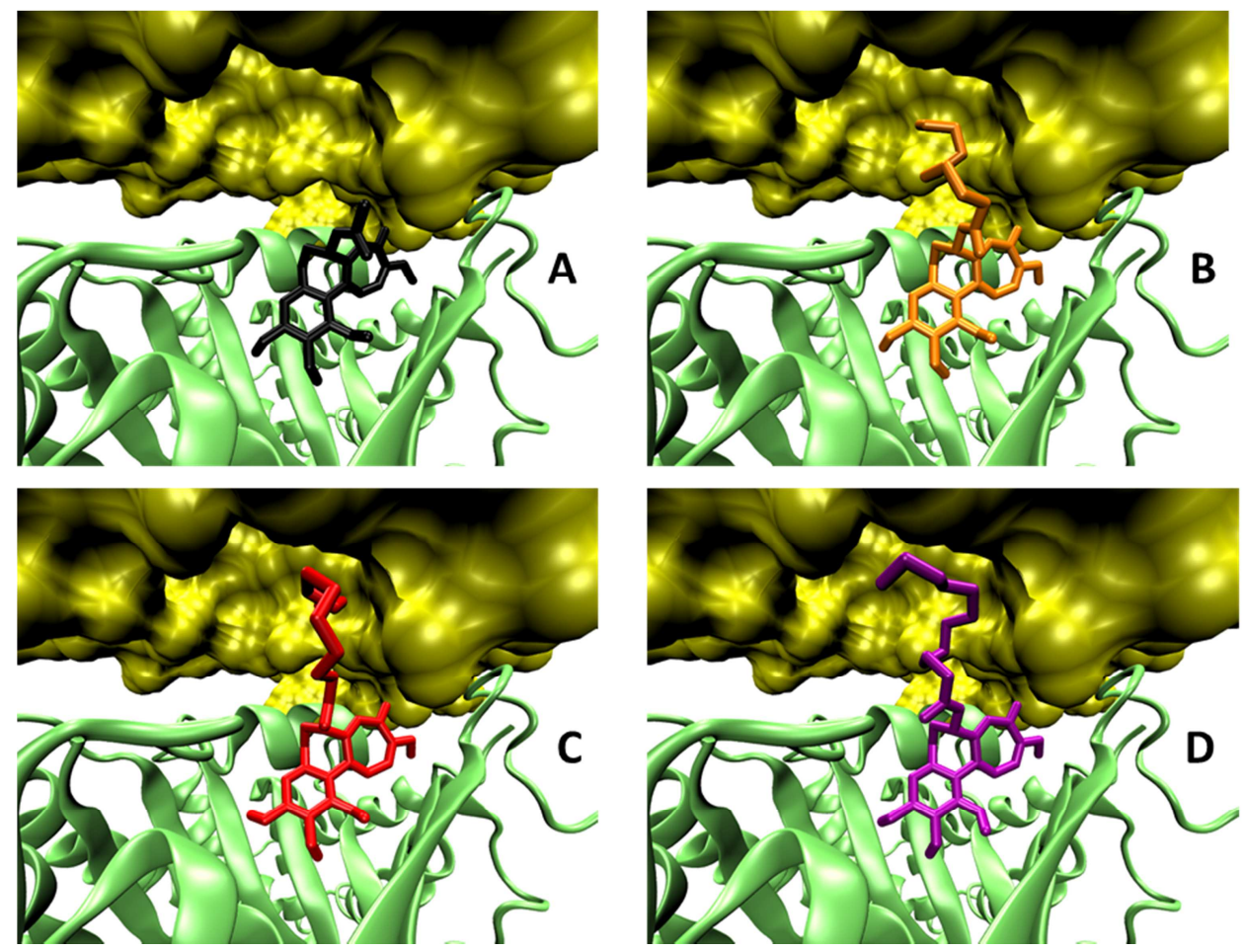

Figure 6.22. Structures of colchicine (A), 75 (B), 76 (C) and 77 (D) at the colchicine binding site. The $\alpha$ - and $\beta$-tubulin subunits are coloured in yellow and green, respectively.

\section{Conclusions}

- Most of the synthesized compounds have a high cytotoxic activity in the nanomolar range in all cell lines studied. Of the tested compounds, those with $\mathrm{N}$-acyl residues of 10-12 carbon atom length (compounds

\footnotetext{
${ }^{193}$ More detailed information about 2D interactions at colchicine binding site on Figure 4.34 (p. 172) for compound 75, Figure 4.35 (p. 173) for compound 76 and Figure 4.36 (p. 174) for compound 77.
} 
75, 76 and 77, Figure 6.23) show particularly high cytotoxicities (picomolar range) towards the HT-29 cell line, thus two or three orders of magnitude more cytotoxic than colchicine itself. In this same cell line, activities are closely related to the chain length, the highest cytotoxic activity (lowest $\mathrm{IC}_{50}$ values) being reached with compound 76 , which bears an undecanoic acid chain.

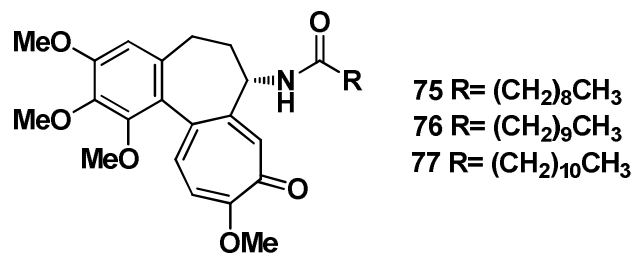

Figure 6.23.

- As regards the percentage of tubulin polymerization, 82-85 (Figure 6.24) are able to inhibit the process, being even more active than colchicine.

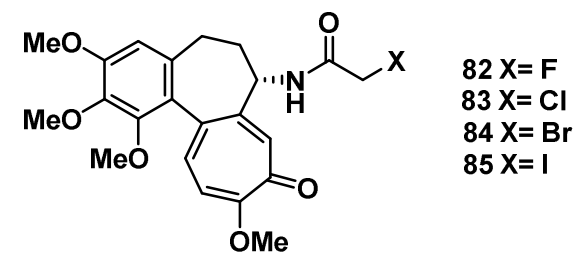

Figure 6.24.

From compounds with aliphatic $N$-acyl residues, only compounds 75-77 (Figure 6.23) induce formation of abnormal polymers.

- It has been proven that derivatives 73-77 (Scheme 6.5, p. 237) are polymerization inhibitors like colchicine itself. Most of the tested compounds present lower $I_{50}$ values than colchicine in tubulin polymerization experiments. Compounds 75, 76 and 77 (Figure 6.23) show apparent affinity constants higher than colchicine. All the studied colchicine derivatives, but not colchicine itself, cause extensive arrest of 
the cell cycle in the G2/M phase at concentrations corresponding to the $\mathrm{IC}_{50}$ values.

- It is worth noting that docking calculations have shown that, while the binding site of the colchicine fragment is situated, as expected, at the $\beta$-tubulin domain near the intradimer interface zone that separates the $\alpha$ and $\beta$ subunits, the aliphatic chains of sufficiently long acyl residues, as in compounds $\mathbf{7 5}, \mathbf{7 6}$ and $\mathbf{7 7}$ (Figure 6.23), spans this interface zone and inserts in a hydrophobic pocket located in the $\alpha$-tubulin domain. Since this does not happen with colchicine itself, this may possibly explain the differences in behaviour between the natural alkaloid and its long-chain homologues. 


\subsubsection{Family 3}

\section{Cytotoxicity}

Family 3 consists of colchicine derivatives in which the acetyl group has been replaced by substituted benzoyl groups. The cytotoxicity was measured as previously described. The following graphic represents $I_{50}$ values for all derivatives of this family in the tumor cell lines HT-29 (blue line) and MCF-7 (red line), as well as in the non-tumor cell line HEK-293 (green line). All compounds (Graphic 6.7) exhibit $\mathrm{IC}_{50}$ values in the low nanomolar range.

\section{Family 3}

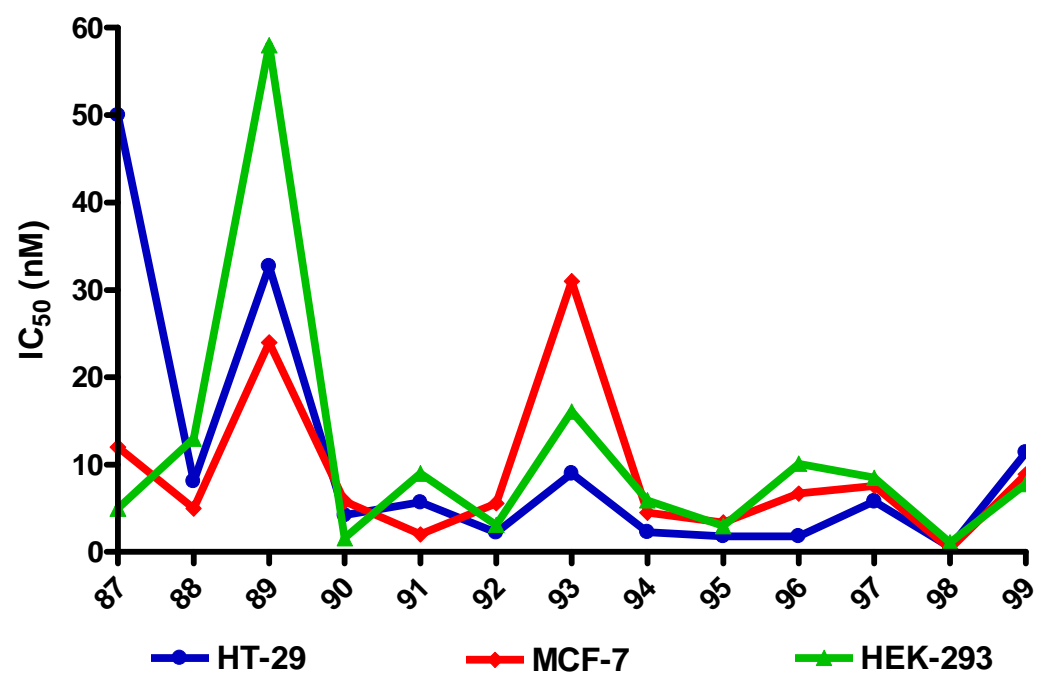

Graphic 6.7. Representation of $I C_{50}$ values of derivatives from family 3.

As shown in the graphic above, all compounds show a higher activity than colchicine in the HT-29 tumor line. Compound 89 (Table 6.5) is that having the highest therapeutic safety margin in both tumoral cell lines. The lowest value of $\mathrm{IC}_{50}$ (highest cytotoxic activity) is obtained with compound 98 (Table 6.8). It is worth noting that chlorobenzoic acid derivatives 94-96 show a higher 
cytotoxicity and also offer a better therapeutic margin that colchicine itself in the HT-29 cell line. ${ }^{194}$

Table 6.8. Cytotoxicity and selectivity coefficients of family 3.

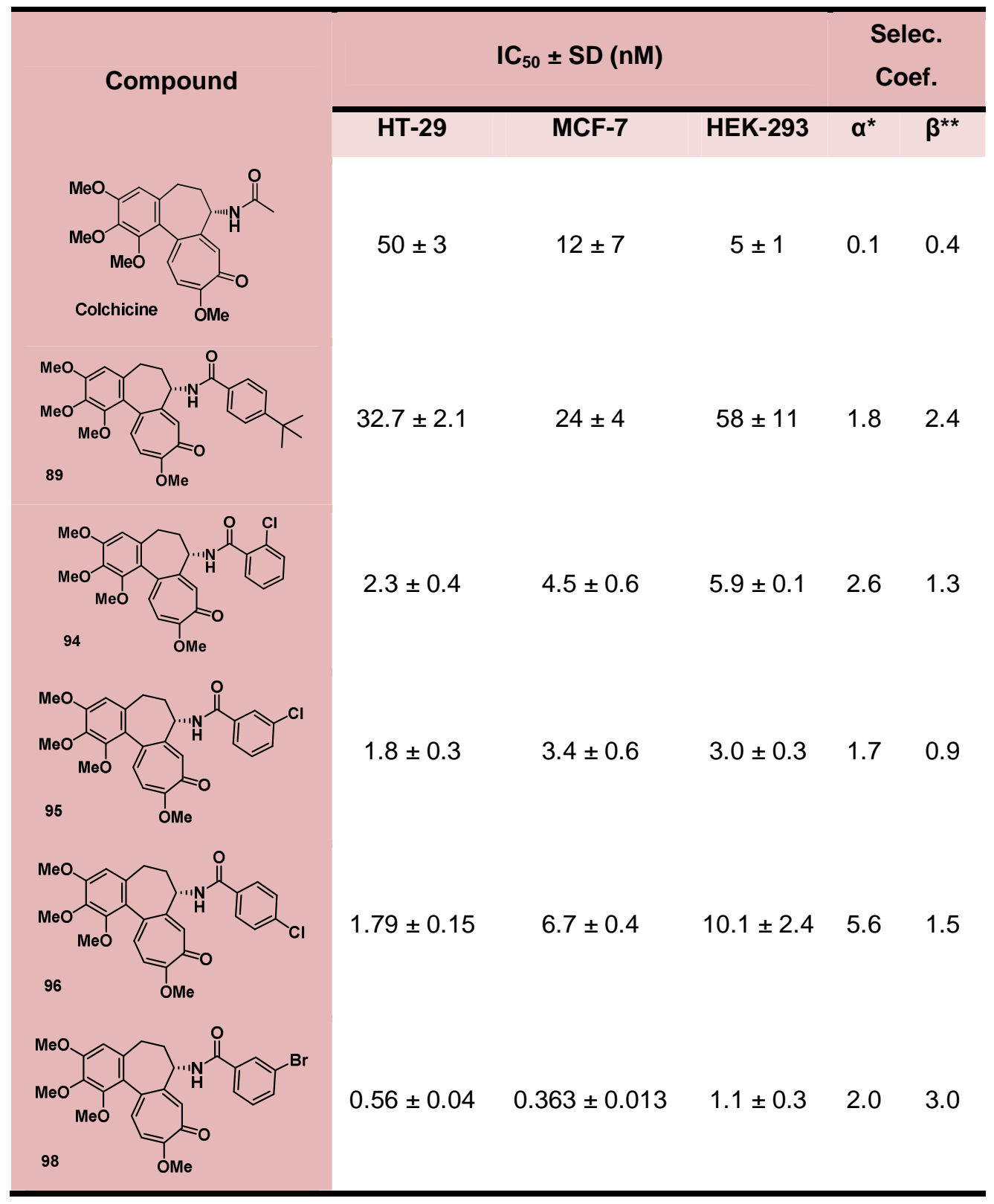

${ }^{194}$ More detailed information about the $\mathrm{IC}_{50}$ values of compounds of family 3 can be found on Table 4.15 (p. 178) in Chapter 4. 
In the A549 tumoral cell line all compounds show $\mathrm{IC}_{50}$ values in the nanomolar range (Table 4.16, p. 180). However, only derivatives 88, 92 and 94 exhibit an activity similar to that of colchicine.

\section{Effect on tubulin polymerization}

The effect on tubulin polymerization was determined in glycerol-assembling buffer (GAB) in the presence of colchicine (as a positive control inhibitor). The percentage of tubulin polymerization of the compounds of family 3 is depicted in Graphic 6.8.

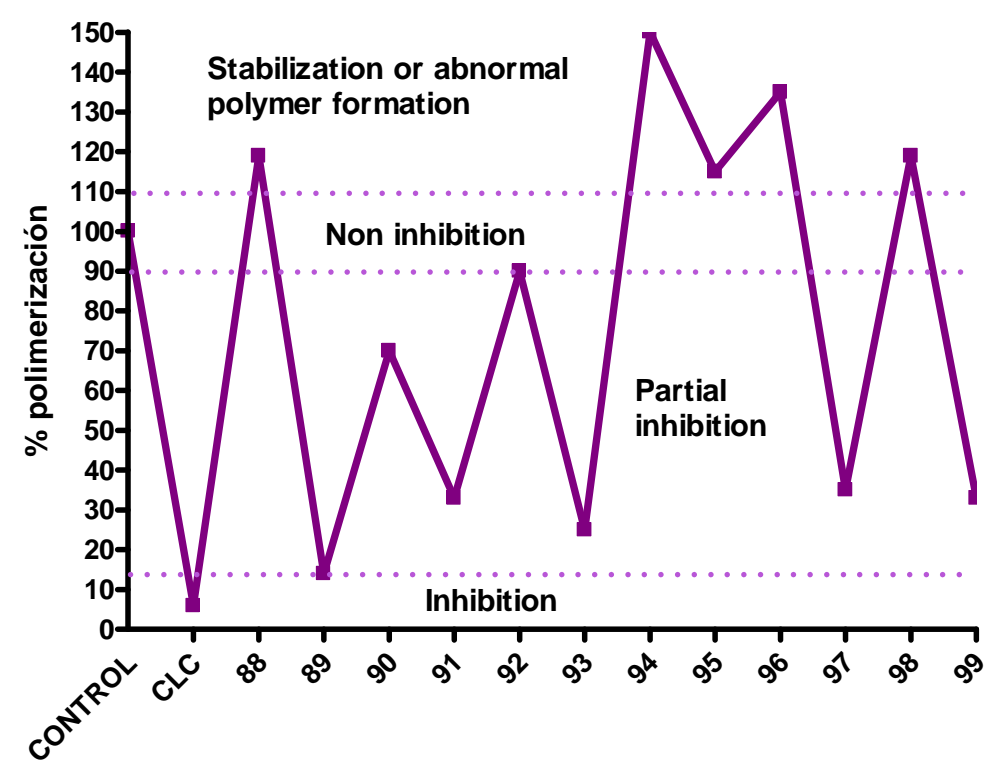

Graphic 6.8. Representation of percentage tubulin polymerization of derivatives of family 3.

Only compound 89 (Figure 6.25) inhibits the formation of microtubules in a similar way to colchicine.<smiles>COc1cc2c(c(OC)c1OC)-c1ccc(OC)c(=O)cc1[C@H](NC(=O)c1ccc(C(C)(C)C)cc1)CC2</smiles>

Figure 6.25. 
Most of these derivatives, such as 90, 91, 93, 97 and 99 (Figure 6.26), could be classified as partial inhibitors of tubulin polymerization.

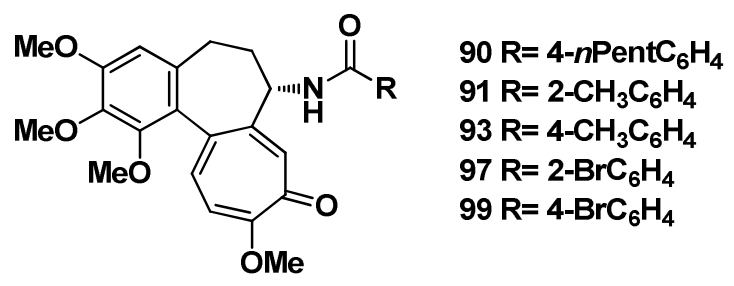

Figure 6.26.

Derivatives 88, 94, 95, 96 and 98 (Figure 6.27) increase the polymer mass.<smiles></smiles>

$88 \mathrm{R}=\mathrm{Ph}$

$94 \mathrm{R}=2-\mathrm{ClC}_{6} \mathrm{H}_{4}$

$95 \mathrm{R}=3-\mathrm{ClC}_{6} \mathrm{H}_{4}$

$96 \mathrm{R}=4-\mathrm{ClC}_{6} \mathrm{H}_{4}$

$98 \mathrm{R}=3-\mathrm{BrC}_{6} \mathrm{H}_{4}$

Figure 6.27.

\section{VEGF, $h T E R T$ and $c-M y c$ gene expression and VEGF protein secretion}

PCR followed by electrophoresis (Figure 4.43, p. 183) was performed in order to reduce the number of compounds to be further investigated. The selected compounds (Figure 4.44, p. 184) are 89, 92 and 94-99.

As regards VEGF gene expression, all compounds show higher inhibition levels than colchicine at $10 \mathrm{nM}$. It is worth highlighting that derivatives $\mathbf{9 4 , 9 5}$ and 96 (Table 6.9) downregulate the expression of the VEGF gene in a percentage similar to that of colchicine at $40 \mathrm{nM} .^{195}$

\footnotetext{
${ }^{195}$ More detailed information about the VEGF gene expression of compounds of family 3 can be found on Graphic 4.14 (p. 185) in Chapter 4.
} 
Table 6.9. \% gene expression and protein secretion for compounds of family 3.

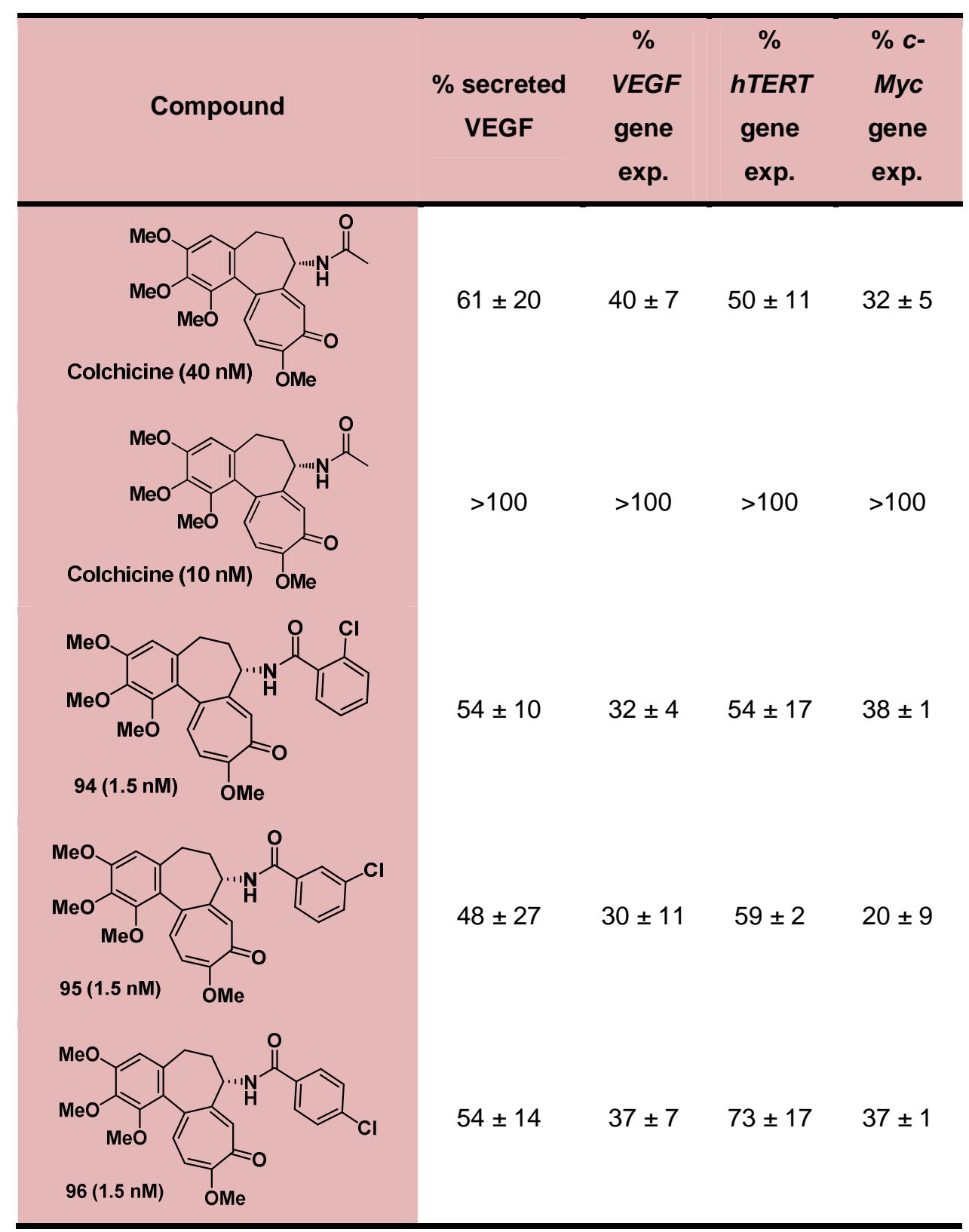

While the compounds display similar inhibitory capacities on the expression of the $h T E R T$ gene as colchicine at $40 \mathrm{nM}$, they are much more active than 
colchicine at $10 \mathrm{nM}$, even if their activities were measured at a $1.5 \mathrm{nM}$ concentration. ${ }^{196}$

As regards the expression of the $c-M y c$ gene, all compounds show higher higher inhibitory activities than colchicine at $10 \mathrm{nM}$. It is worth noting that compound 95 (20\% gene expression at $1.5 \mathrm{nM})$ presents a higher activity than colchicine (32\% gene expression) at $40 \mathrm{nM}$ concentration, a value around 25 times higher. ${ }^{197}$

Finally, as regards the secretion of the VEGF protein, all compounds show higher inhibitory activities than colchicine at $10 \mathrm{nM}$. Derivatives 94, 95 and 96 (54\%, 48\% and 54\% gene expression, respectively, Table 6.9) perform better than colchicine at $40 \mathrm{nM}$ (61\% protein secretion), whereas 89 and 99 (61\% and $62 \%$ protein secretion, respectively) show a similar protein secretion to that of the natural alkaloid at $40 \mathrm{nM}^{198}$

\section{Docking}

Docking calculations show that compounds 94-96 are situated at the colchicine site (Figure 6.25), located in the interface $\alpha \beta$-tubulin in a similar conformation exhibited by the crystallographic structure of the DAMAcolchicine (data obtained from 1SA0 PDB). Docking studies indicate that derivative 94 (2-chlorobenzoyl) places the chlorine atom in a position opposite to the groove of the a-tubulin, while 95 (3-chlorobenzoyl) and 96 (4chlorobenzoyl) guide the chlorine atom into this groove (Figure 6.28). ${ }^{199}$ The

\footnotetext{
${ }^{196}$ More detailed information about the $h T E R T$ gene expression of compounds of family 3 can be found on Graphic 4.15 (p. 186) in Chapter 4.

${ }^{197}$ More detailed information about the $c-M y c$ gene expression of compounds of family 3 can be found on Graphic 4.16 (p. 186) in Chapter 4.

${ }_{198}$ More detailed information about the VEGF protein secretion of compounds of family 3 can be found on Graphic 4.17 (p. 187) in Chapter 4.

${ }_{199}$ More detailed information about 2D interactions at colchicine binding site on Figure 4.46 ( $p$. 189) for compound 94, Figure 4.47 (p. 190) for compound 95 and Figure 4.48 (p. 191) for compound 96.
} 
three derivatives of chlorobenzoic acid exhibit different interactions with tubulin, but all of them increase the polymer mass formed.
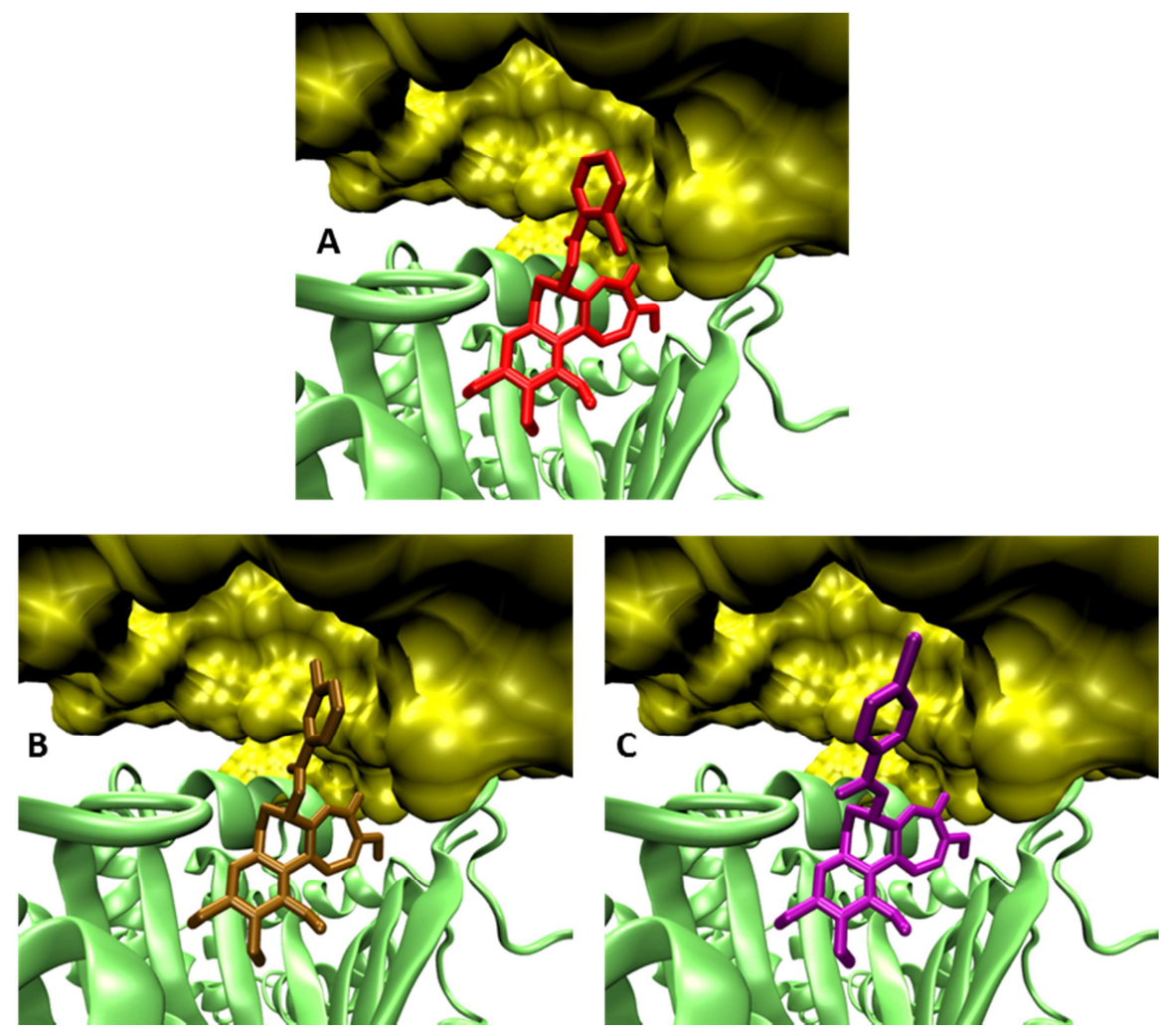

Figure 6.28. Panel A: Binding site of compound 94 (red). The $\alpha$ - and $\beta$-tubulin subunits are coloured in yellow and green, respectively. Panel B: Binding site of compound 95 (brown). Panel C: Binding site of compound 96 (purple).

\section{Conclusions}

- The synthetic derivatives of family 3 exhibit nanomolar cytotoxicity in all the cell lines studied, particularly in the HT-29 cell line in which they outweigh the cytotoxic activity of colchicine. It is worth noting that derivative 98 (Figure 6.29) exhibits an activity in the picomolar range. 


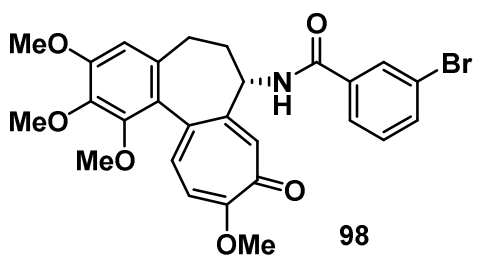

Figure 6.29.

- As regards the tubulin polymerization process, only compound 89 (Figure 6.30) inhibits the formation of microtubules in a similar way to colchicine.<smiles>COc1cc2c(c(OC)c1OC)-c1ccc(OC)c(=O)cc1[C@@H](NC(=O)c1ccc(C(C)(C)C)cc1)CC2</smiles>

Figure 6.30.

Compounds 88, 94, 95, 96 and 98 (Figure 6.31) have the effect of increasing the polymer mass.

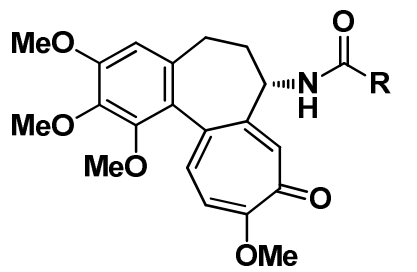

$88 \mathrm{R}=\mathrm{Ph}$

$94 \mathrm{R}=2-\mathrm{CIC}_{6} \mathrm{H}_{4}$

$95 \mathrm{R}=3-\mathrm{ClC}_{6} \mathrm{H}_{4}$

$96 \mathrm{R}=4-\mathrm{ClC}_{6} \mathrm{H}_{4}$

$98 \mathrm{R}=3-\mathrm{BrC}_{6} \mathrm{H}_{4}$

Figure 6.31.

- As regards the expression of the three studied genes (VEGF, hTERT and $c-M y c)$, all compounds show greater inhibitory activities than colchicine. Notably, chlorobenzoic acid derivatives 94 (ortho), 95 (meta) and 96 (para) show greater inhibitory activities for all genes and VEGF protein secretion than colchicine at $40 \mathrm{nM}$, even if tested at concentrations 25 times lower. 

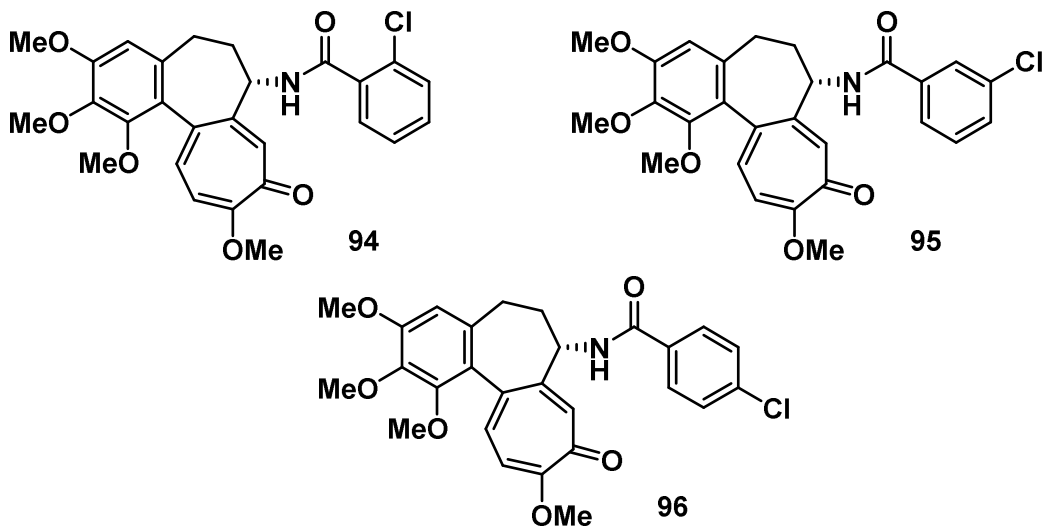

Figure 6.32. 


\subsection{Summary and conclusions}

\section{Cytotoxicity}

The majority of the synthetic colchicine analogues present $\mathrm{IC}_{50}$ values in the low nanomolar range. Furthermore, derivatives 75 and 77 having aliphatic, long-chain $\mathrm{N}$-acyl residues, and the benzoyl derivative 98 (Figure 6.33) show $\mathrm{IC}_{50}$ values in the picomolar range.<smiles>CCCCCCCCCC(=O)N[C@H]1CCc2cc(OC)c(OC)c(OC)c2-c2ccc(OC)c(=O)cc21</smiles><smiles>CCCCCCCCCCCC(=O)N[C@H]1CCc2cc(OC)c(OC)c(OC)c2-c2ccc(OC)c(=O)cc21</smiles><smiles>CCCCCCCCCCC(=O)N[C@H]1CCc2cc(OC)c(OC)c(OC)c2-c2ccc(OC)c(=O)cc21</smiles><smiles>COc1cc2c(c(OC)c1OC)-c1ccc(OC)c(=O)cc1[C@@H](NC(=O)c1cccc(Br)c1)CC2</smiles>

Figure 6.33.

\section{Effect on tubulin polymerization}

The majority of the synthetized compounds inhibit the tubulin polymerization process either completely or partially. It is worth noting that compounds $\mathbf{7 5}$ and 77 (Figure 6.33) induce the formation of abnormal polymers at concentration in which colchicine inhibits tubulin polymerization.

\section{VEGF, $h T E R T$ and $c-M y c$ gene expression and VEGF protein secretion}

In order to measure the secretion of the VEGF protein and the expression of the VEGF, hTERT and $c-M y c$ genes, a number of compounds of the three families were selected according to their cytotoxicity (Chapter 4). Graphic 6.9 represents values for VEGF gene expression (orange line), hTERT gene expression (purple line) and $c-M y c$ gene expression (green line) in the presence of each of the selected compounds. 


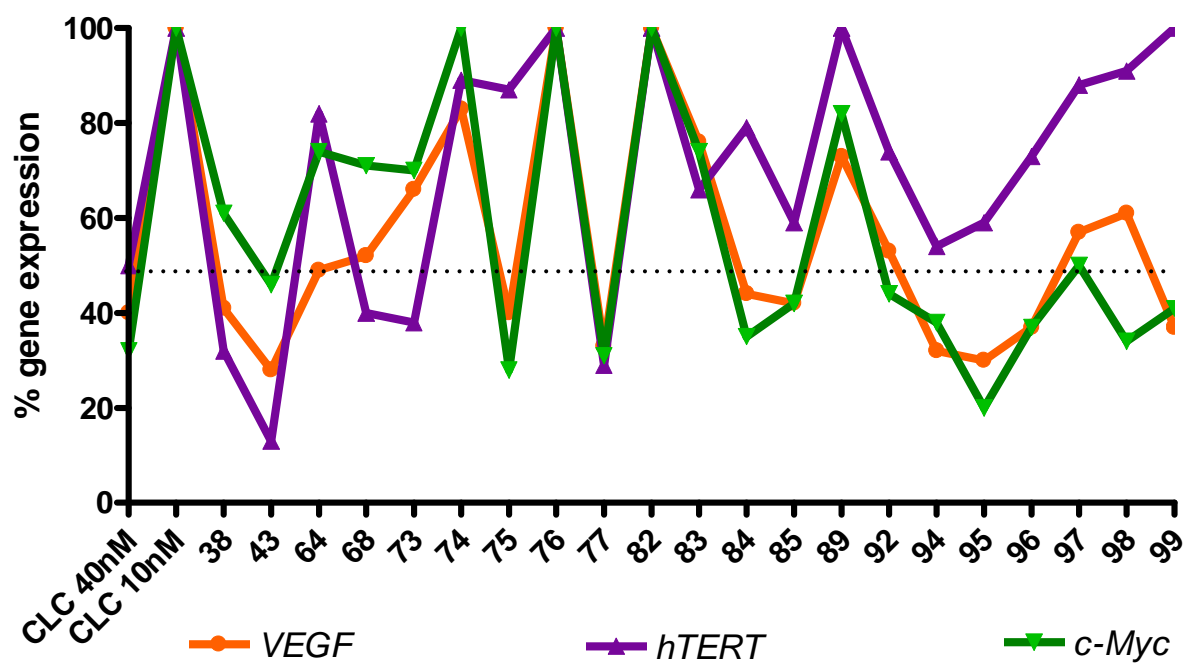

Graphic 6.9. Representation of percentage of gene expression.

As shown in the graphic, compound 77 (Figure 6.33) is the most active, as it reduces the expression of the three genes studied to around $30 \%$ of the control value.

a-Aminoacyl derivatives 38 and $\mathbf{4 3}$ (Figure 6.34) display a dual activity against the VEGF and $h T E R T$ genes and reduce their expression to levels below $50 \%$. Compound $\mathbf{4 3}$ is particularly active as it is able to dowregulate the expression of the $h T E R T$ gene to around $15 \%$ of the control value.
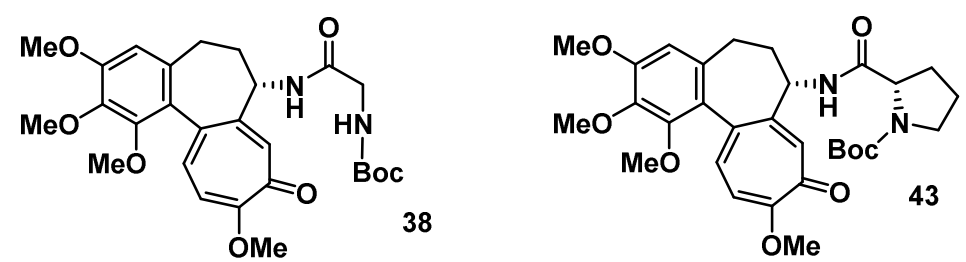

Figure 6.34.

Compounds 75, 84, 85, 94, 95 and 96 (Figure 6.35) are also worth mentioning because they display a dual activity against the VEGF and $c-M y c$ genes and downregulate their expression to values below $50 \%$. Several 
studies have highlighted the role of the $c-M y c$ gene in the regulation of angiogenesis. Indeed, activation of the $c-M y c$ gene is sufficient to trigger VEGF expression. ${ }^{200}$ Thus, our results open the possibility that the compounds under study reduce the expression of the VEGF gene through the regulation of the expression of the $c-M y c$ gene.<smiles></smiles><smiles></smiles><smiles>COc1cc2c(c(OC)c1OC)-c1ccc(OC)c(=O)cc1[C@H](NC(=O)CI)CC2</smiles><smiles>COc1cc2c(c(OC)c1OC)-c1ccc(OC)c(=O)cc1[C@H](NC(=O)c1ccccc1Cl)CC2</smiles><smiles>COc1cc2c(c(OC)c1OC)-c1ccc(OC)c(=O)cc1[C@H](NC(=O)c1cccc(Cl)c1)CC2</smiles><smiles>COc1cc2c(c(OC)c1OC)-c1ccc(OC)c(=O)cc1[C@H](NC(=O)c1ccc(Cl)cc1)CC2</smiles>

Figure 6.35.

Regarding the secretion of VEGF protein, only some of the benzoyl derivatives of family 3 (compounds $\mathbf{8 9}, \mathbf{9 4 - 9 6}$ and $\mathbf{9 9}$, Figure 6.36) reduce the secretion of VEGF-A protein to percentages between $40-50 \%$, close to the value observed with colchicine $(40 \%)$.

\footnotetext{
200 a) Rahden, B. H. A.; Stein, H. J.; Pühringer-Oppermann, F.; Sarbia, M. Neoplasia, 2006, 8, 702-707. b) Baudino, T. A.; McKay, C.; Pendeville-Samain, H.; Nilsson, J. A.; Maclean, K.H.; White, E. L.; Davis, A. C.; Ihle, J. N.; Cleveland, J. L. Genes Dev., 2002, 16, 2530-2543.
} 

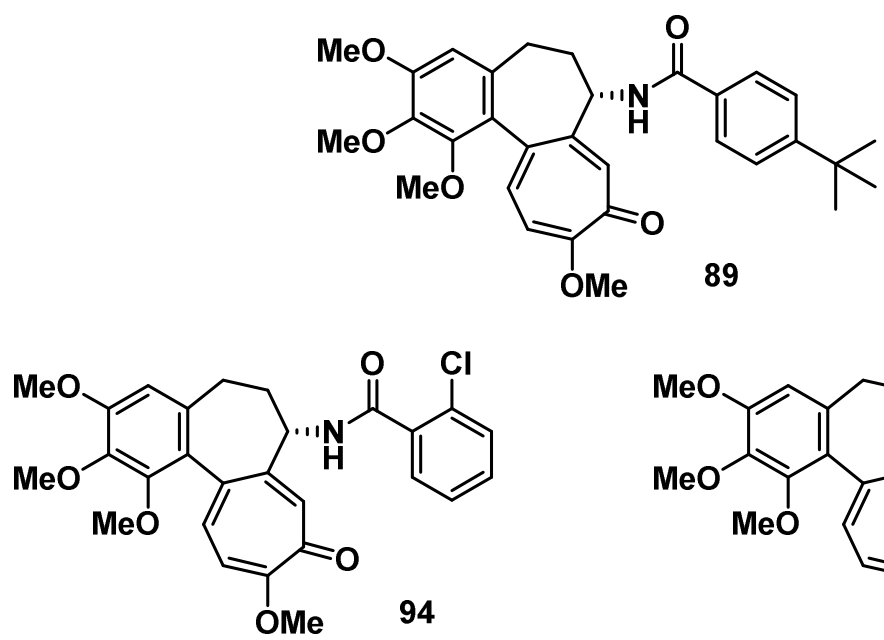<smiles></smiles><smiles>COc1cc2c(c(OC)c1OC)-c1ccc(OC)c(=O)cc1[C@@H](NC(=O)c1ccc(Cl)cc1)CC2</smiles><smiles>COc1cc2c(c(OC)c1OC)-c1ccc(OC)c(=O)cc1[C@@H](NC(=O)c1ccc(Br)cc1)CC2</smiles>

Figure 6.36. 



\section{CAPÍTULO 7}

\section{PUBLICACIONES Y}

\section{COMUNICACIONES A}

\section{CONGRESOS DERIVADAS}

\section{DE LA TESIS DOCTORAL}
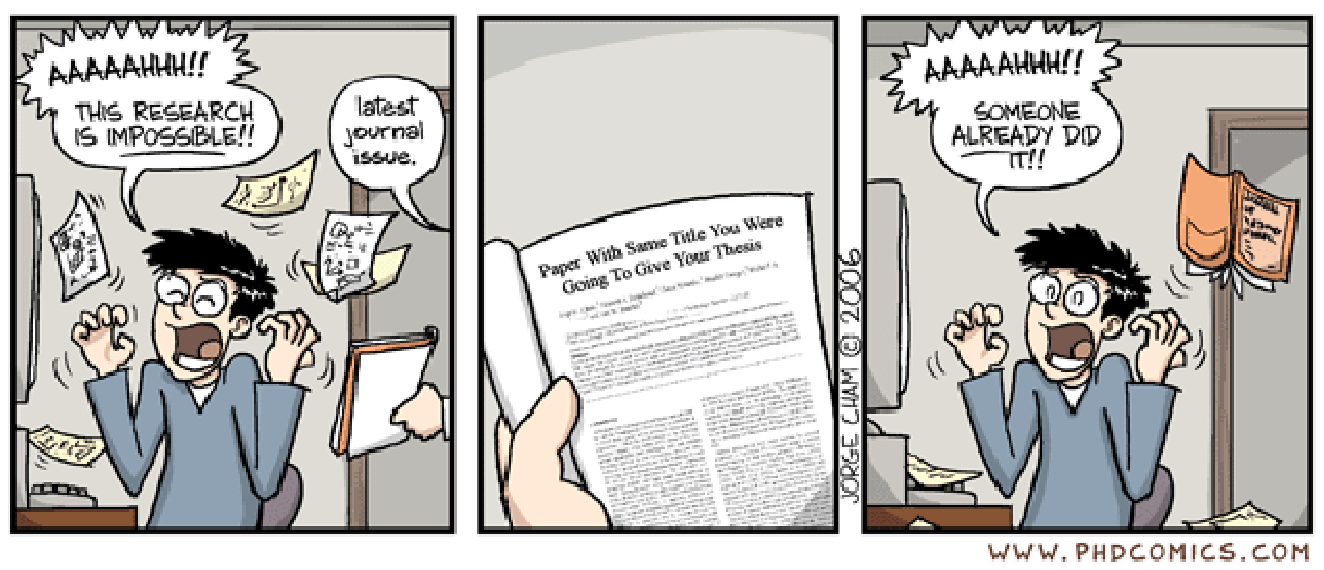



\section{CAPÍTULO 7: PUBLICACIONES Y COMUNICACIONES A CONGRESOS DERIVADAS DE LA TESIS DOCTORAL}

\subsection{COMUNICACIONES A CONGRESOS}

- XXXV Reunión bienal de la real sociedad española de química. La Coruña, España. Julio-2015. Póster. "Síntesis y evaluación biológica de derivados de colchicina y aminocombretastatina." Agut, R.; Conesa, L.; Marzo-Mas, A.; Falomir, E.; Murga, J.; Carda, M.; Marco, J. A.

- XXIII Young research fellow meeting. Lille, Francia. Febrero2016. Póster. "Synthesis and biological evaluation of colchicine derivatives." Marzo-Mas, A.; Falomir, E.; Murga, J.; Carda, M.; Marco, J. A.

- XXVI Reunión bienal de química orgánica. Punta Umbría, Huelva, España. Junio-2016. Póster. "Synthesis and biological evaluation of $\mathrm{N}$-acyl colchicine derivatives." Marzo-Mas, A.; Falomir, E.; Murga, J.; Carda, M.; Marco, J. A.

- V SEQT Summer School. Sant Feliu de Llobregat, Barcelona, España. Junio-2016. Póster: "Synthesis and biological evaluation of colchicine derivatives." Marzo-Mas, A.; Falomir, E.; Murga, J.; Carda, M.; Marco, J. A.

- III Simposio de Jóvenes Investigadores (SEQT). Barcelona, España. Junio-2016. Comunicación oral: "Synthesis and biological evaluation of colchicine derivatives." Marzo-Mas, A.; Falomir, E.; Murga, J.; Carda, M.; Marco, J. A. 


\subsection{PUBLICACIONES DERIVADAS DE LA TESIS DOCTORAL}

Los resultados de esta tesis han sido publicados en los siguientes artículos.

- Título. "Interactions of long-chain homologues of colchicine with tubulin"

Autores: Marzo-Mas, A.; Barbier, P.; Breuzard, G.; Allegro, D.; Falomir, E.; Murga, J.; Carda, M.; Peyrot, V.; Marco, J. A.

European Journal of Medicinal Chemistry. 2017, 126, 526-535, doi:10.1016/j.ejmech.2016.11.049.

En la actualidad se encuentran en proceso de ser próximamente enviados a publicar tres artículos más relacionados con los derivados de la colchicina. 


\section{CAPÍTULO 8 ESPECTROS SELECCIONADOS}

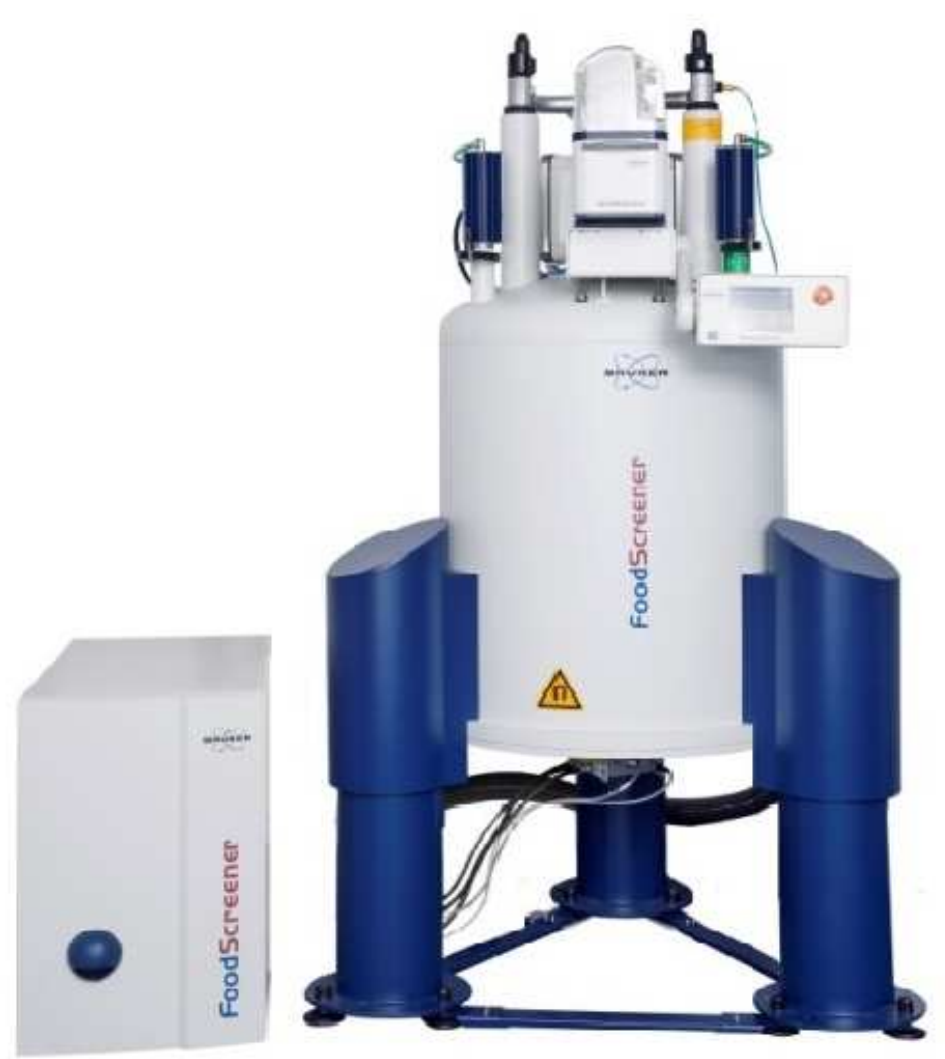





\section{CAPÍTULO 8: ESPECTROS SELECCIONADOS}
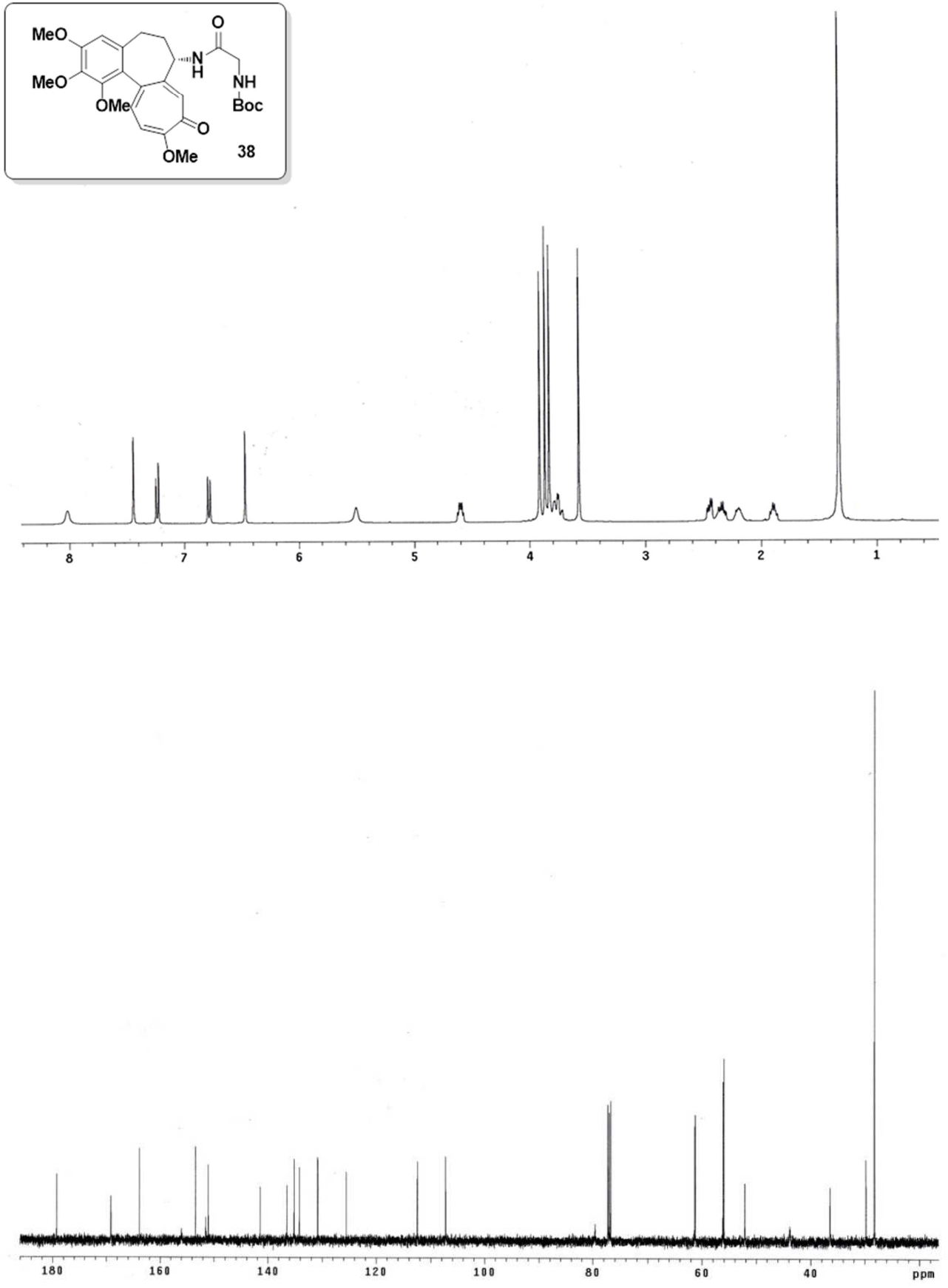

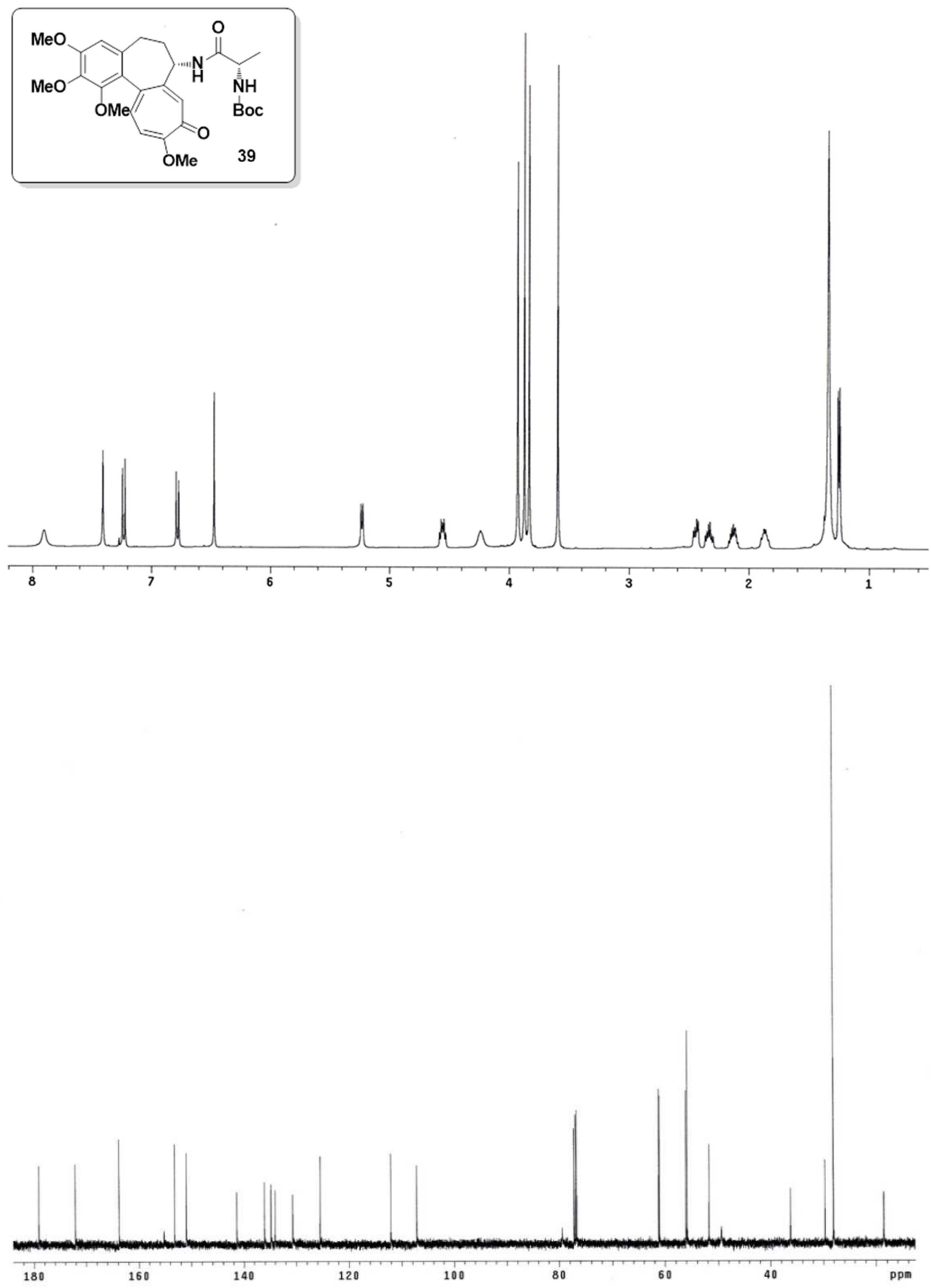

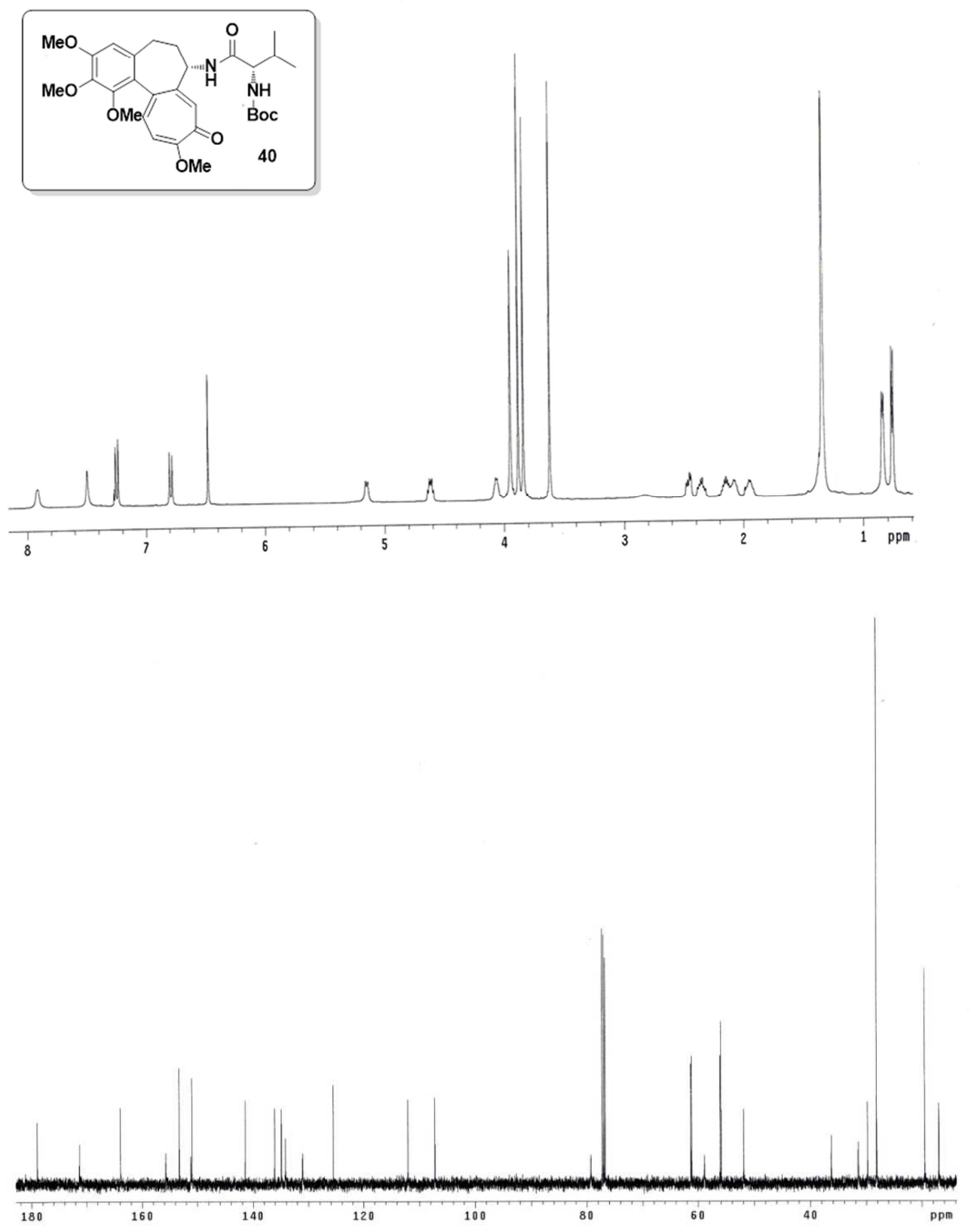

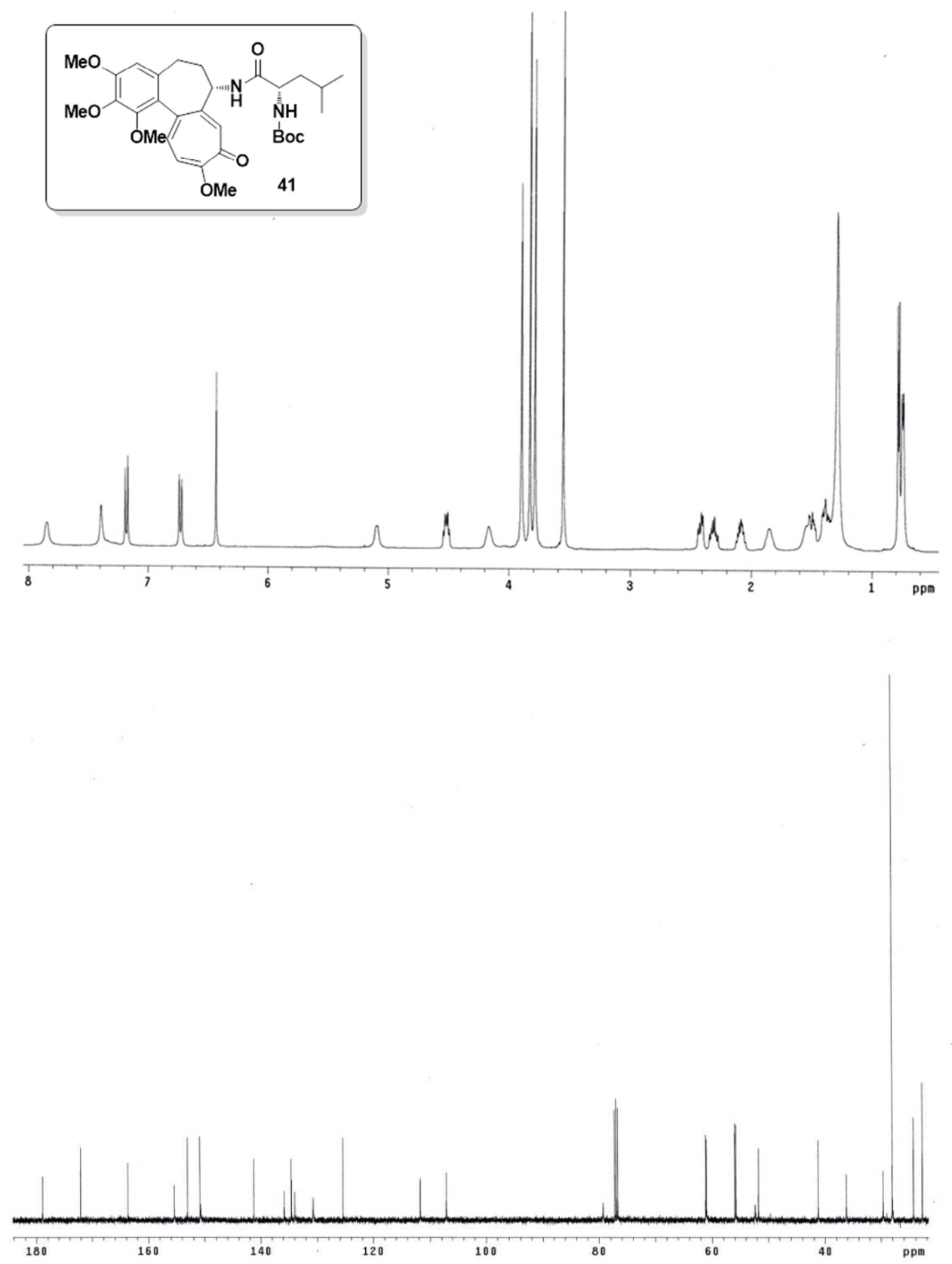

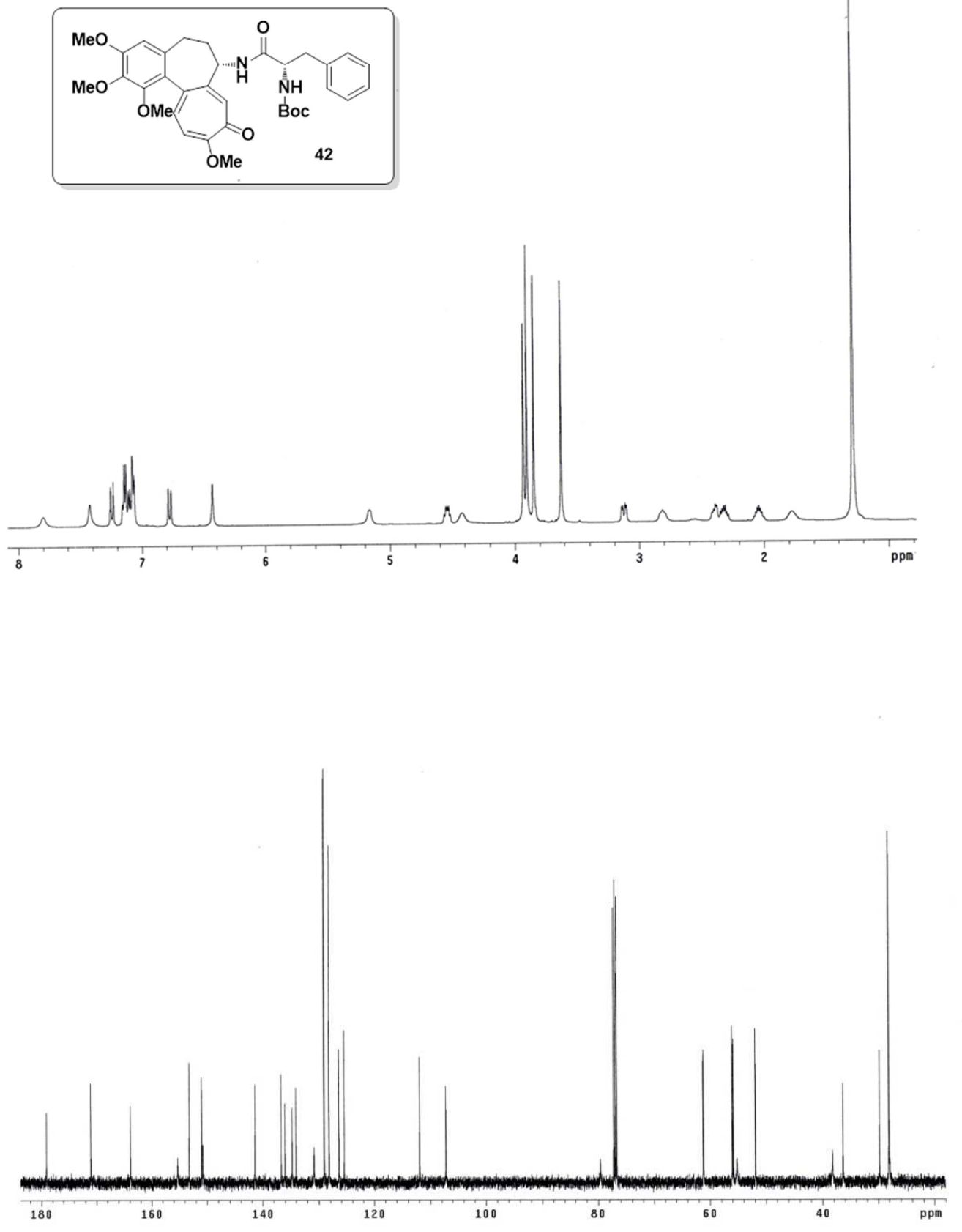


$$
\text { OMe } 43
$$
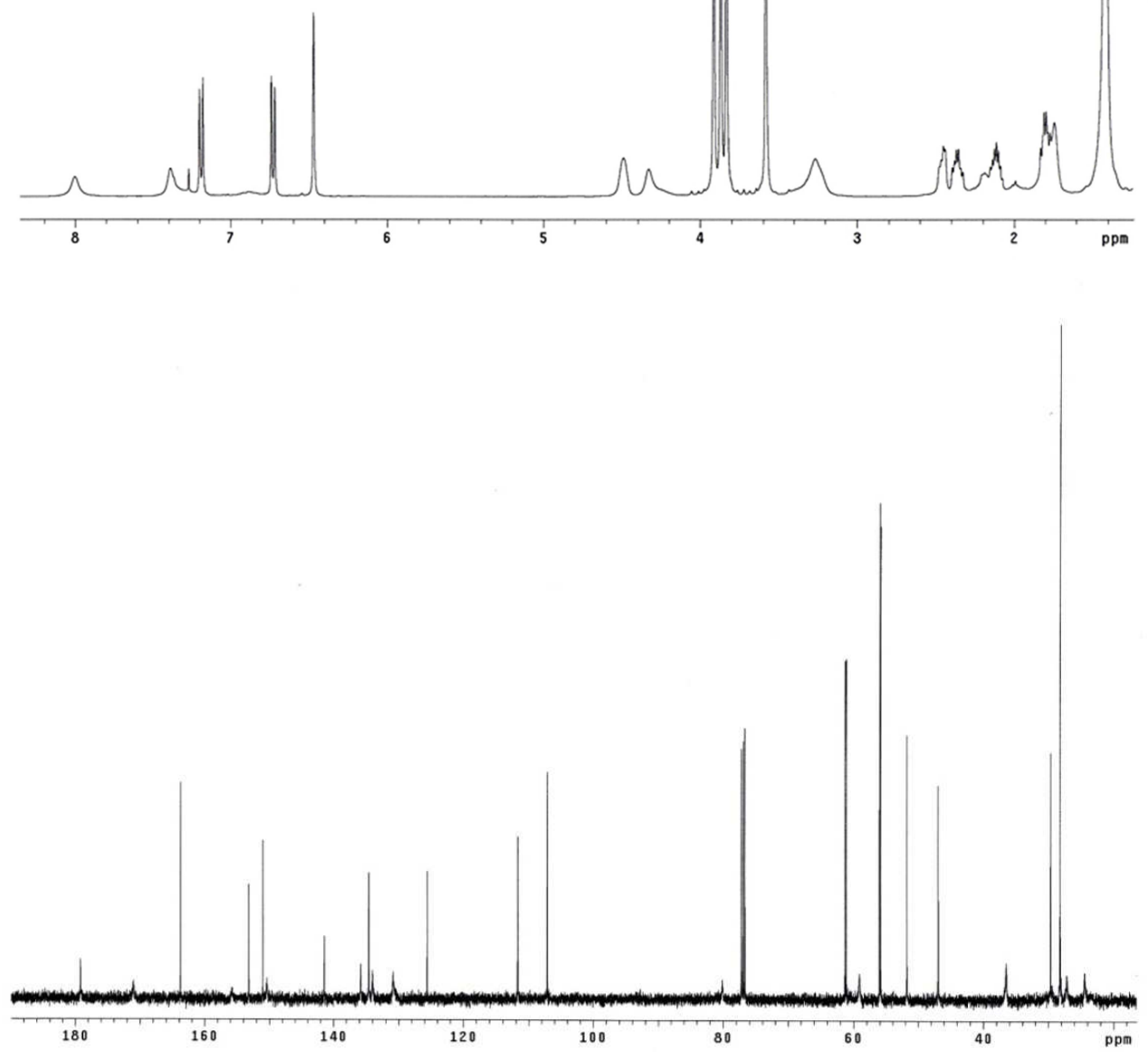

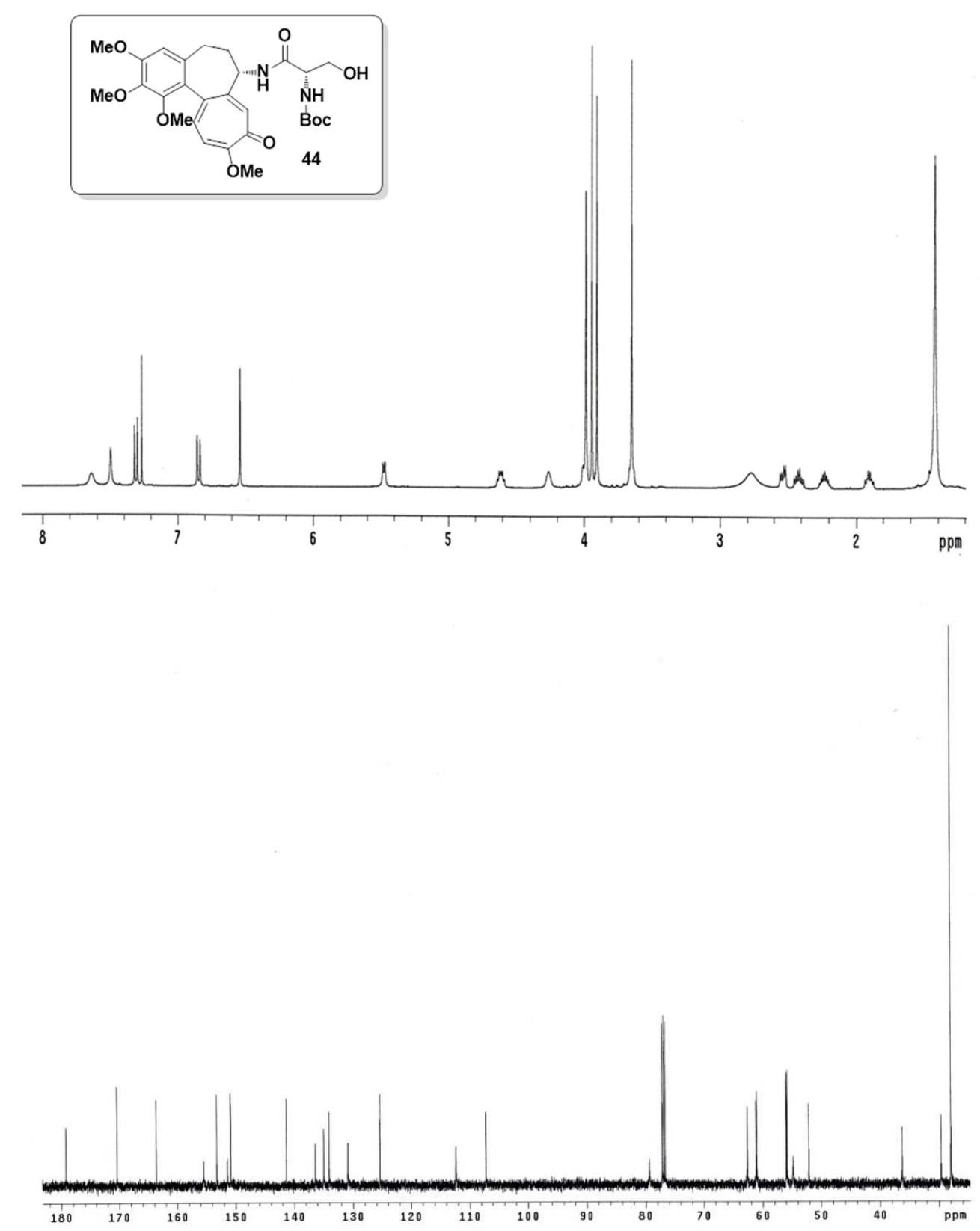

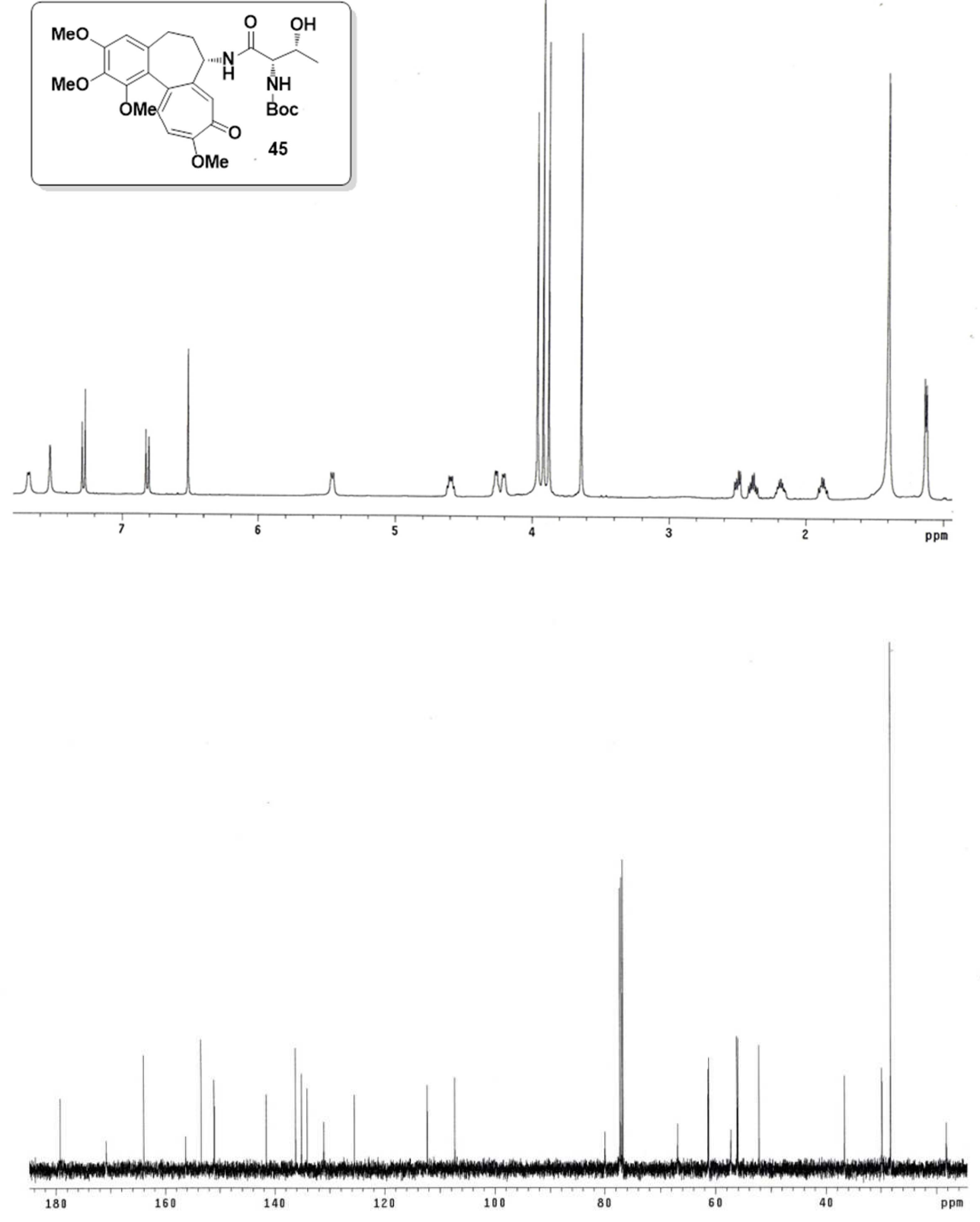

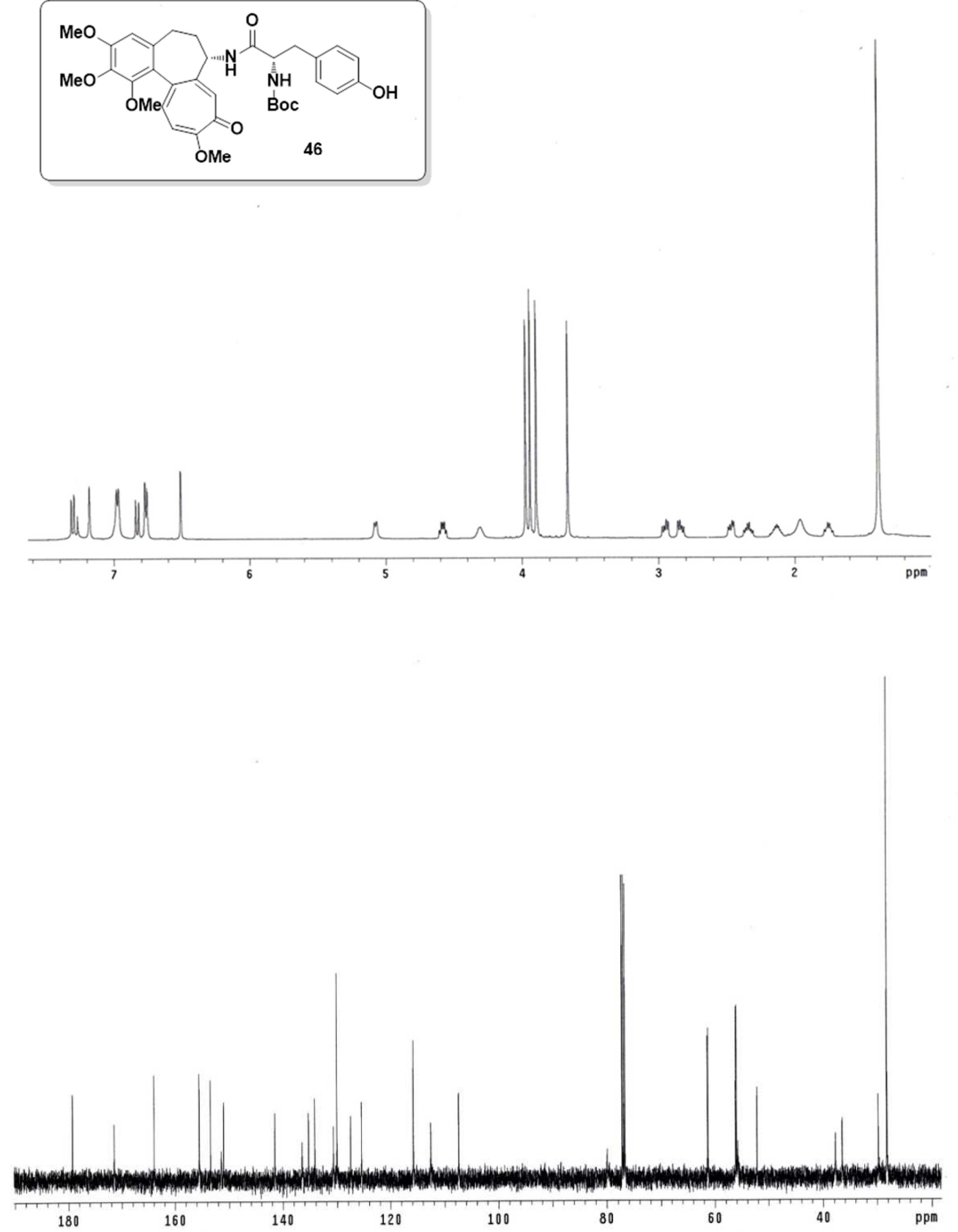

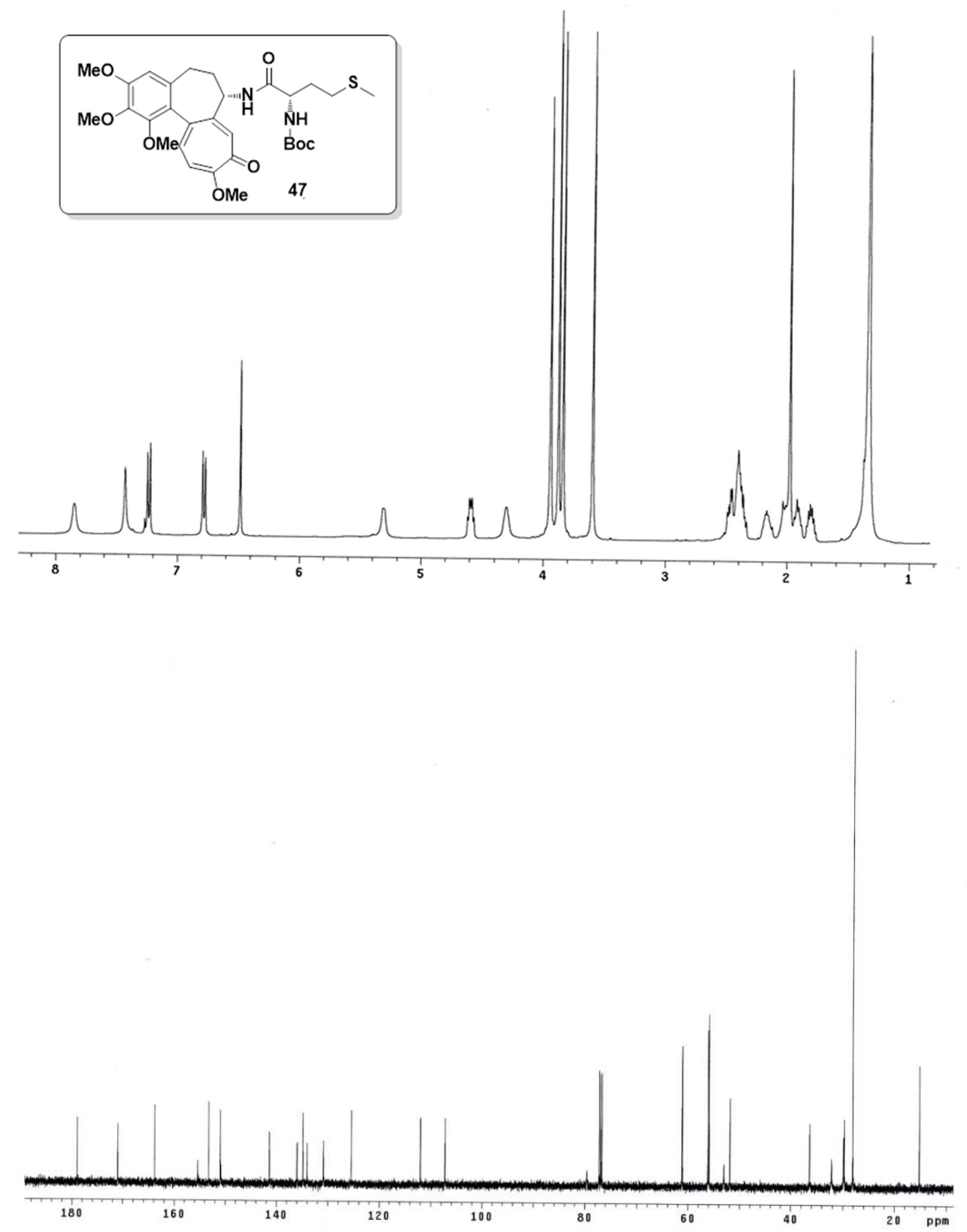

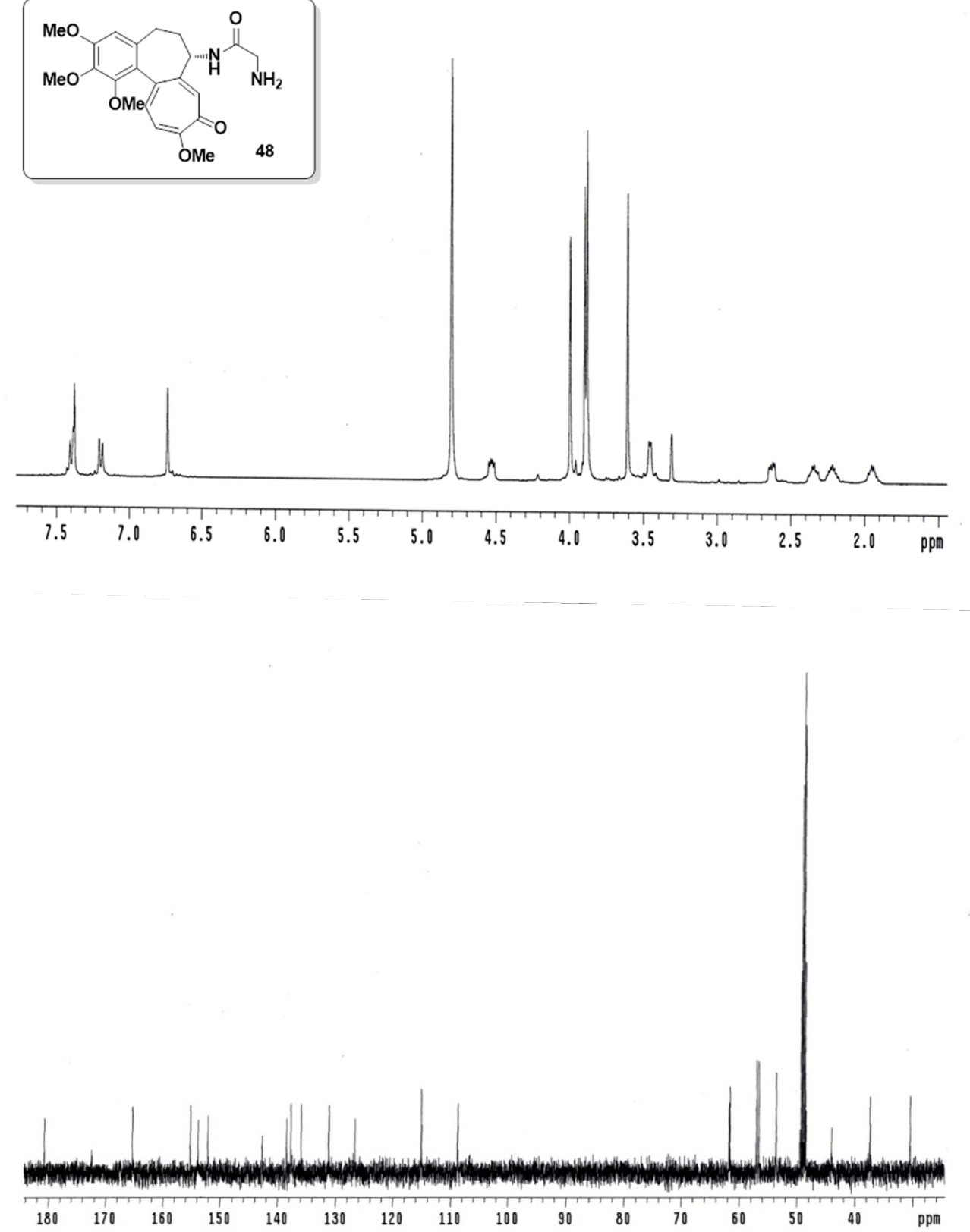

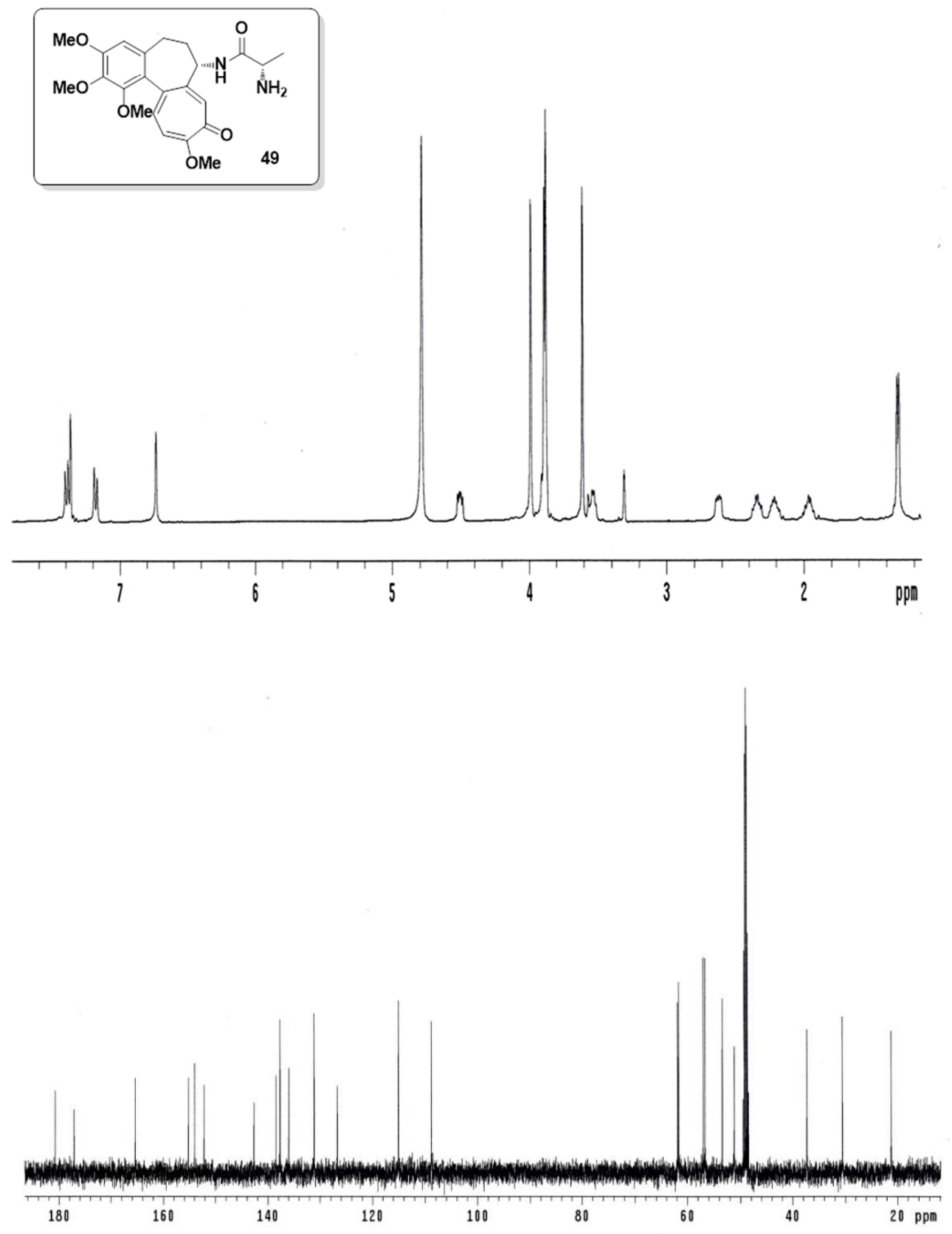

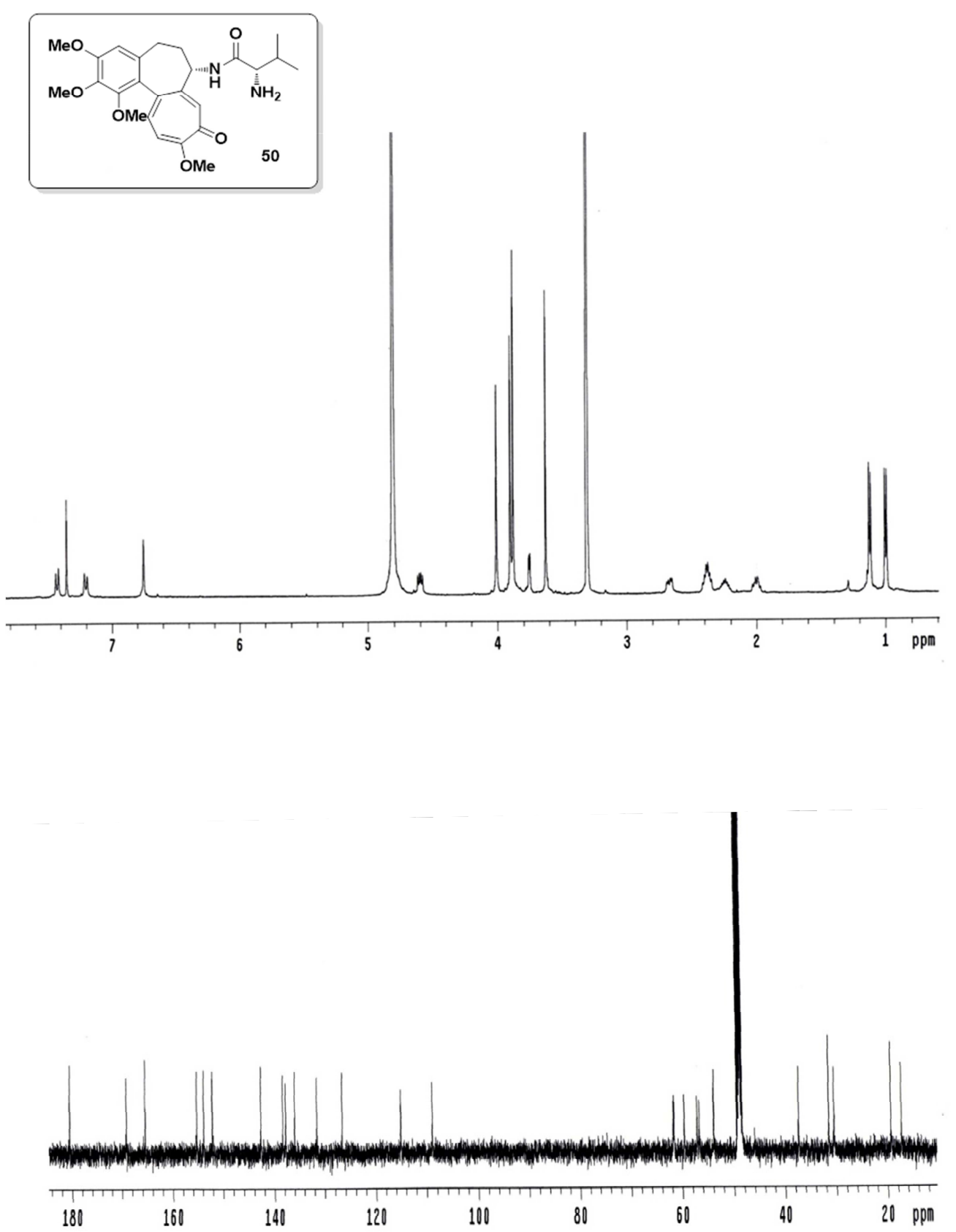

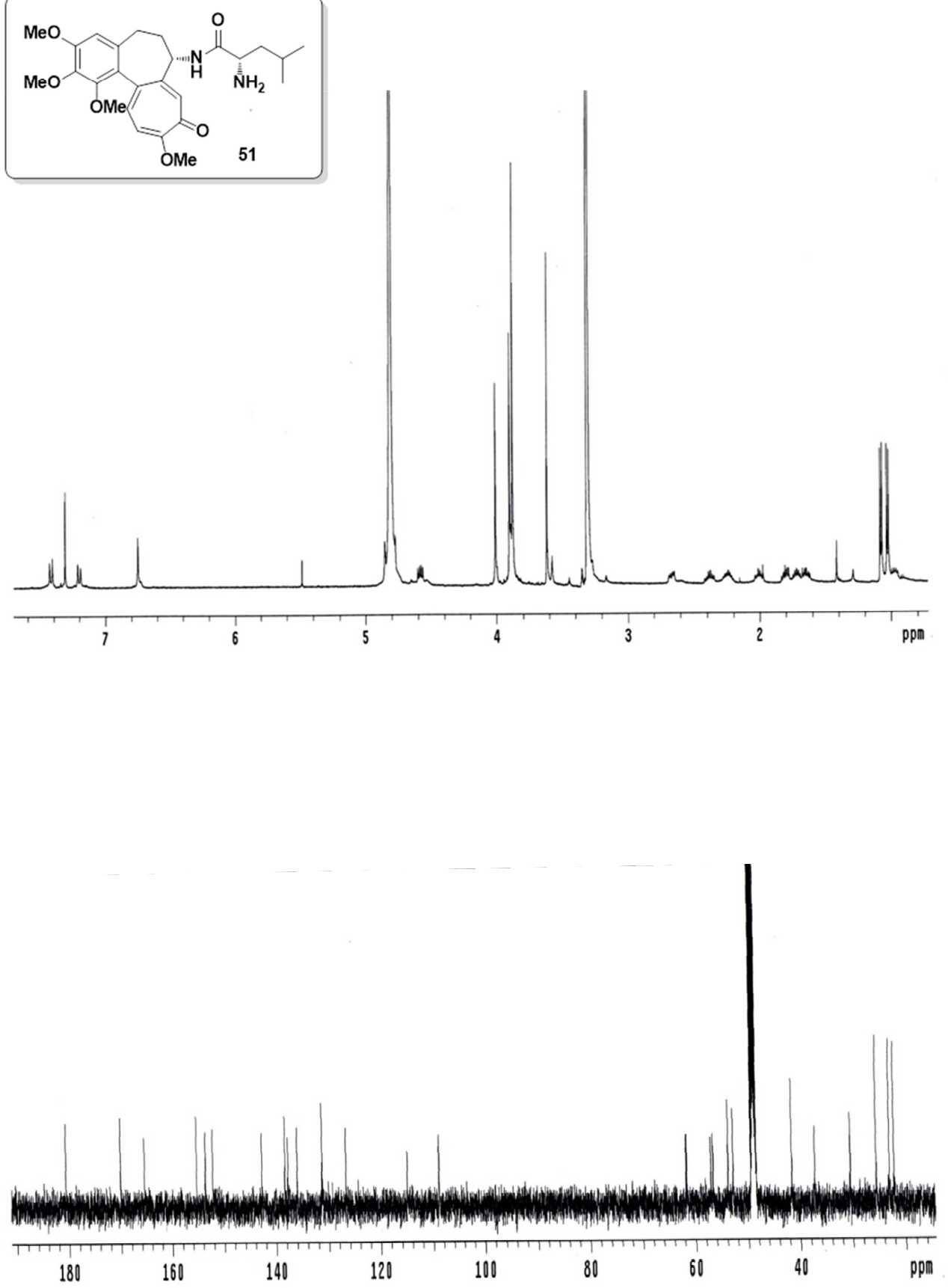

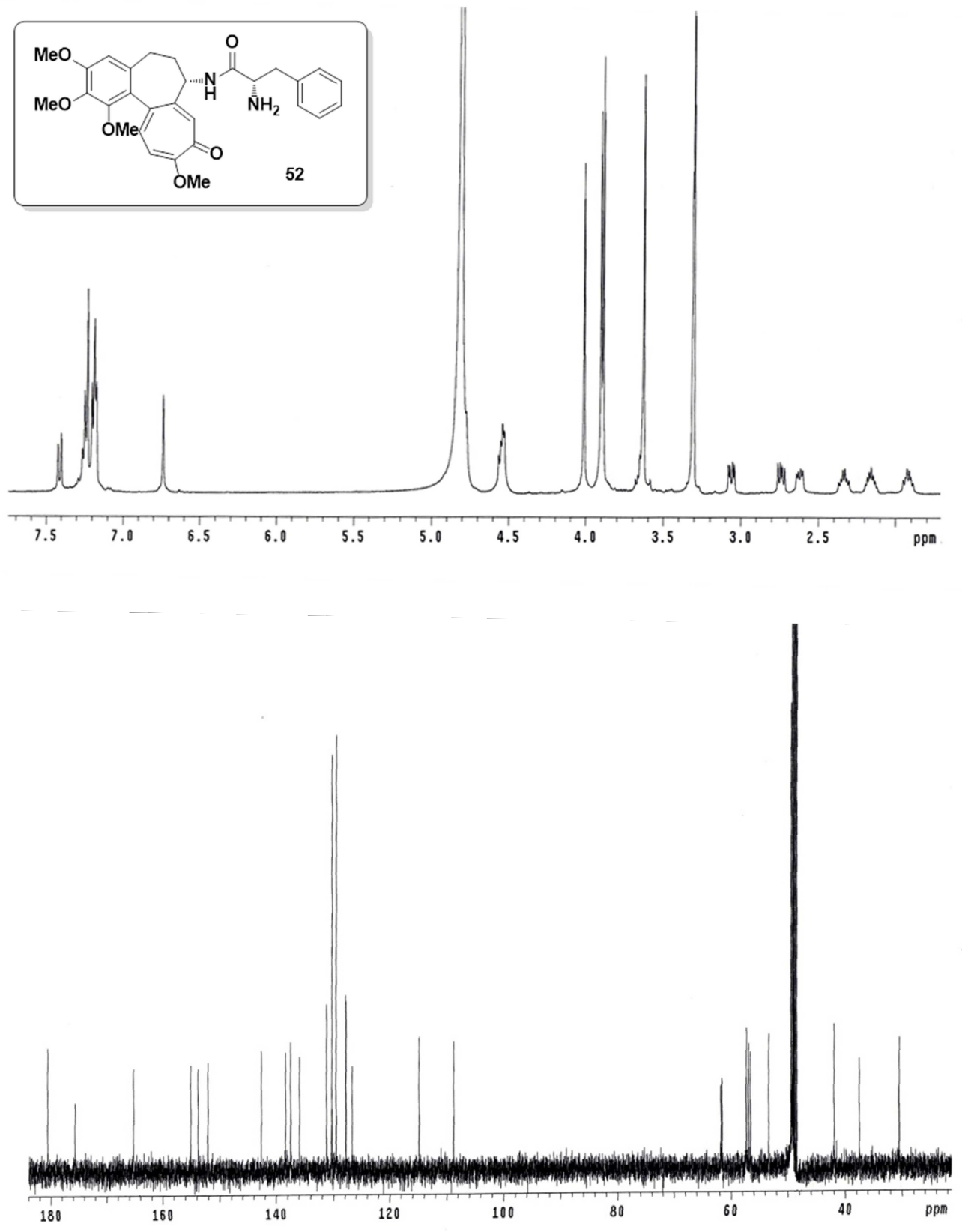

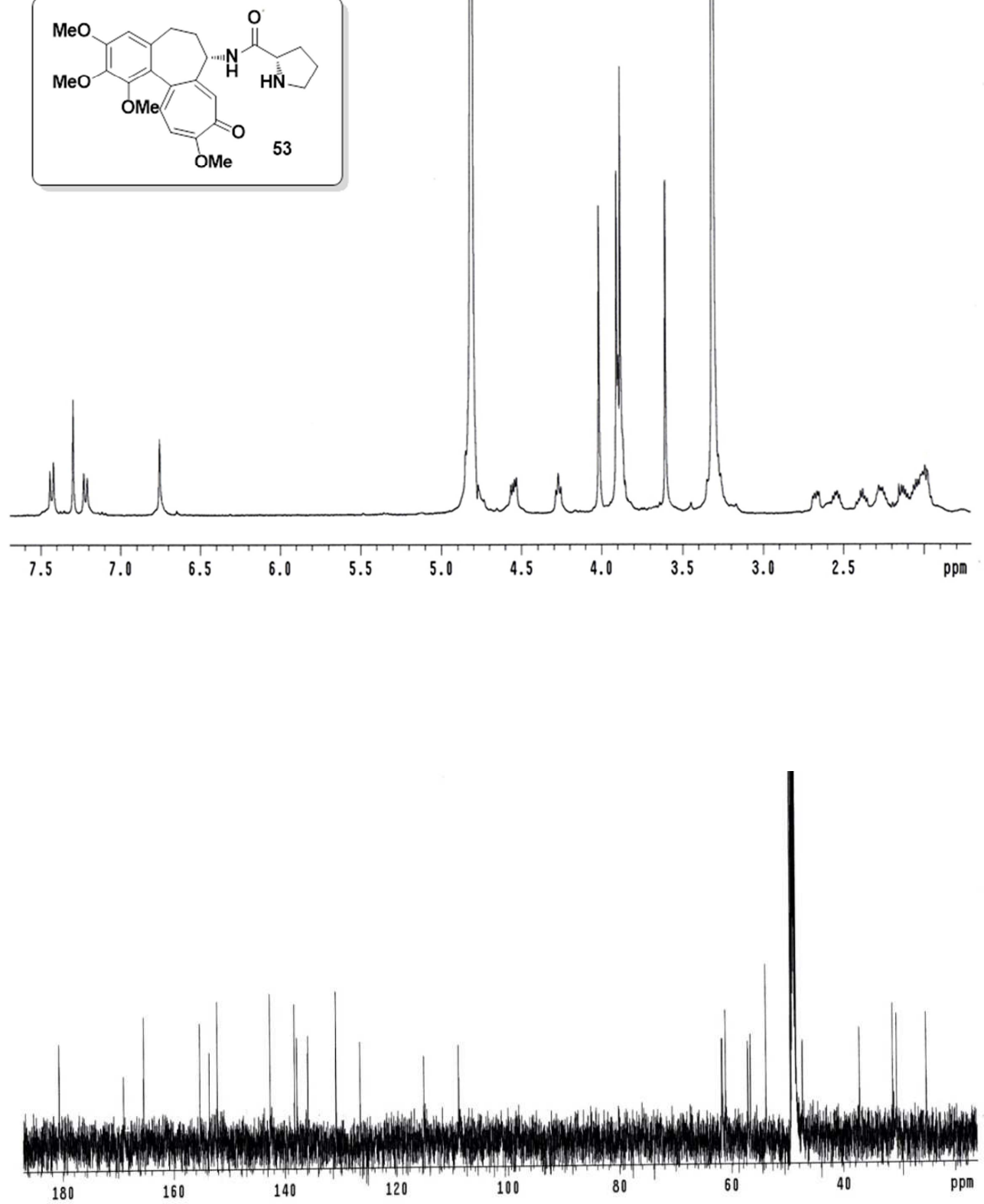

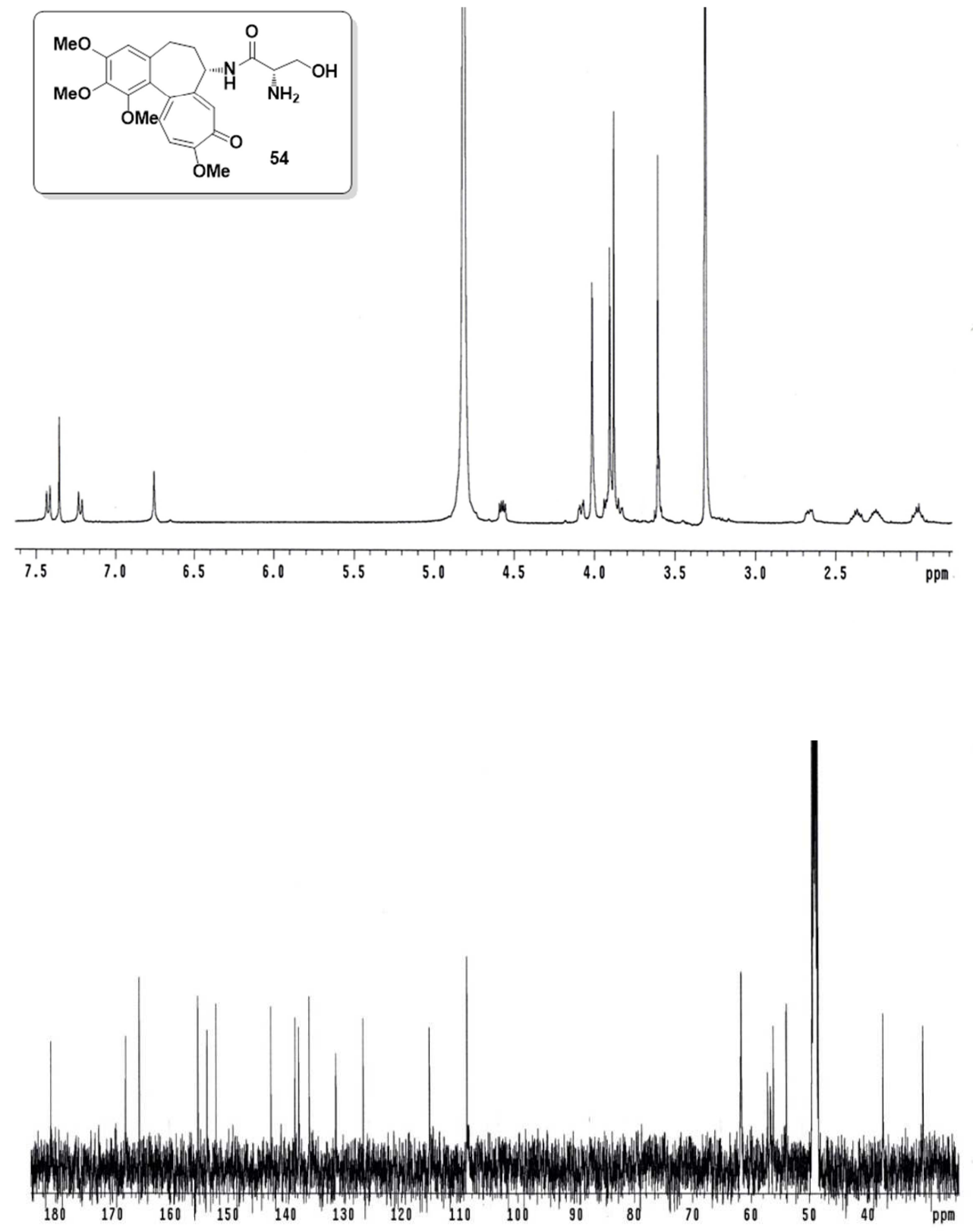

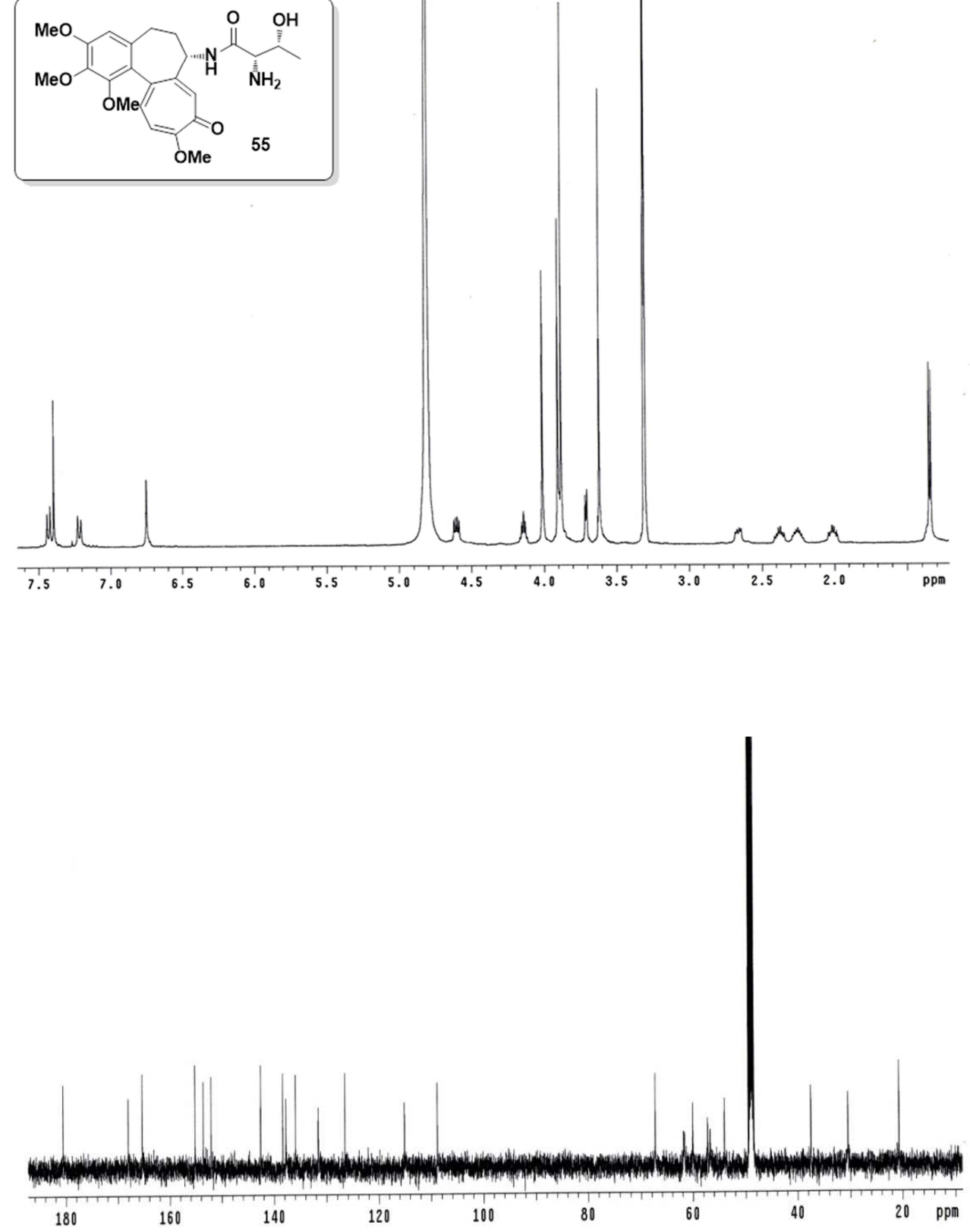

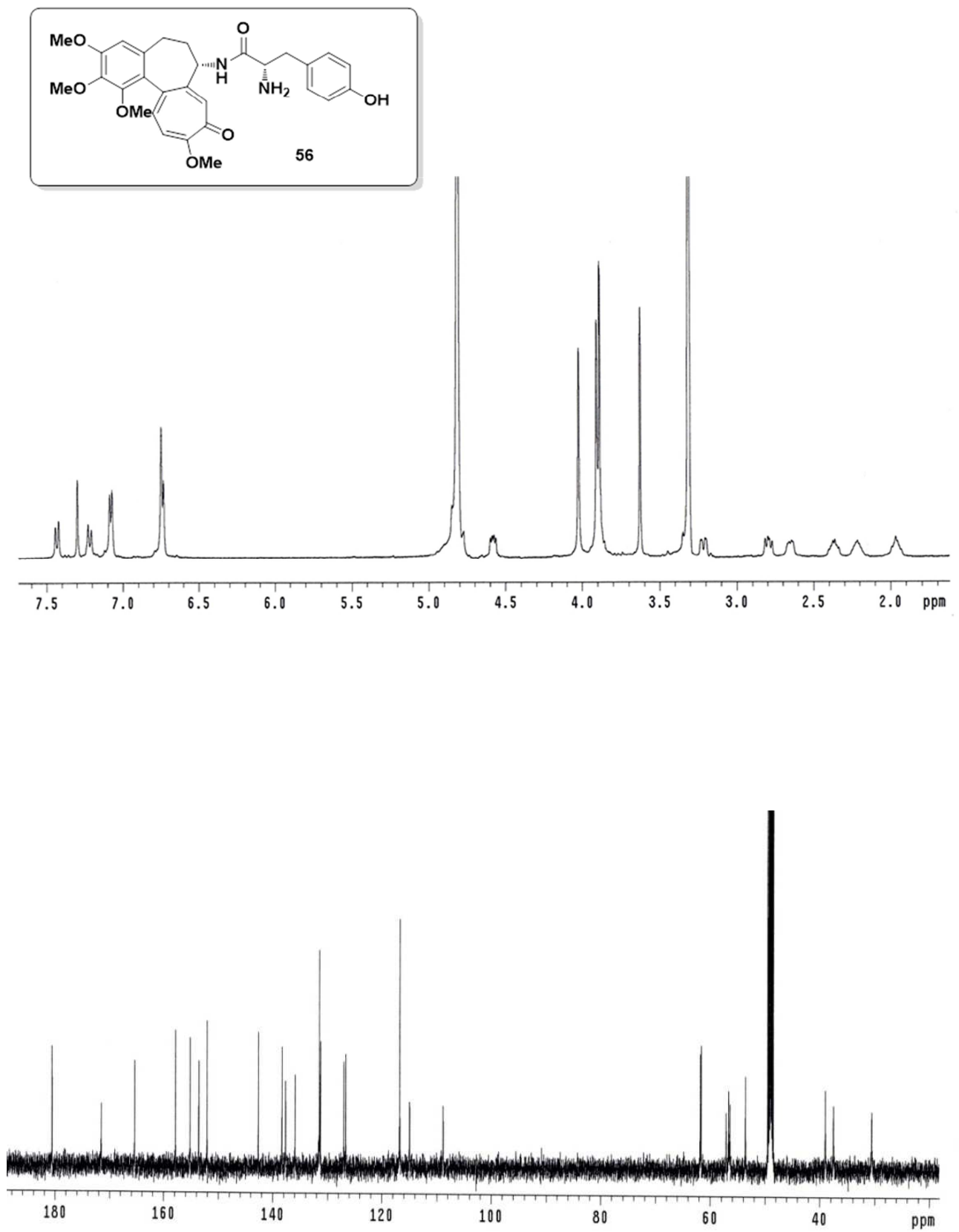

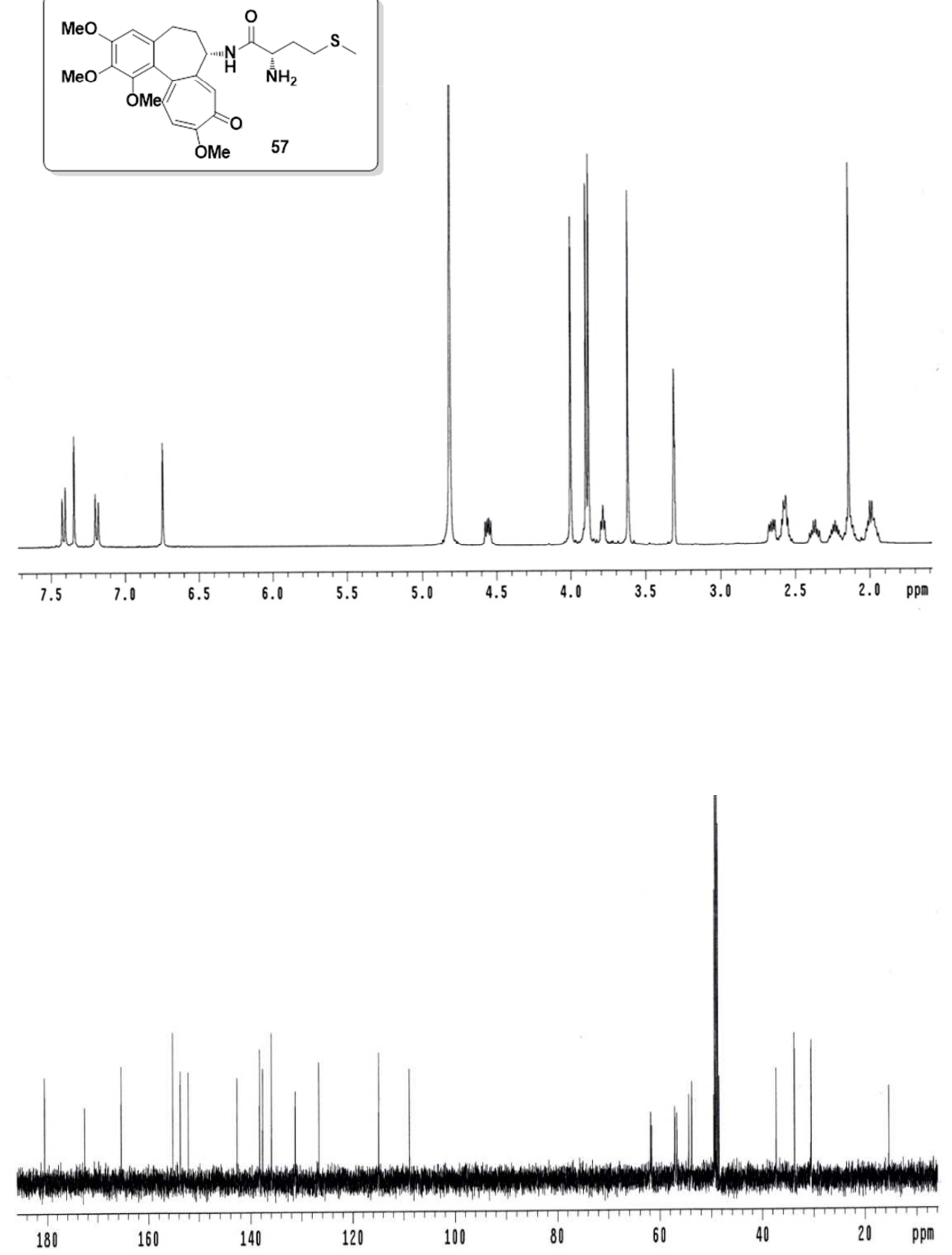

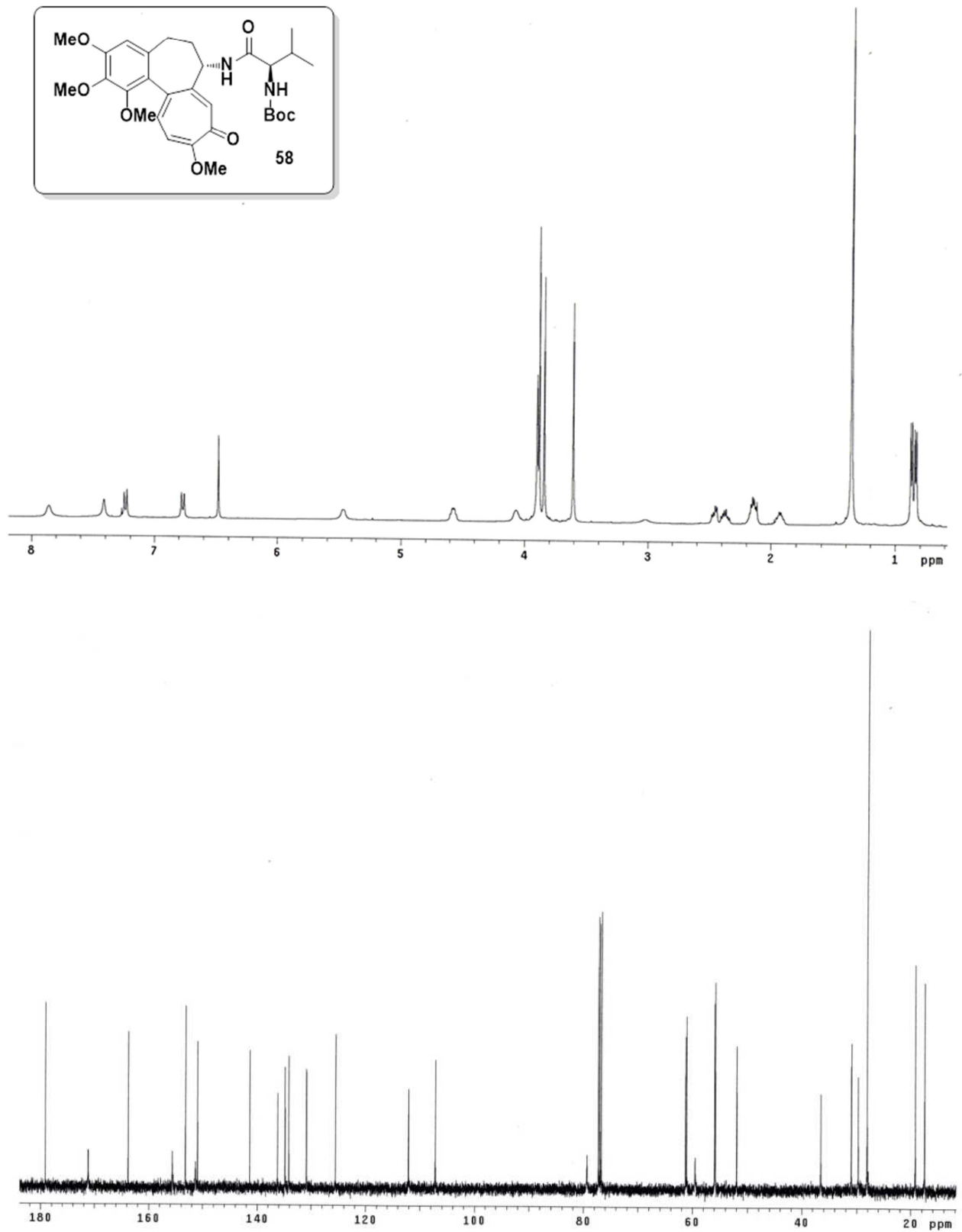

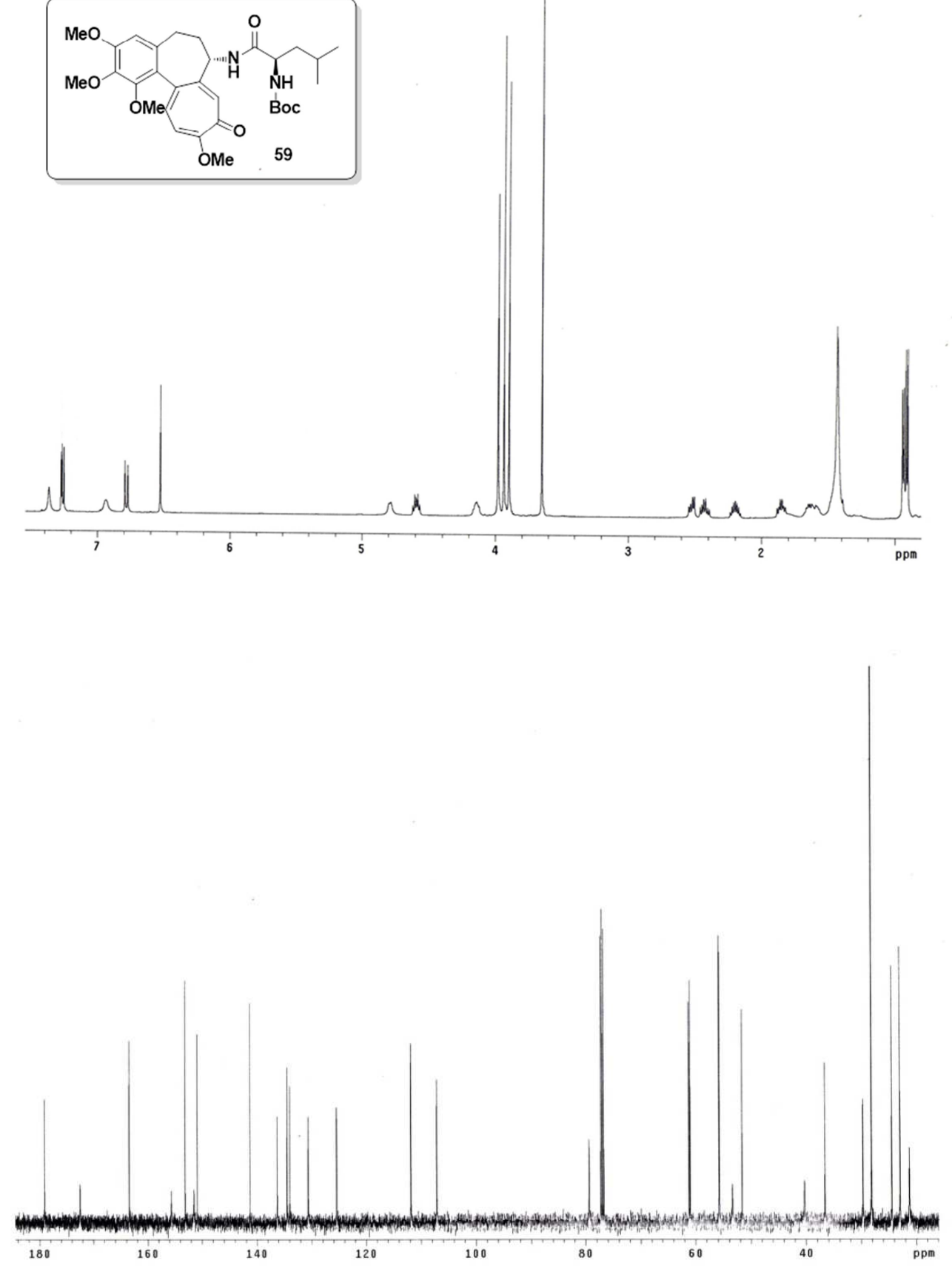


$$
\text { (n) }
$$
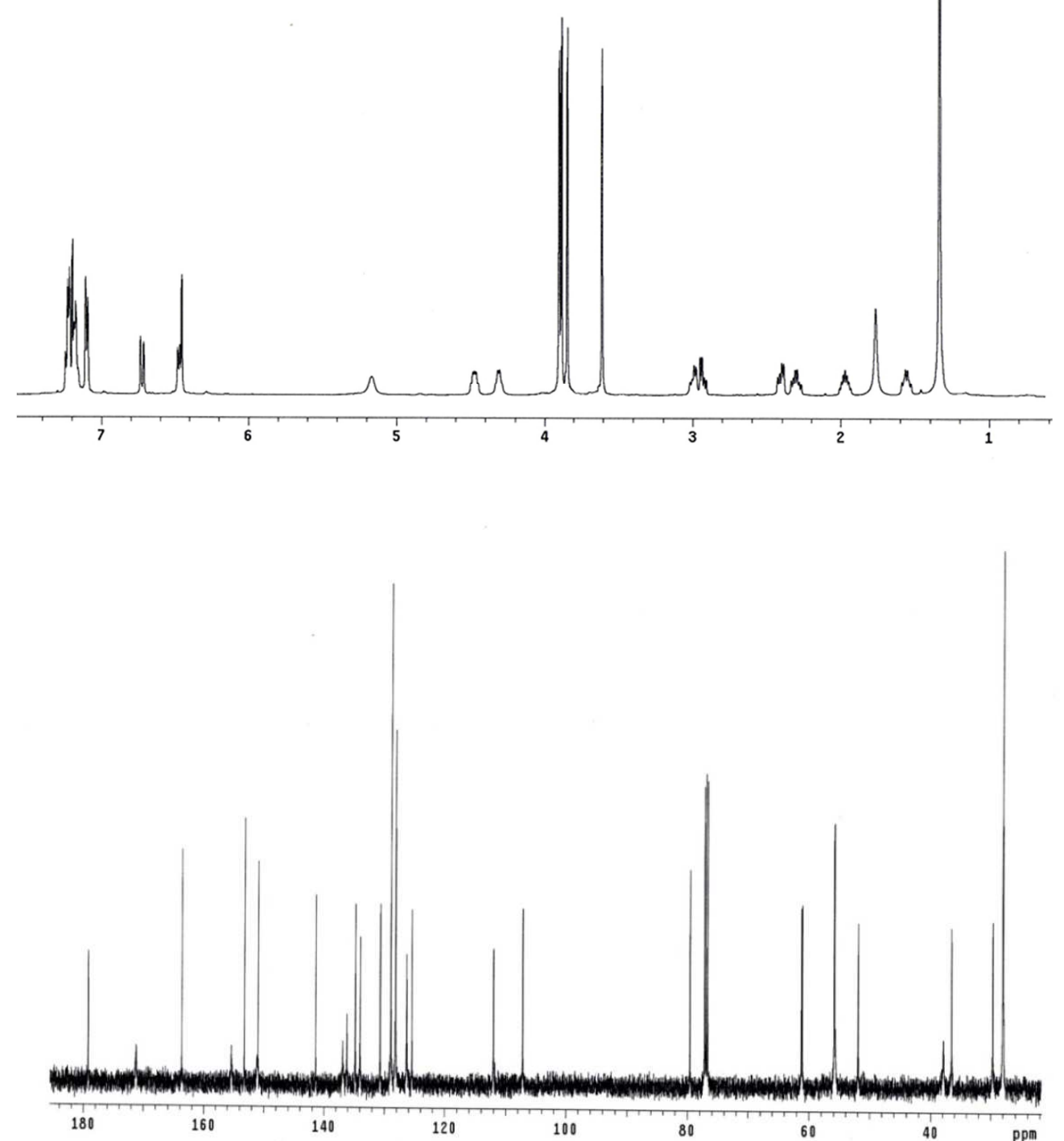

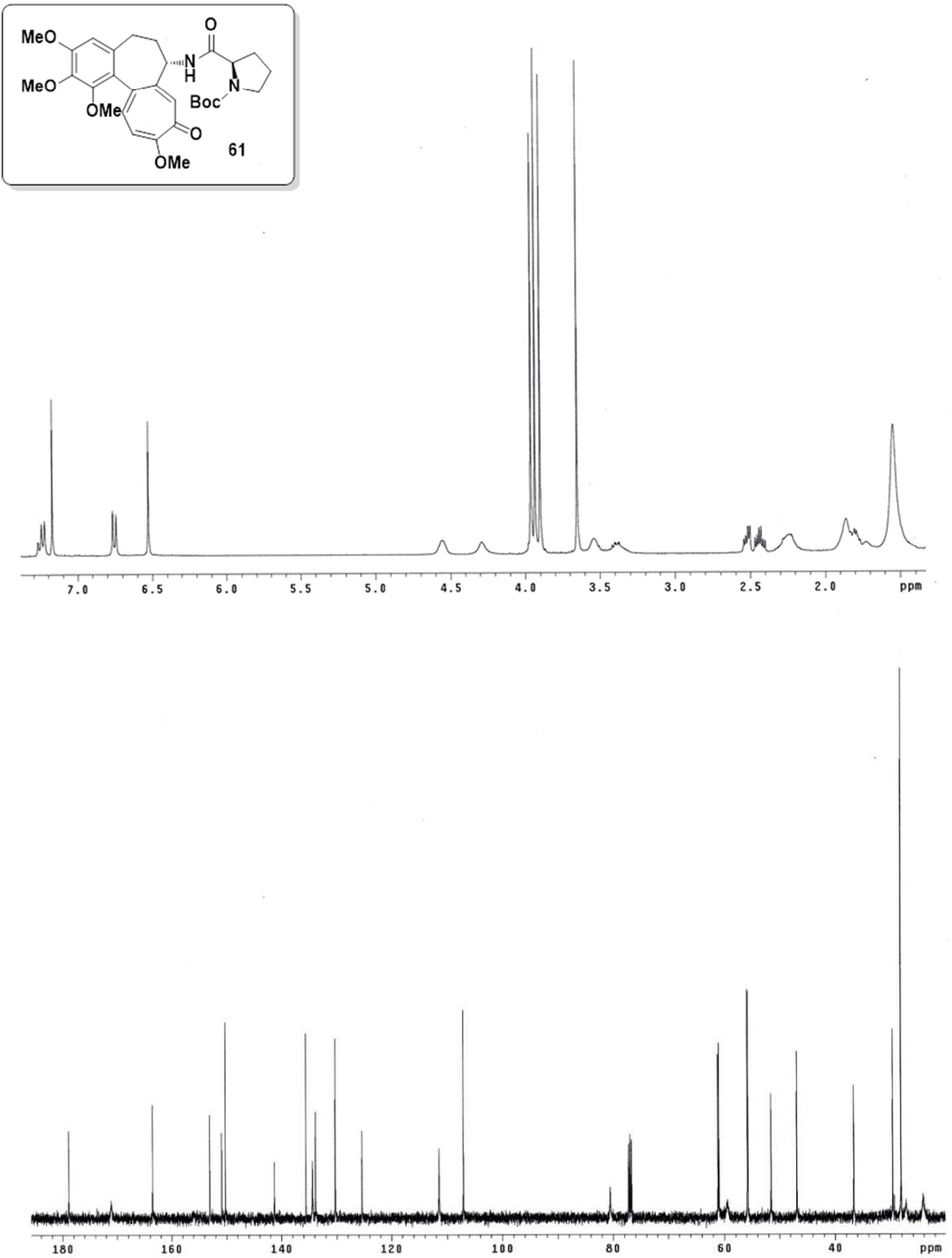

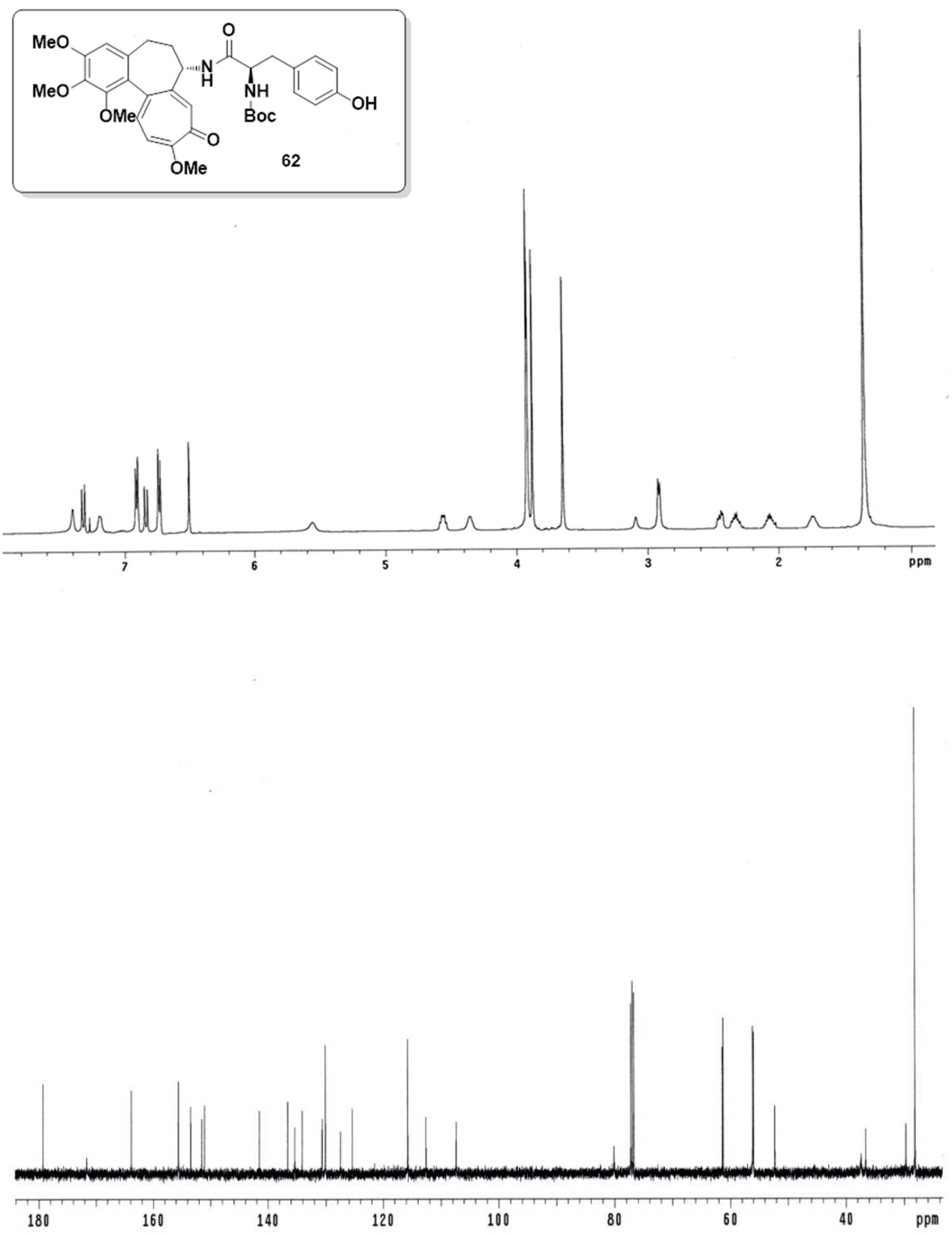

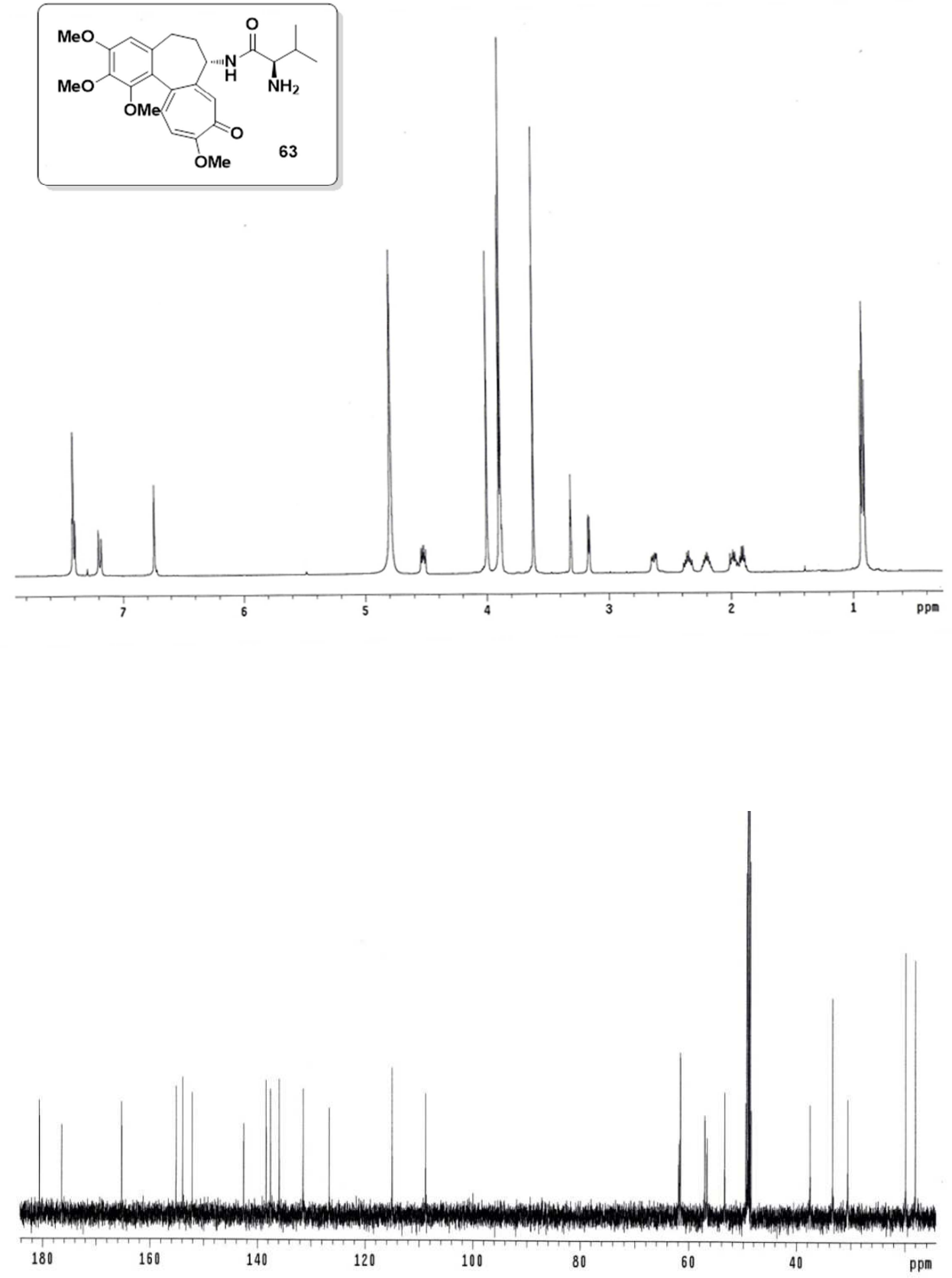

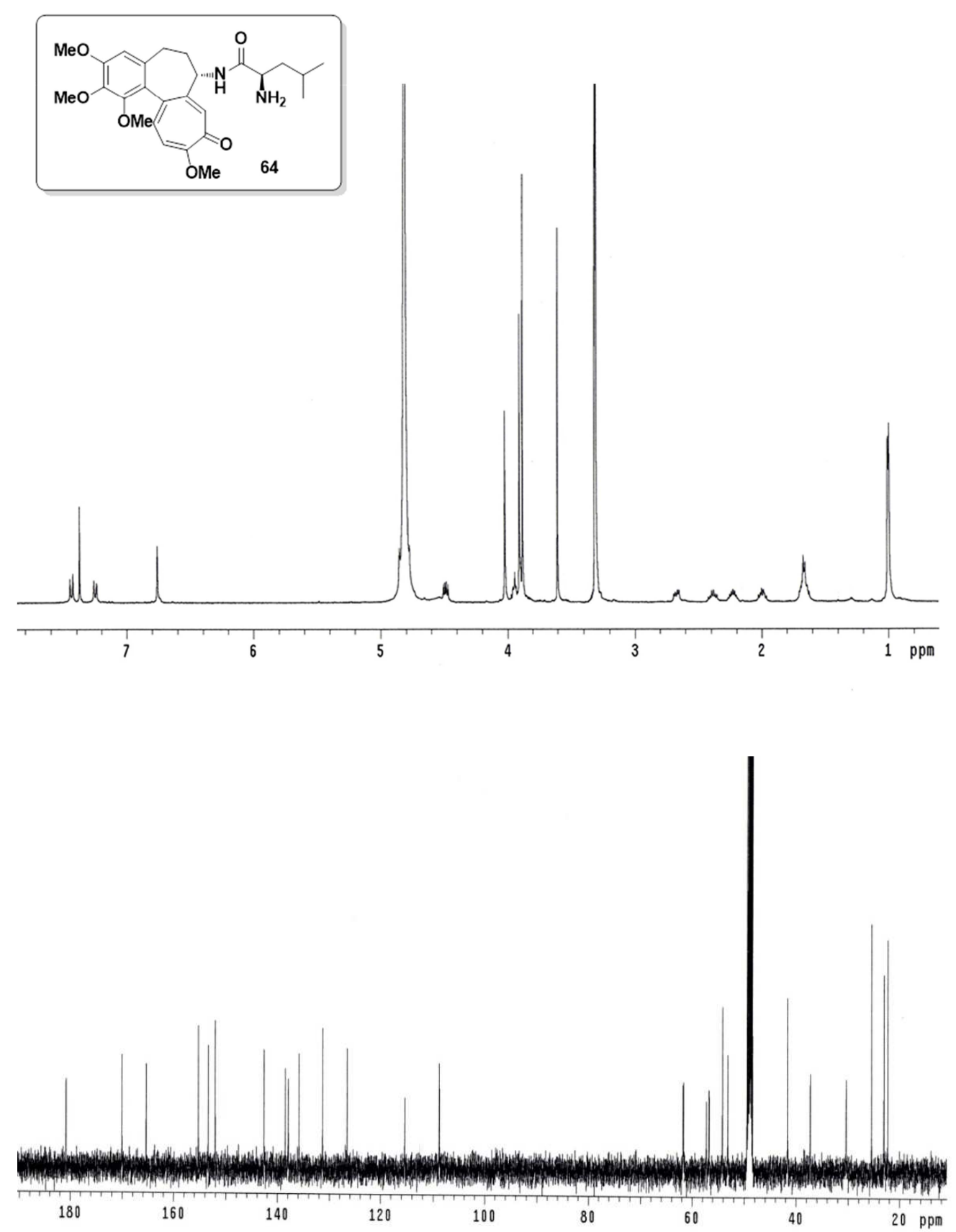

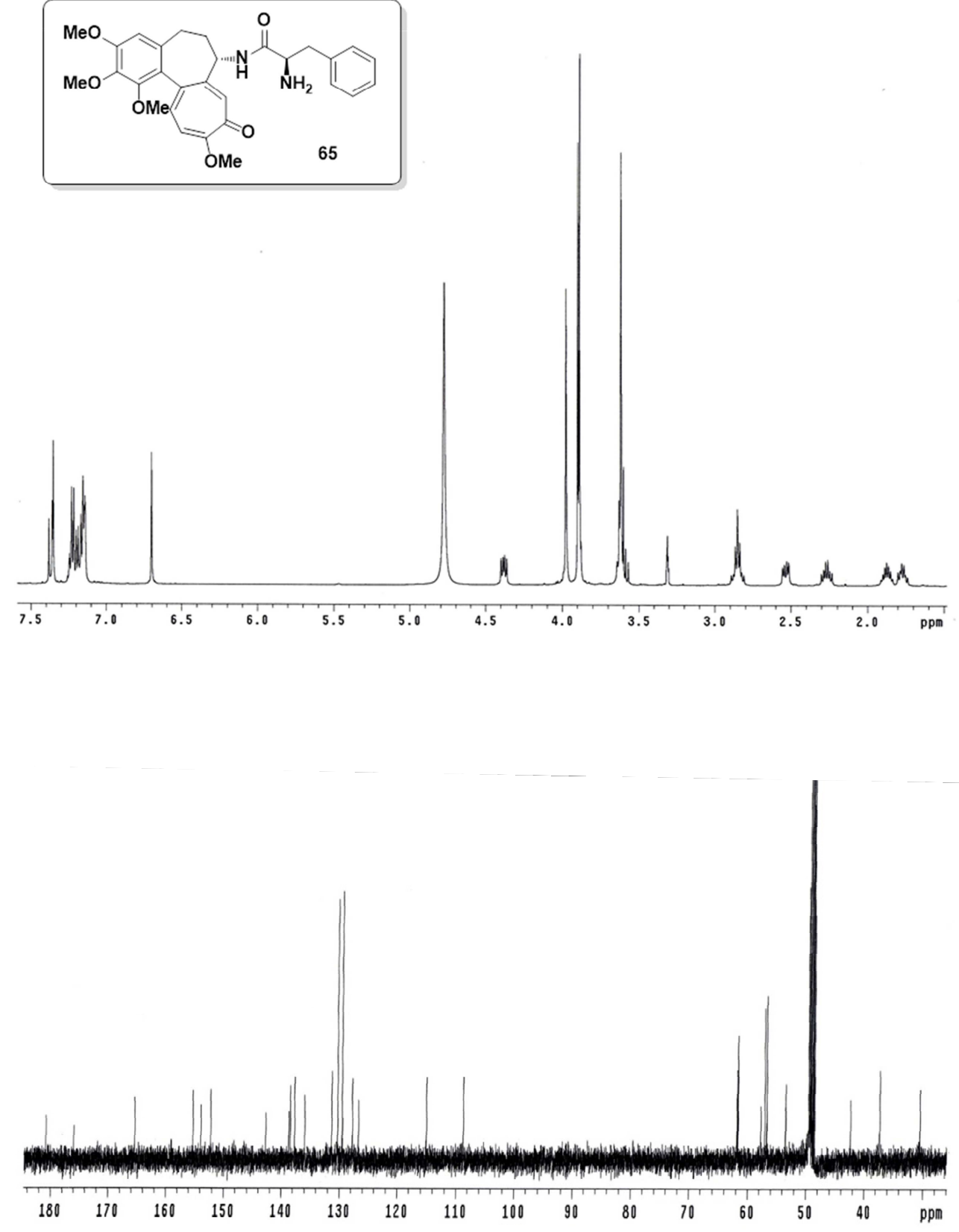

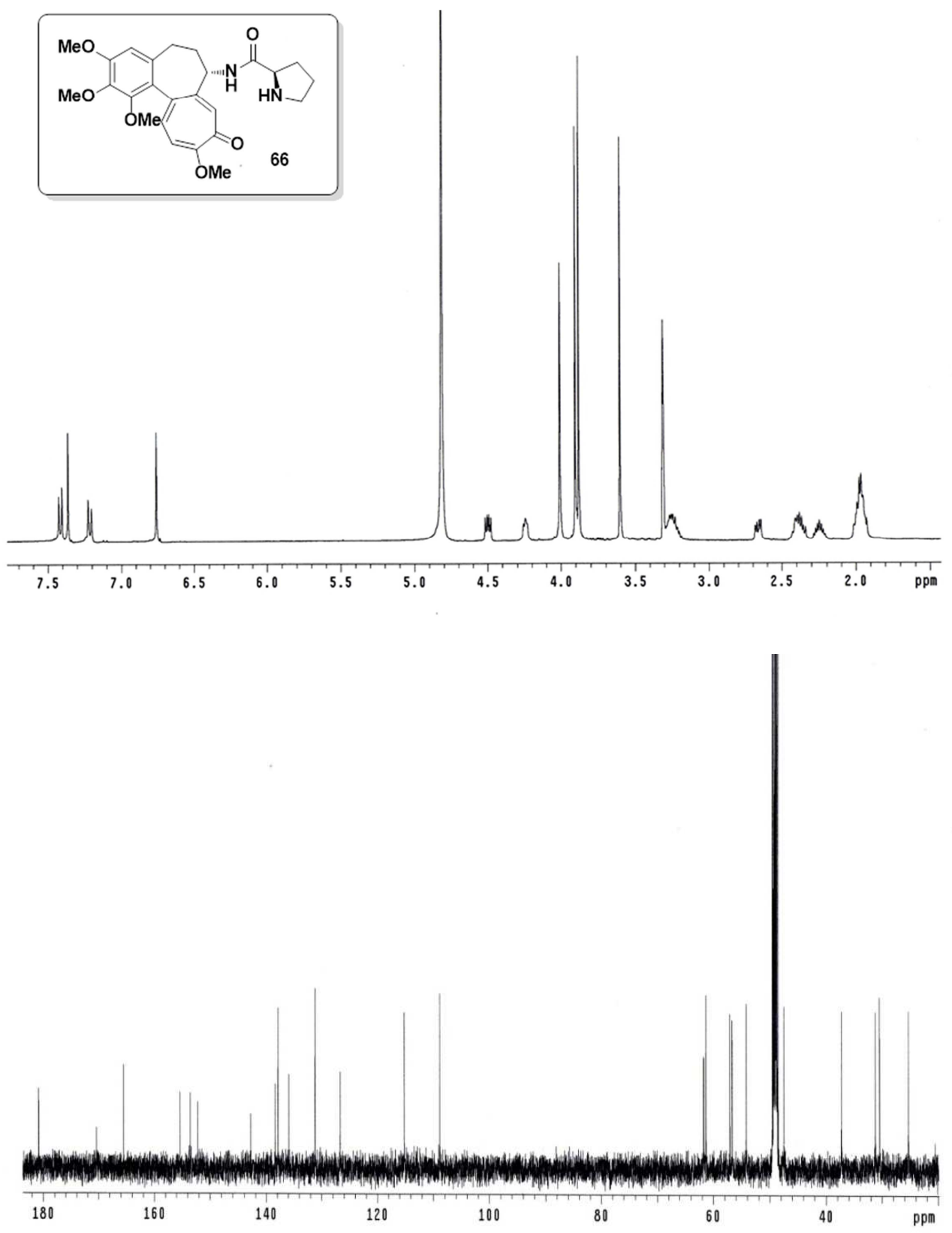

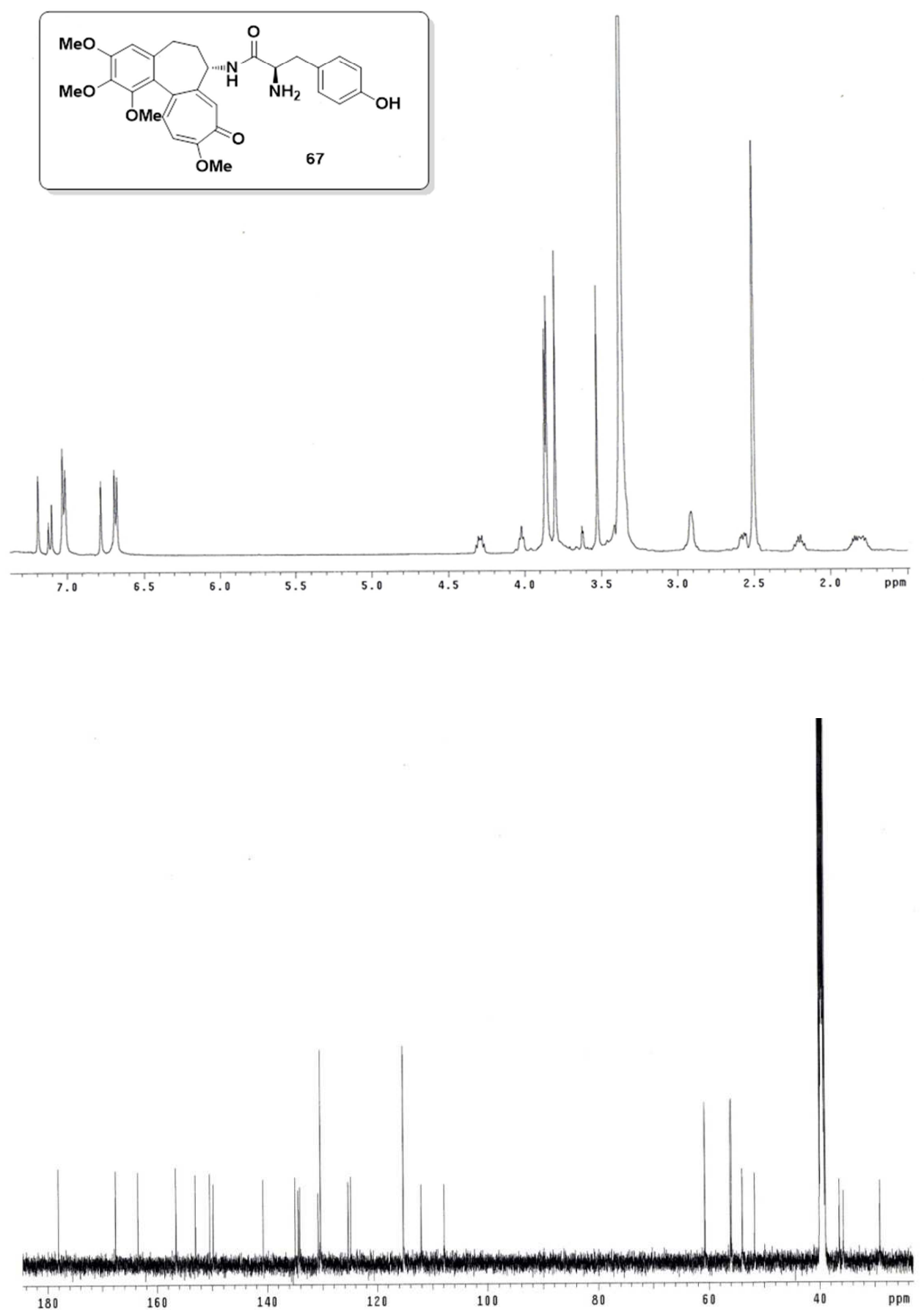


$$
\text { OMe }
$$
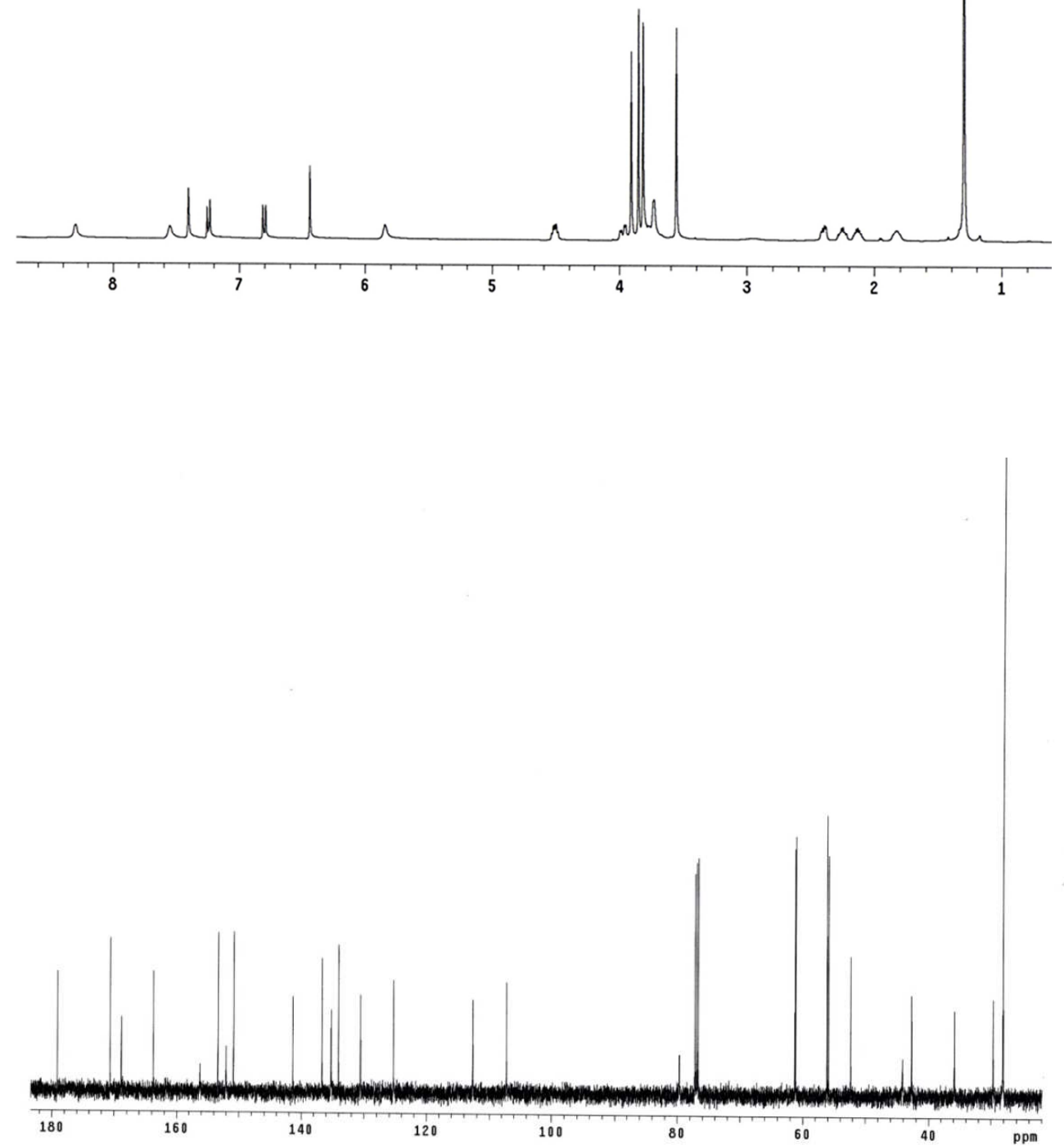

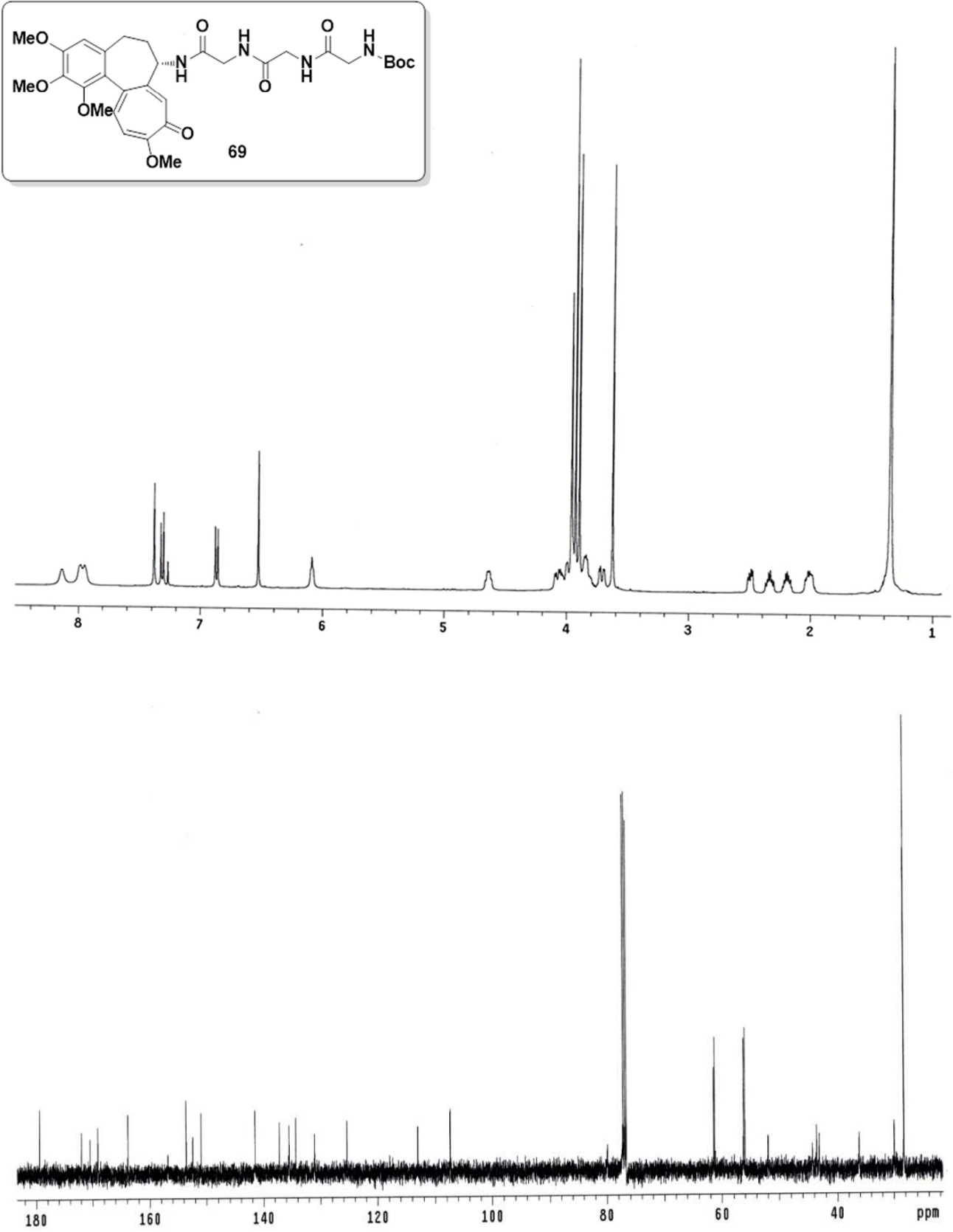

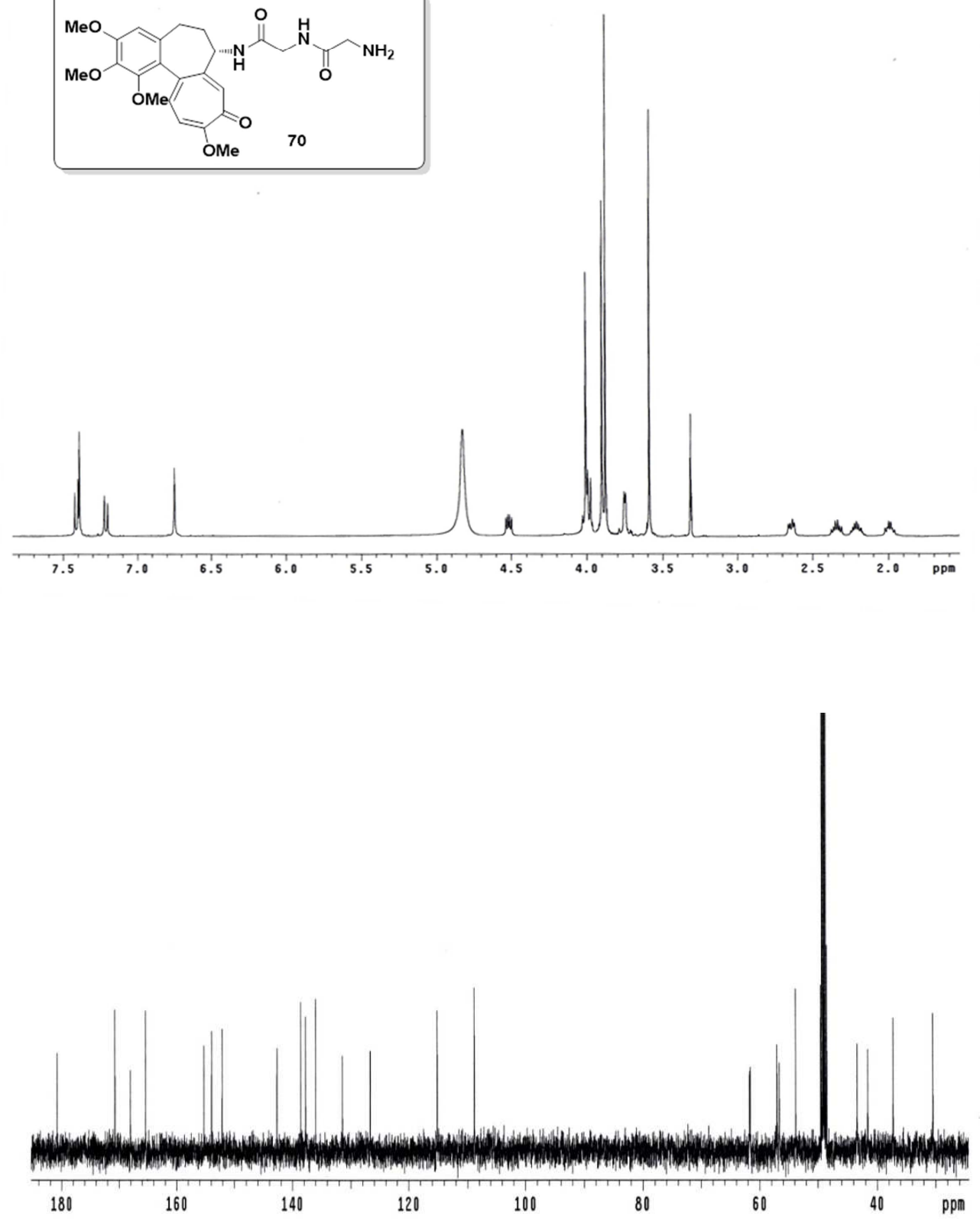

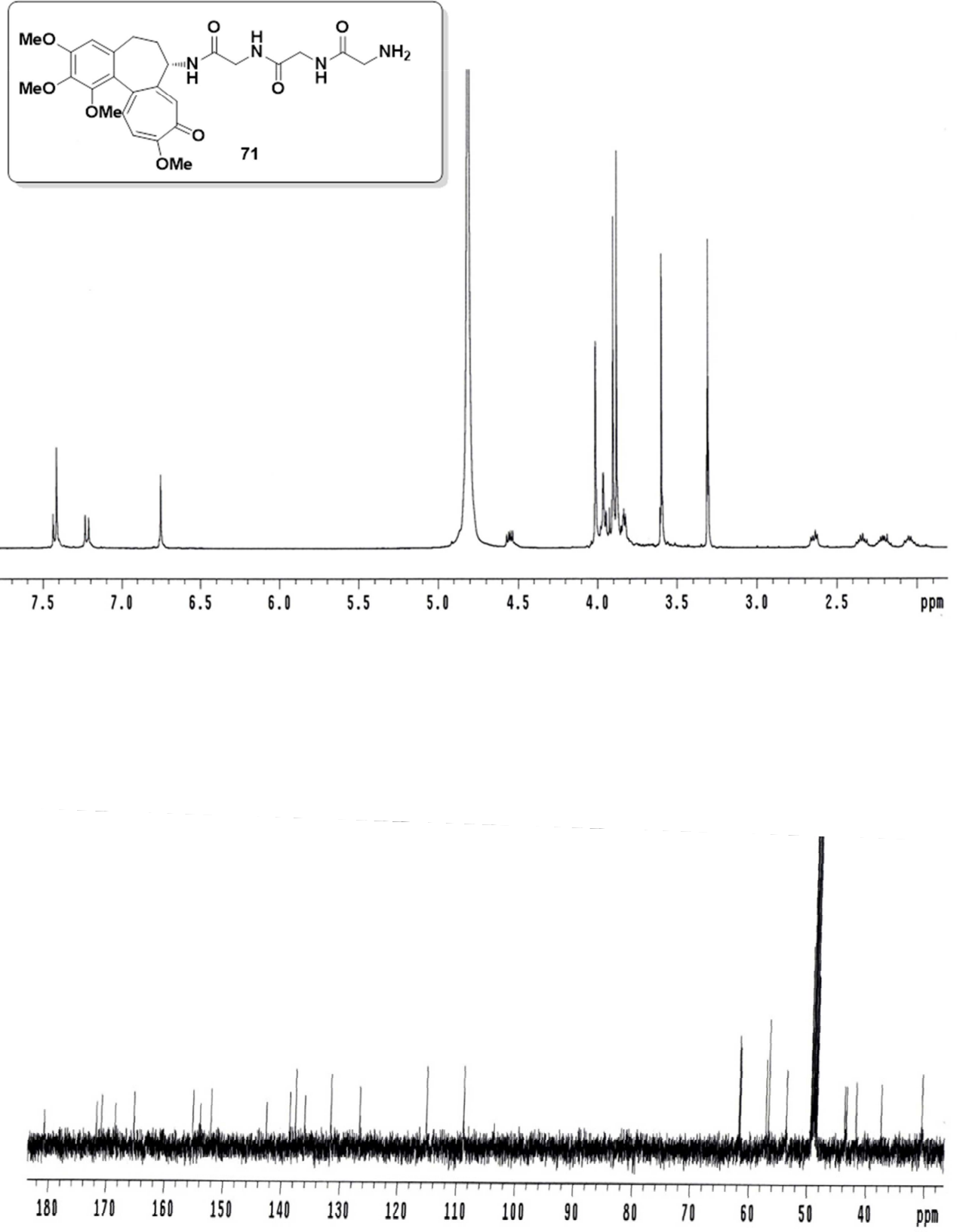

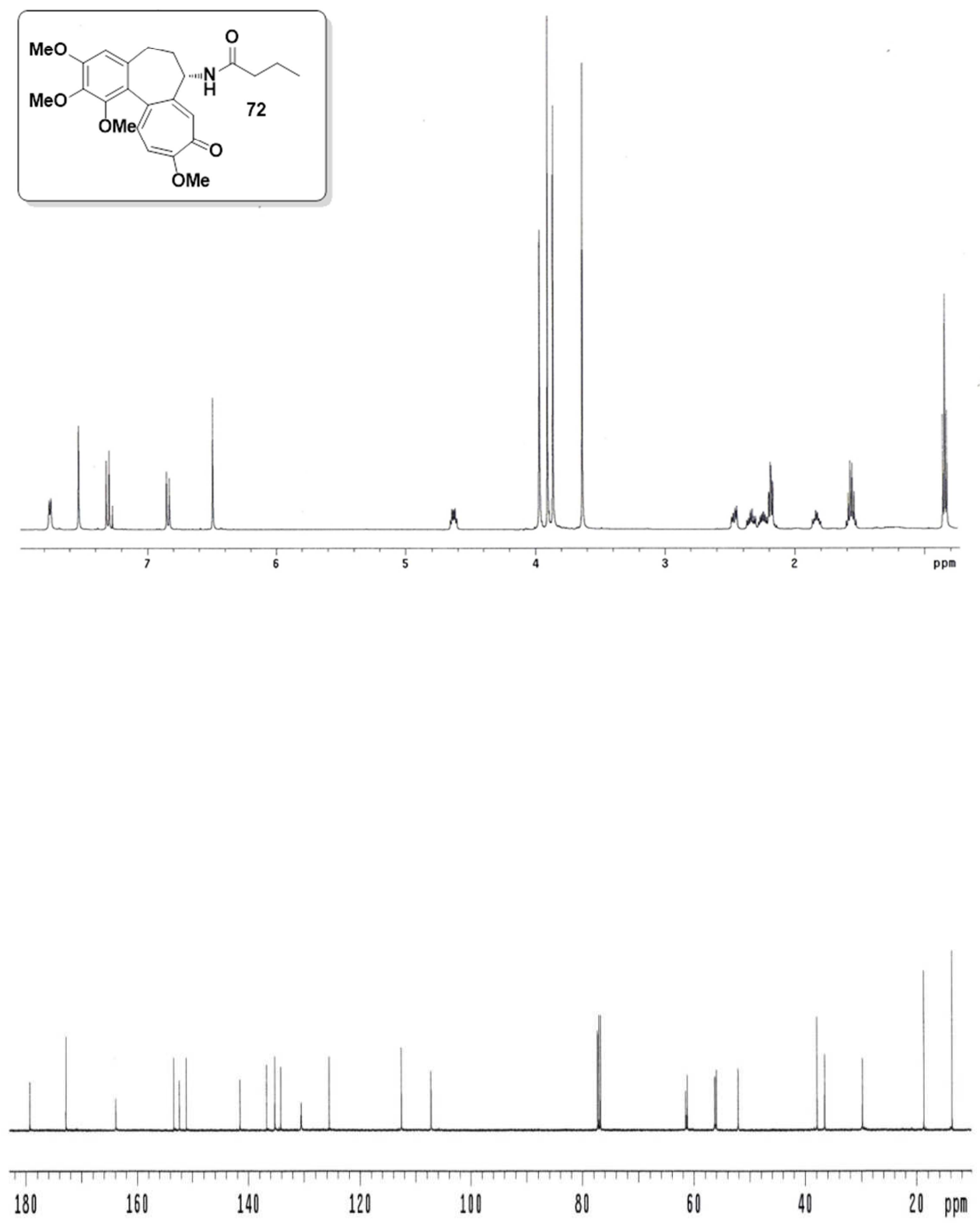

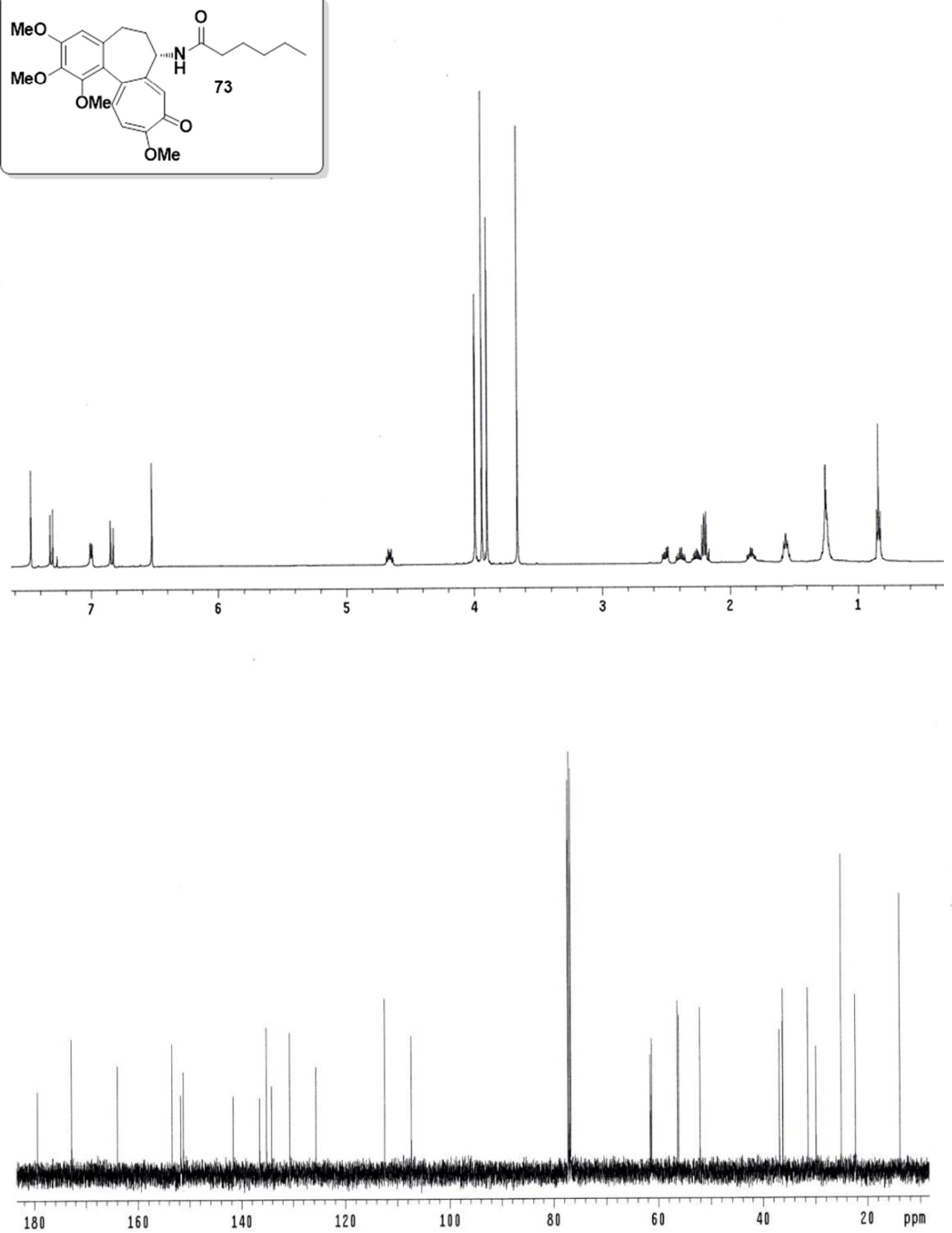

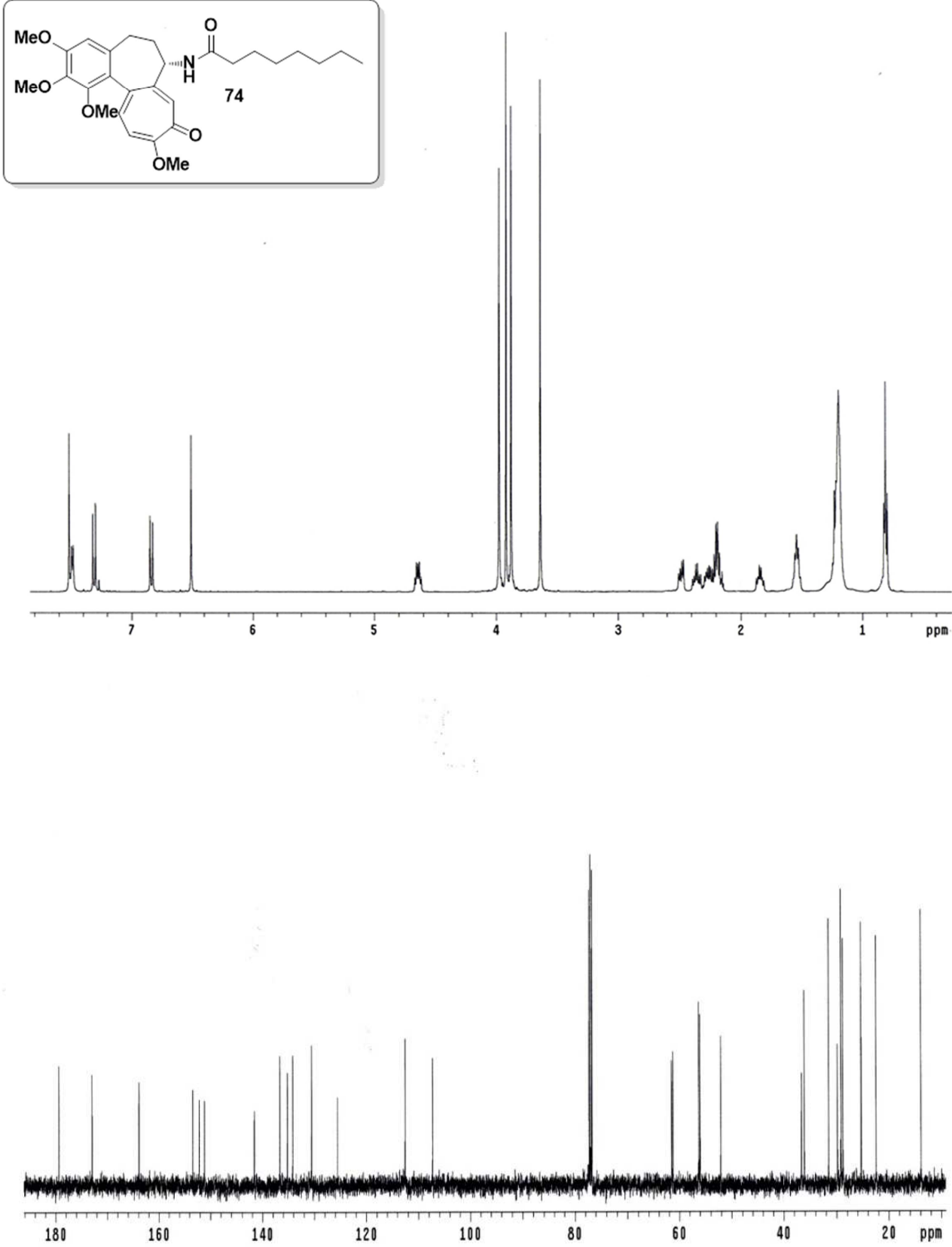

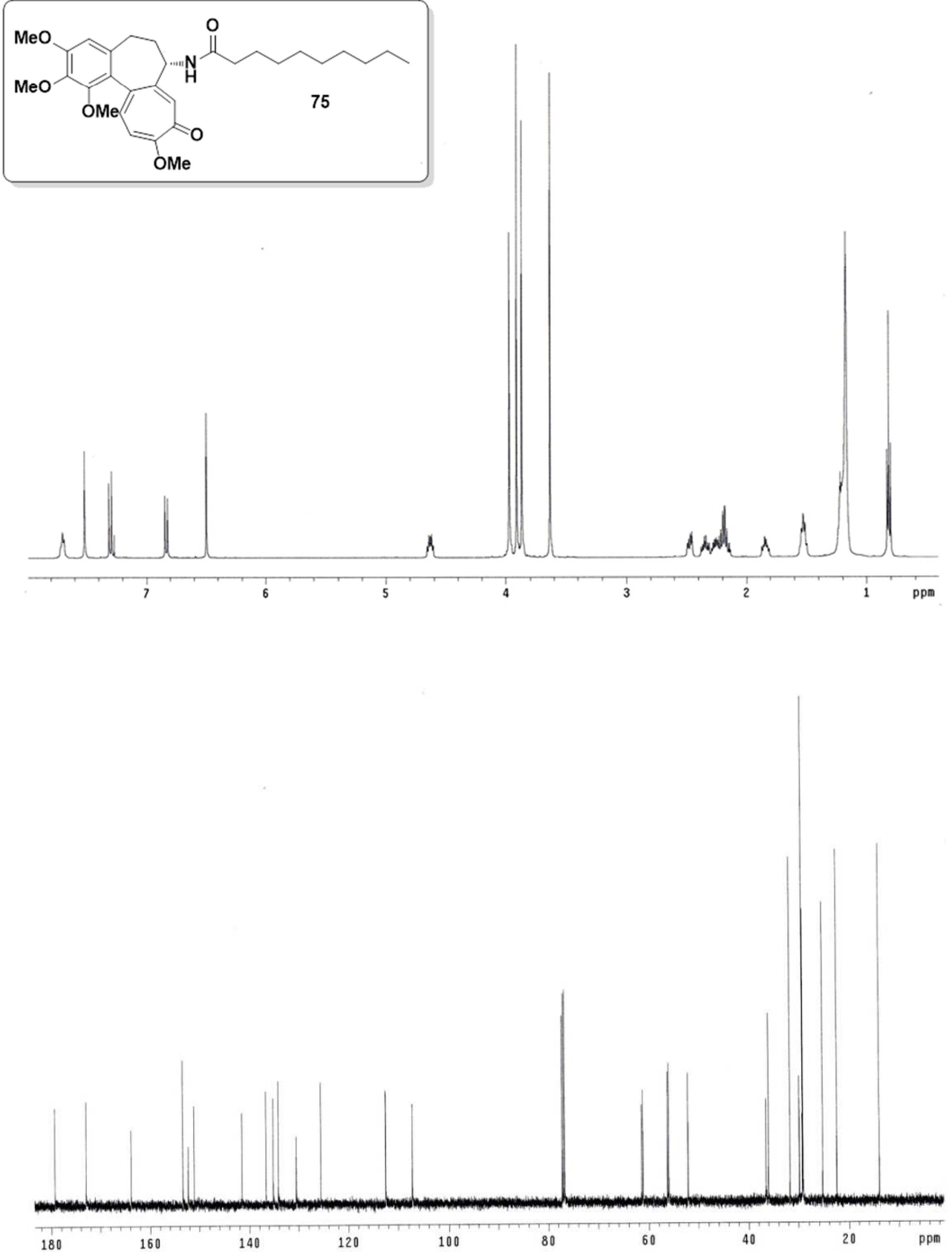

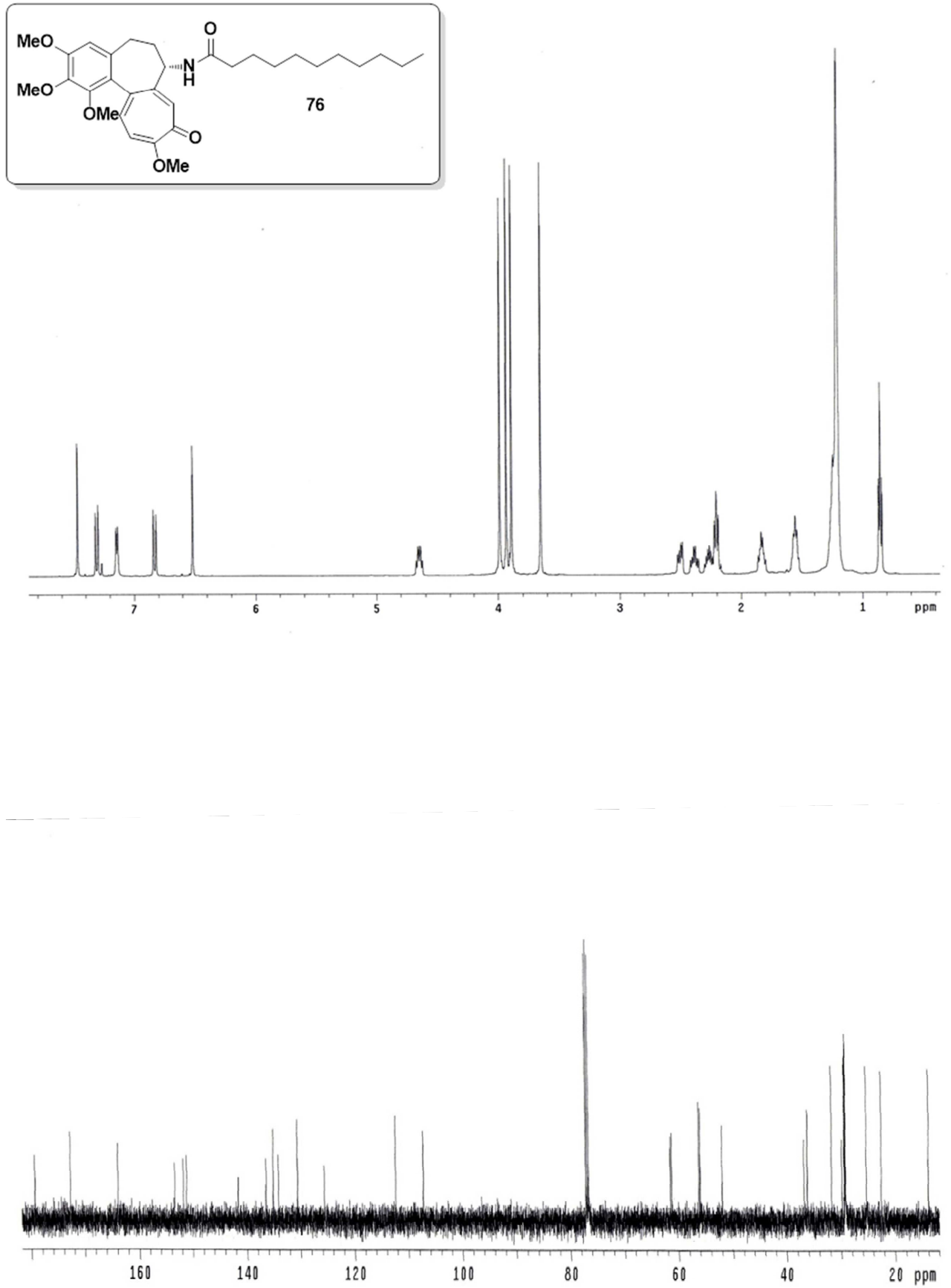

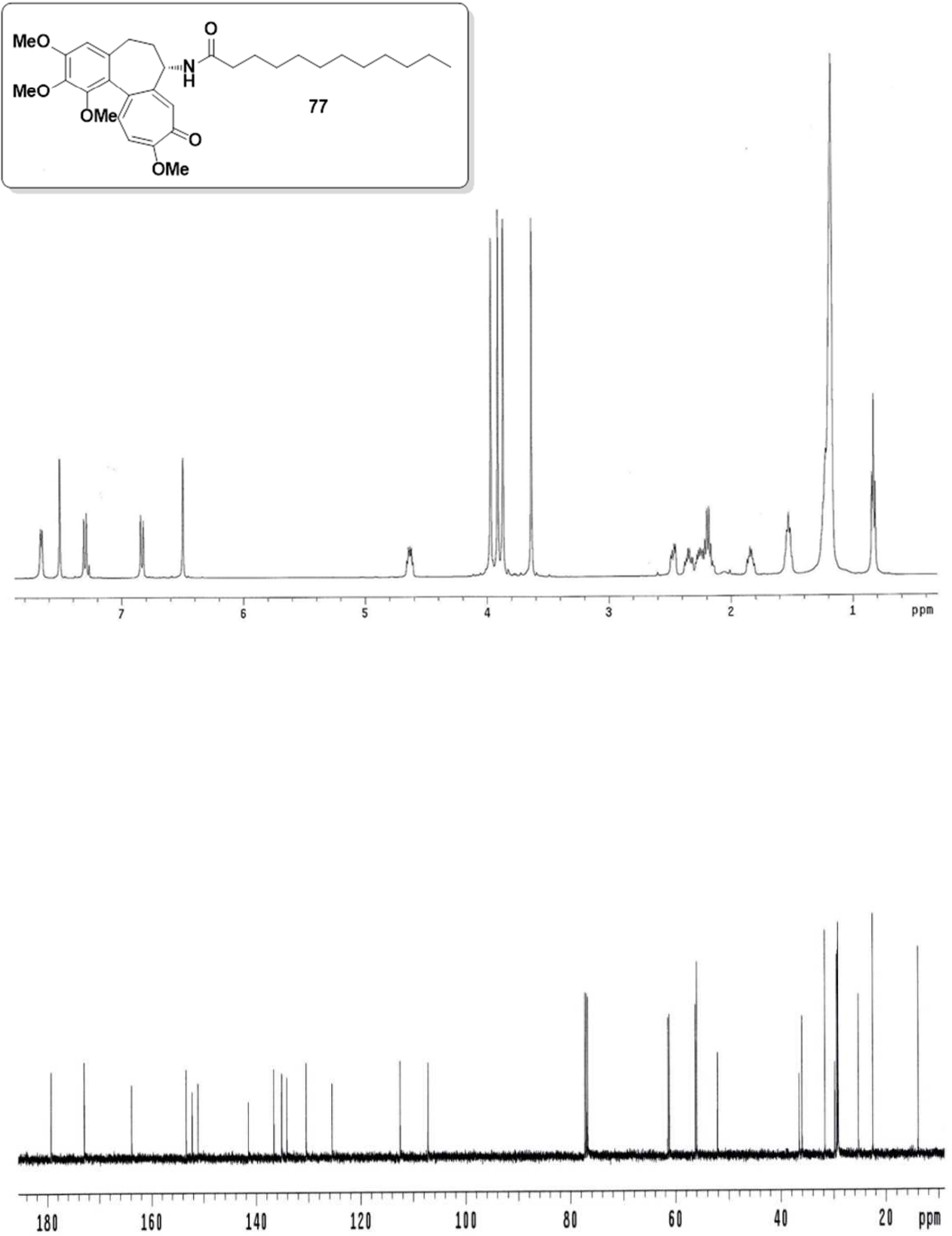

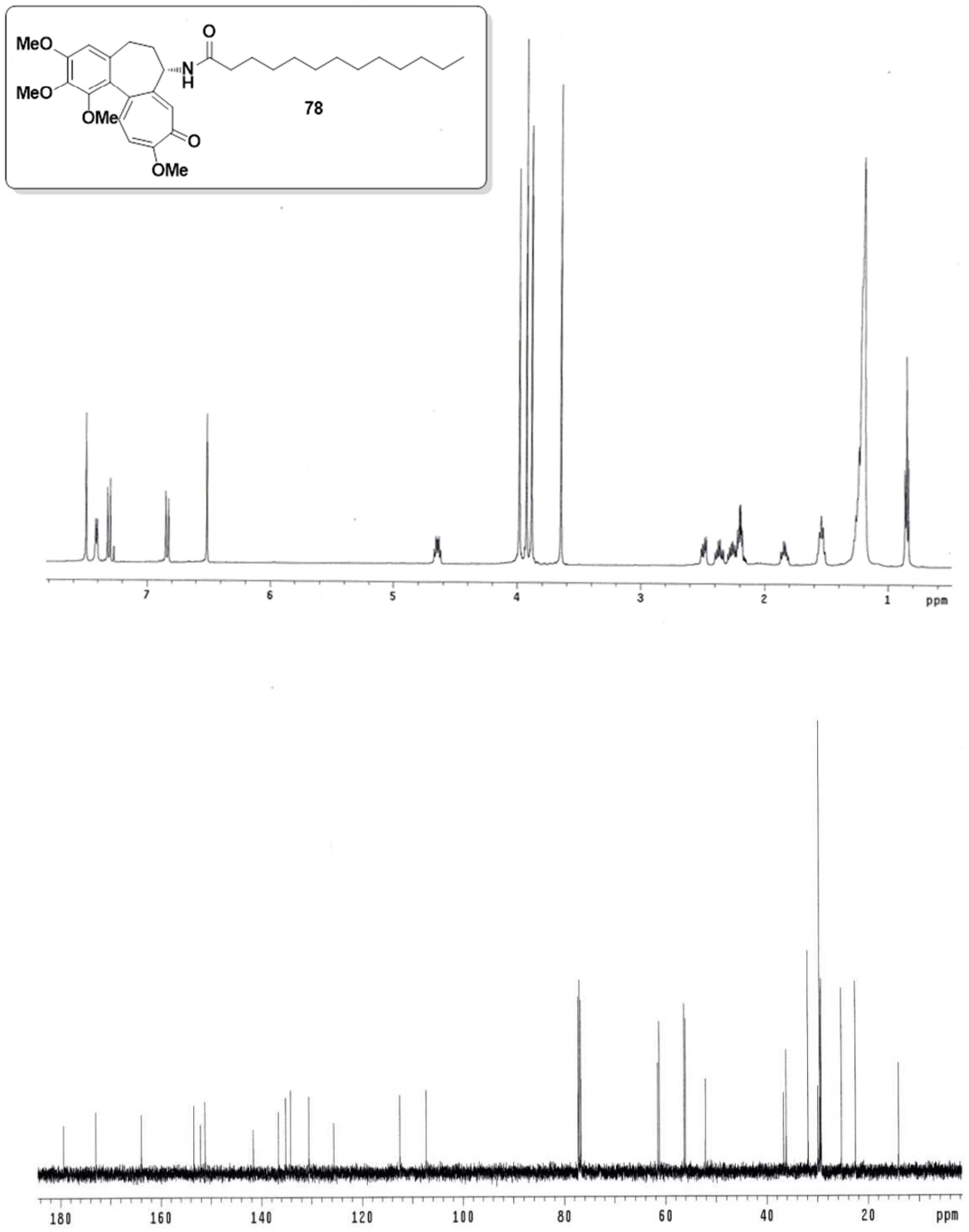

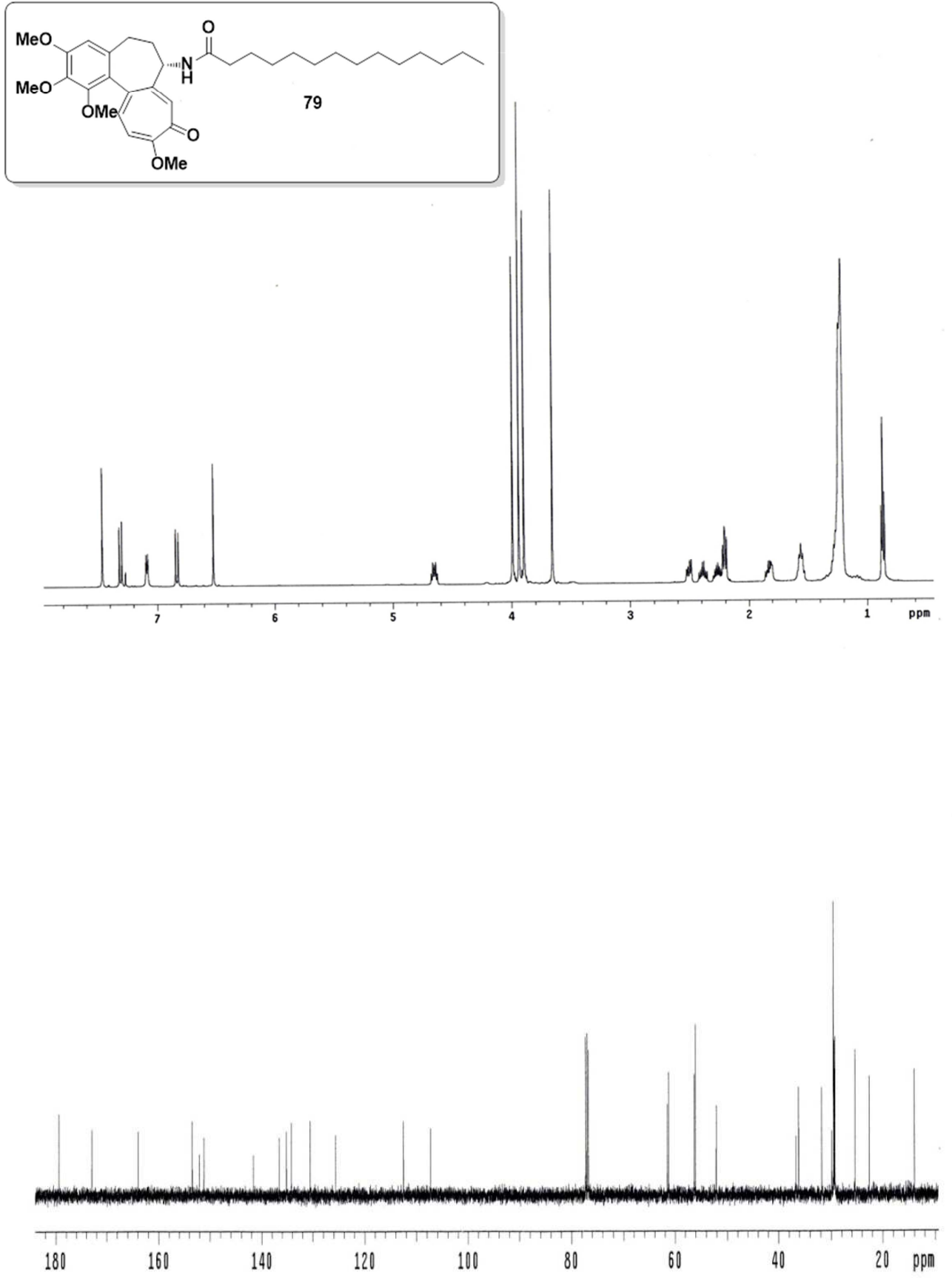

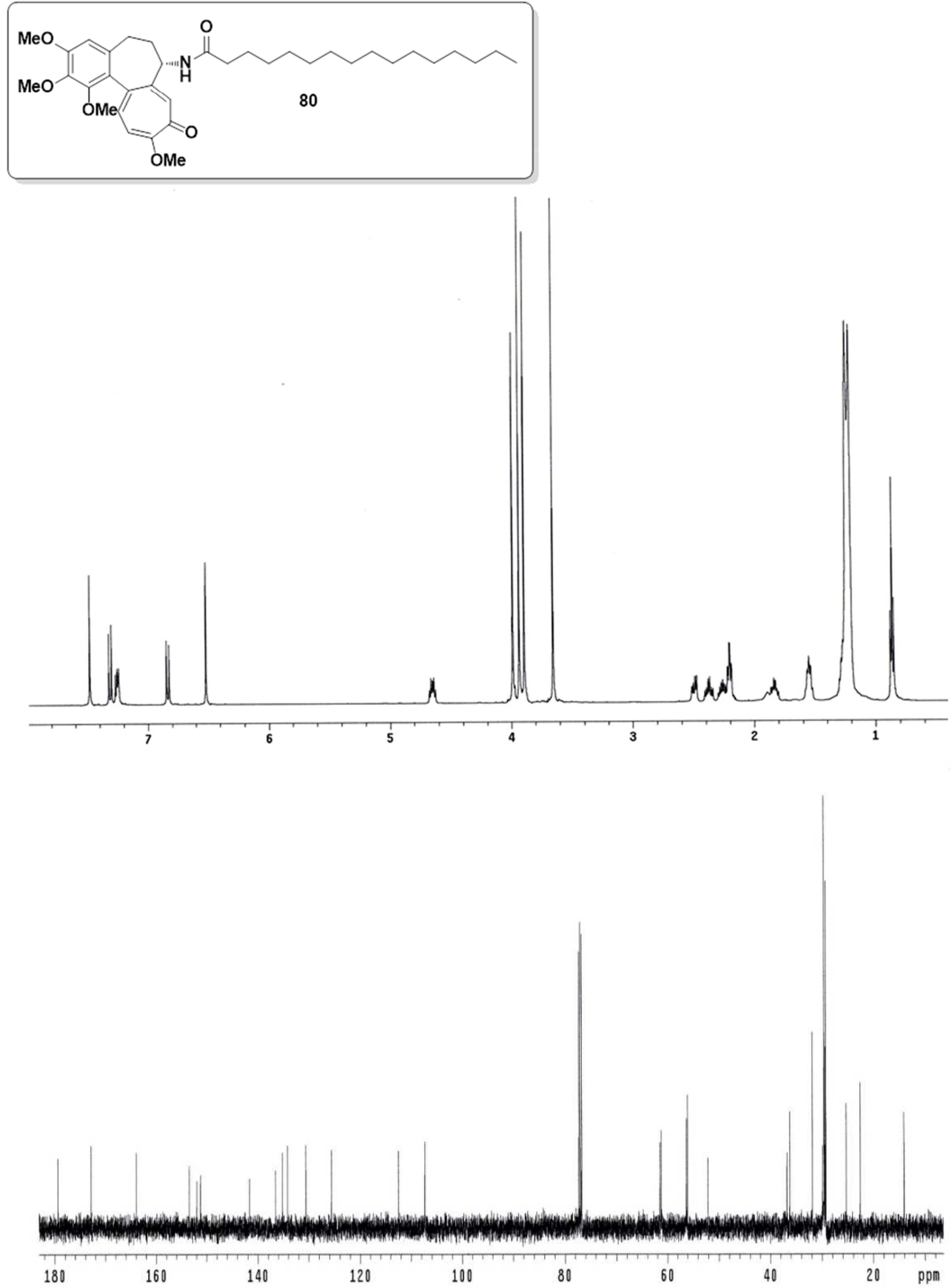

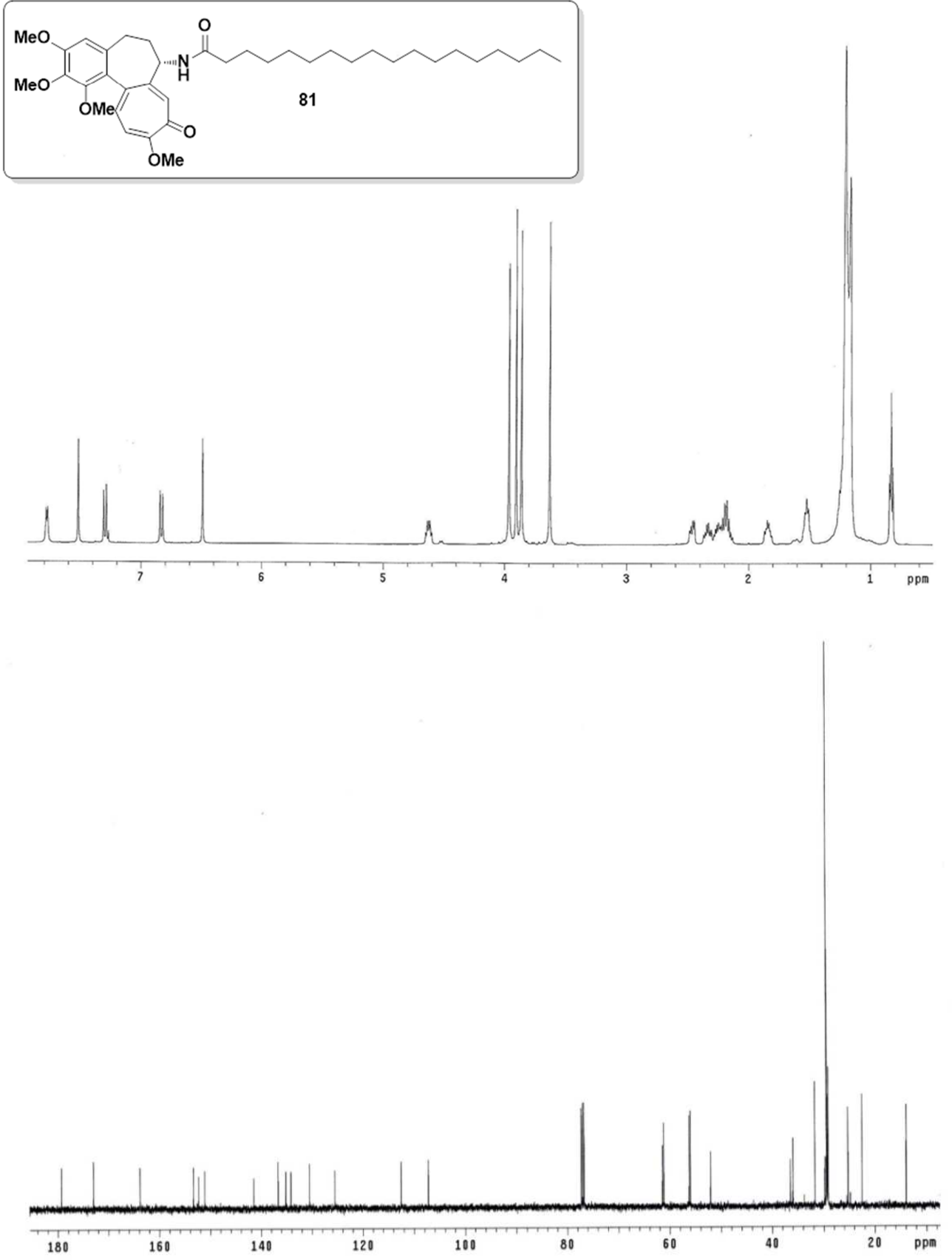

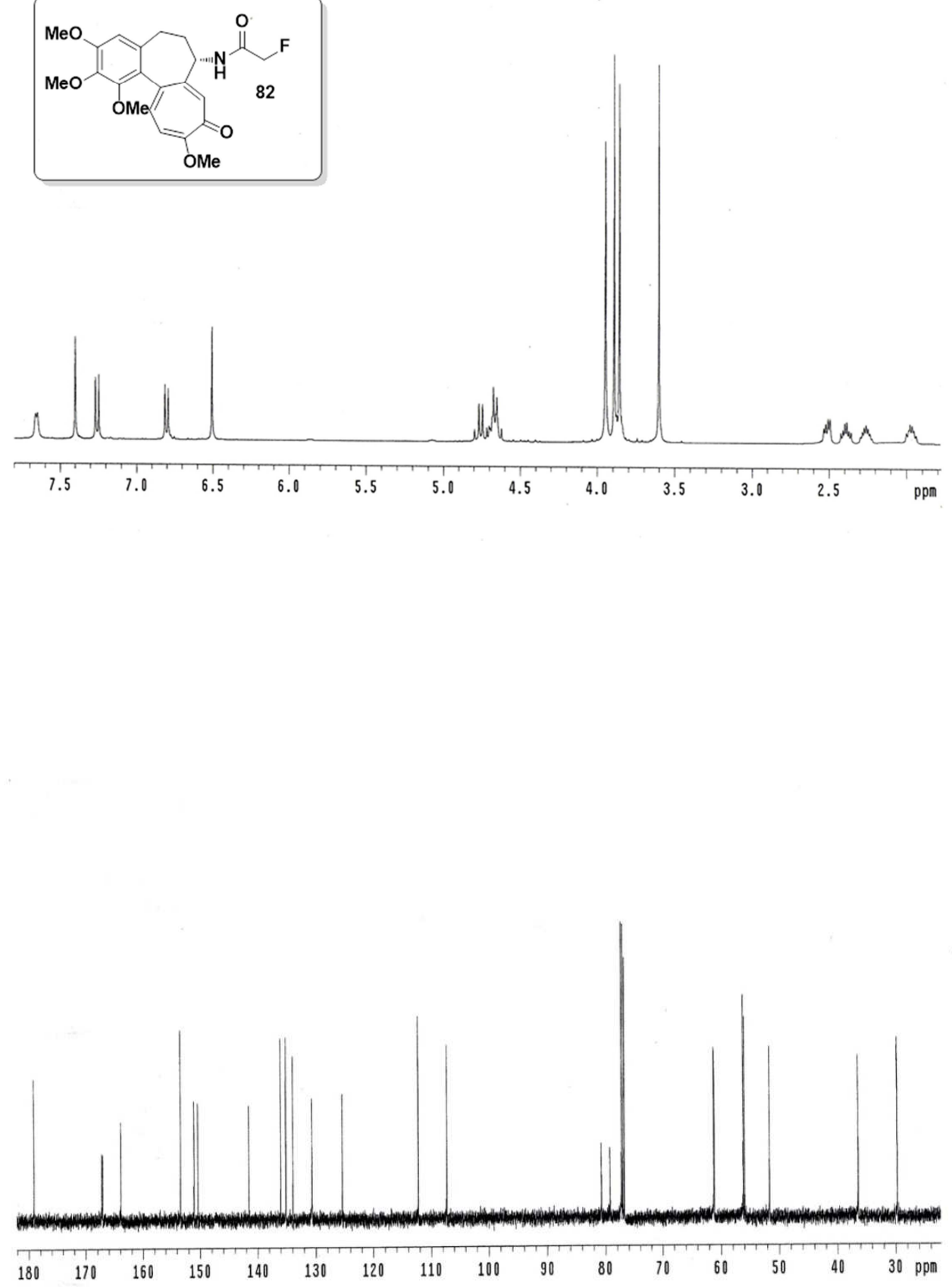

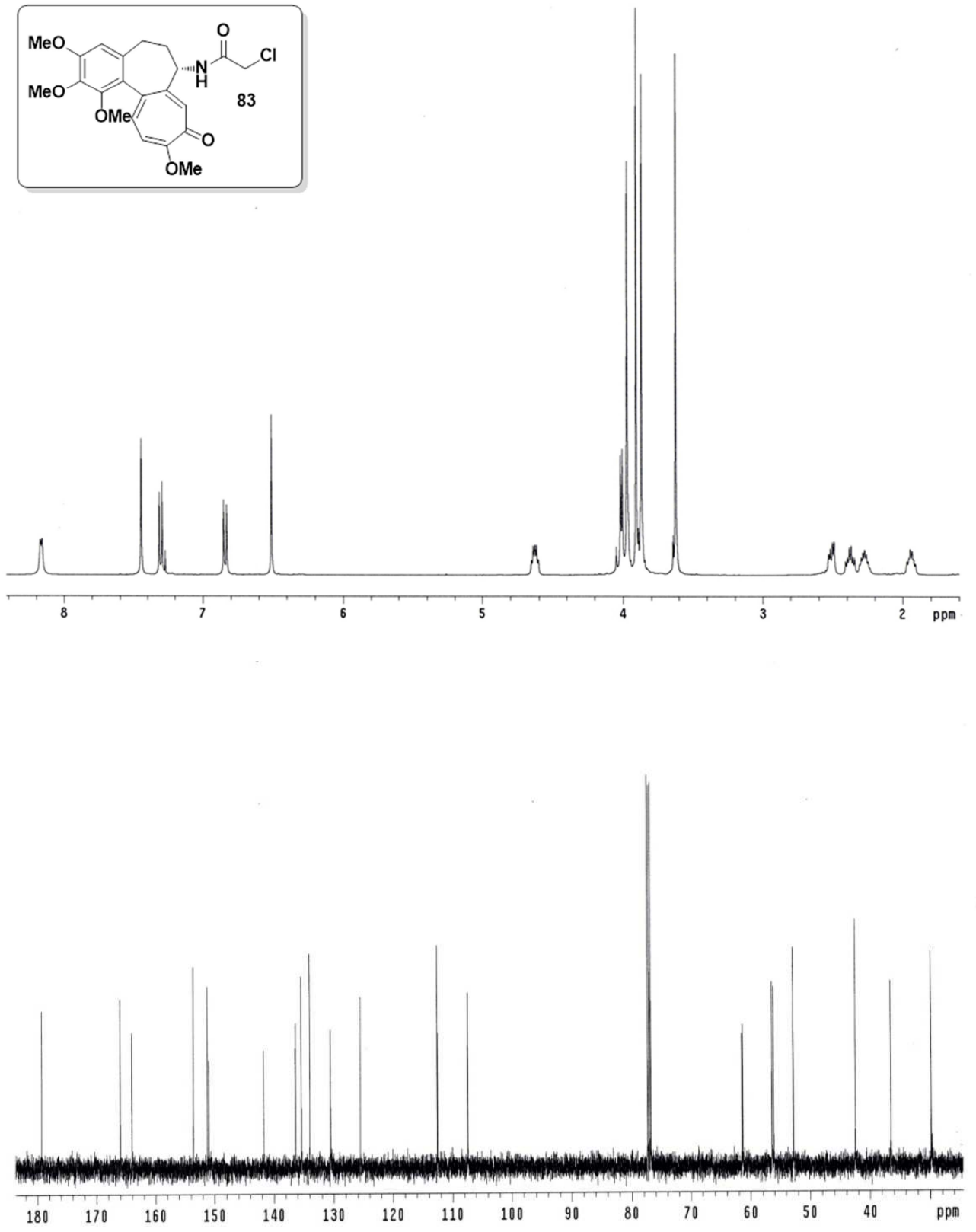

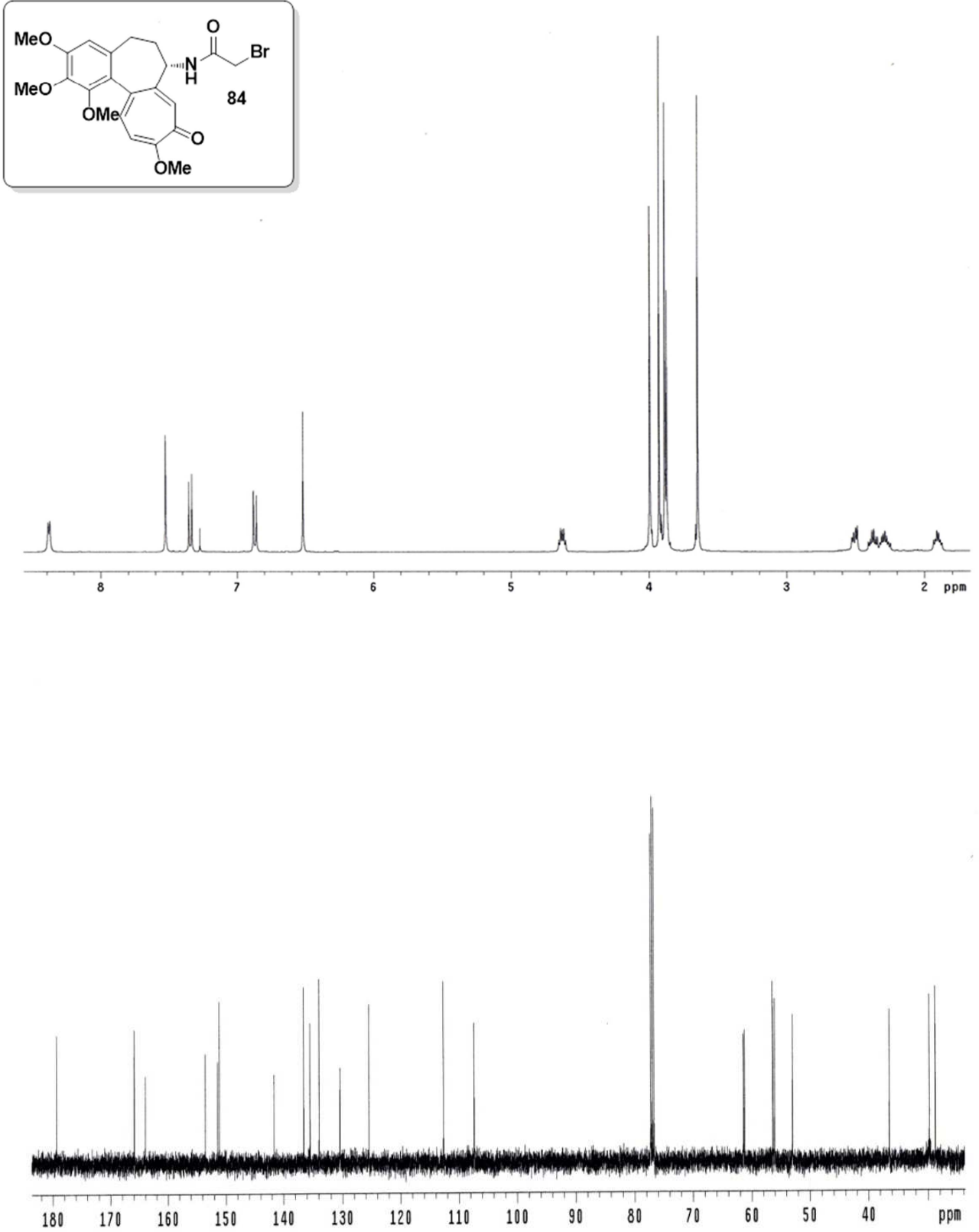

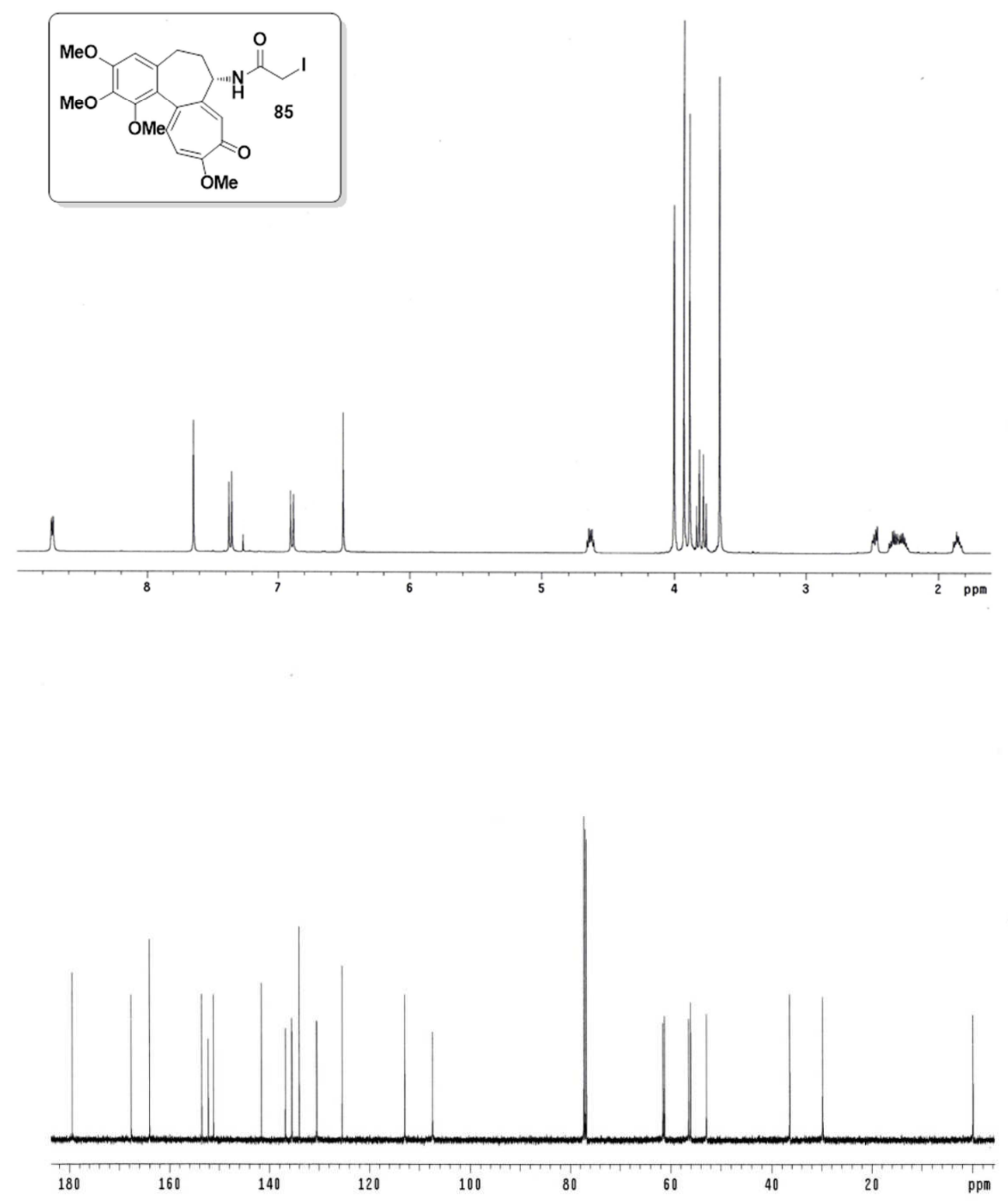

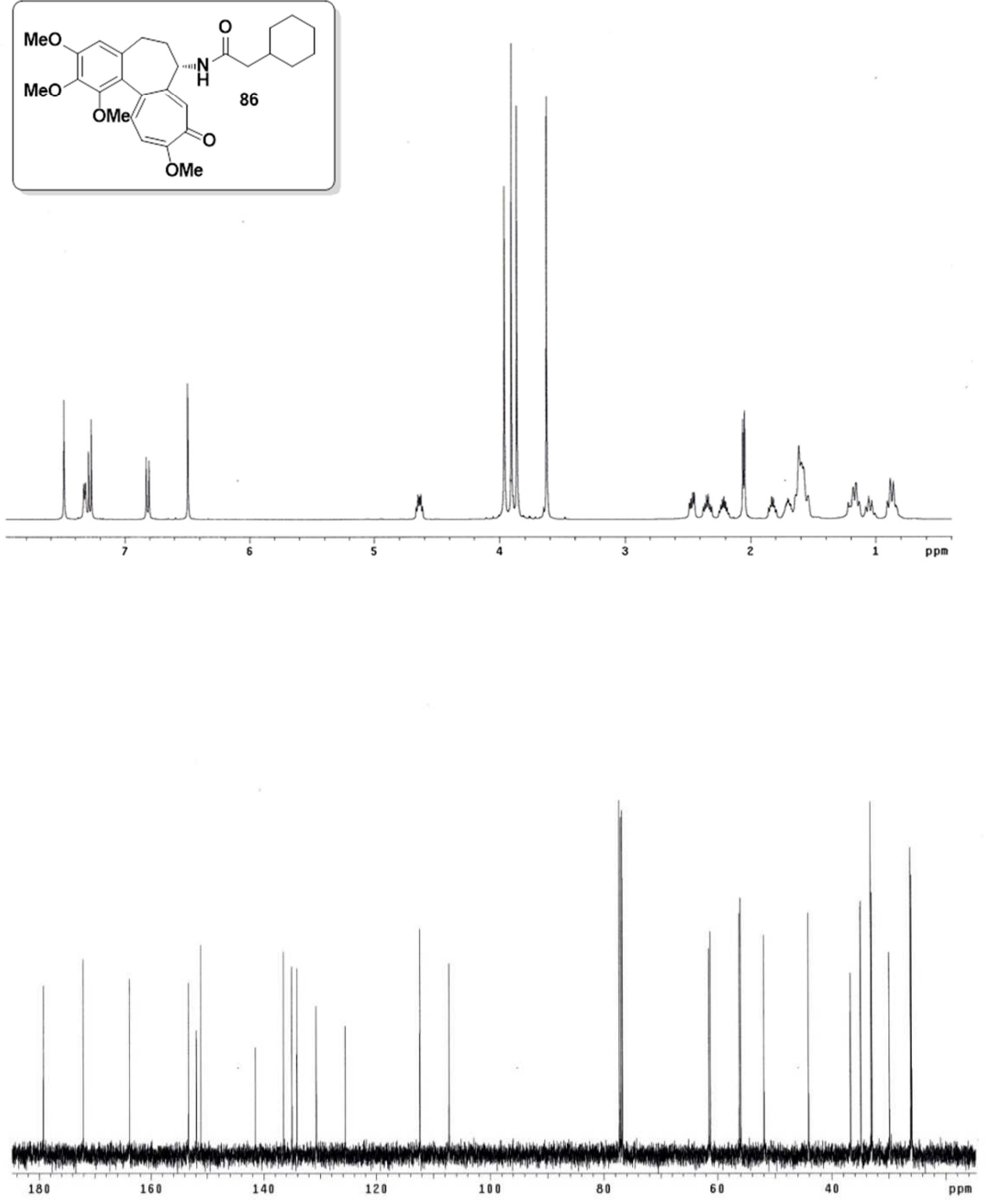

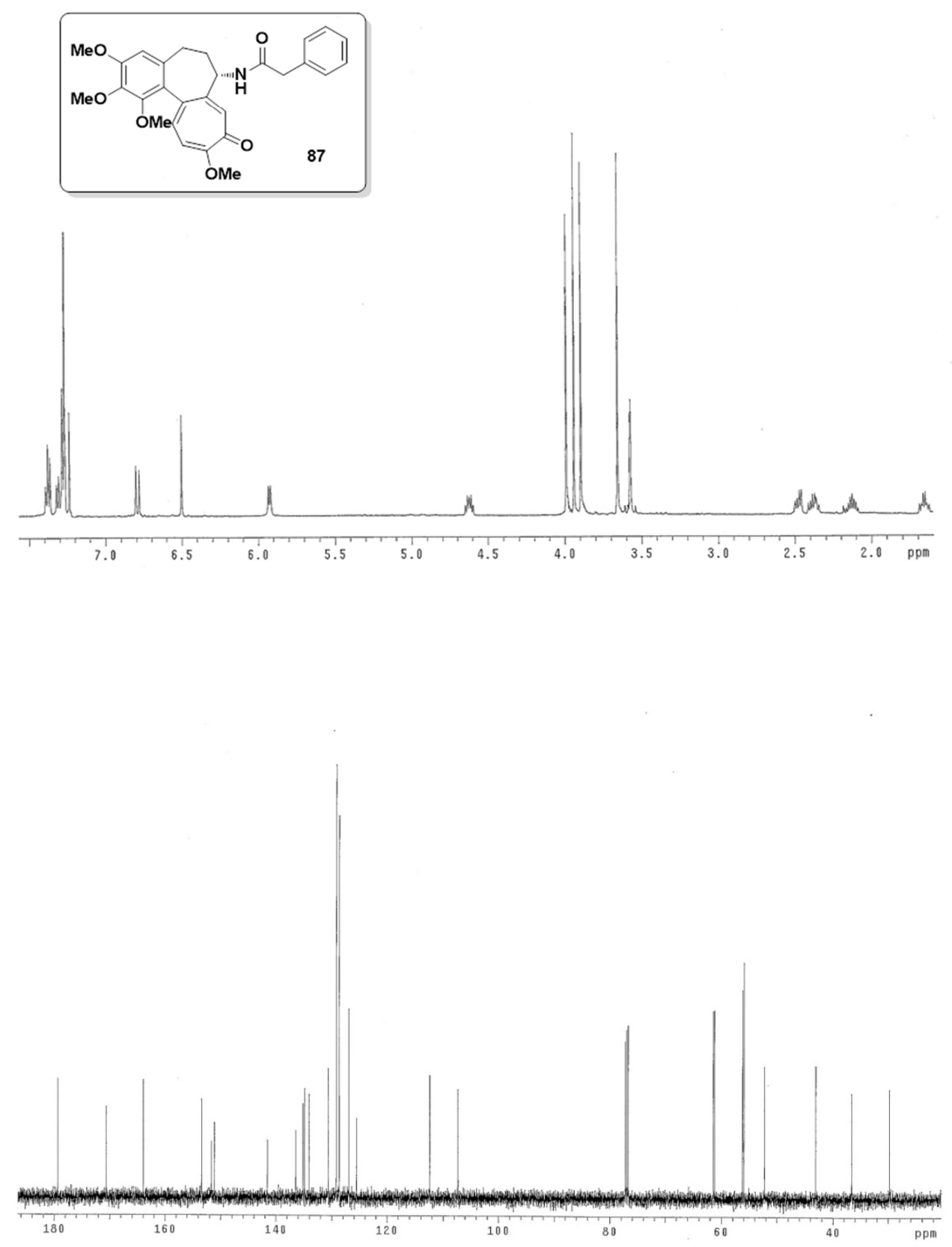

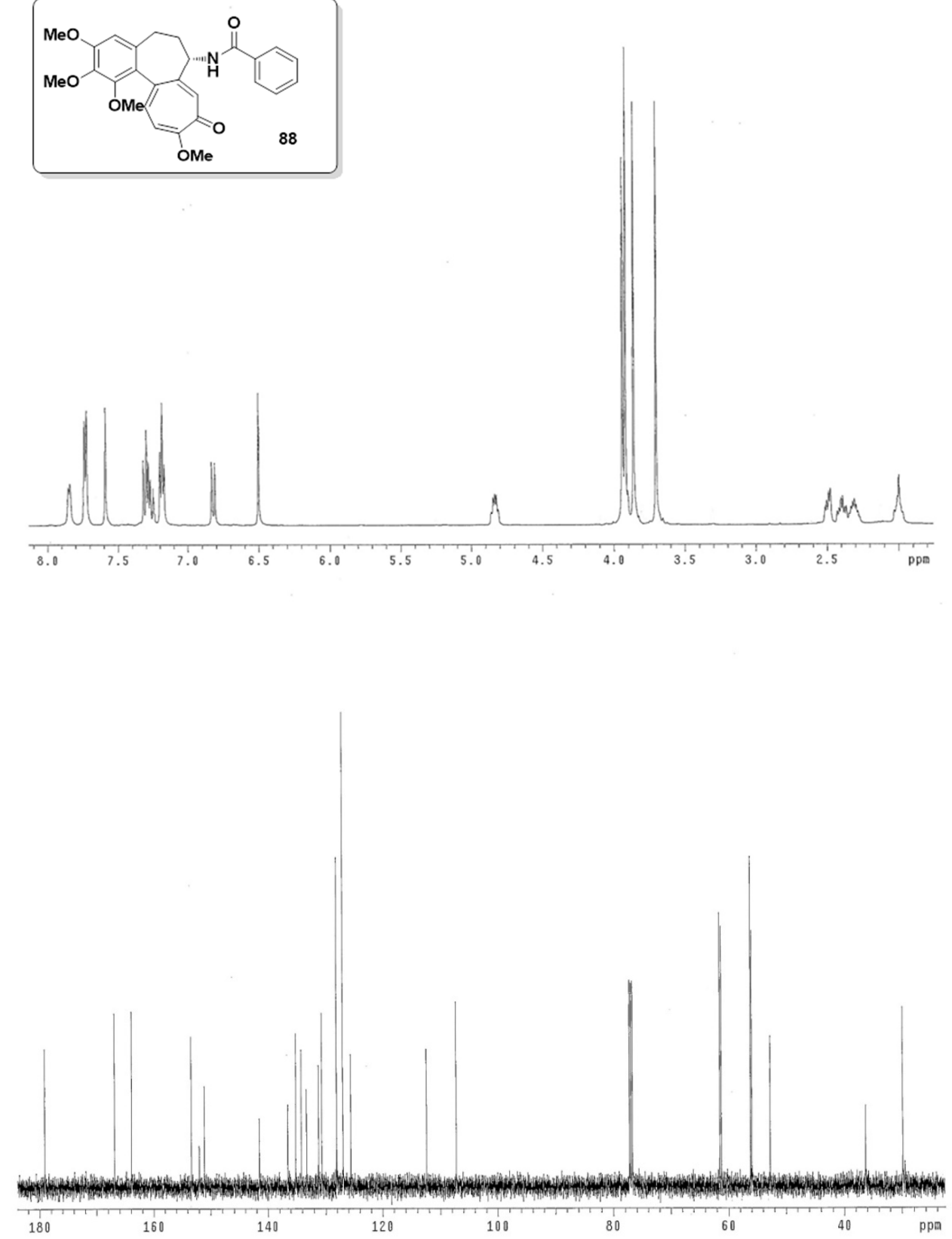

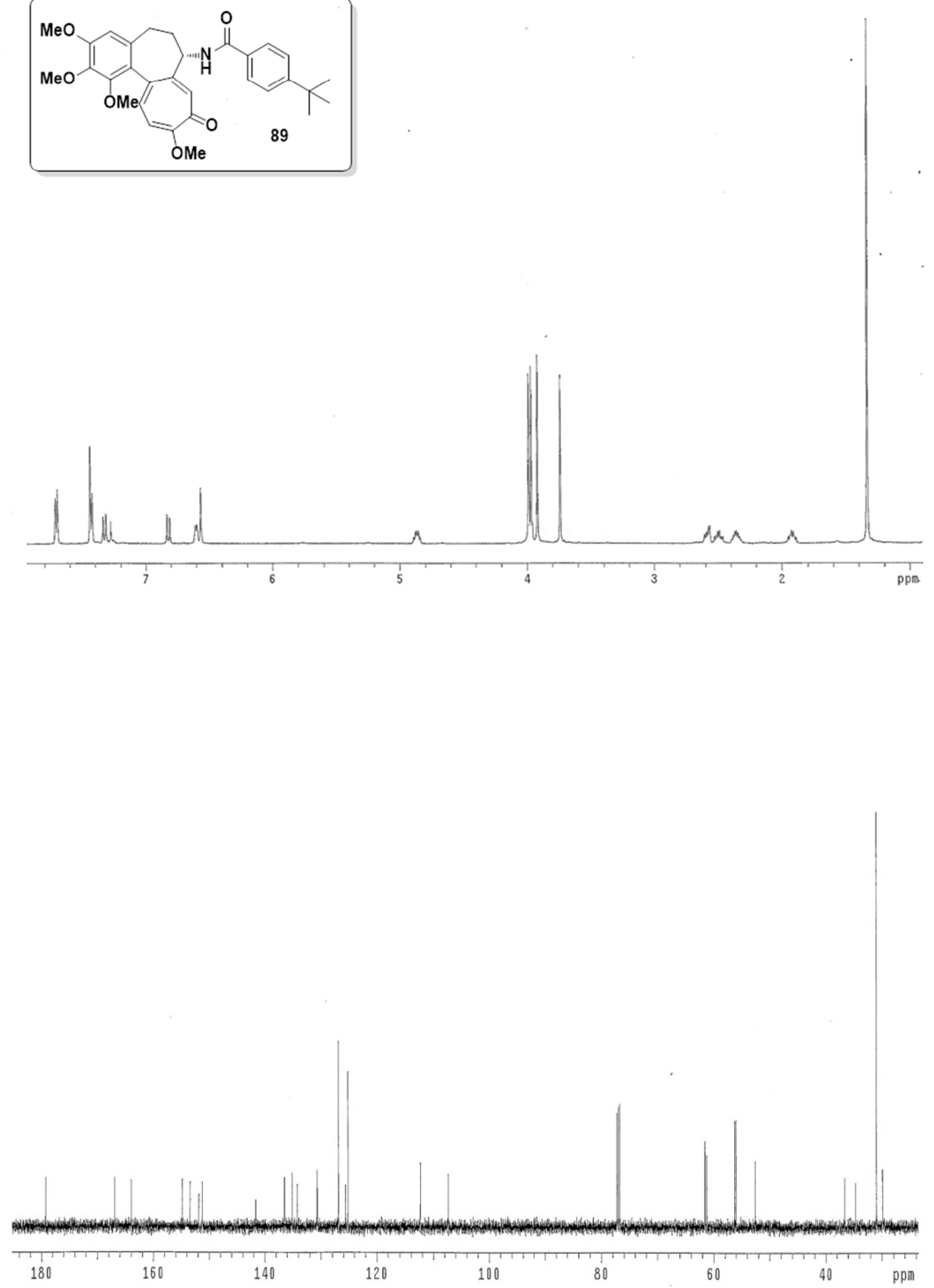

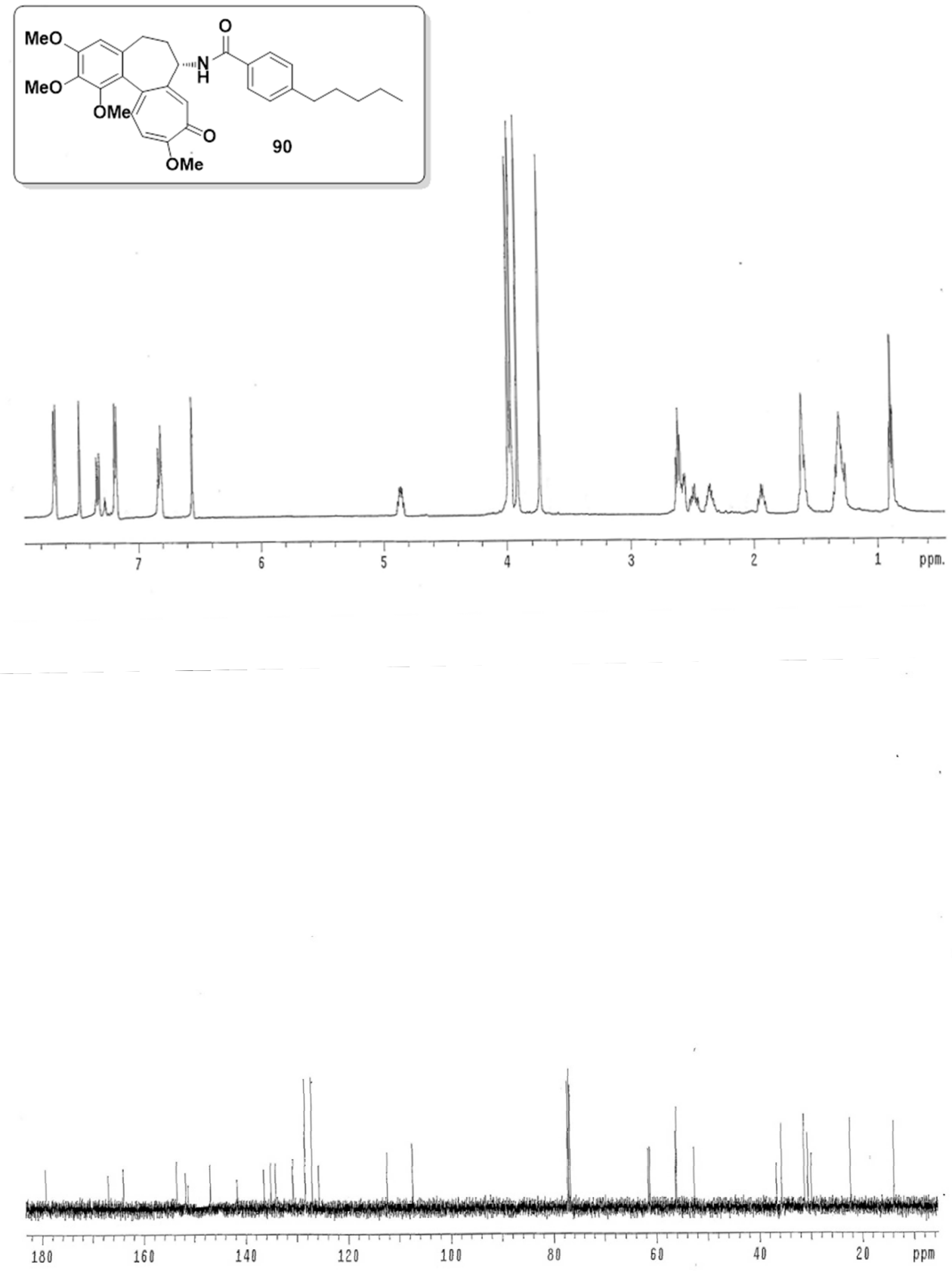

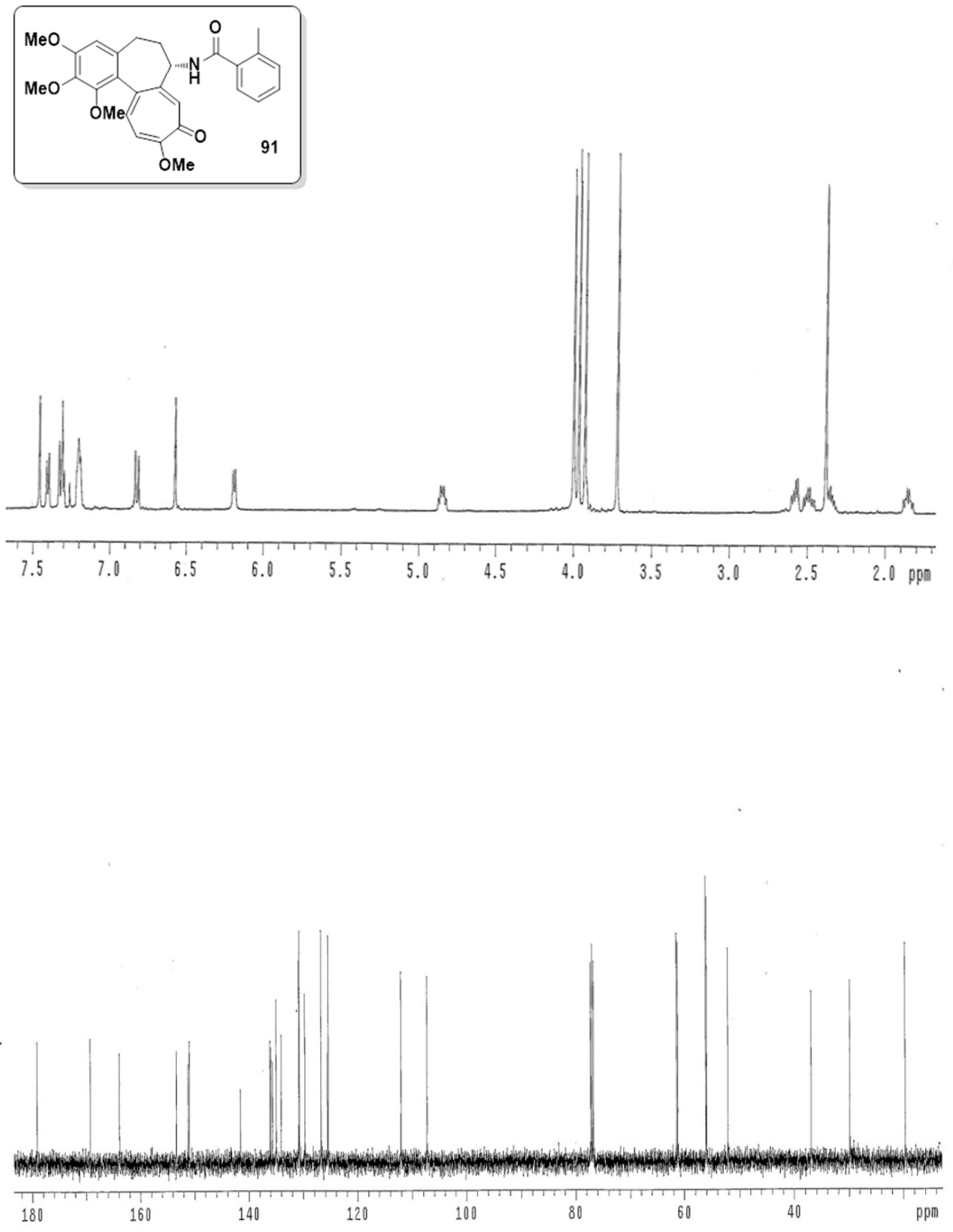

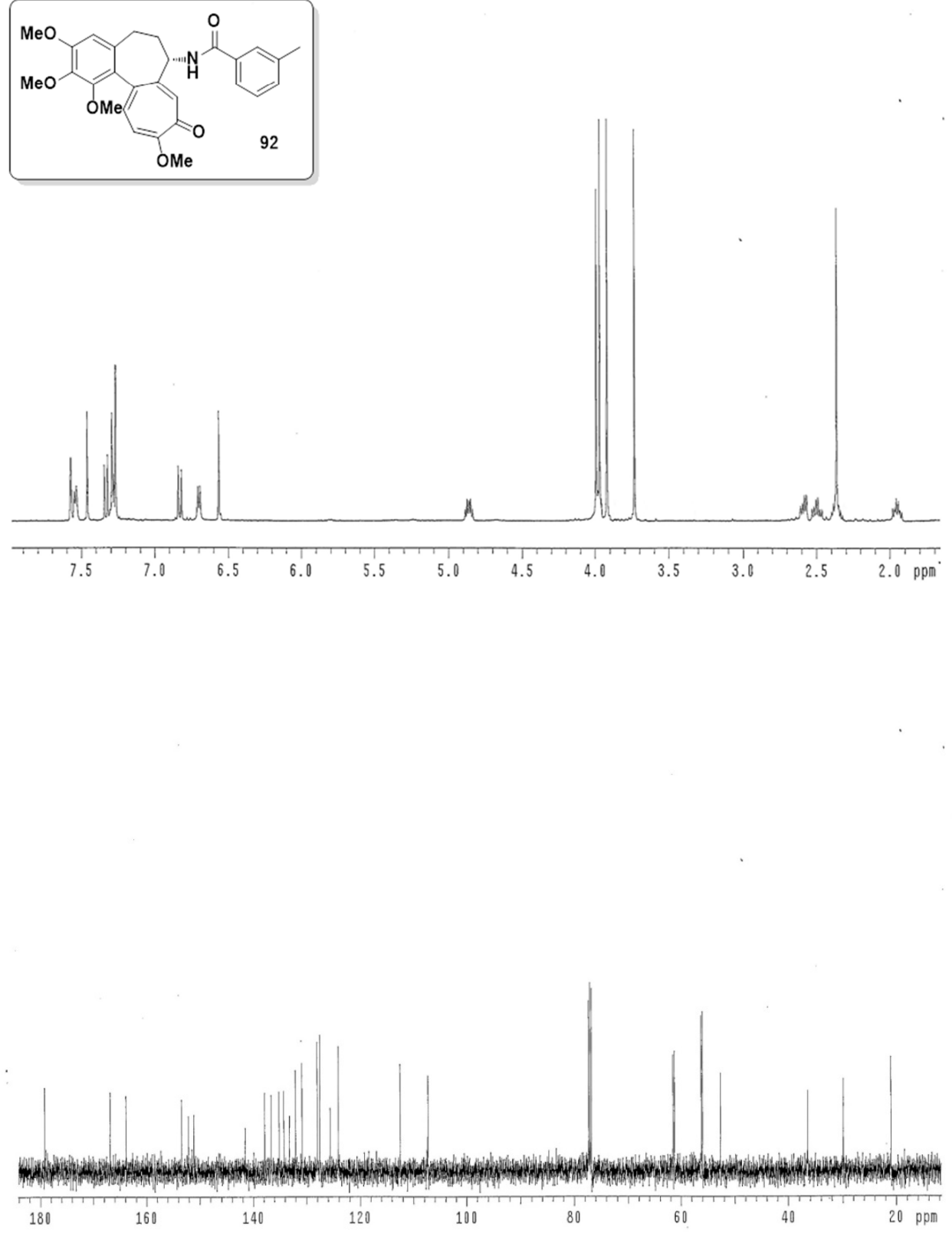

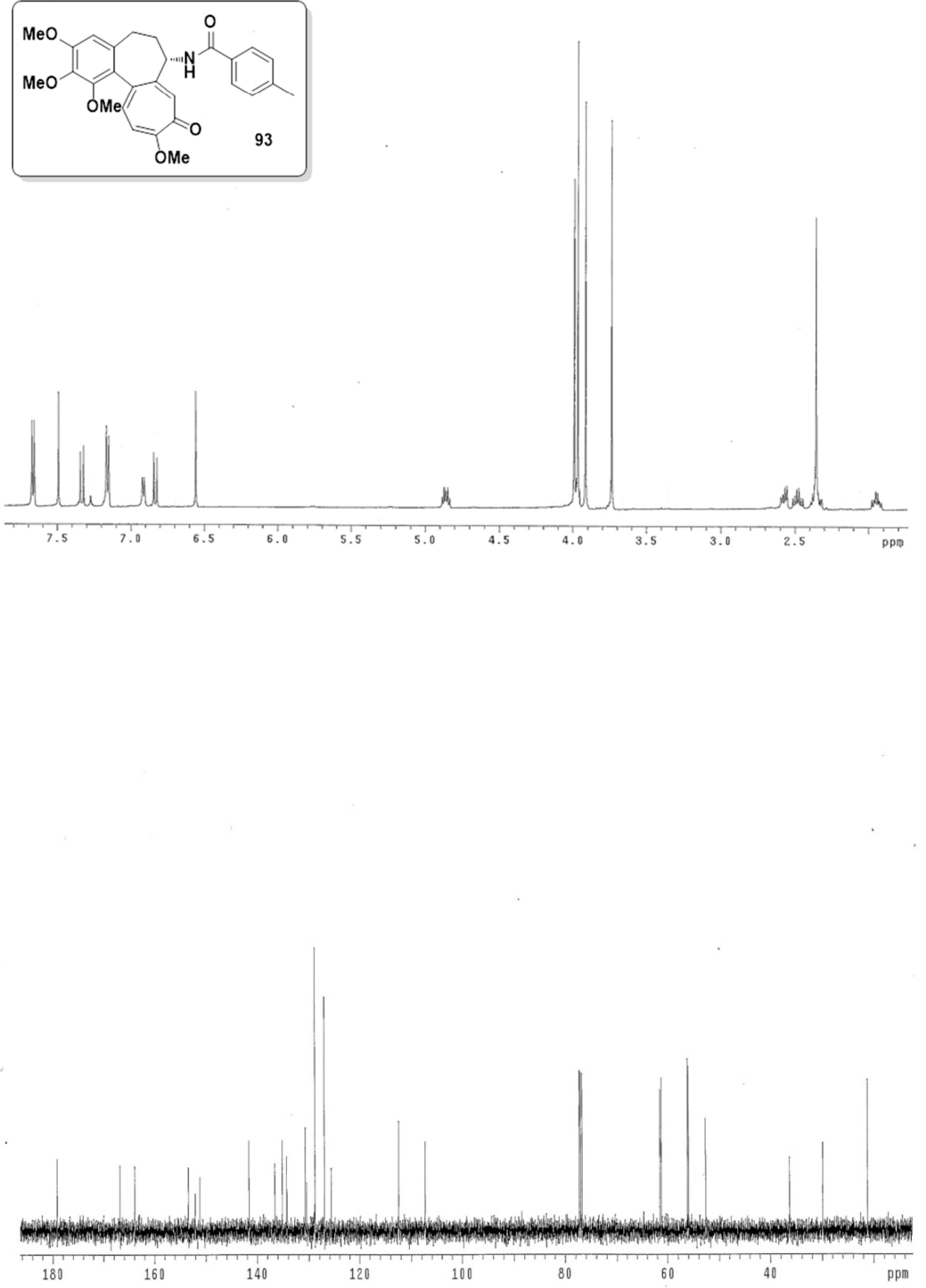

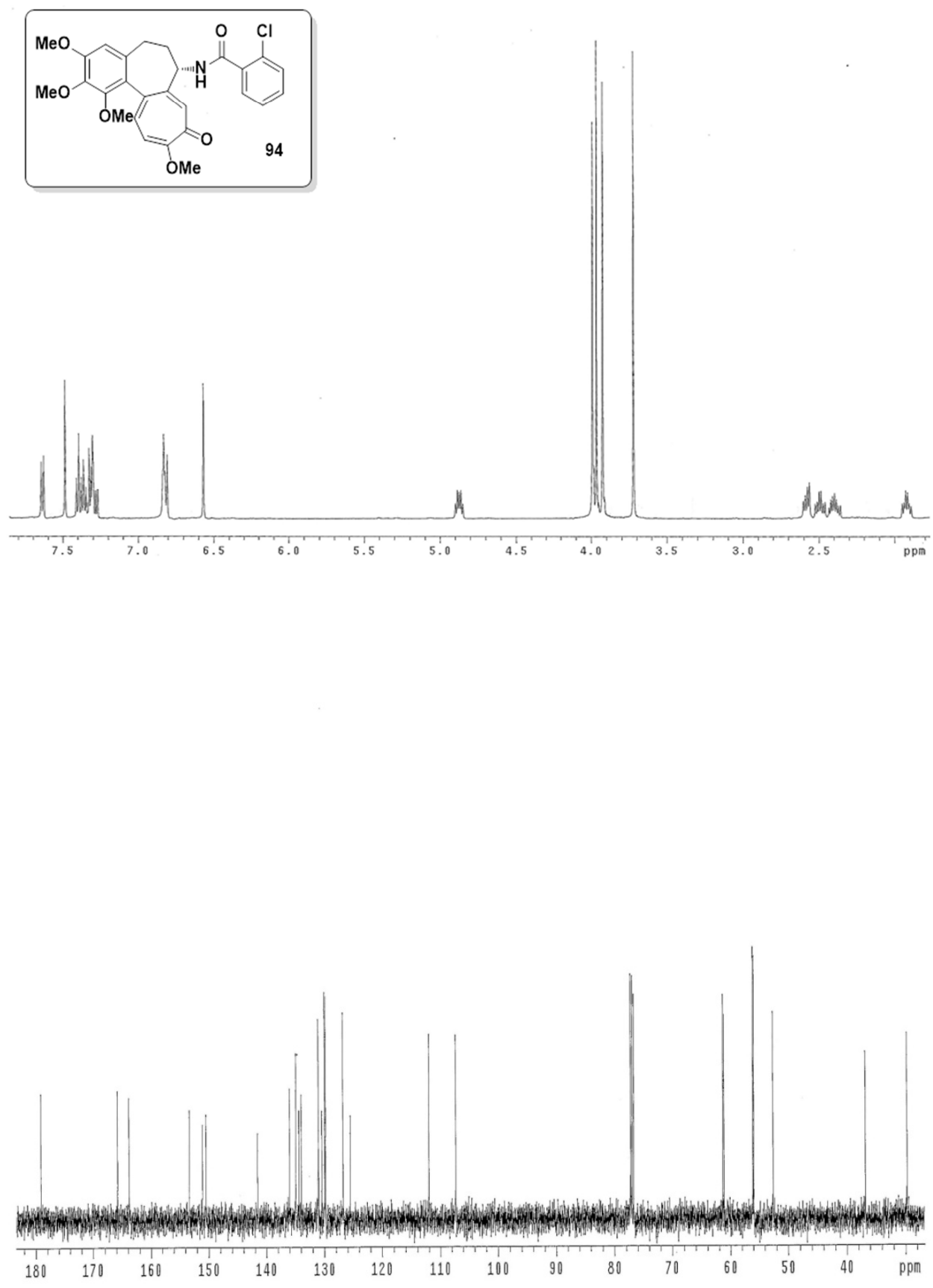

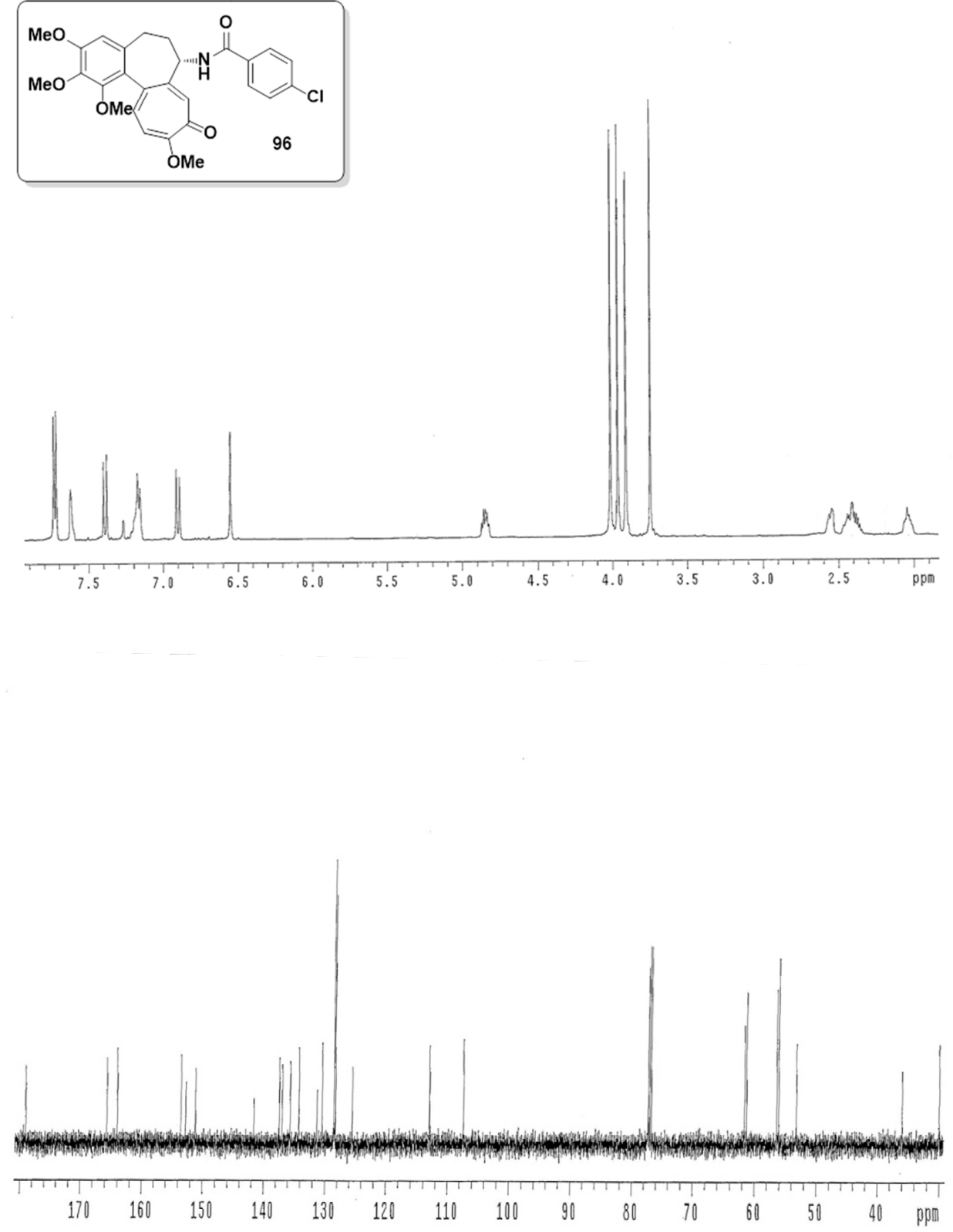

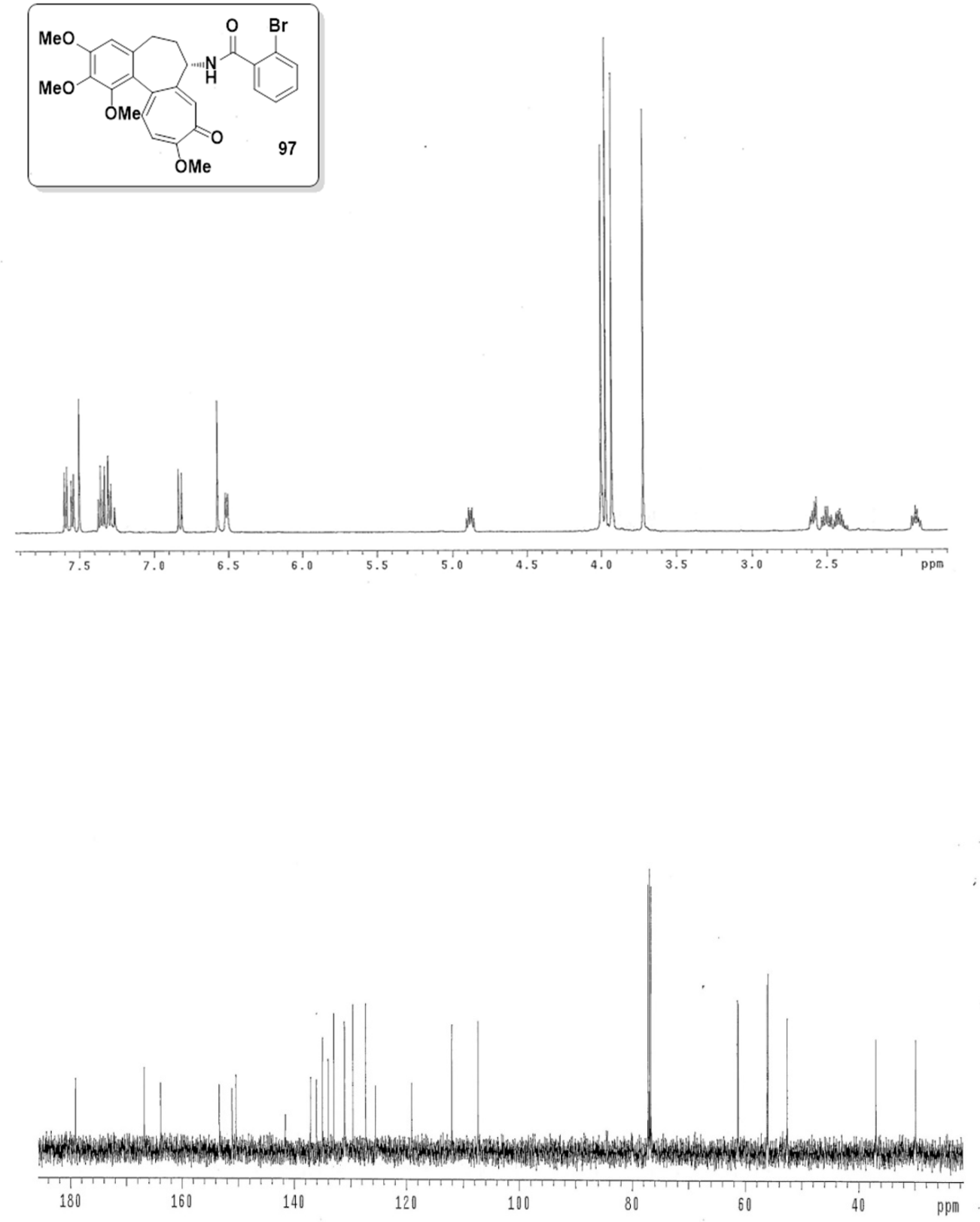

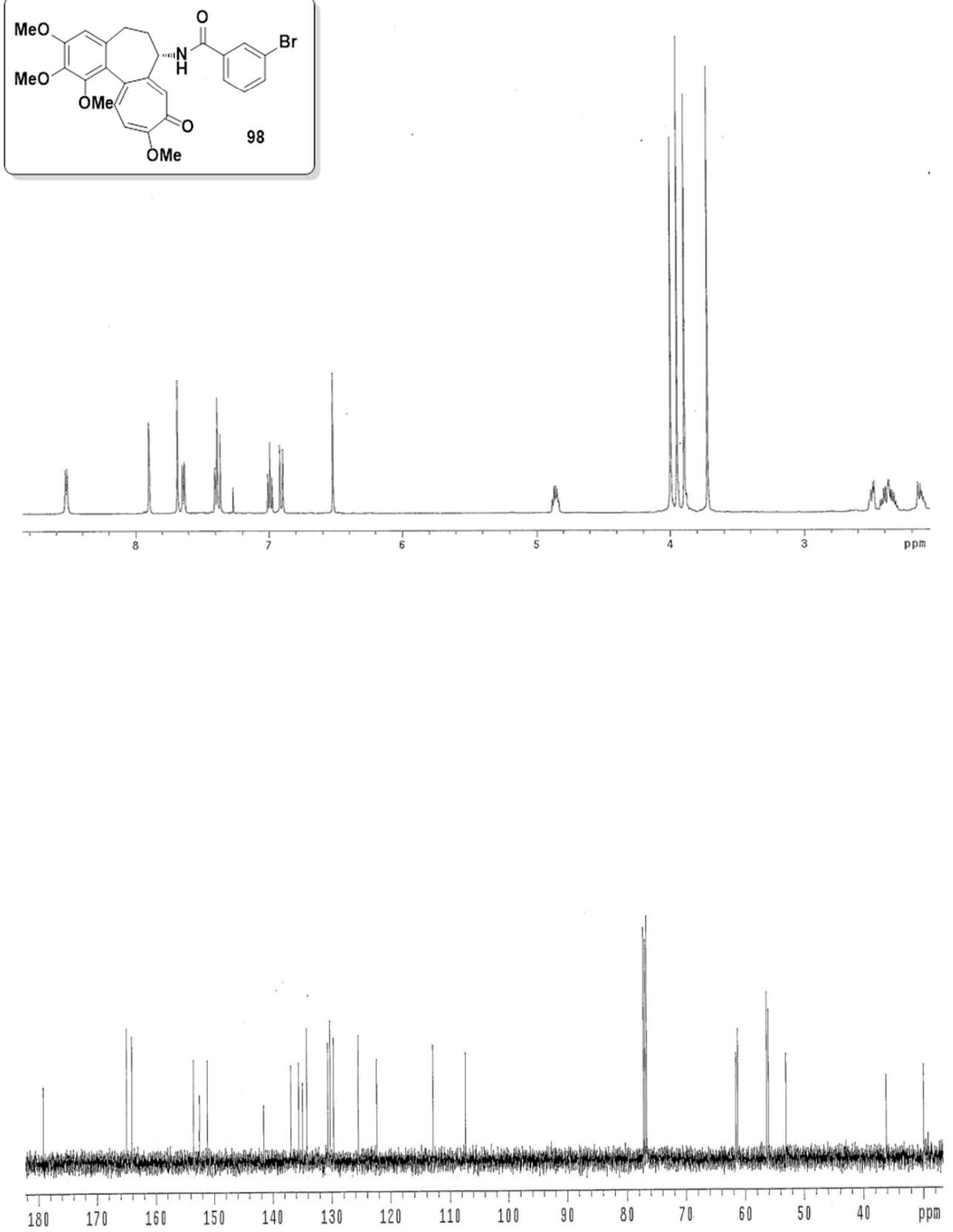

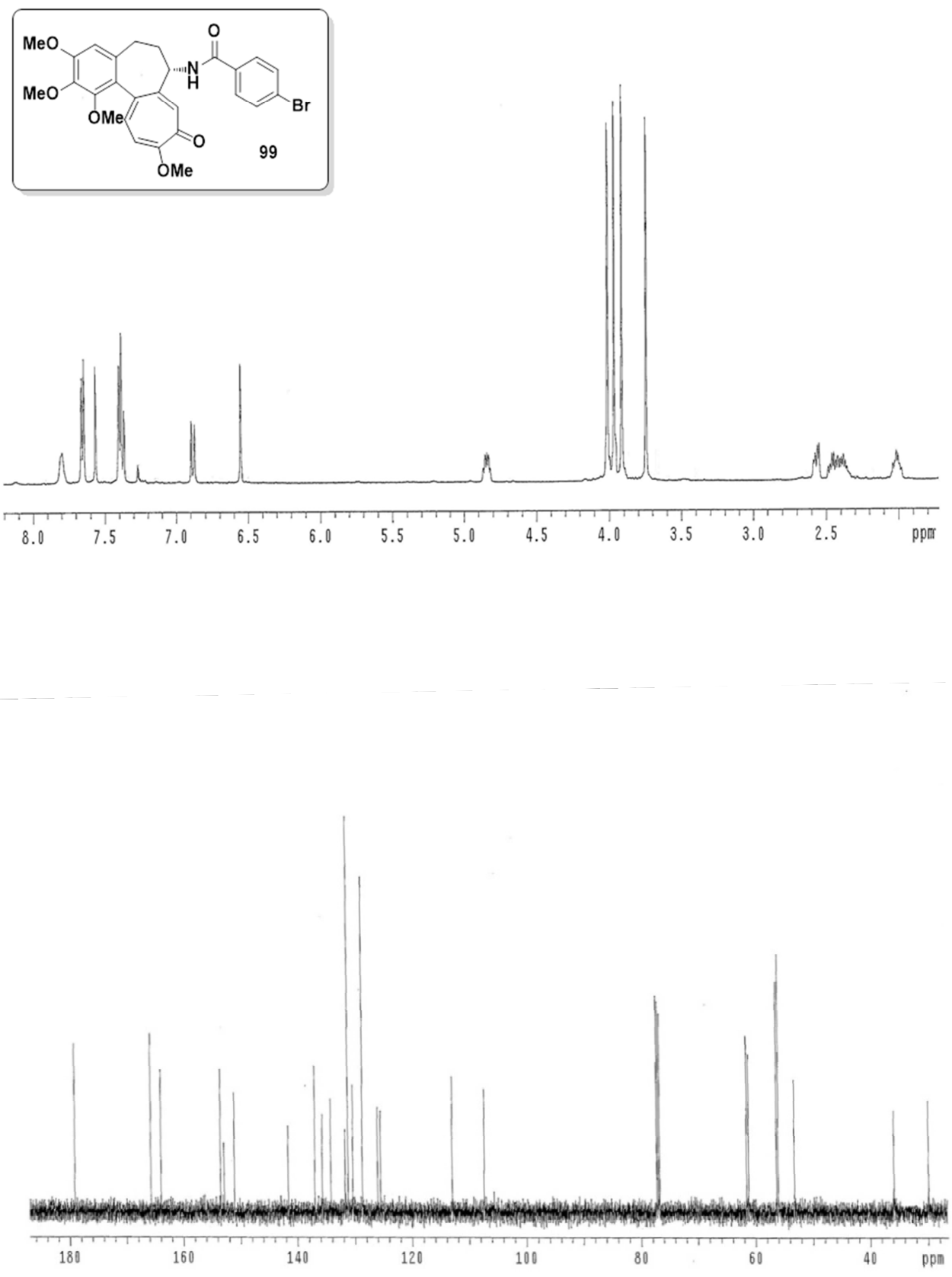